\title{
8 Modellentwicklung von der Mikro- zur Makrowelt
}

Um zu prüfen, ob die Welt des Kleinsten tatsächlich Relevanz für Prozesse im Menschen haben könnte, die mit Entscheidungen zu tun haben.

\subsection{Quantenphysikalische Annäherung}

Was ist Realität im naturwissenschaftlichen Sinn und woraus leitet sie sich ab?

\subsection{1 Über die Illusion der Materie und die Verbindung zum Wellenmodell}

Ich möchte diesem Kapitel einen Gedanken von Stephan Weinberg voranstellen, denn mit den folgenden Seiten beginnt der zweite Teil meiner Zielsetzung, dem konkreten Versuch, die Phänomene bei SyA und Intuition als ein von seinen Wurzeln her, quantenphysikalisches Phänomen' zu beschreiben. Wie sich zeigen wird, findet sich in den heutigen Experimenten und Interpretationen bereits alles, was dazu nötig ist.

„Unser Problem ist nicht, dass wir unsere Theorien zu ernst nehmen, sondern dass wir sie nicht ernst genug nehmen “

Stephen Weinberg (in Zeh 2011: 1).

Allein diese Ergebnisse auch anzunehmen, könnte die Herausforderung sein. Bekannt ist nämlich, dass die ,materiellen Grenzen' eine reine Illusion darstellen, die überwunden werden muss, sollen auch Phänomene verstanden werden, die sich bisher einer Erklärung entziehen.

Nachfolgend startet nun die vertiefte Untersuchung zu Säule 4 , Theorie zum Quantenverhalten in Makrosystemen' und somit die Ausarbeitung der Hauptkategorie ,Übertragungswege' aus dem Codierungsprozess.

\subsubsection{Die Illusion der Materie}

Aus den bisherigen Erkenntnissen wird ersichtlich, dass es einen Zusammenhang zwischen Materie, Energie und Information gibt, der über das übliche Verständnis weit hinausgeht. Mit der These einer Verschränkung wird auch die Notwendigkeit deutlich, sich mit dem bisher allgemeingültigen Konzept von Materie und unserer Realität auseinanderzusetzen. Dies scheint insofern notwendig, da eine der fundamentalsten Überzeugungen in der Vorstellung einer, festen Materie' besteht, auf die nicht durch mentale, geistige Prozesse Einfluss genommen werden kann. Ohne eine Veränderung dieser Vorstellung wird vermutlich jede damit nicht korrespondierende Erklärung ignoriert oder abgelehnt werden.

Die folgenden Ausführungen setzen deshalb die Überlegungen in Kap. 4.2.2 fort, in denen die Konzepte von Wiener und C.F. von Weizsäcker mit der Unterscheidung Materie, Energie und Information behandelt wurden. Die Frage, die hier beantwortet wer- 
den soll, lautet: Was ist Realität im naturwissenschaftlichen Sinn und woraus leitet sie sich $\mathrm{ab}$ ?

Weizsäcker weist bei seinem Versuch einer Sprachnormierung darauf hin, dass in den ,exakten' Wissenschaften der ,Name einer Wesenheit mit dem Namen ihres quantitativen Maßes “ verwechselt wird. Er unterscheidet die drei Wesenheiten ,Materie“, ,Bewegung', ,Form‘ von ihren drei Maßgrößen ,Masse‘, ,Energie‘, ,Information“.

Die bekanntesten Messgrößen in der Physik (in der Quantenphysik auch Observable ${ }^{137}$ genannt) sind sicherlich Energie $(E)$, Masse $(m)$ und Lichtgeschwindigkeit $(c)$. Größen, um die sich fast alles in der klassischen Physik dreht und die wohl zur bekanntesten Formel der Physik kombiniert wurden:

$$
E=m c^{2}
$$

Diese Formel steht für die von Einstein gefundene Beziehung zwischen Energie und Masse und ist eine der Konsequenzen seiner speziellen Relativitätstheorie. Sie bezieht sich auf ein Objekt, das sich mit relativ zum Beobachter konstanter Geschwindigkeit bewegt $\mathrm{t}^{138}$.

„Die Relativitätstheorie hat uns in gewissem Sinne die Identität der beiden Substanzen gelehrt. Erhaltung der Materie heißt in heutiger Terminologie Erhaltung der Masse; und Energie und Masse sind relativistisch äquivalent" (Weizsäcker 2002: 344-345). Masse ist insofern nicht mit Materie identisch, sondern nur eine Erscheinungsform selbiger. Mit Bezug auf Einstein's Erkenntnis unterscheidet er darüber hinaus Materie und Bewegung als Substanz, wobei Bewegung als ,das Bewegende' definiert wird und nicht als „, der aktuelle Prozess des Bewegtseins“ (vgl. ebd. 360-361). Die Energie bewegt demzufolge das, was sich als Masse (Atome, Moleküle ...) im Raum manifestiert hat und ist nicht selbst bewegt. Das, was als Frequenzen wahrgenommen wird, entspricht nach diesem Verständnis der bewegten Masse und ist Ausdruck einer dahinter wirkenden Energie. Wir werden sehen, dass diese Beschreibung mit der heutigen Vorstellung des Quantenvakuums respektive des Vakuumfeldes korrespondiert. Aus diesem Grund lässt sich Energie letztlich auch nur indirekt messen, über die Wechselwirkungen mit ihrem Umfeld, was durch Frequenzen und Frequenzänderungen zum Ausdruck kommt.

Für die Energie selbst existieren unterschiedlichste Formen, wie beispielsweise thermische und elektrische Energie, Gravitationsenergie, Atomenergie oder auch kinetische oder potentielle Energie. Egal aus welcher Quelle sie stammen, sie werden letztlich alle

${ }^{137}$ Im Unterschied zu den scheinbar realen, eindeutigen Messwerten der verschiedensten Wissenschaftsdisziplinen bezieht sich die ,Observable' in der Quantenphysik immer auf einen Wert, von dem man weiß, dass er einer von vielen möglichen ist und somit aus einer Wahrscheinlichkeitsverteilung herrührt. Camejo bezieht sich auf Bohr und Heisenberg, nach denen ,, in der Quantenmechanik nur messbaren Größen ein Realitätswert zugesprochen werden kann " (Camejo 2007: 153) und Heisenberg sehr stolz darauf war, dass in seine Theorie der Matrizenrechnung nur beobachtbare und messbare Größen einflossen.

${ }^{138}$ Diese Beziehung ,relativ zum Beobachter` wurde bereits in Kap. 4.2.2 relevant. Signalübertragung im konventionellen Sinn entspricht genau einer solchen Relativbeziehung. Wird keine Energie respektive Signale gesendet, findet auch keine Relativbewegung mehr statt und der Term $\mathrm{c}^{2}$ wird obsolet. Dieser Zusammenhang wird beim Thema Quanten-Teleportation noch relevant. 
gleichbehandelt und mit Joule (J) als Einheit versehen. Unter Masse $(\mathrm{kg})$ versteht man, vereinfacht ausgedrückt, die gesamte Menge an Materie in einem Körper. Formal stellt die Masse ${ }^{139}$ die Widerstandskraft gegen eine Beschleunigung, also die Trägheit eines Körpers, dar. Einstein gelang es eine Äquivalenz zwischen Energie und Masse herzustellen und zu zeigen, dass Masse (Materie) letztlich nur sehr dicht gepackte Energie ist.

Genau zum gleichen Ergebnis kommt Planck 1944: „As a man who has devoted his whole life to the most clearheaded science, to the study of matter, I can tell you as a result of my research about the atoms this much: There is no matter as such! All matter originates and exists only by virtue of a force which brings the particles of an atom to vibration and holds this most minute solar system of the atom together " (Planck 1944). Planck gilt als der Urheber der Quantentheorie und auf ihn geht auch die Erweiterung von Einstein' s Formel zurück:

$$
E=m c^{2}=h v
$$

Damit gilt der Dreiklang, Energie ist Masse ist Frequenz, mit $v$ als Frequenz und $h$ als Plancksches Wirkungsquantum. $h$ ist eine Naturkonstante (genauso wie $c$ ), die eine zentrale Rolle in der Quantenphysik einnimmt. Heute weiß man, dass die Planck'sche Formel eine universelle Bedeutung hat, die alle Formen von Energie umfasst. Betrachten wir uns die Materie genauer, wird auch deutlich, wie Planck zu diesem Verständnis kommen konnte.

Zuvor soll zunächst noch einmal darauf hingewiesen werden, was in der klassischen Physik unter Materie verstanden wird: Als Materie werden dort die Elementarteilchen angesehen, die eine Ruhemasse besitzen und sich von außen betrachtet nicht bewegen. Ursprünglich war darunter das kleinste nicht mehr teilbare Atom verstanden worden, aus dem sich alles andere aufbaut. Demgegenüber werden der Strahlung im klassischen Verständnis die Entitäten zugeordnet, die keine Ruhemasse besitzen. Diese Vorstellung hat sich mittlerweile dahingehend geändert, dass alle Entitäten mit einem Spin $1 / 2$ (Quark, Proton, Neutron, Elektron, Neutrino) zur Gruppe ,Materie' gezählt werden, wobei das Quark die kleinste Entität darstellt. Aber auch dieses Verständnis wird mittlerweile infrage gestellt ${ }^{140}$. Als Folge wird in den meisten Lehrbüchern nur noch von Materie gesprochen, ohne präzise Definition. Wie gleich zu sehen sein wird, kann die Aussage von Planck - es gibt keine Materie - sehr anschaulich dargestellt werden.

Allgemein bekannt ist, dass das Atom sich durch Protonen, Neutronen und Elektronen aufbaut. Allerdings handelt es sich nicht um feste Bahnen, auf denen sich die Elektronen bewegen bzw. zwischen denen sie springen, wie Bohr annahm und in den Schulen vermittelt wird (Abb. 38).

\footnotetext{
${ }^{139}$ Masse $(\mathrm{kg})$ und Gewicht $(\mathrm{N})$ sind nicht das Gleiche, was schon durch die Einheiten deutlich wird. Das Gewicht in Newton (N) angegeben bezieht die Gravitationskraft, die auf einen Körper wirkt, mit ein.

${ }^{140}$ Eine sehr anschauliche und ausführlichere Beschreibung auch zur Entwicklung des Materiebildes findet sich bei (Camejo 2007: 27ff).
} 

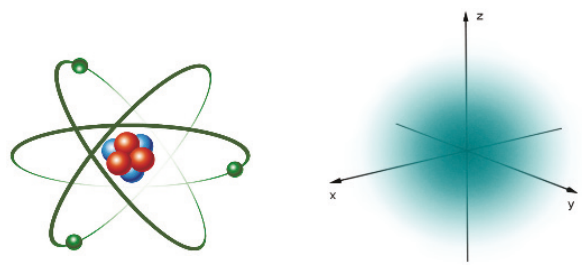

$$
\text { Orbital s }\left(l=0, m_{l}=0\right)
$$

Abb. 38 | Klassisches Bohrsches Atommodell und quantenmechanische Realität

Links Bohr's Vorstellung von Elektronen auf Bahnen. Rechts die gefundene quantenmechanische Wahrscheinlichkeitsdichte eines Orbitals (Ein-Elektron-Wellenfunktion). Gezeichnet wird meist nur der Bereich, innerhalb dessen es eine 90 \%-ige Wahrscheinlichkeit gibt das Elektron zu finden. (Image: CC RJHall).

Mittels des Bohrschen Atommodells lassen sich nur das Wasserstoffatom und einige ähnliche Atome befriedigend erklären (Camejo 2007: 151f). Nach den Erkenntnissen der Quantenphysik gibt es vielmehr das Problem, dass sich nur räumliche Aufenthaltswahrscheinlichkeiten $\left|\Psi_{e}(\mathrm{xyz})\right|^{2}$ (mit $\Psi_{e}$ als Zustandsfunktion des Elektrons) für die Elektronen beschreiben lassen, die sich vom Zentrum des Atomkerns bis ins Unendliche erstrecken (Abb. 39): Die sogenannten ,Wolken negativer Elektrizität" (Schrödinger 1935b: 811). Auch hier wird die räumliche Verteilung der Elektronen als Atomorbital bezeichnet.

Aus diesem Grund kann dem Atom, nach der Vorstellung der Quantenphysik, keine absolute Größe zugeordnet werden, da es keine definierte Grenze besitzt. Die unterschiedlichen Größen der Atome ergeben sich aus den chemischem Bindungstypen (z. B. Ionen-, Van-der-Waals-, Metallbindung etc.), womit die feste Struktur und räumliche Ausdehnung als erstes als Illusion enttarnt wird.

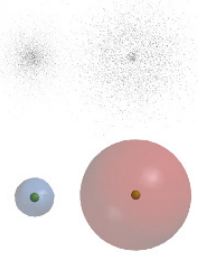

1s

\section{2s}
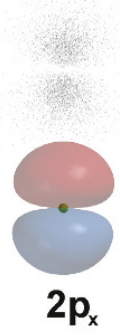
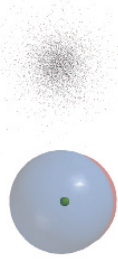

$2 p_{y}$

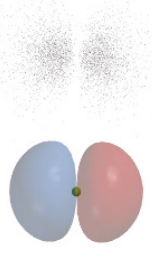

$2 p_{z}$

Abb. 39 | Verteilung von Elektronen der ersten und zweiten Elektronenschale ${ }^{141}$.

Die obere Reihe zeigt die Verteilung der Wahrscheinlichkeitsdichte $|\Psi(x y z)|^{2}$ als Punktwolke, die untere Reihe als sog. Isowolke oder Grenzflächendiagramm innerhalb deren sich das Elektron mit einer 90 \%-igen Wahrscheinlichkeit aufhält. (Image: AOs-3D-dots, gemeinfrei)

${ }^{141}$ Unter http://www.orbitals.com/orb/index.html findet sich eine wesentlich umfangreichere Palette verschiedenster Verteilungsdarstellungen. 
Betrachten wir nun die Protonen und Neutronen des Atomkerns, so werden diese nach heutiger Vorstellung im Wesentlichen von Quarks ${ }^{142}{ }^{143}$ gebildet. Zwei Up-Quarks und ein Down-Quark bilden ein Proton, ein Up-Quark und zwei Down-Quarks bilden ein Neutron (Hawking 2004: 87) (Abb. 40).

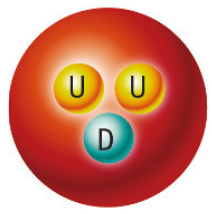

Proton

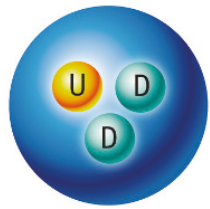

Neutron

Abb. 40 | Proton und Neutron

gebildet durch unterschiedliche Konfigurationen von Up- und Down-Quarks. (eigene Darstellung)

Im Standardmodell der Elementarteilchenphysik bilden die Quarks damit die Grundbausteine der Materie. Tatsächlich hat man noch keine freien Quarks beobachten können, genauso wenig wie es bisher gelungen ist ihre Größe zu bestimmen. Bis zu einer Größe von $10^{-16} \mathrm{~cm}$ konnte bisher kein Wert ermittelt werden, woraus die Vermutung abgeleitet wird, dass es keine kleineren Teile mehr gibt. Entsprechend wurde auch keine innere Struktur erkannt, was dazu führt, dass sie als punktförmige Elementarteilchen betrachtet werden; was im Übrigen vollumfänglich auch für Elektronen zutrifft. Insofern scheint die Aussage ,Protonen und Neutronen bestehen aus' schwer zu halten und es scheint treffender formuliert: „Richtig wäre es zu sagen, dass Protonen und Neutronen innere Freiheitsgrade besitzen, die mit dem Quarkmodell gut beschrieben werden können “ (Görnitz und Görnitz 2002: 123). Da sie darüber hinaus immer nur in Gruppen auftreten, lassen sich ihre Größenangaben nur aus Rückschlüssen ableiten. Klar scheint zu sein, dass nur ca. 1 \% der Masse von Proton und Neutron von der Masse der Quarks herrühren. 99 \% resultieren aus Bewegungs- und Bindungsenergien zwischen Quarks und Gluonen. Das Äquivalent dieser Bewegungs- und Bindungsenergie von 1 Milliarde Tonnen würde in einen Kubikzentimeter passen (Zeilinger 2007: 72).

Zur Veranschaulichung der Größendimensionen setzt Abb. 41 Atome und Quarks ins Verhältnis. Wie bereits beschrieben, kann es sich dabei nur um Werte handeln, auf die man auf der Basis von experimentellen Ergebnissen gekommen ist und die sich aus dem Zusammenhang mit bestimmten Bindungszuständen ergeben. Hingewiesen sei auf den Umstand, dass sich physikalische Realität auch aus Ableitungen ergeben kann und nicht nur eine physische Beobachtung voraussetzt, nicht unähnlich dem Untersuchungsgegenstand dieser Arbeit.

${ }^{142}$ Der Begriff Quarks geht auf Gell-Mann zurück (Gell-Mann 1964).

${ }^{143}$ Darüber hinaus gibt es in der Teilchenphysik noch eine Vielzahl weiterer Untergruppen, bekannt auch unter dem Begriff Elementarteilchenzoo. Ein regelmäßiges Update findet sich bei der Particle Data Group unter http://pdg.lbl.gov/. 


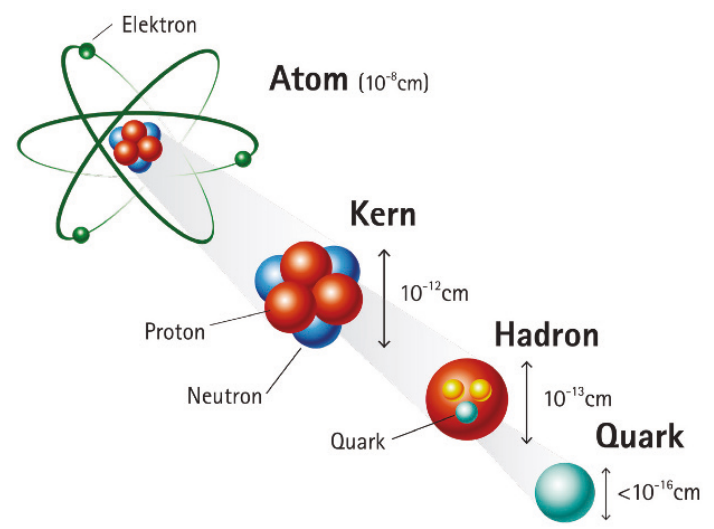

Abb. 41 | Mikroskopischer Größenvergleich von Atom bis Quark (eigene Darstellung).

An dieser Stellte bietet sich ein kleines Gedankenexperiment an, um die Illusion einer festen, materiellen Welt weiter zu untergraben:

Nehmen wir an, wir wollen das Volumen der 7 Milliarden aktuell auf der Erde lebenden Menschen berechnen, das nur durch das ausgefüllt wäre, was wir derzeit als kleinste Form der Materie ansehen können. Einmal zusammengesetzt aus den Atomkernen (1) und ein zweites Mal nur zusammengesetzt aus den Quarks (2). Der leere Raum zwischen Elektronen und Kern respektive Quarks wird vernachlässigt, wohlwissend, dass für das Erscheinungsbild der Form dieser Raum eine wichtige Funktionalität hat und Kräfte beinhaltet. In diesem Gedankenexperiment geht es aber nur um das, was als Materie verstanden wird. Verzichtet wird deshalb auch auf die Berücksichtigung der Elektronen, da sie sich überall aufhalten können und derzeit (genauso wie Quarks) noch keine innere Struktur aufweisen. Insofern füllen sie auch keinen Raum aus und können als punktförmig ohne Dimension betrachten werden. Gleichwohl werden sie in der Fachliteratur mit der gleichen Ausdehnungsdimension wie Quarks aufgeführt sind (Durchmesser 10 $0^{-16}$ $\mathrm{cm})$. Darüber hinaus nehmen wir zur Vereinfachung an, dass der Mensch nur aus Wasser aufgebaut ist, was ja zum größten Teil zutrifft und dass die Weltbevölkerung im Mittel $70 \mathrm{~kg}$ schwer ist.

Daten: In der Chemie wird die molare Masse für 6,022 $\times 10^{23}$ Wassermoleküle mit 18 $\mathrm{g}$ angegeben. Daraus ergeben sich für einen $70 \mathrm{~kg}$ schweren Menschen $2,34 * 10^{27}$ Wassermoleküle. Ein $\mathrm{H}_{2} \mathrm{O}$-Molekül besteht aus 8 Protonen $\mathrm{O}+8$ Neutronen $\mathrm{O}+2$ Protonen $\mathrm{H}=18$ Elementarteilchen für den Atomkern; 18 Elementarteilchen $* 3$ Quarks $=54$ Quarks.

Volumen Atom: $\quad V_{\text {Atom }}=\frac{4}{3} \pi r^{3}=\frac{4}{3} \pi\left(0,5 * 10^{-12} \mathrm{~cm}^{3}\right)^{3}=0,5 * 10^{-36} \mathrm{~cm}^{3}$

Volumen Quark: $\quad V_{\text {Quark }}=\frac{4}{3} \pi r^{3}=\frac{4}{3} \pi\left(0,5 * 10^{-16} \mathrm{~cm}^{3}\right)^{3}=0,5 * 10^{-48} \mathrm{~cm}^{3}$ 
Volumen Weltbevölkerung bestehend aus Atomkernen:

$$
\begin{aligned}
V_{\text {Atom }} & =\text { Volumen Atom * Elementarteilchen * Wassermoleküle * Menschen } \\
& =\left(0,5 * 10^{-36} \mathrm{~cm}^{3}\right) * 18 *\left(2,34 * 10^{27}\right) *\left(7 * 10^{9}\right) \\
& =147 \mathrm{~cm}^{3} \\
& =0,15 \mathrm{l}
\end{aligned}
$$

als dichteste Packung $P=\frac{\mathrm{N} * \frac{4}{3} \pi r^{3}}{a^{3}}$; mit $P$ als Packungsdichte, N Anzahl der Teilchen und $a$ als Abstand zwischen den Teilchenmittelpunkten: $a=2 * r$

würde sich das Volumen nur auf zirka 0,3 $l$ verdoppeln.

Volumen Weltbevölkerung bestehend aus Quarks (unter der Annahme einer Größe von $\left.10^{-16} \mathrm{~cm}\right)$

$$
\begin{aligned}
\mathrm{V}_{\text {Quark }} & =\text { Volumen Quark } * \text { Quarks } * \text { Wassermoleküle } * \text { Menschen } \\
& =\left(0,5 * 10^{-48} \mathrm{~cm}^{3}\right) * 54 *\left(2,34 * 10^{27}\right) *\left(7 * 10^{9}\right) \\
& =442 * 10^{-12} \mathrm{~cm}^{3} \\
& =\text { ca. } 4,42 * 10^{-14} l
\end{aligned}
$$

Als Ergebnis für Atome ergibt sich ein Glas mit 0,15 1 Inhalt oder als gepackte Variante (die Zwischenräume nicht ausgefüllt) mit ca. 0,3 1 nur unwesentlich mehr. Für die Variante mit Quarks liegt das Ergebnis bei einer maximalen Größe von $10^{-14} \mathrm{~cm}^{3}$.

Dieses kleine Gedankenexperiment veranschaulicht Planck's Aussage von der NichtExistenz der Materie und macht seine Gleichsetzung von Energie und Masse nachvollziehbar. Aus der bisherigen Unmöglichkeit Quarks direkt zu beobachten lässt sich vermuten, dass Quarks, wie der gesamte Teilchenzoo, letztlich nur Energiepakete darstellen und bestimmte definierte Energieformen repräsentieren.

Diese Energieformen sind nun die, die eine über unsere räumlichen Grenzen hinausgehende Interaktion zwischen Systemen ermöglichen und die Basis für Phänomene wie SyA und Intuition zu liefern vermögen. Interaktionen, die in Gestalt von konstruktiven und destruktiven Interferenzen wirken.

Ketterle geht bei seiner Nobelpreisrede in Bezug auf die destruktiven Interferenzen noch einen Schritt weiter (Ketterle 2002: 1144):

\section{„atoms plus atoms add up to vacuum!“}

Nochmal mit Weizsäcker: Das Faktum (das Konkrete) setzt sich nach Weizsäcker immer aus Materie und Form zusammen, was er am Beispiel eines Schrankes (Form) und dem Holz (Materie) aus dem er gefertigt ist, veranschaulicht (Weizsäcker 1961: 361). Aber auch das Holz besteht wiederum aus Molekülen und weiter aus Elementarteilchen, die die Form der jeweilig größeren Entität (Holz) aufbauen. Wie oben gesehen, bestehen diese Elementarteilchen nun nicht aus Materie, sondern sind pure Energie (Wellen mit spezifischen Frequenzen), die deshalb auch über die scheinbar räumlich abgrenzbare Gesamtentität hinauswirken kann. In diesem Sinn müsste heute bei Wiener statt ,Materie' eher der Begriff ,Stoff' (von lat. materia, = Stoff) Verwendung finden, als Repräsen- 
tant für all das, was physische Körper aufbaut und in der Erscheinung von Elementarteilchen einen Spin $1 / 2$ besitzt (wie beispielsweise Quarks, Atome, Moleküle, aber auch Elektronen ...). Zeilinger fasst für den Aufbau der Materie analog zusammen: ,, Sie hat nur drei verschiedene Bestandteile, Up-Quark, Down-Quark und Elektron. Dazu kommen noch der Kleber, Photonen und Gluonen, der das Ganze zusammenhält " (Zeilinger 2007: 72-73). Für die Zusammensetzung dieser drei Bestandteile ist auch nach ihm die Information verantwortlich:

„Information ist der fundamentale Baustein des Universums“ (ebd. 73).

Aus den eben vorgenommenen konkreten Größen- und Zustandsvergleichen ergibt sich somit die gleiche Beobachtung wie aus den Überlegungen zur Information in Kap. 4.2. Der physikalische Formalismus

$$
E=m c^{2}=h v
$$

erweitert mit der Information $I$, als Ergebnis der Äquivalenzüberlegungen ergibt:

$$
E=m c^{2}=h v=f(I)
$$

Mit Energie $E$, Masse $m$, Lichtgeschwindigkeit $c$, Frequenz $v$, Plancksches Wirkungsquantum $h$ und Information $I$ als Funktion, womit sich Energie und Materie in eine Funktion von $I$ und umgekehrt überführen lassen.

\section{Auf dem Weg von der Materie zum unendlich Kleinen verschwindet die Materie, um der Energie und schließlich der Information Platz zu machen.}

Ein kleiner Ausflug:

Die ,Form', wie sie Weizsäcker versteht, die der jeweiligen Entität ihre äußere Erscheinung gibt, findet ihren materiellen Ausgangspunkt bisher in den Quarks. Die Wahl ihrer Zusammensetzung entscheidet, was ein Proton, was ein Neutron werden soll. Denkt man hier weiter, stellt sich die Frage, wo die Information letztlich ihren Ursprung hat, wie sich daraus Quarks und darauf aufbauend weitere strukturierende Formen modellieren. Die Frage stellt sich zumindest solange man den Quarks kein eigenes Bewusstsein zubilligt. Hierzu gibt es heute noch keine Antworten, sondern nur philosophische Überlegungen.

Folgen wir dem Modell, dass Information den Ausgangspunkt der Entwicklung unserer Realität darstellt, dann bekommt der Bibelspruch ,Im Anfang war das Wort “(Offenbarung 19.13) eine ganz zentrale Bedeutung. Damit wird ein immaterieller Zugang beschrieben, der sich in der Welt erst realisieren muss, in gleicher Weise wie bei Wiener, Weizsäcker u. a. Ähnliches findet sich in der östlichen Lehre mit dem Konzept von Brahman, das in den Veden als ,heiliges Wort' bezeichnet wird, der Geist der alles durchdringt. ,Durch das Wissen des, großen Wortes': aham brahma asmi, ich bin Brahman ', wurde Brahman zum Weltall: und so jeder, der dasselbe weiß" (Brihadaranyaka Upanishade 1.4.9.). Oder ist es ein Bewusstsein, das sich emergent aus den sich dann 
entwickelnden Entitäten (Teilchen- bzw. Energiearten) herausgebildet hat, oder ist es ein Gott, wie er in den Religionen angenommen wird? An diesem Punkt sind wir vermutlich an der Schnittstelle zum metaphysischen Bereich angekommen, der im Rahmen dieser Arbeit nicht weiter vertieft werden kann. Festgehalten soll nur werden, dass es eine große Bewegung unter den Naturwissenschaftlern gibt, die eine Erklärung in einer rein physikalischen Emergenz suchen und eine Gegenbewegung, die sich davon löst.

\subsubsection{Die Illusion von Teilchen, Lokalität, Zeit}

Mit der oben vollzogenen Betrachtung sind wir noch im Teilchenmodell der Physik geblieben. Die Quantenphysik stellt dieses Modell nun durch Experimente und Beobachtungen in mehrfacher Hinsicht infrage:

1. Das Erscheinungsbild eines Teilchens hängt von der Beobachtungssituation ab und verwandelt sich in einem unbeobachteten Moment in ein Wellenbild.

2. Zustände sind wahrscheinlichkeits- bzw. möglichkeitsabhängig und nicht deterministisch festgelegt.

3. Wellen entwickeln sich nicht kontinuierlich, sondern ergeben sich durch viele Einzelereignisse.

4. Es scheint keinen leeren Raum zu geben.

5. Zeit verhält sich in keiner Weise mehr wie ein nach vorne gerichteter Zeitpfeil.

Mit dieser Veränderung von einem Teilchen- zu einem Wellenverständnis werden nun konsequent die Beobachtungen (Kap. 8.1.1.1) in ein Modell überführt, das Energie und Information tatsächlich als sehr viel relevanter für unsere Realität erscheinen lässt als bisher angenommen. Gleichzeitig werden die Vorstellungen von Planck, Weizsäcker, Görnitz, Wiener u. a. fundiert hinterlegt. Das Modell ermöglicht ein Verständnis, das die Phänomene bei SyA aus naturwissenschaftlicher Perspektive beschreibt.

Alle fünf Aspekte lassen sich durch das Doppelspalt- (Abb. 42) und seiner Variante, dem Delayed-Choice-Experiment, darstellen. ${ }^{144}$

${ }^{144}$ Eine Gruppe von Physikern verfolgt derzeit einen Ansatz, genannt, quantum retrocausality', der eine kausale Erklärung liefern würde. Aus ihrer Sicht kann die Gegenwart sehr wohl die Vergangenheit beeinflussen. Die Vorträge zu einer Konferenz 2016 in San Diego finden sich unter (Sheehan 2017) oder als einzelne Paper unter https://aip.scitation.org/toc/apc/1841/1? expanded=1841 

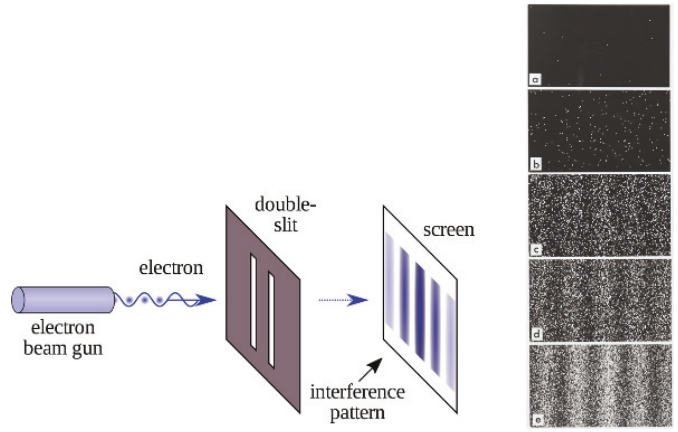

Abb. 42 | Doppelspaltexperiment und seine experimentelle Demonstration

Das linke Bild (CC NekoJaNekoJa) stellt eine Prinzipskizze eines Doppelspaltexperimentes dar. Das rechte Bild (CC Tonomura) zeigt das Interferenzmuster eines realen Doppelspaltexperiments. Jeder Punkt steht für das Ankommen eines Elektrons auf dem Schirm. Anzahl Elektronen: 10 (a), 100 (b), 3.000 (c), 20.000 (d), 70.000 (e) (Tonomura u. a. 1989: 120).

\section{Doppelspalt-Experiment}

Ein Elektronenstrahl (aber auch Photonen, Neutronen, Atome) wird durch zwei parallele Schlitze geschickt und auf einem Schirm ${ }^{145}$ (z. B. Fotoplatte oder andere Detektoren) aufgefangen (Reineker u. a. 2007: 451-452). Drei Varianten treten nun in Erscheinung:

1. Verschließt man einen Spalt, so zeigen sich hinter dem jeweils offenen Spalt Streifen, die das Auftreffen der Elektronen anzeigen.

2. Öffnet man beide Spalten, so findet man keine zwei Streifen, was üblicherweise bei Teilchen zu erwarten wäre, sondern ein Interferenzmuster ${ }^{146}$. Erstaunlicherweise zeigt sich dieses Interferenzmuster auch, wenn die Elektronen soweit reduziert werden, dass sie praktisch einzeln den gesamten Weg von der Quelle bis zum Detektor zurücklegen. Im letzten Fall entsteht der Eindruck, dass die einzelnen Elektronen mit sich selbst interferieren. Aus diesem Experiment leitet sich die Vorstellung der Wellennatur der Elementarteilchen ab. Die Teilchenvorstellung war deshalb nicht aufrechtzuhalten, weil auch die Teilchen, die mit sich selbst interferiert haben, sich als ganze Teilchen erwiesen (ebd. 450).

3. Sind beide Spalten offen und wird jetzt versucht, den Weg der Elektronen zu erkennen, womit eine Beobachtungssituation kreiert wird, so erscheinen wiederum nur zwei Spalten. Das Interferenzmuster verschwindet.

In der experimentellen Demonstration von Abb. 42 (a) bis (e) (Tonomura u. a. 1989) lässt sich die scheinbare Teilchennatur als auch die Wellennatur erkennen. Jedes Elektron erzeugt auf dem Schirm einen Punkt. Je mehr Elektronen gesendet werden, desto

\footnotetext{
${ }^{145}$ Eine ausführliche Darstellung findet sich in (Greenstein und Zajonc 2005: 1-21).

${ }^{146}$ Interferenzmuster sind Überlagerungen zweier oder mehrerer Wellen. Als Ergebnis ergibt sich eine Superposition dieser Wellen.
} 
deutlicher bildet sich der Wellencharakter ab, der erst bei großer Intensität deutlich in den Vordergrund tritt. Wie man sehr schön erkennen kann, wird im Experiment der Wahrscheinlichkeitscharakter der Quantenwelt offensichtlich. Die einzelnen Einschläge lassen sich nicht deterministisch vorhersagen, wie es in der klassischen Welt üblich ist, zusammen bilden sie jedoch ein Verteilungsmuster.

Mithilfe diese Versuches lässt sich auch das quantenphysikalische Verständnis zur Superposition veranschaulichen (Reineker u. a. 2007: 450): Ist der Zustand eines Elektrons vor dem Schirm noch als ein Zustand $|\Psi\rangle$ zu beschreiben, so liegen nach Durchgang durch den Spalt zwei Teilzustände $\left|\Psi_{1}\right\rangle$ und $\left|\Psi_{2}\right\rangle$ vor. Beide Teilzustände zusammen ergeben dann eine Superposition.

$$
|\Psi\rangle=\frac{1}{\sqrt{2}}\left(\left|\Psi_{1}\right\rangle+\left|\Psi_{2}\right\rangle\right)
$$

Diese Gleichung beschreibt zunächst nur die Wahrscheinlichkeitsfunktion für die Zustände hinter dem Schirm. Für die Wahrscheinlichkeit die Teilchen tatsächlich am Ort $x$ auf dem Schirm zu finden, bedarf es, wie schon bei Neumann Kap. 4.2.2.4 ausgeführt, die Berechnung der Wahrscheinlichkeitsdichte.

$$
|\Psi(\mathrm{x})|^{2}=\frac{1}{2}\left[\left|\Psi_{1}(\mathrm{x})\right|^{2}+\left|\Psi_{2}(\mathrm{x})\right|^{2}+\left|\Psi_{1}(\mathrm{x})\right\rangle\left\langle\Psi_{2}(\mathrm{x})|+| \Psi_{2}(\mathrm{x})\right\rangle\left\langle\Psi_{1}(\mathrm{x})\right|\right]
$$

Die Terme eins und zwei stehen für die Wahrscheinlichkeit, dass die Teilchen durch Spalt 1 oder Spalt 2 geflogen sind. Die weiteren Terme beschreiben das Interferenzmuster.

Weshalb in einer Beobachtungssituation sich ein klassisches Bild zeigt, wird durch eine genaue quantenphysikalische Betrachtung ebenfalls anschaulich. Für die Beobachtung bedarf es einer Wechselwirkung mit einem Detektor (z. B. Lichtblitz oder induzierter Stromstoß). Diese Wechselwirkung beeinflusst den Zustand des Teilchens und liefert eine konkrete Information über den Ort. Mit diesem tiefen Eingriff auf physikalischer Ebene verschwindet die Unbestimmtheit und dadurch die Superposition der Quarticle ${ }^{147}$. Konsequenterweise löst sich dann die Interferenz (Term 3 und 4) auf und es verbleiben nur noch Term 1 und 2. Ein Teil der Physiker spricht jetzt vom Kollaps der Wellenfunktion, von vielen Möglichkeiten zu einem Faktum, bei gleichzeitigem Verschwinden der ursprünglich vorhandenen anderen Möglichkeiten. Ein anderer Teil der Physiker spricht bei einem solchen Vorgang von Dekohärenz, einem Verlust der Superposition und Übergang in Zustände ohne Interferenz. Diese gängigen Erklärungsmodelle werden jedoch zweifelhaft, wenn die wechselwirkungsfreien Messverfahren herangezogen werden. Ein solches Verfahren stellt das Mach-Zehnder-Interferometer (ebd. 493) zur Verfügung. Wenn keine Wechselwirkung existiert, wie erklärt sich dann die Zustandsveränderung?

Als weitere Konsequenz wird auch verständlich, weshalb die Quantenphysik erkannt hat, dass Kontext (Lapkiewicz u. a. 2011) und Beobachter eine zentrale Rolle für den

${ }^{147}$ In diesem Zusammenhang werde ich weiterhin für den Begriff des Teilchens in der Quantenphysik den Begriff ,Quarticle' verwenden, der auf Wilczek (Wilczek 2017) zurückgeht und quantenphysikalische Teilchen beschreibt, für die die Unbestimmtheitsrelation gilt. 
Ausgang eines Experimentes spielen. Ihre Wechselwirkung mit dem zu beobachtenden System verändert das System und damit auch die $\Psi$-Funktion. Wie dieses Geschehen zu verstehen ist, wird heute noch nicht einheitlich beantwortet. Die Kollaps-Interpretation und die Dekohärenztheorie kommen zu unterschiedlichen Auslegungen. Neue Experimente im Kontext von Verschränkungsuntersuchungen ermöglichen eine Überwindung dieser Pole. Beide Ansätze spielen eine wichtige Rolle für das weitere Verständnis und werden noch vertieft betrachtet, deshalb mehr dazu in diesem Kap. und in Kap. 8.1.2. Eine weitere Einschränkung ergibt sich aus dem Zweifel einer besonderen Rolle des Bewusstseins beim Messprozess (ebd. 458), auf das ebenfalls weiter unten und im Kap. 8.1.3 eingegangen wird.

Vergleichen wir das quantenphysikalische Wellenmodell mit EM-Wellen oder Wasserwellen so lässt sich folgendes konstatieren:

EM-Wellen erscheinen zwar als kontinuierliche Wellen, unterliegen aber den gleichen Gesetzmäßigkeiten, da sie als EM-Strahlung aus Quanten aufgebaut sind. Diese scheinbar kontinuierlichen klassischen Wellen setzen sich konsequenterweise ebenfalls aus vielen Einzelereignissen zusammen, zumindest wenn man sie misst. Sie unterscheiden sich nur durch Wellenlänge und Frequenzen und bilden das gesamte EM-Strahlungsspektrum ab, von Radio- bis Gammawellen. Licht-Photonen sind dabei ebenfalls Quanten, nur dass sie für uns als sichtbares Licht erscheinen.

Das Gleiche gilt im Grunde auch für Wasserwellen. Die scheinbar einheitliche, an der Oberfläche sichtbare Welle setzt sich aus vielen kleinen Einzelwellen zusammen, die zudem auch noch unterschiedliche Frequenzen und Wellenlängen haben. Sichtbar ist deshalb auch hier nur die Superposition des Gesamtsystems.

Mit diesen Erkenntnissen sind die Punkte 1 bis 3 (Beobachtungsabhängigkeit, nicht deterministisch, Wellen zusammengesetzt aus vielen Einzelergebnissen) unterlegt und der Unterschied zur klassischen Vorstellung veranschaulicht. Die verbreitete Vorstellung, dass sich diese Phänomene nur im rein Mikroskopischen und bei sehr niedrigen Temperaturen ereignen und beobachten lassen, wird als nächstes widerlegt.

\section{Quantenphysik in Makrosystemen und Hochtemperatur}

Die experimentellen Entwicklungen führen die Evidenz von quantenphysikalischen Möglichkeiten auch in unserer normalen Umwelt vor Augen. Dies liefert die Voraussetzung für Quantenprozesse in biologischen Systemen.

Mittlerweile wurde das Doppelspalt-Experiment nämlich erfolgreich mit Makrosystemen durchgeführt, wozu Bose-Einstein-Kondensate nahe dem Nullpunkt (Ketterle 2002) und komplexe Moleküle wie Fullerene (Sezer u. a. 2015; Gerlich u. a. 2011; Arndt u. a. 1999) zählen. In diesen Fällen sprechen die Physiker von Materie-Wellen. In weiteren Versuchen konnte das Mikrogitter durch ein Gewebeskelett von Algen ersetzt werden (Sclafani u. a. 2013). Damit lässt sich zeigen, dass Zellen respektive deren Gewebestruktur wie ein Doppelspalt zu wirken vermögen, hinter dem eine quanten- 
physikalische, kohärente ${ }^{148}$, wellenmäßige Ausbreitung der Information möglich ist. Die Nachweismöglichkeit mit ihrer Technologie erstreckt sich nach Arndt u. a. bis zur Größe von Viren, Proteinen und darüber hinaus (Arndt und Hornberger 2014; Hackermüller u. a. 2004).

Die Forscher können zeigen, dass dieses Verhalten in biologischen Makrosystemen mit deren Speicherfähigkeit von Energie zusammenhängt und der quanten-klassische Übergang z. B. bei $\mathrm{C}_{70}$ Fullerene im Bereich von über 600 bis $2.700{ }^{\circ} \mathrm{C}$ liegt. Verantwortlich dafür wird die thermische Emission von Photonen (ebd.) gemacht, die in thermischen Nicht-Gleichgewichts-zuständen eben nicht notwendigerweise ihren kohärenten Zustand verlieren und dekohärieren. Gleichzeitig wird auch die Vorstellung überholt, dass quantenphysikalische Experimente nur bei nahe $0{ }^{\circ} \mathrm{C}$ durchgeführt werden können.

Neue Experimente (Tomkovič u. a. 2014) zeigen, dass spontan emittierte Photonen unter gewissen Umständen (hier ein in der Nähe befindlicher Spiegel) ein verschränktes Atom-Photon System aufbauen. Dabei fungiert das emittierte Photon quasi als kohärenter Strahlenteiler für die Materiewelle der Atome, vergleichbar dem Teiler zwischen den beiden Spalten des Doppelspaltexperiments. Diese Beobachtung eröffnet zusammen mit dem Experiment von Sclafani u. a., bei dem die Zellstruktur der Alge als Doppelspalt fungiert, eine Option für die Erklärung einer quantengleichen, wellenartigen Ausbreitungsdynamik von Photonen in Algen (Chin u. a. 2013), welche in Kap. 8.2, Biologie, noch eine Rolle spielen wird. In diesem Fall würde die Skelettstruktur wie bei Sclafani u. a. das Gitter bilden und die Photonen würden sich als Welle innerhalb der Zelle ausbreiten, bei gleichzeitigem Aufbau einer Atom-Photon-Verschränkung. Ein Mechanismus, der auch im Kap. 8.3, Neurowissenschaften, zum Tragen kommt. Nach den oben erwähnten Experimenten stellt die Temperatur in den Zellen ebenfalls keine verhindernde Größe mehr dar und wird deshalb irrelevant für die Frage von Quantenprozessen in lebenden Entitäten sein.

\section{$\underline{\text { Welle-Teilchen-Dualismus }}$}

In fast allen wissenschaftlichen Abhandlungen wird auf Grund der obigen Beobachtung von einem Welle-Teilchen-Dualismus gesprochen und gerne auch als unumstritten dargestellt. Tatsächlich existieren einige kritische Anmerkungen zu diesem Modell und zahlreiche alternative Erklärungen. Drei werden hier näher betrachtet, denn sie sind für den Übergang von der Quanten- zu Makrowelt relevant:

1. Kopenhagener Interpretation

2. De-Broglie-Bohm-Theorie

3. Erweiterte De-Broglie-Führungswellen-Theorie

${ }^{148}$ lat.: cohaerere $=$ zusammenhängen; Kohärenz beschreibt hier alle Korrelationen (Beziehungen, Zusammenhänge) zwischen physikalischen Größen. Sie ist eine physikalische Eigenschaft von Wellen, die Interferenzphänomene ermöglicht. 
$\mathrm{Zu}$ (1) Kopenhagener Interpretation (KI)

Die oben bereits beschriebene Idee, dass sich die Elektronen wie eine Welle ausbreiten und erst durch die Beobachtung zu einem Faktum kollabieren, entspricht der KI. Sie haben allerdings zunächst keine definierte Position im Raum, und deshalb kann auch jedes Elektron durch beide Spalten gleichzeitig gehen und mit sich selbst interferieren. Zudem wird hier die Vorstellung vertreten, dass das Elektron erst durch den Prozess der Messung entsteht.

\section{$\mathrm{Zu}$ (2) De-Broglie-Bohm-Theorie (DBBT)}

Die erste Idee in der Quantenphysik, dass Teilchen sich wie Wellen verhalten, geht auf De Broglie zurück (Broglie 1987). Er verwendete auch als erster den Begriff der Führungswelle (engl. ,pilot wave'), ohne jedoch Angaben zu ihrer physikalischen Grundlage zu liefern. Auf ihm basiert das heutige Konzept des, Quantenvakuums' (Bush 2015: 49). In späteren Jahren unterzog er seinen Ansatz einer Neuinterpretation (Broglie 1970), indem er den von Bohm entwickelten Ansatz, bekannt unter ,Bohmscher Mechanik' (Bohm und Hiley 1982), mit einbezog. Beide Theorien firmieren heute gemeinsam unter, De-Broglie-Bohm-Theorie'.

Die alternative Vorstellung der Bohmschen Mechanik geht von einer immer vorhandenen, definierten Position des Elektrons aus. Seine Position wird jedoch von einer Führungswelle beeinflusst. Während in diesem Modell die Elektronen nur durch ,einen' Spalt wandern, durchläuft die Führungswelle beide Spalten gleichzeitig. Durch den gleichzeitigen Durchgang der Führungswelle durch die Spalten entstehen Interferenzen, die die beobachtbaren Interferenzmuster verursachen. Unter Beobachtung (Messung am Spalt) tritt eine Störung der Führungswelle bereits am Spalt auf und verrät so den Weg des Elektrons (Balken statt Interferenzmuster). Die Lokalisation ergibt sich erst durch diese Messung.

Bohm verwendet bei seinen Berechnungen sowohl die zeitabhängige Schrödingergleichung als auch eine Führungsgleichung, in der die Wellenfunktion das Teilchen führt. Beide Modelle (KI und DBBT) lassen sich experimentell nicht unterscheiden, da sie jeweils die exakt richtigen Werte für die Messungen liefern. Ihr zentraler Unterschied bezieht sich nur auf den Beitrag zur Erklärung der Phänomene wie dem Doppelspalt. Neueste Experimente (Mahler u. a. 2016) konnten die Annahmen von Bohms Theorie exakt bestätigen und werden vermutlich dieser wenig beachteten Interpretationsvariante neuen Auftrieb geben.

\section{Zu (3) Erweiterte De-Broglie-Führungswellen-Theorie (EDBFT)}

Experimente im Bereich der Strömungsmechanik mit mikrokleinen Tropfen (Couder und Fort 2006) zeigen überraschend hohe Ähnlichkeit mit Quantenverhalten ${ }^{149}$. SilikonTropfen schweben über einer Oberfläche von vibrierendem Silikonöl (Bad), angetrieben durch ihr eigenes Wellenfeld (Abb. 43). Die Vibration ist auf eine Frequenzschwelle des

\footnotetext{
${ }^{149}$ Quantenverhalten wie: ,, single particle diffraction, tunneling, wave-like statistics in confined geometries, quantized orbits, spin states, orbital-level splitting, and more" (Bush 2015: 48).
} 
Bades eingestellt, bei der sich keine Kohärenz zwischen Bad und Tropfen zeigt, weshalb der Tropfen nicht ins Silikonöl eintaucht und kein ununterscheidbarer Teil des Ganzen wird. Die Tropfen oberhalb der Oberfläche bleiben stabil, wohl aber finden Wechselwirkungen zwischen Bad und Entität statt. Diese Beobachtung übertragen Bush und andere auf ein Modell der ,wandernden Tropfen', das näher bei De Broglie als bei Bohm lieg $\mathrm{t}^{150}$. Berechnungen und Überlegungen führen zur Idee, dass in diesen Experimenten der Übergang von der Quanten- in die Makrowelt beobachtbar ist und dass die Quantenwelt entsprechend aufgebaut sein könnte.

Der Ablauf am Doppelspalt verhält sich danach analog zu einer realen Welle, die auf ein Hindernis trifft, wobei sich die Elektronen mithilfe ihres selbst generierten Wellenfelds auf der Welle des Vakuumfeldes reitend im Raum ausbreiten und selbstgesteuert einen Spalt aussuchen, jedoch zunächst ohne von außen wahrnehmbare spezielle räumliche Lokalisation. Auch hier ergibt sich die Lokalisation erst durch eine Messung.

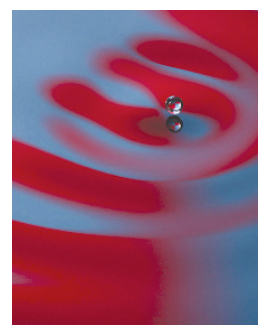

Abb. 43 | Tanzender Tropfen

(Image aus Bush 2015). Ein Silikontropfen schwebt über einer Oberfläche aus Silikonöl. Dies gelingt durch unterschiedliche Schwingungsfrequenzen von Tropfen und Öl. Auf der Oberfläche des Öls bildet sich ein Wellenfeld, das die Wechselwirkung sichtbar werden lässt.

Interessant ist die erstmalig entwickelte Vorstellung einer direkten Verbindung von elektromagnetischem Feld (EMF) und dem Feld des Quantenvakuums. La Peña und seine Gruppe weisen diesen Zusammenhang über die Verbindung von der De-BroglieWellenlänge zur Natur von EM-Wellen und deren Vibrationen sehr klar nach (Peña u. a. 2015).

Demnach stammt die Führungswelle aus dem Vakuum- bzw. Null-Punkt-Feld und strukturiert das Gesamtsystem. Die Vibrationen der Entitäten wiederum, also die Schwingungen dessen was wir als Partikel/Entitäten wahrnehmen, triggern die Führungswelle, indem sie selektiv mit Wellen im Vakuumfeld in Resonanz treten. Diese Resonanzwechselwirkung verstärkt wiederum die EM-Führungswelle und macht sie und die Entitäten selbst für uns wahrnehmbar (Bush 2015: 49 u. 52). Die moderne Erweiterung erscheint nach Bush als eine plausible Möglichkeit, die Brücke zwischen Mikro- und Makrokosmos zu schließen.

\footnotetext{
${ }^{150}$ Bei Bohm gibt es keine wirkliche Unterscheidung zwischen dem Teilchen und seiner Führungswelle. Bei De-Broglie dagegen kann dem Quarticle eine größere Eigenständigkeit zugesprochen werden.
} 
Im Quantum Magazin wird Bush (Damiano u. a. 2016) mit den Worten zitiert: „, This is a classical system that exhibits behavior that people previously thought was exclusive to the quantum realm, and we can say why. [...] The more things we understand and can provide a physical rationale for, the more difficult it will be to defend the 'quantum mechanics is magic' perspective" Bush in (Wolchover 2014). Bush weist mit seinem Modell einen Weg auf, der die Inkonsistenzen der KI überwindet und nachvollziehbare Zusammenhänge anbietet, zumindest aber die Möglichkeit eröffnet, neu Theoriebildungen anzustoßen. Aus dem jetzigen Ansatz von Bush reduzieren sich zumindest die Unterschiede zwischen Quanten- und klassischer Physik auf wenige Merkmale.

An gleicher Stelle kommen aber auch einige kritische bzw. zweifelnde Stimmen zum Ausdruck, die dem Konzept der Führungswelle noch nicht folgen wollen. Einer der Interviewpartner stellt fest: Die Theorie ,, only describes simple interactions between matter and electromagnetic fields " Wallace (in Wolchover 2014).

Für einen neutral Außenstehenden wirft diese Aussage natürlich Fragen auf: Welche Ergebnisse benötigt eine Physik, um Theorien auszusortieren, die offensichtliche Lücken besitzen? Wie lässt sich wieder eine Offenheit für neue Theoriebildungen generieren, wenn Beispiele aus der Physik selbst diese nicht initiieren können? Die KI mit ihrer rein mathematischen Wirklichkeitskonstruktion lässt in jedem Fall viele Fragen offen, die sich für das Phänomen SyA und Intuition stellen.

Unterschiede und Gemeinsamkeiten:

Der wesentliche Unterschied der drei Modelle liegt in ihren Annahmen. So geht die KI von einer reinen Wahrscheinlichkeitsbetrachtung aus, bei der vor der Messung nichts existiert und festgelegt ist, wohingegen die DBBT und EDBFT rein deterministisch interpretiert werden. Alle drei Theorien beinhalten allerdings das Konzept der Nicht-Lokalität, das Korrelationen bzw. Wechselwirkungen auch über räumliche und zeitliche Entfernungen zulässt, wie sie nachfolgend im Delayed-Choice-Experiment auftreten und auch über kosmische Distanzen nachgewiesen wurden (Leung u. a. 2018). Im Gegensatz zur KI bieten die beiden anderen Ansätze einfacher nachvollziehbare Modelle für das, was als Fernwirkung (spooky actions) bezeichnet wird und in SyA beobachtet werden kann, denn die Wellenfunktion bei Bohm und De-Broglie bindet letztlich alle Entitäten des gesamten Universums zusammen. Im Gegensatz zur reinen Wahrscheinlichkeitsbetrachtung im Kopenhagener Ansatz bleibt auch hier die Wahrscheinlichkeitsrechnung gültig, nur ergeben sich die Resultate aus den Aktionen und Wechselwirkungen aller involvierten Entitäten und nicht nur rein zufällig; letztlich auch zwischen der Messapparatur und dem Bediener (Mahler u. a. 2016: 1). Auch wenn die letzten beiden Modelle als deterministisch angesehen werden, beinhalten sie keine deterministische Festlegung der Zukunft. Die unüberschaubare Komplexität, ausgelöst durch die Wechselwirkungsmöglichkeiten aller Entitäten über Raum und Zeit, ermöglicht eine sich immer weiter entwickelnde Emergenz neuer Möglichkeiten.

Mit der DBBT und der EDBFT erscheint nun eine neue Frage: Handelt es sich um lokale oder nicht-lokale Theorien bzw. Realitäten? In unserer Wahrnehmung scheint die Nicht-Lokalität die richtige Antwort. Durch die Verbindung mittels Führungswelle 
schrumpft das Universum andererseits zu einem einzigen Ort zusammen, der zwar ausgedehnt ist, in dem jedoch alles miteinander in Verbindung steht. Strenggenommen kann man auch hier von einer Superposition sprechen, eine Überlagerung von lokal und nicht-lokal, von Verbindung und Trennung, abhängig von der Perspektive. Aus der Perspektive eines Menschen würden wir auch nicht von nicht-lokal sprechen, wenn Störungen bei Nerven im Gehirn zu Problemen an den Füßen führen oder grundsätzlich mentale Probleme (z. B. Trauer) Herzprobleme nach sich ziehen. Würde eine beliebige Zelle im Körper die gleiche Antwort geben? Zeh meint zur Wirklichkeitskonstruktion der Quantenphysik, dass sie den „Begriff lokaler realer Zustände aufgeben muss - nicht aber den einer global definierten Realität" (Zeh 2011: 25). Die Antwort in erster Näherung würde er somit als Problem der Dimensionen auffassen. Die Antwort zweiten Grades könnte das Problem als komplementäres Phänomen beschreiben, bei dem durch eine Beobachtung (Messung) nicht beides (lokal und nicht-lokal) gleichzeitig erkannt werden kann.

Aus Bohm's Sicht lässt sich das Problem einer wechselseitigen Wirkung über Entfernung oder Superpositionen interner Zustände in jedem Fall nicht einfach auf separierte Teilsysteme reduzieren, wie es in den meisten Modellen geschieht. Entsprechend wird der DBBT von einigen Wissenschaftlern eine holistische Perspektive zugeschrieben: „to see the world as an undivided whole" (Greenstein und Zajonc 2005: 166). Sie ist, wie es aussieht, aktueller als je zuvor ${ }^{151}$.

\section{$\underline{\text { Welle - Teilchen - Unterscheidung im Rahme der QFT }}$}

Wie bereits in Kap. 5.3.6 ausgeführt, werden in der QFT Systeme, die sich aus mehreren Teilchen zusammensetzen als Quantenfelder betrachtet. Mit der QFT erweitert sich jetzt der Anwendungsbereich quantenphysikalischer Überlegungen. Die Behandlung der Quantenmechanik in diesem Kapitel ist deshalb nötig, weil sich auf ihrer Ebene der erste Übergang zur Information verorten lässt. Mit der Erweiterung auf QFT entspricht das quantenphysikalische Verhalten nicht mehr dem des einzelnen Teilchens, sondern nur noch dem des gesamten Feldes. Konsequenterweise werden in der QFT deshalb Teilchen und Wellen gleichbehandelt, was damit auch den Welle-Teilchen-Dualismus der Quantenmechanik grundsätzlich auflöst (Kuhlmann und Stöckler 2015: 226). Die bisher in diesem Kapitel vorgestellten Modelle resultieren noch aus dem Versuch der Quantenmechanik einzelnen Entitäten gezielte Eigenschaften zuzuordnen.

Große Mehrteilchensysteme besitzen jedoch ein Bündel solcher Eigenschaften, die ein ganzes Feld aufspannen, welches ebenfalls mit einer Wellenfunktion $\Psi$ beschrieben

${ }^{151}$ Eine Bestätigung würde auch Bell recht geben, der zu einem ausgewiesenen Unterstützer der Führungswellen-Theorie wurde und zu dieser Theorie verlauten ließ: Sie, die Führungswelle, ,, seems to me so natural and simple, to resolve the wave-particle dilemma in such a clear and ordinary way, that it is a great mystery to me that it was so generally ignored " (Wolchover 2014). Denn er ging ebenfalls von einem existierenden Mechanismus aus: ,, there must be a mechanism whereby the setting of one measuring device can influence the reading of another instrument, however remote "Bell in (Josephson und Pallikari-Viras 1991: 199). 
werden kann und sich deutlich über den normalerweise beobachtbaren Ausdehnungszustand hinaus erstreckt. Im klassischen Sinne sind damit die von jeder Entität abstrahlenden EMF zu sehen. Im quantenphysikalischen Sinn kommen alle Verschränkungszustände hinzu.

In Anbetracht dessen, dass dem Vakuum ein Quantenzustand mit einer Wellenfunktion zugebilligt wird und mit ihr unendlich viele Freiheitsgrade fundamentaler Felder repräsentiert werden (Zeh 2011: vgl. 24), gleichzeitig die Kosmologie das Universum mit einer Wellenfunktion für den Kosmos beschreibt (Görnitz und Görnitz 2009), liegt es nahe den Übergang vom Photon zum Kosmos in der gleichen Logik zu behandeln:

$$
\Psi_{\text {Vakuum }} \Psi_{\text {Photon }} \Psi_{\text {Atom }} \Psi_{\text {Molekül }} \Psi_{\text {Organ }} \Psi_{\text {Mensch }} \Psi_{\text {Kosmos }}
$$

Mit jeder Größenordnung erweitern bzw. verändern sich die Möglichkeiten der Beziehungen zwischen den Quantenfeldern. Es wird offensichtlich, dass es unter dieser Perspektive keinen Sinn macht, noch von Teilchen zu sprechen. Aus Sicht von Zeh können die Wellenfunktionen der mikroskopischen Einzelentitäten immer nur vorübergehend als „,separat existierend betrachtet werden“, da sie sich „mit der Umgebung und dadurch häufig auch mit der internen Wellenfunktion verschränkt " (Zeh 2011: 100).

D. h. die Verschränkung der jeweiligen Subsysteme (Atom, DNA, Mensch) ist für sich genommen jeweils stärker als die Wechselwirkung mit der Umgebung, was zum Eindruck einer Dekohärenz führt. Gleichzeitig ist sie nicht ohne diese Verschränkung zu denken, nur entzieht sich diese Verschränkung mit der Umgebung einer direkten Beobachtung. Allgemein gilt: ,,Bei wechselwirkenden Quantenfeldern [...] müssen die internen Energieeigenzustände durch eine stabil verschränkte Feldkonfiguration beschrieben werden - eine Situation, die sich wegen ihrer Komplexität gewöhnlich einer quantitativen oder gar exakten Behandlung entzieht " (ebd.).

Keine quantitative oder exakte Behandlung bedeutet den zwingenden Rückgriff auf qualitative Messformen, wollen wir etwas über die Systeme aussagen.

Abschließend zur Frage ,Welle oder Teilchen?` zwei Zitate, die den aktuellen Stand sehr treffend beschreiben:

„Students should not be led to doubt that electrons, protons and the like are particles [...] The waves cannot be observed in any way than by observing particles. "(Mott 1964: 409)

„The electron is either here, or there, or somewhere else, but wherever it is, it is a point charge. " (Feynman u. a. 1965)

Die erste Aussage lässt sich ebenso als treffend betrachten wie die von Feynman. Unsere Beobachtung nimmt nur so etwas wie Partikel wahr, was letztlich aber nur Punktladungen sind. Auch Zeh interpretiert beispielsweise Photonen als ,, intern punktförmig “ (Zeh 2011: 101). Unglücklicherweise führt die Umsetzung der ersten Empfehlung sehr leicht zum Glauben, dass wir es mit fester Materie zu tun haben und zum Ausblenden aller anderen Optionen. 


\section{Delayed-Choice-Experiment und Quanten-Radierer}

Das was sich beim Doppelspaltexperiment zeigt, hängt davon ab, was wir beobachten wollen. Dass dies auch in unserem Zeitverständnis rückwärtslaufen kann, veranschaulicht eine modifizierte Form dieses Experimentes. Beim Delayed-Choice-Experiment wechselwirkt ein Quantensystem mit einem anderen System. Das andere System kann eine automatische Vorrichtung oder ein Experimentator sein (Reineker u. a. 2007: 492; Greenstein und Zajonc 2005: 39-44), die die experimentellen Vorgaben erst ändern, nachdem z. B. die Elektronen bereits durch die Spalten getreten sind. Ergäbe die Ausgangseinstellung ein Interferenzmuster am Schirm und der Aufbau wird im Nachgang Richtung Teilchenbild mit zwei Spalten verändert, so zeigt sich tatsächlich das Teilchenbild (Jacques u. a. 2007). Zentral bei diesem Experiment ist, dass der Versuchsleiter zwar messen, diese Ergebnisse aber erst nach Änderung der Einstellungen anschauen darf.

Nach unserem alltäglichen Weltbild müsste nach Passieren der Spalten das Wellenbild erscheinen. Es drängt sich der Eindruck auf, dass das Teilchen mit dem Experimentator auch über die Entfernung verbunden ist und zeitgleich, oder gar schon vorausschauend, die Veränderung in der Einstellung mitbekam bzw. antizipiert.

Dass Quantenobjekte wissen, was die richtige Wahl ist, macht sich auch die Arbeit mit Quantencomputern oder Feynman mit seinen Pfadintegralen zunutze. Ein Umstand, der mit einer Verschränkungstheorie, die das Umfeld mit einbezieht, in Übereinstimmung wäre. Damit zeigt sich auch die Relevanz des Gesamtaufbaus. Ein Ergebnis entwickelt sich in der Quantenwelt nicht in zeitlich wohldefinierten Schritten. Für wohldefinierte Schritte wäre der Zeitpunkt nach Durchgang durch die Spalten bereits zu spät. Dass die Zeit aber tatsächlich irrelevant ist, zeigen Gedankenexperimente und reale Experimente, die auch dann noch erfolgreich sind, wenn die Einstellungsänderung erst am nächsten Tag oder Milliarden von Jahren später vorgenommen wird; z. B. für die Untersuchung der Strahlung von Quasaren (Reineker u. a. 2007: 492).

Durchgeführte Experimente zeigen tatsächlich diese theoretische Vorhersage einer Veränderung der beiden Zustände erst nach der Messung und sogar eine Gleichzeitigkeit von Welle- und Teilchenverhalten (Kaiser u. a. 2012; Peruzzo u. a. 2012); eine typische quantenphysikalische Überlagerung. Die Autoren der beiden Veröffentlichungen stellen in ihrer Conclusio die bisher naive Unterscheidung von Welle und Teilchen infrage. Da beides gleichzeitig als Überlagerung erscheint, stellt sich die Frage, ob es einen prinzipiellen Unterschied der beiden Zustände überhaupt gibt, oder ob sie nicht tatsächlich ausschließlich ein Beobachtungsphänomen darstellen.

In einem ähnlichen Experiment, allerdings nicht mit einer Doppelspaltanordnung wohl aber mit einem Delayed-Choice-Versuchsaufbau in Verbindung mit einer Quanten-Teleportation, gelang es Photonen sogar erst im Nachgang zu verschränken, zu einem Zeitpunkt als die Photonen schon lange gemessen und Verschränkungspaare nicht länger existent waren (Ma u. a. 2012b). Die Experimentatoren realisierten damit ein Gedankenexperiment, welches der Physiker Peres bereits 2000 entwickelt hatte (Peres 2000). 
Mithilfe einer GHZ-Versuchsanordnung ${ }^{152}$ und Photonen konnten Ma und Kollegen zeigen, dass auch wenn erst im Nachgang zur Messung die Wahl der Versuchseinstellung getroffen wurde, die Ergebnisse streng korrelierten. Solange niemand die Messergebnisse vorher auswertet, verhielten sich Photonen entsprechend den Versuchseinstellungen. Was bedeutet, dass nach unserem Zeitverständnis die Photonen zum Zeitpunkt der Messung bereits wussten, was später eingestellt werden würde. Die Autoren der Studie formulierten entsprechend: „This can also be viewed as ,quantum steering into the past'“ (Ma u. a. 2012b: 479).

Der im Verständnis der KI formulierte Erklärungsansatz lautet: Das entfernte Objekt hat sich instant verändert, was eine geisterhafte Fernwirkung erfordert. Demgegenüber heißt es nach dem Verständnis der Dekohärenztheorie: „Der Quantenzustand ist bereits nichtlokal und erfordert daher keine Fernwirkung mehr" (Zeh 2011: 86). Auch hier wird eine existierende Verbindung auf fundamentaler Ebene herausgestellt. Der Raum zwischen Quantenobjekten ist demzufolge nicht leer und auch die Zeit verhält sich nicht wie wir üblicherweise glauben, sondern ermöglicht ein wechselseitiges Wissen, womit auch Punkt 4 (Nichtexistenz eines leeren Raumes) verifiziert ist.

Wir haben es in den drei letzten Fällen mit dem zu tun, was als Quanten-Radierer (Quantum Eraser) bekannt ist. In einem solchen Experiment ist es möglich, ein früheres Messergebnis wieder rückgängig zu machen und z. B. ein Interferenzmuster wieder erscheinen zu lassen. Klassisch gesprochen heißt das dann, dass die Information wieder ausradiert (vernichtet) wird. Hierzu bietet Zeh aus der Dekohärenztheorie heraus eine andere Antwort an:

„Ein ,Radieren“ (also eine Transformation der physikalisch vorliegenden Information in unkontrollierbare, also etwa thermische Freiheitsgrade) würde die Dekohärenz nur verstärken. Der sogenannte Quantenradierer erfordert eine Refokussierung der Superposition auf das lokale System - also den physikalischen Vorgang einer Rekohärenz, der nur bei mikroskopischen Systemen realisierbar ist “ (ebd. 86). Die Ausdehnung der quantenphysikalischen Mechanismen auf den Homo Physicus als Mixed-System widerspricht diesem Verständnis nicht. Denn die mentalen Vorgänge bei SyA und Therapie erscheinen genau in dieser Weise, nur auf mentaler und damit auf mikroskopischer Ebene. Umstellungen oder Reintegrationen in der Aufstellung, genauso wie Umdeutungen und emotionaler Neuaufbau von Beziehungen entsprechen exakt einer solchen Refokussierung bzw. Rekohärenz.

Nach Feynman lässt sich dieses Paradoxon ,, auch als Summe der beiden Möglichkeiten auffassen ' und es bedeutet nicht, dass erst in diesem Augenblick die Wellenfunktion kollabiert. Vielmehr wird eine der beiden bis dahin nur als Möglichkeiten existierende Historie zur Realität, die andere wird gelöscht “" (Reineker u. a. 2007: 458-459). Seine nach ihm benannten Feynman-Diagramme veranschaulichen diese Option sowohl gra-

${ }^{152} \mathrm{GHZ}$ steht für Greenberger, Horner, Zeilinger, die Entwickler dieses Experiment. In Kap. 8.1.4 wird es näher beschrieben. 
phisch (Abb. 44) als auch mathematisch (8.6). In seinen Beschreibungen zu Beispielen wird deutlich, dass für ihn die Vorstellung eines in der Zeit zurücklaufenden Vorgangs kein Problem darstellt. „Der Weg eines solchen rückwärts laufenden Elektrons kann sogar so lang sein, dass es bei Experimenten im Labor wirklich in Erscheinung tritt" (Feynman 1992: 115).

Der mathematische Ausdruck lautet:

$$
\Psi_{g}=\Psi_{1} \Psi_{2}+\Psi_{2} \Psi_{1}
$$

Mit $\Psi_{g}$ als Gesamtzustand des Systems, $\Psi_{1}$ als Ausgangs-Zustand und mit $\Psi_{2}$ als EndZustand. Die Reihenfolge gibt den Zeitpfeil der Entwicklung an, mit 1-2 Richtung Zukunft und 2-1 Richtung Vergangenheit. Formal benötigt es in jedem Fall die Berücksichtigung beider Varianten in der Gleichung, um ein mit dem Experiment korrespondierendes mathematisches Ergebnis zu erzielen (Greenstein und Zajonc 2005: 66). Damit liegt immer auch eine Superposition von Vergangenheit und Zukunft vor.

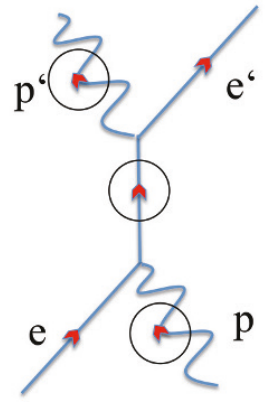

a)

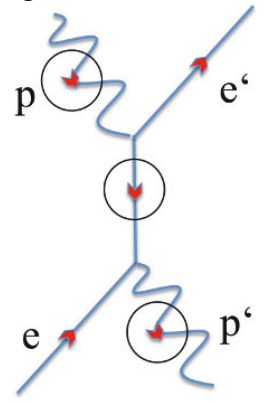

b)

Abb. 44 | Feynman-Diagramme

(a) mit einer Vor-Beziehung entsprechend einer Wirkung von der Vergangenheit in die Zukunft.

(b) mit einer Nach-Beziehung entsprechend einer Wirkung von der Zukunft in die Vergangenheit.

Mit e und e' als Elektron sowie p und p' als Photon jeweils vor und nach dem Zusammenstoß (eigene Darstellung).

Feynman lässt mit seinem Konzept der Pfadintegrale und der damit verbunden Aufsummierung aller Möglichkeiten viele Optionen der Interpretation zu. In Bezug auf eine ähnliche wie in Abb. 44 dargestellten Variante, dass das Photon sowohl in der Zeit nach vorne und nach hinten laufen kann, führt er aus: ,, Was die Berechnung (und die Natur) angeht, ist das alles ein und dasselbe (und alles genauso gut möglich) “ (Feynman 1992: 113).

Womit auch der letzte, der eingangs aufgelisteten Punkte, seine Bestätigung findet. Es gibt keinen eindeutig von der Vergangenheit in die Zukunft gerichteten Zeitpfeil. Vergangenheit und Zukunft können Einfluss auf den Zustand eines Systems nehmen. 


\section{Übertragung auf SyA und Therapie}

Interpretiert man diesen Zusammenhang, so ergibt sich eine mögliche Schlussfolgerung in der Form, dass alles was in der Gegenwart noch kein Faktum geworden ist, sondern sich nur im Möglichkeitsraum (mentaler Raum) bewegt, in der Vergangenheit verändert werden kann. Betrachten wir das Geschehen im therapeutischen oder grundsätzlich im Gesundheitsbereich, so finden sich hierzu sehr passende Parallelitäten. Das Faktum eines amputierten Armes lässt sich nicht wieder zurückentwickeln (im Sinne von Zeh eine echte Dekohärenz), anders als es bei defekten Zellen, teilweise auch Nerven oder mentalen Zuständen beobachtbar ist. Letztere würden bei Zeh als virtuelle Dekohärenz interpretiert. Bei SyA ist sehr häufig das Phänomen erlebbar, dass Geschehnisse in der Vergangenheit, die mentaler Natur waren, sich nach der Aufstellung vollständig verändert bzw. aufgelöst haben (siehe Bsp. 3 in Kap. 3.2.1, Reaktion eines weit entfernten Umfeldes). Gleiches gilt auch für positive Entwicklungen gesundheitlicher Zustände im Anschluss zu Aufstellungen.

\subsubsection{Neuinterpretation der Wellenfunktion}

Wie aus den verschiedenen Interpretationen hervorgeht, bestehen sehr unterschiedliche Verständnisse über das, was die Wellenfunktion repräsentiert. Im Folgenden soll der Versuch einer Neuinterpretation vorgenommen werden, der die verschiedenen Perspektiven miteinander versöhnt und wie bei der Information eine Normierung bedeuten würde.

Nach Schrödinger ist die $\Psi$-Funktion ,jetzt das Instrument zur Voraussage der Wahrscheinlichkeit von Maßzahlen. In ihr ist die jeweils erreichte Summe theoretisch begründeter Zukunftserwartung verkörpert, gleichsam wie in einem Katalog niedergelegt" (Schrödinger 1935c: 823). Im ähnlichen Sinne formuliert Heisenberg: „,Die Naturwissenschaft beschreibt und erklärt die Natur nicht einfach so, wie sie san sich ist. Sie ist vielmehr ein Teil des Wechselspiels zwischen der Natur und uns selbst.[...] Was wir beobachten, ist nicht die Natur selbst, sondern Natur, die unserer Art der Fragestellung ausgesetzt ist" (Heisenberg 2006: 40; in Capra 2010: 141). Eine Beschreibung anlässlich 100 Jahre Quantenphysik formuliert das KI-Verständnis noch schärfer: "The complete knowledge of a system is described by its wave function, and from the wave function one can calculate the possible values of every observable quantity" (Kleppner und Jackiw 2000).

Die Wellenfunktion im Verständnis der KI wird heute als reine Wahrscheinlichkeitswelle verstanden, die zwar die Möglichkeiten der Entitäten gewichten, aber deren Realität verneinen. Born führte zwar die Wahrscheinlichkeitsinterpretation für Schrödinger's Wellenfunktion ein, aber erst Pauli bezog sie ausschließlich auf das Auftreten von Teilchen. Pauli geht sogar noch weiter wenn er formuliert, dass: ,, das Erscheinen eines bestimmten Teilchenortes bei der Beobachtung als eine außerhalb der Naturgesetze stehende Schöpfung aufgefasst werden muss “ (Zeh 2011: 98). Im Gegensatz zur Teilchenperspektive dehnt Zeh das Verständnis der Wellenfunktion auf Quantenfelder aus und damit auf realistische Umstände: Bei der Quantisierung von Feldern „,muss man die 
quantenmechanischen Wellenfunktionen dagegen konsequenterweise als Wahrscheinlichkeitsamplituden für Feldstärken interpretieren “(ebd.). Denn: „,Die Dekohärenz besagt aber, dass sich die relevanten Superpositionen bei Messungen praktisch irreversibel auf verschränkte Zustände von System, Apparat und Umgebung ausdehnen, also nicht mehr nachzuweisen sind, wenn man ,lokal' nur den Apparat betrachtet" (ebd. 99). In diesem Verständnis ist der Messprozess selbst zentraler Mitverursacher der jeweils sich zeigenden Wellenfunktion und ihrem spezifischen Wert und geht mit in die Messung ein ${ }^{153}$. Es verbirgt sich also etwas weit weniger Übernatürliches in der Wellenfunktion als bei Pauli. Von Neumann's spätere Formulierung geht wieder auf Born's Ansatz zurück, wenn er $\Psi$ als ,Wahrscheinlichkeit für neue Wellenfunktionen-also als einen Kollaps “ (ebd. 98) betrachtet.

Wir finden nun auch bei Zeh das Verständnis des Mitwirkens des Umfeldes und damit letztlich auch des Bedieners, vergleichbar (Mahler u. a. 2016). Deutlich wird aber auch, dass sich hinter den Vorschlägen die oben herausgearbeitete Unterscheidung von rein mathematischer Größe (wie bereits in Kap. 4.2.2 in Zusammenhang mit Information geschehen) und tatsächlichem Realitätsbezug verbirgt.

Da die mathematischen Berechnungen dennoch die Ergebnisse und unsere wahrnehmbaren Realitäten korrekt wiedergeben, hat sich das counter-intuitive Verständnis der Quantenphysik eingebürgert: „, Quantum mechanics is just counterintuitive and we just have to suck it up”, wie Seth Lloyd (in Wolchover 2014) zitiert wird.

In diesem Sinne argumentieren auch Fuchs und Peres wenn sie erklären, dass Quantentheorie keine Interpretation benötigt. Interessanterweise tun sie dann genau das: „From this [..], it is clear that a wavefunction is only a mathematical expression for evaluating probabilities and depends on the knowledge of whoever is doing the computing. “ Und weiter ,, Collapse is something that happens in our description of the system, not to the system itself. Likewise, the time dependence of the wavefunction does not represent the evolution of a physical system. It only gives the evolution of our probabilities for the outcomes of potential experiments on that system" (Fuchs und Peres 2000: 71). Die Autoren veranschaulichen ihre Perspektive mit einem Beispiel, indem für einen Außenbeobachter die Wahrscheinlichkeit 50/50 ist, wenn er nicht weiß, welche Entscheidung von zwei Optionen jemand anderes getroffen hat. Also eine klassische Superposition. Dies ändert sich sofort zu einem Faktum, wenn er die Information von dieser Person bekommt. Auch wenn es sich bei dem Beispiel um eine klassische Situation handelt (zwei Sorten von Kuchen), repräsentiert das Ergebnis der Berechnung das Wissen des Beobachters, analog zur Wellenfunktion, und schließt diesen mit in das Ergebnis ein. Deshalb kommen sie zu dem Schluss, ,no wavefunction exists either before or after we conduct an experiment" (ebd.).

Führen wir diesen Ansatz weiter, so zeigt sich am Ende einer physikalischen Messung das Ergebnis physischer Observablen, die sich, mit Ergänzung zu bisherigen Überlegungen, aus der Quanteninformation manifestieren. Als Konsequenz lässt sich eine real existierende Information annehmen, die gemessen wird und nicht nur eine Wahrschein-

${ }^{153}$ Siehe dazu auch Kap. 0 und 8.2.3 
lichkeit ohne Hintergrund. Die Quanteninformation kann sich als physikalische Größe zeigen, muss aber nicht. Die aus vorhergehenden Überlegungen (Kap. 4.2) logisch ableitbare Erweiterung auf alle möglichen Informationen wird auch im folgenden Gedanken unterstützt: ,, The perception of reality by biosystems is based on different, and in certain respects more effective principles than those utilised by the more formal procedures of science. As a result, what appears as random pattern to the scientific method can be meaningful pattern to a living organism. The existence of this complementary perception of reality makes possible in principle effective use by organisms of the direct interconnections between spatially separated objects shown to exist in the work of J.S. Bell " (Josephson und Pallikari-Viras 1991: 197).

Als ,Wahrscheinlichkeit', auf die sich die Wellenfunktion bezieht, kann nur ,das Manifestieren an sich' verstanden werden. Eine Information ist vorhanden, sie zu lokalisieren wird nur in direktem Zusammenhang mit einer spezifischen Messapparatur möglich und ist nur mit dieser richtig zu interpretieren.

Mit der folgenden Neuinterpretation der Wellenfunktion Psi ( $\Psi)$ wird der Versuch unternommen, die scheinbare Unvereinbarkeit der Interpretationen von KI und Dekohärenztheorie zu überwinden und zu einem kohärenten System zusammen zu führen.

Ausgehend von dem in Kap. 4.2.4 definierten Informationsbegriff ...

\section{Information ist etwas, was eine Entität repräsentiert. und}

Eine Entität ist etwas, was sich gegenüber einem Umfeld unterscheiden lässt.

schlage ich eine neue Interpretation zu $\Psi$ bzw. $|\Psi|^{2}$ vor, skizziert in Abb. 45:

$\Psi \quad$ Psi als Ausdruck einer möglichen Beobachtungssituation und der Abhängigkeit von einem Messvorgang.

Die Wellenfunktion $\Psi$ repräsentiert eine spezifische Beobachtungssituation in Abhängigkeit von einem spezifischem Messvorgang. D. h. in $\Psi$ ist alles enthalten, was man über den Zustand eines Quarticles oder eines Systems und der von ihnen getragenen Information wissen kann. Im Unterschied zur rein physikalischen Interpretation sind darin auch alle anderen, nicht nur durch physikalische Messapparaturen erfassbare Informationen enthalten.

$|\Psi|^{2} \quad \mathrm{Psi}^{2}$ als Ausdruck der tatsächlichen Einbindung eines Beobachters und Ergebnis der Interaktion von Entität und Beobachter.

Die Wahrscheinlichkeitsamplitude (= Wahrscheinlichkeitsdichte) repräsentiert den realen Messvorgang, bei dem das zu untersuchende System mit seinen spezifischen Möglichkeiten $\Psi$ in Verschränkung mit einem Beobachter tritt, der aufgrund der Verschränkungssituation ebenfalls mit $\Psi$ gekennzeichnet werden kann. Beide spannen einen gemeinsamen Raum auf, dessen Wahrscheinlichkeit sich zu manifestieren erst durch den realen Beobachter ermöglicht wird. $\Psi$ in diesem Sin- 
ne repräsentiert nur den Ausschnitt der Wirklichkeit, der sich in einer gemein-samen Übereinstimmung von Beobachtetem, Messapparatur und Beobachter befindet. Alle Informationen außerhalb dieser überschneidenden Gemeinsamkeiten werden nicht in der jeweiligen $\Psi$-Funktion erfasst.

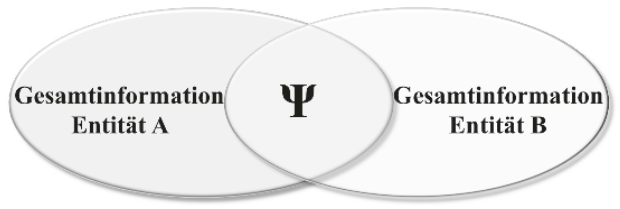

Abb. 45 | Neu-Definition von Psi

als Ausdruck einer speziellen, unter Beobachtung stehenden und von einer speziellen Messanordnung abhängigen, geteilten Realität. Für $\Psi$ sind nur die Größen relevant, die einen gemeinsamen, identischen Raum zwischen beiden Entitäten aufspannen (eigene Darstellung).

Nähere Erläuterung:

Aus den Betrachtungen im Kap. 4.2 Information - Energie - Materie wurde abgeleitet, dass sich mithilfe der Wellenfunktion die Information beschreiben lässt, die eine Entität vollständig repräsentiert. Die Natur hat mit den Qubits den grundsätzlichsten Weg gefunden, um Information auf elementarer Ebene (Atom, Elektron, Photon etc.) zu speichern, was dazu führt, dass die Wellenfunktion ,alle' möglichen Informationen einer Entität beinhaltet.

Wäre der Forscher nun allwissend und würde alles nur mit EINER Messung erfassen wollen, so würde die Wellenfunktion für dieses gesamte Wissen stehen. Im wirklichen Leben möchte der Experimentator mithilfe einer Messung jedoch nun ein ganz spezielles Problem mit einer ganz speziellen Messapparatur untersuchen. In diesem Moment repräsentiert Psi nur diesen einen Versuchsaufbau mit den Möglichkeiten den dieser lässt. Womit die Wellenfunktion das Spektrum dieses Problems konstituiert, was physikalisch auch als Definition des Zustandes diese Systems (A) interpretiert wird. Die Wellenfunktion ergibt sich damit als Ergebnis einer Unterscheidung eines Beobachters. Würde der Beobachter eine andere Perspektive oder eine andere Messapparatur wählen, ergäbe sich automatisch auch eine neue Wellenfunktion. Dies ist dann der Fall, wenn das aktuell betrachtete System (A) mit einem anderen System (B) wechselwirkt und damit die Perspektive auf ein erweitertes System (A-B) gelegt wird. Die Physiker mit Bezug zur KI sprechen dann vom Kollaps der Wellenfunktion, was in der Tat zutrifft, denn die alte Ausgangssituation gibt es aufgrund der Wechselwirkung mit der Messapparatur und dem Bediener nicht mehr.

Psi selbst sagt somit nichts über das System an sich aus, sondern nur über den Ausschnitt eines Ganzen, der vom Forscher untersucht wird. Insofern stimmt Schrödinger's Aussage, dass Psi all das beinhaltet, was wir über ein (genau dieses) System wissen können. Eine andere Forschungsfrage, eine andere Messapparatur oder sogar ein anderer Forscher führt demzufolge automatisch zu einer neuen Wellenfunktion. Womit die Wellenfunktion mehr über den Forscher (Beobachter) aussagt, als über das System selbst, 
analog dem Verständnis der Systemtheorie. Damit ist die Veränderung bzw. der Kollaps der Wellenfunktion ein mathematisch-versuchstechnisches und kein grundsätzliches Problem, wie es oben auch Fuchs und Peres interpretieren.

Das grundsätzliche Problem wird in der Dekohärenztheorie von Zeh behandelt (Zeh 2011), wenn er eine allgemeine Verschränkung schon aufgrund des Urknalls postuliert, und dass durch eine Wechselwirkung ein beobachtetes System mit seinem Umfeld dekohäriert, damit für einen Beobachter ununterscheidbar wird. Mit Fokussierung auf eine Frage und den damit gewonnen Informationen lässt sich schließlich wieder ein für die Frage kohärentes, unterscheidbares System mit einer spezifischen Wellenfunktion konstituieren. Damit liegt genau der Umstand vor, den die Quantenphysiker zur Untersuchung von Quarticle bewusst und unter großem Aufwand herstellen müssen und den jede einzelne Wissenschaftsdisziplin für ihr Forschungsfeld zu organisieren sucht: Reduktion auf einen genau bestimmten Aspekt der Wirklichkeit.

Die hier neu gefundene Interpretation, übertragen auf verschiedene Disziplinen (Tab. 14), eröffnet ein neues Verstehen der Zusammenhänge und ein Überwinden der so heiß diskutierten Entweder-oder-Postulate. Mit der Annahme von Zeh (Zeh 2011), dass die Welt auch ohne menschliche Systeme existiert und die Umwelt die Rolle des Beobachters einzunehmen vermag sowie der quantenphysikalischen These, das ,Nichts' als ,komplexes, strukturreiches Gebilde' anzusehen, gewinnt die ontologische Perspektive eine verallgemeinerte Rolle und die Systemtheorie demgegenüber eine spezifische Unterscheidungsfunktion. SyA lassen sich demzufolge allgemein als phänomenologisch begründbar und konstruktivistisch ausdifferenzierbar deuten. Mit einem gewagten weiteren Schritt erscheint die Quantenphysik als das grundsätzliche Modellgebäude, in dem die Relativitätstheorie nur für bestimmte Rahmenbedingungen und Unterscheidungen ihren Gültigkeitsbereich findet. Hier speziell der Kontext von Beobachtungssituationen.

Tab. 14 | Gegenüberstellung spezifischer vs. grundsätzlicher Perspektiven verschiedener Disziplinen Entwurf eines neuen Verständnisses, wie verschiedene Theorieentwürfe innerhalb einer Disziplin zueinander stehen können. Als Ergebnis ergibt sich eine Integration der verschiedenen Theorien anstatt einer Entweder-oder-Unterscheidung. (eigene Darstellung)

\begin{tabular}{|c|c|c|}
\hline Disziplin & Spezifisch & Grundsätzlich \\
\hline Quantenphysik & $\Psi$ in der & $\Psi$ in der \\
\hline Physik & Kopenhagener Deutung & Dekohärenztheorie \\
\hline Philosophie & Relativitätstheorie & Quantenphysik \\
\hline $\begin{array}{c}\text { System- } \\
\text { Aufstellung }\end{array}$ & Systemtheorie & Ontologie \\
\hline
\end{tabular}




\subsubsection{Von Qubits in die Realität}

Wie lässt sich nun der Prozess der Manifestation von Realität vorstellen? Die Ausgangsfrage hierzu lautet: , Wann und warum bricht das Superpositionsprinzip zusammen, wie es in der Kopenhagener Deutung stillschweigend für alle Quantenmessungen angenommen wird? “ (Zeh 2011: 3). Mit der Neuinterpretation der Wellenfunktion haben wir zwar eine Antwort auf das mathematische versus reale Problem gefunden, nicht aber auf den in der Realität ablaufenden Prozess. Wir wissen mittlerweile auch was Information sein kann und wie der Messprozess Information kreiert. Nur wie kann aus abstrakter Quanteninformation Energie und Stoff werden? Wie lässt sich erklären, dass durch die Potentiale vieler scheinbar einzelner Lichtquanten tatsächlich ein sichtbares Potentialfeld aufgebaut wird, in deren Mulden sich reale Atome verteilen (Abb. 46). Entsprechende Experimente werden derzeit in einigen Labors mit dem Ziel praktiziert, Quantencomputer zu entwickeln (Goldschmidt u. a. 2016; Buluta u. a. 2011; Anderlini u. a. 2007).

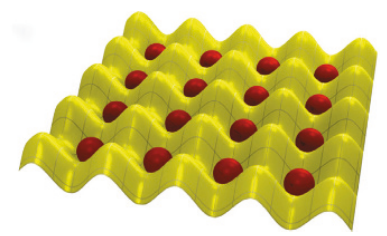

Abb. 46 | Rubidium-Atomverteilung in einem optisches Lichtgitter

(Image aus Buluta u. a. 2011) Die Rubidium-Atome verteilen sich gleichmäßig auf ein energetisches Potentialfeld und veranschaulichen, dass sich Potentiale in beobachtbaren Realitäten widerspiegeln.

Im physikalischen Verständnis setzt sich Licht aus einer Menge von einzelnen Lichtquanten zusammen oder Wahrscheinlichkeitswellen. Aus der Perspektive der KI stellen diese Lichtquanten ,nur' Potentiale ${ }^{154}$ dar, die sich offensichtlich im Raum zu einer tragfähigen Welle konfigurieren können. Aus der realistischen Perspektive von De-Broglie, Bohm und Zeh (Kap. 8.1.1.2) handelt es sich um reale Größen, die aber auch erst durch die Messung im Raum sichtbar werden. In jedem Fall entsteht für einen Beobachter etwas Reales. Wenn die Intension eine Information ist, die sich über Energie in Materie verdichten kann, dann müsste dieser Prozess beschreibbar sein. Die bisherigen Interpretationen sagen nach wie vor nichts darüber aus, wie die Quarticle respektive Wellen ihre Verdichtung im Moment der Messung bekommen. Darauf zielt exakt die Frage am Ende von Kap 8.1.1 in Bezug auf die Herkunft von Photonen und Quarks sowie der weiteren Strukturierung der Welt.

Deshalb soll nun der Versuch der Beschreibung eines Prozesses vom Qubit zur Realität unternommen werden, mit dem Ziel, die Gedanken zur ,Information', deren Manifestation und deren Übertragung mit einem physikalischen Modell zu hinterlegen.

${ }^{154}$ Potential (von lat. potentia „Stärke, Macht“), im allgemeinen auch verstanden als nicht ausgeschöpfte Möglichkeiten. 


\section{Ein paar Grundlagen vorweg}

Wenn wir davon ausgehen, dass die Information, die die Entitäten aufbaut, irgendwo gespeichert wird, stellt sich die Frage: Wo? Dazu gibt es derzeit zwei naturwissenschaftliche Antworten: im Spin der Quarticle und in den EM-Wellen. Die aktuellen physikalischen Konzepte rund um diese beiden Größen sollen deshalb zunächst untersucht werden.

\section{Quantenvakuum (Null-Punkt-Feld, Vakuumfeld)}

Vom Quantenvakuum (siehe auch Kap. 5.3.6) nimmt man an, dass es den Ausgangspunkt sogenannter Quanten-Fluktuationen darstellt, die zur Bildung von Quarticle-Anti-Quarticle-Paaren führt. Ursache dafür ist die Interaktion der virtuellen Energie des Vakuums mit geladenen Quarticle. Es gibt berechenbare Wahrscheinlichkeiten, dass aufgrund dieser Schwankungen etwas Messbares auftaucht, was auch tatsächlich passiert, wenn man dieses Vakuum einsperrt, also Grenzen setzt. So nimmt man an, dass sich als Folge dieser Vakuumfluktuation u. a. der Casimir-Effekt beobachten lässt (Gambassi 2009). Die Annahme von De-Broglie ist nun, dass ein Überschuss an Quarticle, die eben nicht sofort wieder mit ihrem Anti-Quarticle zerfallen, die Grundlage der uns bekannten Welt darstellen und dass über dieses Feld alles mit allem verbunden ist. Diese realen, aber für uns nur indirekt wahrnehmbaren Wellen resultieren aus der Überlagerung aller möglichen Felder und stellen eine Superposition dieser Felder dar. Diese Interpretation lässt sich aus den Experimenten und Berechnungen von Bush und Peña ableiten (Bush 2015; Peña u. a. 2015). Peña kann auch eine direkte Verbindung von Quantenvakuum und EM-Welle herleiten.

Eine alternative Theorie (Haramein 2013b, 2013a), die mit ihrem Ansatz im Widerspruch zum Standardmodell steht, interpretiert das Universum als holographisches Fraktal, aber ebenfalls als Vakuumfeld bestehend aus reiner Energie. Als wesentlicher Unterschied seines Ansatzes geht er von Schwarzen Löchern in Planck-Größe aus, die das Vakuumfeld bilden. In seinen Berechnungen vermag er einige heute noch existierende Abweichungen sehr präzise zu korrigieren. Die bisherigen experimentellen Nachweise scheinen seinem Ansatz recht zu geben (Heiße u. a. 2017; Antognini u. a. 2013). Ausgehend von seinen Überlegungen kommt Haramein zu dem Schluss, dass alles mit allem über das Vakuumfeld verbunden ist.

\section{Quanten und Qubits}

Der Brockhaus definiert Quanten „, [zu lateinisch quantum »wie groß«, „wie viel «], als eine allgemeine Bezeichnung für kleinste, unteilbare Einheiten physikalischer Größen “. Physikalische Größen können elektrische Ladung, Wirkung, Drehimpuls etc. sein. Deutlich wird hier die Nicht-Gleichstellung mit einem klassischen Objekt. Gemeint ist vielmehr eine kleinste, diskrete Einheit, die durch einen Zustandswechsel der jeweiligen physikalischen Größe erzeugt wird. Den- 
noch werden üblicherweise Photonen als Quanten verstanden, als kleinste Einheit des EMF für den Bereich des sichtbaren Lichtes und bekommen damit eine quasi objekthafte Zuschreibung. Für das restliche EM-Spektrum wie Radio- oder HFWellen spricht man zwar auch von Photonen, sinnvollerweise aber besser von Quanten. Andere Formen von Quanten sind beispielsweise: Higgs-Boson (verantwortlich für das Auftreten von Masse), Gluon (Kraftfeld, Übertragung starker Wechselwirkung im Proton und Neutron des Kerns), Graviton (Gravitationsfeld), Quant des Drehimpulses, Magnon (Magnetfeld). Analog zum Photon wird der Begriff Quant auch für die Träger dieser quantisierten Größen verwendet, z. B. bei den Eichbosonen oder den Quasiteilchen (Elementaranregung von Festkörpern). Leicht ersichtlich ist, dass die Unschärfe in der Sprache auch eine Unschärfe im Verständnis nach sich zieht. Alternativ betrachtet lässt sich auch die Interpretation ableiten, dass selbst diese Unschärfe und Dualität Ausdruck unserer Realität ist, in dem das eine nicht ohne das andere geht, solange die Beobachterseite eingenommen wird.

Wie in Kap. 4.2.2 bereits vorgestellt, bilden Qubits (Quanten-Bit) die kleinste Informationseinheit eines Quantenzustandes. Da Information auch als ,Unterschied' definiert wurde, repräsentiert der Zustandswechsel, der mit einem Quant beschrieben wird, genau die dadurch gewonnene Information. Das besondere gegenüber einem klassischen System liegt letztlich in der Unterscheidung von drei Zustandsvarianten. Zwei in unserer Welt wahrnehmbar und unterscheidbare Messergebnisse $|0\rangle$ und $|1\rangle$ (stellvertretend für vor und nach dem Zustandswechsel) und eine für uns nicht wahrnehmbare Superposition aller weiterer Möglichkeiten dieses Quantensystems. Die Spinausrichtung stellt eine solche messbare Unterscheidung dar. Sie wird auch als eine der Optionen bei Quanten angesehen, mit deren Hilfe Informationen codiert und gespeichert werden können.

\section{Spin}

Der Spin repräsentiert eine quantenmechanische Eigenschaft eines Quantenobjektes und verhält sich physikalisch wie ein Drehimpuls. Im Gegensatz zum kontinuierlichen Verlauf in der klassischen Physik ist auch er quantisiert, besitzt also nur feste Werte. Des Weiteren werden die Drehrichtungen, Rotation' rechts (positiv) und links (negativ) unterschieden. Befinden sich z. B. zwei Elektronen in einem Molekül, so unterscheiden sich immer ihre Spinrichtungen ${ }^{155}$. Diese Rotation erzeugt wiederum ein Magnetfeld, das gemessen werden kann. Unterscheiden lassen sich die Quarticle durch ihre, Spinquantenzahl' $(0,+1 / 2,-1 / 2,+1,-1$ ...), die unveränderlich ist. Veränderlich ist jedoch die ,Spinausrichtung' einzel-

${ }^{155}$ Deshalb ergibt sich aus der Messung eines der Elektronen automatisch der Zustand des anderen Elektrons. Dieses Verhalten macht sich die Physik für ihre Messungen zunutze, um beispielweise verschränkte Systeme nachzuweisen. 
ner Quarticle und der Gesamtspin aus mehreren Quarticle ${ }^{156}$. Mit seiner Hilfe werden zwei fundamentale Quarticlearten - Bosonen und Fermionen - unterschieden.

Eine ,Spinpolarisation' realisiert sich durch eine gemeinsame Ausrichtung eines Ensembles ${ }^{157}$ von mehreren Quarticle ${ }^{158}$. Alle Spins zeigen in die gleiche Richtung mit der Folge, dass die im System enthaltene Information über das gesamte System verteilt ist. In einem solchen Fall spricht man auch von Kohärenz des Ensembles.

Verschränkungszustände lassen sich entsprechend daran erkennen, dass die Summe einzelner Messergebnisse eine Gesamtheit ergeben muss, z. B. bei Einzelentitäten minus und plus Drehimpuls, bei Ensembles die gleich Spinausrichtung. Aus diesen Zusammenhängen wird bereits offensichtlich, dass Spins Quanteninformation tragen können, was mittlerweile auch mehrfach nachgewiesen wurde (Amsüss u. a. 2011).

\section{Bosonen}

Sie besitzen einen ganzzahligen Spin und alle Quarticle können den gleichen Zustand und damit auch den gleichen Platz einnehmen wie z. B. Photon, Gluon, Graviton (postuliert, aber noch nicht nachgewiesen), Bose-Einstein-Kondensat, Cooper-Paare aus Photon und Elektron (Reineker u. a. 2007: 423). Innerhalb desselben Systems lassen sie sich nicht unterscheiden, was sie zu Konformisten macht (Wilczek 2017; Jolie 2002). Photonen sind die Vermittler der EM-Wechselwirkung und damit übertragen sie Kräfte, ohne dass sie selbst Masse oder Ladung besitzen. Sie geben also den Impuls für eine Bewegung und sind nicht selbst die Bewegung, wie Weizsäcker zu Beginn von Kap. 8.1.1.1 bereits zum Ausdruck gebracht hat.

Bei Vorgängen mit nicht-unterscheidbaren Quarticle (Bosonen) werden die Amplituden addiert, womit sich die Intensität (z. B. Energie oder Kraft der Wechselwirkung) erhöht.

${ }^{156}$ Der Spin kann nicht als Eigenrotation eines Quantenobjektes verstanden werden, da Quarticle keine genau definierte Achse haben. Hawking interpretiert den Spin als Mitteilung, wie das Quarticle aus verschiedenen Richtungen aussieht. „Ein Teilchen mit dem Spin 0 ist ein Punkt: Es sieht aus allen Richtungen gleich aus. Ein Teilchen mit dem Spin 1 ist dagegen wie ein Pfeil: Es sieht aus verschiedenen Richtungen verschieden aus. Nur bei einer vollständigen Umdrehung (360 Grad) sieht das Teilchen wieder gleich aus. Ein Teilchen mit dem Spin 2 ist wie ein Pfeil mit einer Spitze an jedem Ende. Es sieht nach einer halben Umdrehung $(180 \mathrm{Grad})$ wieder gleich aus. Entsprechend sehen Teilchen mit höherem Spin wieder gleich aus, wenn man Drehungen um kleinere Bruchteile einer vollständigen Umdrehung vollzieht. [Darüber hinaus gibt es Teilchen], die nach einer Umdrehung noch nicht wieder gleich aussehen: Es sind dazu vielmehr zwei vollständige Umdrehungen erforderlich! Der Spin solcher Teilchen wird mit 1/2 angegeben " (Hawking 2004: 87f).

${ }^{157}$ Ein Ensemble ist in der Physik ein gleichartig präpariertes System von Teilchen. Bose-Einstein-Kondensate sind dementsprechend dreidimensionale Ensambles, die sich mit einer $\Psi$-Funktion beschreiben lassen.

${ }^{158}$ Diesen Effekt macht man sich in der Magnetresonanztomographie zunutze. 


\section{Fermionen}

Sie bauen das Atom auf, besitzen einen 1/2-zahligen Spin und können nicht den gleichen Zustand und deshalb auch nicht den gleichen Raum einnehmen (PauliPrinzip) (Reineker u. a. 2007: 424). Fermionen lassen sich innerhalb desselben Systems durch die dabei auftretende Änderung zumindest einer physikalischen Eigenschaft (z. B. Spin) unterscheiden (Galindo und Pascual 2012: 233), was sie zu Individualisten macht ${ }^{159}$ (Wilczek 2017). Zu ihnen gehören Quark, Proton, Neutron, Elektron, Neutrino. Sie repräsentieren das, was wir gemeinhin unter Materie verstehen.

Bei Vorgängen mit unterscheidbaren Quarticle (Fermionen) werden Wahrscheinlichkeiten addiert und somit die Vielfalt an möglichen Erscheinungsformen erhöht.

\section{Anyonen}

Anyonen ${ }^{160}$ stellen virtuelle Quarticle dar, die zwischen Fermionen und Bosonen switchen bzw. beide ineinander überführen (Arovas u. a. 1985).

Entdeckt und mit ihrem Namen versehen wurden sie von Wilczek (Wilczek 2017; Arovas u. a. 1985), mit einer Wismut-Antimon-Legierung erstmals 2004 nachgewiesen u. a. von Hsieh u. a. (Hsieh u. a. 2009). Es handelt sich bei ihnen um exotische Quasiteilchen, deren Materiezustand aus den kollektiven Eigenschaften vieler Quarticle hervorgeht.

Beobachtungen haben ergeben, dass es im dreidimensionalen Raum nur Bosonen und Fermionen geben kann. Im zweidimensionalen Raum sind Bosonen und Fermionen nur zwei Spezialfälle. Dazwischen repräsentieren Anyonen ein Kontinuum von Möglichkeiten. Bosonen und Fermionen lassen sich deshalb auch interpretieren als extreme Ausprägungen von Anyonen.

Zwei Eigenschaften zeichnen sie aus (Wilczek 2017):

1. Ihre Fähigkeit zur Stabilität durch die von ihnen gebildeten Zöpfe. Durch sie lassen sich hoch stabile Verschränkungen von Elektronen erzeugen, auch unter normalen Umgebungsbedingungen.

2. Ihre Erinnerungsfähigkeit, wie Wilczek formuliert. „Many-anyon systems build up a gigantic collective memory" (ebd.). Diese Erinnerungsfähigkeit hängt mit ihrem speziellen Aufbau, den sogenannten Knoten ${ }^{161}$ zusammen. Sie lassen sich im Gegensatz zum zwei- und dreidimensionalen Zustand in einem

${ }^{159}$ Nach dem Verständnis der Supersymmetrie ergibt sich der Unterschied zwischen Bosonen und Fermionen durch ihren symmetrischen, respektive antisymmetrischen Zustand, wohingegen sie innerhalb ihrer Klassen als identisch und nicht-unterscheidbar angesehen werden (Galindo und Pascual 2012: 233; Schwabl 2004: 212). Fermionen werden jedoch unterscheidbar, wenn sie sich innerhalb desselben Systems (z. B. Atom) befinden.

${ }^{160}$ Nicht zu verwechseln mit Anionen aus der Chemie, einem negativ geladenen Ion.

${ }^{161}$ Knoten sind in diesem Zusammenhang eine Größe für Mathematiker und werden von ihnen als kontinuierliche Kurve im Raum gesehen. 
vier-dimensionalen Zustand sehr leicht entwirren. Nun ist die vierte Dimension, die Zeit, die auch in der Relativitätstheorie mit dem Raum (drei Dimensionen) zu einer Raum-Zeit verbunden ist. Wilczek macht diese Beziehung (Bewegung im dreidimensionalen Zopf, aber eingebunden in der Raum-Zeit) für ihren stabilen Verschränkungszustand verantwortlich.

Fast drängt sich der Verdacht auf, dass es sich hier nicht um eine zufällige Synchronizität zwischen Relativitätstheorie und Quantenphysik handelt, sondern um einen fundamentalen Zusammenhang. Neue Überlegungen gehen wohl auch deshalb davon aus, dass sich die Raum-Zeit aus der Relativitätstheorie als emergentes Phänomen einer quantenphysikalischen Verschränkung ergibt (Lin u. a. 2015; Moreva u. a. 2014). Auch hier wird der Unterschied zwischen internem und externem Beobachter relevant für die Wahrnehmung der Zeit, analog zur Wahrnehmung der Geschwindigkeit.

Von Bedeutung ist noch, dass die Eigenschaften zweidimensionaler Entitäten von ihrem Material und ihrer Oberflächenstruktur abhängen. Die in ihnen enthaltenen Fehlstellen tragen dabei entscheidend zur Stabilität der Zöpfe und ihrer Verschränkung bei.

Solche Umstände, in denen sich Materie verhält als wäre sie zweidimensional, sind Oberflächenschichten (Filme, Membrane, Schnittstellen, Phasenübergänge) mit einer oder wenigen Atomlagen. Im technischen Bereich sind dies z. B. Graphit oder Supraleiter (Hsieh u. a. 2009; Tillemans 2011) und die oben erwähnte Wismut-Antimon-Legierung.

Damit liegen Anyonen genau zwischen Bosonen und Fermionen und entsprechen dem fehlenden Bindeglied zwischen den fundamentalen Quarticlesorten. Sie besitzen wohl nicht umsonst die Fähigkeit zwischen Bosonen und Fermionen hin und her zu switchen. Auch die Forscher um Keilmann gehen davon aus, dass Bosonen kontinuierlich in Anyonen und weiter bis zu Fermionen verwandelbar sind und vice versa (Keilmann u. a. 2011). Auf diese Quarticleform wird in Kap. 8.3 noch vertieft eingegangen, denn die Vorstellung, dass zirkulierende Anyonen in topologischen Quantencomputern, die fähigste künstliche Intelligenz auf zweidimensionalen Materialien sein werden, ist für Wilczek (Wilczek 2017) eine sehr realistische Vorstellung und kann mit Mechanismen in unserem Gehirn in Verbindung gebracht werden.

\section{Quantenfeld}

Ein Quantenfeld (siehe auch Kap. 5.3.6) repräsentiert größere Ansammlungen von Fermionen und Bosonen, letztlich das, was wir als Energie oder Stoff wahrnehmen können. Größere Moleküle und Systeme mit variierenden Teilchenzahlen gehören zu dieser Kategorie. Zuständig ist die QFT, die aus der Quantenmechanik in Kombination mit den Prinzipien klassischer Feldtheorien zu einer erweiterten Theorie entwickelt wurde (Kuhlmann 2014: 50). Hier werden sowohl Objekte als auch die Observablen quantisiert und als Quantenfeld interpretiert. 
Der Welle-Teilchen-Dualismus wird durch ein Verständnis wechselwirkender Felder ersetzt (Kuhlmann und Stöckler 2015: 226). Die Entitäten werden nicht durch einzelne Attribute (Spin, Größe, Farbe etc.) beschrieben, sondern nur als Bündel von Eigenschaften, die zusammen das ganze Feld aufspannen. Zentral ist demzufolge die Relevanz von Beziehungen und der sich daraus entwickelnden Zustände und Eigenschaften.

\section{Elektromagnetisches Feld}

Wie oben bereits ausgeführt, ergibt sich das EMF aus Bosonen, Fermionen und den sehr skurrilen, virtuellen Anyonen und deren Zusammenspiel. Auch hier sind Quanten die kleinste Einheit und Qubits die Träger von Information. Wie unter Quantenvakuum und in Kap. 8.1.1.2 bereits ausgeführt, lässt sich eine direkte Verbindung von Quantenvakuum und EM-Welle herleiten.

\section{Phasenübergänge}

Für die Wechselwirkung von Entitäten mit ihrer Umgebung stellen Phasenübergänge den wesentlichen und letztlich kritischen Bereich dar. Hier entscheidet sich auch, ob die von Zeh angenommene zwingende Dekohärenz (Wechselwirkung mit der Umgebung) tatsächlich so zwingend ist, oder ob es Möglichkeiten der Beibehaltung getrennter Entitäten gibt bzw. getrennter Kohärenzen von verschränkten Systemen.

Neben den bereits aufgeführten Anyonen existieren tatsächlich zwei weitere Prozesse, die in den Phasenübergängen wirksam sind und gleichzeitig erheblichen Einfluss auf die Eigenschaft von Materialien ausüben. Für beide gab es 2016 den Nobelpreis in Physik (The Royal Swedish Academy of Sciences 2016a, 2016b). Für Phasenübergänge im zweidimensionalen Raum und unter Beteiligung eines Magnetfeldes entdeckten Kosterlitz / Thouless einen speziellen Mechanismus (den Kosterlitz-Thouless-Phasenübergang), der im Zusammenhang mit topologischen Defekten auftritt (Kosterlitz und Thouless 2013, 1973). Bei ihrem Mechanismus ändert sich das zweidimensionale System an der Oberfläche durch Wirbel von Spins (Quantenwirbel), die an verschiedenen Stellen der Oberfläche auftreten und sich verändern. Die Spins richten sich an der Oberfläche anders aus und ändern dadurch unvermittelt das Verhalten des Materials in einem sehr weiten Bereich, ohne dass deren innerer Aufbau involviert ist. Sie erkannten die wesentlich größere Relevanz der Oberfläche für die Eigenschaft des Materials, als dessen innerer Aufbau.

Haldane entdeckte ergänzend einen Effekt (Haldane 1988), der sich im eindimensionalen Raum abspielt. Reiht man die eindimensionalen Spins in einer Reihe auf, ergibt sich für die Kette ein Gesamtspin, z. B. 1/2. Topologisch unterscheidet sich eine solche Kette von einer mit einem Gesamtspin von 1, was u. a. durch die Veränderung eines Spins erreicht werden kann. In der Festkörperphysik ändert dieser topologische Unterschied beispielsweise das magnetische Verhal- 
ten und zwar erheblich, verursacht durch die Wechselwirkung benachbarter Spins. So entscheiden sie, ob aus dem gleichen Grundmaterial Isolatoren, Halbleiter oder Leiter werden. Die dort relevante Anregungsenergie, als wichtige Information abgeleitet von den aneinandergereihten Spins, ist aufgrund der hohen Komplexität (Vielzahl von Spins und möglichen Konfigurationen) allerdings nur schwer berechenbar.

Die sich an der Oberfläche von zweidimensionalen, topologischen Strukturen kreuzenden Spinreihen (sogenannte Energiebänder oder nur Bänder) mit gegenläufigen Ladungen entsprechen Supraleitern. Die Spinrichtung gibt vor in welche Richtung der Strom fließt. Dies wird durch ihre Verdrillung offensichtlich von Natur aus unterstützt. Der Josephson-Effekt für Supraleiter (Josephson 1962) und vor allem seine Erweiterung auf nicht-magnetische Systeme (Gaury u. a. 2015) ermöglicht so einen quantenphysikalischen Verschränkungszustand über Energiebarrieren hinaus in allen möglichen stofflichen Konfigurationen. Bei Josephson bilden sich dabei sogenannte Cooper-Paare, die es bei den hier beschriebenen gegenläufigen Energiebändern nicht braucht, aber den gleichen verschränkenden Effekt bewirkt. Das besondere bei den Bändern ist das Nicht-Benötigen eines magnetischen Feldes, vergleichbar dem verallgemeinerten Josephson-Effekt. Somit haben wir einen stabilen, kohärenten, verschränkten Quantenprozess vorliegen, der sich auch bei Umgebungstemperatur und in zweidimensionalen Übergangsphasen realisiert.

Beide Effekte treten beispielsweise wegen, Wirbeln' oder trotz ,Fehler' in der Oberfläche auf. Sie unterstützen ausgedehnte Eigenschaftsänderungen, die heute in der Festkörperphysik als ,topologische Isolatoren' intensiv erforscht und angewandt werden (Kane und Mele 2005). Kane und Mele dehnten die oben beschriebenen einbändigen Spinreihen auf Multiband- und interagierende Systeme aus. Solche Isolatoren funktionieren mittlerweile auch bei Umgebungstemperaturen.

Interessanterweise dienen zunehmend ontologische Strukturen, besonders topologische Ansätze, wie sie bei Koserlitz/Thouless, Haldane (Haldane 1988) und bei Wilczek genutzt werden, für eine eher realistische Beschreibung der Quantenphysik. Ganz besonders verspricht man sich mit ihnen Quanten-Computer realisieren zu können.

\section{Zusammenfassung und mögliche Konsequenzen}

Zunächst muss festgehalten werden, dass alle hier aufgenommenen Entitäten (vom Vakuumfeld über Anyonen bis zum Quantenfeld) erst einmal ausschließlich aus der Brille der unbelebten Natur untersucht und beschrieben sind. Die Messergebnisse und die daraus abgeleiteten Theorien bewegen sich immer noch auf der fundamentalsten Ebene und damit in der reinen Physik und anorganischen Chemie. Dennoch sind an einigen Stellen Beschreibungen und Analogien aufgetaucht, die sehr leicht in die belebte Natur überführt werden können, zumindest in Form von Analogien. Wie aber schon im Kontext der Quantenfelder festgehalten, scheitert die Quantenmechanik als Physik der Quar- 
ticle bereits an kleinen Vielquarticle-Systemen. Die QFT übernimmt an dieser Stelle, vermag aber keine detaillierten Berechnungen vorzunehmen, sondern muss ihre verallgemeinernden Ansätze immer mit realen Beobachtungen in Verbindung bringen. Es geht deshalb im Grunde um eine indirekte Beweisführung mithilfe von Experimenten und Feldbeobachtungen.

Als weitere Erkenntnis liegt eindeutige Evidenz sowohl für kurzlebige als auch für ausgesprochen langlebige Verschränkungszustände vor, die weitreichende Kohärenzen aufrechterhalten können; Kohärenzen, die auch bei Umgebungstemperatur existieren und die die vermutete, sofortige Dekohärenz zumindest über relevante Zeitskalen verhindert.

Die Tatsache, dass bisher keine Quarticle mit Spin 3/2 (supersymmetrische Teilchen) und 2 (Gravitonen) entdeckt wurden, könnte damit zusammenhängen, dass es sich bei ihnen um Entitäten 2. Ordnung in Sinne der Kybernetik handelt. Also um Etwas, das nur durch Beobachtung von Beobachtung entsteht, weswegen es keine eigene Realität besitzt und letztlich nur so scheint als ob. In diesem Fall einfach ausgedrückt, man verfolgt vielleicht die falschen Schlussfolgerungen, denn aus den Überlegungen zum Gluon, könnte Gravitation eine emergente Eigenschaft dieses Quarticles sein, nachdem es bereits für die starke Wechselwirkungskraft im Kern verantwortlich gemacht wird.

Wilczek hat mit seiner Entdeckung und seinen Gedanken den Weg für einen beschreibbaren Übergang von einer immateriellen Welt in eine reale Welt bereitet. Die Vorstellung über eine Supersymmetrie und der damit verbundenen Quantenstatistik ${ }^{162}$ als ein rein abstrakter Erklärungsansatz, kann durch eine ,realistische' Vorstellung ergänzt oder gar abgelöst werden.

„Nature, in her abundance, provides materials to embody all theoretically consistent possibilities. Trusting in that principle, I strive to exercise what Richard Feynman called 'imagination in a straitjacket', expecting that"

„If you build it (imaginatively), they will come (physically) “(Wilczek 2017).

Mit diesem Spruch kommt er zur gleichen Erkenntnis wie Capra 1975, 42 Jahre vor ihm (Capra 2010), dass wir unsere Welt selbst kreieren.

Wilczek's Idee der Imagination einer physikalischen Realität geht mit einer Besonderheit im Konzept der Anyonen einher. Hier ist die Zeit als beobachtbare, berechenbare Größe enthalten. Die Zeit emergiert als ein Ergebnis der Verwirbelung und damit als Ergebnis der topologischen Struktur. Interessanterweise sorgen ähnliche topologische Besonderheiten bei den Phasenübergängen von Haldane (Haldane 1988) und Kosterlitz/Thouless (Kosterlitz und Thouless 2013, 1973) für zeitliche Stabilität verschränkter Systeme. Ein Zusammenhang zu den neuen Annahmen, dass sich Raum-Zeit aus

${ }^{162}$ Die Supersymmetrie geht von einer Parallelität von Eigenschaften bei Bosonen und Fermionen aus (Superpartner), da sie bisher unterschiedlichen Kategorien zugeordnet wurden, aber dennoch zusammen wirken müssen. Das dabei bei Makrosystemen (vielteiligen Quantensystemen) beobachtbare Verhalten wird dann mit der Quantenstatistik behandelt. 
solchen Verschränkungen ergibt, erscheint insofern sehr plausibel. Die vermutete Annahme, dass unsere Zeitwahrnehmung in diesem Übergang vom Virtuellen zum Konkreten zu suchen ist, liegt nahe. Damit könnte sich auch erklären lassen, wie es zu scheinbaren Veränderungen in der Vergangenheit kommen kann, wie das DelayedChoice-Experiment veranschaulicht. In gleicher Weise wie Wilczek die Knoten nutzen möchte (Wilczek 2017), um auf der Ebene von Quanten-Computern den zeitlichen Ablauf von Berechnungen zu speichern und sie wieder rückverfolgen zu können, in gleicher Weise lässt sich vorstellen, wie diese Knoten auch in unserer Realität zurückverfolgt werden können, um an bestimmten Stellen veränderte Operationen vorzunehmen; Veränderungen, die sich entsprechend ihrer jeweiligen Freiheitsgrade wieder im Jetzt bemerkbar machen können.

Eine zweite relevante Besonderheit wird sowohl durch Wilczek's Anyonen (Wilczek 2017) als auch durch die Ansätze von Kosterlitz/Thouless (Kosterlitz und Thouless 2013, 1973) und Haldane (Haldane 1988) beschrieben: Das Auftauchen einer Verbindung zu Strukturen, in diesem Fall topologischen Strukturen. Diese sind in der Lage Informationen auch bei Zustands- respektive Formänderungen zu speichern. Etwas, was als nötige Fähigkeit für das Vergleichen von Strukturähnlichkeiten angenommen werden muss. Wie sonst kann das Gleiche in unterschiedlichen Ausdrucksformen erkannt werden? Hier lässt sich ein direkter Zusammenhang zu den Ideen von Lucadou und Schweitzer (Kap. 4.2.2), als auch mit der Arbeitsweise von Quanten-Computern bzw. unseres Gehirns vermuten.

Hilfreich scheinen die Erkenntnisse zu den Übergängen auch für eine Modellierung zu sein, wie Informationen mittels Spins gespeichert werden können. Man stellt sich eine Oberfläche mit einer unendlichen Vielzahl von Quarticles und deren Spins vor (Abb. 47), die für eine spezifische Entität definiert ausgerichtet sind und deren Zustände und Eigenschaften festlegt.

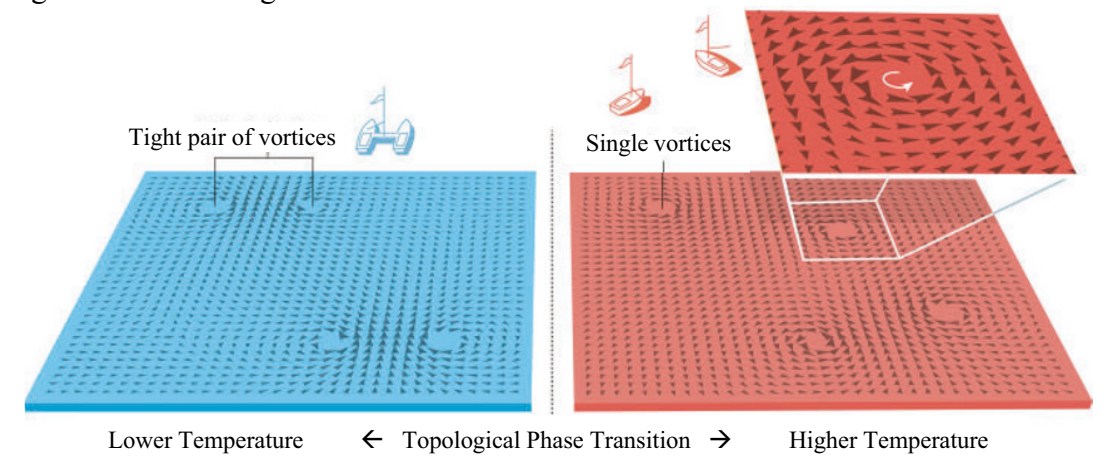

Abb. 47 | Spinwirbel in zweidimensionalen Oberflächen

(Aus Popular science background - The Nobel Prize in Physics 2016; (C) Johan Jarnestad / The Royal Swedish Academy of Sciences 2016 / nobelprize.org) Jede Spinveränderung und jeder Spinwirbel verändert die Eigenschaften der betroffenen Entität. Insofern sind kleinste Veränderungen auch für makroskopische Verhaltensweisen hoch relevant. 
Stellt man sich weiter vor, dass ...

a) innerhalb dieser unzähligen Spins an bestimmten Stellen einzelne Spinveränderungen vorgenommen werden (z. B. deren Ausrichtung), die die Eigenschaft und damit das Erscheinungsbild der Gesamtentität erheblich verändern können (Haldane-Effekt) oder

b) statt einer Veränderung einzelner Spins verschiedene Quantenwirbel das Gesamtsystem verändern können (Koserlitz/Thouless-Effekt),

... so wird deutlich, dass alleine über die Art und Weise der Verteilung dieser sogenannten Fehlstellen unvorstellbar viel Möglichkeiten generiert werden können. Die hier betroffenen Spins der Elektronen lassen sich zudem schwach mit den Spins der Kerne und deren Quarks koppeln (Amsüss u. a. 2011), was die Vielfalt an Kombinationen weiter in unvorstellbare Größen treibt. Da die vorgestellten Experimente und ihre Weiterentwicklung sich auch in dünnen Schichten bewegen und damit dreidimensionale Konfigurationen relevant sind, erhöht sich die Vielfalt weiter um eine dritte Dimension ${ }^{163}$. Jede dieser Möglichkeiten kann als Ausdruck und Repräsentanz für eine bestimmte Information betrachtet werden. Durch deren Kopplung zu topologischen Systemen, die ja auch strukturelle Informationen speichern, wird anschaulich, dass auf diese Weise nahezu unendlich viele Informationen gespeichert und abgerufen werden können.

Für diese Informationscodierung und -speicherung kommen nicht nur Elektronen, Photonen oder auch Atomkerne infrage, sondern auch Ionen, Dipol-Dipol-Verbindungen und Verbindungen unterschiedlicher Spin-Kombinationen zu einem Raum (Astner u. a. 2017; Amsüss u. a. 2011). Amsüss und seine Kollegen zeigen sogar die kohärente Verbindung von Elektronenspin und Photon, die für einen langen Informationstransfer bei Umgebungsbedingungen über einer Großstadt verwendet werden. Zudem wiesen sie eine Spin-Kopplung zum Atomkern des Kohlenstoffs nach, was sie explizit als ersten Schritt zu einem Quantenspeicher auf der Basis von Ensembles von Atomkernen ansehen.

Somit drängt sich der Eindruck auf, dass quantenbasierte Informationsspeicherung überall stattfinden kann und dass wir tatsächlich von einer allgemeinen Verschränkung, beginnend beim Quantenvakuum, ausgehen können. Dass die Wissenschaft sie noch nicht früher entdeckt hat, mag mit unzureichender Technik zusammenhängen, möglicherweise aber eher von einer bisher dazu noch nicht vorhandenen theoretischen Vorstellung.

\section{Das Modell: Vom Qubit zur Realität}

Nun sollten alle Ingredienzien vorhanden sein, um ein Modell der Entwicklung vom Quantenvakuum bis zu unserer Realität zu beschreiben (Abb. 48), vom Virtuellen zum Konkreten.

Ausgehend vom Quantenvakuum, von dem nach wie vor unklar ist, wo es seinen Ursprung hat, erscheinen Bosonen (Higgs-Boson, Photon, Gluon etc.) als erste unter-

\footnotetext{
${ }^{163}$ In einer fortführenden Arbeit wäre die Berechnung solcher Größenordnungen zur Erfassung der tatsächlichen Dimension an Möglichkeiten, hilfreich.
} 
scheidbare Entität. Damit manifestiert sich ein erster Unterschied aus dem Meer aller Möglichkeiten. Ein Unterschied, der allerdings immer noch alle Information trägt, die im Quantenfeld mit der Dimension Null existiert.

Am Übergang von der Dimension Null zur Dimension 1 (Photon, Gluon etc.) scheint das Higgs-Boson beteiligt zu sein, da es einen Spin Null trägt, was eine dimensionslose Größe darstellt. Damit lässt sich das Higgs-Boson als erstes Übergangselement oder als erste Übergangsphase interpretieren.

Das Wechselspiel zwischen den ersten Bosonen und dem Quantenfeld lässt sich anhand des Modells der EDBFT und den wandernden Tröpfchen auf einem durch Oberflächenspannung getrennten Medium veranschaulichen. Mit Zunahme der Unterscheidung vom Vakuumfeld bildet sich eine immer größere Dekohärenz und Eigenständigkeit aus. Damit lässt sich auch vorstellen, dass die wechselseitige Wahrnehmung abnimmt.

\begin{tabular}{|c|c|c|c|}
\hline $\begin{array}{l}\text { Übergangs- } \\
\text { prozess }\end{array}$ & $\begin{array}{l}\text { Kopenhagener } \\
\text { Interpretation }\end{array}$ & Beispiele & Dimensionen \\
\hline Quantenvakuum & 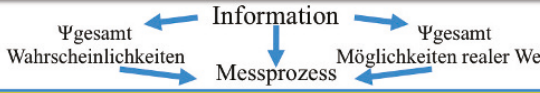 & ellen & 0 \\
\hline $\begin{array}{l}\text { Bosonen } \\
\text { Spin } 0 \text { und } 1\end{array}$ & Intensität $\quad \Psi_{\mathrm{B} 1}+\Psi_{\mathrm{B} 2}$ & $\begin{array}{l}\text { Higgs-Boson (0) } \\
\text { Photon, Gluon (1) }\end{array}$ & 1 \\
\hline Anyonen & & $\begin{array}{c}\text { virtuelle } \\
\text { Superposition }\end{array}$ & $2+t$ (Zeit) \\
\hline $\begin{array}{l}\text { Fermionen } \\
\text { Spin } 1 / 2\end{array}$ & $\begin{aligned} \text { Wahrscheinlichkeiten } & \Psi_{\mathrm{F} 1} \Psi_{\mathrm{F} 2} \\
\Psi_{\mathrm{F}(\mathrm{x} y z, t)} & =\Psi_{\mathrm{F} 1} \Psi_{\mathrm{F} 2}+\Psi_{\mathrm{F} 2} \Psi_{\mathrm{F} 1}\end{aligned}$ & $\begin{array}{l}\text { Elektron, Quark } \\
\text { Proton, Neutron }\end{array}$ & $3+t$ \\
\hline $\begin{array}{l}\text { Quantenfeld } \\
\text { Spin }+-1 / 2,+-1, \ldots\end{array}$ & $\Psi_{\mathrm{Feld}}=\left(\Psi_{\mathrm{F} 1} \Psi_{\mathrm{x}}+\Psi_{\mathrm{x}} \Psi_{\mathrm{F} 1}\right)^{\mathrm{x}}$ & $\begin{array}{c}\text { Moleküle } \\
\text { Molekülverbände }\end{array}$ & $3+t$ \\
\hline $\begin{array}{l}\text { Phasenübergänge } \\
\text { in Makrosystemen }\end{array}$ & L & $\begin{array}{l}\text { Magnete, Organe } \\
\text { ebewesen, Kosmos }\end{array}$ & $3+t$ \\
\hline
\end{tabular}

Abb. 48 | Vom Qubit zur Realität

Aus dem Vakuumfeld lösen sich Bosonen, die sich unter Zuhilfenahme von Anyonen zu Fermionen wandeln. Fermionen bauen Quantenfelder und damit unsere bekannte Realität bis hin zu Lebewesen und dem Kosmos auf. An den Phasenübergängen besteht jeweils die Einflussmöglichkeit für Überraschendes. (eigene Darstellung)

Die sich gebildeten Bosonen, die Kräfte vermitteln, stoßen nun einen weiteren Prozessschritt an. Mithilfe der virtuellen Anyonen verwandeln sie sich an einem zweidimensionalen Phasenübergang zu Fermionen, unter Mitnahme aller in ihnen gespeicherten Informationen ${ }^{164}$. Ausgangspunkt bei den Fermionen sollten Elektronen und Quarks sein,

${ }^{164}$ Ein solcher Phasenübergang ist auch der äußere Rand unseres Universums oder jedes anderen Universums, wozu auch der Ereignishorizont von schwarzen Löchern zählen sollte. Von daher sollte tatsächlich Information über diesen Ereignishorizont hinaus gelangen. 
beide ohne innere Struktur und deshalb räumlich überall und nirgends. Bereits hier stellt sich wieder die Frage: Woher wissen die Anyonen was sie zu konfigurieren haben, zumal auch noch zwischen zwei unterschiedlichen Quarks differenziert wird? Das ist die gleiche Frage, die sich jetzt auch für die Quarks stellt. Zusammen mit Gluonen ${ }^{165}$ bilden nun zwei unterschiedliche Quarks entweder ein Proton oder ein Neutron. Die letzten Beiden bauen zusammen mit Elektronen Atome auf und diese wiederum Moleküle und weiter ganze Molekül-Ensembles, womit wir bei Quantenfeldern angekommen sind. An den Phasenübergängen der Quantenfelder kann es zu Kohärenz und damit zu einer weiteren Verschmelzung kommen, muss aber nicht. Die Natur hat offensichtlich verschiedene Verfahren entwickelt, um Entitäten voneinander getrennt zu halten. Zum einen sind das unterschiedliche topologische Strukturen in Form von verdrillten Energiebändern, zum anderen sind dies unterschiedliche Frequenzspektren oder Magnetfelder. Mit den unterschiedlichen Spinreihen und den Verwirbelungen zeigt sich zudem, dass die Natur neben dem inneren Aufbau auch sehr viele Optionen zur Eigenschaftsveränderung an den Oberflächen geschaffen hat. Hier drängt sich sofort der Vergleich zum Menschen auf. Ein stabiles inneres System kann durch ein verändertes Oberflächenverhalten (Lachen, Weinen, böser Blick etc.) völlig unterschiedliche Zustände repräsentieren.

Die Natur hat aber auch gezeigt, dass es verschiedene Formen von Brücken gibt, mit deren Hilfe Grenzen (Phasengrenzen) überwunden werden können und ein gemeinsames Ganzes aufgebaut wird (Josephson-Effekt), ohne die innere Struktur der beteiligen Entitäten zu verändern. Auch wenn mittlerweile in den physikalischen Experimenten eine Überwindung von begrenzenden Voraussetzungen, wie Magnetfeld und sehr kalten Temperaturen, stattgefunden hat, so lässt sich zumindest für das Magnetfeld festhalten: Die Erde als unser Lebensraum weist ein permanentes Magnetfeld aus, das für Lebewesen eine zentrale Bedeutung für seine körperlichen Lebensfunktionen besitzt. Im Kap. 8.2 und 8.3 wird darauf eingehend eingegangen. Allein daraus sollten sich schon die gleichen Möglichkeiten ableiten lassen, wie sie in den rein physikalischen Experimenten beobachtbar sind. Diese oben vorgestellten Phasen und Übergänge sind in ihrer theoretischen und praktischen Behandlung bezogen auf Energie und Kräfte sehr weit fortgeschritten, wenngleich nach wie vor noch viele Fragen offen sind.

Was bisher wenig untersucht wurde, sind all die Aspekte, die mit Information außerhalb anorganischer Entitäten einhergehen sowie deren Speicherung und Weitergabe. Auf einer prinzipiellen Ebene gibt es Ansätze der Erklärung (Kap. 4.2.2 - Wiener, Weizsäcker, Görnitz, Josephson, Lucadou und Schweitzer). Auf der konkreten, die tatsächlich vorstellbar ist, wie Information gespeichert und weitergegeben werden kann, gibt es die Verschränkung und seit wenigen Jahren das Konzept der Teleportation. In beiden Fällen werden bisher nur rein physikalische und codierte Information behandelt.

Mit der Idee, dass die Information in den Spin-Konfigurationen zu suchen ist und mithilfe der EDBFT sich miteinander in Beziehung setzen kann - und zwar jedwede

${ }^{165}$ Der Einfachheit halber wird auf den gesamten Teilchenzoo verzichtet und nur das Gluon stellvertretend betrachtet. 
Information, werden bisherige prinzipielle Vorstellungen konkretisiert und teilweise auch erweitert. Zur Vervollständigung benötigt es jetzt nur noch eine Ausformulierung dessen, wie die Interaktion zwischen den Entitäten und Spins zu neuen Informationsmustern kommt.

Aus den bisherigen Betrachtungen wurde deutlich, dass aus dem Vakuumfeld emergierte Bosonen Träger von Spins und damit Qubits sind, in denen die Gesamtinformation des gesamten Vakuumfeldes in Form von Überlagerungen enthalten ist. Der Umfang dieser Informationen wird mit Entropie umschrieben und kann berechnet werden. Durch weitere Umwandlungsprozesse entstehen immer konkretere Entitäten mit immer spezifischeren Informationen. Paradoxerweise benötigen wir mit der Ausdifferenzierung der Entitäten immer mehr Information über diese Information statt weniger. Information, die letztlich in der Gesamtstruktur und den Spins der Entität durch deren Ausrichtung und Kopplungen codiert ist. In dieser Codierung sind auch topologische Informationen enthalten, die Erkennungsprozesse von anderen topologischen Strukturen ermöglichen. Die Gesamtinformation des Vakuumfeldes geht nicht verloren, tritt aber immer mehr in den Hintergrund und wirkt von dort aus verdeckt weiter.

Treten zwei oder mehr Entitäten in Wechselwirkung, so finden Veränderungen auf Spin-Ebene und topologischer Ebene statt, die im neuen, verschränkten System ebenfalls codiert sind. Aufgrund der topologischen Strukturen und Knoten lassen sich alte Informationen jedoch wieder zurückholen. Je größer die Ensembles werden, desto mehr Spins und topologische Strukturen lassen sich abbilden und speichern und desto komplexer werden Messversuche. In solchen Systemen benötigt es sehr viele unterschiedliche Messanordnungen, um auch nur die wichtigsten Informationen erfassen zu können. Das Gesamtsystem lässt sich vergleichen mit einer Computerfestplatte, die mit zunehmender Größe immer mehr Speicherplatz besitzt, in dem Informationen codiert sind. Da für organische Systeme nicht nur Energie, Masse etc., sondern auch ganz andere Größen für das Überleben relevant sind, kann mit Sicherheit angenommen werden, dass diese Informationen ebenfalls in den Spins codiert und abrufbar vorliegen.

Über EMF stehen die Entitäten schließlich auch über nähere Distanzen miteinander in direktem Kontakt und damit auch die ihnen innewohnenden Spins mit ihrer Information. Analog dem tanzenden Tropfen und dem Silikonöl-Medium kann es bei einer Trennung bleiben, zur Annäherung oder zur Verschmelzung kommen. Dies ist zunächst auf Makroebene abhängig von der Ähnlichkeit der Frequenzen, inwieweit sie Überlagerungen zulassen. Mit Zunahme der Nähe werden die Spin-Konfigurationen schließlich nachhaltig beeinflusst und festgelegt. Diese Konfigurationen charakterisieren schließlich den Zustand und das Verhalten der jeweiligen Entität und schaffen Realität.

\subsubsection{Idee einer Normierung der physikalischen Theorien}

Mit den bisherigen Ausführungen wird deutlich, wie Information zur makroskopischen Realität werden kann. Sie liefern auch Anhaltspunkte die bestehenden physikalischen Theoriegebäude in einem neuen Licht zu sehen. Auch wenn dies für diese Forschung nicht zwingend notwendig erscheint, soll zur Erzeugung einer stimmigen Konsistenz 
des Gesamtzusammenhangs ein Versuch zur Normierung der bestehenden physi-kalischen Theorien unternommen werden. Dies geschieht in der Hoffnung auf ein einheitliches Modell, auf welches in den folgenden Kapiteln einfacher Bezug genommen werden kann und das die Komplexität der bisherigen Ausführungen verdichtet.

Eine Auffälligkeit an Ähnlichkeit lässt sich zwischen Higgs-Boson (The Royal Swedish Academy of Sciences 2013a, 2013b) und Vakuumfeld feststellen. Im Standardmodell der Elementarteilchenphysik bekommen alle Quarticle ihre Masse erst durch die Wechselwirkung mit dem, allgegenwärtigen' Higgs-Feld. Dieser ca. $4 \%$ für uns sichtbaren Masse stehen ca. $96 \%$ der Gesamtmasse des Universums (Dunkle Energie und Dunkle Materie) gegenüber. Das Vakuumfeld selbst wird im alternativen Bild von De-Broglie als Überlagerung realer Felder angesehen aus dem heraus Teilchen-Antiteilchen-Paare hervorgehen und die als Führungswellen den Quarticlen einen strukturellen Rahmen geben. Es liegt auf der Hand beide (Higgs-Feld und Vakuumfeld) als äquivalent anzusehen, als Ausgangspunkt der von uns wahrnehmbaren Welt.

Aus den in Kap. 8.1.1.4 geschilderten Zusammenhängen lässt sich Gravitation als eine Wechselwirkung zwischen ähnlichen Systemen aufgrund einer Verschränkungs-situation verstehen. Im Teilchenzoo lässt sich diese Wirkung dem Gluon zuschreiben, das mit seinem Gegenpart, dem Photon, aus dem Higgs-Boson (Spin 0, neutrale Ladung und sehr schneller Zerfall) hervorgeht. Rein theoretisch müssten sich daher für die beiden Quarticle Photon und Gluon gleiche, aber gegenläufige Werte ergeben. Tatsächlich werden beide mit Ladung 0 und Masse 0 angegeben und beide mit Spin 1. Sollte es einen Unterschied geben, so bleibt nur der Spin, der sich dann von +1 beim Photon in ein -1 beim Gluon spiegeln lassen müsste und vice versa, abhängig vom Zeitpfeil. Genau dieser Umstand findet sich in der Form, wie der Spin für beide beschrieben ist:

$$
\text { Spin Parität }=1^{-} \text {. }
$$

Der Begriff Parität bezeichnet in der Physik genau so eine Raumspiegelung und die Symmetrieeigenschaft, wobei die Zeit unveränderlich bleibt.

Im Gegensatz zum Gluon strebt das Photon mit Lichtgeschwindigkeit weg. Konsequenterweise muss es für dieses Wegstreben ein gegengerichtetes Pendant geben, was eben durch das Gluon realisiert werden sollte. Als Gemeinsamkeit dieser Einzelentitäten zu den anderen Bosonen (Bose-Einstein-Kondensat oder Cooper-Paare), die als Entitäten von Ensembles auftreten, lässt sich die Ununterscheidbarkeit ansehen. In diesem Sinne weisen sie zum einen eine Ähnlichkeit mit dem Higgs-Boson (Ununterscheidbarkeit) auf und zum anderen eine Ähnlichkeit mit den Photonen und Gluonen, deren Bestrebung zu sein scheint, sich innerhalb des Ensembles auszugleichen.

Maximale Ähnlichkeit führt somit zur Verschmelzung und Nicht-Unterscheidbarkeit. In diesem Sinn lässt sich die Wellenfunktion auch als Ausdruck der Unterscheidbarkeit interpretieren. Mit Abnahme der Unterscheidbarkeit findet eine Annäherung und Austauschbarkeit bzw. Gleichheit der Einzelentitäten statt, wie es im Extremfall bei den Bosonen und im Quantenvakuum zu beobachten ist. Mit Abnahme der Unterschiede und einer Annäherung an einen gemeinsamen Energiezustand reduzieren sich die abstoßenden Kräfte und die gemeinsamen Wechselwirkungskräfte beginnen miteinander zu 
interagieren; im besten Fall bis zur völligen Verschmelzung, womit wir wieder im Vakuumfeld respektive Quantenvakuum sind.

Unterscheidbarkeit ist aber immer an die Existenz eines Außenbeobachters oder eines Außen gekoppelt. Aus dieser Perspektive scheint die Suche nach einer eigenständigen dritten Komponente, der Gravitation, die neben der Quantenfeldtheorie und der allgemeinen Relativitätstheorie existieren soll, nicht schlüssig zu sein. Die Gravitation müsste sich aus der Quantenfeldtheorie selbst erklären können. Mit den neuesten Entwicklungen, dass auch in mathematischen Modellen die Verbindung von Relativitätstheorie mit ihren Wurmlöchern (Susskind 2016) und der QFT mit ihren Verschränkungen Wege gefunden wurden, beide Systeme miteinander zu verbinden, anstatt wie bisher üblich, sie als nebeneinander stehend zu betrachten, scheint dieser Zusammenhang ein mathematisches Äquivalent gefunden zu haben. Einstein-Rosen-Brücken (Wurmlöcher) über die gekrümmte Raumzeit und verschränkte Subsysteme sind demnach das Gleiche. (Der Ansatz von Susskind beinhaltet zudem exakt den Messaufbau, der bei SyA Verwendung findet, weshalb auf ihn in Kap. 8.1.4 noch einmal Bezug genommen wird.)

Als weiteres Puzzleteil auf diesem Weg scheint die ebenfalls neueste Veröffentlichung zur nicht notwendigen Existenz der Dunklen Materie herangezogen werden zu können (Verlinde 2017). Auch Verlinde geht von der Gravitation als einem emergenten Phänomen aus, vergleichbar der Temperatur als Folge der Bewegung von Quarticle. „,The observed phenomena that are currently attributed to dark matter are the conesquence [sic!] of the emergent nature of gravity and are caused by an elastic response due to the volume law contribution to the entanglement entropy in our universe" (Verlinde 2017: 35).

Aus seinen Überlegungen schließt er auf Zustandsveränderungen von Qubits, die in den Strukturen der Raum-Zeit gespeichert sind, mit Entropie und verschränkter Quanteninformation in Zusammenhang stehen und durch ihre Veränderungen Gravitation erscheinen lassen. Mit seiner Annahme, dass ,, our universe is entirely dominated by dark energy and that ordinary matter only leads to a small perturbation " (ebd. 36), kommt er zur gleichen Beschreibung wie wir sie bei EDBFT und den tanzenden Tropfen kennengelernt haben. Auch daraus lässt sich eine Äquivalenz von Vakuumfeld und Dunkler Energie ableiten. Er kommt genauso wie Haramein, Wilczek u. a. zu einem holistischen Bild des Universums.

Schon aus den anfangs vollzogenen Überlegungen zu Photon und Gluon, als zwei Seiten desselben, bedarf es keiner Dunklen Materie. Das was als solche wahrgenommen oder besser geschlussfolgert wird, sind vermutlich Wechselwirkungskräfte zwischen dem Gesamten (Vakuumfeld) und seinen separierten Teilen oder zwischen Entitäten untereinander, die sich aus $\mathrm{Zu}$ - und Abnahme (bei Verlinde ist das eine elastische Komponente) von Unterschieden und einer damit einhergehenden Änderung der ,Oberflächendurchlässigkeit' ergibt. Auch wenn die Dunkle Materie für Physiker so offensichtlich erscheint, ist sie noch nie beobachtet worden, sondern muss indirekt abgeleitet werden. Genauso wie bei Haramein (Haramein 2013b, 2013a) benötigt es hier keine Sonderkonzepte, sondern alles lässt sich aus den bestehenden Grundlagen konsistent erklären. 
Haramein postuliert in jedem System ein schwarzes Loch bis hinunter zum Proton, und dass darüber alles mit allem verschränkt sein. Aus dieser Überlegung lässt sich das schwarze Loch als Wurmloch interpretieren, das am Ereignishorizont in Verbindung mit einem unterscheidbaren Umfeld kommt. Dieser Ereignishorizont wäre in diesem Sinne wieder ein Phasenübergang mit all den dort anzutreffenden Gesetzmäßigkeiten, die sich je nach Übergang zwar unterscheiden können, letztlich aber dasselbe sind. Insofern wäre Haramein's Modell eine dritte Variante neben dem Standartmodell und der EDBFT, nur dass es sich möglicherweise durch eine geschicktere Interpretation und mathematische Behandlung auszeichnet. Mit Tegmark's ausschließlich mathematischen Bild, ,our universe is not just described by mathematics - it is mathematics " (Tegmark 2008, 2007: 1) besteht möglicherweise ein vierter Zugang zum Gleichen, nur dass in diesen Modellen ein anderer Schwerpunkte gesetzt wird. Bei Übertragung auf die Wellenfunktion müssten sich die einzelnen Terme in der Rechnung jeder dieser vier Ansätze unterscheiden, am Ende jedoch das gleiche Ergebnis zeitigen.

Die gesuchte vereinheitlichte Theorie würde sich deshalb auch als bereits existent darstellen lassen, mit der QFT als übergeordnete Theorie und der Allgemeinen Relativitätstheorie für die Besonderheit an den Rändern und damit als Beschreibung von Phasenübergängen und schwachen Kopplungen (Abb. 48) unter Anwesenheit eines Beobachters. Vergleichen wir den Formalismus der Gravitation im Rahmen der Allgemeinen Relativitätstheorie (Einstein 1915) und deren Auftreten, so scheint sie prinzipiell identisch mit der Wellenfunktion im Rahmen der QFT (Tab. 15).

Neueste Forschungen scheinen diese Annahme zu unterstützen, indem sie feststellen, dass die Gravitation einer QFT-Beschreibung unterliegen sollte (Belenchia u. a. 2018). Beide, Gravitation und Wellenfunktion, werden nicht als Kraft ${ }^{166}$ verstanden und beide werden als Welle bezüglich ihrer Ausbreitungsform beschrieben; mit einer Geschwindigkeit im Vakuum, die der Lichtgeschwindigkeit entspricht.

Mit den in dieser Arbeit entwickelten Überlegungen, dass es sich nicht nur um Wahrscheinlichkeiten, sondern um reale Möglichkeiten handelt, welche in realen Wellen eingebettet sind, findet auch eine vollständige Ankopplung an eine wie auch immer entstandene ,Realität' statt. Der wesentliche Unterschied der beiden aktuell fundamentalsten Theorien liegt dennoch im Verständnis der Ausbreitungsgeschwindigkeit der Information. Aber auch hier wurde in dieser Arbeit bereits eine Kopplung entwickelt. Von Beginn an besteht für eine räumlich und zeitlich existente Entität immer eine Phasen-

${ }^{166}$ Wie bei Einstein stellt auch Haramei's Ansatz eine geometrische Lösung für die Zusammenhänge dar, denn die bis heute gültige und experimentell nachgewiesene Gültigkeit der Allgemeinen Relativitätstheorie basiert auf einer Krümmung der Raumzeit und lässt die Gravitation als die Folge dieser Krümmung erscheinen und nicht als Folge einer Kraft. Mit der Quanten-Schleifengravitation gibt es zudem noch einen Ansatz, der ebenfalls ohne Kräfte auskommt, den Gesetzen der Quantenmechanik gehorcht und mit den gleichen Knoten und Spin-Netzwerken arbeitet, wie sie bei den Anyonen bereits beschrieben wurden. Nach ihr bekommt die Zeit ihre Bedeutung durch Veränderung der Netzwerke und durch die aufeinanderfolgende Verknüpfung der Knoten. Die Quanten der Gravitation (Graviton) in der QFT werden in der Quanten-Schleifengravitation zu Loops (Schleifen) (Pullin 2017; Rovelli 2011). 
grenze zu einem vorhandenen Umfeld. Eine solche Phasengrenze setzt jedoch immer einen außenstehenden Beobachter voraus.

Tab. 15 | Vergleich Gravitation und Wellenfunktion

Der Unterschied besteht nur in der Ausbreitungsgeschwindigkeit von Information. Bei der ART geht dies nur maximal mit Lichtgeschwindigkeit. In der QFT liegt die Information instantan im Gesamtsystem vor. (eigene Darstellung)

\begin{tabular}{c|c|c}
\hline & $\begin{array}{c}\text { Gravitation } \\
\text { in der ART }\end{array}$ & $\begin{array}{c}\text { Wellenfunktion } \\
\boldsymbol{\Psi} \text { in der QFT }\end{array}$ \\
\hline $\begin{array}{c}\text { Kraft } \\
\begin{array}{c}\text { Ausbreitungs- } \\
\text { geschwindigkeit } \\
\text { im Vakuum }\end{array}\end{array}$ & 0 & 0 \\
\hline $\begin{array}{c}\text { Ausbreitungsform } \\
\text { Informations- } \\
\text { verteilung }\end{array}$ & Wichtgeschwindigkeit $c$ & Lichtgeschwindigkeit $c$ \\
\hline
\end{tabular}

Die Bewegung an dieser Phasengrenze würde dann den Gesetzmäßigkeiten der Relativitätstheorie unterliegen mit der bekannten Gesetzmäßigkeit von ,Nichts ist schneller als Licht'. Alles was sich innerhalb dieser Phasengrenze bewegt unterliegt jedoch der QFT, womit das Postulat ,Nichts ist schneller als Licht' keine Gültigkeit mehr besitzt. Im Inneren von Systemen besitzt das Konzept der ,Verschränkung' mit einer instantanen Informationsverteilung Gültigkeit.

Abb. 49 veranschaulicht den möglichen Zusammenhang wie ART und QFT verbunden sein können in einer zweidimensionalen Darstellung. Durch die zugrundeliegende Raum-Zeit wäre eine exakte Darstellung nicht nur dreidimensional, sondern auch in sich verdreht und gekrümmt.

Aus dem Urknall entwickeln sich Entitäten jeweils mit einer eigenständigen PsiFunktion, die sich innerlich ausdifferenzieren und sich gleichzeitig mit Lichtgeschwindigkeit entsprechend der ART ausdehnen. Innerhalb der Gesamtausdehnung bleiben die Entitäten verschränkt. Diese Verschränkung verändert sich allerdings von $100 \%$ zu einer immer kleiner werdenden Verschränkungsintensität. Grund ist die Ausdifferenzierung, auch innerhalb der jeweiligen Entitäten, die Gemeinsamkeiten reduzieren, aber nie auf Null gehen werden. Die neuen Modelle zeigen, dass zwischen den Blasen, die eine Entität repräsentieren auch raum-zeitliche Krümmungen bestehen, die letztlich aus der ART heraus als Tunnel beschrieben werden. Auf diese Weise kann sowohl die ART mit ihren tunnelartigen Verbindungen als auch die QFT mit ihrer allgemeinen Verschränkung, die derzeit gültigen Modelle bestätigen. Es besteht auch kein Widerspruch durch die maximale Ausbreitungsgeschwindigkeit an den Rändern, welche auch für die Randzonen der individuellen Entitäten Gültigkeit besitzt. 
Mit diesem Modell bestünde auch eine Antwort darauf, weshalb die ART bei sehr kleinen Radien unbrauchbare Ergebnisse produziert. Zu Beginn gilt das Regime der Quantenwelt mit ihren Quanten. Erst mit Existenz von Bosonen, Fermionen und vor allem sich daraus bildenden Ensembles entstehen Dimensionen und Beziehungen, die für die ART Relevanz bekommen. Nicht von ungefähr bezieht sich ihre Relevanz auf Relationen, die immer auf andere angewiesen sind. Am anderen Ende der Ausbreitung, an den Rändern der jeweiligen Entitäten besteht wiederum ein zweidimensionaler Phasenübergang, der ebenfalls keine Radien mehr besitzt. Je näher die ART an diese Phasenübergänge herankommt, desto irrelevanter wird ihre Gültigkeit, da jetzt wieder die Gesetzmäßigkeiten der Phasenübergänge der Quantenwelt relevant werden. Insofern lässt sich die Quantentheorie als Universaltheorie betrachten, wie es auch Leggett in einem Vortrag in Heidelberg formulierte (Spillner 2009).

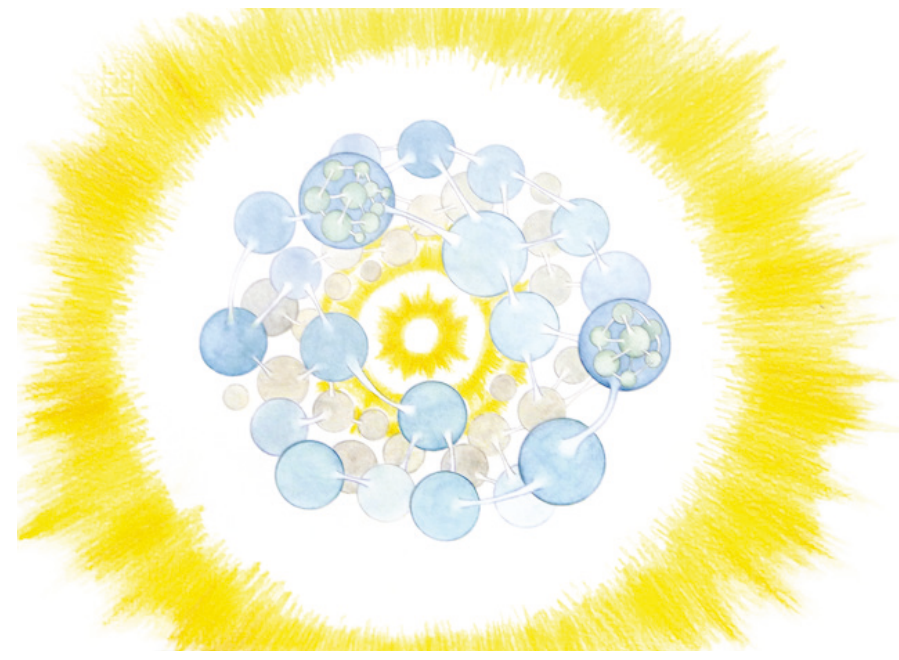

Abb. 49 | Möglicher Zusammenhang ART und QFT

Ausgehend von einem Urknall entwickeln sich eigenständige Entitäten, die sich immer weiter ausdifferenzieren, hier als Bubbles dargestellt. Die Bubbles lassen sich als verschränkt im Sinne der QFT und durch Wurmlöcher verbunden (ART). (Bild erstellt von Petra Weinmann.)

Neueste theoretische Ansätze und experimentelle Daten aus der Kosmologie scheinen in eine ähnliche Richtung zu deuten. Die theoretischen Ideen und Berechnungen von Mersini-Houghton (Valentino und Mersini-Houghton 2017a, 2017b; Mersini-Houghton und Holman 2009) in Verbindung mit dem , dark flow' Modell und aktuellen Daten (Atrio-Barandela u. a. 2015) führen zu einem Mulitverse-Modell, in dem die Universen in Energiemulden kosmischer Dimensionen lokalisiert sind und Wechselwirkungen auf angrenzende Universen ausüben, vergleichbar Abb. 46 mit der Rubidium-Atomverteilung auf der Lichtwelle im Mikrokosmos. Mersini-Houghton spricht in ihrem Modell 
von 2009 ebenfalls von nichtlokaler Verschränkung jenseits unseres Horizonts (,superhorizon entanglement'). Als beobachtbares Ergebnis einer solchen Wechselwirkung ergeben sich demnach die Ungleichverteilung der kosmischen Hintergrundstrahlung mit ihren kälteren Regionen und den Galaxienclustern. Gleichzeitig gelingt es mit diesem Modell bestehende Anomalien im kosmologischen Standard-Modell zu erklären.

\subsubsection{Conclusio aus der Illusion der Materie}

Aus den Kapiteln zur Illusion der Materie lassen sich verschiedene Rückschlüsse ableiten.

\section{$\underline{\text { Konsequenzen aus der Illusion der Materie }}$}

Kurz zusammengefasst liegt eine eindeutige Evidenz vor, den sichtbaren Körper nicht als reale Grenze seiner Wechselwirkungsmöglichkeiten anzusehen. Diese sichtbare Grenze hängt nur mit der Art und Arbeitsweise unserer 5 Sinne zusammen. Auf elementarer Ebene bleiben nur Energie und Information als relevante Größe übrig, was bedeutet, dass prinzipiell alle auf dieser Ebene existierenden Möglichkeiten auch für Lebewesen angenommen werden können. Der Homo Physicus als Mixed-Zustand zwischen Quanten- und klassischer Welt lässt sich daraus in jedem Falle ableiten.

\section{Konsequenzen aus dem Doppelspalt-Experiment}

Aus diesem Experiment lässt sich klar ableiten, dass Phänomene, die auf der Quantenebene ablaufen, keine deterministischen Vorhersagen zulassen, sondern nur Wahrscheinlichkeiten für das Auftreten eines Ereignisses. Auch die prinzipiell vorhandene deterministische Ausgangslage der DBBT und der EDBFT führen durch die enorme Komplexitätszunahme zu einer nicht mehr deterministischen Verhaltensweise; verursacht durch eine Führungswelle auf der unendlich viele Wechselwirkungen stattfinden und die damit sowohl Einfluss als auch Unbestimmtheit ermöglicht. Diese Startsituation wird durch die weiteren Ausdifferenzierungen von Entitäten noch weiter gesteigert, weshalb Wahrscheinlichkeitsaussagen die konsequente Folge sind. Dies entspricht den Bedingungen von Unbestimmtheit und Komplexität, wie sie bereits im Rahmen der VUCA-Welt herausgearbeitet wurden.

Sowohl experimentell (Kohärenz in Nicht-Gleichgewichtssystemen, Temperaturen über $600^{\circ} \mathrm{C}$ ) als auch theoretisch (Energiehaushalt als Garant der Kohärenz) liegt Evidenz vor, die die Fixierung auf die reine Elementarebene und isolierte Systeme bei Temperaturen nahe dem Nullpunkt überwindet. Als Folge sind ganz wesentliche Gegenargumente falsifiziert.

Die Variante des Delayed-Choice-Experimentes scheint eine Möglichkeit zu liefern, wie der menschliche Beobachter mit in das Experiment eingebettet werden kann und weshalb Repräsentanten in Aufstellungen auch mit technischen Bauteilen und Codes in Beziehung treten können. Darüber hinaus bestehen auch Modelle, um eine Veränderung der Vergangenheit zu beschreiben und auch zu realisieren. Eine Refokussierung und 
eine Rekohärenz ermöglichen verdeckte oder überlagerte Informationen wieder zugänglich zu machen.

Erstaunlicherweise existiert für jedes der Quantenphänomene respektive Experimente eine exakte Entsprechung auf der psycho-physischen Ebene von Menschen. Dies ist eigentlich nur zu erwarten, wenn die gleichen Prozesse zugrunde liegen. Entsprechend der Aussage von Bush ${ }^{167}$, erscheint die Quantenwelt in keiner Weise mehr so counter-intuitiv wie bisher angenommen. Sie entspricht vielmehr in vollem Umfang menschlichen Erfahrungen, sofern wir die bisher ausgeschlossenen oder ignorierten Erfahrungen einschließen. Selbst die Aussage, ,das sind ja nur Zufälle', wenn Menschen an jemanden denken und just in diesem Moment von ihm angerufen werden, bekommt unter dem bisher Herausgearbeiteten eine begründbare Realität ohne Zufallsbezug.

\section{Konsequenzen aus der Interpretation der Wellenfunktion}

Offensichtlich ist, dass die KI keine Antwort liefert, was Welle oder Teilchen tatsächlich sind und wie sich daraus Realität schaltet. Ihre rein mathematische Aussage gibt per Definition schon keine Antwort auf die Realität, sondern bildet nur Möglichkeiten von Erscheinungen ab, die sich aus der jeweiligen Kombination von Beobachtetem - Messapparatur - Beobachter ergeben. Zweifellos gelingt dies in ausgezeichneter Weise. Als reine mathematische Wahrscheinlichkeit ohne konkrete Realitätsanbindung kann nur eine indirekte Beweisführung über den Output von Experimenten geleistet werden. Die KI als Begründung für die Phänomene bei SyA oder Intuition heranzuziehen scheitert deshalb, denn es gibt keine aus ihr ableitbare Begründungsoption. Damit könnte an diesem Punkt meine Forschung auch schon beendet werden, denn statistische Evidenz wurde schon ausreichend nachgewiesen.

Gefunden wurde eine Interpretation der Wellenfunktion, die sowohl dem mathematischen Ansatz als auch der Beobachtungssituation Rechnung trägt und verständlich macht, weshalb sie bzw. ihr Quadrat einen realistischen Ausdruck für Messergebnisse darstellt. Daraus abgeleitet lassen sich die unterschiedlichen Polaritäten (Psi in den unterschiedlichen Interpretationen, Beziehung Quantenphysik - Relativitätstheorie, Ontologie - Systemtheorie, phänomenologisch - konstruktivistisch) miteinander in Beziehung bringen und einem grundsätzlichen bzw. spezifischen Bereich zuordnen.

\section{Konsequenzen aus dem Welle-Teilchen-Dualismus}

Die EDBFT mit den springenden bzw. gleitenden Tröpfchen weisen auf eine Option auch im biologischen Kontext hin. Das Experiment veranschaulicht nämlich den Umstand, dass es trotz gleicher Ausgangsbasis (das Bad als auch die Tröpfchen bestehen aus dem gleichen Medium) nicht zwingend zu einer Verschmelzung (Kohärenz bzw. Dekohärenz) kommen muss. Entscheidend sind die Frequenz- und damit die Erregungsunterschiede der beteiligten Entitäten. Die sich unterscheidende Eigenfrequenz des Bades verhindert ein Eintauchen des Tröpfchens. Der jeweilig dekohärente Zustand wird aufrechterhalten bzw. die Kohärenz beider Systeme wird vermieden. Dennoch besteht

${ }^{167}$ Siehe weiter oben im Kontext der erweiterten De-Broglie-Führungswellen-Theorie (EDBFT) 
bei ausreichender Nähe die Option, Zustände (Wellenfunktionen) durch gegenseitige Wechselwirkungen zu beeinflussen und diese auch von außen zu beobachten.

Dieser Vorgang bildet eine hochgradig phänomenologische Ähnlichkeit mit beobachtbaren Interaktionen zwischen Menschen, die im Wesentlichen aus dem gleichen Medium aufgebaut sind. Nehmen wir eine Kultur (Familie, Organisation, Land), welche sich im Prinzip als kohärentes System beschreiben lässt. Die Einzelelemente (Menschen) sind solange mit dem Gesamtsystem kohärent, solange sie in absolut gleicher Weise (quasi stereotyp) denken und agieren. Entwickeln sie andere Gedanken und anderes Verhalten, so manifestiert sich dieses auch in Form anderer Frequenzen und SpinKonfigurationen. Die Einzelentität wird unterscheidbar und löst sich aus dem Gesamtsystem. Solange noch gewisse Ähnlichkeiten bestehen, lässt sich eine wechselseitige Beeinflussung beobachten, durch interaktive Unruhen an den Berührungspunkten. Darüber hinaus bewegt sich die Entität weitgehendst selbstgesteuert und gleichzeitig gelenkt von der Führungswelle (Gesamtheit der Anderen), die das Gesamtfeld und seine Möglichkeiten strukturiert und die Freiheitsgrade für das Einzelsystem definiert. Ab einem bestimmten Unterschied von Einzelentität und Gesamtsystem gehen die wechselseitigen Beeinflussungen gegen Null und die Systeme leben nebeneinander her, beobachtbar nur über Fehl- bzw. Leerstellen im Gesamtsystem. Die von Zeh (Zeh 2013) formulierte Rekohärenz (die Wiederherstellung einer Kohärenz) kann über Gespräche und wiederfinden von Gemeinsamkeiten erzeugt werden (Refokussierung).

Für jedes physikalische System sind Störungen letztlich energetisch ungünstig. Das normale Bestreben ist der Versuch, wieder auf den energetischen Grundzustand zu kommen, was meist durch eine kohärente Struktur zum Ausdruck kommt. Energetischer Grundzustand oder energetisch günstig kann jedoch für unterschiedliche Kulturen ganz unterschiedlich beantwortet werden. Für das Gesamtsystem z. B. Organisation oder Land bedeutet die Zunahme von Unterschieden in der Regel einen Zusatzaufwand, um den Bedürfnissen aller gerecht zu werden. Als natürliches Verhalten kann aus dessen Perspektive deshalb der Versuch, Einheitlichkeit zu erzeugen, als Versuch interpretiert werden, schonend mit Ressourcen umzugehen. Einheitlichkeit (zu starke Kohärenz) geht allerdings oft einher mit fehlenden Kristallisationskeimen, an denen sich neue Ideen konstituieren; genau das, was die Überlebensfähigkeit von Systemen in sich verändernden Umwelten sichert.

Auf der anderen Seite können für Einzelentitäten (Person, Team) zu große Unterschiede zum übergeordneten System einen erheblichen Mehraufwand und damit Energieaufwand bedeuten, was gefühlt zum Phänomen Stress führt und auf Körperebene dem biologischen System Energie raubt. Energie, die fehlt, um Fehlstellen bzw. Fehlentwicklungen innerhalb des kohärenten Systems des Lebewesens angemessen zu begegnen. Die vom System wahrgenommene Information über Fehlentwicklung bedarf Energie um entsprechende Reparatur-, respektive Rekohärenzprozesse zu initiieren. Als Ergebnis treten körperliche oder psychische Krankheiten auf.

Die Experimente mit flüssigen Medien wie dem Silikonöl und den wandernden Tropfen bei der EDBFT lässt sich, zumindest in erster Näherung, auch gut auf den Menschen an 
sich übertragen; besteht dieser doch zu $75-50 \%$ aus Wasser ${ }^{168}$ und wechselwirkt in stärkerem Maße mit der Umgebungsfeuchtigkeit der Natur und den Photonen und Quarticles des Umfeldes. Stellt man sich den Bereich der Haut als zweidimensionale Oberfläche vor, mit einer systemabhängigen Frequenz und im Wesentlichen aufgebaut aus Wasser als dynamisches Medium, so lässt sich die Führungswelle gut auf diesen Oberflächenzustand übertragen. Korrespondierende, ankommende Quarticle sollten einer ähnlichen Wechselwirkung unterliegen wie der wandernde Tropfen. Je nach Übereinstimmung der EM-Frequenzen und Spin-Konfigurationen kommt es zu einer vollständigen, teilweisen oder zu keiner Wechselwirkung. Dies könnte auch erklären, weshalb manche Menschen Krankheiten vom Umfeld annehmen und andere verschont bleiben.

Der abnehmende Wasseranteil im Körper vom Kleinkind zum alten Menschen erklärt vielleicht auch die hohe Sensibilität und implizite Lernfähigkeit in jungen Jahren und die Abnahme der Sensibilität und Lernfähigkeit im fortgeschrittenen Alter. Je mehr Wassermoleküle, desto einfacher, weil automatischer, ist ein Lern- und Veränderungsprozess.

\section{$\underline{\text { Konsequenzen aus der Entwicklung von Qubits in die Realität }}$}

Die bisherigen Zusammenhänge unterstützen Antworten, inwieweit Superposition und damit Interferenzen auch auf biologische Systeme bzw. auf die Informationsverarbeitung bei Menschen übertragbar sind. Die theoretischen Modelle und Experimente speziell zu den Phasenübergängen sind offensichtlich gut mit der EDBFT kompatibel. Zusätzlich zeigen sie Wege auf, wie Kohärenz und Dekohärenz unter normalen Umweltbedingungen und zwischen Makrosystemen verhindert bzw. beibehalten werden können (topologische Energiebänder, Frequenzunterschiede). Es wurde auch offensichtlich, wie Informationen und damit verbundene Zustände und Eigenschaften durch Spins und Spin-Konfigurationen der Quarticle, speziell auf den Oberflächen, gespeichert werden und wie dadurch beobachtbare Realität entsteht und modifiziert wird. Veränderungen der Spins verändern die Information des Systems und schließlich dessen Eigenschaften und Verhalten. Durch topologische Konfigurationen lassen sich so auch nicht identische Informationen in Beziehung bringen. Die im technischen Sinn verwendeten Qubits lassen sich als extrinsisch betrachten, die künstlich erzeugt und mit aufgeprägten Zeichencodes versehen werden. Demgegenüber stehen die intrinsisch erzeugten Qubits, die sich emergent aus einer Entwicklungsgeschichte heraus konstituieren und die quasi unendlich viele Zustände einnehmen und speichern können. Das EMF stellt schließlich die für uns im klassischen Sinne messbare Form dar. Es enthält alle Informationen der Quanten und Qubits, verbirgt sie allerdings durch die Form des Auftretens. Die in ihr enthaltenen Informationen sind deshalb nur indirekt beobachtbar, beispielsweise an synchronen Erscheinungen und Verhaltensweisen. Eine solch indirekte Beobachtung ist jedoch nicht untypisch für physikalische Untersuchungen.

${ }^{168}$ Laut WHO beträgt das Gesamtkörperwasser (total body water, TBW): Kinder $75-60 \%$, Männer 65 - $60 \%$, Frauen 55 - $50 \%$, mit dem Alter stark abnehmend; davon $64 \%$ intrazellulär (innerhalb der Zellen) und $36 \%$ extrazellulär (zwischen den Zellen). 
Es gibt keinen ersichtlichen Grund, weshalb diese von der Natur entwickelte Realität nicht auch bei organischen Lebewesen Anwendung finden sollte. Schließlich sind Zellen aus Quarticle aufgebaut und werden als makroskopische Entität letztlich durch die Spin-Konfigurationen im Gesamtsystem zu einer ganz spezifischen, informationstragenden Einheit.

\section{Konsequenzen aus der Normierung physikalischer Ideen}

Die Arbeiten von Lin und Moreva und deren Gruppen zeigen (Kap. 8.1.1.4) dass interne und externe Wahrnehmungen unterschiedlichen Gesetzmäßigkeiten gehorchen, die äquivalent zu den Aussagen der ART bzw. der QFT sind. Entsprechend sind meine Ableitungen aus dem Prozess vom Qubit zur Realität und insbesondere die Idee der emergenten Zeit aus den Knoten vollständig deckungsgleich zu den neuen Ideen der Schleifen-Quantengravitation.

Danach ist der Verzicht auf Dunkle Materie, wie es in neuesten Konzepten herausgearbeitet wurde und die ausschließliche Fokussierung auf die Dunkle Energie, als Äquivalent zum Vakuumfeld und den sich daraus entwickelnden Entitäten, scheinbar übereinstimmend mit dem Modell der Wechselwirkung, wie sie sich aus meinen quantenphysikalischen Überlegungen ergaben. Die Verbindung von ART und QFT wie sie u. a. von Susskind entwickelt wurde (Susskind 2016), legt die Grundlage für ein konsistentes Erklärungsmodell, das eine Verschränkung von Quantenfeldern und eine damit verbundene instantane Informationsübertragung bzw. -wahrnehmung ermöglicht, auch bei organischen Lebensformen.

Daraus lassen sich alle Phänomene bei SyA und Intuition als quantenphysikalisch begründbar und nicht im Widerspruch zur Relativitätstheorie stehend ansehen.

\section{Übertragung auf SyA}

Sollten SyA und Intuition auf diese Ebene der Physik wie vermutet zurückgreifen, sind auch dort getroffene Vorhersagen Wahrscheinlichkeitsaussagen und keine deterministischen Ergebnisse. Experimente müssten tatsächlich den oben beschriebenen, wahrscheinlichkeitsbasierten Evidenzmessungen entsprechen. Konsequent höhere Signifikanzen als die Gaußverteilung würden dann bereits auf Quanteneffekte hinweisen. Gleichzeitig ermöglicht es Repräsentanten den Zugriff auf nicht-lokale, ontologische Gegebenheiten auch rückwirkend in die Vergangenheit. Die phänomenologische Wahrnehmung wird konstruktivistisch durch die Wechselwirkung zwischen den Entitäten modifiziert und durch Veränderungen von Spin-Konfigurationen gespeichert, die schließlich eine Verhaltensveränderung bewirken.

Konkret scheint die Bestätigung einer verbreiteten These einen Evidenzhinweis zu liefern: Je höher der energetische Austausch, desto klarer die Wahrnehmung, da sich das Interferenzmuster klarer vom Hintergrund abhebt. Dies würde jedoch nur für lokale Nähe Gültigkeit besitzen, in denen die Entitäten direkt miteinander wechselwirken. Bei SyA trifft dies für die Aufstellungssituation vor Ort auch zu. Damit könnte sich erklären, weshalb fremde oder eher unerfahrene Gruppenmitglieder erst mit Berührung durch den Fallbringer starke körperliche Wahrnehmungen entwickeln. Durch das Auflegen der 
Hände des Fallbringers auf den Rücken des Repräsentanten findet eine maximale lokale Interaktion der beiden Körperfelder statt, mit maximalem Energieaustausch und maximaler Wechselwirkung zwischen den Spins der beiden Körperfelder. Dass hier ein Energieaustausch stattfindet, ist beispielsweise durch Wahrnehmung der Körperwärme verifiziert. Als weitere Möglichkeit wäre ein aufeinander Einschwingen denkbar, wie es in kommunikativen oder therapeutischen Settings praktiziert wird. Durch das Anstreben eines gleichen, kohärenten energetischen Zustandes (Anpassung auf den Erregungszustand des Gegenübers) kommt es auch zur Anpassung der EM-Frequenzen analog der tanzenden Tröpfchen. Folglich würde sich auch die Menge ähnlicher, wechselwirkender Frequenzen zwischen den Teilnehmern erhöhen. EEG, EKG oder HautleitwiderstandsDaten müssten sich angleichen bzw. aufeinander reagieren. Konsequenterweise würde dies dann zu verstärkter Überlagerung und mithin zur Erhöhung der wahrnehmbaren Intensität führen, mit Verbesserung der Wahrnehmung der inneren Zustände des Gegenübers. Ein Teil dieser Zusammenhänge wurde im Rahmen der Experimente zu Entscheidungstheorie und Intuition bereits nachgewiesen. In Kap. 8.2 und 8.3 wird dies noch weiter untersucht.

Bei einer Aufstellung werden Wahrnehmungen an Brüchen von gemeinsamen Kohärenzen gemacht. Die Störungen (Leer- und Fehlstellen oder zumindest Veränderungen an den Wellenfunktionen der Beteiligten) weisen auf Unterschiede hin, die durch Suchbewegungen in Richtung einer kohärenten Gesamtsituation (wieder) ausgeglichen werden sollen.

Die Suche nach neuen, vielversprechenden Kristallisationskeimen mittels SyA bedeutet die Suche nach Unterschieden im Feld und nach kohärenter Anschlussfähigkeit auf eine Ebene, die dem bewussten Verstand nur schlecht zugänglich ist. Ist das Ziel die Wiederherstellung von energiesparendem Zusammenleben (z. B. Team, Familie), so bedeutet dies die Suche nach Störstellen und Unterschieden und die Suche nach Möglichkeiten einer neuen Übereinstimmung. Die gefühlte Wahrnehmung der Repräsentanten würde damit den Turbulenzen im kohärenten Wellenbad entsprechen. Die Bewegung hin zu einer guten Lösung entspräche der Reduzierung dieser Unterschiede bis hin zu einer Gesamtkohärenz (Rekohärenzprozess). Dabei ist anzunehmen, dass mit der Integration des Neuen sich auch die Wellenfunktion des Gesamtsystems (Gruppe plus Einzelperson) verändern wird.

In Bezug auf Wirtschaftskontexte und deren Repräsentation mittels SyA ergibt sich ebenfalls ein sehr anschauliches Beispiel. Frühe Entwicklungen und deren Ideen sind aufgrund der allgemeinen Verschränkung bereits von Beginn an auf der Ebene des Quantenfeldes existent. Die Ideen sind zunächst in den Elementarteilchen respektive den Quantenfeldern, die die Ideengeber (Menschen) repräsentieren, codiert. In diesem Stadium ist die Intensität dieser Informationsfelder jedoch noch sehr klein im Vergleich zur Gesamtbevölkerung. Je mehr Menschen diese Ideen aufgreifen und sich damit beschäftigen, desto größer wird die Intensität und desto einfacher wird die Idee als Resonanz spürbar. Im normalen Alltag, besonders wenn wir auf unsere eigenen Ideen und Begrenzungen konzentriert sind, wird unser Bewusstsein kaum solch niederschwellige 
Informationen und Resonanzen wahrnehmen. Umfangreiche Marktstudien können dies nur teilweise ausgleichen, denn sie müssten die Nester entdecken, in denen neue Entwicklungen entstehen. SyA sind dazu viel früher und kostengünstiger in der Lage. Das mentale Öffnen ermöglicht den Repräsentanten, mit sehr niederschwelligen Informationen in Resonanz zu treten. Als Unsicherheit bleibt nur die Interpretation der Wahrnehmungen. In jedem Fall lassen sich aber die dabei entstehenden intuitiven Ideen nutzen.

Es gibt somit ausreichende theoretische Konzepte und experimentelle Beobachtungen, die eine Übertragungsmöglichkeit oder besser eine Integration menschlicher Erfahrungen in quantenphysikalische Beschreibungen als realistisch erscheinen lassen. Zumindest gibt es bisher keinerlei Argumente, die gegen eine Ausdehnung quantenphysikalischer Beschreibungen und Zusammenhänge sprechen. Offen bleibt jetzt nur noch eine tatsächliche Beobachtung im biologischen Kontext und letztlich bei Menschen. Vor diesem Schritt werden zur Ausschließung häufig formulierter Einwände noch die Themen Verschränkung und Messproblem vertieft betrachtet und mit einem konkreten Modell der Informationsübertragung plausibilisiert.

\subsubsection{Verschränkung und Dekohärenz}

An unterschiedlichen Stellen, besonders aber im Kap. 4.2, 5.3 und 8, wurde bereits auf das Thema ,Verschränkung' verwiesen und verschiedenste Experimente vorgestellt. Über das Phänomen existieren allerdings, auch innerhalb der Physik, unterschiedliche und teilweise auch sehr konträre Vorstellungen. Da jedoch SyA und Intuition nicht ohne diese Grundlage erklärt werden können, soll im Folgenden das Wesentliche zusammengefasst sowie der Stand der Forschung in konzentrierter Form vorgestellt werden. Dies ist auch deshalb notwendig, da die Entwicklungen der letzten Jahre einige der heute noch verbreiteten Annahmen infrage stellen oder gar widerlegen. Zum Zweiten soll überprüft werden, ob das Phänomen der Verschränkung tatsächlich auf Menschen anwendbar ist.

Neben der Modellentwicklung zur Säule 5 ,Nachweisverfahren zur Nicht-Lokalität', Säule 6 ,Dekohärenzmodell von H.-D. Zeh' und Säule 8 , Überwindung des TemperaturParadigmas' werden entsprechend die Unterkategorien ,Lokal versus Nicht-Lokal' und ,Verschränkung' ausgearbeitet.

\subsubsection{Verschränkung allgemein}

Von Verschränkung spricht man ganz allgemein, wenn der Zustand eines Quantensystems nicht durch die Einzelzustände seiner Subsysteme bestimmt wird, sondern nur als Ganzes verstanden und gemessen werden kann. In der Sprache der Physik: Die Wahrscheinlichkeitsverteilung der Ergebnisse, die an einem Teil eines Quantensystems gemessen werden, wird durch die Messung an einem anderen Teil des gleichen Quantensystems beeinflusst. Wie bereits ausgeführt, geht man bei den Einzelzuständen in der Regel von Quarticle wie Photonen, Elektronen, Atomen etc. aus. Im Falle der Ver- 
schränkung spannen die verschränkten Quarticle ein wohldefiniertes Ganzes auf, dessen Gesamteigenschaft beschreibbar und messbar ist.

Die Möglichkeit Ein-Teilchen-Systeme per Addition zu kombinieren und daraus auf das Ganze zu schließen, funktioniert in einem solchen System nicht. Dies steht im Gegensatz zu unserem bisherigen klassischen naturwissenschaftlichen Verständnis. Auf den ersten Blick bietet sich eine Analogie zur Systemtheorie an, bei der ein Gesamtsystem (Team, Organisation etc.) ebenfalls mehr ist als die Summe seiner Teile und ebenfalls nur als Ganzes verstanden werden kann. Physikalisch gibt es aber doch noch ein paar Spezifika, die berücksichtigt werden müssen und mit denen wir uns zunächst auseinandersetzen wollen.

\section{$\underline{\text { Teilchenkonzept der Verschränkung - Compton-Effekt }}$}

Das verbreitete Verständnis über das Entstehen von Verschränkung spielt im Teilchenmodell und ist mit dem Compton-Effekt (auch Compton-Streuung) verbunden. Dieser Effekt trifft auf alle physikalischen Prozesse zu, in denen Quarticle wechselwirken (Camejo 2007: 74-85; Greenstein und Zajonc 2005: 64-65). Abb. 50 veranschaulicht diesen Mechanismus anhand einer Wechselwirkung von Photon und Elektron.

Ein einfallendes Photon trifft auf ein Elektron und trennt sich anschließend wieder. Für das Verständnis der Verschränkung ist dabei relevant, dass nach dem Trennprozess die beiden Quarticle nicht getrennt vorliegen, wie wir es in der klassischen Physik erwarten. Die beiden Quarticle zeigen stattdessen einen sogenannten Überlagerungszustand (die sogenannte Superposition), der unabhängig von der räumlichen und zeitlichen Entfernung bestehen bleibt. Im Extremfall befinden sich die beiden Quarticle jeweils an der entgegengesetzten Seite des Universums und wissen dennoch voneinander.

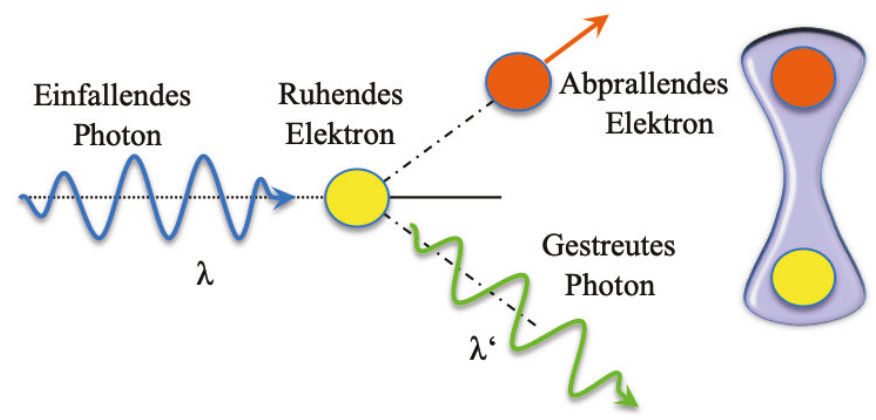

Abb. 50 | Verschränkung dargestellt mithilfe der Compton-Streuung.

Mit $\lambda$ als einfallende Wellenlänge und $\lambda$ ' als veränderte, gestreute Wellenlänge (eigene Darstellung). Nach einer Interaktion zwischen einfallendem Photon und ruhendem Elektron und einer nachfolgenden Separierung bleibt eine Überlagerung (Superposition) zwischen abprallendem Elektron und gestreutem Photon bestehen. Beide Entitäten bleiben verschränkt. (eigene Darstellung) 
Dieses Phänomen ist in der Physik als Nicht-Lokalität bekannt und wurde von Einstein Zeit seines Lebens abgelehnt. Er vermutete dahinter nicht verstandene Zusammenhänge, die er bis zu seinem Tod zu erforschen suchte. Denn letztlich wurde mit diesen Beobachtungen eine fundamentale Annahme verletzt, dass Eigenschaften von Quarticle über große Entfernungen von anderen Quarticle ohne direkte Wechselwirkung nicht beeinflusst werden können. Dieses Postulat ist bekannt unter dem Begriff des, lokalen Realismus' und wurde u. a. von Hensen und seinen Kollegen schließlich 2015 und 2017 vollständig und zweifelsfrei experimentell widerlegt, u. a. über kosmische Distanzen (Handsteiner u. a. 2017; Hensen u. a. 2015).

\section{Wellenkonzept der Verschränkung - Doppler-Effekt}

Der Compton-Effekt wird üblicherweise für das Teilchenmodell des Lichtes beschrieben und zur Berechnung der Veränderung der Wellenlänge der beteiligten Systeme genutzt. Weniger bekannt ist der Umstand, dass diese Wellenlängenveränderung auch mit dem reinen Wellenmodell beschreibbar ist und sich im Doppler-Effekt ${ }^{169}$ wiederfindet. Der Verschränkungseffekt kann somit äquivalent auf das Wellenmodell übertragen werden (vgl. Camejo 2007: 84).

\section{Vier weitere Verschränkungsmöglichkeiten}

1. Quarticle können nicht nur verschränkt sein, wenn sie miteinander interagieren, sondern auch, wenn sie von der gleichen Quelle emittieren (Siegfried 2016). Dies trifft beispielsweise für die Photonen eines Lasers zu, wie sie von Hensen und anderen bei Verschränkungsexperimenten üblicherweise verwendet werden. Dieser Zusammenhang bekommt besonders in Kap. 8.2 bei den biologischen Systemen eine relevante Bedeutung.

2. Verschränkung kann auch entstehen, wenn die am Ende verschränkten Quarticle A und D gar nicht selbst miteinander in Kontakt waren, sondern nur verschränkte Zustände übertragen werden; wenn also die Verschränkung von AB und CD über unterschiedliche Quellen erfolgt und der verschränkte Zustand selbst auf AD übertragen wird. Das Verfahren ist unter ,Entanglement Swapping' bekannt und wird in Kap. 8.1.4 noch näher erläutert: ,, One can entangle without any direct interaction particles which were independent of each other or, what is more important for us, construct entanglement of higher order “ (Pan u. a. 2012: 779). Siehe auch (Pan u. a. 2001; Żukowski u. a. 1993).

3. Als neue, vierte Form wurde die Möglichkeit einer direkten, wechselwirkungsfreien Verschränkung über das Vakuumfeld erkannt (Sabín u. a. 2012; Olson und Ralph 2012). Analog dem Delayed-Choice-Experiment beeinflussen die Parameter sowohl

${ }^{169}$ Je nach Bezugssystem und Beobachtungssituation scheint beim Doppler-Effekt dieselbe Welle unterschiedliche Frequenzen zu haben. Eine einfallende EM-Welle mit einer Wellenlänge $\lambda$ wird nach Zusammenstoß und erneuter Trennung vom Elektron zu $\lambda^{\prime}$ (aus Sicht des Elektrons) mit $\lambda^{\prime}>\lambda$ (siehe auch Abb. 50). Diese wellentheoretische Annäherung führt zu den gleichen Ergebnissen wie sie mithilfe der Compton-Streuung erhalten wird (vgl. Camejo 2007: 84f). 
die Zukunft als auch die Vergangenheit, ohne dass die beteiligten Qubits zu irgendeinem Zeitpunkt miteinander interagiert haben und ohne Entanglement Swapping. Die sich zeigenden starken Korrelationen und Informationstransfers, bei räumlicher als auch zeitlicher Separierung, werden aus Sicht der Autoren ausschließlich mittels des Skalarfeldes des Quantenvakuums erzeugt. Damit erhält der theoretische Ansatz aus Kap. 5.3.6, der Fernwahrnehmungs-Phänomene mit dem Skalar- und VektorFeld in Zusammenhang bringt, möglicherweise doch noch seine Berechtigung und Unterstützung. Die Forscher kommen auf diese Erklärung, da selbst bei der Einstellung, bei der ein Photonenaustausch verboten ist, die Qubits Verschränkungskorrelationen aufweisen. Als weiteres Resultat betrachten sie das Geschehen als QuantenTeleportation über Zeitgrenzen (past-future entanglement) hinweg und als neue Form eines Quantenspeichers. Auf diese Weise kann ihrer Ansicht nach auch Information P (past) aus benachbarten Quanten-Feldern codiert, klassisch gespeichert und zu einem späteren Zeitpunkt $F$ (future) wieder reaktiviert werden, dies unabhängig von weiteren Interaktionen nach P. (vgl. Sabín u. a. 2012). Mit ihrem Ansatz liegt neben Verdrillungen und Knoten eine weitere Möglichkeit vor, zeitabhängige Information zu speichern und zu anderen Zeiten wieder abzurufen bzw. auch noch zu verändern.

4. Mit Susskind ist seit neuestem noch eine 5. Verschränkungsoption hinzugekommen. Er führt in seinen Überlegungen ART und QFT zusammen und veranschaulicht die Gleichheit von Tunnel- und Verschränkungsphänomenen. Verschränkung findet daraus abgeleitet über eine Verbindung von ,Schwarze Löcher' und einem damit verbundenen Tunneln statt (Susskind 2016: 556). Damit bewegt sich Susskind in der gleichen Logik wie Haramein, der eine solche Verbindung bis hin zu den einzelnen Protonen ermittelte. Bei Haramein ist jede physikalische Entität über ,Schwarze Löcher' der Protonen gekoppelt (Haramein u. a. 2008). Der Ansatz wird bei der Quanten-Teleportation noch relevant, weshalb er hier aufgenommen wurde.

\section{Erweiterter Geltungsbereich}

Der Mechanismus der Verschränkung gilt heute nicht nur für die Quarticle, für die die Physik zuständig ist, sondern er bildet mittlerweile auch die Grundlage für das Verständnis der Chemie. So werden die Elektronen, die sich im Umfeld eines Atomkerns befinden (Abb. 51), als verschränkt angesehen, weshalb sie nicht einzeln bzw. separiert gemessen werden können; genauso wie Moleküle, z. B. $\mathrm{H}_{2}+$-Ionen (Abb. 52), als verschränktes System betrachtet und berechnet werden. Nach diesen auf der Quantenphysik beruhenden Schlussfolgerungen stellen ,, alle organisch-chemischen Bindungen Überlagerungszustände" (Polley 1997: 9) dar, die im Wesentlichen auf den Gesetzen der Quantenmechanik basieren. 


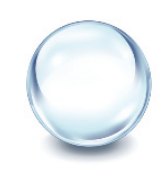

Abb. 51 | Die Elektronen um einen Atomkern liegen nicht separiert vor sondern sind nach quantenphysikalischem Verständnis verschränkt und bilden deshalb eine Ganzheit. Ihr Aufenthaltsort ist mit einer $\Psi-$ Funktion berechenbar. Die gängige Darstellungsform der Orbitale ist letztlich nur eine Hilfskonstruktion. (Crystal ball_Fotolia_37959026)

Die aktuellen Versuche zeigen, dass heute keine belastbare Aussage getroffen werden kann, bei welcher Größe von Makrosystemen die Grenze solcher Verschränkungen erreicht ist. Dies wird auch an der auf den Kosmos bezogenen Psi-Funktion deutlich (Kap. 8.1.1.2).

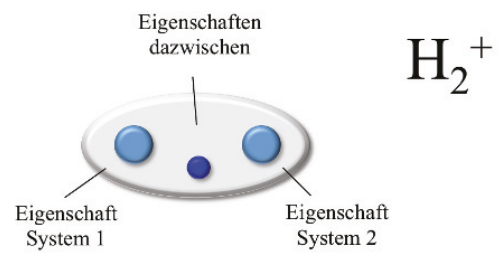

Abb. 52 | Überlagerung (Superposition) zweier Wasserstoff-Ionen mit einem Elektron

Der Aufenthalt des Elektrons bleibt quantenphysikalisch unbestimmt und lässt sich deshalb nur mit Wahrscheinlichkeiten bezüglich des möglichen Aufenthaltsortes berechnen. Entsprechende Darstellungen sind bereits im Kap. 8.1.1.1 vorgestellt worden. (eigene Darstellung)

Für die experimentelle Forschung besteht die Herausforderung darin, Wege zu finden, wie die Schwierigkeit des Nachweises der Interferenz- und damit auch Verschränkungsfähigkeit bei Zunahme der Größe der Makrosysteme gelöst werden kann. Entscheidend für diesen Ansatz ist die immer kleiner werdende de-Broglie-Wellenlänge. Die Theorie besagt nämlich: Je kleiner die de-Broglie-Wellenlänge, desto schwieriger der Nachweis eines quantenphysikalischen Verhaltens. Einfacher ausgedrückt: Überlagerungen, wie sie mit Verschränkung einhergehen, haben nur sehr kurze Reichweiten. Soweit die heutige Theorie. Dass die quantenmechanischen Überlagerungen im mikroskopisch Kleinen auftreten und makroskopische Systeme nicht beträfen, war deshalb die anfängliche Grundannahme. Kohärenzen und damit Quanteneigenschaften würden auf dem Weg vom Photon zum Kosmos irgendwo verlorengehen. Die Schrödingergleichung (8.6) und das mit ihr verbundene Superpositionsprinzip (8.7) legt diese Grenze auf jeden Fall nicht fest. Sie sind in ihrem Formalismus nach oben hin offen.

$$
\hat{\mathrm{H}}|\Psi\rangle=\mathrm{E}|\Psi\rangle
$$

Der Hamiltonoperator $(\hat{\mathrm{H}})$, der die Zeitentwicklung eines Eigenzustands $(\Psi)$ des Hamiltonoperators beschreibt, ist proportional der Energie (E) des Zustandes des Systems mal der Superposition eines Systems (8.7):

$$
|\Psi\rangle=\sum_{\mathrm{i}=1}^{\mathrm{n}} \mathrm{c}_{\mathrm{i}}\left|\Psi_{\mathrm{i}}\right\rangle
$$


Mit $|\Psi\rangle$ als Gesamtzustand, der durch die Überlagerung seiner Einzelzustände $\left|\Psi_{\mathrm{i}}\right\rangle$ beschrieben wird, mit $c_{i}$ als komplexe Wahrscheinlichkeitsamplitude.

Aus der de-Broglie-Gleichung, die jedem Teilchen und jedem zusammengesetzten Körper eine Welle zuordnet,

$$
\lambda=\frac{\mathrm{h}}{\mathrm{p}}
$$

mit $\lambda$ als die de-Broglie-Wellenlänge, $\mathrm{h}$ als das Planck'sche Wirkungsquantum und $\mathrm{p}$ dem Impuls eines Photons, ergeben sich zwar Beschränkungen, die letztlich aber eher messtechnischer Natur sind. Denn aus dem Zusammenhang

und

$$
\mathrm{p}=\frac{\mathrm{E}}{\mathrm{c}}
$$

$$
\mathrm{E}=\mathrm{mc}^{2}
$$

mit $\mathrm{p}=$ Impuls des Photons, $\mathrm{E}=$ Energie, $\mathrm{c}=$ Lichtgeschwindigkeit und $\mathrm{m}=$ Masse, lässt sich $\lambda$ auch folgendermaßen schreiben:

$$
\lambda=\frac{\mathrm{h}}{\mathrm{mc}}
$$

Die Wellenlänge und die beobachtbaren Quanteneffekte hängen damit im Wesentlichen von ihrer Masse ab. Je größer die Masse, desto kleiner kann die Wellenlänge bei Interferenzen beobachtet werden. Für größere Teilchen werden solche Interferenzen auch Materiewellen oder de-Broglie-Welle genannt.

Aber auch hier war die Entwicklung nicht aufzuhalten. Ein Schritt in die Richtung, Kohärenzen bei Makrosystemen zu messen, konnte bereits 1999 durch Einsatz neuer Messtechnologie realisiert werden. Mit einem Interferometer gelang es Arndt und seinen Kollegen (Aspelmeyer und Arndt 2012) für sogenannte C60-Buckminster-Fullerene Materiewelleninterferenzen nachzuweisen (Abb. 53).

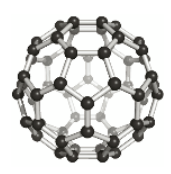

Abb. 53 | Buckminster-Fulleren C60

(Von Sponk (talk) - erstellt mit Pymol (0.99rc2) und Gimp (2.6.10), (C BY-SA 3.0) Für solche Fullerene konnten Materiewelleninterferenzen nachgewiesen werden.

Abb. 54 zeigt ein entsprechendes Experiment mit diesen Farbmolekülen. Die nicht-lokale Natur der Quantenphysik auch für den Makrobereich kann mithilfe solcher Beugungsversuche an massereichen Molekülen mustergültig dargestellt werden. 


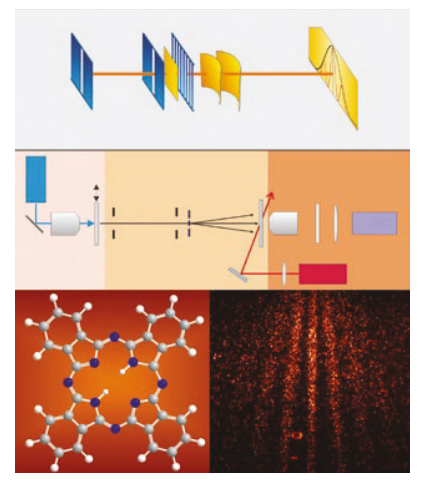

Abb. 54 | Interferenzmuster zum Materiewellennachweis des Farbmoleküls PcH2

Die Moleküle setzen sich aus 400 Atomen und Massen um 7.000 atomare Einheiten zusammen und gehören damit bereits zur Makrowelt. Die Grafik ist Spektrum der Wissenschaften entnommen (Aspelmeyer und Arndt 2012).

Spekulativ könnte auch formuliert werden, dass sich die für das Vakuumfeld angenommenen realen Wellen in der EDBFT als Überlagerung auch aus den makroskopisch riesigen Entitäten wie Galaxien ergeben (Greenstein und Zajonc 2005: 43).

\subsubsection{Unterschiedliche Verständnisse zur Verschränkung und Dekohärenz}

Es ist nun offensichtlich geworden, dass Materie zwar eine für unsere Realität relevante Wesenheit darstellt, ihre wesentlichen Eigenschaften jedoch von dahinterliegenden Prozessen ausgehen, die eine über ihre äußerliche Form hinausgehende, kohärente Wechselwirkung ermöglicht. Diese Wechselwirkungen werden mit den Konzepten der Verschränkung und Dekohärenz beschrieben, die aus den bisherigen Überlegungen abgeleitet, verantwortlich für die Phänomene von SyA und Intuition sein könnten. Deshalb werden die beiden Konzepte im Folgenden untersucht.

\section{Verschränkung im Verständnis der Kopenhagener Deutung}

Der Begriff der Verschränkung geht auf Erwin Schrödinger (1935) zurück. Nach ihm kommt es zwangsläufig zur Verschränkung, wenn zwei physikalische Systeme in Wechselwirkung miteinander treten:

,When two systems, of which we know the states by their respective representatives, enter into temporary physical interaction due to known forces between them, and when after a time of mutual influence the systems separate again, then they can no longer be described in the same way as before, viz. by endowing each of them with a representative of its own. I would not call that one but rather the characteristic trait of quantum mechanics, the one that enforces its entire departure from classical lines of thought. By the interaction the two representatives (or $\Psi$ functions) have become entangled " (Schrödinger 1935a: 555). 
Interessanterweise beschreibt Schrödinger im gleichen Artikel auch ein Szenarium, in dem Entflechtung (Auflösung der Verschränkung oder Disentanglement) durch Zugewinn von Informationen möglich wird ${ }^{170}$. Also letztlich die Möglichkeit, durch Beobachtung eines der Systeme, dieses aus der Überlagerung (Superposition) zu separieren. Das Gleiche finden wir bei Zeh unter der Bezeichnung ,Refokussierung' und ,Rekohärenz' (Zeh 2013).

,, To disentangle them we must gather further information by experiment, although we knew as much as anybody could possibly know about all that happened. Of either system, taken separately, all previous knowledge may be entirely lost, leaving us but one privilege: to restrict the experiments to one only of the two systems. After reestablishing one representative by observation, the other one can be inferred simultaneously. In what follows the whole of this procedure will be called the disentanglement" (Schrödinger 1935a: 555).

Und noch wesentlicher: In der Regel bleibt bei den Diskussionen zu Schrödinger's Verschränkungsdefinition die Tatsache unberücksichtigt, dass im Summary des zitierten Papers ausdrücklich darauf hingewiesen wird, dass zumindest eine Übereinstimmung zwischen den beteiligten Systemen vorhanden sein muss, es aber auch mehr sein dürfen.

„The two families of observables, relating to the first and to the second system respectively, are linked by at least one match between two definite members, one of either family. The word match is short for stating that the values of the two observables in question determine each other uniquely and therefore (since the actual labelling is irrelevant) can be taken to be equal. In general there is but one match, but there can be more" (ebd. 563).

Aus diesen Überlegungen lässt sich auch eine gänzlich andere Interpretation als üblich ableiten. Die verbreitete Ansicht im Verständnis der KI ist eine vollständige Auflösung der Verschränkung zwischen den betroffenen Systemen. Im Gegensatz dazu kann jetzt auch angenommen werden, dass sich eine Separierung im Weiteren nur auf die untersuchte Übereinstimmung (Interferenz/Superposition) bezieht, die mit dieser Wellenfunktion korrespondiert, nicht aber gleich alle anderen Übereinstimmungen auflöst. Da die Wellenfunktion $\Psi$ einen konkreten Zustand definiert, muss sie sich verändern, wenn der Zustand sich verändert. Das ergibt die mathematische Logik und ist in Übereinstimmung mit der vorgenommenen Neudefinition der Psi-Funktion in Kap. 8.1.1.3 Dies als Kollaps zu interpretieren, ist jetzt eine Sache. Damit aber schon eine vollständige Trennung auf allen möglichen weiteren Verschränkungsebenen zu resümieren, eine andere. Eher ist anzunehmen, dass durch Hinzuziehen der neuen Bedingungen sich eine neue $\Psi$-Funktion ergibt, die den neuen (quantenmechanischen) Zustand adäquat beschreibt. Dies lässt sich somit auch als ein Ergebnis unserer Messanordnung und Rechenoperationen interpretieren und nicht als ein Ergebnis der tatsächlich realen Gegebenheiten. Neue Überlegungen zur Interpretation der Kausalität (Näger 2016) unterstützen die Idee

${ }^{170}$ Diese Ausführungen von Schrödinger sind allerdings wenig in der öffentlichen Diskussion bekannt. 
einer kausalen Abhängigkeit der scheinbar reinen Zufallskorrelationen bei Verschränkungsexperimenten, wie sie bei den ERP-Untersuchungen auftreten.

Schrödinger ging in diesem zitierten Paper immer von einem Beobachter aus, der die Informationen über beide Systeme kannte und vergleichen konnte, was logischerweise immer ein außenstehender Beobachter sein musste. ,The probability relations which can occur between two separated physical systems are discussed, on the assumption that their state is known by a representative in common " (ebd. 563). Verzichten wir auf diesen Außenbeobachter und begeben uns selbst als Teilsystem (in der Rolle als Mensch) in das Gesamtsystem (viele Menschen) lassen sich wiederum ganz andere Schlussfolgerungen ziehen, wie wir noch sehen werden.

\section{Verschränkung im Verständnis der Dekohärenztheorie}

Wo die Grenzen für Verschränkungsphänomene liegen ist, wie bereits festgestellt wurde, mehr als offen. H.-D. Zeh stieß in den 70er Jahren die Tür zu einem viel weiterführenden Verständnis von Verschränkung auf, indem er das Universum in seiner Definition einschloss und Verschränkung als normalen Grundzustand definierte. In seiner Antwort auf einen typischen Irrtum, dass nämlich „Verschränkung eine gelegentlich auftretende, aber normalerweise instabile Quanteneigenschaft ist, die speziell präpariert werden muss “ wird dies sehr deutlich: ,Verschränkung ist eine ganz allgemeine Eigenschaft quantenmechanischer Systeme, die im Prinzip immer als Subsysteme des ganzen Universums zu betrachten sind. Daher müssen umgekehrt separierende Zustände speziell präpariert werden“ (Zeh 2011: 84). Folglich: „Der Quantenzustand ist bereits nichtlokal und erfordert keine Fernwirkung mehr " (ebd. 86). Der Zustand eines entfernten Objektes wird auch nicht instantan verändert, sondern: ,, Wegen der Nichtlokalität des Quantenzustands ist die zu teleportierende Eigenschaft (oder eine kausale Vorstufe dazu) bereits nach dessen Präparation in einer seiner Komponenten am gewünschten Ort. Diese Komponente muss dann nur noch durch Dekohärenz zu einer eigenständigen ,Welt' werden "(ebd.).

Sein Ansatz steht damit im Widerspruch zum Verständnis der KI. Nach deren Verständnis kollabiert die Wellenfunktion eines Systems bei einer Messung (wie bereits kennengelernt), also bei Wechselwirkung mit anderen Systemen und nimmt einen isolierten Zustand ein. Es kommt zur Entschränkung (Disentanglement), und das Gesamtsystem verliert deshalb seine typischen quantenmechanischen Eigenschaften.

In seinem Modell der Dekohärenztheorie wird die Welt dagegen als völlig quantenmechanisch angesehen, entstanden aus den universellen Überlagerungen aller physikalisch möglichen Ereignisse, zu denen auch Messapparatur und Beobachter gehören (ebd. 77-88). Nach ihm beschreibt die Dekohärenz eine ,"Dislokalisierung der Superposition “ (ebd. 81). Die dekohärierten Eigenschaften sind ,quasi-klassisch'. Danach ist auch die Vorstellung reines Wunschdenken und falsch, dass die Dekohärenz ,einzelne Komponenten der nichtlokalen Superposition (oder alle bis auf eine) zum Verschwinden " (ebd. 81) bringt. Auch dreht er den Spieß gegenüber dem klassischen Verständnis um, wenn er annimmt: „Dekohärenz entsteht durch einen störenden Einfluss der Umgebung auf 
das System “ (ebd.). Vielmehr ,stört' (beeinflusst) bei reiner Dekohärenz „,das System die Umgebung und nicht umgekehrt. Der Dekohärenzeffekt am System selber ergibt sich nur als Konsequenz der daraus resultierenden Verschränkung " (ebd. 86).

Er vermutet im Rahmen seiner Dekohärenztheorie, dass kohärente Superpositionen und damit Verschränkungen nur solange existieren, solange die Welt nichts von ihnen weiß. In dem Moment, in dem beispielsweise Photonen in Wechselwirkung mit einer solchen Superposition treten, wird die Superposition zerstört. Es kommt zur Dekohärenz. Die Beobachterfunktion wird durch die Umgebung übernommen. Daraus schließt er, dass Quanten-Superpositionen bei makroskopischen Systemen nur deshalb nicht beobachtet werden können, weil wir nicht in der Lage sind, sie ausreichend lange zu isolieren, um Dekohärenz zu verhindern. Dekohärenz und der scheinbare Verlust der Verschränkung ist somit ein Beobachterproblem. Die $\Psi$-Funktion kollabiert also nicht, sondern wir können sie nur nicht messen. Die Information selbst bleibt aber weiterhin im System vorhanden.

Zeh geht somit davon aus, dass wir bei Messungen, solange wir sie nicht speziell präparieren, immer Verschränkungszustände messen. Nur wissen wir nichts davon bzw. können sie ausmitteln. Wenn man so will, ist das Universum mit in den Ergebnissen enthalten. Nach diesem Verständnis, das sich zunehmend bei den Physikern durchsetzt $^{171}$ (Friebe 2015: 60; Tegmark und Wheeler 2001), kommt es im normalen Umfeld (dem sogenannten offenen Quantensystem) sofort zu unkontrollierbaren Wechselwirkungen mit der Umgebung und damit geht die Superposition, also die quantenmechanische Interferenzfähigkeit für uns als teilnehmender Beobachter verloren.

Aus Zeh's Überlegungen drängt sich konsequenterweise eine logische Schlussfolgerung auf (Zeh 2011): Die in der Physik vorgenommenen Anstrengungen bei den Versuchsanordnungen, in denen Quarticle gemessen werden sollen, dienen im Wesentlichen nur zur Isolierung der zu untersuchenden Elemente oder Systeme; Anstrengungen, die Messungen vor allem im Tiefsttemperaturbereich nahe dem absoluten Nullpunkt zum Ziel haben. Dort können die Wechselwirkungen auf Elementarebene recht gut kontrolliert und blockiert werden. Ansonsten könnten wir gar keine Aussagen über die kleinsten Systeme unserer Welt treffen ${ }^{172}$.

Eine daraus abgeleitete zweite logische Schlussfolgerung ist für unser gewohntes Denken ausgesprochen verstörend. Wenn eine Verschränkung nicht erst herbeigeführt werden muss, sondern von Haus aus schon existent ist, müsste das bedeuten, dass Informationen bereits im gesamten Universum verteilt vorliegen sollten. Eine Idee, wie sie von zahlreichen Forschern mittlerweile geteilt wird (siehe Kap. 8.1.1), in der Variante der Vakuum-Verschränkung auch untersucht und mit der Normierung der physikalischen Theorien (Kap. 8.1.1.5) beschrieben wurde.

${ }^{171}$ Bei einer Umfrage 1999 anlässlich einer Tagung über Quanten-Computer in Cambridge bekannten sich von 90 befragten Physikern nur noch 8 zur KI und dem Kollaps, 30 für Interpretationen ohne Kollaps und damit für die Dekohärenz-Interpretation und 50 entschieden sich, wegen dem ,grassierenden terminologischen Wirrwarr` erst gar nicht (vgl. Tegmark und Wheeler 2001).

${ }^{172}$ Für viele sind auch heute noch kleine Moleküle und niedrige Temperaturen die Voraussetzung für das Phänomen der Verschränkung (Hümmler 2017: 159), auch wenn sich die Welt weitergedreht hat. 


\subsubsection{Neuere Entwicklungen}

Und die Bestrebungen gehen weiter, die Grenze der beobachtbaren Verschränkung in immer größere Skalen auszudehnen. Ursache für diese Entwicklungen sind die Bemühungen um Fortschritte auf dem Gebiet der Quanten-Information, des Quantencomputers und der Quanten-Kryptographie; aus wirtschaftlicher und technischer Perspektive ausgesprochen lukrative Einsatzgebiete. Hier werden Antworten auf die Frage gesucht, ab welcher Größe oder vielleicht besser unter welchen Bedingungen Quantenphänomene verloren und in die ,quasi-klassische' Realität übergehen. Mittlerweile gelingt es bereits vollständige Atomrümpfe so miteinander zu verschränken, dass auf jedes einzelne der Qubits zugegriffen werden kann ohne den Verschränkungszustand aufzulösen (Friis u. a. 2018). Der Rekord liegt derzeit bei 20 aneinandergereihten Kalziumatomen, bei denen einzelne Paare der Atomrümpfe verschränkt wurden und sich die Verschränkung selbständig auf die umliegenden Ionengruppen ausdehnte. Realisiert wurden so genuine Vielteilchenverschränkungen. Auf diese Weise lassen sich stabile Quantencomputer realisieren, wie die Autoren betonen.

\section{Hybride Verschränkungen}

Das Verständnis über Verschränkungsbedingungen erweiterte sich durch Überlegungen zu hybriden Quantenschaltungen. Solche Schaltkreise kombinieren mehrere unterschiedliche physikalische Systeme, um die jeweiligen Stärken und Vorteile zu nutzen. Ein guter Überblick findet sich bei Xiang u. a. (Xiang u. a. 2013).

Die Spannbreite der Elemente, die in hybriden Quantenkreisläufen koppeln, umfasst Atome, Spins, supraleitende Qubits, Hohlräume und Festkörper-Apparaturen wie beispielsweise Supraleiter und nanomechanische Systeme (Membrane oder MikrowellenResonatoren). So wurde u. a. 2009 lichtgetragene Information in Rubidiumwolken gespeichert und per An- und Ausschaltung wieder selektiv freigesetzt (Lvovsky u. a. 2009). All diese Elemente können auf beliebige Art miteinander verschränkt und zur Speicherung von (Quanten-)Information genutzt werden. Beeinfluss- und steuerbar werden sie durch elektrische Ströme (von Elektronen oder Ionen), Ladung und Mikrowellenfelder. Ihre im Experiment gezeigten Kohärenzzeiten belaufen sich von $<100 \mathrm{~ms}$ bis $>20 \mathrm{~s}$ (ebd.). Für die hier genannten Hohlräume und Resonatoren gilt: ,, The quantized electromagnetic field in the cavity can interact with an atom (or spin or SC qubit) and exchange energy with it. Thus, a cavity can serve as a data bus ${ }^{173}$ in quantum information processing and transfer quantum data between different qubits. [...] In general, atoms and spins couple to conventional cavity systems, while SC qubits easily couple to $S C$ resonators, such as $S C$ coplanar waveguide $(C P W)$ resonators and $L C$ resonators, playing the role of cavities " (ebd. 629). Dies gelingt mittlerweile auch für Hohlraumresonatoren bei Raumtemperatur in Verbindung mit Audiofrequenzen (Cripe u. a. 2018). Solche konventionellen Hohlräume finden sich auch in Zellen und zellaufbauenden Strukturen (Kap. 8.2 und 8.3), weshalb der Mechanismus hier vorgestellt wird. Abb. 55

${ }^{173}$ Unter ,Data Bus' versteht man ein System zur Datenübertragung zwischen Teilnehmern bzw. Steckplätzen. 
veranschaulicht Aufbau und Wirkungsweise solcher Apparaturen. Im Hohlraum (a) sind Quarticle oder ganze Ensembles stationär gefangen, was auch für den hier dargestellten CPW-Resonator (b) gilt.

(a)

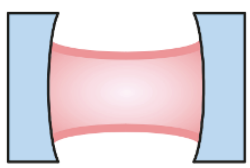

(b)

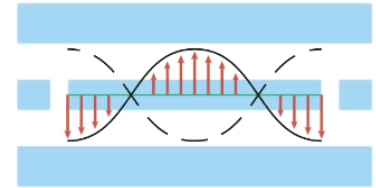

Abb. 55 | Schematische Darstellungen von (a) einem Hohlraum- und (b) einem CPW-Resonator Image entnommen (Xiang u. a. 2013: 629). Innerhalb dieser Hohlräume bzw. Röhren lassen sich Quarticle oder ganze Ensembles von Entitäten fangen und ihr Verhalten beobachten.

Im Unterschied zum reinen Hohlraumresonator ermöglicht Letzterer die Untersuchung ausgedehnter kollektiver Spinausrichtung von Ensembles z. B. bei Flüssigkeiten oder auf Oberflächen von Substraten (Abb. 56). Eine typische Anwendung ist die Kernspintomographie (MRT).

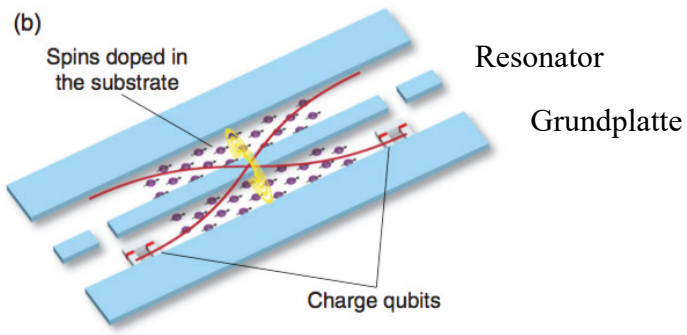

Abb. 56 | Ausgerichtete Spinensembles im koplanaren Resonator

Die Spins sind über das elektrische und magnetische Feld mit dem CPW-Resonator gekoppelt. Die Ladungs-Qubits repräsentieren zusätzliche supraleitende Qubits, die ebenfalls an den Resonator gekoppelt sind. Auf diese Weise können die Spins und supraleitenden Qubits indirekt gekoppelt und als Data-Bus genutzt werden. Die Ladungs-Qubits sind im elektrischen Feld der Grundplatte integriert, wohingegen die Spins mit dem magnetischen Feld des Resonators verbunden sind. Image entnommen (Xiang u. a. 2013: 638).

„Building a practical quantum information processor will profit from a hybridization of different quantum systems in order to fulfill the requirements of long storage times, fast processing speeds, long-distance information transfer, and scalability “ (Astner u. a. 2017).

Eine der neusten Entwicklungen stellt die rein quanten-optische Nutzung von Phononen (Quasiteilchen des Photons) zur Kontrolle von mechanischen Oszillatoren dar (Hong u. a. 2017). Auch hier wird ein Übergang von der Quantenwelt in die klassische Welt realisiert und Licht als Vermittler von zeitlichen und räumlichen Kohärenzeigenschaften verwendet, um Quanten-Information zu speichern. 


\section{Verschränkung in Supraleitern}

Den Gegenpol zum Gefangenenzustand von Ensembles im Resonator bildet der Mechanismus bei schon lange bekannten Supraleitern (Abb. 57). In ihnen fließen widerstandsfrei elektrische Ströme, was bedeutet, dass sie keine bzw. nur sehr schwache Wechselwirkungen mit dem Umfeld eingehen.

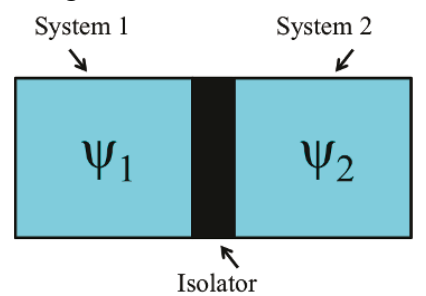

Abb. 57 | Supraleiter aus zwei Systemen mit trennendem Isolator

Die scheinbar isolierten Systeme $\Psi_{1}$ und $\Psi_{2}$ spannen dennoch einen gemeinsamen verschränkten $\mathrm{Zu}-$ stand auf, der über eine gemeinsame $\Psi$-Funktion beschrieben werden kann. (eigene Darstellung)

Josephson hat für Supraleiter nachgewiesen (Josephson 1962), dass sich ein Quantensystem über zwei scheinbar getrennte Systeme trotz zwischenliegendem Isolator erstrecken kann, mit dann nur noch einer $\Psi$-Funktion. System 1 und 2 sind über sogenannte Cooper-Paare ${ }^{174}$ gekoppelt. Auch hier liegt eine Verschränkung über beide Systeme vor.

Entgegen des verbreiteten Verständnisses handelt es sich bei den eben genannten Supraleitern nicht immer um Systeme im Tiefsttemperaturbereich von $0-77 \mathrm{~K}$. Zum einen hat Josephson den Effekt selbst bereits auf biologische Systeme ausgedehnt (Josephson und Pallikari-Viras 1991: 204-205), zum anderen wurde der Effekt auch prinzipiell auf photonische und fermionische Anregungszustände erweitert (Gaury u. a. 2015). Als Ergebnisse der Gruppe um Gaury sollten solche Tunneleffekte in allen oszillierenden, kohärenten und damit verschränkten Systemen ablaufen, in denen mehr als ein Weg zum Energie- oder Informationstransport verwendet wird. Er schließt damit alle Geräte und Materialien ein, die eine elektrische Resonanz aufweisen. Ihr ermittelter Gültigkeitsbereich erstreckt sich bis hin zu Raumtemperatur oder Frequenzen im THzBereich. Zum THz-Bereich gehört das sichtbare Licht. Zudem weisen alle lebenden Organismen elektrische Resonanzfähigkeit auf.

Möglicherweise gibt es sogar bei den Supraleitern ein direktes Pendant in der Biologie. Zumindest deuten entsprechende Entdeckungen auf einen supraleitenden Mechanismus bei organischen Materialien hin, was ebenfalls bei normaler Umgebungstemperatur ablaufen soll (Little 1964). Zwar bestehen derzeit noch erhebliche Schwierigkeiten diese Temperaturen zu realisieren, dennoch wurden neue Materialien und Eigenschaften auf der Basis dieser Modelle in den letzten Jahren bereits entwickelt (Lebed 2008; Dressel und Drichko 2004). Es sollte nicht verwundern, wenn auch hier entsprechende

${ }^{174}$ Elektronen, die sich paarweise über den Isolator hinweg in einer schwachen Kopplung zusammenschließen. 
Prozesse im Bereich der Natur entdeckt werden. Auf den ersten Blick bestehen nämlich gewisse Ähnlichkeiten zwischen manchen der organischen Strukturen und beispielsweise unserer DNA oder verschiedenen Elementen aus langen C-Ketten wie Kohlenhydraten, Lipiden, Proteinen.

\section{$\underline{\text { Kopplung makroskopischer mechanischer Oszillatoren mit Spins von Atomen }}$}

Eine typisch hybride Messanordnung stellt das folgende Experiment dar. Als Nebenprodukt zur Hochpräzisionsmessung eines Membrans aus Siliziumnitrid entwickelten Forscher eine Vorrichtung, mit der makroskopisch mechanische Oszillatoren mit Spins von Atomen (hier Milliarden tiefgekühlter Cäsium-Atome) über Licht verschränkt werden können (Møller u. a. 2017). Die Reaktion der Cäsium-Spins zeigt Zustandsänderungen des Membrans an und umgekehrt konnte das Membran die manipulierten Veränderungen bei den Spins registrieren. Diese Anordnung kann aus ihrer Sicht auch für einen Verschränkungszustand über große Entfernungen und damit zur Realisierung einer Quantenkommunikation zwischen mechanischen und atomaren Systemen verwendet werden.

Die Kopplung makroskopischer, fast sichtbarer Objekte gelang auch Riedinger ((Riedinger u. a. 2018) und Ockeloen-Korppi (Ockeloen-Korppi u. a. 2018). Riedinger verschränkte zwei mechanische Oszillatoren über $20 \mathrm{~cm}$ mittels Photonen bei $80-90 \mathrm{mK}$, wobei nach Aussage dieser Forschergruppe auch $75 \mathrm{~km}$ mit normalen Telekommunikationskabeln und normale Temperaturen kein Problem darstellen. Ockeloen-Korppi verschränkten zwei Aluminium-Trommelfelle mit jeweils einer Breite eines menschlichen Haares mittels Mikrowellen. Die Verschränkung war nur abhängig von den Mikrowellen und konnte uneingeschränkt aufrechterhalten werden. Gleichzeitig verhinderte die Mikrowelle die thermische Störung und hielt so die Verschränkung bis zu 30 Minuten aufrecht.

\section{$\underline{\text { Schwache Quantenmessung }}$}

Die ,schwache Quantenmessung' repräsentiert verschiedene Verfahren, die schon seit längerem eindeutig widerlegen, dass jede Messung den Zusammenbruch der Wellenfunktion nach sich zieht oder das System nachhaltig verändert. Sowohl Haroche mit dem Mikrowellen-Resonator (Brune u. a. 1996) als auch Wineland mit seiner Laserkühlung (Schmidt u. a. 2005) haben es geschafft Quanten zu beobachten, ohne dass diese Schaden nehmen und dekohärieren, wofür sie 2012 den Physik-Nobelpreis bekamen.

Bei einer sogenannten ,schwachen Quanten-Messung' konnten auch Rozema u. a. mittels eines GHZ-Aufbaus nachweisen, dass es eine Interaktion zum System gab, aber ohne Kollaps bzw. Dekohärenz (Rozema u. a. 2012). Wie sie feststellten, führten die schwachen Interaktionen zu einer Zunahme an Störungen und Effekten bzgl. der Genauigkeit der Messergebnisse, aber nicht zu falschen oder keinen Ergebnissen, was auf eine irreversible Dekohärenz geschlossen hätte.

Offensichtlich gibt es Situationen und Arrangements, die Dekohärenz und damit den Verlust von Quanteneigenschaften verhindern und die Verschränkung nur reduzieren, aber nicht zum Erliegen bringen. 
Starke Quantenmessung und nicht-lokale Superposition gleichzeitig.

Okamoto und Takeuchi realisierten eine von Aharonov und Vaidman (Aharonov und Vaidman 2003) entwickelte theoretische Lösung, wie eine starke Quantenmessung vorgenommen werden kann, ohne dass die Superposition dekohäriert. Es konnte gezeigt werden, dass ein Photon beobachtbare physikalische Effekte gleichzeitig an unterschiedlichen Plätzen bewirken kann. „This experimental demonstration, where the strong measurement and non-local superposition seem co-existing, provides an alternative to weak measurements as a way to explore the nature of quantum physics. [...] the unusual physical properties of preselection and postselection in quantum theory "(Okamoto und Takeuchi 2016: 1). Es ist damit evident, dass auf Quantenebene eine Verschränkung erhalten bleibt und gleichzeitig gemessen werden kann; letztlich nur abhängig vom Messarrangement. Und es scheint weiter evident, dass auf dieser Ebene Wirkungen in die für uns vermutete Zukunft als auch in die scheinbare Vergangenheit angestoßen werden können.

Damit steht dieses Ergebnis im Widerspruch zu Heisenbergs Unbestimmtheitsannahme (Steinberg 2016) und eben auch im Widerspruch zur Kollaps- oder irreversiblen Dekohärenz-Interpretation.

\section{Nicht-Lokalität in fast-klassischen Zuständen - Rekohärenzbestätigung}

Kwiat (2001) und Wang (2006) konnten Zehs Annahme bestätigen, dass die Nicht-Lokalität in den fast-klassischen Zuständen ,in verborgener Weise' vorhanden ist. Dazu bedurfte es noch nicht einmal größerer Ensembles, sondern nur einfache Photonen. In ihren Experimenten lagen zu Beginn weitestgehend getrennte Zustände und nur schwache gemeinsame Korrelation vor. Sie demonstrierten den in der Realität vorhandenen Normalfall, dass üblicherweise in der Quantenkommunikation keine vollständige Verschränkung der beteiligten Entitäten vorliegt.

Im Verlauf der Experimente wurden schließlich aus unvollkommen verschränkten Photonenpaaren maximal verschränkte erzeugt. Damit wurde ein weiteres Mal die Annahme widerlegt, dass verschränkte Quarticle durch Wechselwirkungen mit der Umwelt ihre Verschränkung vollständig verlieren. Das Gegenteil war sogar der Fall. Sie konnten zeigen, dass sich hinter jedem klassischen Zustand beliebige Quantenzustände verbergen, die herausgefiltert werden können, wodurch sie einen perfekten, quanten-klassischen Mixed-Zustand präsentierten.

Entsprechend der Annahme von Schrödinger (wie oben beschrieben), nach der eine Verschränkung auch aufgelöst werden kann, sofern die passenden Informationen vorliegen, lässt sich umgekehrt eine Verschränkung auch wieder herstellen; was prinzipiell auch von Zeh mit seiner Rekohärenz gesehen wird (Zeh 2013). Im Rahmen quantenmechanischer Fehlerkorrekturverfahren, die bei der Entwicklung von Quantencomputern benötigt werden, konnte die kohärenzzerstörende Wechselwirkung mit der Umgebung wieder rückgängig gemacht werden. Strunz u. a. führen aus (Strunz u. a. 2002): ,,Allgemein ist schnelle Dekohärenz das Schicksal von Superpositionen jener Systemzustände, die aufgrund ihrer Wechselwirkung mit der Umgebung von dieser unterschieden werden 
können. Superpositionen von Zuständen eines offenen Quantensystems, die von der Umgebung nicht unterschieden werden können, sind wesentlich stabiler " (ebd. 49). [...] „Dementsprechend erwarten wir, dass umgebungsinduzierte Fehler Superpositionszustände dann unversehrt belassen, wenn aufgrund der auftretenden Fehler zwischen einzelnen Komponentenzuständen nicht unterschieden werden kann“ (ebd. 52). [...] „Entscheidend dafür ist, dass die Umgebung nicht mehr als unbeobachtbare Ansammlung vieler Freiheitsgrade angesehen wird; ganz im Gegenteil, gezielte Messungen an der Umgebung müssen ausgeführt werden, die es erlauben, Kohärenzverluste im System durch geeignete unitäre Operationen zu korrigieren “ (ebd. 51).

Das bedeutet: Bei einem System, das von der Umgebung nicht oder nur schwer unterscheidbar ist, lässt sich eine Superposition, also eine (quantenmechanische) Überlagerung, relativ gut aufrechterhalten. Umgekehrt, wenn Wechselwirkungen des Systems mit der Umgebung bekannt sind, führen genaue Beobachtungen bzw. entsprechende Messungen zur Erzeugung einer Dekohärenz bzw. einer Wiederherstellung der Kohärenz, je nachdem welche System-Umwelt-Relation ich wähle. Dies gilt offensichtlich nur für Wechselwirkungen, die bekannt sind. Wechselwirkungen, die nicht bekannt sind bzw. nicht untersucht werden, lassen sich demzufolge als weiterhin kohärent betrachten. Systeme mit vielen unterschiedlichen Systeminformationen und Subzuständen können deshalb für bestimmte Aspekte dekohärent (unterscheidbar) erscheinen und gleichzeitig kohärent in Bezug auf andere Informationen und Zustände sein.

Zwei interessante Aspekte fallen auf:

1. Analog zur QFT, bei der es zur Überlagerung unterschiedlicher Felder kommt, führt eine Veränderung in einem Teilaspekt (einem spezifischen Feld) nicht automatisch zur Dekohärenz aller anderen Aspekte (Felder). Vergleichbar auch dem GHZ-Experiment, bei dem alle involvierten Subsysteme miteinander verschränkt bleiben.

2. Dieser Zusammenhang von Kohärenz und Dekohärenz ist auch bei der Arbeit mit Personen oder Gruppen bekannt, wie sich am Beispiel einer therapeutischen Sitzung gut veranschaulichen lässt. In der Regel wird an bestimmten Verhaltensoder Belastungsthemen gearbeitet. Solange der Fokus nur auf diesem spezifischen Aspekt bleibt, kann der Eindruck entstehen, dass dies das spezielle Problem des Klienten sei. Der Klient ist somit als dekohärent zu bezeichnen - er und sein Problem lassen sich vom Umfeld unterscheiden und erscheinen als Faktum. Erweitert der Therapeut aber seinen Fokus auf das Umfeld, so wird meist deutlich, dass es verschiedene Wechselwirkungen zwischen Klient und Umfeld gibt - die Dekohärenz des Klienten beginnt sich in Richtung Kohärenz mit seinem Umfeld zu verschieben; typisch für systemische Therapierichtungen. Tatsächlich wird es aber weitere Kohärenzen (gemeinsame Verbindungen und Bedingtheiten) zwischen Klient und Umfeld geben, die wir in einer solchen Sitzung nicht sehen und damit nicht unterscheiden können. Für all diese lässt sich eine Kohärenz definieren, für all das, was wir unterscheiden können eine Dekohärenz. 
Photon-Photon-Wechselwirkung über zwischengeschaltetes Atom

Wie sich eine vollständige Informationsweitergabe mittels Photon-Photon-Kommunikation unter Zuhilfenahme von Atomen als Zwischenspeicher realisieren lässt, zeigten Hacker u. a. (2016). Sie realisierten ein deterministisches Photon-Photon-Gatter, also ein stark gekoppeltes System, unter Zuhilfenahme eines Rubidium-Atoms. Der Trick in ihrer Versuchsanordnung liegt in der wechselseitigen Beeinflussung der beiden Photonen indirekt über ein Atom. Die Photonen geben die von ihnen getragene Information an das Atom ab, wo sie gespeichert wird und von weiteren Photonen zu einem späteren Zeitpunkt aufgenommen und weitergetragen werden. Photonen lassen sich somit als Kuriere und Atome als Quantenspeicher betrachten. Dass die beiden Photonen tatsächlich verschränkt waren, zeigte der zweite Teil ihres Experimentes. Im Anschluss an deren indirekten Kontakt über das Atom wurde eines der Photonen manipuliert mit der Folge, dass auch das zweite Photon sich entsprechend dieser Manipulation verhielt. Die Forscher realisierten damit eine eindeutige Photon-Photon-Wechselwirkung über ein zwischengeschaltetes Atom und mit dem dazugehörigen Tatbestand eines verschränkten Quantensystems. Hacker u. a. (ebd.) liefern mit ihren Ergebnissen einen wesentlichen Beitrag zum Verständnis von Informationsübertragung in biologischen Systemen und den Neurowissenschaft, wie wir noch sehen werden.

Die Grundlage dieser Versuche lieferte die bereits erwähnte Methode von Haroche u. a. (Brune u. a. 1996). Mit ihrer Methode lassen sich Lichtquanten mittels eines Mikrowellen-Resonators untersuchen. Mikrowellen-Resonatoren erzeugen EM-Schwingungen durch die Nutzung der Eigenresonanz von Hohlräumen mit gut leitenden Wänden. Form und Größe des Hohlraums bestimmen bei welcher Frequenz eine Eigenresonanz (elektrische als auch magnetische) auftritt (Universität Bern 2006). Wie mit Ionen in EM-Fallen lässt sich Quanteninformation auch zwischen Atom und Photon über weite Strecken austauschen. Die Quanteninformation selbst ist in stationären Quantenbits gespeichert (Pollmann 2013), z. B. in Atomen, und über die Kopplung mit der Eigenschwingung des Resonators raum- und zeitübergreifend in Kontakt mit anderen Ensembles verschränkt. Da die atomaren Energieniveaus der beteiligten Stoffe mit der Eigenschwingung des Resonators gekoppelt sind, lassen sich Messungen vornehmen und Aussagen über den zu untersuchenden Stoff treffen. Konsequenterweise gilt dies vice versa - der Stoff bekommt so auch die Schwingung des Resonators mit, womit wir eine Verschränkung zweier Systeme haben.

\section{Virtuelle Photonen (Stickstoff-Leerstellen-Defekte) und Mikrowellen}

Forschergruppen ist es bei Umgebungstemperatur und über Dipol-Dipol-Kopplungen (Dolde u. a. 2013; Jelezko u. a. 2004) sowie mithilfe von Mikrowellen (Greiner u. a. 2017; Rong u. a. 2015; Liu u. a. 2013; Amsüss u. a. 2011) gelungen Quantenzustände mit Diamanten zu koppeln. Aktuell gelang dies auch für die Verschränkung von zwei Diamanten bei Ensembles über eine Distanz von $5 \mathrm{~mm}$ (Astner u. a. 2017) und bei einzelnen Spins über 3 m (Pfaff u. a. 2014) und 10 s Kohärenzzeit bei 98 \%-iger Übertragungsgenauigkeit (Yang u. a. 2016). 
Grundlage für diese Möglichkeit bieten u. a. negativ geladene Defekte in Diamanten, die als Quantenspeicher verwendet werden können. Hierzu werden Stickstoffatome anstelle von Kohlenstoffatomen in die Diamantstruktur eingebaut. Das Stickstoffatom (N) bildet dann zusammen mit den danebenliegenden Leerstellen $(\mathrm{V})^{175}$ ein Quantensystem. Über die virtuellen Photonen der NV-Defekte werden Verschränkungen zwischen verschiedenen Ensembles realisiert (Abb. 58). Diese Unregelmäßigkeiten bilden, obwohl die Interaktionen ausgesprochen schwach sind, einen sehr langlebigen Zustand auch bei Raumtemperatur, der an- und ausgeschaltet werden kann. Deshalb können diese NVDefekte zum Aufspüren schwacher elektrischer und magnetischer Felder genutzt werden, ohne auf Tieftemperatur-Detektoren zurückgreifen zu müssen. Die MikrowellenResonatoren bei den Diamanten haben die gleiche Rolle wie ein Data Bus in einem normalen Computer. Die Forscher konnten mit ihren Versuchen ebenfalls nachweisen, dass der Spin der Atomkerne in der Lage ist Quanteninformation zu speichern. Aus Sicht der Forscher können auf diese Weise Milliarden von NV-Defekten kollektiv verschränkt werden (Vienna University of Technology 2017) und so Ensembles mittels virtueller ${ }^{176}$ Photonen über Hohlräume und Defekte hinweg koppeln.

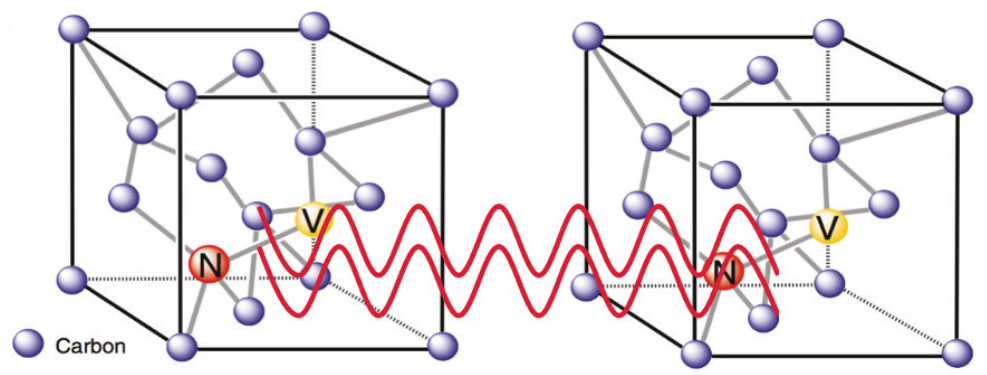

Abb. 58 | Kopplung über Stickstoff (N)-Leerstellen (V)-Defekt zwischen Diamanten Image basierend auf (Xiang u. a. 2013). Über die NV-Kopplung lassen sich Diamanten über Entfernung langlebig, auch bei Raumtemperatur, miteinander verschränken und verhalten sich als ein System.

In diesen Experimenten entscheidet die Magnetfeldrichtung darüber, ob der einzelne Diamant oder das verschränkte Diamantensystem untersucht wird. Die Annahme, dass Dekohärenz zum Verlust der Information führt, ist auch hier widerlegt. Sowohl das verschränkte System als auch die Subsysteme lassen sich im Wechselspiel untersuchen.

Ganz praktisch lassen sich daraus NV-basierte Sensoren herstellen, die einzelne Spins auch in thermischen Umgebungsbedingungen detektieren (McGuinness u. a. 2013). Aus dieser Anwendung ergibt sich die Option, dass unter ähnlichen Bedingungen in biologischen Systemen, sehr leicht quantenphysikalische Kohärenzen und entsprechende

\footnotetext{
${ }^{175}$ Leerstelle $=$ engl. vacancy

${ }^{176}$ Virtuelle Photonen repräsentieren in der QFT die Wechselwirkung zwischen Elementarteilchen vergleichbar den Photonen in der Quantenmechanik. Man stellt sie sich als kurzlebiger Zwischenzustand von Teilchen vor, die sich im realen Zustand befinden und miteinander wechselwirken.
} 
Messungen und Informationsübertragungen unter Umgebungsbedingungen möglich werden (Bruderer u. a. 2016; Wu u. a. 2016). Indem Nano-Diamanten mit eingebautem NV-Defekt in Zellen lebender Organismen eingebracht werden, lassen sich über deren Kopplung mit den umgebenden biologischen Strukturen, Innensichten unter in vivo Bedingungen auf Nanoebene generieren. Mit diesem Nachweis ist auch ein Beweis für Quantenkohärenz in thermischen Nicht-Gleichgewichtssystemen und normalen Umweltbedingungen erbracht und mithin die Möglichkeit von Quanten-Kommunikation und Quanten-Teleportation in lebenden Organismen, denn mit solchen Messungen werden nichts anderes als die Übertragung verschränkter Zustände vorgenommen.

\section{Verschränkung im Rahmen der Quanten-Teleportation}

Die Quanten-Teleportation treibt die Erkenntnisse über Verschränkungsmöglichkeiten in normalen Umgebungen unaufhaltsam weiter. Verschiedene Gruppen zeigen, dass Verschränkungszustände über Glasfaser vermittelbar sind. Zeilinger's Gruppe machte über $400 \mathrm{~m}$ den Anfang unter der Donau (Zeilinger 2007: 281ff; Ursin u. a. 2004) und andere Gruppen führten diese Experimente innerhalb von Städten weiter (Rosenfeld u. a. 2017; Sun u. a. 2016; Valivarthi u. a. 2016). Sie erreichten aktuell bis zu $30 \mathrm{~km}$ in der Ausdehnung.

Neueste Entwicklungen setzten eine ebenfalls von Zeilinger's Gruppe begonnene Entwicklung fort (Villoresi u. a. 2008) und realisierten Quanten-Teleportation durch die freie Atmosphäre von La Palma nach Teneriffa über $143 \mathrm{~km}$ (Ma u. a. 2012a) und global mithilfe eines Satelliten (Yin u. a. 2017) bis $2400 \mathrm{~km} .2017$ wurde auch von der ersten Boden-zu-Satellit-Teleportation berichtet (Ren u. a. 2017). Speziell die Satellitenvermittlung arbeitet mit vieldimensionalen Verschränkungen. Dabei werden ganze Quantenfelder und ihre zeitlichen Schwankungen (Noh u. a. 2009) und ganz aktuell auch mehrere Zustände (,Hyperentanglement') gleichzeitig übermittelt (Steinlechner u. a. 2017; Xie u. a. 2015). Steinlechner und seine Kollegen schickten die Photonen 1,2 km durch die vielfach belastete Luft über Wien.

In allen Fällen waren die Verschränkungszustände robust gegenüber Umwelteinflüssen der realen Welt. Beim Einsatz von Hyperentanglement-Zuständen wurde auch deutlich, dass mit der Dimensionalität der Zustände auch deren Stabilität gegenüber Umwelteinflüssen zunimmt: „The size of the entangled quantum state can increase with the number of particles or, as in the present paper, with the number of involved dimensions. We explore a quantum system that consists of two photons which are 100-dimensionally entangled " (Krenn u. a. 2014).

Mit einer modifizierten Konfiguration hat eine Gruppe von Zeilinger (Lemos u. a. 2014) mittlerweile eine Quantenkamera patentieren lassen, die Materialprüfungen ermöglicht, bei der verschränktes, aber unterschiedliches Laserlicht zum Einsatz kommt (Abb. 59). Infrarotlicht trifft auf eine Materialprobe, die für sichtbares Licht undurchdringlich ist und das sichtbare Licht als verschränktes Pendant trifft auf die Kamera. Auf der Fotoplatte erscheinen gleichzeitig ein Negativ und ein Positiv der Aufnahme (quasi die beiden möglichen Zustandsvarianten), wobei das von der Kamera eingefangene 
Licht zu keinem Zeitpunkt die Materialprobe gesehen hat. Damit vermag eine normale Kamera das Innenleben undurchdringlicher Materialien abzubilden.

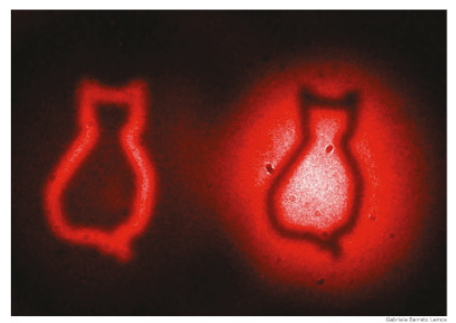

Abb. 59 | Abbildung einer Katzenschablone auf einem Silizium-Plättchen durch verschränkte Photonen. Image von ${ }^{C I Q O Q I ~ / ~ G . ~ B . ~ L e m o s ~ u . ~ a . ~ 2014 . ~ D a s ~ m i t ~ d e m ~ S i l i z i u m-P l a ̈ t t c h e n ~ i n t e r a g i e r e n d e ~ I n f r a r o t-~}$ licht teilt seine Information mit dem mit ihm verschränkten sichtbaren Licht. Dieses sichtbare Licht trifft auf die Fotoplatte einer Kamera und hinterlässt dort die Information aus dem Silizium-Plättchen als Überlagerung von Positiv- und Negativaufnahme. Das sichtbare Licht hat das Silizium-Plättchen mit der dort eingravierten Katzenschablone nie gesehen.

\section{Heiße Verschränkung und offene Quantensysteme}

Mit zu den wichtigsten Entwicklungen gehören die Untersuchungen von Verschränkungen in heißen Umgebungen. Darunter fallen alle Kohärenz- und Verschränkungsphänomene, die bei Temperaturen deutlich über dem absoluten Nullpunkt bis hoch in den Bereich unserer normalen Umweltbedingungen stattfinden, wie die oben beschriebenen Experimente mit den NV-Defekten. Nicht zuletzt wegen Zeilingers Quanten-Teleportation und Experimenten mit Bakterien (Engel u. a. 2007) und Algen (Collini u. a. 2010) wurde es nötig, die theoretischen Konzepte und ihre angenommenen Grenzen zu überdenken.

Einen ganz wesentlichen Schritt in der Theoriebildung für heiße Verschränkungen und über sehr lange Distanzen gelang Duan u. a. wiederum im Zusammenhang mit Überlegungen für Quantenkommunikation, dem Bestreben nach sicheren Übertragungsverfahren sowie der Realisierung von Quanten-Repeatern ${ }^{177}$ (Duan u. a. 2001). Voraussetzungen für ihren Ansatz ist zum einen, dass die Verschränkung selbst nicht über einzelne Photonen hergestellt wird, sondern über größere Ensembles von Atomen und zum anderen, dass sie über Licht-Photonen gekoppelt werden. Photonen bilden sehr häufig die Informationsbrücke zwischen den Atomen. In den Atomen selbst findet, wie schon gesehen, schließlich die anhaltende Informationsspeicherung statt. Im damaligen Fall ließen sich über mehrere Millisekunden stabilen Kohärenzen erzeugen: „Long-lived excitations in atomic ensembles can be viewed as waves of excited spins " (ebd. 414), wie Duan formuliert. Zusätzlich können sie langwellige EM-Wellen zum Informationstransfer verwenden, was bedeutet, dass hier der oben beschriebene Mixed-Zustand der Informationsübertragung zwischen klassisch und quantischen Zuständen erfolgt: ,, We

\footnotetext{
${ }^{177}$ Quanten-Repeater fangen verschränkte Signale auf, bereitet diese wieder auf und leiten sie weiter.
} 
can also use the established long-distance EME ${ }^{178}$ states for faithful transfer of unknown quantum states through quantum teleportation, with the set-up "(ebd. 416). Zur Vereinfachung ihrer Demonstration platzierten sie ihre Atome in ringförmigen Hohlräumen.

Wie wir im Kapitel Neurowissenschaften noch sehen werden, sind alle ihre Bedingungen in den Mikrotubuli und Axonen der Nervenzellen erfüllt. Ihre Überlegungen erklären experimentell nachgewiesene Verschränkungen bei makroskopisch großen Objekten bei Raumtemperatur (Maynard u. a. 2015; Phillips u. a. 2001), die sich ausgesprochen robust gegen Dekohärenz und Fehler verhalten.

Lange Zeit ging man davon aus, dass die thermische Energie der Umwelt gegenüber der Energie auf Elektronenebene vernachlässigbar sei, da Letztere mehrere hundertmal größer ist. Aufgrund dieser großen Energiedifferenz könne das Quantenverhalten auf der Mikroebene auch nicht gestört werden. Entsprechend wurde geschlussfolgert, dass das Quantenverhalten bei hohen Temperaturen verloren gehen und es zu Dekohärenzen kommen würde. Einer der Meilensteine in dieser Frage wurde durch die Arbeiten von Galve u. a. erzielt, als die Gruppe nachhaltige Quanteneffekte bei hohen Temperaturen bis zu 50 Kelvin $\left(-223^{\circ} \mathrm{C}\right)$ messen konnte( Galve u. a. 2010). Für typische quantenphysikalische Experimente sind das hohe Temperaturen.

Weitere theoretische und experimentelle Forschungen in Bezug auf nanomechanische Oszillatoren führten zu einem Verständnis, das Vedral folgendermaßen zusammenfasst: ,, no matter what systems we look at, a general rule says that if the interaction strength between the subsystems is larger than the thermal energy due to their coupling to the environment, entanglement should exist between these subsystems provided that they are in thermal equilibrium with the environment " (Vedral 2010). Dies galt für Experimente bis zu 50 Kelvin. Galve u. a. stellten aber auch fest, dass dies jedoch nicht für thermische Nicht-Gleichgewichtszustände zutrifft. Zu dieser Kategorie gehören die Versuche mit den $\mathrm{C}_{70}$ Fullerenen im Doppelspalt (Kap. 8.1.1.2), bei denen der quantenklassische Übergang im Bereich von über 600 bis $2.700{ }^{\circ} \mathrm{C}$ liegt. Aufgrund der Interferenzmuster ist auch bei ihnen eine sichtbare Kohärenz und damit Verschränkung aufgetreten, was auf die thermische Emission von Photonen zurückgeführt wurde.

Solche Nicht-Gleichgewichtszustände sind aber auch typisch für biologische Prozesse bei Umgebungstemperatur, den sogenannten ,offenen Quantensystemen'. Unter solchen Bedingungen, dass es also hohe Interaktionen zwischen den Subsystemen gibt und gleichzeitig thermische Nicht-Gleichgewichtszustände vorliegen, kann Quantenkohärenz auch bei viel höheren Temperaturen existieren und damit schließlich für lebende Systeme und Umgebungstemperatur relevant werden. Hier wird auch die Theorie von Duan u. a. relevant. Solche Systeme sind zudem in der Lage, ,Fehlerkorrekturen' in der Verschränkung vorzunehmen. Die Überlegungen zielten explizit auf Erklärungen in Bezug auf Quantenphänomene bei Alltagsbedingungen. Eine gute Zusammenstellung der Erkenntnisse zu diesem Thema liefern Guerreschi u. a. (Guerreschi u. a. 2012).

${ }^{178}$ EME steht für Electromagnetic Energy. 
Vedral, der sich ebenfalls mit der Übertragung der Verschränkung auf biologische Systeme beschäftigte, stellte fest, dass: ,, The most exciting macroscopic and 'hot' nonequilibrium systems we know are, of course, the living ones. We can, in fact, view any living system as a Maxwell's demon ${ }^{179}$, maintaining life by keeping its entropy low against the environmental noise - that is, by being far from equilibrium " (Vedral 2010: 770), womit die oben beschriebenen Bedingungen voll erfüllt sind. Und er schloss seine Ausführungen zu ,Hot Entanglement' mit einer für unsere Untersuchungen sehr aktuellen Überlegung: ,could it be that life does not just keep its entropy low, but rather, also aims to keep its quantum entanglement high if and when needed for an increased efficiency of energy transport? " (ebd.)

\section{Klassische Verschränkung}

Unser Weg im Erforschen der Verschränkung ist allerdings noch nicht zu Ende. Im Januar 2016 veröffentlichten Forscher der Universität Jena Experimente (Guzman-Silva u. a. 2016), in denen ein Informationstransfer mithilfe einer ,klassischen' Verschränkung vollzogen wurde. Damit, so scheint es, funktioniert die Teleportation von Informationen und Eigenschaften nicht nur in der Quantenwelt, sondern auch in der klassischen Welt. Ausgehend von mathematischen, algebraischen Strukturen (Aiello u. a. 2015; Ghose und Mukherjee 2014; Holleczek u. a. 2011; Luis 2009; Qian und Eberly 2011; Spreeuw 1998, 2001) entwickelte sich die Annahme, dass eine ,quantenmechanische Verschränkung' auch in der klassischen, lokalen Physik möglich sein müsste. Damit ergibt sich die Option, Informationen und Zustände zwischen zwei Systemen auf der Basis EMF zu teilen. Licht produziert ein solches EMF, genauso wie jede Form von Wärmestrahlung. Es bedarf also keinerlei komplizierter Quantenstatistik mehr.

Dabei werden ausschließlich Informationen ausgetauscht, ohne dass Materie oder Energietransport stattfindet. Im Unterschied zur vorher behandelten Quantenverschränkung wirkt diese Form der Verschränkung nur lokal und wird deshalb auch als ,klassische Verschränkung' bezeichnet.

In diesem Fall wurden Eigenschaften von (radialpolarisierten) Lichtstrahlen miteinander gekoppelt und Informationen sofort und vollständig übertragen - also teleportiert. Aus Sicht der Forscher wird in diesem Experiment eine bestimmte Polarisationsrichtung eines Lichtstrahls mit der Information über die räumliche Struktur des Strahls auf klassische Weise verschränkt. Hochgeschwindigkeits-Teilchen, die einen solch präparierten Lichtstrahl durchfliegen, hinterlassen Spuren, die gemessen werden können. Die Forscher sehen zahlreiche Anwendungen im Bereich von Geschwindigkeitsmessungen und für die Informationsübertragung im Rahmen der Telekommunikation.

\footnotetext{
${ }^{179}$ Maxwell's Dämon ist ein Gedankenexperiment bei dem die Entropieänderung bei Messungen immer mit einbezogen werden muss. Dies verdeutlicht zum einen den Zusammenhang zwischen Information und Energie, analog Masse und Energie. Zum anderen wird damit die Berücksichtigung eines Beobachters ebenfalls evident, der durch eben diese Beobachtung das Ergebnis beeinflusst. Entwickelt wurde es von dem Physiker J. C. Maxwell 1871.
} 
Was bedeutet dies nun im Allgemeinen?

Es lässt sich schlussfolgern, dass nun auch das Phänomen der Verschränkung keine ausschließliche Eigenschaft der Quantenwelt mehr darstellt, sondern auch für die klassische Welt Gültigkeit besitzt (Hashemi Rafsanjani u. a. 2015). Informationsaustausch ohne beobachtbaren Materie- und Energietransfer ist damit auch für den lokalen Bereich anzunehmen, und zwar immer dann, wenn EM-Prozesse und Wechselwirkungen im lokalen Spiel sind. Damit kann als derzeit einziges Unterscheidungskriterium für Quantenund klassische Welt nur noch die Nicht-Lokalität angesehen werden.

In ihrer Conclusio bringen die Forscher aus Jena ihre Hoffnung zum Ausdruck, dass ihre Ergebnisse den Weg zu einer hybriden Infrastruktur zwischen klassischer und quantischer Kommunikation ermöglichen.

Als ein typisches Exemplar eines klassisch-quantischen Hybriden kann indes jedes biologische System und damit auch der Mensch angesehen werden. Die EM-Prozesse auf der Mikroebene und damit der Quanten und Elementarteilchen sind die Voraussetzungen für das als Makrosystem beobachtbare System Mensch und eine Bestätigung für die Existenz eines Homo Physicus. Eine, wie auch immer geartete Kommunikation zwischen diesen Ebenen darf wiederum angenommen werden, um die Lebensfähigkeit des Gesamtsystems zu sichern.

\subsubsection{Conclusio zur Verschränkung und Dekohärenz}

Beginnend mit den letzten Ergebnissen zu klassischer Verschränkung kann konstatiert werden, dass die Vielfalt der Verschränkungsansätze keine quanten-klassische Unterscheidung mehr ermöglicht. Ein Umstand, der bereits für die Quantenphysik 2002 erkannt wurde: ,, The variety of known partial results, in particular, about entanglement measures, makes it today obvious that there is no one-parameter classification of entanglement. This Letter concerns classifications related to what is called quantum nonlocality “"(Collins u. a. 2002: 1). Als einziges Unterscheidungskriterium bleibt demnach nur noch die ,Nicht-Lokalität‘. Nach diesem neuen Verständnis der Physik ist der Mechanismus der, Verschränkung' sowohl für die Quantenwelt als auch für die klassische Welt incl. der Biologie in gleicher Weise gültig.

Aus dem Verständnis der Quantenphysik entstehen Quarticle erst durch den Messprozess und der damit verbundenen Beobachtung. Dies setzt nicht zwingend das Vorhandensein eines bewussten Beobachters voraus, sondern kann nach Zeh auch durch die Umwelt erfolgen (Zeh 2011). Konsequenz dieser Beobachtung und Nicht-Beobachtung ist das Erscheinen von Wellenbildern und Teilchenbildern. Für beide muss es folglich auch eine Beschreibung für den Verschränkungsvorgang geben. Wenn nun der Compton-Effekt als Verschränkungsprozess bei Quarticle angesehen wird, so stellt der Doppler-Effekt das Pendant für das Wellenbild dar und damit repräsentieren EM-Feldvarianten ebenfalls eine Verschränkung. Des Weiteren wurden Verschränkungen im rein quantenphysikalischen als auch im klassischen Bereich nachgewiesen. Als praktische 
Konsequenz darf deshalb allgemein von einer Verschränkung gesprochen werden, unerheblich auf welche Weise sie zustande kommt.

Diese Verschränkungen basieren auf Wechselwirkungen, die sich vom Vakuumfeld bis in die kosmische Dimension von Galaxien erstrecken und in einem derzeit bekannten Temperaturbereich von -273 bis $2700{ }^{\circ} \mathrm{C}$ reichen, incl. normaler Umweltbedingungen über Städten. Enthalten sind darin klassische Photon-Atom-, Vakuum-, virtuelle-, Dipol-Dipol-, Atom-, Spin-, Ensemble-Ensemble, NV-Defekt- bis hin zu makroskopischen Oszillator-Verschränkungen. Die Spannbreite reicht von Einzel-Quarticle bis hin zu Milliarden-Ensemble und von schwacher bis starker Quantenmessung unter Beibehaltung von Superpositionen. In gleicher Weise wie Dekohärenz erzeugt werden kann, lässt sich auch reversibel eine Rekohärenz darstellen, bei der keine bzw. schwache Korrelationen entstehen, was in den Experimenten teilweise durch einfaches An- und Ausschalten gelingt. Mitnichten verschwindet die Information oder wird nachhaltig verändert.

Es sieht so aus, als ob die für die Schrödinger-Gleichung gültige Bedingung, no ban exist', es also keine Einschränkungen gibt, in analoger Weise auch für die Verschränkungen gilt. Zu berücksichtigen sind allerdings die unterschiedlichen Zusammenhänge und Rahmenbedingungen, die Verschränkungen ermöglichen. So finden sich im physikalisch isolierbaren Kontext andere Bedingungen wie in Nicht-Gleichgewichts-Zuständen der realen Welt. Als begrenzendes Limit kristallisieren sich nur unsere Möglichkeiten des experimentellen Aufbaus heraus. Dieses Limit ist letztlich wohl dem Versuch geschuldet, isolierte, vom Umfeld abgekoppelte Systeme zu untersuchen, um auf diese Weise so etwas wie eine objektiv Beschreibbarkeit zu ermöglichen. Ein Unterfangen, das aufgrund der Dekohärenztheorie jedoch nur eine scheinbare, aber keine tatsächliche Isolierung zur Folge hat.

Dass heute noch in vielen Fällen Laserlicht als zentrales Medium zur Herstellung von Verschränkung Verwendung findet, ist wohl auf messtechnische Gründe zurückzuführen. Licht, über das die zu verschränkenden Systeme miteinander in Wechselwirkung treten und Information austauschen. Licht, das zudem relativ einfach manipulier- und kontrollierbar ist.

Die gefühlt objektiv wiederholbaren Messungen ergeben sich aufgrund eines Versuchs, hochgradig redundante Anordnungen zu konstituieren, bei denen das Wissen oder besser die Erwartungshaltung über den Ausgang des Experimentes ebenfalls kollektiv vergemeinschaftet ist und als solche in die Psi-Funktion Einzug hält. Für hochisolierte Quarticle oder Energieformen scheint dieser Ansatz, vergleichbar der Newtonschen Mechanik, ausreichend brauchbare Ergebnisse zu liefern. Geht es aber darüber hinaus in das weite Feld der spezifischen Information, so werden sich kleinste Unterschiede bemerkbar machen und der Einfluss eines Beobachters wird sichtbar.

Lokale Welleninterferenzen, die zwingend bei Wechselwirkungen entstehen und Interaktionen von Quarticle, führen zu einer quantenphysikalischen als auch klassischen 
Verschränkung. Manche dieser Verschränkungen sind lokal beobachtbar, z. B. durch direkte Zustands- oder Verhaltensveränderungen, in jedem Fall wirken sie auch nichtlokal. Aufgrund dessen, dass die für uns klassisch erscheinenden Zustände tatsächlich auf dahinterliegende weitreichende Quantenzustände und Superpositionen basieren, handelt es sich bei allem was wir wahrnehmen um Mixed-Zustände, bei denen das Universum mitgemessen wird, wie Zeh (2011) formuliert hat. Mixed-Zustände, deren Verschränkungszustand reduziert, aber auch wieder vervollständigt werden kann, bieten besonders bei lebenden Systemen die Möglichkeit, Informationen zwischen Quantenwelt und klassischer Welt wechselwirken zu lassen. Im Gegensatz zur verbreiteten Annahme folgen aus solchen Wechselwirkungen auch keine zwingenden Veränderungen im Außen oder das Separieren (Kollabieren) der Informationen und Zustände. Veränderungen im Außen ergeben sich erst durch ausreichende Unterschiede und Erreichung bestimmter Schwellenwerte, die schließlich Einfluss auf relevante Energieniveaus ausüben. Energieniveaus, die zu messbaren Reaktionen und Handlungen führen. Wesentlich ist, dass die Informationen erhalten bleiben, aber die Intensität der Verbindung (Verschränkung) variieren kann, was ebenfalls Einfluss auf die Energieniveaus mit sich bringt.

Wie gezeigt wurde, können hochempfindliche Resonatoren kleinste Veränderungen auf Spinebene detektieren und vice versa. Ob sich eine solche Messung schließlich als Zustandsänderung bemerkbar macht, hängt somit von der Empfindlichkeit des Messgeräts und der Interpretationsqualität des Experimentators ab.

Nicht-lokale Effekte treten schließlich auf, wenn sich die verschränkten Teilsysteme räumlich oder zeitlich trennen oder wenn Energiebarrieren (Wände, Faraday'scher Käfig etc.) zwischen sie treten. Diese nicht-lokalen Effekte sind heute auch die einzigen Effekte, die Quantenphysik und klassische Physik unterscheiden und noch keinen klassischen Bezug aufweisen. Zu beobachten sind sie nur, wenn wir darauf achten und/oder spezielle Untersuchungsmethoden anwenden, ansonsten erscheinen sie als Zufall, Schicksal oder werden gar nicht wahrgenommen.

Zusammenfassend ergibt sich:

Alle bisher vorgebrachten Bedenken gegen eine Verschränkung und damit stabile Kohärenz auf Makroebene, wie auch unter normalen Umfeldbedingungen, sind als widerlegt zu betrachten. Genauso ist die Vorstellung obsolet geworden, die eine Nicht-Einflussmöglichkeit von Quarticle auf die Makroebene annimmt. Sobald Makrosysteme Resonatoren wie Membrane oder Hohlräume aufweisen, deren Veränderung größere Einheiten steuern, ist eine Kopplung von Qubitänderungen auf Spinebene im Makrosystem wahrnehmbar. Technisch wird diese z. B. mit dem MRT bereits ausgenutzt.

Eine weitere Option eröffnen die Experimente mit NV-Defekten in Diamanten, denn sowohl Kohlenstoff, aus dem Diamanten aufgebaut sind, als auch Stickstoff sind Elemente, die sich in lebenden Systemen finden. Sollten sich entsprechende Strukturen in Makroorganismen finden, ist auch zu vermuten, dass entsprechende Verschränkungsmechanismen direkt übertragbar sein sollten.

Und auf eine weitere Besonderheit soll noch hingewiesen werden: Die Option Photon-Atom-Photon-Verschränkung, bei der die Photonen als Kuriere agieren und die 
Atome als Speicher, von denen die gespeicherte Information zu beliebigen Zeiten abgerufen werden kann, eröffnet den grundsätzlichen Zugang für Datenübertragung und Datennutzung auch in Organismen.

Mit diesen Überlegungen sind die Säulen 4 (allgemeine Verschränkung) und 5 (Paradigma der sehr kalten Temperatur) implementiert und schließlich ist für Säule 6 (Quanteneffekte in Makro- und biologischen Systemen) eine technische und für biologische Systeme mindestens schon die theoretische Grundlage gelegt.

\section{Übertragung auf SyA}

Einige der Ergebnisse lassen sich sehr gut auf das Geschehen bei SyA anwenden und ermöglichen Erklärungsansätze für beobachtbare Phänomene. Dies trifft besonders vor dem Hintergrund zu, dass keine der bisher vorgestellten Messtechniken der Physik bedeutungshaltige Informationen bei Menschen in direkter Weise zu ermitteln vermögen.

Mit der von Schrödinger formulierten Interpretation, dass eine einzige Kopplung zwischen Entitäten (Photon bis Milliarden-Ensemble) bereits ausreicht, um eine Verschränkung zu realisieren, kann sofort ein direkter Bezug zu den Phänomenen bei SyA hergestellt werden. Unterstützt durch die neuen Erkenntnisse zur Nicht-Lokalität in fast-klassischen Zuständen ließe sich daraus der Beginn einer SyA erklären; nämlich der Moment, bei dem die Repräsentanten durch Berührung durch den Fallbringer und in gesammelter Achtsamkeit (Fokussierung) auf ihre Plätze geführt werden. Dieser Prozess lässt sich als Übergang von einer allgemeinen bzw. teilweisen Verschränkung zu einer maximalen Verschränkung interpretieren. Interagiert ein System (der Fallbringer) mit den Repräsentanten (R) kommt es zu dieser Verschränkung. Als Interaktion darf hier eine physikalische Interaktion angenommen werden, die durch Austausch von Photonen, Wärmestrahlung oder anderer physikalisch-chemischer Entitäten wie Atem realisiert wird. Damit ist die Eigenschaft (Information) des Systems unmittelbar bei R. Die damit verbundene Störung löst bei R Prozesse aus, die schließlich zu Wahrnehmungen werden. Diese Wahrnehmungen entsprechen dem Entstehen einer eigenständigen Welt und damit der Dekohärenzforderung.

Sichtbar wird das, was untersucht wird und worauf sich die Repräsentanten in der Aufstellungsgruppe fokussieren, analog den physikalischen Untersuchungen. Da wir nicht alle Aspekte eines Systems untersuchen können, bleiben die nicht untersuchten Informationen und Zustände kohärent im System und sind deshalb für uns nicht sichtbar. Es lassen sich nur die Aspekte bearbeiten, die durch unsere Beobachtung unterscheidbar und deshalb dekohärent werden.

Zwischengespräche oder Ablenkungen erfordern immer wieder eine Refokussierung. Dadurch besteht aber auch die Möglichkeit, analog zu den oben beschriebenen Experimenten, die Kohärenz an- und abzuschalten. Gleichzeitig können durch kontinuierliche erneute Fokussierungen (Refokussierung und Rekohärenz) die Freiheitsgrade möglicher Wechselwirkungen und Dekohärenzen reduziert werden. Das heißt, wir können die Gefahr von unerwünschten anderen Einflüssen oder das Abdriften in eine falsche Richtung zumindest reduzieren. 
Unter der Annahme, dass sich Menschen, Familien oder Organisationen als Quantenfelder interpretieren lassen, führt eine Veränderung an einem Teilaspekt nicht automatisch zum Zusammenbruch (Dekohärenz) aller anderen, kohärenten Verbindungen. Die schwache Quanten-Messung übertragen auf SyA liefert wiederum die Grundlage für die Möglichkeit, dass wir Informationen aufnehmen und untersuchen können, ohne das System sofort auch schon zu verändern. Die nicht eintretende vollständige Dekohärenz erlaubt das Spiel mit Alternativen und Untersuchungen des Möglichkeitsraums, entsprechend dem, was bei der Suche nach einem guten Lösungsbild in Aufstellungen passiert.

Fokussierung auf das Ziel und das zu betrachtende System, plus ständige, neue Konzentration auf die eigene Wahrnehmung in Bezug auf beide, verhindert die Dekohärenz und das Erzeugen von Fakten. Die Superposition kann somit bis zum Ende der Aufstellung aufrechterhalten werden. Erst mit dem Abschlussbild und darauf aufbauenden Handlungen werden Fakten geschaffen, die für die Makrowelt von Bedeutung sind. Veränderungen in der SyA und ihre emotionale Verankerung können ihre Wirkung über die verbleibenden Kohärenzzustände im nicht anwesenden Ursprungssystem entfalten. Veränderungen am Ursprungssystem (Dekohärenzeffekte) sind der Verschränkung Ursprungssystem-Fallbringer-Gruppe geschuldet.

Konzentrieren sich die Repräsentanten am Ende der Aufstellung wieder auf sich entrollen sie sich, wie man in der Aufstellungssprache sagt - verschwinden die übernommenen, repräsentierenden Wahrnehmungen sofort wieder, da die Verschränkung quasi abgestellt wird.

\section{$\underline{\text { Fazit }}$}

Für SyA ergibt sich somit die theoretische Möglichkeit, dass zunächst über den Weg der Verschränkung die Informationen lokal im räumlichen Kontext der Aufstellung geteilt werden. Im Weiteren, nicht-lokalen Prozess können die Informationen aus dem Aufstellungsprozess schließlich über den Fallbringer mit dem Herkunftssystem in Kontakt gebracht werden.

Lassen sich Verschränkungen in SyA nun nicht nur theoretisch ableiten, sondern auch tatsächlich in Makrosystem Mensch messen, und wenn ja, wie?

Um diese Frage allgemeingültig zu beantworten, bedarf es jetzt noch eines gemeinsamen Verständnisses über das sogenannte Messproblem. Ein in der Physik ebenfalls kontrovers behandeltes Thema.

\subsubsection{Das Messproblem}

\section{Unterschiede und Ähnlichkeiten in Physik, Soziologie/Psychologie und SyA}

Die Physik als grundlegende Wissenschaft ist spätestens seit der Kopenhagener Interpretation der Quantenmechanik aus dem Jahr 1927 mit der Tatsache konfrontiert, dass auf der Ebene des Mikrokosmos der Beobachter das Messergebnis mit beeinflusst und so die bis dahin vermutete Linearität der Kausalität und damit die Vorhersagbarkeit und 
Berechnung von Ursache und Wirkung nicht mehr gegeben ist. In der Makrowelt wird diese Funktion des Beobachters durch die Theorie des Konstruktivismus gestützt.

Das Messproblem ist in der Quantenphysik deshalb ein sehr wichtiges und bis heute intensiv diskutiertes Thema. Zum einen, weil es Wechselwirkungen zwischen Eigenschaften des Messobjektes und der Messapparatur und zum anderen, weil es unterschiedliche Ansichten darüber gibt, wo die Grenzen quantenmechanischer Messungen liegen. Zudem stellt sich das Problem, ob das Messergebnis bereits vor der Messung im Messobjekt enthalten war oder erst durch die Messung erzeugt wurde. Diese Frage ist bereits im Rahmen des Welle-Teilchen-Dualismus und der Wellenfunktion (Kap. 8.1.1.2) evident geworden.

Zeilinger's Antwort auf diese Frage bietet einen bemerkenswerten Interpretationsrahmen: „Die Natur ist offenbar nicht reich genug, um schon von vornherein Antworten auf alle Fragen festgelegt zu haben. Wenn wir einem System Fragen stellen, die nicht einer wohldefinierten Eigenschaft entsprechen, so existieren diese Fragen eben nicht, ehe wir die Frage stellen " (Zeilinger 2005: 222). Es lässt sich daraus nämlich ableiten, dass bei bereits vorhandener bekannter Eigenschaft und damit bekannter Information sich dieses Ergebnis reproduzieren lässt. Bei unbekannten Eigenschaften entsteht dagegen durch den Messprozess etwas Neues.

Interessanterweise kennen Psychologie und Soziologie ähnliche Fragestellungen, die je nach Schule (Weltanschauung) unterschiedlich beantwortet werden. Auch hier geht es um die Wechselwirkung zwischen Subjekt und Objekt bzw. welche Eigenschaften waren schon da und welche sind erst durch den Kontakt bzw. die Beobachtung erzeugt worden. Und wie ist die System-Umwelt-Relation zu ziehen? Was gehört dazu und was ist ausgeschlossen?

Im Folgenden soll die Frage untersucht werden, ob Möglichkeiten bestehen, physikalische Messverfahren (klassisch und quantenmechanisch) mit psychologisch-soziologischen Ansätzen in Beziehung zu bringen.

\subsubsection{Klassische versus quantenmechanische Messung}

Aus messtechnischen Gründen fokussiert sich die Physik bei ihren Untersuchungen auf beobachtbare Größen wie Energie, Impuls, Spin (Drehimpuls eines Teilchens) oder Ortskoordinaten. Es sollen Größen sein, die eindeutig zu ermitteln sind und keine Interpretation zulassen.

Im Zusammenhang mit Messungen, die Verschränkungen untersuchen sollen, gilt es eine Besonderheit zu berücksichtigen: Betrachten wir die Verschränkung aus der Perspektive der Messtechnik, so muss man feststellen, dass die Verschränkung selbst nicht gemessen werden kann. Es gibt nichts (zumindest nach dem heutigen Verständnis), das sich im Raum zwischen den Quarticle messen ließe und dennoch besteht eine Verbindung; eine Verbindung, die sich letztlich nur aus den Messergebnissen ableiten lässt. 
So nimmt bei der Messung eines der Quarticles sein Partner instantan, also sofort ohne Zeitverzögerung, das für den Gesamtzustand notwendige ergänzende Eigenschaftsprofil an. Besitzt beispielsweise ein aus zwei Quarticle bestehendes System die Zustände $|0\rangle$ und $|1\rangle$ und messen wir an einem der Quarticle den Wert $|0\rangle$, so ist automatisch der Wert $|1\rangle$ für das zweite Quarticle festgelegt. Sehr häufig wird zur Veranschaulichung der Spin verwendet. Ist der Gesamtspin Null, so ergeben sich als Messwerte -1/2 für Quarticle A und +1/2 für Quarticle B.

Etwas vereinfacht darstellen lässt sich dieses Phänomen gut mit einem Stabmagneten (Abb. 60). Im Gegensatz zu einem Quantensystem, bei dem die Verteilung erst durch die Messung entsteht, steht das Ergebnis hier bereits vor der Messung fest, weshalb dieses Beispiel nur zur besseren Veranschaulichung dienen soll.

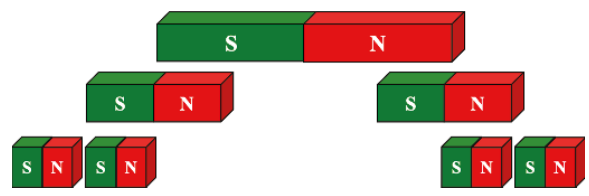

Abb. 60 | Der Stabmagnet spannt ein Gesamtsystem auf, vergleichbar einem Quantensystem was nicht in seine Einzelteile Süd- und Nordpol zerlegt werden. Im Gegensatz zu einem Quantensystem steht hier das Ergebnis jedoch bereits vor der Messung fest. (eigene Darstellung)

Stabmagnete haben einen Nord- und einen Südpol. Messe ich an der einen Seite die abstoßende Reaktion, ist sofort die anziehende Reaktion für die andere Seite festgelegt. Versuche ich jetzt den Magneten auseinander zu schneiden, um die beiden Seiten zu separieren, muss ich feststellen, dass ich keine separierten Hälften bekomme, sondern nur zwei statt einem Magneten, wobei jeder für sich jedoch nur die Hälfte der ab- bzw. anstoßenden Reaktionen zeigt, entsprechend der Formel:

$$
\mathrm{P}=\frac{\mathrm{m}_{\mathrm{magn}}}{\mathrm{l}}
$$

mit $\mathrm{P}=$ Polstärke, $\mathrm{m}_{\mathrm{magn}}=$ magnetischer Moment des Stabes und $\mathrm{l}=$ Länge des Stabes.

Im Unterschied zum quantenphysikalischen Zustand besteht im klassischen System des Magneten die Verteilung Nord- vs. Südpol bereits bevor wir die erste Messung vornehmen und kann von einem Beobachter gewusst werden. Er muss deshalb nicht mehr an das andere Ende des Magneten treten und die Messung dort mit seiner vergleichen.

Im Gegensatz dazu verhalten sich quantenphysikalische Systeme für einen Beobachter signifikant anders. Als Beispiel bietet sich ein Versuchsaufbau (Abb. 61) an, bei dem zwei verschränkte Photonen A und B in zwei unterschiedliche Richtungen geschickt werden, nämlich zu Alice und Bob.

In beiden Richtungen steht ein Strahlenteiler, der das Photon durchlässt (also transmittiert) oder reflektiert. Auf beiden Seiten stehen Quantenzufallsgeneratoren, die tatsächlich rein zufällig festlegen, ob die Quarticle am Strahlungsteiler transmittiert oder 
reflektiert werden. Unabhängige Detektoren, die auf jeder Seite positioniert sind, erfassen diese Ergebnisse. In unserem Fall sind dies Aussagen zur Polarisation der Photonen. Bei verschränkten Photonen verhalten sich beide Photonen immer gleich. Wird eines reflektiert (A1), so wird auch das zweite reflektiert (B1). Wird es transmittiert (A2), wird auch das andere transmittiert (B2). Bei nicht verschränkten Photonen können keine solche Zusammenhänge erkannt werden. Die Ergebnisse wären rein zufällig und in keiner Weise miteinander korreliert. Anhand solcher Messungen kann Verschränkung gezeigt werden.

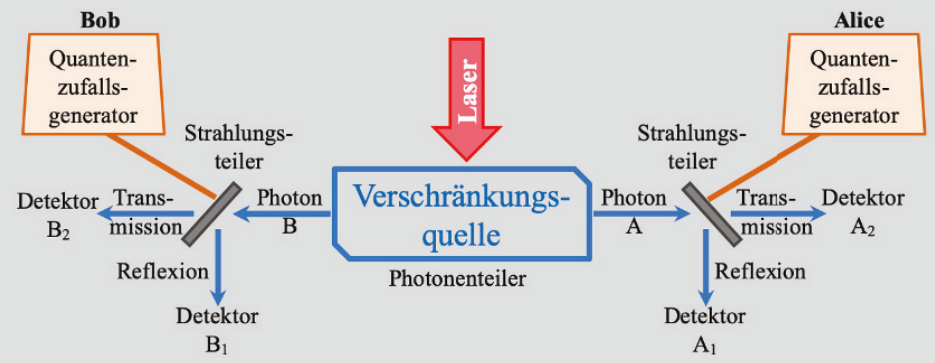

Abb. 61 | Verschränkungsexperiment

(eigene Darstellung). Ein Photonenteiler teilt einfallendes Laserlicht in die Photonen A und B, die zu Alice bzw. Bob weitergeleitet werden. Quantenzufallsgeneratoren lassen die Photonen schließlich durch einen Strahlungsteiler oder reflektieren sie. Bei verschränkten Photonen verhalten sich die Photonen auf Seite A und B immer in Abhängigkeit voneinander. Bei nicht verschränkten Photonen gibt es keine solche Zusammenhänge.

Der Versuchsaufbau legt zu Beginn fest, welche Form von Ergebnissen gemessen werden kann. Der Zufall entscheidet, welches der vier möglichen Ergebnisse sich dann tatsächlich zeigt (A1/B1, A1/B2, A2/B1, A2/B2). Jetzt müssen die Ergebnisse von Alice (A1/A2) mit denen von Bob (B1/B2) verglichen werden, um verschränkte Photonen von nicht-verschränkten Photonen zu unterscheiden. Verschränkte Photonen verhalten sich zu $100 \%$ immer gleich. Demgegenüber zeigen unverschränkte keine solche Gemeinsamkeiten. Würden wir nur die Ergebnisse eines Detektors betrachten, wäre eine Aussage über Verschränkung oder Nicht-Verschränkung unmöglich. Bei einer solchen quantenphysikalischen Messung ist der Beobachter jedoch gezwungen in Kontakt mit allen Detektoren zu treten, um das Ergebnis richtig zu interpretieren.

In der klassischen Physik würde eine einzige Messung ausreichen, weil dadurch das Gesamtsystem festgelegt wäre. Dieser Aufbau geht auf ein Gedankenexperiment von Einstein, Podolsky und Rosen zurück, mit der sie Unzulänglichkeiten in der Quantentheorie nachweisen wollten, weshalb alle vergleichbaren Konfigurationen auch EPR- 
Experiment und die Quelle verschränkter Quarticle als EPR-Quelle bezeichnet wird (Näger und Stöckler 2015).

Und auch hier handelt es sich um einen weitverbreiteten Irrtum. Ein solcher Kontakt mit allen Detektoren ist nur unter der Bedingung notwendig, wenn ich einen Verschränkungszustand von einem klassisch getrennten unterscheiden möchte, wie es bei den ursprünglichen Experimenten beabsichtigt war. Weiß ich demgegenüber sicher, dass eine Verschränkung vorliegt und habe ich auch Kenntnisse über die möglichen Zustände, so reicht auch in der Quantenphysik eine einzige Messung, um auf den verbleibenden Zustand des anderen Detektors zurückzuschließen (siehe dazu noch Kap. 8.1.4.2). Dies darf analog auf die Photonen übersetzten werden, die, hätten sie ein Bewusstsein, bemerken würden, dass ihr entfernter Partner eine Zustandsänderung oder eine Fixierung durch die Messung erfährt. Innerhalb eines Quantensystems bedarf es keinen Beobachter, um Verschränkungszustände zu diagnostizieren.

An diesem Punkt spiegelt sich auch das, was als Messproblem gehandelt wird. Unter welcher Perspektive ist eine solche Messung zu betrachten? Was gehört zu der Messung und was darf vernachlässigt werden? Sind die Photonen als eigenständig zu betrachten? Nach dem Delayed-Choice-Experiment spielen Spiegel, Zufallsgenerator und möglicherweise auch Alice und Bob eine Rolle.

\section{Schrödinger's Katze und Wigner's Freund}

Schrödinger's Katze ist ein weiteres sehr anschauliches Problem der quantenphysikalischen Messung (Schrödinger 1935b: 812). Sie dient gerne zur Veranschaulichung, dass bei makroskopischen Dimensionen keine Kohärenzen und quantenphysikalische Superpositionen zu beobachten sind. Im Gedankenexperiment (Abb. 62 Geschehen innerhalb des größeren Kastens) wird eine Katze zusammen mit einer ,Höllenmaschine' in einen Kasten gesteckt. Ein Geigerzähler (quantenphysikalischer Mechanismus) erfasst den Zerfall einer radioaktiven Substanz und setzt über einen (makroskopischen) Mechanismus Blausäure frei. Ob der radioaktive Zerfall stattgefunden hat und die Katze infolgedessen tot ist, erschließt sich einem Beobachter erst nach dem Öffnen. Bis dahin gibt es keine Information, was in der Psi-Funktion zum Ausdruck kommen würde. Die damit verbundene ,Verschmierung', heute würde man eher Superposition sagen, ändert sich mit dem Öffnen in zwei unterscheidbare, klassische Zustände - tot oder lebendig. Der Überlagerungszustand bleibt einem makroskopischen Beobachter vorenthalten. Die Frage, die in einem solchen Fall immer gestellt wird, lautet: Ist der Beobachter durch Öffnen des Kastens für den Zusammenbruch oder besser die Änderung der Psi-Funktion verantwortlich?

Nach der in Kap. 8.1.1.3 entwickelten Definition der Wellenfunktion würde diese Frage mit Ja beantwortet werden können. Im verbreiteten Verständnis der Physik wird darüber jedoch heftig diskutiert. Vielmehr wird die Frage gestellt: ,, wann genau und wie eigentlich der Kollaps der Wellenfunktion erfolgt? " (Reineker u. a. 2007: 457). Eine Frage, die sehr merkwürdig anmutet, denn man sollte davon ausgehen, dass nicht der Beobachter durch das Öffnen den Tod herbeigeführt hat, sondern dieser unabhängig von ihm eingetreten ist. Mit dem Öffnen wird der dann aktuelle Zustand jedoch für ihn 
sichtbar. Die bereits bekannte Formel (8.4) beschreibt den Superpositionszustand des Systems vor dem Öffnen. Die Terme 1 und 2 repräsentieren tot oder lebendig, der Rest die ,Verschmierung':

$$
|\Psi(\mathrm{x})|^{2}=\frac{1}{2}\left[\left|\Psi_{1}(x)\right|^{2}+\left|\Psi_{2}(x)\right|^{2}+\left|\Psi_{1}(x)\right\rangle\left\langle\Psi_{2}(x)|+| \Psi_{2}(x)\right\rangle\left\langle\Psi_{1}(x)\right|\right]
$$

Mit dem Öffnen fällt die, Verschmierung', also der gemischte Term und einer der beiden Fakten 1 oder 2, weg. Übrig bleibt ein einziges Ergebnis: 1 oder 2; tot oder lebendig.

Aber auch hier gilt, die Entitäten (Katze, radioaktive Substanz, Blausäure und Kasten) selbst wissen was intern passiert ist. Konsequenterweise sollte hier die Wellenfunktion respektive die Wahrscheinlichkeitsdichte als Ausdruck der Beobachtungssituation angesehen werden und dessen, was von außen über das System bekannt ist.

Auf dieses Experiment passen die Gedanken von Pössel, der in Bezug auf die Dekohärenztheorie und das Beobachterproblem folgende Überlegungen anstellte: , Wer die Welt beobachtet oder eine andere Art von Messung vornimmt, nutzt immer nur einen unvollständigen Satz von Informationen. Ein Physiker, der ein Experiment auswertet, beschränkt sich dabei zwangsweise auf einen Ausschnitt der Welt - bestimmte Einflüsse werden dokumentiert (etwa die Feldstärke des direkt am Experiment angebrachten Magneten), andere werden vernachlässigt (etwa das von außen auf den Experimentalaufbau fallende Sonnenlicht). Für solch eine Situation lassen sich, gemittelte Quantenzustände' definieren, in die unser Unwissen über die Details bereits eingebaut ist. Zwischen diesen Zuständen, so stellt sich heraus, gibt es im Allgemeinen keine Interferenzeffekte mehr" (Pössel 2010: 309). Die Interferenzeffekte wurden für den Beobachter zum Faktum, was jedoch entsprechend dem weiteren Verständnis der Dekohärenztheorie nicht heißen muss, dass außerhalb unserer Wahrnehmung nicht weitere Interferenzen bestehen.

Mit Wigner's Freund (Wigner 1995: 252) wollte Wigner das Absurde verdeutlichen, dass die Reduktion der Wellenfunktion von der direkten Messung des Objektes (Kasten mit Katze) abhängen soll, indem er einen zweiten Beobachter, seinen Freund, mit einbezog. Dieser Freund öffnet nun den Kasten, während sich Wigner selbst an einem anderen Ort aufhält (Abb. 62).

Aus Wigner's Sicht kann die Wellenfunktion nicht das Objekt selbst beschreiben, sondern nur einen gemeinsamen Zustand: Freund plus Objekt, und dieses gemeinsame System hätte auch nach der Interaktion eine Wellenfunktion, bis Wigner selbst die Information von seinem Freund bekommt: ,, The answer is that the information available about the object cannot be described by a wave function. One could attribute a wave function to the joint system: friend plus object, and this joint system would have a wave function also after the interaction, that is, after my friend has looked. [...] However, even in this case, in which the observation was carried out by someone else, the typical change in the wave function occurred only when some information (the yes or no of my friend) entered my consciousness. It follows that the quantum description of objects is influenced by impressions entering my consciousness “ (ebd.). 


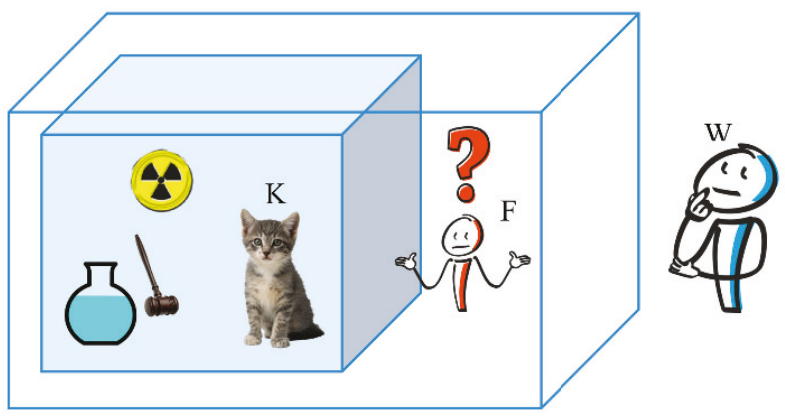

Abb. 62 | Schrödinger's Katze und Wigner's Freund

mit Katze (K), Wigner's Freund (F) und Wigner (W) selbst. Aus Wigner's Sicht kann die Wellenfunktion nicht das Objekt selbst beschreiben, sondern nur einen gemeinsamen Zustand und unser Wissen über diese Situation. (eigene Darstellung)

Aus dieser Perspektive wird wieder offensichtlich, dass der Beobachter eine zentrale Rolle spielt und sich die Wellenfunktion je nach Konstellation von Beteiligten ändert. Es lässt sich eine Psi-Funktion formulieren, die Schrödinger's Katze (K) repräsentiert,

mit ihren Eigenzuständen:

$$
\left|\Psi_{K}\right\rangle=\frac{1}{\sqrt{2}}\left[\left|\Psi_{t o t}\right\rangle_{K}+\left|\Psi_{\text {lebt }}\right\rangle_{K}\right]
$$

$$
|0\rangle_{\mathrm{K}}+|1\rangle_{\mathrm{K}}
$$

Wenn Wigner's Freund (F) nun die Katze beobachtet, erweitert sich die Psi-Funktion auf:

$$
|0\rangle_{\mathrm{K}}|0\rangle_{\mathrm{F}}+|1\rangle_{\mathrm{K}}|1\rangle_{\mathrm{F}}
$$

Kommt jetzt noch Wigner (W) selbst hinzu, weil er wissen möchte, wie das Ergebnis lautet, dann erweitert sich die Funktion noch um einen weiteren Term:

In vollständiger Weise geschrieben ergibt sich:

$$
|0\rangle_{\mathrm{K}}|0\rangle_{\mathrm{F}}|0\rangle_{\mathrm{W}}+|1\rangle_{\mathrm{K}}|1\rangle_{\mathrm{F}}|1\rangle_{\mathrm{W}}
$$

$$
\left|\Psi_{\mathrm{KFW}}\right\rangle_{3}=\frac{1}{\sqrt{2}}\left[|0\rangle^{3}+|1\rangle^{3}\right]=\frac{1}{\sqrt{2}}[|000\rangle+|111\rangle]
$$

Mit dieser Beschreibung erhalten wir eine Form, die als GHZ-Theorem ${ }^{180}$ oder GHZZustand in der Quanten-Teleportation Bedeutung bekommen hat und im Kap. 8.1.4 weitere Verwendung findet.

Dass der Beobachter tatsächlich auf elementarer Ebene Relevanz bekommt, wurde bereits beim Delayed-Choice-Experiment (Kap. 8.1.1.2) deutlich. Die Veränderung der Einstellungen zu einem Zeitpunkt, zu dem die Detektoren schon längst das Ergebnis hätten registrieren müssen oder die beteiligen Quarticle schon lange nicht mehr existieren, veranschaulicht in sehr eindrücklicher Weise die Rolle der Beobachter.

${ }^{180}$ Greenberger-Horne-Zeilinger haben als Erste diesen 3-Entitäten-Zustand untersucht. 
Die Rolle der Beobachtung wird auch noch an einem anderen Experiment deutlich, dem Quanten-Zeno-Effekt (Reineker u. a. 2007: 489ff; Itano u. a. 1990). In diesem Experiment wird durch permanente Beobachtung ein quantenphysikalisches System verlangsamt oder gar zum Stillstand gebracht. Je mehr Beobachtungen, desto anhaltend stabil der Ausgangszustand. Die jüngsten Untersuchungen und Erklärungen bestätigen dieses Phänomen der Nicht-Veränderung unter Beobachtung eindrücklich und zeigen, dass es hier nicht um einen Kollaps geht und die realistischen Erklärungsansätze sehr viel wahrscheinlicher sind (Gosson u. a. 2016; Gosson und Hiley 2014; Patil u. a. 2015). Jenseits der technischen Erklärungen, die in diesen Veröffentlichungen gegeben werden, erscheint es aus den hier entwickelten Überlegungen sehr nachvollziehbar, dass sich bei den Experimenten keine Entwicklungen und damit Veränderungen einstellen. Halte ich meinen Blick ununterbrochen auf ein System, kann sich weder im System noch bei mir ein neues Wissen in Form von Informationen einstellen. Damit ergibt sich keine Notwendigkeit für eine Änderung der Wellenfunktion und damit eines zu beobachtenden Ereignisses.

Mit all diesen Experimenten und theoretischen Ansätzen sollte die Frage nach der Rolle eines Beobachters eigentlich eindeutig beantwortet sein. Stellvertretend für ein Verständnis, das nach wie vor eher am Rande der Wissenschaftsgemeinde zu finden ist, aber dennoch sehr namhafte Vertreter hinter sich weiß, ist von Stapp formuliert:

„Our bodies and brains thus become, in von Neumann's approach, parts of the quantum mechanically described physical universe. Treating the entire physical universe in this unified way provides a conceptually simple and logically coherent theoretical foundation that heals the rupturing of the physical world introduced by the Copenhagen approach. It postulates, for each observer, that each experiential event is connected in a certain specified way to a corresponding brain event. [...] However, von Neumann quantum theory gives, in principle, much more than Copenhagen quantum theory can. By providing an objective description of the entire history of the universe, rather than merely rules connecting human observations, von Neumann's theory provides a quantum framework for cosmological and biological evolution " (Stapp 2001: 1471).

Tatsächlich findet sich in den Lehrbüchern keine einheitliche Meinung und diese Frage wird auch heute noch in verschiedenen Wissenschaften intensiv diskutiert. Aufgehängt sind diese Diskussionen unter dem Begriff ,Heisenbergschnitt', der nachfolgend untersucht wird.

\subsubsection{Heisenberg-Schnitt}

Im Grunde geht es beim Heisenberg-Schnitt um die Frage, inwieweit ein zu untersuchendes System (in diesem Fall ein Quantensystem) unabhängig von Messapparatur und Umwelt angesehen werden kann.

In der KI wird eine Unterscheidung gemacht zwischen der Messapparatur und dem (mikroskopisch kleinen) Quantensystem unbestimmten Zustandes. Dabei wird die Messapparatur als klassisches System betrachtet. Man nimmt an, dass im Moment der 
Messung, also wenn das Quantensystem auf die Messapparatur trifft, der Quantenzustand ,kollabiert', der berühmte ,Kollaps der Wellenfunktion', entsprechend dem Doppelspaltexperiment, bei dem die Wellennatur der Photonen zu einem Punkt mutiert. Die quantenmechanische Unbestimmtheit wandelt sich in ein eindeutiges Messergebnis. Heisenberg und seine Mitstreiter gehen davon aus, dass vor einer solchen Messung kein teilchenhaftes Objekt vorliegt. Aus quantentheoretischer Betrachtung ist dabei unstrittig, dass das Quarticle erst durch die Messung festgelegt und lokalisierbar wird. Im klassischen Weltbild der Physik dagegen wären Photon und Elektron schon vorher existent gewesen. Damit bekommen wir eine Situation, die für den westlich ausgebildeten Betrachter sehr merkwürdig erscheint. Wir erhalten nämlich Messergebnisse, die keine objektiven Aussagen über ein Quantensystem machen können und damit auch nicht über eine vermutete reale Wirklichkeit. Der Einfluss des Messapparates bleibt in diesem Ansatz unberücksichtigt, schlicht weil das Ausmaß seines Einflusses unbekannt ist. Man gibt sich zufrieden mit dem was man hat und blendet das was man nicht hat einfach aus. Insofern wird auch nachvollziehbar, wenn Werner Heisenberg (Zeilinger 2002) zur Überzeugung kommt, dass die Naturwissenschaften uns nur ein ,Bild unserer Kenntnis von der Natur' und nicht ein Bild der Natur selbst liefert.

Aus Sicht einer zweiten Gruppe von Physikern stellte sich bei diesem Ansatz die Frage: Wie kommt es, dass sich Quantensysteme einmal entsprechend der Schrödingergleichung zeitlich ungestört entwickeln und andererseits im Verständnis der KI eine Entwicklung eintritt, bei der das Quantensystem in bestimmten Situationen auf einen Zustand festgelegt wird? Hier hat sich im Gegensatz zur KI ein Verständnis herausgebildet, das die Entwicklung von Quantensystemen immer zeitlich bestimmt sieht und ohne Kollaps - entsprechend eben der konsequenten Interpretation der Schrödingergleichung. Danach handelt es sich um Scheineffekte, wenn bestimmte Zustände festgelegt werden. Dies geht aus der Dekohärenztheorie von Zeh (Kap. 8.1.2.2) und der Viel-Welten-Interpretation von Everett hervor. Zeh schlussfolgert aus seinen Überlegungen, dass die Schrödingergleichung aufgrund der experimentellen Bestätigungen der Dekohärenztheorie sehr wohl auf makroskopische Systeme anwendbar ist und vermutlich universelle Gültigkeit besitzt. In seinem Ansatz ist die Trennung zwischen Messapparatur und Quantensystem aufgelöst. Zur Realisierung benötigt es allerdings eine Perspektivenerweiterung, in der die für geschlossene Systeme gültige Schrödingergleichung die Hinzunahme der Messapparatur erfährt und wie nachfolgend ausgeführt wird, auch weitere Elemente. Es entsteht erneut ein abgeschlossenes System, jetzt aber unter Einschluss der Messapparatur und der Umgebung. Wenn in der Quantenphysik in der jüngeren Zeit von offenen Quantensystemen gesprochen wird, wird immer auf dieses Prinzip zurückgegriffen.

Eine vollständige Beschreibung eines Messprozesses sieht dementsprechend folgendermaßen aus: In der Regel existiert bei einem Messprozess neben der Messapparatur (M) und dem Quantensystem (QS) auch noch der Beobachter (B) in Person des Versuchsleiters und die Umgebung (U). Nach diesem Verständnis erstreckt sich der vollständige Quantenmessprozess auf alle beteiligten Systeme (M-Q-B-U), die in diesem Fall als verschränkt betrachtet werden müssen. Dieses Verständnis hatte auch C.F. v. 
Weizsäcker (Kap. 4.2.2.8), der von einer untrennbaren Kette zwischen Objekt und Subjekt sprach.

Eine Darstellung des Heisenberg-Schnitt's in Anlehnung an Zeh (2011) veranschaulicht sehr gut, wie sich das Verständnis von wichtigen Quanten-Physikern unterscheidet, was bzw. wer alles im Messprozess zu berücksichtigen ist (Abb. 63). Damit geht es um die Frage, welche Wechselwirkungen mit der Schrödingergleichung erfasst werden müssen.

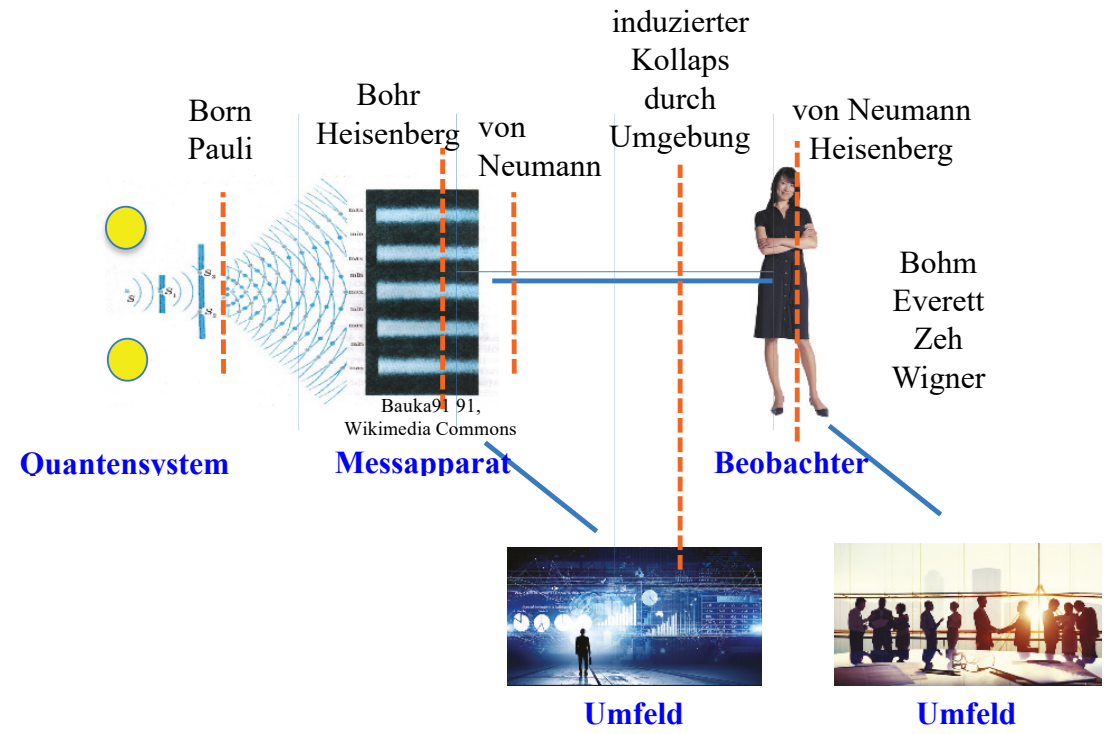

Abb. 63 | Heisenberg-Schnitt in Anlehnung an H.-D. Zeh

mit Quantensystem $=\mathrm{QS}$; Messapparat $=\mathrm{M}$; Beobachter $=\mathrm{B}$, Umfeld $=\mathrm{U}$ (eigene Darstellung). Die senkrechten gestrichelten Linien veranschaulichen die Position, an der die jeweiligen Physiker eine Trennung von Quantensystem und Messapparat annahmen.

Dieser sogenannte Heisenberg-Schnitt beschreibt die Position, an der das zu messende Quantensystem vom Messapparat getrennt werden darf. Die Frage, die sich dabei jedoch stellt, war: Was gehört alles zum Messapparat dazu? Tab. 16 gibt eine Kurzzusammenfassung nach Zeh (ebd.) mit einigen eigenen Anpassungen. 
Tab. 16 | Unterschiedliche Perspektiven auf den Heisenberg-Schnitt nach Zeh, mit kleineren Anpassungen durch den Autor. (eigene Darstellung)

\begin{tabular}{|c|c|}
\hline Born / Pauli & $\begin{array}{l}\text { Sie bezogen ihre KI direkt auf das zu messende Quantensystem und } \\
\text { sahen es zunächst auch außerhalb der Naturgesetze stehend. }\end{array}$ \\
\hline Heisenberg & $\begin{array}{l}\text { Auch nach ihm soll der Schnitt zwischen dem Quantensystem und der } \\
\text { Messapparatur vollzogen werden. Dennoch zieht er später den Be- } \\
\text { obachter mit ein. }\end{array}$ \\
\hline Bohr & $\begin{array}{l}\text { Er erweiterte den Rahmen und schloss die Messapparatur teilweise } \\
\text { ein. Der Wechsel zu den makroskopischen Eigenschaften erfolgt nach } \\
\text { Bohr allerdings erst nach dem Klick des Detektors. }\end{array}$ \\
\hline $\begin{array}{l}\text { von } \\
\text { Neumann }\end{array}$ & $\begin{array}{l}\text { Da er ein Wellenpaket auch auf den Zeiger der Messapparatur bezog, } \\
\text { wurde jetzt Quantensystem und Messapparatur als ein verschränktes } \\
\text { System verstanden. Er formulierte explizit eine Wechselwirkung zwi- } \\
\text { schen QS und M im Rahmen der Schrödingergleichung. Andererseits } \\
\text { nahm er den Beobachter in die quantenmechanische Beschreibung mit } \\
\text { auf. Er forderte vom Beobachter das Annehmen eines bestimmten Zu- } \\
\text { standes und verlegte damit den Auslöser letztlich ins Bewusstsein des } \\
\text { Beobachters (Neumann 1996). }\end{array}$ \\
\hline $\begin{array}{l}\text { Induzierter } \\
\text { Kollaps }\end{array}$ & $\begin{array}{l}\text { Verschiedene Forscher schlugen schließlich auch vor, die Umgebung } \\
\text { des Systems QS-M mit in die Gesamtverschränkung einzubeziehen, } \\
\text { da die Interaktion mit z. B. Gasmolekülen der Umgebung unvermeid- } \\
\text { lich sei (induzierter Kollaps durch die Umgebung). }\end{array}$ \\
\hline $\begin{array}{l}\text { Wigner } \\
\text { Heisenberg }\end{array}$ & $\begin{array}{l}\text { Wigner nahm zunächst das Bewusstsein des Beobachters in den Mess- } \\
\text { prozess mit auf. Zudem stellte er die Frage, ob ein zwischengelagerter } \\
\text { Beobachter den Kollaps auslöst oder erst der Endbetrachter. Interes- } \\
\text { sant in diesem Kontext ist, dass bereits Heisenberg den Beobachter } \\
\text { für die Bahn des Teilchens verantwortlich macht, da die Bahn erst } \\
\text { durch dessen Beobachtung entstehen würde. Insofern ist nicht ganz } \\
\text { klar, wo Heisenberg anzusiedeln ist. }\end{array}$ \\
\hline $\begin{array}{l}\text { Bohm } \\
\text { Everett } \\
\text { Zeh } \\
\text { Wigner }\end{array}$ & $\begin{array}{l}\text { Bohm geht wie Everett von der uneingeschränkten Gültigkeit der } \\
\text { Schrödingergleichung aus und verzichtete vollständig auf den Kol- } \\
\text { laps. Letztlich zog Everett mit seiner Viel-Welten-Theorie auch die } \\
\text { Umwelt des Beobachters mit ein. Die Dekohärenztheorie von Zeh un- } \\
\text { terstützt diese Ansicht. Sie fordern eine einheitliche Behandlung aller } \\
\text { beteiligter Systeme und liefern damit den größten Gegensatz zur Ko- } \\
\text { penhagener Deutung. Wigner übernahm diese Perspektive nachdem } \\
\text { ihm die Dekohärenztheorie bekannt wurde. }\end{array}$ \\
\hline
\end{tabular}

Anmerkungen zu Tab. 16:

Born/Pauli, Heisenberg und Bohr (oberhalb der dicken Trennlinie) sahen die Messapparatur letztlich ähnlich, nämlich klassisch. Unterhalb der dicken Trennlinie öffnet sich das Verständnis hin zur Integration des Beobachters in den Messprozess, was wie be- 
schrieben neue Experimente auch zweifelsfrei bewiesen haben. In jedem Fall sind aus den Perspektiven von Everett, Zeh oder Wigner die Ergebnisse der Delayed-ChoiceExperimente am Doppelspalt nicht mehr so merkwürdig, wie manchmal dargestellt. Es hat also den Anschein, als ob ein Ereignis solange es noch nicht wirklich gemessen und damit sichtbar wurde, rückgängig gemacht bzw. beeinflusst werden kann.

Hierzu passt auch eine Arbeit von Fuchs und Peres, in der die Frage, ob Quantenmechanik auch auf den Beobachter anwendbar sei, mit einem klaren Ja beantwortet wurde (Fuchs und Peres 2000). Voraussetzung sei nur, dass er für eine quantenmechanische Beschreibung zugänglich sei und von daher würde sie nichts hindern, einen Kollegen zu quantisieren.

Arbeiten von Atmanspacher u. a. (Atmanspacher und Primas 2006; Atmanspacher u. a. 2002) und Walach u. a. (Walach und Stillfried 2011) zeigten ebenfalls einen solchen Zusammenhang. Weiter wurde von Peres und Fuchs nachgewiesen, dass ein rückwärts gerichteter Zeitpfeil, entsprechend den Feynman-Diagrammen, nicht nur mathema-tische, sondern auch für die reale Welt Gültigkeit besitzt. Diese Gültigkeit wurde bisher nur als ,unser Wissen über die Welt' interpretiert, nicht aber als eine objektive, vollständig beschreibbare Realität an sich. Dieser Zusammenhang wurde aktuell von Goswami und Kollegen bestätigt (Goswami u. a. 2018), in dem sie mithilfe von ,optischen Quantenschaltungen' Prozesse mit unbestimmten Reihenfolgen realisierten. Dabei wurden zwei Operationen A und B in eine quantenphysikalische Superposition bzgl. ihrer Reihenfolge des Ablaufs gebracht. Ziel war es, für Berechnungen und Kommunikationsprozesse, hochdimensionale Überlagerungen von Informationen in Zeit und Raum und damit Qubits zu realisieren. Aus diesen Versuchsanordnungen lässt sich die Frage nach der Reihenfolge des ,Henne - Ei-Problems' nur als Überlagerung beider Entwicklungsrichtungen interpretieren.

Auch reichen mittlerweile zwei Messungen aus, um alle möglichen Fragen über einen transportierten/teleportierten Zustand eines hochdimensional verschränkten Quantensystems ermitteln zu können (Bavaresco u. a. 2018) und nicht mehr hunderte oder tausende Messungen. Lebende Systeme, wie ein Beobachter, würden einem solchen hochdimensional verschränkten Quantensystem entsprechen.

\subsubsection{Unterschiede/Ähnlichkeiten in Physik, Soziologie/Psychologie und SyA}

Bezogen auf den vorgestellten Heisenberg-Schnitt lässt sich, basierend auf Fuchs und Peres (Fuchs und Peres 2000), formulieren: Wenn ich ein System betrachte, in dem der Beobachter Einfluss auf das Messergebnis ausübt oder davon betroffen ist, MUSS ich den Beobachter mit in die Rechnung aufnehmen. SyA lassen sich nicht mit gängigen Erklärungsansätzen beschreiben, erfüllen aber den von Fuchs und Peres geforderten quantenmechanischen Formalismus.

Die Frage, was wir eigentlich messen, scheint auch in der modernen Physik nicht ganz einfach beantwortbar zu sein. Gleichwohl wird gerade da sehr viel Wert auf Präzision und Widerspruchsfreiheit gelegt und vermutlich kommt auch aus diesem Anspruch heraus eine innere Reserviertheit oder gar Ablehnung gegenüber Wissenschaften wie 
Psychologie und Soziologie. Die Freiheitsgrade, dessen was man messen kann, sind bei Letzteren einfach ausgesprochen groß. Betrachten wir die Messprozesse in der Physik einmal genauer, können wir feststellen, dass die Welten gar nicht so unterschiedlich scheinen.

In Übereinstimmung mit dem Heisenberg-Schnitt (in Anlehnung an Born/Pauli, Abb. 63), aber analog zur klassischen Physik, wird in vielen Schulen der Psychologie und Soziologie von getrennten Systemen ,, ausgegangen. Entsprechend zur klassischen Physik hat sich lange das Bild vom Menschen als komplexe Maschine gehalten und hält sich heute noch, was nicht zuletzt in der Medizin gut beobachtbar ist. Auch in den klassischen Theorien der Psychologie und Soziologie ging man davon aus, dass das menschliche Wesen zwar durch sein Umfeld geprägt wird, aber zu einem Zeitpunkt X sich davon weitestgehend unabhängig entwickelt “ (Gehlert 2016). Damit war auch hier der Fokus auf das scheinbar unabhängige Wesen gerichtet. In der Pädagogik findet sich der klassische Ansatz im Lehr- und Lernkonzept des ,Nürnberg Trichters': Deckel auf, Wissen reinfüllen, neues Wissen ist gelernt! „Der Glaube an objektive Wahrheiten und Fähigkeiten ist noch heute in unseren Vorstellungen tief verwurzelt " (ebd.). Auch der Glaube, dass alles, was zu beobachten ist auch wahrgenommen wird, ist weit verbreitet. Das Phänomen der selektiven Wahrnehmung oder der Pygmalion-Effekt (Bestätigen der Erwartungshaltung) ist vermutlich nur einem kleinen Teil der Bevölkerung bekannt.

Ebenso wurden Fähigkeiten und Handlungen von Menschen sehr lange unabhängig von ihrem Umfeld gesehen. Bedauerlicherweise ist dies auch heute noch zu beobachten, nicht zuletzt in den Wirtschaftsunternehmen. Wie bewerte ich als Führungskraft ein auffallendes, nicht leistungsbereites Verhalten eines Mitarbeiters? Und wie, wenn ich denselben Mitarbeiter außerhalb der Firma als engagiert und kommunikativ erlebe? Welche Schlüsse ziehe ich jetzt? Führe ich sein Verhalten auf eine hohe Freizeitorientierung zurück, auf einen vielleicht nicht angepassten Führungsstil mit zu viel Bevormundung und wenig eigenem Spielraum oder auf eine Unsicherheit resultierend aus fehlender Kompetenz?

Die modernen Richtungen der Psychologie und Soziologie berücksichtigen genau diese Zusammenhänge und Kontexte. Im Konzept der Systemtheorie (Luhmann, Wilke, u. a.) und der systemischen Familientherapie (Mailänder Schule etc.) wird die Beziehung Umfeld - Systemelement (Mensch, Gruppe, Unternehmen, Land) in den Fokus der Betrachtung gestellt. Dies steht im Gegensatz zu Richtungen der humanistischen Psychologie, in der der Mensch im Mittelpunkt steht und das Umfeld nur als störender Kontext wahrgenommen wird. Wesentliche Eckpfeiler des systemischen Verständnisses, wie die Einbindung des Beobachters in das Beobachtete (Bateson 1985) oder der Konstruktivismus (Watzlawick, von Förster), dass alles von einem Beobachter konstruiert wird und es keine objektive Perspektive gibt, lassen sich eins zu eins auf die modernen Ansätze der Quantentheorie übertragen. Auch hier stellt sich die Frage: Existiert die Information bereits im Vorfeld oder ist sie erst durch den Beobachter - respektive die Aufstellung - und unsere Interpretation entstanden? Existiert eine bestimmte Verhaltensweise schon immer oder wird sie erst durch unsere Erwartung, den Kontakt und/oder die Interaktion mit dem Umfeld erzeugt? 
Analog zum Doppelspaltexperiment können wir auch in der Soziologie und Psychologie feststellen, dass je nachdem wie Personen oder Gruppen auf etwas schauen bzw. etwas erwarten, sich dieses zeigt; genauso wie die Intention, also die Erwartung in der Quantenphysik das Ergebnis beeinflusst. Alles andere wird ausgeblendet, obwohl es ebenfalls da ist oder zumindest möglich ist. Der Beobachter erzeugt sich respektive konstruiert sich seine Welt, wie es der Konstruktivismus formuliert. Nichts anderes findet in der Physik statt bei der Interpretation der Phänomene und ihrer Erklärungen. Weltbilder entscheiden darüber, was akzeptiert und was abgelehnt wird. Die reine Mathematik ist hilfreich beim Modellieren und Überprüfen, unterliegt aber auch der Interpretation und Bedeutungsgebung ihrer Axiome und Resultate.

Und analog zum Delayed-Choice-Experiment lassen sich in der Therapie Zustände, Erlebnisse und Vorstellungen rückgängig machen bzw. modifizieren. Dies gilt sowohl für körperliche als auch geistig/psychische Zustände und mitunter reichen dazu ein paar Minuten bis zu wenigen Stunden - vielleicht sogar auch rückwirkend in der Zeit.

Was immer wir auch als Messung ansehen, im modernen Verständnis ist immer der Beobachter, seine Intention, seine Systemgrenze, die er zieht, sowie die Relation, die er herstellt, entscheidend für das Resultat. Was ist die Wirklichkeit? - Dies ist die Grundfrage von Orpheus im Blockbuster ,Matrix', die sich sowohl in der Physik als auch in fast allen anderen Wissenschaften stellt. Die Antwort fällt heute in der modernen, wissenschaftlich gebildeten und aufgeschlossenen Welt anders aus, als sie noch vor wenigen Jahren gelautet hätte oder wie sie in nicht-wissenschaftsaffinen Kulturen gegeben würde. Man darf wohl mit gutem Recht die Behauptung aufstellen, dass für diese Entwicklung ganz stark unser Verständnis von Messprozessen und den daraus generierbaren Erkenntnissen einen Beitrag leistet.

Und schließlich sind bei SyA, wie bei Neumann (Kap. 4.2.2.4), die Stellvertreter ebenfalls gefordert einen bestimmten Zustand einzunehmen, um repräsentierende Wahrnehmungen generieren zu können, womit sie zwingend Teil des Systems werden. Damit kann hier eine weitere Parallele und die Anschlussfähigkeit zur Systemtheorie und zu SyA gezogen werden.

\subsubsection{Informationsübertragung und Quanten-Teleportation}

Bisher wurde der Schwerpunkt auf die grundsätzlichen Erkenntnisse und Theorien in der Quantenphysik gelegt, um prinzipiell zu überprüfen, ob sich Quantenphysik als Erklärungsoption anbieten kann. Nachdem dies zum jetzigen Stand zweifelsohne bejaht werden darf, bietet sich mit der Quanten-Teleportation (QT) eine Struktur an, die hohe Ähnlichkeit mit den Strukturen bei SyA aufweist. Aus diesem Grund soll die QT als letzter Baustein von Kap. 8.1 untersucht und als möglicher Übertragungsmechanismus vorgestellt werden. Als Ergebnis ergibt sich eine Antwort zu Säule 7 und der Hauptkategorie ,Übertragungswege' ganz allgemein. 


\subsubsection{Allgemeiner Hintergrund zur QT und zum GHZ-Experiment}

Die Methode ${ }^{181}$ der QT, bei der Quanteninformation zwischen Systemen ausgetauscht wird, geht auf Bennett und seine Kollegen zurück (Bennett u. a. 1993). Sie gingen noch von einem ,,spin-exchange measurement " aus. Ihre Absicht bestand in der Übermittlung des Zustandes eines Quarticle an einen Empfänger, ohne das Quarticle selbst zum Empfänger zu transportieren und damit eine direkte Verschränkung zu organisieren. Den ersten experimentellen Nachweis lieferte vier Jahre später Zeilinger mit seiner Gruppe (Bouwmeester u. a. 1997). Das Verfahren wurde mittlerweile bis zur Informationsübertragung über Satelliten weiterentwickelt. Auf diesem Prinzip bauen auch die terrestrisch atmosphärische QT, wie die über $148 \mathrm{~km}$ von Las Palmas nach Teneriffa auf (Ma u. a. 2012a).

„Quantum teleportation allows for the transfer of arbitrary unknown quantum states from a sender to a spatially distant receiver, provided that the two parties share an entangled state and can communicate classically. [...] optimal choice for carrying information in the form of 'flying qubits '“ (Takeda u. a. 2013: 315). Wie bereits in Kap. 8.1.2.3 an einigen Beispielen vorgestellt wurde, lassen sich mit diesem Verfahren auf verschiedene Weise Informationen über verschränkte Systeme, auch bei normalen Umweltbedingungen, deterministisch sicher teleportieren. Technisch konnten Kohärenzzeiten von bis 6 Stunden nachgewiesen werden (Zhong u. a. 2015). Eine gute Übersicht über den Stand der Entwicklung bis 2015 findet sich bei Pirandola und Kollegen (Pirandola u. a. 2015). Ganz aktuell wurde auch herausgearbeitet, dass tatsächlich jeder verschränkte Zustand einen Quantenkanal realisieren kann und sich damit nicht nur ausgewählte, sondern alle darin vorhandenen Informationen teleportiert lassen (Cavalcanti u. a. 2017). Dies gelang sogar in Fällen nicht vollständiger Bell-Zustandsmessungen oder ineffektiver Detektoren. Solche Rahmenbedingungen gelten ebenso bei biologischen Systemen, wie wir in Kap. 8.2 noch sehen werden.

Das Prinzip zur Erzeugung verschränkter Photonen, die in der QT (Zeilinger 2007; Camejo 2007: 248) zum Einsatz kommen, wurde in Kap. 8.1.3.1 Abb. 61 bereits veranschaulicht. Die QT setzt an diesem Punkt auf. An einem Photonenteiler werden die mit einer EPR-Quelle erzeugten Photonen in unterschiedliche Richtungen geleitet (Abb. 64). Bei der klassischen 3-Quarticle-QT ist nun das Ziel, den Zustand eines Quarticle (A) (üblicherweise geht man dabei von einem unbekannten Ausgangszustand aus), mittels eines verschränkten Photonenpaars (B und C) von Alice an Bob zu teleportieren.

${ }^{181}$ Die folgenden Inhalte wurden im Wesentlichen bereits 2014 und 2015 veröffentlicht und in diesem Kapitel zusammengefasst und überwiegend wortwörtlich wiedergegeben (Gehlert 2015a, 2014). 


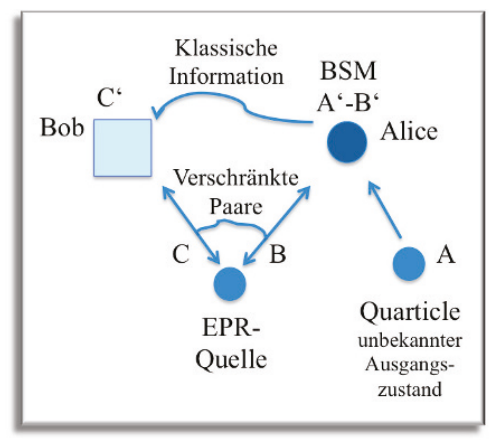

Abb. 64 | Experimentelle Anordnung zur QT unter Beteiligung von 3 Quarticle

(eigene Darstellung). Alice verschränkt Quarticle A mit B mittels einer Bell-State-Messung (BSM) zu A'-B', wobei B bereits mit C verschränkt ist. Misst Bob nun Quarticle C, so erhält er Information über den Zustand von A. Notwendig ist hierzu nur die Information über die Art der von Alice durchgeführten Verschränkung, die er jedoch nur auf normalem Übertragungsweg, als klassische Information, bekommen kann.

Die ursprüngliche Überzeugung von Bennett war, dass Alice den Zustand des Teilchens (A) nicht selbst messen darf, da es sonst zu einer Überlagerung mit ihrem eigenen $\mathrm{Zu}$ stand käme und damit der reine Zustand von A nicht mehr an Bob weiterleitbar sei (Bennett u. a. 1993). Alice führt deshalb nur eine Bell-State-Messung ${ }^{182}$ (BSM) aus, wobei sie A mit B verschränkt zu A'-B'. Auf einem klassischen Kanal (Telefon, Mail ...) teilt Alice ihre Einstellungsparameter und Ergebnisse Bob mit. Führt Bob jetzt seine Messung an $C$ aus und erhält damit C', so kann er sofort den Zustand von A bestimmen. Nach dem klassischen Verständnis wird davon ausgegangen, dass A jetzt die übertragene Information verloren hat, welche sich nach der Messung von Bob bei C' befindet.

Bereits 1990 veröffentlichten Greenberger, Horner und Zeilinger (GHZ) eine Arbeit, in der sie einen Ansatz vorstellten, der lokale Theorien und versteckte Variable ausschließen sollte. In dieser Arbeit wurde ein 3-Quarticle-System beschrieben, das das statistische Verfahren von Bell überflüssig machen sollte. 2008 erweiterten sie ihre Methodik auf 4-Quarticle mit zwei unabhängigen EPR-Quellen bzw. generell auf MehrQuarticle-Systeme (Greenberger u. a. 2008, 1990). Sie konnten damit Verschränkungen und Quanten-Informations-Übertragung darstellen. Abb. 64 stellt die kleinste Form eines solchen Mehrteilchensystems dar.

Bereits der Ansatz 1990 entsprach im Prinzip dem Vorschlag von Bennett (Bennett u. a. 1993), nur noch ohne den Begriff der Teleportation explizit zu verwenden. In der Veröffentlichung 2008 bezog sich der GHZ-Ansatz dann sehr direkt auf die Teleportation mit einer Erweiterung zum ,Entanglement Swapping'. In ihrer Arbeit weisen GHZ darauf hin, dass hier nicht nur die einzelne Information jedes der Partikel teleportiert

${ }^{182}$ Mit einer BSM (Bell-State-Measurement) werden die Zustände eines Quantensystems gemessen. Die Methode geht auf John Bell zurück, mit der er verschränkte und klassische Zustände unterscheiden konnte. 
wird, sondern dass die Verschränkung selbst teleportiert wird (Entanglement Swapping). Übersetzt könnte man deshalb sagen, dass es sich um die Teleportation der Beziehungsstruktur handelt. Des Weiteren betonen sie, dass solange keine Störungen auf das System einwirken die 100 \%-ige Sicherheit der gleichen Ergebnisse gewährleistet ist. Damit ist auch ausgedrückt, dass es keine Störungen bei einem der beteiligten Systeme bis zum Abschluss der Messungen geben darf. Dies wurde in einer Veröffentlichung 2011 noch einmal explizit bestätigt (Lapkiewicz u. a. 2011: 490). Sie zeigen im Gegensatz zu Bennett's Überzeugung, dass Alice sehr wohl hätte messen dürfen, zumindest dann, wenn ihr ihr eigener Zustand bekannt ist.

Physikalisch ausgedrückt handelt es sich bei einem solchen GHZ-Experiment um einen verschränkten Quantenzustand von mehr als zwei Subsystemen ( $>2$ ). In jedem Subsystem müssen dabei mindestens zwei Untersysteme vorhanden sein und damit muss mindestens eine 2-Dimensionalität vorliegen. Anders ausgedrückt handelt es sich deshalb um Mehrteilchensysteme und mithin um Quantenfelder. In der GHZ 4 QuarticleVersuchsanordnung (Abb. 65) wird mit zwei verschränkten Paaren von Quarticle gearbeitet (A-B und C-D), die zunächst völlig unabhängig voneinander aus zwei unterschiedlichen ERP-Quellen entstanden sind.

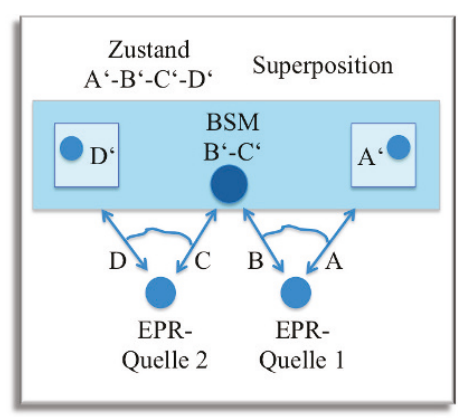

Abb. 65 | GHZ-Anordnung zur QT unter Beteiligung von 4 Quarticle

(eigene Darstellung). Bei 4 Quarticle-Systemen wird durch die Verschränkung von zwei (B'-C') aus jeweils unterschiedlichen Quellen kommenden Quarticle das Gesamtsystem (A'-B'-C'-D') verschränkt.

Im Versuch wird im Folgenden jeweils ein Teil eines der Paare (B) mit einem Teil des anderen Paars (C) über eine Bell-State-Messung (BSM) miteinander verschränkt (B'C'). Als Folge sind dann automatisch alle 4 Quarticle miteinander verschränkt (A'-B'C'-D') und die Information der ursprünglich einzelnen Quarticle ist über das Gesamtsystem in Form einer Superposition verteilt. Mit diesem Verfahren konnten die Forscher die oben beschriebene Annahme widerlegen, dass bei einer QT, wie sie in Abb. 64 und Abb. 65 dargestellt sind, der Kontakt zu A verloren gehen würde, und zwar aufgrund des Messprozesses und der damit verbundenen Dekohärenz. Ganz im Gegenteil verändert sich A zu A' und bleibt Teil des Systems. Wie in den Arbeiten von 1998 und 2008 
gezeigt werden konnte, liegt jetzt eine Superposition und damit Verschränkung über das Gesamtsystem A'-B'-C' respektive A'-B'-C'-D' vor. Nehmen wir die 2-dimensionalen Subsysteme als Qubits, ergibt sich für die Superposition eines solchen Systems in allgemeiner Form:

$$
\left|\Psi_{G H Z}\right\rangle_{N}=\frac{1}{\sqrt{2}}\left[|0\rangle^{\mathrm{N}}+|1\rangle^{\mathrm{N}}\right]
$$

mit N für Anzahl der Subsysteme. Bezogen auf die kleinste GHZ-Konfiguration von 3Qubit folgt

$$
\left|\Psi_{\mathrm{GHZ}}\right\rangle_{3}=\frac{1}{\sqrt{2}}\left[|0\rangle^{3}+|1\rangle^{3}\right]=\frac{1}{\sqrt{2}}[|000\rangle+|111\rangle]
$$

und damit exakt die gleiche Schreibweise wie für die Anordnung bei Wigner's Freund (8.17).

Für Abb. 64 ergibt sich entsprechend:

$$
\left|\Psi_{\mathrm{GHZ}}\right\rangle_{3}=\frac{1}{\sqrt{2}}\left[|\mathrm{ABC}\rangle+\left|\mathrm{A}^{\prime} \mathrm{B}^{\prime} \mathrm{C}^{\prime}\right\rangle\right]
$$

Für Abb. 65 ergibt sich entsprechend:

$$
\left|\Psi_{\mathrm{GHZ}}\right\rangle_{4}=\frac{1}{\sqrt{2}}\left[|\mathrm{ABCD}\rangle+\left|\mathrm{A}^{\prime} \mathrm{B}^{\prime} \mathrm{C}^{\prime} \mathrm{D}^{\prime}\right\rangle\right]
$$

Abb. 66 repräsentiert eine vereinfachte Darstellung. Analog zu den Überlegungen von GHZ und Susskind (Susskind 2016: 555-559) sind alle Subsysteme miteinander maximal verschränkt ${ }^{183}$.

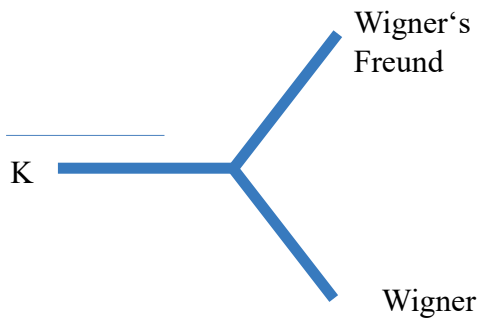

Abb. 66 | GHZ-Zustände von Wigner's Freund-Gedankenexperiment

Tensor-Netzwerk (eigene Darstellung in Anlehnung an Susskind (ebd. 556), in dem die Katze, Wigner's Freund und Wigner sich in einem gemeinsamen Verschränkungszustand befinden.

Susskind zeigt nun weiter auf, dass wenn in einer solchen Konfiguration eines der drei Subsysteme betrachtet und damit unterschieden wird, die Gesamtverschränkung keinesfalls zusammenbricht. Wird Wigner wieder separiert, verbleiben Wigner's Freund (F) und die Katze (K) in verschränktem Zustand.

${ }^{183}$ Susskind greift bei seinen Überlegungen auf verdrillte Brane zurück. Brane (abgeleitet von Membran) sind dieser Vorstellung nach in der vierdimensionalen Raum-Zeit eingebettet und diese wiederum in einer noch höher dimensionalen Ebene, dem sogenannten Bulk. Brane stehen in Verbindung mit topologischen Strukturen und mit dem Vakuumfeld (Greene 1998); womit wiederum eine Verbindung zu den bekannten Phasenübergängen von Wilczek, Kosterlitz/Thouless und Haldane konstruiert werden darf. Auch dort handelt es sich um verdrillte topologische Strukturen. 
oder alternativ geschrieben

$$
|0\rangle_{\mathrm{K}}|0\rangle_{\mathrm{F}}+|1\rangle_{\mathrm{K}}|1\rangle_{\mathrm{F}}
$$

$$
\left|\Psi_{\mathrm{GHZ}}\right\rangle_{\mathrm{W}}=\frac{1}{2}\left[\left|0_{\mathrm{K}} 0_{\mathrm{F}}\right\rangle\left\langle 0_{\mathrm{K}} 0_{\mathrm{F}}|+| 1_{\mathrm{K}} 1_{\mathrm{F}}\right\rangle\left\langle 1_{\mathrm{K}} 1_{\mathrm{F}}\right|\right]
$$

„, That means that the density matrix is a sum of projection operators on unentangled pure states. In other words no two parties are entangled but any one party is maximally entangled with the union of the other two " (ebd. 557).

Dies bedeutet wiederum, dass hier ein Mixed-Zustand zwischen verschränkten und separierten Subsystemen vorliegt, die beliebig zusammengeschlossen und getrennt werden können, wie bereits an anderer Stelle gesehen. Kommen Wigner oder noch weitere Subsysteme erneut hinzu, entsteht wieder ein Multi-Quarticle-Ensemble, in dem alle maximal verschränkt sind.

Aus Susskind's Perspektive kann ein weiterer Beobachter (bei Susskind wird dieser weitere Beobachter als Einstein bezeichnet) die Rolle eines Über-Beobachters einnehmen, der nicht Teil des Systems sein würde, dieses jedoch manipulieren bzw. von außen beobachten kann. Ganz im Sinne der bisher herausgearbeiteten Modellbildung stellt Susskind fest, dass ein solcher Über-Beobachter die Dinge im Rahmen der KI zwar einfach, aber unbefriedigend macht, weshalb er mit folgendem Statement abschließt:

,Sooner or later we will have to give up the security of an asymptotically cold boundary, and formulate a theory in which the universe is a highly interconnected network of entangled subsystems, with no preferred uber-observer " (ebd. 563). In Susskind's Perspektive gibt es offensichtlich diesen Überbeobachter nicht, da er immer Teil des Systems ist.

\section{Unterschied Bell und GHZ}

Mit GHZ-Experiment und Bell's Ungleichungs-Test existieren zwei äquivalente Verfahren zur Unterscheidung von quantenmechanischem und klassischem Verhalten, nur dass beim GHZ-Experiment mit drei Quarticle drei Messungen ausreichen, um die Gültigkeit der Quantenmechanik mit ihrer Nicht-Lokalitätsannahme zu bestätigen. Bell's Ansatz demgegenüber setzt eine ausreichend große Anzahl an Messungen voraus, um statistisch verwertbare Aussagen zu bekommen. Eine Besonderheit beim GHZ-Experiment ist deshalb das Nicht-Benötigen der Bellschen Ungleichung und somit der Verzicht auf Wahrscheinlichkeitsbetrachtung, da nur perfekt korrelierte Zustände gemessen werden.

\section{Geschwindigkeit der Informationsübertragung und der Begriff des Sendens}

Gerne wird zurückgreifend auf diesen Verschränkungsmechanismus die Idee formuliert, dass mithilfe dieser Technik Informationen von A nach B über sehr weite Entfernungen gesendet werden könnten. Aus der Perspektive der Dekohärenztheorie wird der Zustand von A nicht gesendet und der Zustand von B ändert sich nicht instantan, sondern er ergibt sich aus der Nicht-Lokalität des Quantenzustandes. Wie bereits in Kap. 8.1.2.2 zitiert, ist nach Zeh die neue Information bereits nach der Präparierung am gewünschten Ort und muss dort nur noch dekohäriert, also gemessen werden. 
Betrachten wir nochmals die Grundidee des ,Sendens‘. Aus dem Verständnis der Physik kann mit einer solchen Verschränkung keine Information über ein Signal gesendet werden und schon gar nicht schneller als mit Lichtgeschwindigkeit (siehe auch Kap. 4.2.2). Ein solches Signal ließe sich bei seiner Reise durch den Raum beobachten, da es seinen Energiezustand abhängig von Ort und Zeit, $E=E(x, t)$, ändert. Die Energiewelle wandert sozusagen durch den Raum. Wie bereits festgestellt, gelingt eine solche Messung und damit Beobachtung für verschränkte Quarticle nicht. Die Vorstellung darüber, wie dieser Austausch an Information tatsächlich funktioniert, also wie Quarticle A wissen kann, was bei Quarticle B passiert, wurde in Kap. 8.1.1 und 8.1.2 und mit der allgemeinen Verschränkung von Zeh beschrieben.

Die Aussage ,nicht schneller als Lichtgeschwindigkeit' ergibt sich, wie bereits beschrieben, aus Einstein's Relativitätstheorie, die ein solches Verhalten (senden) für materielle Objekte und Informationen verbietet und dies immer aus der Perspektive eines Beobachters beschreibt. Nun kann aber voneinander abhängige Information nachweislich bei verschränkten Systemen gemessen werden, deshalb sprechen Physiker von einer sogenannten (nicht-lokalen) Korrelation der Systeme oder dass die Information im System verteilt ist.

Jetzt könnte man sich noch vorstellen, dass A und B eine Art Morse-Code schon im Vorfeld ausgetauscht haben. A und B bräuchten nur ihren Dechiffrierschlüssel über die Signale zu legen und könnten sie so übersetzen.

Quantenmechanisch ergibt sich jedoch ein Problem. Um einen solchen Morse-Code zu nutzen, müssten genau definierte Impulse erzeugt werden. Solche Impulse lassen sich in der Quantenwelt nicht deterministisch festlegen. In jedem quantenmechanischen Prozess finden Zufallsereignisse statt, sodass sich ein solcher Code nicht zuverlässig erzeugen und transportieren lässt. Ob das Teilchen im obigen Photonenexperiment transmittiert oder reflektiert oder welche Spin- oder Drehimpulsrichtung gemessen wird, kann nicht vorherbestimmt werden.

Aus den verschiedenen Rahmenbedingungen lässt sich nun auch ableiten, worauf sich das Verständnis der Physik - keine Information schneller als Lichtgeschwindigkeit bezieht. Nur über die passenden Einstellungen und den Vergleich der Ergebnisse aller Detektoren sind die richtigen von den falschen Informationen zu unterscheiden. Hierzu müsste Alice zeitgleich und damit instantan mit ihrer Information über die Messung bei Bob sein, was nach Einstein für Makrosysteme unmöglich ist. Dass ich etwas messe, gibt mir noch keine Information. Erst wenn diese Messung mit einer Bedeutung versehen werden kann, erhalte ich eine Information und die bekomme ich im Photonenexperiment erst, wenn die Messungen an den Detektoren in Beziehung gesetzt worden sind. Was bedeutet, dass Alice und Bob sich auf klassischem Weg austauschen müssen, was eben nur unter Einstein's Bedingung für Außenbeobachter funktioniert.

Zudem bleiben alle sonstigen möglichen Informationen, die das Gesamtsystem darüber hinaus in sich trägt, die aber nicht mit dem Messprozess und den Voreinstellungen übereinstimmen, verdeckt und unberücksichtigt. 


\section{Innen- statt Außenperspektive}

Bei den ursprünglichen Experimenten, bei denen es darum geht, verschränkte von klassischen Systemen zu unterscheiden, muss Alice ihre Einstellungen und ihre Messergebnisse mit Bob teilen, um sichere Information über das Experiment zu erhalten. Aus diesem Grund wird auch der klassische Kanal benötigt, auf dem diese Informationen ausgetauscht werden. Bei den neuen Anwendungen im Rahmen der Informationstechnologie, bei denen Information codiert und gesendet werden, bedarf es ebenfalls des Abgleichs der Messergebnisse, um die Zeichenfolgen richtig zu decodieren oder unerwünschte Lauschangriffe zu erkennen.

Anders sieht es innerhalb des verschränkten Systems selbst aus, also zwischen den Quarticle oder anderen Quantensystemen. Diese wissen, wie bereits ausgeführt, sehr wohl, welchen Zustand bzw. welche Information sie tragen oder repräsentieren. Damit führt ein Ereignis (z. B. Messung) bei einem der Subsysteme konsequenterweise schon zur vollständigen Information bei allen, da die Information über das Gesamtsystem verteilt ist. Weiß der Experimentator beispielsweise, dass das System nur durch Spin up und Spin down repräsentiert ist, so weiß er bei seiner Messung automatisch auch was bei den Kollegen vorliegt, wenn er selbst Spin down misst. Wenn jede Messung absolute Sicherheit und Klarheit darüber gibt, welcher Zustand bei den anderen Subsystemen vorliegt, wird noch nicht einmal ein außenstehender Beobachter ausgeschlossen. Bei genauerer Betrachtung ist dieser Beobachter aber doch nicht wirklich außenstehend, denn er muss Insiderwissen über mögliche Zustände des Systems besitzen. Da in unserem Fall doch wieder alle Beteiligten sich innerhalb des Systems bewegen, sind sie instantan in Verbindung mit allen Informationen und mithin nicht an die Vorgaben der Relativitätstheorie gebunden.

Die einzige Problematik, die sich deshalb noch stellt, ist die Interpretation der Information, die die Subsysteme aufnehmen. Da Zeilinger und seine Gruppe (Lapkiewicz u. a. 2011) nachwiesen, dass die Ergebnisse auch in der Quantenphysik immer kontextabhängig sind, bestimmt das einzelne Subsystem über die Interpretation der Information. Damit ist letztlich diese Interpretation von Wissen, Verständnis und Bezugsrahmen des Subsystems abhängig und kann folglich auch unterschiedlich ausgelegt werden. Interessanterweise findet sich die gleiche Aussage auch in der Systemtheorie und ebenfalls bei Weizsäcker und Görnitz wieder.

\section{Ergänzung}

Bei solcher Form der QT nimmt die Qualität der Verschränkung mit der Anzahl der Versuche ab bis sie schließlich völlig in sich zusammenbricht. Von Lucadou hat in seinem Modell der Pragmatischen Information (MPI) (siehe Kap. 4.2.2.9) darauf hingewiesen, dass bei wiederholter Verwendung der exakt gleichen Versuchsanordnung und des gleichen Effekts nicht-lokale Korrelationen verschwinden, da die Gesetze der Statistik verletzt werden. Dies gilt besonders für kleinzahlige Ensembles. Deshalb scheinen sich auch räumlich höherdimensionale (Krenn u. a. 2014) und vielfache, hyperverschränkte (Xie u. a. 2015) Zustände signifikant stabiler zu zeigen. 


\subsubsection{Strukturvergleich QT und SyA}

Führen wir uns jetzt die Experimente grafisch vor Augen und vergleichen sie mit der Struktur der SyA, so werden die Parallelitäten zwischen quantenphysikalischer und Aufstellungs-Konfiguration sichtbar. Eine Parallelität, die aufgrund der bisherigen Ergebnisse auf eine fundamentale Homologie schließen lässt.

\section{QT 1}

Wir betrachten nun die beiden Phasen Ia und Ib der Dissertations-Aufstellung von Schlötter:

Abb. 67 zeigt die Gegenüberstellung des Aufstellungssystems in Phase Ia (b) und in Phase Ib (c) der Dissertation von Schlötter im Vergleich zu einer klassischen QT mit 3 Quarticle (a).

In Bild (b) ist die Ausgangssituation skizziert, in der Schlötter mit den Klienten-Systemen Aufstellungen zur Erfassung der Ist-Situation vornahm (Phase Ia). In dieser Vorbereitungsphase wurden im direkten Kontakt zwischen Fallbringer und Facilitator (B) (= Aufstellungsleiter) das Anliegen, die Zielsetzung und die benötigten Systemelemente herausgearbeitet und anschließend wurde das System über Repräsentanten aus den Unternehmen im Raum gestellt. Da der Fallbringer in irgendeiner Form bereits mit dem System als Familienmitglied, Projektmitglied etc. verbunden ist (A), entspricht diese Vorgehensweise dem BSM (Bell-State-Measurement - Verschränkung zwischen Photon aus der EPR-Quelle und dem Teilchen mit dem unbekannten Ausgangszustand) im QTExperiment. Die gefundenen Plätze wurden kartographiert und die Aussagen aufgenommen und transkribiert.
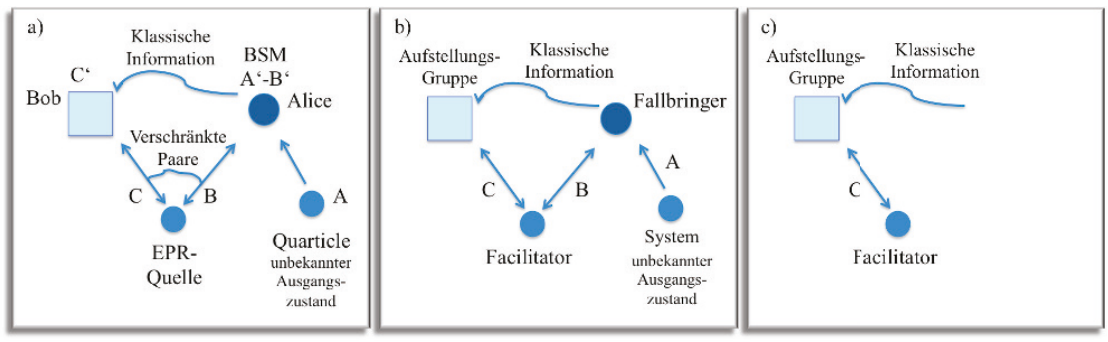

Abb. 67 | Gegenüberstellung QT und SyA in der Dissertation von Schlötter (eigene Darstellung). (a) zeigt die klassische 3-Teilchen-QT, (b) veranschaulicht die SyA zusammen mit den beteiligten Firmen zur Ermittlung der Ausgangssituation, Phase Ia, (c) veranschaulicht die Untersuchung zur Wiederholbarkeit der Wahrnehmungen während der Aufstellungen, Phase Ib.

In der Untersuchungsphase (Phase Ib) übernahmen dann zunächst Figuren die Positionen der in der Vorbereitung gefundenen Plätze der Systemelemente, um dann sukzessive durch Probanden ersetzt zu werden, die sich als Repräsentanten zur Verfügung stellten (Abb. 68). Fallbringer und Aufstellungsgruppe sind räumlich und zeitlich getrennt und 
nur über den Facilitator, der die Funktion der verschränkten Photonen übernimmt, verbunden, wie Alice und Bob, die ebenfalls räumlich getrennt und über die verschränkten Photonen verbunden sind. Aus diesem Grunde entspricht die Dissertations-Aufstellung zu $100 \%$ der Konfiguration einer QT.

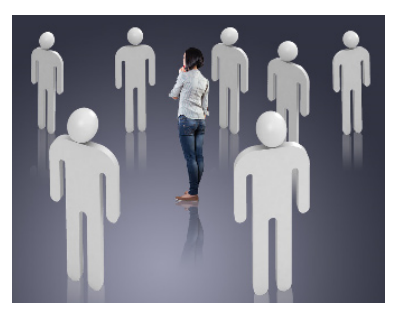

Abb. 68 | Testanordnung zur Überprüfung der ,repräsentierenden Wahrnehmung'

Schlötter ersetzt die Repräsentanten bei seiner Überprüfung durch personengroße Figuren. Die Versuchsteilnehmer stellen sich dann sukzessive auf die einzelnen Plätze und fühlen sich dort ein, nur noch umgeben von den Figuren. (eigene Darstellung)

Die bereits stehenden Figuren teilen die Art der Beziehung im und zum System mit, wodurch eine 'klassische Informationsübertragung' wie im QT-Experiment stattfand. Im Versuchsaufbau hatten diese Repräsentanten keine darüber hinausgehenden Informationen, also auch keine weiteren Interna über das System. Zudem ist der Fallbringer zum jetzigen Zeitpunkt nicht mehr anwesend. Die einzigen Verbindungen sind nur noch der Facilitator und die Repräsentanten. Der Facilitator entspricht jetzt der EPR-Quelle. Im nächsten Schritt werden die Repräsentanten durch den Facilitator auf ihre Positionen geführt, wobei er seine Hände auf die Schultern der Repräsentanten legt (C). Das Ganze findet in ruhiger, gesammelter Aufmerksamkeit statt. Dies entspricht der Verschränkung zwischen dem Photon und Bob und es entspricht dem von Neumann geforderten speziellen Bewusstseinszustand. Der Facilitator wechselt jetzt in die Rolle des Versuchsleiters und notiert nur noch die Wahrnehmungen und Interpretationen der Repräsentanten. Bei den Dissertations-Aufstellungen zeigt sich wie bereits beschrieben eine überragende Übereinstimmung der Wahrnehmung an den unterschiedlichen Plätzen.

\section{QT 2}

Nun zum Ablauf in einer klassischen SyA (siehe Abb. 69). In Phase I werden üblicherweise keine zwei Phasen unterschieden, außer man trennt zwischen Auswahl der Forschungsfrage und Auswahl der Systemelemente (I-A) und der ersten Aufstellung (I-B). In jedem Fall lassen sich immer wieder Phänomene beobachten, die sehr deutlich auf den QT-Mechanismus hinweisen. Unter bestimmten Umständen treten bei diesen normalen Aufstellungssettings Merkwürdigkeiten auf, die für die meisten Aufsteller selbst befremdlich sind. Noch während des Klärungsprozesses zwischen Fallbringer und Facilitator reagieren einzelne Gruppenmitglieder mit körperlichen und emotionalen Wahrnehmungen, obwohl sie eigentlich noch in der Zuhörerrolle sein sollten und noch nicht als Repräsentanten ausgewählt und an ihre Plätze geführt wurden. 


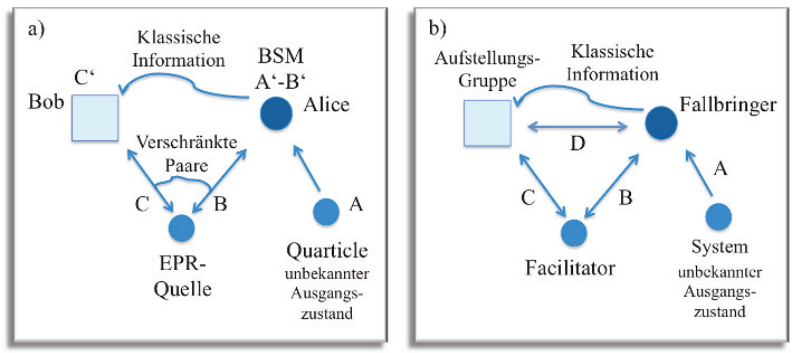

Abb. 69 | Gegenüberstellung QT und normale SyA

(a) zeigt die klassische 3-Teilchen-QT, (b) veranschaulicht die normale, klassische SyA. Fallbringer, Facilitator und Aufstellungsgruppe sind räumlich gleichzeitig anwesend (eigene Darstellung). Neben der (klassischen) Information über die Darstellung der räumlichen Zuordnung darf auch von einer Information mittels direkter Verschränkung zwischen Fallbringer und Aufstellungsgruppe ausgegangen werden.

Im Unterschied zur Dissertations-Aufstellung sind bei einer klassischen (normalen) SyA Fallbringer, Facilitator und Aufstellungsgruppe von Anfang bis Ende zusammen in einem Raum. Die Gruppe hört dem Vorgespräch (B) zwischen Fallbringer und Facilitator zu und bekommt auch mit, wie und wohin die Repräsentanten gestellt werden (klassische Information). Wenn wir davon ausgehen, dass sich Facilitator, Aufstellungsgruppe und Fallbringer noch nicht kennen, würde die Verschränkung (D) in Bild (b) spätestens dann stattfinden, wenn die ausgewählten Repräsentanten durch den Fallbringer an ihre Plätze geführt werden. Die Repräsentanten könnten jetzt die Information über die Verschränkung mit dem Fallbringer bekommen, der die Funktion der EPR-Quelle übernehmen kann.

Am Ende der ersten Aufstellung, wenn die Repräsentanten an ihre Plätze geführt wurden und erste Rückmeldungen gegeben haben, kann sich der Facilitator beim Fallbringer vergewissern, ob sie sich im richtigen System befinden. Dieses Vergewissern findet vor allem dann statt, wenn die Repräsentanten Irritationen zeigen oder Schwierigkeiten haben, zueinander passende Wahrnehmungen zu generieren. Dies entspricht genau dem Justierungsprozess im klassischen QT-Experiment. Die dabei durch den Fokus eingebrachte zusätzliche Information führt zu Anpassungsprozessen (Refokussierung) und die Aufstellungsgruppe wird arbeitsfähig, weil wieder maximal verschränkt für das zu untersuchende Thema.

Nun sind SyA üblicherweise keine 3-Quarticle-Systeme, auch wenn man einen Menschen als Quarticle definiert, sondern deutlich vielzahliger, womit eine GHZ-Anordnung eine geeignetere Darstellungsform bietet. Zudem entspricht die GHZ-Konfiguration in noch stärkerem Maße einer SyA.

In der Gegenüberstellung (Abb. 70) des strukturellen Aufbaus des GHZ 4-QuarticleExperiments (a) und der SyA (b) fällt die Ähnlichkeit ins Auge. Ein zu untersuchendes 
System A-B, das sich in der Regel aus mehreren Subsystemen zusammensetzt, wobei der Fallbringer ein Teil dieses Systems ist, teilt sich auf in Fallbringer B und , Rest' A.
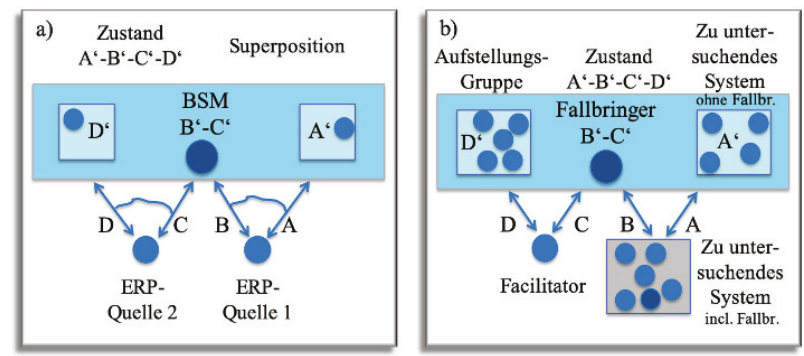

Abb. 70 | Struktur GHZ-Experiment für ein 4-Quarticle-System (a) und SyA (b)

(eigene Darstellung). Die Strukturen in der quantenphysikalischen Versuchsanordnung und der SyA sind direkt vergleichbar.

Fallbringer B und Facilitator $\mathrm{C}$ gehen dann üblicherweise in nahen und intensiven Kontakt, um das Ziel der Untersuchung und die aufzustellenden Elemente zu bestimmen. Nehmen wir nun wie bisher an, dass diese Nähe zu einer physikalischen Interaktion auf der subatomaren (Photon-, Elektron-, Atom- und Molekül-)Ebene führt, so kann man von einer Verschränkung im Sinne Erwin Schrödinger's sprechen (B'-C').

Diese physikalische Nähe ist üblicherweise auch für Fallbringer und zu untersuchendes System anzunehmen. Damit entspricht das zu untersuchende System einer EPRQuelle 1 von der zwei verschränkte Subsysteme A und B ausgehen. Der Facilitator entspricht einer EPR-Quelle 2 besonders dann, wenn er vorher schon in intensivem Kontakt mit den Mitgliedern der Aufstellungsgruppe (D') stand.

In letzterem Fall kommt es, wie bereits beschrieben, zu der immer wieder beobachtbaren Merkwürdigkeit, dass die Gruppenmitglieder ab dem Zeitpunkt des Kontaktes Facilitator mit Fallbringer (C'-B') Wahrnehmungen in Bezug auf Systemelemente und damit Subsysteme des zu untersuchenden Systems A' haben. Wenn man sich die Aufstellungsstruktur genau ansieht, wird deutlich, dass es noch einen gespiegelten QT-Prozess im Bild (b) zwischen Fallbringer-Facilitator-Aufstellungsgruppe geben kann. Die Merkwürdigkeit, dass einzelne Gruppenmitglieder bereits reagieren bevor sie ausgewählt und auf ihre Plätze geführt wurden, wird dann möglich, wenn eine Verschränkung zwischen Facilitator und Gruppenmitgliedern bereits im Vorfeld entstand. Und in der Tat ist dieses Phänomen häufig dann beobachtbar, wenn Facilitator und Repräsentanten sich gut kennen, oft zusammengearbeitet haben und alle sich gut auf die gesammelte Aufmerksamkeit einlassen können. Sie sind sozusagen schon mit Elementen der Aufstellungsthematik über den Facilitator verbunden/verschränkt und haben damit Zugang zum Herkunftssystem des Fokus. Dadurch kann gezeigt werden, dass es sich ebenfalls um eine QT handeln müsste. Würde die Vorstellung der Raumkoordinaten wirklich tragen, dürfte es dieses Phänomen nicht geben, womit dieser Erklärungsversuch tatsächlich hinfällig geworden ist. 
Tatsächlich ergibt sich neben der Verschränkung über die direkte Berührung und der damit verbundenen maximalen Interaktion der Körperfelder noch eine zweite Form der Verschränkungsmöglichkeit. Neben der Verschränkungsannahme, die ggf. schon länger zwischen $\mathrm{C}$ und D besteht, gibt es auch hierfür noch eine alternative Erklärung. Die Gesamtgruppe ist ab dem Zeitpunkt des Zusammentreffens zumindest schwach verschränkt, eben über Atem, Blick und Körperstrahlung.

Wir wissen, dass durch Einatmen von Bazillen Krankheiten übertragen werden, was in diesem Sinne nichts anderes als eine physikalische Verschränkung höherdimensionierter Entitäten darstellt. Genauso ist es unmöglich, ohne eine physikalische Interaktion jemanden zu sehen. Beim Sehvorgang besteht eine Interferenz von EM-Wellen bzw. Photonen, deren Repräsentanz im Gehirn einen Seheindruck vermittelt. Auch dies lässt sich als Verschränkung zweier physikalischer Systeme interpretieren.

Mit Beginn der Beschreibungen des Fallbringers findet eine Fokussierung und infolgedessen eine Maximierung der Verschränkungszustände statt. Die Ausrichtung auf ein Thema dekohäriert dieses und die damit verbundenen Entitäten und Zusammenhänge vom Umfeld, bei gleichzeitiger Kohärenzerhöhung zwischen den Entitäten. Dass diese Maximierung der Verschränkung durch einen eher mental getriebenen Prozess vollzogen wird, ergibt sich aus den Fällen, in denen völlige Blindaufstellungen erfolgen. Nur der Fallbringer weiß welches Thema bearbeitet wird und wer wofür steht. Da dieses Verfahren ebenfalls sehr gut funktioniert, auch für Themen, bei denen keiner der Gesamtgruppe mit den untersuchten Themen in direktem Kontakt steht, drängt sich sogar eine Kopplung über das Vakuumfeld auf. Damit bietet sich eine weitere Parallele zu rein physikalischen Experimenten an.

Spätestens wenn der Fallbringer die einzelnen Mitglieder der Aufstellungsgruppe an ihre Plätze führt (mittels Kontaktes der Hände auf den Schultern), kommt es zu weiteren körperlichen Interaktionen. Auch hier darf eine physikalische Interaktion auf der subatomaren Ebene angenommen werden, denn direkte Körperkontakte führen häufig, speziell bei unerfahrenen Repräsentanten, zu unmittelbaren deutlichen Verbesserungen der Wahrnehmung. Folglich sind sowohl Fallbringer als auch Facilitator und AufstellungsGruppe verschränkt, was in der Form B'-C'-D' zum Ausdruck gebracht werden soll. Aufgrund der ursprünglichen Verschränkung von zu untersuchendem System (A) und Fallbringer (B) liegt damit entsprechend dem GHZ-Theorem eine Verschränkung und Superposition über das Gesamtsystem A'-B'-C'-D' vor.

Entsprechend dem GHZ-Theorem ist deshalb davon auszugehen, dass die Informationen, die sich aus der Aufstellung und dem Lösungsbild ergeben, zeitgleich im nicht lokal vorhandenen ,Rest' des zu untersuchenden Systems existent sind. Diese Informationen müssen auch nicht mehr erst zu den Subsystemen auf klassischem Wege transportiert werden. Sprich, hier benötigt es keine explizite verbale oder nonverbale Kommunikation. Würde zeitgleich an allen Subsystemen eine Messung vorgenommen werden, müsste überall mit $100 \%$-iger Sicherheit die gleiche Informationslage gemessen werden können. 


\section{Zwischenresümee QT}

Verschränkung im Gesamtsystem und damit verbundene Kohärenz in der Aufstellungsgruppe stellen vermutlich die Hauptmechanismen der ersten Phase dar. In dieser Phase wird eine phänomenologische Diagnose vorgenommen, die durch Rückmeldungen des Fallbringers in vielen Fällen sofort und in manchen, wie bei den SyA in Kap. 3.3.3, erst später bestätigt wird.

Die Verschränkungs- und Informationsprozesse verlaufen bisher absolut identisch zu den QT-Experimenten. Da Schlötter und Andere (Kap. 3.3) wissenschaftlich nachweisen konnten, dass die Informationen, die in der Aufstellungsgruppe erscheinen, nicht von dieser gewusst werden konnten und gleichzeitig eine sehr hohe Signifikanz zum Kontext des untersuchten Systems aufwiesen und damit experimentell zweifelsfrei bestätigt wurden, kann es nur noch darum gehen, zu verstehen, wie diese Fakten zustande kommen. Die Interpretation über Raumsprache scheidet in diesen Fällen wie gezeigt wurde aus. Die klassische Physik kann ebenfalls keine Antworten liefern im Gegensatz zur Quantenphysik. Bei Letzterer liegen gut erforschte und beschriebene Mechanismen vor, die in vollem Umfang auf die vorliegenden Phänomene zutreffen.

\section{Parallelen zum Quanten-Computing in der Übergangs- und Lösungsfindungs-Phase}

Nachdem in der Phase I herausgearbeitet bzw. sichtbar wurde, wie sich die Situation im untersuchten System darstellen könnte, wird mit der Übergangsphase (Phase II) begonnen, in der Suchprozesse stattfinden. Der Übergang in die finale Lösungsphase (Phase III) findet dabei meist kontinuierlich statt.

Die Arbeitsweise während der SyA und damit die Intention wird Richtung einer Lösung verändert, die zu Beginn vom Fallbringer formuliert wurde. In der Aufstellung werden verschiedene Möglichkeiten durchgespielt, wobei die Repräsentanten versuchen durch Wahrnehmen von Impulsen, die jeweils mit ,besser' oder ,schlechter' bewertet werden, ein Lösungsbild zu generieren. Die Repräsentanten müssen keine Idee oder gar ein Wissen von den Lösungsoptionen haben. Gesucht wird eine Lösung, die für alle Repräsentanten ein gutes Gefühl auf ihren Plätzen vermittelt. Lösungen auch für sehr komplexe und/oder unbekannte Herausforderungen sind üblicherweise innerhalb weniger Minuten bis nicht viel länger als eine Stunde gefunden.

Auf den ersten Blick scheint der Prozess analog zu dem Rechenprozess eines herkömmlichen Computers mit ja/nein (0/1) Antworten zu laufen. Tatsächlich gibt es aber alle Möglichkeiten dazwischen: ein bisschen mehr, ein bisschen weniger, ja - aber, unter den und den Bedingungen. Bei genauer Betrachtung lassen sich all die Möglichkeiten finden, die in Verbindung mit den beim Quantum-Computing beschriebenen Qubits definierbar sind. Die Logik dahinter entspricht dem Herausfiltern einer Lösung, die am besten für das betroffene System geeignet ist. Während des Suchprozesses sind zahlreiche Superpositionen an Möglichkeiten vorhanden, von denen auf die richtige Antwort heruntergerechnet wird. Görnitz schreibt mit Bezug auf Rechenprozesse im QuantenComputer: ,, dass während des Rechenprozesses keine Fakten entstehen dürfen. Erst am Ende der Berechnung wird eine Messung durchgeführt, die dann-allerdings nur mit 
einer gewissen Wahrscheinlichkeit - ein richtiges Ergebnis liefert “ (Görnitz und Görnitz 2009: 113). Diese Messung am Ende entspricht dem Abschlussbild, mit dem die SyA beendet wird.

Die Aufstellungsgruppe ist in der Lage in extrem kurzer Zeit sehr komplexe und verdeckte Sachverhalte zu analysieren und Lösungsansätze zu entwickeln, die weit über das Potential und Wissen der einzelnen Repräsentanten hinausgehen. So lassen sich beispielsweise Strategie- oder Marketingfragen innerhalb weniger Stunden beantworten, wofür eine klassische Vorgehensweise Wochen und Monate benötigen würde - bei gleich gutem oder besserem Ergebnis, wie Praxiserfahrungen ${ }^{184}$ gezeigt haben. Menschen und soziale Systeme sind scheinbar in der Lage Lösungen zu generieren, die nicht deterministisch vorgegeben sind und weit über die Einzelkompetenzen hinausgehen.

Dabei wird nicht logisch-rational gearbeitet, was dem klassischen Computer entspricht, sondern parallel mit allen Möglichkeiten gleichzeitig, entsprechend den Superpositionen zwischen den Qubits im Quanten-Computer. Erst bei Zwischenabfragen/messungen entstehen kurzzeitig Fakten (schwache Quantenmessung), die eine Orientierung, aber noch kein finales Ergebnis darstellen, wohl aber eine Veränderung der Informationslage. Eine erneute Refokussierung nach den Abfragen verbessert wieder die Wahrnehmungsfähigkeit der Repräsentanten. Das für die Zukunft leitende Ergebnis/Faktum entsteht erst am Ende des Gesamtprozesses im Abschlussbild.

\section{Dekohärenz, QT 3 und Quanten-Zeno-Effekt}

Mit dem Abschlussbild ist der Möglichkeitsraum auf der Ebene der Ideen und Vorstellungen fixiert (in der KI: zum Faktum kollabiert; in der Dekohärenz-Theorie: ausreichend separiert, unterscheidbar und eigenständig geworden) und das Ende der Lösungsphase (Phase III) erreicht. In der Regel geht zu diesem Zeitpunkt der Fallbringer selbst in die Aufstellung, um das Abschlussbild zu erleben. Die Repräsentanten gehen wieder in ihre eigene Rolle zurück, durch Fokussierung auf sich selbst und damit wieder in einen dekohärenten Zustand.

Solange die Repräsentanten in der SyA in der gleichen gesammelten Aufmerksamkeit waren, hat sich die Aufstellungsgruppe im Gleichklang befunden (Kohärenz) und jedes Element konnte so kleinste Veränderungen im System wahrnehmen, was nach der abschließenden Individualisierung nicht mehr möglich ist. Dass es immer wieder vorkommt, dass Repräsentanten Schwierigkeiten haben aus der Rolle heraus zu gehen und dabei das Gefühl haben, noch mit Teilen aus der Rolle verbunden zu sein, weist ebenfalls auf den quantenmechanischen Effekt der Verschränkung hin. Durch die Interaktion mit dem repräsentierten Systemelement sind sie nicht mehr wie vorher eigenständig, sondern in einem verschränkteren, gemeinsamen Zustand.

Im Organisationskontext findet direkt im Anschluss der SyA meist eine Überprüfung der Ergebnisse und Überlegungen statt, wie diese in den Alltag transferiert werden können. Auf kognitiver Ebene erfolgt eine Nacharbeitung der Ergebnisse. Damit ergibt sich

${ }^{184}$ Bei den Praxiserfahrungen handelt es sich um verschiedene Rückmeldungen von Kollegen und Mitgliedern meiner Experimentiergruppe. 
eine vollständige, homologe Verbindung zwischen den Empfehlungen aus der Entscheidungstheorie und dem 5-Phasen-Modell in Kap. 3.2.4.: Sich 1. mit dem Thema, den Zielen, Kontext, Intention etc. bewusst befassen, 2. unbewusst sammeln, 3. intuitive Impulse wahrnehmen und 4. kognitive Prüfung.

In der Realisierungsphase IV (die Zeit danach) zeigt sich nun das dritte Phänomen, das auf die QT hinweist: Erstaunlich häufig kann im direkten Anschluss an eine SyA ein signifikant verändertes Verhalten von Personen wahrgenommen werden, die der Aufstellung nicht beigewohnt haben und sich tatsächlich räumlich weit weg befanden. Beispiele hierfür sind ,Kontaktaufnahme' nach Jahren und Jahrzehnten, $180^{\circ}$-Drehung, was die eigene Haltung zu einem Thema betrifft, überraschendes Entgegenkommen, was bisher unvorstellbar war. Wenn die QT aus Phase I, II und III die richtige Beschreibung des dahinter liegenden Mechanismus ist, ergibt sich jetzt die zwingende Schlussfolgerung, dass wieder eine QT vorliegt, jetzt nur in umgekehrter Richtung. Von der Aufstellungsgruppe ,fließt' die Information des Abschlussbildes via Verschränkung zurück zum Ursprungssystem. ,Spooky action' zum Dritten. Mit dieser ,Rück-Teleportation' ins nicht anwesende Ursprungssystem werden ebenfalls die Erkenntnisse von GHZ bestätigt.

Ein letzter Bezug zur Quantenmechanik: Besonders in Familienaufstellungen hat sich als hilfreich erwiesen, das Lösungsbild wirken zu lassen und nicht ständig zu schauen, ob sich schon etwas getan hat. Es geht darum, das ,Unzufriedenstellende der Ausgangssituation' loszulassen. Sowohl in Familien als auch in Teams und Organisationen ist es sinnvoll den Fokus auf das Lösungsbild, die Neuausrichtung zu legen. Ständige Beobachtung des ,Alten' wird den gewünschten Veränderungsprozess Richtung Lösungsbild verlangsamen. Hier ist eine deutliche Parallele zum Quantum-Zeno-Effekt zu beobachten. Also der Effekt, dass unter ständiger Beobachtung die Prozesse (z. B. radioaktiver Zerfall) zum Stillstand gebracht werden können. Loslassen des Alten und Fokussierung auf das Neue vermeidet der Quanten-Zeno-Effekt auch in sozialen Systemen, so zumindest die These.

\section{Realisierungswahrscheinlichkeit von Aufstellungen}

Gerne wird die Effektivität von Aufstellungen in Bezug auf ihre Wirkung in der realen Umwelt als Maß für die Glaubwürdigkeit der Methode herangezogen und untersucht. Dass dieser Ansatz tatsächlich an der falschen Seite der Problemstellung, Glaubwürdigkeit' ansetzt, wird mit folgender Überlegung deutlich:

Nach einer Aufstellung ist natürlich nicht gesichert, dass alle in der Aufstellung eingebundenen Subsysteme über eine beliebig lange Zeit ungestört bleiben. Wie zu Recht in der Quantenphysik angenommen wird, finden in unserer Makrowelt ständig physikalische Interaktionen von System und Umwelt statt. Zeh formuliert deshalb, dass Verschränkungen den normalen Zustand für unseren Lebensraum darstellen und das Vermeiden einer solchen, die zentrale Herausforderung für die Experimente bedeutet. 
Störungen durch lokale andere Einflüsse (z. B. Kontakte) bei einem der beteiligten Subsysteme im Anschluss bedeuten in unserem Fall also eine sofortige weitere Überlagerung mit anderen Informationen und Intentionen. Diese können die Ergebnisse der Aufstellung natürlich verwässern, verändern oder ganz aufheben. Genau aus diesem Grund kann nicht mit einer 100 \%-igen Manifestation des Aufstellungsergebnisses in der uns wahrnehmbaren Realität gerechnet werden. Hier macht die in der Quantenphysik typische Wahrscheinlichkeitsaussage wieder Sinn.

Wahrscheinlichkeitserhöhend scheint der Grad der Intensität und Emotionalität des Fallbringers zu sein, was aber in entsprechenden Untersuchungen noch fundiert werden müsste.

Als weiteres Hindernis für eine 1:1-Realisierung darf die Erkenntnis aus der Intuitionsforschung angesehen werden, bei der erkannt wurde, dass die unterbewusste Information und Intention mit den Zielen und Vorlieben des Empfängers korrelieren müssen, wollen sie sich erfolgreich realisieren. Auch hier muss eine relativierende Wirkung angenommen werden.

Relevanter für Glaubwürdigkeit von SyA und Intuition erscheint insofern eher eine Übereinstimmung mit dem Ist-Zustand, wie es Schlötter untersuchte und was einer phänomenologischen Diagnose entspricht.

\subsubsection{Conclusio aus der quantenphysikalischen Annäherung}

Quintessenz aus der physikalischen Betrachtung

Die Experimente und Erkenntnisse in der neueren Physik weisen nicht nur auf eine Überwindung lange Zeit aufrechterhaltener Paradigmen hin. Vielmehr existiert eine vollständige Übereinstimmung mit physikalischen Modellen der jüngeren Zeit:

1. Es lässt sich ein vollständiger, in sich geschlossener Prozess vom Quantenvakuum bis hin zum Kosmos beschreiben und mit Übergangsmechanismen versehen. Lebende Systeme bilden darin eine spezifische Entität, die ohne Brüche der Gesetzmäßigkeiten interpretierbar sein sollte.

2. Das zu untersuchende System, die Messapparatur und der Beobachter sind zwingend miteinander verschränkt, weshalb Messungen vom Beobachter abhängen und es keine objektiven Ergebnisse geben kann.

3. Kein heute existierender Messprozess vermag alle im System vorhandenen Informationen abzurufen. Deshalb liefert jede Messung nur ganz spezielle Ergebnisse und letztlich immer nur einen unvollständigen Satz an Informationen, aber nie alles.

4. Ergebnisse unterliegen immer einer Interpretation, weshalb sich objektive Resultate verbieten.

5. In unserer Welt existieren auch Situationen, die wir als eine Steuerung der Vergangenheit ansehen können und damit Korrelationen in die Vergangenheit hinein existieren. 
6. Schwache Quanten-Messungen vernichten keine Überlagerung und verändern deshalb keinen Quantenzustand nachhaltig oder lassen ihn gar ganz zusammenbrechen.

7. Schwache Überlagerungen lassen sich zu vollständigen Überlagerungen und damit zu maximaler Verschränkung modifizieren.

8. Die Nicht-Lokalität in jedem klassischen Zustand ist in verborgener Weise vorhanden und damit erscheinen klassische Objekte nur vordergründig klassisch.

Dass diese Beschreibungen nicht nur auf Quantensysteme und damit auf mikroskopische Dimensionen zu projizieren sind, wird von Penrose sehr deutlich formuliert (Penrose 2009: 218). Er weist darauf hin, dass die Quantenwelt die Ursache für die für uns sichtbare klassische Welt darstellt und somit mit dieser in Wechselwirkung tritt.

\section{Schlussfolgerungen aus der QT und dem GHZ-Theorem}

„Im Zusammenhang mit dem GHZ-Theorem lassen sich folgende wesentliche Aussagen beschreiben, die in analoger Weise auch für SyA zutreffen:

- Es handelt sich um Mehrteilchensysteme und damit um Quantenfelder.

- Im Gesamtaufbau liegen gleichzeitig Mix-Zustände von Quanten- und klassischen Systemen vor.

- Es braucht keinen zusätzlichen klassischen Informationskanal.

- Sicherzustellen ist nur der Akt der Verschränkung zwischen den Subsystemen.

- Die Verschränkung bricht nach der Messung nicht zusammen, sondern bildet über alle Subsysteme eine Superposition aus und liegt instantan im gesamten System vor - zumindest solange keine Störung von außen erfolgt.

- Teleportiert wird auch die Verschränkung selbst.

- Die Interpretation der Information hängt vom Beobachter ab und kann nicht als kontext-unabhängig angesehen werden. " (Gehlert 2014)

Sowohl im GHZ-Experiment als auch bei SyA zeigen sich Phänomene, die über unsere normale klassische Vorstellung und unser scheinbares Zeiterleben hinausgehen. Sie befinden sich jedoch in vollständiger Übereinstimmung mit unserem Wissen über die Quantenwelt. Insofern erscheint die Vermutung richtig, dass die Quantenphysik in keiner Weise counter-intuitiv ist, sondern unser bisheriges Verständnis bzw. unsere Interpretationen nur ein solches vermittelt.

Damit sind auch Antworten auf das quantenphysikalische Messproblem mit einem möglichen Kollaps der Superposition, der Übertragungsproblematik ,nichts ist schneller als Licht' und der Interpretation von Informationen in einer Weise beantwortet, dass sie keine Relevanz mehr - im Sinne von Einschränkung - für die Experimente und ihre Ergebnisse aufweisen.

Im Grunde repräsentieren GHZ-Experimente beliebige vielteilige Quantenfelder. Gehen wir jetzt weiter davon aus, dass Lebewesen aufgrund ihrer metastabilen EM-Bauweise 
ihrer Basiselemente (Atome, Moleküle, Synapsen ...) makroskopische Quantenfelder darstellen, die wiederum miteinander interagieren, so lässt sich die Funktionsweise von SyA analog dazu in Beziehung setzen. Alle derzeit beobachteten Phänomene im Rahmen von Aufstellungen ließen sich nachvollziehbar erklären und das auf dem Boden der Naturwissenschaften (vgl. Gehlert 2014).

Bei SyA benötigt man aufgrund der GHZ-Modalitäten zudem keine Bell-Statistik, sondern nur den Abgleich zwischen Fallbringer und Repräsentanten. Der Fallbringer kann sofort erkennen, ob eine Verschränkung vorliegt, indem die Wahrnehmungen mit seinem Erleben oder seinem Kenntnisstand übereinstimmen. Als dritter Abgleich darf die Überprüfung der Ergebnisse der Aufstellung im Realitätscheck, z. B. bei technischen Geräten in der Werkstatt, angesehen werden. Exakt diese Bedingungen lagen bei allen den erstaunlichen Beispielen in Kap. 3.3.3 vor.

\section{Übertragung auf die Interaktion zwischen Menschen}

Aus den Verschränkungs-Experimenten ${ }^{185}$ wurde deutlich, dass mit Zunahme der Dimensionalität, also der räumlichen Ausdehnung, und mit der Zunahme unterschiedlicher Zustände die Stabilität der Kohärenz von Quantensystemen gegenüber Umwelteinflüssen zunimmt. Zum Zweiten wurde von den Forschern ebenfalls herausgearbeitet, dass mit Zunahme der internen Wechselwirkungen ein System sich ebenfalls gegen äußere Einflüsse immer besser zu schützen vermag. Übertragen wir diese physikalischen Vorgaben auf Lebewesen, so lassen sich alle drei Vorgaben direkt auf sie anwenden. Sie sind räumlich höherdimensional ausgebreitet, besitzen eine Überlagerung von unendlich vielen unterschiedlichen Zuständen und weisen eine höhere innere Wechselwirkung auf als gegenüber dem Umfeld, da sie sich ansonsten auflösen würden.

Daraus abgeleitet lassen sich zumindest zwei Möglichkeiten der physikalischen Interaktion darstellen. Zum einen sind biochemischen Prozesse im menschlichen Körper EM-Natur, die sich über den gesamten Körper ausdehnen und die nicht an der Körpergrenze enden. Dies begründet die Annahme, dass Interaktionen zwischen Menschen bei räumlicher Nähe oder körperlichem Kontakt mit physikalischen Reaktionen einhergehen und damit zu den gleichen Verschränkungen führen, wie sie auf subatomarer Ebene erforscht sind (siehe Abb. 71).

Experimentell ließen sich bisher indirekte beobachtbare Kohärenzen bei Menschen bzw. bei Kopplungen zwischen Menschen und technischen Geräten nachweisen (Kap. 3.2.3 Entscheidungstheorie, Kap. 3.3.2 und 3.3.3 SyA, Kap. 4.1.3 Intuitionsforschung).

Solche indirekten Messungen stehen durchaus im Einklang mit physikalischen Experimenten, denn auch dort sind viele Zustände nur indirekt messbar. Die Verschränkungsexperimente zeigen sehr deutlich die Möglichkeit einer Wechselwirkung zwischen Untersuchungsobjekt - Messapparatur - Beobachter und seinem Bewusstsein.

\footnotetext{
${ }^{185}$ Die folgenden Inhalte sind im Wesentlichen übernommen aus (Gehlert 2015a).
} 


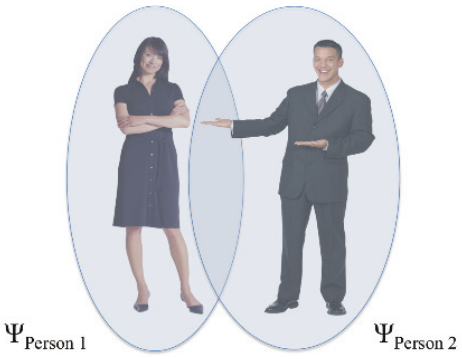

Abb. 71 Physikalischer Kontakt über Körperkontakt, Energiefelder oder Photonen-Emission (eigene Darstellung).

Diese Interaktionen sind physikalisch mit dem Compton-Effekt bzw. Doppler-Effekt (Kap. 8.1.2) beschreibbar, die dann automatisch eine Verschränkung der betroffenen Systeme nach sich ziehen. Gleichzeitig ist damit eine Ausdehnung von der Quantenmechanik zur Quantenfeldtheorie verbunden, da wir es jetzt nicht mehr mit kleinzahligen Quarticle zu tun haben. Abb. 72 zeigt die Ausdehnung von $\Psi$ von der Mikro- zur Makrowelt.

Nach der Logik der Quantenphysik repräsentiert ein von einem Gesamtsystem abgegebenes Teilsystem die $\Psi$-Funktion des Gesamtsystems, da es mit diesem verschränkt ist. Also repräsentiert die $\Psi$-Funktion eines Quarticle, das von einem System abgeben wird, die $\Psi$-Funktion dieses Systems, analog zum Versuchsaufbau von Wigner's Freund und der GHZ-Konfiguration.

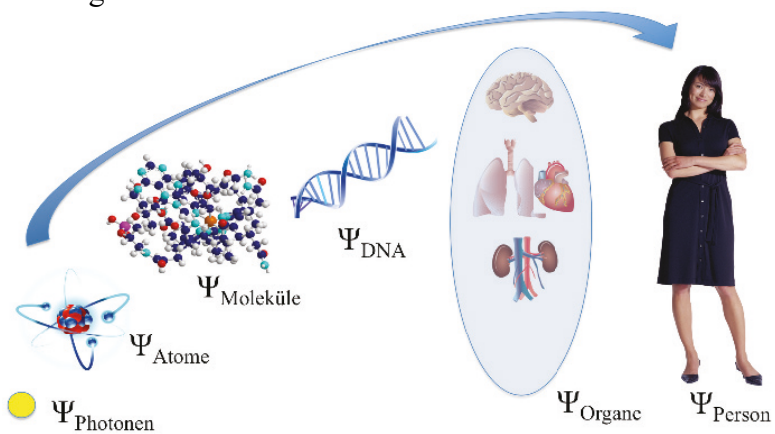

Abb. $72 \mid$ Ausdehnung von $\Psi$ von der Mikro- zur Makrowelt

(eigene Darstellung). Mit der gleichen Logik mit der $\Psi$ bis zu Milliarden-Ensembles ausgedehnt wurde, wird es jetzt bis zum Gesamtsystem Mensch erweitert. Auf jeder Stufe beschreiben die $\Psi$-Funktionen das jeweilige System vollständig.

Selbiges gilt konsequenterweise auch für die abstrahlenden EM-Wellen. Unter bestimmten Voraussetzungen kann nun die Möglichkeit angenommen werden, dass sich zwischen den anwesenden Personen eine Kohärenz der Wellenfunktionen aufbaut, bei dem das Gesamtsystem dann eine gemeinsame Wellenfunktion bildet und so durch die 
Superposition aller Teilnehmer die Informationen des Fallbringers auch den anderen Anwesenden zur Verfügung stehen. Die resultierende Wellenfunktion lässt sich dann beschreiben durch:

$$
\Psi_{S y A}(\vec{x}, \mathrm{t})=\sum_{\mathrm{i}=1}^{\mathrm{n}} \mathrm{c}_{\mathrm{i}} \Psi_{\mathrm{i}}(\overrightarrow{\mathrm{x}}, \mathrm{t})
$$

Mit $\Psi_{\mathrm{i}}(\overrightarrow{\mathrm{x}}, \mathrm{t})$ als Wellenfunktion aller einzelnen beteiligten Personen i am Ortsvektor $\mathrm{x}$ zum Zeitpunkt t. In der Quantenphysik ist allerdings zu berücksichtigen, dass es sich zunächst nur um Wahrscheinlichkeiten (Kopenhagener Interpretation) bzw. um Möglichkeiten (Everett - Bohm) handelt, die erst durch Messung zum Faktum werden. Aus diesem Grund ändern sich die Schreibweise und die Bedeutung ihrer Komponenten:

$$
\left|\Psi_{\text {SyA }}\right\rangle=\sum_{\mathrm{i}=1}^{\mathrm{n}} \mathrm{c}_{\mathrm{i}}\left|\Psi_{\mathrm{i}}\right\rangle
$$

Der Gesamtzustand $\left|\Psi_{S y A}\right\rangle$ wird durch die Überlagerung seiner Einzelzustände $\left|\Psi_{\mathrm{i}}\right\rangle$ beschrieben, mit $c_{i}$ als komplexe Wahrscheinlichkeitsamplitude. Befinden sich diese $\mathrm{Zu}-$ stände über ihrem Grundzustand, werden sie gemeinhin auch als ,Erregungszustände' (excitation state oder excited state) bezeichnet. Analog zur Physik gilt auch in der Kommunikation zwischen sozialen Systemen, dass diese umso besser gelingt, je ähnlicher sich ihre Erregungszustände gestalten. In der Kommunikation und Therapie spricht man dann davon, sich auf die gleiche Wellenlänge zu begeben. Auch hier findet sich somit sogar eine wortwörtliche Parallele zwischen Physik und Psychologie, die vermutlich ebenfalls nicht zufällig, sondern einer sehr guten Intuition entsprungen ist. Denn auch die Interferenz von Wellen gelingt um so besser, je ähnlicher ihre Frequenzen und damit ihre Erregungszustände sind.

Selbst bei Unterschieden in den $\Psi$-Funktionen, sogenannte Potential-Barrieren, gibt es durch den Josephson-Effekt die Möglichkeit diese Barrieren zu überwinden. In seiner verallgemeinerten Form ist er auf zwei makroskopische Wellenfunktionen, die schwach miteinander gekoppelt sind, übertragen worden.

Die einzige Schwierigkeit diesen Formalismus tatsächlich anzuwenden, besteht im direkten Handling dieser physikalischen Größe $\Psi$ für psycho-soziale Systeme. Auch wenn wir sie in der Neudefinition entsprechend erweitert haben, wird sie üblicherweise nur mit Zahlen aus der physikalischen Welt gespeist. Der Vollständigkeit halber müssten mathematische Wege gefunden werden, die auch psychologische und biologische Informationen in diese Form bringen. Tatsächlich erscheint das heute nicht mehr unmöglich, lernen ja bereits Computer Gefühle von Menschen zu erkennen und adäquat darauf zu reagieren.

Nachdem unter Physikern nach wie vor die Frage diskutiert wird, inwieweit die Wellenfunktion real und damit auch mit einer tatsächlichen Welle gleichgesetzt werden kann, scheint mit der Neu-Definition diese Diskrepanz beantwortet zu sein. In jedem Fall bildet sich der mathematische Formalismus in der konkreten Welt ab und lässt die Wellenfunktion als physikalisch reale Größe erscheinen. In Anbetracht der praktischen Ergebnisse wie sie sowohl in den quantenphysikalischen als auch bei den oben aufgeführten Untersuchungen zur Entscheidungstheorie- und Intuitionsforschung vorliegen und sich bei der SyA zeigen, scheint mir dieser Rückschluss nicht allzu gewagt. Unter- 
stützt wird diese Annahme von Veröffentlichungen der letzten Jahre, die sowohl Möglichkeiten kohärenter als auch deterministischer Informationsübertragung über weite Distanzen in unserem normalen Umfeld erzeugen und nachweisen konnten. Diese neuen QT-Verfahren zeigen Wege auf, in denen QT auch ohne eine klassische, direkte Verschränkung funktioniert. Neben diesen Verfahren, die Informationsübertragung mittels Verschränkung über große Distanzen, als auch lokal über kohärente Wellenfelder ermöglicht, existieren auch quantenphysikalische Modelle und Experimente, die eine scheinbare zeitliche Rückbezüglichkeit in die Vergangenheit demonstrieren. Damit wird ein Phänomen erklärbar, das bei SyA ebenfalls zu beobachten ist, wenn Aufstellungsergebnisse von der Aufstellungsgruppe wieder zurück ins Originalsystem gespiegelt oder besser transportiert werden. Die heutigen Kenntnisse in der Quantenphysik sind soweit fortgeschritten, dass weder ein Zusammenbruch der Verschränkung und der damit verbundenen Informationen noch eine irreversible Dekohärenz nötig werden. Im Gegenteil sind Verfahren entwickelt und verifiziert worden, die ein beliebiges An- und Ausschalten von Verschränkungszuständen realisieren und das bei beliebigen Umweltbedingungen.

Zur Vervollständigung werden jetzt noch Experimente und Theorien gesucht, die direkte Wechselwirkungen und damit Kohärenz- und Verschränkungs-Effekte auch in biologischen Systemen bestätigen. Als Konsequenz würden sich dann die hier geschlussfolgerten Zusammenhänge und Modelle als belastbar erweisen.

\section{Das Messproblem und seine Konsequenzen}

Zusammenfassend wirft die Beschäftigung mit dem ,Messproblem` vier zentrale Klassen von Fragestellungen auf, die deutlich machen, wie schwierig es ist, ein sofort und allgemeingültiges Ergebnis aus Beobachtungen abzuleiten:

Messproblem 1 Welchen Heisenberg-Schnitt wähle ich? Welche System-Umwelt-Relation ist für meine Beobachtung die relevante und welche Systemgrenze ziehe ich damit?

Die Wahl dieses Schnittes bestimmt meine Theorie und umgekehrt und hat Einfluss auf die Interpretation meiner Messergebnisse. Bleibe ich auf der Ebene der Elementarteilchen oder wage ich mich auf die Ebene lebender Systeme? Eine solch veränderte Perspektive erweitert auch die Wahrnehmung und hat schließlich Auswirkungen auf Theoriebildung und experimentelle Ansätze und Ergebnisse. Im Idealfall entsteht eine konsistente Theory of Everything (ToE) wie sie der Physik schon seit Anfang des 20. Jahrhundert vorschwebt, jetzt allerdings ausgedehnt auf alle Ebenen unserer Umwelt und des Lebens.

Messproblem 2 Wie interpretiere ich die Ergebnisse - klassisch oder als Überlagerung und was hat alles Einfluss?

Gehe ich also von einer Separierung und Eigenständigkeit oder von Wechselwirkungen respektive von unsichtbaren Einflüssen und Kor- 
relationen aus? Im ersten Fall nehme ich an, dass die Eigenschaft oder das was sich messen und beobachten lässt ausschließlich im untersuchten System steckt. Im zweiten Fall ist mir bewusst, dass das was sich zeigt nur meiner Messanordnung, meiner Frage bzw. Intention und meiner Fähigkeit zur Interpretation geschuldet ist.

Messproblem 3 Wann entsteht das was sich zeigt? War es schon vor der Messung vorhanden oder ist es erst durch die Messung entstanden und realisiert worden? Oder ist es gar beides?

Im ersten Fall können wir von phänomenologischen Voraussetzungen ausgehen. Es zeigt sich etwas, was schon vor der Untersuchung existent war. Wir entdecken es nur wieder. Im zweiten Fall konstruieren wir das Ergebnis, ausgehend von unseren Fähigkeiten und Vorstellungen. Das, was sich zeigt, hat im Extremfall nichts mit der Ausgangssituation zu tun - was dem konstruktivistischen Prinzip entsprechen würde. Schließich, im dritten Fall, nehmen wir etwas auf, was schon vorhanden ist oder noch etwas weitergedacht, wir filtern ,Etwas' aus dem Meer aller Möglichkeiten heraus. Es ist ,Etwas' da, auf das wir aufbauen. Durch unsere Fähigkeiten, Vorstellungen und Erwartungen modellieren wir es jedoch innerhalb unserer Grenzen. Im dritten Fall hätten wir eine Überlagerung von Phänomenologie und Konstruktivismus.

Messproblem 4 Wie gehen wir mit dem ,Heisenbergschen Unbestimmtheits-Prinzip' um? Konzentrieren wir uns auf die Details oder fokussieren wir auf das große Ganze?

Nach diesem Prinzip kann ich nicht gleichzeitig präzise den Ort eines Atoms und eines damit wechselwirkenden Elektrons bestimmen. Bestimme ich exakt den Ort des Atoms bleibt die exakte Position des Elektrons unbestimmt und vice versa. Zur Übertragung und Veranschaulichung bietet sich gut die hierarchische Gliederung der Wissenschaftstheorien von Tegmark und Wheeler an. Konzentrieren wir uns auf die Mikroebene und damit auf Quantenfeldtheorie und allgemeine Relativitätstheorie und messen dort, verlieren wir Informationen über den Menschen und sein soziales Verhalten als Ganzes. Für solche Informationen und Messungen sind Psychologie und Soziologie zuständig. Konzentrieren wir uns auf Letztere, gehen die Information im Mikrokosmos verloren. Was gewinnen und was verlieren wir, abhängig von unserer Wahl? Beides gleichzeitig geht nicht - wie das ,Heisenbergsche Unbestimmtheits-Prinzip' lehrt! Messproblem 4 handelt letztlich auch von der Systemgrenze in Bezug auf die Wissenschaftsgebiete und ihren Theorien.

Zeilinger und seine Gruppe schlossen ihre Veröffentlichung mit einem Statement, dem wohl aus psychologischer und soziologischer Perspektive nichts mehr hinzuzufügen ist: 
„According to Wheeler, Bohr said that no elementary phenomenon is a phenomenon until it is a registered phenomenon. We would like to extend this by saying that some registered phenomena do not have a meaning unless they are put in relationship with other registered phenomena " (Ma u. a. 2012b: 483).

Die in Bezug auf die Quantenphysik aufgeworfenen prinzipiellen Fragen ,Was messen wir eigentlich und wann treten die Messergebnisse in unsere Realität?' scheinen zumindest für SyA und Intuition in dieser Arbeit beantwortbar zu sein. Sie treten in unsere Realität, in dem Moment, in dem wir eine Intention und eine damit verbundene Frage stellen bzw. unser inneres System (Bewusstsein) offen für Wahrnehmungen ist. Dies darf durchaus in einem inneren, auch unterbewussten Kontakt mit unterschiedlichen Entitäten geschehen. Und es geschieht wie bei einem guten Therapeuten: Dieser ist sich seines eigenen Zustandes bewusst und er vermag deshalb Störungen wahrzunehmen, sie als Unterschied zu interpretieren und auch einem Gegenüber zuzuordnen. Nichts anders passiert bei SyA.

Mit der sehr leichten Beeinflussbarkeit solcher Messprozesse wird allerdings auch ein Thema evident: Die Versuchsbeteiligten vermögen die Ergebnisse nachhaltig zu beeinflussen. Dies wurde auch bei den Beispielen zu den SyA in Kap. 3.3.3 offensichtlich. Mit den bisher erkannten Zusammenhängen wird damit auch plausibel, dass alle Experimente und Messungen, bei denen Menschen beteiligt sind einem teilweise erheblichen Bias unterliegen. Dies könnte auch die Uneinheitlichkeit der Forschungsergebnisse bei Entscheidungstheorie und Intuitionsforschung erklären. Die Erwartungshaltung, die sich auch in der Psi-Funktion ausdrückt, erscheint konsequenterweise auch im Messergebnis.

Gut übertragbar erscheint dieser Zusammenhang auch auf die in den Sozialwissenschaften verwendete Terminologie , Intersubjektivität'. Dieser neue Begriff verdeutlicht zwar die subjektive Interpretation der Ergebnisse, läuft jedoch Gefahr, durch den damit verbundenen Eindruck einer großen Menge, eine Scheinobjektivität durch die Hintertüre wieder einzuführen. Denn allein kulturelle Prägungen führen wieder zu scheinbar objektiven, letztlich aber nur kollegialen intersubjektiven Eindrücken.

\section{$\underline{\text { Fazit }}$}

In den bisherigen Untersuchungen wurde eine kontinuierliche Entwicklung vom Vakuumfeld bis in den Kosmos gezogen. Auf diesem Weg vom ,Nichts' zum Universum wurde deutlich, wie sich Information in Energie und weiter in Stoff (Materie) wandelt. Qubits realisiert durch Spins und Spinpolarisationen kreieren innere und äußere Strukturen und üben an den Phasengrenzen Einfluss auf angrenzende Entitäten aus; Entitäten, die sich durch weitere Ausdifferenzierung immer mehr voneinander unterscheiden und auch raum-zeitlich voneinander trennen. Entitäten, die scheinbar getrennt (dekohärent), unter der Oberfläche letztlich aber doch quantenphysikalisch verschränkt und kohärent bleiben. Diese Verschränkung auf Elementarebene ermöglicht einen nicht-lokalen Einfluss auf alles im Kosmos befindliche, solange eine ausreichende Interferenzfähigkeit besteht, was bedeutet, dass es Freiheitsgrade zwischen interagierenden Systemen geben 
muss, die in Wechselwirkung treten können. Kleinste Quanten (Unterschiede) verändern Spins und damit letztlich EM-Wellen. Diese Spin- bzw. Wellenänderungen repräsentieren eine zugängliche Information, von der die empfangene Entität entscheidet, ob dies für sie eine relevante Information darstellt. Beim jetzigen Stand der Untersuchung führen die Erklärungen allerdings nur bis zu scheinbar automatischen Wechselwirkungen, bei denen wir üblicherweise nicht von Entscheidungen ausgehen, sondern von in den Entitäten angelegten Potentialitäten. Überwunden ist die Reduzierung auf Energie, denn auch ein (bewusster) Beobachter muss mitbetrachtet werden. Des Weiteren wird nicht mehr nur von Spinrichtungen, sondern auch Strukturen und Formen ausgegangen, die gespeichert, abgerufen und wiedererkannt werden können.

Verschiedene Forscher, die für Verständnissprünge in der Geschichte der Wissenschaft gesorgt haben, wie beispielsweise Wiener (Kap. 4.2.2.6) oder Josephson (Josephson und Pallikari-Viras 1991: 204-205), denken diesen Prozess der Entwicklung jedoch weiter. Sie gehen davon aus, dass alle lebenden Formen diesen Prinzipien unterliegen. Damit lässt sich bezogen auf Entscheidungen folgende Entwicklung annehmen: Entscheidungen, die auf Elementarebene vermutlich automatisch, in höher entwickelten Entitäten zunächst unbewusst und bei noch höher entwickelten Entitäten dann unbewusst und schließlich bewusst wahrgenommen und vollzogen werden.

Offen sind damit zwei Fragen:

1. Woher wissen Bosonen, Fermionen und die sich daraus entwickelnden größeren Strukturen was sie konstituieren sollen?

2. Wie und wo lässt sich die angenommene Entwicklung vom Automatischen über das Unbewusste hin zum Bewussten nachvollziehen?

Frage 1 scheint derzeit nur spekulativ philosophisch beantwortbar und tangiert auch spirituelle Verständnisse. Frage 2 wird im nächsten Kapitel untersucht.

Mit den bisherigen Ergebnissen sind fast alle Unterkategorien zur Hauptkategorie ,Übertragungswege“ positiv beantwortet. Es konnte der Nachweis ,lokaler und nichtlokaler' Informationsübertragung in normalen Umweltbedingungen und zwischen Makrosystemen erbracht werden. Dazu bedarf es eines ,Verschränkungsprozesses ', welcher ebenfalls für Makrosysteme in normalen Umgebungstemperaturen vielseitig realisierbar ist, und schließlich veranschaulichte das ,Messproblem“ die zwingende Einbindung des Beobachters in die quantenphysikalische Gleichung. Bisher spricht nichts gegen die Möglichkeit quantenphysikalisch basierter Informationsübertragung.

Zusammen mit der eindeutigen und plausibel nachgewiesenen Existenz intuitiver Methoden aus Kap. 3 sowie deren notwendiger Berücksichtigung bei komplexen Entscheidungsprozessen könnte der Eindruck einer ausreichenden , wissenschaftlichen Legitimation' entstehen.

Tatsächlich aber hat sich am grundlegenden Problem der Nicht-Akzeptanz, einer auf Quantenphysik beruhenden Informationsübertragung, noch nicht viel geändert. Nicht nur, weil die theoretischen Konzepte von Wiener, Weizsäcker und Görnitz oder der 
GQT (Kap. 4.2) in der physikalischen Gemeinschaft nicht ausreichend anerkannt werden. Auch nicht, weil der aktuelle Stand der Quantenphysik sowohl in der Physik als auch außerhalb noch nicht ausreichend bekannt ist. Sondern weil es derzeit noch erhebliche Zweifel an der Existenz quantenphysikalischer Prozesse in biologischen Systemen und damit verbundener Informationsübertragungen gibt, die über den Austausch von Energie hinausgehen.

Somit ist alleine die Unterkategorie ,zwischen lebenden Systemen' noch offen und damit die Frage nach der Art und Weise von Entscheidungsprozessen auf dieser Ebene.

Zur Vervollständigung werden deshalb jetzt Experimente und Theorien gesucht, die Kohärenz- und damit Verschränkungs-Effekte auch in biologischen Systemen wie Pflanzen, Tiere und Mensch bestätigen; idealerweise auch Phänomene, die Informationsübertragung und Entscheidungsprozesse mit beinhalten. Nur dann würden sich als Konsequenzen die hier geschlussfolgerten Zusammenhänge und Modelle als belastbar erweisen. Sie würden auch die im Tao der Physik (Capra 2000) beschriebenen Ideen bestätigen.

\subsection{Biologische Systeme und Physik}

Eine Brücke zwischen toter Materie und Mensch sowie Informationsübertragung und Entscheidungen auf biologischer Ebene

Mit den folgenden Untersuchungen und Schlussfolgerungen werden Antworten und Modelle für die aus der Codierung hervorgegangene Kategorie, Übertragungswege zwischen lebenden Systemen' entwickelt und gleichzeitig Säule 8 , Überwindung des Temperatur-Paradigmas' gefestigt und Säule 9 , Überwindung des Makrosystem-Paradigmas' unterlegt.

Greenstein und Zajonc bezogen sich auf Bohr, als sie im Rahmen der Welle-TeilchenDiskussion formulierten: „Mental pictures draw their elements from our sense world, but nothing like the quantum world has ever appeared to our senses " (Greenstein und Zajonc 2005: 20). Sie schlagen mit ihrer Sicht eine quanten-klassische Brücke, die im allgemeinen Verständnis jedoch schon ausgeblendet wird, wenn sich die kognitive Funktion der Wahrnehmung auf rein physikalische Informationsverarbeitung reduziert, wie in Kap. 3.2.3 bereits vorgestellt (Pfister u. a. 2016: 7). Wie es auch Al-Khalili und McFadden beschreiben, wird dort ausschließlich akzeptiert, dass wir nur physikalische Signale wahrnehmen, ohne diesen jedoch eine weitere Bedeutung zuzusprechen (AlKhalili und McFadden 2015: 23).

Es besteht somit keine Frage, ob es Interaktionen auf der EM- und Quantenebene gibt, wohl aber, welche Form von Information da eigentlich vermittelt wird. Relevant ist vor allem, ob sich quantenphysikalisches Verhalten über relevante Zeiträume in normalen Umgebungsbedingungen und in biologischen Lebensformen zeigt, denn nur dann 
sind die Gesetze der Quantenwelt auch auf makroskopische Dimensionen und normale Lebensbedingungen übertragbar. Deshalb entscheidet sich an dieser Schnittstelle, ob die Voraussetzung, Information mittels Quantenprozessen zugänglich zu machen, eine realistische Modellierung liefert und sich gegen kritische Bewertung behaupten kann. Denn die folgenden Bemerkungen stehen stellvertretend für die verbreitete Sichtweise: „, Quanteneffekte hätten in der Biologie eine ungefähr ebenso wichtige Rolle wie für das Funktionieren einer Dampfmaschine: Sie sind immer da, aber mehr oder weniger bedeutungslos, wenn man verstehen will, wie eines dieser Systeme funktioniert" (AlKhalili und McFadden 2015: 119). In diesem Fall formulierten die Autoren die gängigen Einwände, hier bezogen auf Enzyme, die quantenphysikalische Tunneleffekte zeigen.

Mit dem Thema Biophysik betreten wir ein Feld, das erst in den letzten Jahren für einen kleinen Teil der Physiker und für interdisziplinäre Forschungsgruppen quantenphysikalische Relevanz bekam. Es handelt sich um einen Teilbereich der sogenannten offenen Quantensysteme, der Quantenbiologie und Quantenchemie. Im Grunde stellt die Quanten-Teleportation über den freien Raum, wie sie Zeilinger praktiziert, einen Hybridzustand dar, der als Übergangsbereich zwischen der normalen Quantenphysik und offenen Quantensystemen anzusehen ist. Die Verhältnisse in lebenden Systemen sind für Forscher noch eine Spur komplizierter. Eine eindeutige Isolierung und Messbarkeit quantenphysikalischer Effekte, wie sie heute von Forschern angestrebt wird, ist dort bisher nur schwer möglich. Der Grund liegt im ständigen Energieverbrauch lebender Systeme und dem Problem sie so zu isolieren, dass eine eindeutige Messung möglich wird, wie es in Kap. 8.1.2.3 (Heiße Verschränkung und offene Quantensysteme) bereits kurz angerissen wurde. Aus diesem Grund haben wir es hier auch mit nicht-trivialen Quantensystemen zu tun.

Betrachten wir die Gesetze der Quantenmechanik genauer, so können wir feststellen, dass alle bio-molekularen Strukturen durch sie bestimmt werden. Die sich daraus ergebenden Formen der Moleküle und ihre biologische Funktion stehen wiederum in engem Zusammenhang und führen zu Theorien der Molekularbiologie (Küblbeck und Müller 2007: 8). Dennoch gibt es eine verbreitete Meinung, quasi ein Paradigma, die es als unwahrscheinlich ansieht, so etwas wie quantenmechanische Prozesse und Interferenzphänomene in lebenden Systemen beobachten zu können. Ein wesentlicher Grund dafür liegt in den energetischen, ständig aktiven Umweltbedingungen, wonach es zu einer vermuteten sofortigen Störung und in der Folge zur Dekohärenz kommen muss. Einer Dekohärenz, die quantenmechanische Superposition ausschließt und nur noch klassische Prozesse zulässt. Im Grunde steht die Forschung in der Biologie an einer ähnlichen Stelle wie die Physik kurz vor der Entdeckung des Quants. Es gibt sehr viele Fragen, die heute noch nicht oder noch nicht eindeutig beantwortet werden können. Solche, wie die Frage nach der Entstehung von Mutationen.

Wie im Kapitel zu Verschränkung und Dekohärenz bereits ausgeführt, kennen die Forscher mittlerweile Theorien und Möglichkeiten, wie stabile Verschränkungen unter Störeinflüssen bestehen können und wie sich solche umweltinduzierten, kohärenzzerstörenden Einflüsse auch wieder rückgängig machen lassen. In diesem Verständnis be- 
sitzen thermische Nicht-Gleichgewichtszustände, wie sie lebende Organismen darstellen, wesentlich größere Möglichkeiten Kohärenz und Verschränkung stabil zu halten (Guerreschi u. a. 2012: 3) als bisher angenommen. Zurückgeführt werden diese größeren Quanten-Freiheitsgrade auf das Verhältnis der Schwingung lebender Organismen in Bezug auf ihre Umgebungstemperatur. Denn jeder Organismus hat eine spezielle EM Eigenfrequenz und molekulare Schwingung, mit deren Hilfe der Organismus seine Beziehung zu seinem Umfeld bestimmt. Diese Gegebenheit wird im Weiteren näher beleuchtet

Bereits Schrödinger betrachtete Lebewesen eher als Phänomene, die den Gesetzen der Quantenphysik unterliegen anstatt den Gesetzen der klassischen Physik. Schrödinger formulierte demnach auch ein zur Thermodynamik gegenläufiges Modell, wonach die Grundlage der Vererbung, Ordnung aus Ordnung' sei (Al-Khalili und McFadden 2015: 67-68). Enge geordnete Beziehungen und damit Wechselwirkungen, so scheint es, helfen eine Verschränkung zu konstituieren, die sich als relativ robust gegen Störeinflüsse erweisen kann (siehe auch Kap. 8.1.2). Die ständigen Energietransfers in thermischen Nicht-Gleichgewichtszuständen wiederum scheinen als Fehlerkorrekturprozess $\mathrm{zu}$ fungieren.

Lässt sich nun auch experimentell zeigen, dass die Natur Mittel und Wege gefunden hat, quantenmechanische Phänomene zu nutzen oder gar ihre Prozesse darauf aufzubauen, wäre das eben beschriebene Paradigma - keine Quantenprozesse in lebenden Organismen - widerlegt und unsere 9. Säule bestätigt. Gleichzeitig wäre die von den Forschern aus Jena, im Rahmen ihrer klassischen Verschränkungsexperimente (Kap. 8.1.2.3) angedachte ,hybride' Infrastruktur zwischen klassischer und quantischer Kommunikation von der Natur selbst realisiert.

Auf den folgenden Seiten werden stellvertretend für ausgewählte Lebensformen Beispiele untersucht, die Hinweise auf solche Quanteninformationsprozesse liefern können. Vor allem sollen nicht nur energetische, sondern auch qualitative Informationsübertragungen ermittelt werden, denn nur sie widerlegen die klassischen Vorstellungen. Gleichzeitig würde deutlich, dass die Physik im Bereich des Lebendigen Einzug gehalten hat und nicht nur für tote Stoffe eine Rolle spielt. Bei Fels finden sich hierzu weitere umfangreiche Recherchen (Fels u. a. 2015).

\subsubsection{Biophysik bei Mikroorganismen und Pflanzen}

\subsubsection{Delokalisierung von Protonen in Enzymen}

Enzyme sind in sehr unterschiedlichen Proteinstrukturen aufgebaut, die ihre Spezialisierung verursachen. Diese Proteinstrukturen sind für chemische Transformationen zuständig. Forscher identifizierten nun eine quantenphysikalische Delokalisierung von Protonen innerhalb von Netzwerken von Wasserstoffverbindungen solcher Proteinstrukturen, was die Lebensdauer bestimmter Isotope dramatisch stabilisiert (Wang u. a. 2014). Eine solche Delokalisation bedeutet eine quantenphysikalische Superposition 
über relevante Zeiträume. Damit wurde das Verhalten von Protonen in biologischen Systemen in Bezug auf Wasserstoffbindungen verständlich. Dass diese Kohärenz und damit Superposition durch die Umgebungstemperaturen sogar gestützt, statt behindert werden, wurde ebenfalls nachgewiesen (Godbeer u. a. 2014).

Passend zu diesen Erkenntnissen werden Enzyme als die Motoren des Lebendigen angesehen, von denen sich in jeder Zelle unseres Körpers Hunderte oder sogar Tausende solcher Molekülmaschinen befinden sollen (vgl. Al-Khalili und McFadden 2015: 76). Die Autoren stellen auch heraus, dass die gängigen Erklärungsmodelle für ihrer Wirkungsweise nicht mit den beobachtbaren Reaktionszeiten übereinstimmen und dies nur mit einem quantenphysikalischen Tunneleffekt erklärbar sei (ebd. 100-101).

\section{$\underline{\text { Homologe Verbindung zur Physik }}$}

Hier findet sich eine erste quantenphysikalische Superposition in Mikroorganismen, die mehrere Zustände gleichzeitig repräsentiert und nicht sofort in einen der möglichen $\mathrm{Zu}$ stände dekohäriert. Deutlich wird auch die Wirkung von veränderten Oberflächenstrukturen auf Eigenschaften von Entitäten, in diesem Fall der Position der Protonen, vergleichbar den im Kap. 8.1.1.4 vorgestellten Spinwirbel in zweidimensionalen Oberflächen (Abb. 47). Und schließlich lassen sich auch Tunneleffekte beobachten, die den Enzymen ihre schnelle Arbeitsweise ermöglichen.

\subsubsection{Quantenphysik in Bakterien und Algen}

Die Geschichte zur Untersuchung der Photosynthese ${ }^{186}$ läuft bereits seit 1949, wie Fleming in seiner aktuellen Veröffentlichung darlegt (Fleming 2017). Dennoch gehen wesentliche Arbeiten der jüngeren Zeit auf Fleming (Engel u. a. 2007; Lee u. a. 2007) und seine Mitarbeiter zurück. 2007 haben zwei Teams von ihm erstmals den experimentellen Beweis geliefert, dass bei der Photosynthese im Green sulphur bacteria und beim Rhodobacter sphaeroides bacteria zum einen eine klare Kohärenz von angeregten Zuständen und zum anderen Tunneleffekte zu beobachten waren, bis hin zu Raumtemperatur (Malý u. a. 2016; Panitchayangkoon u. a. 2010). Andere Forschergruppen bestätigten diese Ergebnisse auch für andere Spezies (Hildner u. a. 2013; Collini u. a. 2010). Die Reaktionszentren der Antennen bilden dabei Energiefallen, die die eingefangene Lichtenergie nutzen, um $\mathrm{CO}_{2}$ (Kohlenstoffdioxid) in Biomasse (Kohlehydrate) umzuwandeln. Der Speicher der Energie und damit auch der transportierten Information sind die Moleküle und ihre chemischen Bindungen. Beobachtet werden konnte eine schwache Kopplung der Moleküle durch elektronische und vibrierende Zustände. Damit finden wir auf biologischer Ebene die im Kap. 8.1.2.3 beschriebenen Verschränkungen von Photon-AtomPhoton sowie der damit verbundenen Möglichkeiten wieder.

Sie gestalteten dazu einen Versuchsaufbau, bei dem sie die Moleküle mit einem Laser anregten und die Erregungszustände (Exzitons) bei ihrer Kohärenz-Dynamik bis in den Reaktionscenter des Bakteriums direkt visualisierten. Beobachtbar waren lang andau-

${ }^{186}$ Dieses Kap. 8.2.1.2 ist in großen Teilen übernommen aus (Gehlert 2015b). 
ernde Kohärenzen (>660 fs) zwischen angeregten Elektronenzuständen über den gesamten Lichtsammelkomplex hinweg. Die Forscher führten das Beobachtbare auf den Einfluss beteiligter Proteine zurück, da durch diese Zellbewegungen realisiert werden. Proteinmoleküle werden heute als die Art von Umfeld angesehen, in der Verschränkung sehr gut möglich ist.

In Abb. 73 ist das Geschehen, das die Teams von Fleming beobachteten, veranschaulicht. Photonen treffen auf wenige Nanometer große Ansammlungen von Proteinen, den sogenannten Lichtsammelkomplexen oder Antennen.

Nach dem konventionellen Verständnis wird die Energie der Photonen dann von Molekül zu Molekül weitergereicht. Zu erwarten wären ungleichmäßige Sprungbewegungen. Der Weg, der gewählt wird, ist dabei rein zufällig. Die Forscher beobachteten aber etwas ganz anderes und beschreiben es folgendermaßen: Die Energie des Photons wird ultraschnell $\left(10^{-12}\right.$ Sek. $=$ billionste Sekunde $)$ in wellenartiger, kohärenter Bewegung an das Reaktionszentrum weitergeleitet. Dabei werden viele Farbträger gleichzeitig angestoßen. Aus Sicht der Forscher ein eindeutig quantenmechanisches Verhalten. Wie beim Doppelspaltexperiment löschen sich die Wellen aus oder verstärken sich. Die Photonen scheinen gemäß den Gesetzen der Quantenmechanik verschiedene Wege gleichzeitig zu gehen. $95 \%$ der ursprünglichen Energie kommt im Zentrum an, nur $5 \%$ gehen in Form von Wärme verloren. Dies entspricht aus ihrer Sicht keinem normalen molekularen Prozess, sondern nur einem quantenmechanischen Tunneleffekt. All diese Beobachtungen erfolgten bei Umgebungstemperatur.

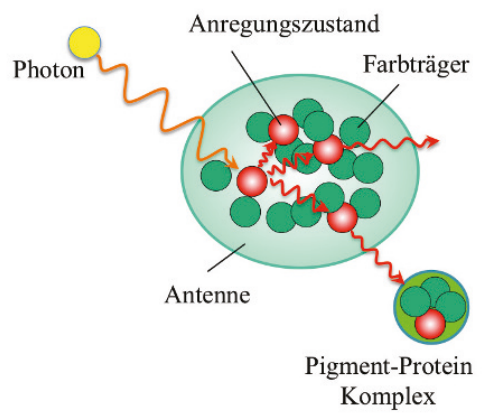

Abb. 73 | Erste Schritte im Lichtsammelkomplex von Bakterien während der Photosynthese (eigene Darstellung in Anlehnung an (Chin u. a. 2013: 114)). Gezeigt wird das Auftreffen eines Photons auf den Lichtsammelkomplex, der sogenannten Antenne eines Bakteriums, von wo die Energie des Photons wellenartig und ohne Energieverlust auf alle Farbträger gleichzeitig weitergeleitet wird.

Die Gruppe von Plenio veröffentlichte hierfür ein quantenphysikalisches Erklärungsmodell in Nature (Chin u. a. 2013). Ihr Kerngedanke ist die gleichmäßige Vibration bestimmter Proteine innerhalb eines verrauschten Umfelds. Damit halten sie die Energie innerhalb ihres Systems am Fließen und grenzen sich gleichzeitig von ihrem Umfeld ab. Neuere Veröffentlichungen diskutieren aktuell, ob die Vibrationen tatsächlich einen quantenphysikalischen oder doch nur einen klassischen Ursprung haben (Duan u. a. 
2017). Festzuhalten bleibt dennoch, dass die Vibration für eine ultraschnelle Verteilung der eingefangenen Energie sorgt und das gleichzeitig für unterschiedliche Verarbeitungszentren. Mit der Existenz von quantenphysikalischer und klassischer Verschränkung scheint, wie in Kap. 8.1.2 gezeigt, der Unterschied nicht wirklich ausschlaggebend zu sein.

Ringsmuth u. a. stellten einen Zusammenhang zum Wirkmechanismus für molekulare Netzwerke her (Ringsmuth u. a. 2012). Das räumliche Ausmaß an Kohärenz scheint bei großen molekularen Verbünden und Umgebungstemperatur von den EM Verhältnissen (den Frequenzen) abzuhängen und nicht von den thermischen Zuständen, wie üblicherweise vermutet wird. Sind diese Frequenzen durch eine uneinheitliche Frequenzlandschaft gestört, lösen sich die Kohärenzen sehr schnell auf und dekohärieren, wie Dostál u. a. (2012) zeigen konnten.

Plenio (wie auch andere) (Chin u. a. 2013) kommen damit zu einem ähnlichen Schluss: Die Natur hat einen Weg gefunden, über den sie hocheffizienten Energietransport innerhalb lebender Systeme realisiert und der nicht als kontinuierlicher Prozess von einem Molekül zum anderen zu interpretieren ist. Der bisher übliche Ansatz, dass es aufgrund der Nähe zu anderen Systemen sofort zu Interaktionen und damit Dekohärenzen kommt, ist auch hier nicht mehr zu halten. Plenio's Gruppe vermutet aufgrund von Modellrechnungen sogar, dass bei zu großer Kohärenz der Energietransport wieder schlechter wird. Aus ihrer Sicht ist ,, an interplay between creation of entanglement for short distances and times (through coherent interaction) followed by the destruction of entanglement for longer distance and times (through dephasing noise) seems to be necessary for optimal transport " (Caruso u. a. 2010). Ebenfalls deutlich wurde bei ihnen die Reversibilität des Austausches der Energiequanten sowie eine Ladungstrennung, welche von den spezifischen Schwingungen der Farbmoleküle herrührt und von Proteingerüsten, die ein breitbandiges Hintergrundrauschen unterstützen.

Die Kohärenz erstreckt sich wohl nicht nur auf sehr eng begrenze Areale innerhalb des Lichtsammelkomplexes, sondern, entsprechend einer Modellrechnung (Sarovar u. a. 2010), über den gesamten Lichtsammelkomplex und alle Moleküle hinweg. Dies wird im Kap. 8.3 Neurowissenschaften noch relevant.

Goldbeter u. a. konnten ergänzend dazu zeigen, dass nicht nur Vibrationen, resultierend von einem elektrischen Ursprung, stabil und großflächig robust sein können, sondern auch solche, die allein aus einem biochemischen Ursprung herrühren (Goldbeter u. a. 2012). Aus ihrer Sicht handelt es sich um Vibrationen, die aufgrund von Feedbackschleifen aus den regulierenden Netzwerken entstehen, ausgelöst durch Zell-zu-ZellKommunikation mittels Austausch verschiedener Elemente. Ihrer Ansicht nach werden durch den gemeinsamen Rhythmus gemeinsame Eigenschaften geteilt. Damit liegt sogar aus biochemischer Sicht eine Kohärenz vor, die wesentlich für ein zeit- und energieeffizientes Verhalten ist sowie für eine auf das Gesamtsystem aufgespannte Information. Eine Sicht, die wohl auch Duan teilt (siehe oben). Zudem besitzt der Zellrhythmus weitere Funktionen, wie z. B. die Fähigkeit des Encodierens von Frequenzen und der damit transportierten Information. Das Encodieren der Amplituden und damit der Intensität spielt auch aus Sicht von Goldbeter nur eine untergeordnete Rolle. 
Die Entscheidung, wie viel Lichtenergie aufgenommen werden soll, treffen solche Antennen offensichtlich nicht zufällig. Die ersten Erkenntnisse dazu wurden 2009 veröffentlicht (Calhoun u. a. 2009). Sie konnten in vivo nachweisen, dass photosynthetische Komplexe ihre strukturelle Anpassung und damit ihre Energielandschaft verändern. Die damit verbundene Funktionsänderung ermöglicht eine effiziente Übertragung der Energie bei schlechten Lichtverhältnissen und ein Ableiten überschüssiger Energie bei guten. Gruber und seine Kollegen identifizierten diesen Mechanismus, der die Aufnahme abhängig von Umweltbedingungen reguliert (Gruber u. a. 2016), nun sehr präzise. Zur Vermeidung von Energieverschwendung findet ein Kontrollmechanismus durch Untereinheiten statt, der von der Einstrahlungsintensität angeregt, die Aufnahme von Photonen reversibel begrenzt. Mittlerweile weiß man, dass dieser Mechanismus nicht nur in Bakterien und Algen vorkommt, sondern in allen höheren Pflanzen, so auch in Spinat (Al-Khalili und McFadden 2015: 157).

Auf den ersten Blick erscheint dies wie eine normale energieabhängige Ab- und Anschaltung. Auf den zweiten Blick wird deutlich, dass hier Qubits repräsentiert werden, mit Superpositionen von Möglichkeiten. Und bei einem dritten Blick wird deutlich, dass es sich um eine Entscheidungssituation handelt, die durch Abgleich unterschiedlicher Konfigurationen ausgelöst wird. Die Antenne besitzt also gespeicherte Information zu unterschiedlichen Situationen, die durch bestimmte Anregungszustände (Anordnung von Molekülkonfigurationen und deren schwankende Aktivierungspotentiale) repräsentiert sind. Gleichzeitig liegt offensichtlich auch eine qualitativ bewertete Situation vor, was bedeutet, dass je nach Situation die Antennen auf eine der Varianten zurückgreifen, um effizient zu arbeiten oder das Gesamtsystem energetisch zu schützen bzw. gar das Überleben zu sichern.

In einem umgekehrten Kontext, bei fluoreszierenden Proteinen, ergaben neueste Forschungen ein Zusammenspiel zwischen quantenphysikalischem und klassischem Prozess (Armengol u. a. 2018). Eine entsprechende Kombination von Aktivitäten erwies sich dort als relevant für das Strahlungsverhalten. Es drängt sich damit der Eindruck auf, dass die Natur, je nach Bedarf und Situation, ganz unterschiedliche Prozesse nutzt und kombiniert und keinesfalls nur auf eine Variante festgelegt ist.

\section{$\underline{\text { Homologe Verbindung zur Physik }}$}

Die anfangs genannten Exzitons sind bekannt aus Halbleitern, Isolatoren und Kristallen. Dort bilden sie gekoppelte Elektronen-Loch-Paare, die als virtuelle Quarticle Anregungszustände, also Energie, durch ihre Hostsysteme transportieren. Dabei bewegen sie sich immer gemeinsam und in Form einer (Polarisations-)Welle durch das System. Sie entstehen beispielsweise durch die oben beschriebene Absorption von Photonen unter Wechselwirkung mit Elektronen. Die Elektronen werden angeregt, verändern dadurch ihre Position und hinterlassen ein entgegengesetzt geladenes Loch. In der klassischen Physik wird die dabei wirkende Kraft mit der Coulomb-Kraft beschrieben, die räumlich weitreichend wirkt. Verständlicherweise besteht in analoger Form eine quantenmechanische Erklärung. Diese stabile Elektron-Loch-Verschränkung lässt sich als Analogie 
zu den Cooper-Paaren genauso wie zu den NV-Defekten in Diamanten interpretieren. Alle drei Korrelationen repräsentieren Verschränkungszustände und Energietransport ohne Energieverlust und damit ohne Wechselwirkung mit ihrem Umfeld. Abgeleitet aus den quantenphysikalischen Überlegungen darf hier von einer klassischen Verschränkung ausgegangen werden, die neben Energie auch Informationen trägt, womit ein Pendant für Verschränkungszustände in Mikroorganismen besteht.

Darüber hinaus vermag selbsterzeugtes Licht von Zellen in gleicher Weise Information zu übertragen, wie es moduliertes Licht in physikalischen Experimenten vollführt. Ebenfalls redundant zeigt sich das Phänomen reversibler Prozesse, in denen Übergänge von Energiequanten auch wieder rückgängig gemacht werden. Diese Übergänge gehen gleichzeitig einher mit einer Photon-Atom-Photon-Kopplung, die, wie nachgewiesen, zum Austausch und zur Speicherung von Quanteninformation in der Lage ist. Gespeicherte Information, die zwischen unterschiedlichen Umweltbedingungen unterscheidet und entsprechende Entscheidungen respektive Verhaltensweisen auslöst.

Der von den Forschern erkannte Zusammenbruch der Kohärenzen bei uneinheitlichen Frequenzregionen führt im Umkehrschluss auf das gleiche Phänomen wie bei den Phasenübergängen der reinen Physik. Zöpfe, Bänder oder einheitliche, größere Frequenzregionen wie beim Silikonöl bilden stabile und klar unterscheidbare Übergänge, die eine Kohärenz innerhalb des Systems aufrechterhalten. Auffallend ist auch die Parallelität von Proteingerüst (mit spezifischer Eigenfrequenz) und Hintergrundrauschen bzw. den wellengleichen Ausbreitungsbewegungen mit den Versuchen an den Fullerenen. Einerseits handelt es sich in beiden Fällen um Farbmoleküle, zum anderen wurden bei den Fullerenen ebenfalls Zellstrukturen zur Erzeugung kohärenter Wellen verwendet, die sich vom Hintergrund unterscheiden lassen. Und schließlich zeigen sich auch hier Kohärenzen bei Umgebungstemperatur. Alles weist auf eine fundamentale Homologie hin.

\subsubsection{Informationsübertragung per Licht auf Zellebene}

Wie es aussieht, bietet die ,klassische Verschränkung' mithilfe von Licht tatsächlich eine auch experimentell überprüfbare Option. Wie bereits vorgestellt, ließ sich mithilfe kohärenten Laserlichts und den dabei beeinflussten Spins extremste Geschwindigkeitsmessungen von Objekten durchführen. Aus diesen Experimenten leitete man die Möglichkeit sogenannter, klassischer Verschränkungen' ab. Eine Verschränkung also, die nur lokal realisierbar ist. Dass die dabei vorkommende Informationskopplung nicht nur für räumliche Gegenstände funktioniert, sondern auch für andere Informationsarten, machen die folgenden Experimente deutlich.

Trushin beschäftigte sich mit der Frage, inwieweit biologische Strahlung Informationen trägt, die die Zellkommunikation und verschiedene Aspekte ihres Lebens betreffen (Trushin 2003). Kolibakterien wurden in verschiedenen Nährböden gezüchtet und durch eine klare Glaswand getrennt (Abb. 74). 


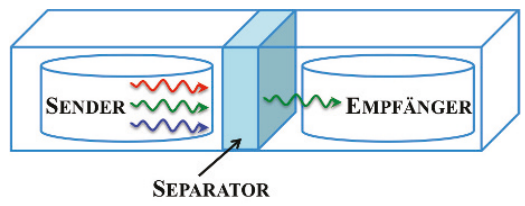

Abb. 74 | Typischer Versuchsaufbau zur Messung physikalischer Signale zwischen biologischen Systemen wie Zellen, Bakterien oder auch Menschen. Ein Sender, der bestimmte Signale stimulieren oder unterdrücken soll, wird von einem Empfänger, der auf die Signale reagieren soll, durch einen Separator getrennt. Der Separator soll sicherstellen, dass keine chemischen Interaktionen stattfinden können und wird abhängig von den zu untersuchenden Effekten gewählt (durchsichtig, nicht-durchsichtig; schallabsorbierend oder nicht etc.). (eigene Darstellung)

Parallel dazu gab es eine weitere Versuchsanordnung, in der die Klarglasscheibe durch eine für UV- bzw. sichtbares Licht undurchlässige Trennwand ersetzt wurde. Um auch den Einfluss von natürlichem Licht zu eliminieren, wurden die Behälter von Alufolie umschlossen. Bei diesen Versuchen konnte er eine gegenseitige Beeinflussung ohne direkten Kontakt ${ }^{187}$ nachweisen. Er führte dies auf eine EM-Verbindung, resultierend aus der Biophotonenstrahlung zurück, denn im Versuchsaufbau mit undurchsichtiger Trennwand war keine Beeinflussung des Wachstums zu beobachten. Damit legen diese Phänomene in der Tat nahe, dass mikrobiologische Kulturen über physikalische Felder wechselwirken.

2007 veröffentlichten Farhadi u. a. vergleichbare Versuche mit menschlichen Darmkrebszellen (Farhadi u. a. 2007). Auch sie konnten eine nicht-chemische und nichtelektrische Informationsübertragung zwischen abgeschotteten Zellkolonien nachweisen. Im Versuch wurde eine Kultur von Darmkrebszellen Wasserstoffperoxid $\left(\mathrm{H}_{2} \mathrm{O}_{2}\right)$ ausgesetzt und sollte als Sender fungieren. Andere Kulturen ohne $\mathrm{H}_{2} \mathrm{O}_{2}$-Kontamination wurden in unterschiedlichen Entfernungen zur Senderkultur positioniert. Untersucht wurde, ob diese Empfängerkulturen ohne chemische, elektrische oder mechanische Wechselwirkung auf die Senderkultur reagieren, von der sie nur durch eine transparente Glasscheibe getrennt waren. Das für Zellen toxische $\mathrm{H}_{2} \mathrm{O}_{2}$ schädigte die Proteinkonzentration und anderes und veränderte sowohl die Senderkultur als auch die Empfängerkulturen signifikant.

Sie ließen sich von Ohnishi und Kollegen inspirieren, die zeigten, dass in Zellkulturen die Teilung von Leber-Krebszellen (HepG2) durch Chi-Energie gehemmt werden konnte (Ohnishi u. a. 2005). Eine 5- und 10-minütige Chi-Behandlung war in der Lage, die Anzahl der Krebszellen um 30,3\% und 40,6 \% im Vergleich zu einer Kontrollgruppe zu reduzieren. Die Messung erfolgte nach 24 Stunden, dem Zeitraum, der zur Verdopplung dieser Zellkultur benötigt wird. Mit Aluminium oder schwarzem Acryl wurde die Chi-Energie geblockt, bei transparentem Acryl hingegen traten die positiven Wirkungen auf. Aufgrund ihrer und anderer Experimente kamen sie zum Schluss, dass Chi-Energie mit Infrarotlicht in Zusammenhang stehen muss. Fels formulierte zu seinen Versuchen ganz allgemein, ,that the cell populations use two (or more) frequencies for cellular

\footnotetext{
${ }^{187}$ Direkten Kontakt meint chemische oder elektrische Wechselwirkung bei direkter Interaktion.
} 
information transfer, which influences at least energy uptake, cell division rate and growth correlation. Altogether the study strongly supports a cellular communication system, which is different from a molecule-receptor-based system and hints that photontriggering is a fine tuning principle in cell chemistry" (Fels 2009).

Dass es sich bei den bisherigen und noch folgenden Untersuchungen um keine Einzelergebnisse handelt, geht aus einem Review von Scholkmann u. a. hervor. Sie liefern einen Überblick über die bis 2013 erfolgten wissenschaftlichen Veröffentlichungen zum Thema nicht-chemische und nicht-kontaktbasierte Zell-zu-Zell Kommunikation (Scholkmann u. a. 2013).

\section{Homologe Verbindung zur Physik}

In diesen Versuchen wurde offensichtlich bedeutungshaltige Information per Photonen und nicht nur Energie übermittelt, vergleichbar der QT, was schlicht einen qualitativen Austausch auf mikrobiologischer Ebene voraussetzt.

\subsubsection{Schall als Träger von Information}

Mit einer weiteren Untersuchung an Bakterien kommen wir noch einmal auf den Anfang dieses Kapitels zurück, jedoch mit einem veränderten Fokus. Dass Schall für uns als Träger von Information angesehen wird, scheint nicht weiter verwunderlich. Schließlich ist fast jedem das Phänomen des Hörens von Tönen am eigenen Leib bekannt. Dass er aber auch eine wesentliche Rolle für das Wachstum von Bakterien spielt, wurde mit den Arbeiten von Matsuhashi u. a. mit Bacillus carboniphilus deutlich (Matsuhashi u. a. 1996). Dieses Bakterium war seinerzeit eine neuentwickelte Spezies, die Kohlenstoffmaterial wie Grafit zum Wachstum benötigt (Fujita u. a. 1996).

In einem früheren Experiment konnten sie zeigen, wie die Zellen zunächst um Graphitkristalle herum wuchsen und nach und nach auch weiter entfernte Sporen zu wachsen begannen. Die Forscher vermuteten hinter dem Wachstum der entfernteren Sporen einen Prozess, der durch Signale der ersten Zellen veranlasst wurde. In dieser, darauf aufbauenden Untersuchung (Matsuhashi u. a. 1996) beobachteten die Forscher das Wachstum von Bacillus carboniphilus-Stämmen unter Beeinflussung anderer Bakterien, die allerdings in räumlich und chemisch getrennten Behältern (Petrischalen) lokalisiert waren. Im Experiment wurden unterschiedliche Bakterien als Signalgeber-Zellen (Sender) eingesetzt, um beim Signalempfänger, dem Bacillus carboniphilus, das Wachstum und damit die Koloniebildung zu beeinflussen, und zwar in einem Umfeld, in dem das Empfängerbakterium normalerweise nicht wächst. Die Signalgeber-Zellen konstituierten quasi aus der Distanz unterschiedliche Wachstumsbedingungen, auf welche das Bacillus carboniphilus reagiert. Dass die Signalgeber Einfluss ausübten, wurde im Rahmen der Experimente auch bestätigt, denn in Abwesenheit solcher Signalgeber-Zellen konnte kein Wachstum beobachtet werden. Im Versuch waren Sender- und Empfänger-Bakterien in transparenten Kunststoffschalen lokalisiert und entweder durch transparente Scheiben oder durch unterschiedlich dicke Eisenbarrieren getrennt. Das Ganze jeweils in einer Plexiglas-Box von der Umwelt isoliert. Aus Sicht der Forscher fungiert die Ple- 
xiglas-Box als hervorragender Akustikbehälter. Die wichtigsten Teile der Experimente wurden von drei unabhängigen Forscherteams anderer, unabhängiger Institute wiederholt und bestätigt

Als Signalgeber-Zellen wurden neben den Bacillus carboniphilus selbst drei weitere Bakterien verwendet:

Bacillus subtilis (B. subtilis; bekannt auch als Heubakterium, zählt zu den Fäulnisbakterien im Boden, dient u. a. zur Durchfallbekämpfung beim Menschen)

Escherichia coli E. coli; bekannt auch als Kolibakterium, Vorkommen im menschlichen und tierischen Darm, dient $u$. a. als Vitaminproduzent in der Darmflora)

Micrococcus luteus (M. luteus; zählt zu den Luftkeimen, ist Teil der normalen Hautflora des Menschen, dient u. a. als Indikator bei der Überprüfung von Antibiotika)

Wie erwartet, übertrugen sich im Experiment die Wachstumssignale von einer Petrischale auf die andere, wobei die Wachstumsstärke vom Typ der Signalgeber abhing. Auch eine Variante mit einer Vergrößerung des Abstandes zwischen den Petrischalen hatte keinen Einfluss auf die Wachstumsrate. Die Forscher erkannten noch eine weitere wichtige Einflussgröße: Als entscheidend für die Stärke des Wachstums stellt sich der Entwicklungsgrad der Signalgeber-Zellen heraus. Nur teilweise entwickelte Sender führten zu signifikant niedrigerer Wachstumsrate beim Empfänger. Dass der Entwicklungsstand respektive die Qualität der Sender (Einflussnehmer) in direktem Zusammenhang mit seiner Wirkung steht, ist auch in sozialen Systemen ein bekanntes Phänomen (Führung, Lehre, Gruppenprozess etc.).

Zur Ermittlung der Signalart (chemisch: gasförmig oder physikalisch: akustisch, magnetisch, elektrisch oder thermisch) wurden verschieden dicke Eisenplatten $(0,5 ; 1 ; 1,5$; $2 \mathrm{~mm}$ ) als Trennung verwendet. Tatsächlich waren selbst bei der dicksten Variante noch deutliche Wachstumssteigerungen zu beobachten, wie die folgende Tab. 17 veranschaulicht. Zur Kontrolle wurden die Experimente auch ohne Signalgeber (gekennzeichnet mit ,kein') durchgeführt. Hinzugenommen wurde mit Experiment 1 noch das Ergebnis bei Verwendung einer transparenten Petrischale. Es macht den Unterschied der Wachstumsraten im Verhältnis zu den Eisenplatten deutlich.

Offensichtlich ist die wachstumstreibende Wirkung in Experiment 1 zu beobachten, bei der transparente Petrischalen (Acryl-Glas) zum Einsatz kamen. Demgegenüber fallen die Werte bei Verwendung von Eisenplatten deutlich ab, gehen jedoch in der Regel nicht auf Null. Was die Autoren nicht erklären konnten, waren die sehr unterschiedlichen Werte. Sicher war jedoch, dass es sich aufgrund der Versuchsanordnung nicht um chemische Übertragungswege handeln konnte. In einem Unterexperiment konnte nämlich auch mit offenem Luftzug über den Sender- und Empfängerkulturen keine Wachstumsbeeinflussung beobachtet werden. Die Autoren schlossen darüber hinaus ultraviolettes, sichtbares oder Infrarot-Licht genauso aus wie Mikrowellen. Nicht komplett ausschließen konnten sie ungewöhnliche Formen von EM-Wellen. Allerdings hielten sie 
eine akustische Übertragungsart aufgrund der Kunststoffbehälter und des Außengehäuses am wahrscheinlichsten. Ihrer Ansicht nach entstehen die Schallwellen durch Vibration intrazellulärer Organellen wie Membrane, Chromosome und dem Cytoskelett. Letzteres ist im Wesentlichen durch Mikrotubuli ${ }^{188}$ aufgebaut, die im Kap. 8.3 zu Neurowissenschaften näher betrachtet werden.

Tab. 17 | Effizienz des Wachstums von B carboniphilus Kolonien

bei unterschiedlichen Bedingungen. Ergebnisse und Darstellung wurden (Matsuhashi u. a. 1996) entnommen. Bei Experiment 1 wurde transparentes Acryl-Glas verwendet, wohingegen bei den Experimenten 2 bis 4 Eisenplatten unterschiedlicher Dicke zum Einsatz kamen. Ohne Signalemitter konnte auch kein Wachstum beobachtet werden, siehe hierzu die jeweiligen Vergleichswerte. Fragen warfen die scheinbar unsystematischen Wachstumswerte bei unterschiedlichen Dicken des Eisenisolators auf.

\begin{tabular}{|c|c|c|c|c|}
\hline & \multicolumn{4}{|c|}{$\begin{array}{l}\text { Effizienz des Wachstums von B. carboniphilus Kolonien in } \\
\text { \% nachdem sie Signale von B. subtilis durch transparentes } \\
\text { Acryl-Glas oder durch Eisenplatten hindurch empfangen } \\
\text { hatten. }\end{array}$} \\
\hline Signalemitter & \multicolumn{4}{|c|}{ durch Acryl-Glas (Petrischalen) } \\
\hline $\begin{array}{l}\text { Experiment } 1 \\
\text { B. subtilis } \\
\text { kein }\end{array}$ & $\begin{array}{c}99,0 \\
0,0\end{array}$ & & & $\begin{array}{l}- \\
-\end{array}$ \\
\hline \multirow{2}{*}{ Signalemitter } & \multicolumn{4}{|c|}{ durch Eisenplatten unterschiedlicher Dicke (mm) } \\
\hline & 0,5 & 1,0 & 1,5 & 2,0 \\
\hline $\begin{array}{l}\text { Experiment } 2 \\
\text { B. subtilis } \\
\text { kein }\end{array}$ & - & $\begin{array}{c}15,3 \\
0,0\end{array}$ & $\begin{array}{c}16,4 \\
0,1\end{array}$ & - \\
\hline $\begin{array}{l}\text { Experiment } 3 \\
\text { B. subtilis } \\
\text { kein }\end{array}$ & $\begin{array}{l}0,2 \\
0,0\end{array}$ & $\begin{array}{c}12,4 \\
0,0\end{array}$ & $\begin{array}{l}7,4 \\
0,0\end{array}$ & $\begin{array}{l}6,0 \\
0,0\end{array}$ \\
\hline $\begin{array}{l}\text { Experiment } 4 \\
\text { B. subtilis } \\
\text { kein }\end{array}$ & $\begin{array}{l}6,3 \\
0,1 \\
\end{array}$ & - & - & $\begin{array}{c}10,6 \\
0,1\end{array}$ \\
\hline
\end{tabular}

${ }^{188}$ Mikrotubuli sind röhrenförmige Holzylinder aus Proteinen mit einem Durchmesser von $25 \mathrm{~nm}\left(10^{-9}\right.$ $\mathrm{m})$. Sie sind zum einen für die mechanische Stabilisierung der Zelle zuständig und zum Anderen für die aktive Bewegung der Gesamtzelle, als auch im Zusammenspiel mit anderen Proteinen für Bewegung und Transport innerhalb der Zelle. Im Inneren der Holzylinder befindet sich Wasser mit kohärent ausgerichteten Spins. 
Fassen wir zusammen:

Aufgrund der Versuchsanordnung blieben nur noch akustische und ungewöhnliche Formen von EM-Wellen übrig. Was aber sind solch ungewöhnliche EM-Wellen und welche Hilfe können die Ergebnisse aus Tab. 17 bieten?

Wie wir aus den ersten Beispielen gesehen haben, ergibt die neuere Forschung mehrere Optionen für physikalischen Signalübertrag:

1. Die Schwingungsfrequenz der Proteine und damit eine Stabilisierung gegen Umwelteinflüsse, wie sie von Plenio (Chin u. a. 2013) und anderen bei Bakterien erkannt wurde.

2. Einen Tunnelprozess, wie er bei Bakterien diagnostiziert wurde.

3. Schwach gekoppelte Wellenfunktionen über Energiebarrieren hinweg erzeugen ebenfalls Veränderungen.

4. Licht als Überträger von Information bei Biophotonen und klassischer Verschränkung.

5. Von außen angelegte Schwingung, die die beteiligten Systeme kohärent verbindet.

Wir wissen mittlerweile, dass die Proteine der Zellstruktur von Organismen ihre Information (Bauplan, Befindlichkeit etc.) in ihren Frequenzen codieren und bei Verschränkung mit dem neuen System teilen. Variante 1 käme damit als die , ungewöhnliche EMWelle' infrage. Jedoch würden die Wachstumsraten gleichbleiben oder sich in kontinuierlicher Weise verändern. Beides ist nicht der Fall, womit 1 als alleinige Erklärung ausscheidet. Ebenfalls verabschieden lassen sich Varianten 2, 3 und 5 als einfache Begründung. Wären sie die entscheidenden Parameter, sollte sich ebenfalls eine gleichmäBige Verteilung über jede Dickenvariante zeigen. Bleibt auf den ersten Blick tatsächlich nur Schall als Erklärung. Warum findet sich aber bei dieser Versuchskonfiguration kein korrelierter Wachstumsprozess?

Aus der Tabelle lassen sich nur zwei Versuchsvariable identifizieren: Die Dicke der Eisenplatten und eine unterschiedliche Anzahl von Sporen. Lässt sich nun ein Zusammenhang herstellen zwischen Anzahl der Sporen und der Dicke der Platten?

Wir gehen nun davon aus, dass es sich bei den Bakterien-Kulturen um kohärente Systeme handelt, die durch ihre Eigenschwingungen Schallwellen produzieren, wie die Autoren annehmen. Die unterschiedliche Anzahl der Bakterien in den Versuchen hätte dann Konsequenzen nicht auf die Frequenzen, wohl aber auf die Intensität und damit Amplitude der Schwingung. Mehr Sänger erzeugen eine lautere Musik als weniger Sänger, womit unterschiedliche Energieniveaus vorliegen.

Betrachten wir zunächst die Charakteristik von Schallwellen etwas genauer. Schallwellen können sich nur in Medien ausbreiten und nicht wie EM-Wellen im Vakuum. Die Lage der getroffenen Moleküle bleibt dabei gleich. Sie schwingen nur um ihre Ruhelage in Ausbreitungsrichtung der Schallwelle (bei idealen gasförmigen Medien wie Luft $=$ Longitudinalwelle) oder quer zur Ausbreitungsrichtung (bei festen Stoffen = Transversalwelle) und stoßen die benachbarten Moleküle an. Schallwellen übertragen 
deshalb nur Energie und keine Materie. Beim Durchlauf durch ein festes Medium sind Transversalwellen polarisierbar. Sie lassen sich durch eine Pfeilrichtung beschreiben, die abhängig von der Art der Auslenkung ist (Abb. 75). Läuft die Welle in z-Richtung durch ein Medium, kann die Schwingung in allen möglichen Kombinationen der x- und y-Richtung erfolgen. Diese Schwingungsrichtung nennt man Polarisation. Sie entspricht damit dem Spin bei Elementarteilchen.

Jetzt lassen sich zwei unterschiedliche Szenarien denken:

1. Eine Veränderung der Frequenzen durch Interaktion unterschiedlicher Wellen.

2. Eine Veränderung der Frequenzen durch Interaktion der Schallwelle mit dem Medium, das sie durchläuft.

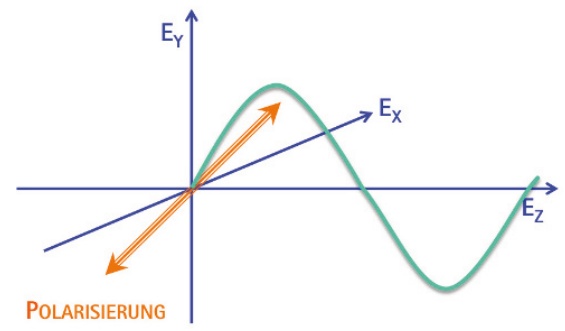

Abb. 75 | Schwingungsrichtung einer linear polarisierten Welle mit den Energiebeträgen $\mathrm{E}$ in $\mathrm{x}, \mathrm{y}$ und z-Richtung. (eigene Darstellung)

$\mathrm{Zu}$ 1) Handelt es sich um annähernd phasengleiche Wellen, also Wellen mit ähnlicher Frequenz, so kommt es zur Überlagerung und Superposition der beteiligten Wellen. Die Frequenz bleibt dabei im Wesentlichen gleich, aber die Amplitude wird höher, es wird also lauter. Die Physik spricht hier von linearen Systemen, da das Superpositionsprinzip gilt. Demgegenüber steht die Option in nicht-linearen Systemen, bei denen keine Superposition entsteht. Dieser Zustand tritt ein, wenn sehr unterschiedliche Schallfrequenzen aufeinandertreffen. Hier kommt es nicht zu einer Überlagerung, aber doch zu einem Energietransfer. Energie springt von einer Frequenz auf die andere. Durch die veränderte Energie kommt es zu einer Frequenzänderung, einer sogenannten Verzerrung.

$\mathrm{Zu}$ 2) Unterschiedliche Medien lassen sich zudem unterschiedlichen Ausbreitungsgeschwindigkeiten zuordnen, die durchaus auch schneller als der Schall in Luft sein können. Ein Teil der Schallenergie wechselwirkt dabei mit dem Medium. An der Grenzschicht oder im Medium selbst, wie der Luft-Eisenplatten-Konstellation im Versuch, geht mit der Energieabsorption eine thermische Erwärmung einher. Ein weiterer Teil geht über Reflexion an den Grenzschichten verloren. Durch die Erwärmung ändert sich die Polarisation der Welle, die durch das Medium läuft.

Im vorliegenden Experiment bedeutet die unterschiedliche Anzahl der Sporen (Sänger) unterschiedliche Geräuschpegel und letztlich unterschiedliche Energieniveaus. Als Folge werden die Eisenplatten von unterschiedlichen Energien getroffen. Gleichzeitig 
entscheidet die Dicke der Platten über den Grad der Absorption und damit der Erwärmung. So besitzt ein dickeres Medium mehr Volumen, um Energie zu absorbieren und gleichzeitig mehr Raum, um die Energie zu verteilen. Heuristisch betrachtet könnte dies bedeuten: Dünne Medien erhitzen sich entsprechend mehr, dickere entsprechend weniger. Je nach Medium könnte dies auch genau anders herum ausfallen oder sich aufheben. Dies ist in voller Übereinstimmung mit der Physik von Schallwellen, die frequenz- und temperaturabhängig ist.

$$
\mathrm{c}=\lambda \mathrm{f}
$$

mit $c=$ Ausbreitungsgeschwingkeit im Medium (Medium abhängig), $\lambda=$ Wellenlänge und $\mathrm{f}=$ Frequenz. Die Temperaturabhängigkeit ergibt sich indirekt über die Abhängigkeit der Wellenlänge von der Temperatur. Das Ergebnis ist eine ,thermische Wellenlänge':

$$
\lambda=\frac{\mathrm{h}}{\sqrt{2 \pi \mathrm{m} \mathrm{k} \mathrm{B}}}
$$

mit $\mathrm{h}=$ Planksches Wirkungsquantum, $\pi=$ Kreiszahl, $\mathrm{m}=$ Masse, $\mathrm{k}_{\mathrm{B}}=$ BoltzmannKonstante, $\mathrm{T}=$ absolute Temperatur.

Ändert sich die Temperatur, ändert sich auch die Frequenz und die Polarisation der das Medium (Eisenplatte) verlassenden Welle. Die Information, die durch die ursprüngliche Frequenz und Polarisation transportiert wurde, ist nicht mehr identisch mit ihrem ursprünglichen Zustand beim Auftreffen. Es ändert sich aber auch die Qualität der Wechselwirkung der aufeinandertreffenden Wellen. Je ähnlicher, die ankommende Welle mit der Eigenfrequenz des Mediums übereinstimmt, desto einfacher bzw. unveränderter läuft sie durch das Medium. Je unterschiedlicher die Frequenzen, desto größer findet Energieaustausch statt und eine Veränderung der austretenden Welle und ihrer Polarisation.

Schöne Beispiele sind Glas oder auch transparente Kristalle. Licht passt in seiner Frequenz zur scheinbaren materiellen Struktur und lässt damit die optische Information durch. Bei Glas ist es die amorphe Struktur, die es dem Licht ermöglicht, in seiner Ganzheit durchzustrahlen. Die amorphe Struktur entsteht durch einen speziellen Abkühlprozess, der eine regelmäßige Anordnung der Atome des verwendeten Quarzes verhindert. Bei transparenten Kristallen führt die angeordnete Struktur der Atome zur Ablenkung bestimmter Wellenlängen des Lichtes, mit gut unterscheidbaren Spektrallinien. Manche solcher Kristalle lassen aber ebenfalls das gesamte Lichtspektrum hindurch, insbesondere bei sehr dünnen Schnitten. In beiden Fällen können wir hindurchsehen. Ändern wir die Farbe des Glases oder seine Temperatur, ändern wir zum einen die innere Struktur der Atome, damit auch automatisch das Schwingungsverhalten und letztlich die Transparenz. Spätestens wenn es glüht, ist die Transparenz aufgehoben. Die Relevanz der Dicke und der Geometrie wird ebenfalls in Verbindung mit Glas deutlich. Je nach Dicke oder Geometrie produziert es unterschiedliche Töne. Glasspieler machen sich diesen Effekt bei ihrer Kunst zunutze.

Nun gilt es noch den Ausgangpunkt der Schallwellen genauer zu analysieren. Wir sind davon ausgegangen, dass es sich bei den Bakterien-Kulturen um kohärente Systeme 
handelt, damit kohärente Frequenzen produziert werden und die gesamte Information über den Bakterienstamm in diesen Frequenzen codiert ist. Diese kohärenten Frequenzen interagieren mit dem Umfeld und bringen die angrenzenden Luftmoleküle in Schwingung. Durch diese Interaktion findet konsequenterweise eine Verschränkung statt, die zumindest dem verallgemeinerten Josephson-Effekt entspricht. Obwohl es keine chemische Bindung gibt, findet eine schwache Kopplung der Systeme statt, was durch den Energie- und damit Elektronenaustausch realisiert wird. Damit darf angenommen werden, dass die Ursprungsinformation auch über Schallwellen codiert und verbreitet wird. Gleichwohl liegt ein Mixed-Zustand vor. Die elektromagnetischen, aber energetisch eher schwachen Potenziale der Zellen sowie ihre an Schallwellen gekoppelte Information.

Wie wir in den vorliegenden Experimenten gesehen haben, kommt es in Summe zu nicht-linearen Veränderungen im Wachstumsprozess der Empfänger-Kulturen. Aus den in diesem Kapitel untersuchten Forschungsarbeiten geht klar hervor, dass für eine erfolgreiche wechselseitige Beeinflussung zweier lebender Systeme eine Ähnlichkeit der Frequenzen entscheidend ist, nicht aber die Intensität.

Damit lässt sich schlussfolgern: Die beteiligten Schallwellen erfahren zumindest aufgrund eines verallgemeinerten Josephson-Kontaktes mit den Sender- und EmpfängerZellen eine Verschränkung. Somit tragen sie alle Informationen über die jeweiligen Zellen mit sich. Durch die unterschiedliche Anzahl von Sporen werden unterschiedliche Energieniveaus bei den Schallwellen initiiert, diese führen zur Polarisations- und Frequenzänderung in den feststofflichen Transfermedien (Eisenplatten) aufgrund thermischer Änderungen. Die Transfermedien wirken wie ein Frequenz- und Polarisationswandler, respektive ein Absorber. Diese Änderungen modifizieren schließlich das Potential der mitcodierten Sender- und Empfängerinformation. Die Passung von Polarisation und Frequenzen nimmt gegenüber einem optimalen Zustand ab. Die Wachstumsrate sinkt. Die Wachstumsdaten weisen auf eine störende Wirkung der Transfermedien auf die reinen EM-Wellen hin. Ansonsten sollten überall zumindest kleine Wachstumsprozesse zu beobachten sein, die den EM-Anteilen entsprechen. Wo sich also welche Wachstumspotentiale entfalten können, scheint von einem Zusammenspiel der EMSchwingungen von Sender und Empfänger, den initiierten Schallwellen und dem thermischen Veränderungspotential eines Transfermediums zusammenzuhängen. Die vorliegende Versuchsanordnung scheint auf reduzierende und aufbauende Effekte hinzuweisen. So könnte bei Experiment 2 die erste, dünne Trennwand die Frequenz und damit verbundene Information fast unbrauchbar machen, was durch Trennwand zwei jedoch wieder kompensiert wird.

Es lässt sich noch ein zweiter Schluss folgern: Mit diesem Experiment liegt ein weiteres Beispiel einer klassischen Verschränkung vor, in dem Schall den Hauptprotagonisten zur Übertragung spielt. Durchläuft die Schallwelle kein Transfermedium, sondern trifft unmittelbar auf den Empfänger, könnten die Frequenzen und Kohärenzen unverändert bleiben und letztlich auch die Information; eine Option, die zu einem späteren Zeitpunkt erneut aufgegriffen wird. Mit dem klassischen Modell der Polarisation liegt zudem ein analoges Konzept zum quantenmechanischen Spin respektive der Spin- 
polarisation vor. Es darf deshalb angenommen werden, dass die Polarisation (ähnlich der Spinpolarisation großer Ensembles) Informationen codiert und transportiert.

Abb. 76 veranschaulicht den Versuchsaufbau zur Illustration der Reichweite ihrer Signale. Auch hier wirkte der Sender (B. subtilis) auf den Empfänger (B. carboniphilus Sporen) entlang eines Acrylic-Zylinders.

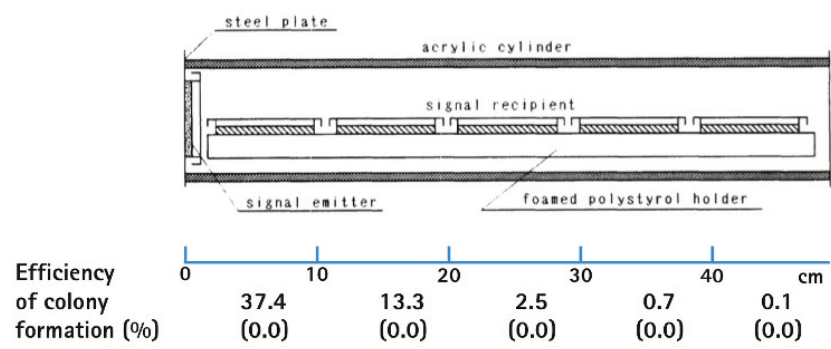

Abb. 76 | Versuchsaufbau und Messergebnisse von Matsuhasi u. a. (1996)

für eine zu untersuchende Reichweite von $50 \mathrm{~cm}$. Mit zunehmender Entfernung vom Sender nahm die wachstumsfördernde Wirkung ab.

Der Einfluss der Sender nimmt über die Distanz ab, wie es auch für EMF typisch ist. Bis $30 \mathrm{~cm}$ sind noch sehr deutliche Effekte zu beobachten. Danach gehen sie zwar gegen Null, lassen sich aber, wenngleich mit sehr geringen Effektstärken, bis auf eine Distanz von $50 \mathrm{~cm}$ messen.

Und noch ein Letztes: In einem weiteren Experiment konnte Matsuhashi et. al. den Zusammenhang der Notwendigkeit gleicher Frequenzen zur Erzielung großer Wirkung auch für Schallwellen nachweisen (Matsuhashi u. a. 1998). B. subtilis und B. carboniphilius weisen die gleichen Schallfrequenzbänder auf und haben deshalb dieses sehr hohe Beeinflussungspotential.

\section{Homologe Verbindung zur Physik}

Die Vermittler von Wirkung scheinen immer wieder Wellen gleicher Frequenz zu sein, die durch Überlagerung Intensität aufbauen. Und auch hier benötigt es keinen direkten Kontakt der Zellsysteme zueinander. Die Vermittlung über virtuelle Träger (Schall, Licht) scheint völlig auszureichen.

\subsubsection{Entscheidungsprozesse und kohärente Informationsspeicherung in Pflanzen}

Ganz aktuell wurden Zellverbände in Pflanzensamen entdeckt, die Entscheidungen über das Auslösen des Keimvorgangs ebenfalls in Abhängigkeit von Umweltinformationen treffen (Topham u. a. 2017). Diese Entscheidungszentrale besteht aus zwei, räumlich getrennten Arten von Zellen, die antagonistisch in Wechselwirkung stehen. Eine ist für die Untätigkeit, die andere für den Start des Keimvorgangs zuständig. Beide Zellenarten 
sammeln Umweltinformationen und entscheiden im Zusammenspiel über den besten Zeitpunkt. Erst bei Übereinstimmung ihrer Einschätzungen erfolgt der Auslöser. Die Forscher vergleichen diesen Gesamtprozess mit Vorgängen im Gehirn, in dem Entscheidungen ebenfalls auf der Basis des Abgleichs von Informationen stattfinden. Ergänzend stellen sie auch topologische Ähnlichkeiten zwischen den Entscheidungszentren der Zellen und des menschlichen Gehirns fest. Interessanterweise schreiben sie den Zellverbänden anwachsende Rechnerleistungen durch verteilte Rechenoperationen zu, die im Gegensatz zu den reduzierten Rechnerleistungen von Einzellern stehen. ,, The joint exploitation of the geometry of a dynamical system and its nonlinear interactions supports decision making and the stepping of variable inputs toward effecting the flipping of a developmental fate switch in seeds " (ebd. 5).

Eine weitere aktuelle Veröffentlichung zeigt einen vergleichbaren Abstimmungsprozess auf der Basis von Samen erzeugter ultra-schwacher Photonenstrahlung (Biophotonen) (Footitt u. a. 2016).

Passend zu den Entscheidungs- und Rechenzentren bei Samen wurde bei Untersuchungen von fleischfressenden Venusfliegenfallen evident, dass diese sowohl zählen als auch Information selektiv über Zeiträume bis zu 4 Stunden speichern können (Böhm u. a. 2016). Die Pflanze löste innere Prozesse in Abhängigkeit von Berührungssignalen an ihren Härchen aus. 2 Berührungen: Zuschnappen; ab 4 Berührungen: in Gang setzen des Verdauungsprozesses, die Intensität des Verdauungsprozesses nimmt mit der Anzahl der Berührungen zu. Kinästhetische Berührungen lösen somit elektrische Impulse aus, die schließlich in hormonelle Signale umgewandelt und als Information mindestens 4 Stunden gespeichert werden. Die Speicherung setzt einen kohärenten Mechanismus über größere Areale voraus und eine Kopplung in und von Zellen und damit eine Verschränkung auf Ebene der organischen Chemie.

\section{$\underline{\text { Homologe Verbindung zur Physik }}$}

Organische Chemie bedeutet letztlich Spinensembles, Aufbau- und Oberflächenstrukturen. Die physikalischen Zusammenhänge (Kap. 8.1.1.4) verdeutlichten, welche Rolle Oberflächen und Atome für die Speicherung von Information einnahmen. Da auch lebende, aber noch nicht-bewusste Lebensformen ebenfalls Informationen und vor allem Muster speichern und verarbeiten müssen, stellt sich die Frage, auf welche Weise sie dies tun. Auch wenn wir noch von eher automatischen Prozessen ausgehen, so zeigen die pflanzlichen Beispiele eindeutig Automatismen, die sich primär im Übergang von der reinen Quanten- zur mikrobiologischen Ebene abspielen. Aufgrund der Schnelligkeit der Abläufe sind auf dieser Ebene derzeit Quantenverarbeitungsprozesse nicht nur möglich, sondern sogar wahrscheinlich. Diese Quantenspeicher in Form von Oberflächen- und Atomstrukturen auf einer rudimentären Ebene sind offensichtlich in der Lage, autonome Verarbeitungsprozesse aufgrund von Mustererkennungen durchzuführen, die der jeweiligen Entität das Überleben sichert.

Genauso wie Atome, Moleküle, Kristalle oder andere anorganische Entitäten ihre Eigenschaften in Form von Spins und topologischen Strukturen speichern, speichern 
höherentwickelte Entitäten ebenfalls Informationen in ihren anorganischen Zellstrukturen, die ebenfalls als Spinensembles und topologische Strukturen zu betrachten sind. Bemerkenswert ist auch die topologische Ähnlichkeit zum Gehirn, wie die Forscher feststellen. Ergibt sich eine stimmige und relevante Kohärenz mit der Umwelt oder anderen Entitäten, folgen Reaktionen, die im Rahmen der Freiheitsgrade der jeweiligen Entitäten liegen. In den bisherigen Beispielen kann deshalb von automatischen Entscheidungen gesprochen werden, die für die weitere Existenz des Systems von Relevanz sind. Mit den Überlegungen der Gruppe von Topham (Topham u. a. 2017) erhöht sich zudem die Rechner- und damit Verarbeitungsleistung mit Zunahme der beteiligten Entitäten, direkt vergleichbar mit der Zunahme von Bits und Qubits in den Computern.

\subsubsection{DNA}

Von Rieper wurde die These untersucht, ob Quanteneffekte Einfluss auf die Informationsprozesse in der DNA haben, denn die DNA fungiert als Informationsspeicher und als Signalüberträger in einem thermischen Nicht-Gleichgewichtszustand (Rieper 2011: 41-54). Zur Berechnung solch quantenmechanischer Prozesse in der DNA wurden in der Quantenchemie verschiedene Techniken entwickelt. Sie ermöglichen zumindest vereinfachte Dynamiken auf der Basis von Experimenten und deren Messergebnissen zu simulieren. In diesem Fall sind verschiedenste Bindungsenergien und Frequenzen von Molekül- und Zellstrukturen bekannt. Vollständige Simulationen sind aktuell noch unmöglich.

Ein Kernelement ihrer Untersuchung war die Energieverteilung zwischen den Nukleinsäuren der DNA. Die DNA (auch DNS = Desoxyribonukleinsäure genannt) setzt sich u. a. aus einzelnen Nukleinbasen (Adenin, Cytosin, Guanin und Thymin) zusammen. Diese Nukleinbasen sind Makromoleküle und liegen in planer Struktur mit umgebenden Elektronenwolken vor. Über Wasserstoffbrückenbindungen bilden diese Nukleinbasen eine Doppelstrangstruktur, die berühmte Doppelhelix der DNA und letztlich der Träger unserer zu vererbenden Gene. Es sei angemerkt, dass wir es hier wieder mit Proteinstrukturen zu tun haben, denn Nukleine sind im Zellkern vorkommende Eiweißverbindungen.

Ihrem Modell nach konnte Rieper eine Delokalisierung von Elektronen und damit Kohärenz zumindest für nahe beieinander liegende Kettenglieder nachweisen und das auch bei Raumtemperaturen. Sie präsentierte damit ein Beispiel, wie chemische Bindungen durch Verschränkungen beschrieben werden können. Ein Ergebnis, das sich konsequent aus der Theorie der Quantenphysik ableiten lässt, nach der jedes Molekül einer eigenen Wellenfunktion entspricht und jede molekulare Verbindung einen Verschränkungszustand zwischen den beteiligten Wellenfunktionen darstellt. In diesem Falle haben wir es mit einer Dipol-Verbindung zu tun, bei der Elektronen von einem System auf ein anderes wechseln, was zur Anziehung führt. Quantenmechanisch ist damit der Vorgang des ,Tunnelns' realisiert. Je nach Variante handelt es sich bei solchen Dipolbindungen um starke oder schwache Wechselwirkungen. Die oben aufgeführten Wasserstoffbrückenbindungen zwischen den Nukleinbasen bilden einen Sonderfall 
einer Dipol-Dipol-Bindung und bilden für solche Bindungstypen die stärkste Wechselwirkung aus.

Dass quantenmechanische Kohärenzen über Energiebarrieren hinweg auch bei schwach gekoppelten Wellenfunktionen, also schwachen Wechselwirkungen möglich sind, zeigt der bereits vorgestellte, verallgemeinerte Josephson-Effekt', mit dem das eben angesprochene ,Tunneln' erklärt wird. Solche Energiebarrieren konstituieren sich über Molekülübergänge, Zellwände oder auch Leerräume zwischen Systemen. Es ist deshalb anzunehmen, dass sich die Kohärenzen auch auf Regionen ausdehnen, die nicht mehr im direkten Einfluss der Dipolmomente liegen. Diesen Aspekt berücksichtigte Rieper in ihrer Dissertation nicht weiter, da sie bereits den geringen Energiebeitrag aus der Dipol-Dipolbindung zwischen den einzelnen DNA-Strängen als zu vernachlässigen ansah. Sie formuliert aber einen sehr klaren Zusammenhang, der sich ebenfalls aus dem modernen quantenphysikalischen Verständnis ergibt: ,, The stronger the entanglement, the more binding energy the molecule has " (ebd 50). Umgekehrt bedeutet dies, dass die energetische Kompaktheit ein Maß für eine Verschränkung darstellt. Je stärker sich Systeme von ihrem Umfeld unterscheiden lassen, desto stärker sind diese Systeme in sich verschränkt und die gesamte Information ist über dieses Gesamtsystem verteilt. Übertragen wir diese Interpretation auf einen Menschen, der scheinbar eindeutig gegenüber seinem Umfeld abzugrenzen ist, so ergibt sich die logische Konsequenz: Die Gesamtinformation, die den Menschen ausmacht, ist über alle seine Subsysteme wie Organe, Zellen, Moleküle, einzelne Atome und letztlich auch Elektronen verteilt.

Aus Rieper's Modellierungen ergeben sich auf jeden Fall keine permanente, sondern nicht-permanente Dipolmomente ${ }^{189}$, die sich aus der Oszillation der Elektronenwolken um ihren Kern entwickeln (ebd. 43). Rieper nimmt an, dass „, This oscillation might be caused by an external field, or induced by quantum fluctuations, as it is given in a DNA strand" (ebd. 44) und dass ein einzelner DNA-Strang einer Kette harmonischer Oszillatoren ähnelt, wobei jede benachbarte Base die Distanz zur anderen Base mit einer Dipol-Dipol-Interaktion überwindet.

Nicht-permanente Dipolmomente, ausgelöst durch Oszillation, deuten auf zu- und abnehmende Verschränkungsintensitäten hin, was nach Plenio (Caruso u. a. 2010) den Informationstransfer eher unterstützt als schädigt.

Aus ihren Betrachtungen zum Informationsprozess ergaben sich weitere wichtige Erkenntnisse. Sie berechnete dazu die ,Shannon Entropie'. Ein, wie bereits vorgestellt, informationstheoretisches Verständnis des Begriffes Entropie. Als Ergebnis zeigte sich eine eindeutig quantenmechanische Korrelation der Nuklein-Basen untereinander. Sie sind zweifelsfrei lokal vermischt, also kohärent und damit verschränkt. Da, wie sie ausführt, das Eintreten potentieller Veränderungen, als auch die Interaktion zwischen beteiligten Systemen linear abhängig ist von der Anzahl der beteiligten Elektronen, erstreckt sich auch die gemeinsame Frequenz über den betroffenen räumlichen Bereich

${ }^{189}$ Der Dipolmoment ist ein Maß für die Polarität eines Moleküls. Aus ihm lässt sich die Bindungsstärke zwischen Molekülen ableiten. Bei nicht-permanenten Dipolmomenten schwankt diese Bindungsstärke. 
(vgl. ebd. 46). Auf diese Weise lassen sich spezielle Basenpaare innerhalb eines speziellen Gens zu einer tautomeren Form und damit zu einer Mutation anregen. Erfasst die DNA diese Mutation schnell genug, führt dies zu einer nachhaltig veränderten DNA. Dies gelingt bereits mit sehr geringem Energieaufwand.

Konsequenterweise ergaben ihre Berechnungen einen eindeutigen Hinweis auf einen quantenphysikalisch getragenen, selektiven Auswahlprozess zur Mutationsbildung, abhängig vom Umfeld (vgl. ebd. 102). Dieser lag um einen Faktor 100 über einem klassisch angenommenen Zufallsprozess. Demnach ergeben sich auch bei ihr eindeutig Effizienzvorteile für quantenmechanisch unterstützte Mechanismen. Dies lässt die plausible Interpretation zu, dass eine Verschränkung mit der Umwelt, eine gezieltere Anpassung an dortige Veränderungen ermöglicht. Womit wiederum das Prinzip der Schnelligkeit und Effizienz in den evolutionären Prozessen zu finden wäre und die Antwort zum Mutationsmechanismus das klassische Verständnis widerlegt.

Entsprechend einer Berechnung von Warnke würden von $10^{85}$ Zellen nur eine einzige eine Mutation tragen (Warnke 2011: 24). Demnach könnte man innerhalb einer Milliarde Jahre nur $10^{45}$ Individuen erwarten, was nach ihm eine Gesamtwahrscheinlichkeit $\left(10^{-85} \times 10^{45}\right)$ für die Entstehung eines mutierten Individuums von $10^{-40}$ bedeuten würde. Er schließt daraus, dass Mutationen nicht von alleine eintreten können und die gängigen Theorien, die den Zufall verantwortlich machen, nicht haltbar sind. Im Vergleich zu Warnke scheint Rieper's Berechnung zwar eine sehr viel geringere Größenordnung für klassische, dem Zufallsprozess unterliegende Mutationen zu ergeben, sie geht jedoch in die gleiche Richtung ${ }^{190}$.

Rieper zeigte mit ihrer Arbeit, wie schwache externe EMF Einfluss auf lebende Systeme haben können. Einflüsse, die über normale, nicht-quantenphysikalische Feldmodelle nicht gefunden werden (Rieper 2011: 70). Eine Erkenntnis, die für die Diskussionen im Bereich Mobilfunknutzung oder Alternativmedizin von Bedeutung sein dürfte.

Und wieder zeigt sich ein Beispiel, wie vermutlich quantenphysikalische Wechselwirkungen erhebliche Auswirkungen auf makroskopische Zustände verursachen. Zum besseren Verständnis Rieper's Erkenntnisse veranschaulicht in Abb. 77. a) und b) stellen zwei unterschiedliche Moleküle im klassischen Verständnis dar. Hier lassen sich unterschiedliche Quantenzustände und damit unterschiedliche Wellenfunktionen zuordnen, bei scheinbar gegenseitiger Unabhängigkeit. Abb. 77c) zeigt das Molekül im Grundzustand $0\left(\left|\psi_{0}\right\rangle\right)$ innerhalb eines extern angelegten Feldes. Angenommen, dieses Molekül im Zustand 0 besitzt einen angeregten Quantenzustand $\left|\Psi_{1}\right\rangle$ der dem von Molekül 1 ähnelt $\left(\left\langle\Psi_{0} \mid \Psi_{1}\right\rangle \approx 1\right)$. Jetzt ist die Situation entstanden, dass sich sowohl der Grundzustand $\left|\Psi_{0}\right\rangle$ als auch der angeregte Zustand $\left|\Psi_{1}\right\rangle$ manifestieren kann. Diese lassen sich aufgrund ihrer Superposition, die durch eine gemeinsame Wellenfunktion zum Ausdruck kommt, nicht mehr unterscheiden. Es liegen damit gleichzeitig mehrere Zustandsmöglichkeiten parallel vor. Mit einer mathematisch bestimmbaren Wahr-scheinlichkeit

${ }^{190}$ Auch bei Al-Khalili wird eine geringere Mutationsrate von 1 zu einer Milliarde $\left(10^{9}\right)$ angegeben (AlKhalili und McFadden 2015: 67). 
entwickelt sich daraus eine Fehlinterpretation, die zur Realisierung des Zustandes $\left|\Psi_{1}\right\rangle$ führt und über den gesamten Kohärenzbereich Einfluss ausüben kann - sprich, der neue Zustand wird großflächig konstituiert. Biologisch gesehen wäre eine Mutation die Folge. Dabei kommt es nicht auf die Größe des Ausschlags, also der Intensität an. Wichtig ist nur eine ausreichende Passung der Frequenz. Je besser die Passung, je größer die Wahrscheinlichkeit einer Fehlinterpretation. Auch ganz schwache Felder können deshalb Wirkung erzielen.

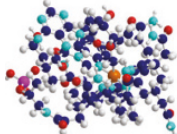

a) $\rho_{0}=|0\rangle\langle 0|\otimes|$
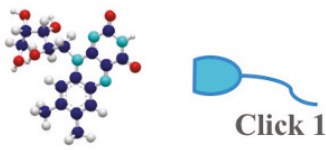

b) $\rho_{1}=|1\rangle\left\langle 1|\otimes| \psi_{1}\right\rangle\left\langle\psi_{1}\right|$
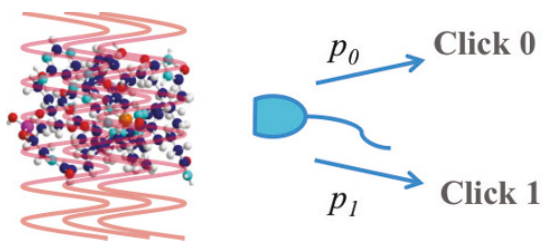

c) $\rho_{0}=|0\rangle\langle 0| \otimes\left(\mathrm{p}_{0}\left|\Psi_{0}\right\rangle\left\langle\psi_{0}\left|+\mathrm{p}_{1}\right| \Psi_{0}\right\rangle\left\langle\Psi_{0}\right|\right)$

Abb. 77 | Moleküle im klassischen und im quantenphysikalischen Verständnis

a) Molekül A mit Zustand $\rho_{0}$, b) Molekül B mit Zustand $\rho_{1}$, c) ein äußerlich angelegtes EM-Feld ändert durch Anregung den Quantenzustand und führt zu Fehl-Codierung. Darstellung in Anlehnung an Rieper (vgl. ebd. 72).

Passend zu den Ergebnissen von Rieper, lassen sich Forschungen in der USA interpretieren. Blank und Goodman beobachteten Interaktionen (mittels EMF) mit der DNA über sehr weite Frequenzbereiche und das bei extrem niedrigen Frequenzen (Extremely Low Frequency (ELF) 3-30 Hz) bis hin zu Radiofrequenzen (Blank und Goodman 2011). Sie interpretierten dies als eine funktionelle Charakteristik von fraktalen Antennen, elektronische Leitfähigkeit und Selbstsymmetrie. Aufgrund dieser Wechselwirkungen können nach ihnen auch chemische Entwicklungen in der frühen geologischen Geschichte oder DNA-Defekte und Mutationen entstehen, aber eben auch Krebs. Diese äußeren EMF beeinflussen beispielsweise unterschiedliche Proteine, die differenziert die schnellen Muskeln im Bereich von ca. $100 \mathrm{~Hz}$ und die langsamen Muskeln bei ca. $10-20 \mathrm{~Hz}$ stimulieren (ebd. 409-410).

Ein weiterer quantenphysikalischer Effekt, nämlich ein extrem spinselektives Verhalten der DNA in Bezug auf die Wechselwirkung mit Elektronen, wurde von einer anderen Forschergruppe beobachtet (Göhler u. a. 2011). Ihre Untersuchungen erfolgten bei normaler Umgebungstemperatur und mit unpolarisiertem Licht. Mit dem unpolarisierten Licht wurde ein weiterer Schritt in Richtung normale Umweltbedingungen gegangen. Als Ergebnis erkennen sie die Wichtigkeit des Spins bei Biomolekülen an, was bisher vernachlässigt wurde, und dass er eine wichtige Rolle bei der Elektronen-DNA- 
Interaktion in biologischen Systemen spielt. Sie bezogen ihre Ergebnisse auf alle Formen von chiralen Molekülen ${ }^{191}$. Zudem schlossen sie auf ein ,pseudo-Magnetfeld' innerhalb der Stränge mit nur wenigen hundert Tesla, das als Spinfilter wirkt und nicht von außen induziert ist. Ihre Überraschung bezog sich vor allem darauf, dass Spineffekte bei Elektronentransfers bisher nur in magnetischen Materialien, in Systemen mit schweren Atomen oder in topologischen Isolatoren bekannt sind. Beispiele, die bisher nur in der klassischen Quantenphysik auftreten und bereits vorgesellt wurden (Kap. 8.1.2.3).

Spins, die gespeicherte Information repräsentieren, scheinen offensichtlich auch relevant für Wechselwirkung und Kohärenz mit der DNA und deren Anpassung an die Umwelt. Neueste Forschung bei der Wildgrassorte (Alloteropsis semialata) scheint diesen ,, lateralen Transfer von großen DNA Fragmenten “ (Dunning u. a. 2019) mit funktionaler Wirkung zwischen entfernt verwandten Arten zu bestätigen. Die Forscher entdeckten in dieser Wildgrassorte 59 lateral erworbene Genfragmente von zumindest 9 unterschiedlichen Spenderarten und dass diese Anpassungsform bei Wildgräsern weit verbreitet scheint. Die Autoren stellen noch keinen Bezug zur hier vorgestellten DNAForschung her, sondern sehen den zugrundeliegenden Prozess derzeit noch als schwer fassbar an.

Übergreifend lässt sich als Schlussfolgerung ein primär frequenzabhängiger Mechanismus vermuten, der mit den bisherigen Überlegungen übereinstimmt. EMF aus dem Umfeld, welche auch aus natürlichen Quellen wie Zellen oder komplexeren Lebensformen emittiert werden, treten in Wechselwirkung mit der DNA anderer Organismen. Dieser Vorgang geht einher mit einer übergreifenden Kohärenz und erhöht die Möglichkeit Mutationen zu realisieren, die mehr Gemeinsamkeiten haben und damit auch besser aufeinander abgestimmt sind. Erweist sich diese neue Mutation als lebensfähig, tritt sie mit dem Umfeld in gleicher Weise in Wechselwirkung - ihre EM-Wellen überlagern sich mit den EM-Wellen ähnlicher Systeme und können dadurch ihre neue Struktur auf diese übertragen. Von außen angelegte Felder können diesen Vorgang auf nicht-lokale Kontakte ausdehnen (siehe Versuche von Trushin (2003) oder Collini u. a. (2010)) und entsprechend der Wellenlogik der Quantenmechanik an vielen Stellen gleichzeitig neue Mutationen implementieren. Mit der Zunahme der Population dieser neuen Mutation erhöht sich deren prozentualer Anteil und damit die Energiedichte dieser speziellen, codierten Information und sorgt für einen sich selbst verstärkenden Effekt.

Al-Khalili und McFadden beziehen sich auf Jordan und Schrödinger, wenn sie feststellen, dass sich Leben von unbelebten Objekten dadurch unterscheidet, dass eine kleine Anzahl hochgeordneter Teilchen einen ganzen Organismus beeinflussen können (AlKhalili und McFadden 2015: 70). Mit der kleinen Anzahl spielen sie auf die 46 DNAMoleküle an, die bei Menschen von den Eltern vererbt werden. Gleichzeitig wird hier

${ }^{191}$ Chirale Moleküle sind die DNA mit ihrer Doppelhelix und beispielsweise auch Enzyme. Die Chiralität selbst bezieht sich auf unterschiedliche räumliche Anordnungen von Atomen oder Molekülen, in Verbindung mit symmetrischen Konfigurationen. 
die 2. Bedingung von Greenstein und Zajonc bestätigt, in der die Mikroebene die Makroebene beeinflusst.

\section{Homologe Verbindung zur Physik}

Bei diesen Forschungen sind die gleichen Phänomene (Spinselektivität) in biologischen Systemen aufgetreten, wie sie in gängigen quantenphysikalischen Experimenten untersucht werden und bisher als nicht-relevant für Makro- bzw. thermische Nicht-Gleichgewichtssysteme erschienen.

\subsubsection{Zusammenspiel von DNA und nicht-kontaktbasierter Informationsübertragung}

Auf dem Weg besser die Entstehung und Wirkungsweise von HIV und anderen Krankheiten zu verstehen, erkannte Montagnier ${ }^{192}$ Zusammenhänge, die die bisherigen in diesem Kapitel vorgestellten Experimente bestätigen und zusammenführen, gleichwohl erheblichen Widerstand in der Wissenschaft auslösten (Montagnier u. a. 2011). Als Folge ergibt sich aus seiner Sicht eine Evidenz für eine nicht-partikel-orientierte Sicht auf das Leben. Er konnte zeigen, dass einige bakterielle und virale DNA-Sequenzen niederfrequente EM-Wellen in hohen wässrigen Verdünnungen induzieren (vgl. ebd. 1). Verantwortlich dafür macht er das sehr niederfrequente EM-Umfeld bei $7 \mathrm{~Hz}$. Die $7 \mathrm{~Hz}$ entsprechen dem natürlichen Strahlungshintergrund der Erde und sind als Schumann-Frequenz ${ }^{193}$ bekannt. Damit entsprechen sie der gleichen Frequenz, die das Gehirn produziert und in der spezielle Erfahrungen im Rahmen mentaler Praxis gemacht werden (siehe Kap. 8.3).

In seinen Untersuchungen konnte er HIV-DNA-Sequenzen, Einzel-Gene und krankmachende Bakterien und Viren identifizieren, die EM-Signale produzieren konnten; interessanterweise in genau der gleichen Frequenz wie es das Blutplasma der infizierten Menschen aufwies. Gleichzeitig war irritierend, dass sich die genetische DNA-Information auf separiertes, reines Wasser mittels EMF übertragen ließ. Das reine Wasser emittierte die gleichen EM-Signale wie die Original-Probe. Montagnier geht von Verunreinigungen im Wassers im nm-Bereich aus, an denen sich die übertragenen Frequenzen manifestieren. Im Prinzip entsprach seine Versuchsanordnung der von Abb. 74. Das Gläschen mit DNA-Schnipseln war von den Wasserbehältern isoliert und nur über eine EMF von $7 \mathrm{~Hz}$ verbunden. ,It was shown clearly that the water nanostructures and their electromagnetic resonance can faithfully perpetuate DNA information" (ebd. 5). In weiteren Versuchen konnte Montagnier und seine Gruppe zeigen, dass die mittels EM-Signalen übertragene Information einzelner DNA-Sequenzen ausreicht, um auf Wirtszellen übertragen zu werden. Die reine EM-Information der Einzelsequenzen führt zur Bildung dieser Sequenzen innerhalb der Wirts-DNA. Neben den Versuchen mit

\footnotetext{
${ }^{192}$ Montagnier erhielt für seine Forschungen 2008 den Nobelpreis in Medizin.

${ }^{193}$ Schumann-Frequenzen liegen bei $7,83 \mathrm{~Hz}, 14,3 \mathrm{~Hz}, 20,8 \mathrm{~Hz} \ldots$ und bilden stehende EM-Wellen um die Erde. Sie sind quasi das Produkt eines makroskopischen Hohlraumresonators, der durch die leitfähige Erdoberfläche und leitfähige Iononsphäre (Untergrenze in 70 - $90 \mathrm{~km}$ Höhe) begrenzt wird. $7,83 \mathrm{~Hz}$ werden als tiefste und fundamentalste Resonanz angesehen.
} 
reinem Wasser machten sie die gleichen Beobachtungen in Blutplasma und roten Blutzellen. Beide trugen die DNA-emittierenden Signale, obwohl die roten Zellen keine zelluläre DNA enthalten. Hier liegt also das gleiche Phänomen der übertragenen EM-Signale vor wie beim reinen Wasser. In diesen Versuchen wurden die Lymphozyten Stück für Stück umgebaut, bis das infektiöse Virus vollständig regeneriert war. Alle Versuche fanden bei normaler Raumtemperatur statt.

In ihrer Erklärung ${ }^{194}$ beziehen sie sich auf die QFT und die Bildung kohärenter Domänen, die durch oszillierende Moleküle ausgebildet werden und als Falle, gleich einem Hohlraumresonator wirken, der sich selbst gebildet hat. Das Energieband unterscheidet sich vom normalen Umfeldrauschen und ist dadurch in der Lage, den kohärenten Status aufrechtzuhalten. An den Rändern werden immer wieder Wirts-Moleküle aufgenommen, die Frequenz und damit der spezifische angeregte Zustand wird auf diese WirtsMoleküle ausgedehnt und so die kohärente Domäne erweitert, bis schließlich die Umbauarbeiten vollendet sind. Hier lässt sich der oben von Rieper geschilderte Mechanismus perfekt adaptieren.

Aus Sicht der Forschungsgruppe ist dieser Prozess auf jede Flüssigkeit übertragbar. Auch Wasser ist danach in der Lage, dissipative Strukturen ${ }^{195}$ zu generieren. Das nötige EM-Feld für Mikroorganismen wird ihrem Verständnis nach durch die Schumann-Frequenz zur Verfügung gestellt. Im menschlichen Körper selbst kann dies durch die Aktivitäten der Nervenzellen erzeugt werden (vgl. ebd. 7).

In Fortsetzung solcher Untersuchungen konnte eine andere Gruppe (Gibson u. a. 2010) zeigen, dass auch rein digitalisierte Genom-Sequenzen gespeichert und auf das Cytoplasma $^{196}$ einer Empfänger-Zelle übertragen und dort als übertragene Eigenschaften hervortreten. Leben ist nicht mehr von Leben entstanden, sondern nur noch aus Information und geeigneten Bausteinen im Umfeld.

\section{Homologe Verbindung zur Physik}

Neben den bereits dargestellten Zusammenhängen, Frequenzabhängigkeit und nicht-lokale Informationsübertragung, offenbart sich an diesem Beispiel ein direkter Bezug zur QT. Information wird, aus der Perspektive einer teilchenorientierten Physik, nicht-lokal übertragen und manifestiert sich in einem neuen Umfeld. Aus der Perspektive des Wellenmodells ergibt sich eine Anschlussfähigkeit an das Modell der ,klassischen Verschränkung' über EMF.

\footnotetext{
${ }^{194}$ Ausführliche Erklärung (Montagnier u. a. 2011: 5-9).

${ }^{195}$ Dissipative Strukturen beschreiben die Fähigkeit, in thermischen und damit offenen Nicht-Gleichgewichts-systemen, selbstorganisierte und geordnete Strukturen auszubilden.

${ }^{196}$ Cytoplasma oder Zellplasma ist eine dicke, zähe wässrige Flüssigkeit, die den gesamten inneren Bereich einer Zelle ausfüllt.
} 


\subsubsection{Biophysik bei Tieren}

Nachfolgend eine kleine Auswahl quantenphysikalischer Phänomene in der Tierwelt.

\subsubsection{Nachhaltige Quantenkohärenz und Verschränkung bei Vögeln}

Ein weiteres Beispiel für Quantenprozesse in lebenden Systemen stellt der 1972 entdeckte Magnetsinn von Vögeln dar (Wiltschko und Wiltschko 1972). Weiterführende Forschung und Experimente (Hiscock u. a. 2016; Wiltschko u. a. 2016; Rieper 2011; Ritz u. a. 2000) brachten eindeutige Evidenz und eine Modellbildung zur Magnetfeldwahrnehmung hervor. Nach heutigem Stand orientieren sich ca. 50 Tierarten am Erdmagnetfeld und nutzen es für ihre Navigation. Derzeit ist keine chemische Reaktion bekannt, die auf solch schwache Magnetfelder $(\sim 50 \mu \mathrm{T})$ ansprechen oder sensibel für deren Ausrichtung wären. Auf der Suche nach Antworten scheinen die Forscher nun fündig geworden zu sein. Basierend auf einem Radikalenpaar-Modell im Auge von Vögeln, nicht-trivialen Quanteneffekten und Spin-Veränderungen, ergeben sich sehr klare Evidenzen für Quantenkohärenz und Verschränkung. Dies wird im Folgenden veranschaulicht am Beispiel eines europäischen Rotkehlchens. Auslöser waren frühere Experimente, bei denen die Orientierung der Rotkehlchen nach Anlegen eines schwachen Feldes verloren ging. Als Ausgangspunkt des Phänomens wird ein fotochemischer Prozess im Auge des Vogels angenommen (Abb. 78).

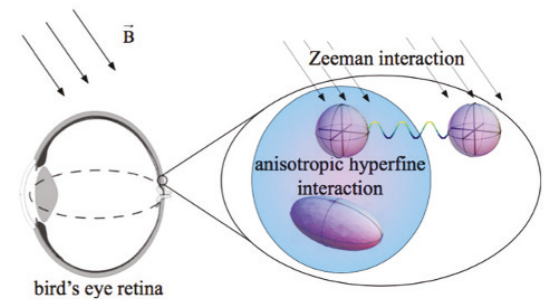

Abb. 78 | Startprozess zur Radikalenpaar-Bildung im Auge von europäischen Rotkehlchen Image und Beschreibung: Rieper (Rieper 2011: 9). Eintreffende Photonen beeinflussen das Spinverhalten zweier Elektronen auf der Augenretina. Darüber hinaus werden die Kernspins der Moleküle an die Elektronen gekoppelt. Das Erdmagnetfeld lässt sich mithilfe des Zeeman-Effektes als eine Anordnung von Spektrallinien vorstellen, an denen sich die Spins der Elektronen und der Kerne der Moleküle ausrichten und orientieren. Auf diese Art und Weise kann der Vogel kleinste Richtungsänderungen wahrnehmen.

Jedes einfallende Lichtteilchen trifft auf die Netzhaut und wechselwirkt dort mit einem Rezeptormolekül unter Freisetzung eines Elektrons. Diese interagieren daraufhin mit einem benachbarten Molekül. Als Ergebnis bilden sich Radikalenpaare, bei denen die zugehörigen Moleküle jeweils ein Elektron zu wenig und eines zu viel haben. In einem zweiten Prozessschritt werden weitere Radikalpaare durch Reoxidation gebildet, welche auch ohne Licht über Minuten stabil bleiben (vergleichbar der Ergebnissen bei Insekten von bis zu 6 Min. (Herbel u. a. 2013)). Diese Elektronen besitzen nun einen quanten- 
mechanischen, räumlich-verteilten Spin, der mit dem Magnetfeld der Umgebung wechselwirkt, ähnlich wie Eisenspäne mit Stabmagneten. Bewegt sich der Vogel, reagiert auch der Spin der Elektronen und löst biochemische Prozesse aus, die dem Rotkehlchen als Richtungsinformation dienen.

Zwei Elektronen werden zu Beginn durch das Photon zu einem Singulett-Zustand ${ }^{197}$ angeregt. Des Weiteren existiert ein Kernspin, der an eines der Elektronen ankoppelt. Es handelt sich hier um eine anisotrope Kopplung, sodass das Molekül eine Ausrichtung zum Spin besitzt (Rieper 2011: 9). Der Zeeman-Effekt beschreibt die Aufteilung von Spektrallinien (hier der magnetischen Energie B) in ihre Einzelkomponenten unter Anwesenheit eines statischen Magnetfeldes (hier das Erdmagnetfeld). Der räumlich-verteilte Spin des Elektrons erfährt durch die Spektrallinien Veränderungen, sobald es auch nur zu kleinsten Richtungsänderungen kommt. Mit Bezug auf Abb. 77 nimmt Rieper an, dass ein schwach oszillierendes Feld in Resonanz mit den beiden für die Navigation wichtigen Quantenzuständen gegangen ist und deshalb Störungen im Magnetsinn des Vogels erzeugt (vgl. ebd. 73).

Mit der Forschung 2016 wurde, auf dem ersten Radikalenpaar aufbauend, die Bildung eines weiteren Radikalenpaares nachgewiesen, das letztlich auch eine Orientierung im Dunkeln ermöglicht und wesentlich zeitstabiler ist. Aktuelle computergestützte Simulationen präzisierten und konkretisierten die bisherigen Erkenntnisse (Hiscock u. a. 2016). In Modellrechnungen zeigte sich eine sehr viel größere Sensibilität für Änderungen bei quantenmechanischer Verschränkung der Spins gegenüber einer nicht-verschränkten Variante. Tatsächlich wurde 2008 (Maeda u. a. 2008) der experimentelle Nachweis für einen möglichen Prozess geliefert, in dem ein magnetisches Feld die Lebensdauer eines Radikalenpaars beeinflusste. Es lässt sich damit annehmen, dass Vögel von einer solch höheren Sensibilität profitieren. Die Frage, die sich die Wissenschaftler dabei noch stellen, bezieht sich auf den Kontext, in dem dieser Mechanismus besonders Bedeutung erlangt. Sind es die Langstreckenflüge oder eher die schnelle Orientierung und Ausrichtung im Schwarm oder für das Verhalten gegenüber Angreifern?

Die Gruppe um Vedral (Gauger u. a. 2011) berechnete auf der Basis des Radikalenpaarmodells in Kombination mit experimentellen Daten eine mögliche Verschränkungsdauer von $10^{-5}$ Sekunden (=10 ms), wobei nach Berechnungen von Hiscock 1 ns ausreichen würde (Hiscock u. a. 2016). Sie übertrifft damit die besten von Menschen produzierten Laborwerte mehr als deutlich. Durch die 2016 veröffentlichte Untersuchung wurde die Verschränkungsdauer experimentell mindestens in den Minutenbereich verschoben. Offensichtlich scheint die Natur Mittel und Wege gefunden zu haben, wie sie Kohärenzen relativ stabil halten kann. Cai und Plenio führen dies auf die gleichen $\mathrm{Zu}-$ sammenhänge zurück, wie sie bei den Bakterien schon beschrieben wurden (Cai und Plenio 2013). Weitreichende Kohärenzen, die nachbarschaftliche Beziehung von Molekülen weit überschreiten, als auch kontinuierliche Störungen, helfen die Verschrän-

${ }^{197}$ Ein Singulett-Zustand bezeichnet den Spinzustand eines Mehrelektronenatoms. Der Gesamtspin des Elektrons ist Null, da sämtliche Elektronen antiparallel ausgerichtet sind. 
kungsdauer in offenen Quantensystemen signifikant zu steigern. Aus Sicht der Forscher weisen die Experimente mit Vögeln starke Indizien für die Verwendung des oben beschriebenen Radikalenpaarmechanismus auf. Dieser Ansatz stellt momentan das einzig brauchbare Modell dar, das sowohl theoretisch als auch experimentell konsistente Erklärungen liefert.

Rieper kam am Ende ihrer Dissertation über, Quantenkohärenz in biologischen Systemen' zu dem eindeutigen Schluss, dass Quanteneffekte in biologischen Systemen allgegenwärtig sind. Sie formulierte dazu zwei präzisierende Sätze: „Life is chemistry, and chemistry is quantum mechanics. “ [...] ,, The change of a single quantum number, the spin, may have macroscopic implication on the direction European Robins choose to fly to “ (Rieper 2011: 115).

\section{Homologe Verbindung zur Physik}

Nachdem Cai und Plenio den chemischen Kompass bei Vögeln als Quanten-Interferometer ${ }^{198}$ betrachten, der die Möglichkeit liefert, Informationen über die Richtung des Magnetfeldes zu generieren, ergibt sich die einfache Schlussfolgerung (Cai und Plenio 2013): Vögel lassen sich als quantenphysikalisches Messgerät zumindest in Bezug auf Erdmagnetfelder interpretieren.

Gleichzeitig liegt mit diesen Erkenntnissen ein konkretes Beispiel vor, das die ersten beiden Bedingungen von Greenstein und Zajonc repräsentieren (Kap. 7.3.1). Bedingung 1 war die ausreichende Entkopplung der Mikro- von der Makroebene. Das Radikalenpaar bewegt sich mit völlig anderen Freiheitsgraden als der Vogel selbst und sucht sich seinen Weg aufgrund von sehr zufälligen Variablen in der Umgebung des Auges. Sitzt der Vogel auf einem Ast oder frisst er, wird das Radikalenpaar keinen Einfluss auf ihn ausüben. Fliegt der Vogel aber und hat er ein bestimmtes Ziel im Auge, so ist sein inneres Erwartungssystem auf die Impulse des Radikalenpaars ausgerichtet und leitet ihn (Bedingung 2). Das Radikalenpaar übt somit Einfluss auf das Makrosystem Vogel aus. Und schließlich darf auch meine Annahme, dass die Temperatur nur als relative Relation angesehen werden kann, als bestätigt gelten (Kap. 7.3.1).

\section{$\underline{\text { Bezug zur SyA }}$}

Die Wirkung der inneren Erwartungshaltung scheint bei Repräsentanten von SyA nicht anders zu sein. Auch sie agieren oder reagieren entsprechend innerer Wahrnehmungen.

\footnotetext{
${ }^{198}$ Mithilfe der Interferometrie lassen sich Informationen aus Wellenüberlagerungen gewinnen. Die Gesamtwelle kann mit dieser Messmethode in ihre Einzelwellen aufgespalten und diese damit bestimmt werden. SQUID's (supraleitendes Quanten-Interferometer) stellen die quantenmechanische Variante dar und beruhen auf dem Josephson-Effekt. Sie dienen zur Erfassung schwächster Magnetfelder. Ergänzt mit ihrem mathematischen Pendant, der Fourier-Transformation, lassen sich solche gemessenen Wellen grafisch darstellen. Im Kap. 8.3 Neurowissenschaften werden wir wieder darauf zurückkommen.
} 


\subsubsection{Geruchssinn reagiert auf Frequenzen und Tunneleffekten}

Untersuchungen bei Fruchtfliegen (Franco u. a. 2011) zeigten ebenfalls experimentelle Evidenz für ein völlig anderes Verständnis in Bezug auf das Phänomen ,Riechen'. Nicht die Form der Moleküle scheint für die Geruchserkennung verantwortlich zu sein, wie bisher angenommen wurde, sondern die Vibration der Moleküle und Tunneleffekte. Untersuchungen (2013) bei Menschen bestätigten diesen Sachverhalt auch dort (Gane u. a. 2013), nur musste für untrainierte Nasen die Menge an veränderten Isotopen erhöht werden. In beiden Fällen wurden Geruchsstoffe mit unterschiedlichen Isotopen von Wasserstoff verwendet - Wasserstoff selbst und Deuterium. Deuterium (auch bekannt als schwerer Wasserstoff) ist ein natürliches Isotop von Wasserstoff und zeichnet sich durch die gleiche Form aus, besitzt aber im Kern zusätzlich zum Proton noch ein Neutron. Durch die ergänzende Masse des Neutrons wird Deuterium schwerer und ändert damit die Frequenz. Auch hier wird ein Elektron aus den Molekülen des Geruchsstoffs, nach dem Kontakt mit dem Rezeptor, herausgelöst und tunnelt durch den Rezeptor. Die veränderte Elektronenladung führt zu einer veränderten Oszillation und löst wieder biochemische Prozesse aus, die der Körper mit bestimmten Gerüchen assoziiert. Nicht nur, dass die Fruchtfliegen die beiden Isotope differenzieren konnten, sie konnten auch auf jeweils eine Variante konditioniert werden. Darüber hinaus vermochten sie die Isotope in Verbindung mit anderen Geruchsstoffen zu unterscheiden. Im Experiment mit Menschen waren diese in der Lage, die Isotope auch nach einer gas-chromatographischen Reinigung zu erkennen, bei der sämtliche mögliche Verunreinigungen entfernt werden. Es war unerheblich, ob es sich um trainierte oder untrainierte Versuchspersonen handelte.

Tatsächlich wurden erste Überlegungen zu Oszillationsmodellen bereits Ende der 1920er Jahre publiziert. In seiner ,Schwingungs-Theorie' betrachtete Dyson die Schwingung zwischen den Molekülbindungen als die relevante Verantwortliche für den Riechprozess (Dyson 1928). Allerdings konnte damit noch nicht die Besonderheit bei chiralen ${ }^{199}$ Formen erklärt werden, die trotz gleichem Aufbau unterschiedliche Gerüche erzeugen (Al-Khalili und McFadden 2015: 187). Wright nahm an, dass die Geruchsrezeptoren selbst chiral aufgebaut sein könnten, und deshalb auch diese Unterscheidung registrieren. Zu dieser Zeit bestand allerdings keine Möglichkeit dies nachzuweisen. In der Folge setzte sich immer mehr die Vorstellung eines Schlüssel-Schloss-Modells (,Passform-Theorie'), durch, bei der die Form des Geruchsmoleküls zum Rezeptor passen sollte (ebd. 188f). Dieses Modell ist heute noch von Biologen die am meisten bevorzugte Variante, obwohl sie in keiner Weise erklären kann, weshalb Duftstoffmoleküle gleicher Formen unterschiedlich riechen (ebd. 189, 191) bzw. Moleküle unterschiedlicher Form gleich riechen. Diese Schwäche versuchten zwei Forscher mit ihrer ,Odotope-Theorie' (auch Schwache-Formen-Theorie genannt) zu beheben (Mori und Shepherd 1994), indem sie annahmen, dass nicht die ganze Form, wohl aber bestimmte chemische Gruppen relevant seien. Jedoch auch sie haben, vergleichbar der ,Schwin-

${ }^{199}$ Chirale Formen von Molekülen sind Spiegelbilder, die nicht miteinander zur Deckung gebracht werden können. 
gungs-Theorie' Probleme zu erklären, weshalb Moleküle mit den gleichen chemischen Gruppen aber anderer Anordnung, unterschiedlich wahrgenommen werden. Beispiele sind Vanille und Isovanillin (ebd. 189).

Schließlich wies Turin bereits 1996 auf diesen Zusammenhang hin und entwickelte die zugrundeliegende Theorie, basierend auf Frequenzabhängigkeit und Quantentunnelprozess (Turin 1996). Aufgrund der gleichen Frequenz traf er die Vorhersage, dass Boranen (Borwasserstoffverbindungen) und Schwefel bzw. verfaulte Eier gleich riechen müssten. Chemisch und von der Struktur her haben beide Stoffe nichts gemein, sodass nur die gleiche Frequenz den Link zum Geruchsempfinden herstellte. Er verglich den Prozess mit einem technisch bekannten Verfahren, der inelastischen Elektronen-Tunnelspektroskopie (IETS). Dabei gibt ein Elektron einen Teil seiner Energie ab, um den Sprung durch eine Energiebarriere realisieren zu können. Durch die Energieabgabe verändert sich seine Frequenz und gleicht sich der Frequenz der Zielmoleküle an. Die gemeinsame Oszillation von Elektron und Rezeptor ermöglichen also die Überwindung von scheinbar unüberbrückbaren Entfernungen und lassen sich als Verschränkung interpretieren. Turin ging nun davon aus, dass das IETS durch ein Molekül, den Geruchsrezeptor, ersetzt wird. Fängt der Rezeptor ein Duftstoffmolekül mit der richtigen Frequenz ein, gelangt das Elektron durch den Tunneleffekt vom Ausgangspunkt (dem Donator) zum Zielpunkt (dem Akzeptor) und löst die Nachrichtenkette bis ins Gehirn, über olfaktorischen Neuronen, aus. Seine Vorhersage, dass die Oszillation das entscheidende Kriterium ist, konnte er mit dem Vergleich von Schwefel-Wasserstoff und Bor-Wasserstoff-Bindungen bestätigen (Al-Khalili und McFadden 2015: 194). Beide liegen bei 76 bzw. 78 Terahertz und besitzen unterschiedliche Formen, zudem ist in der B-H-Verbindung kein Schwefel enthalten (ebd. 195). Auch er bekam zunächst heftigen Widerstand für seine Theorie, die jedoch durch andere Wissenschaftler (Paoli u. a. 2016; Brookes u. a. 2007) auch von der theoretischen Möglichkeit her bestätigt wurde. Brookes und ihre Kollegen stellten ebenfalls Tunneleffekte fest, vergleichbar dem Magnetkompass bei Vögeln. Ihr Ansatz wird als übereinstimmend mit der bekannten Physik angesehen. Gleichwohl ist die Diskussion zu diesem Mechanismus noch nicht final beantwortet und wird derzeit noch kontrovers behandelt (Block u. a. 2015a, 2015b; Turin u. a. 2015). Zentral bei diesen Versuchen scheint allerdings die Gefahr von Verunreinigungen zu sein, die selbst bei Größen von 0,0006 \% bereits wesentliche Verfälschungen erzeugen können (Paoli u. a. 2017).

Schließlich gibt es heute noch eine letzte Theorie-Variante (Durchzugleser-Theorie bzw. Swipe-Card-Theory), in der sowohl die Passform als auch die Frequenz auf Quantenebene eine Rolle spielen. Dieses Modell scheint alle experimentellen Befunde zu erfüllen und wurde von Stoneham das erste Mal erwähnt (Brookes u. a. 2012). Um einen frequenzinduzierten Tunnelprozess überhaupt zu ermöglichen müssen demnach gewisse Passungs-Voraussetzungen erfüllt sein, vergleichbar einer Scheckkarte, die durch ein Lesegerät gezogen wird. Brookes konnte zeigen, dass in der Tat auch die Geruchsrezeptoren chirale Form besitzen und für jede Form eigene Akzeptoren existieren. 


\subsubsection{Biophysik bei Menschen}

\subsubsection{Antioxidative Wirkung von Pflanzen bei Menschen}

Ebenfalls 2007 konnte die antioxidative Wirkung von Grünem Tee auf quantenphysikalische Tunneleffekte zurückgeführt werden (Tejero u. a. 2007). Tejero und seine Gruppe erkannten, dass durch Tunneln der Wasserstofftransfer um ein Vielfaches schneller ist, als die Reaktionsfähigkeit der Lipid-Peroxyl-Radikale.

Grüner Tee ist in verschiedenen Kulturen mit guter Gesundheit und einem langen Leben assoziiert. Man weiß, dass die in ihm enthaltenden Catechine, die als Antioxidantien wirken, eine entscheidende Rolle spielen, indem sie die schädliche Kettenreaktion zwischen Lipiden und freien Radikalen stören. Bis 2007 war jedoch unklar wie diese Catechine, die nur wenige Mikromol $\left(10^{-6}=\right.$ ein millionstel Mol $)$ an Konzentration im Körper aufweisen, wirken. Ihr Modell zeigte die Bildung einer Wasserstoffbrücke mit zwei Sauerstoffatomen. Die dabei gebildete kompakte Struktur und das schmale Energieprofil erlauben für den Wasserstofftransfer sehr große Tunneleffekte. Wie wir gesehen haben, ermöglicht das quantenmechanische Tunneln das Überwinden von Energiebarrieren, was im klassischen Verständnis unmöglich ist. Als Konsequenz ist der Wasserstofftransfer wesentlich schneller an den kritischen Stellen als die Reaktion der freien Radikale mit den Lipiden. Die Radikale werden gefangen bevor sie Schaden anrichten können.

Catechine kommen in sehr vielen Tee- und Obstsorten wie auch in Gemüse und Wein vor und ihre schützende Wirkung gegen Krebs, Entzündungen und Herz-Kreislauf-Erkrankungen ist gut erforscht, wie die Forscher schreiben (Tejero u. a. 2007). Da diese ähnliche gesundheitliche Zuschreibungen aufweisen wie Grüner Tee, darf man davon ausgehen, dass dort vergleichbare Mechanismen ablaufen.

Auffallend ist, dass sich bei Tejero's Modell die gleichen Voraussetzungen finden, wie sie in den Theorien zur Photosynthese für stabile, kohärente Prozesse in NichtGleichgewichtszuständen entwickelt wurden: ,Kompakte Struktur' und damit enge Beziehungen und starke Wechselwirkungen zum einen sowie ,Energieprofile', die sich gegenüber dem verrauschten Umfeld isolieren können.

Quantenmechanische Prozesse sind damit beim Menschen angekommen. Analog zum Tunnelprozess bei der Photosynthese weiß der Wasserstoff bzw. die zugehörige Information an welche Stelle sie tunneln muss, um sich dort zu manifestieren.

\subsubsection{Verarbeitung von Superpositionen beim Hören}

Die Forschungen von Yost stehen im Gegensatz zur üblichen Auffassung, dass wir beim Hören von Geräuschfeldern (z. B. gleichzeitig Auto, Wind, Musik, Föhn) den Sound einzelner Entitäten wahrnehmen (Yost 1992). Seine Untersuchungen machen deutlich, dass tatsächlich beim Empfänger komplexe Frequenzüberlagerungen ankommen und das neurologische System in der Lage ist, die einzelnen Frequenzen den Objekten zuzuordnen. Dabei wird das Gesamtsoundbild erst durch die Neuronen des Gehirns aufgelöst und zugeordnet und nicht schon beim Transport durch die Nervenbahnen. Wie sie beto- 
nen, widerlegen ihre Ergebnisse das bisherige Verständnis, dass die einzelnen Frequenzen durchgeleitet würden.

Damit ist unser Körper auch bei Schallwellen in der Lage, eine Wechselwirkung zwischen ankommenden Informationen und gespeicherten Informationen auf Zell- und Neuronenebene abzugleichen. Als Ergebnis werden mentale Klangbilder zur Verfügung gestellt, die die Außenwelt repräsentieren.

\section{Homologe Verbindung zur Physik}

Im Grunde funktioniert unser Organismus wie eine Laplace-Transformation, die eine Superposition von akustischen Frequenzen entschlüsselt und separiert. Diese Frequenzen treten in Resonanz mit Entitäten der elementaren Ebene wie Atomen und Molekülen, die die Informationen abgespeichert haben und auf kohärente Impulse reagieren. Vergleichbar der Photon-Atom-Photon- erfolgt hier eine Elektron-Atom-ElektronKopplung bzw. eine EMF-Zelle-EMF-Kopplung, über die gleiche Informationsstrukturen erkannt werden.

\subsubsection{Photonenemission bei Menschen}

Wie Pflanzen und Tiere steht auch der Mensch mittels Energieabgabe und Energieaufnahme im Austausch mit der Umwelt, u. a. auch von Licht. Auch hier sollte es demzufolge Prozesse geben, die analog zu den anderen Lebensformen verlaufen.

Wenn von Photonenemission bei Menschen die Rede ist, denken viele vermutlich sofort an die vom Biophysiker F.-A. Popp untersuchten sogenannten ,Biophotonen', die lange ins Reich der Mythen verwiesen wurden. Ein Kritikpunkt in der Auseinandersetzung mit der von Popp postulierten gesundheitlichen Wirkung ist immer wieder die aus physikalischer Perspektive sehr schwache Energie (Popp u. a. 1984). Mit Bezug auf den oben herausgearbeiteten Zusammenhang, dass es nicht auf die Intensität, also Stärke der Energie, sondern auf die Phasenähnlichkeit ankommt, greift dieser Kritikansatz nicht mehr. Dies ist vor allem vor dem Hintergrund bedeutsam, als dass mehrere der bisherigen Beispiele trotz extrem schwacher EM-Werte erfolgreich arbeiten (z. B. Vogelkompass, DNA). Zunehmend intensivere Forschungen zeigen dagegen Evidenz für diesen Ansatz (Prasad u. a. 2014; Van Wijk u. a. 2014), und dass die Biophotonen-Strahlung u. a. in Zusammenhang mit der DNA steht und besonders bei Stress und Krankheiten ansteigt (Kobayashi u. a. 2014; Popp u. a. 1984).

Tatsächlich geht die Entdeckung schwacher Photonenemission von Zellen auf den russischen Biologen Alexander Gurwitsch im Jahre 1923 zurück (Gurwitsch 1988). Popp nannte sie Biophotonen, um sie von der Biolumineszenz (mithilfe von Leuchtstoffen aktiv von Lebewesen erzeugtes Licht) zu unterscheiden. Der Begriff ,Biophotonen' steht als Synonym und Kurzform für ultraschwache Photonenemissionen (UPE) und wird in der Biophysik und Alternativmedizin verwendet. Die Energie solcher Photonen ist sehr niedrig. Popp fand Wellenlängen von $200-800 \mathrm{~nm}\left(2 \times 10^{-7} \mathrm{~m}\right)$ für Zellen und vermutete die gleiche Kohärenz wie bei Laserlicht (Popp u. a. 1984: 35). Über eine solche Kohärenz gab es erheblichen wissenschaftlichen Streit. Er dürfte mit den jüngsten 
Entwicklungen zugunsten der Kohärenztheorie entschieden sein, nachdem sowohl kohärente Interaktionen in Neuronen auf der Basis von Biophotonen, als auch zwischen Atomen und Molekülen nachgewiesen wurden (Choi u. a. 2016; Rahnama u. a. 2011).

Klassischerweise gehen die Kritiker von Popp und von quantenphysikalischen Erklärungsansätzen generell von der Annahme aus, dass ,Quorum sensing' für die Interaktion von Zellen verantwortlich ist und das Geschehen dominiert, also die chemische Kommunikation über die Zelldichte (Fuqua u. a. 1994). Man führt die Fähigkeit von Bakterien, sich gemeinsam zu koordinieren und so Prozesse zu kreieren, wie z. B. die Biolumineszenz oder die Herstellung und Abgabe von Antibiotika, für die sie alleine nicht in der Lage wären, darauf zurück. Es sei nochmals auf das im Kap. 5.3.5 beschrieben ,Morphogenetische Feld' hingewiesen. Quorum sensing entspricht genau diesem ,Morphogenetischen Feld' und darf als Synonym dessen verstanden werden, nur dass sich ,Quorum sensing' auf Einzeller bezieht. In der Biologie beschreibt der Begriff ,Morphogenetisches Feld' die Möglichkeit von Signalmolekülen, sogenannte Morphogene, über unterschiedlich große Reichweiten Gene zu aktivieren, um dadurch bestimmte Muster und Formen auszubilden. Ihre Reichweite hängt von der Stärke der Konzentration an Morphogenen ab, analog der Zelldichte bei, Quorum sensing'. Zur besseren Verdeutlichung sei hier nochmal Prigogine's Beschreibung aufgeführt: „Einer der interessantesten Aspekte der dissipativen Strukturen ist zweifellos ihre Kohärenz. Das System verhält sich danach als ein Ganzes, so als wäre es der Sitz von langreichweitigen Kräften. Obwohl die Wechselwirkungen zwischen den Molekülen nicht über eine Reichweite von einigen $10^{-10} \mathrm{~m}(0,1 \mathrm{~nm})$ hinausgehen, ist das System so strukturiert, als wäre jedes Molekül über den Gesamtzustand des Systems 'informiert' [...]. Embryologen haben vor langer Zeit den Begriff des morphogenetischen Feldes eingeführt und die Hypothese aufgestellt, dass die Differenzierung einer Zelle von ihrer Position in diesem Feld abhängt " (Prigogine und Stengers 1993: 171-172). Auch Prigogine stellt damit eine Kohärenz des Systems fest und bezieht das Geschehen im Umfeld der Gene auf genau diesen Zusammenhang.

Nun weisen die bereits aufgeführten Beispiele sehr deutlich auf den Einfluss selbsterzeugter oder von außen angelegter EMF für die Kohärenzerzeugung hin und stellen den ,Quorum sensing' Ansatz bzw. das ,Morphogenetische Feld' in ein neues Licht. Es darf angenommen werden, dass zumindest nicht alleine die chemischen Interaktionen die beobachtbaren bio-chemischen Prozesse verursachen, sondern die EM-Schwingungen. Dazu passt auch die neu entdeckte ,klassische Verschränkung', die im Kap. 8.1.2.3 vorgestellt wurde. Auch auf diese Art kann nachweislich Information ausgetauscht werden.

Der von Kobayashi und Kollegen vorgestellte konkrete Nachweis der Lichtemission und die begleitenden Ergebnisse bieten Möglichkeiten für weiterführende Überlegungen (Kobayashi u. a. 2009). 2009 zeigten sie, dass der menschliche Körper Licht direkt und rhythmisch emittiert (Abb. 79). Sie stellten fest, dass die ultraschwache Photonenemission unseres Körpers niedriger ist als die Sensitivität unserer Augen. Wie den Bildern zu entnehmen ist, emittiert der menschliche Körper sehr unterschiedlich, sowohl was 
die Tageszeit als auch die Körperstellen betrifft. Am stärksten ausgeprägt erscheinen die Regionen um Mund, Wangen und Kehlkopf. Die Augenregion strahlt demgegenüber etwas schwächer. Dies legt nahe, dass unsere Sehorgane tatsächlich eher eine absorbierende, denn eine emittierende Funktion aufweisen.

Neuere Forschung bestätigt die Unterschiedlichkeit bzgl. der Tageszeit, der Körperregionen als auch bei unterschiedlichen Menschen (Van Wijk u. a. 2014). Die bei Van Wijk dargestellte Körperstrahlung sowie eine verstärkte Photonenstrahlung an den Händen (siehe auch die Chi-Experimente mit Krebszellen in Kap. 8.2.1.3) lässt die der Alternativmedizin behauptete ,Aura' und das ,Heilen mit Händen' sogar als plausibel erscheinen.
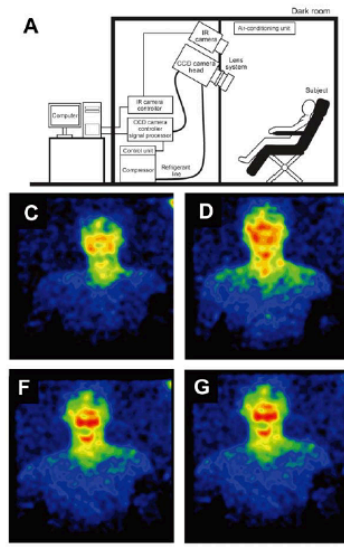
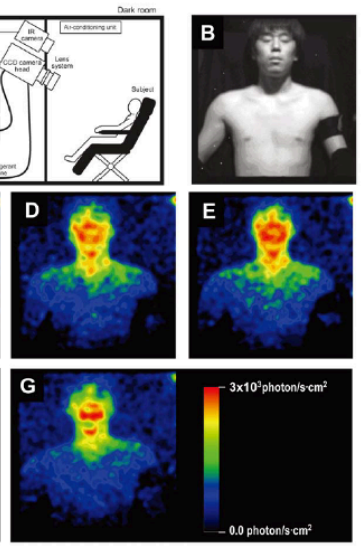
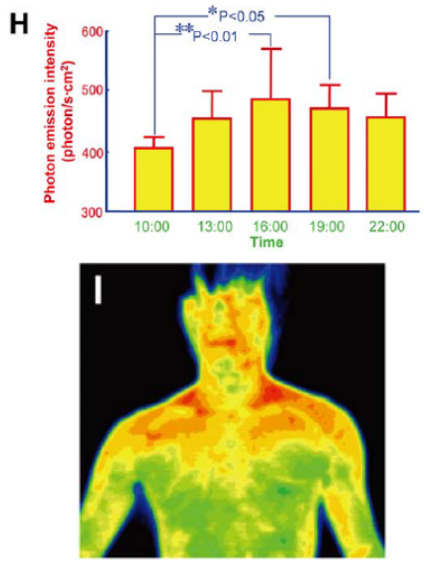

Abb. 79 | Photonen- und thermische Strahlung bei Menschen

Die Bilder A und B stellen die Versuchsanordnung dar. Schwache Photonenstrahlung (Bilder C - G) im Vergleich zu thermischer Strahlung (Bild I) beim Menschen. Bild H verdeutlicht den täglichen Rhythmus der Photonenemission. Images aus der Veröffentlichung von Kobayashi und Kollegen (2009).

Da eine solche Emission in alle Richtungen strahlt (ebd.), können wir davon ausgehen, dass diese sich auch nach innen orientiert. Tatsächlich gibt es entsprechende Nachweise von Biophotonen bereits in Zusammenhang mit unserem Gehirn (Tang und Dai 2014a; Dotta u. a. 2011). Dort dann konsequenterweise in Wechselwirkung mit ihrem zellulären Umfeld. Tatsächlich zeigen neue Erkenntnisse, dass die Strahlungsdichte innerhalb der Zelle um den Faktor 2 höher ist, als von außen messbar (Bókkon u. a. 2010).

Biophotonen werden von nahezu allen lebenden Organismen emittiert, ohne eine vorausgehende Anregung externer Photonen. Man führt ihre Strahlung deshalb auf Veränderungen im Stoffwechsel zurück, z. B. durch Oxidations- und Radikalreaktionen. Wie Kobayashi und Kollegen feststellen, reagieren freie Radikale anschließend mit Lipiden oder Proteinen, wobei sie als Nebenprodukte elektronisch angeregte ultraschwache Photonen erzeugen (Kobayashi u. a. 2009). Hier sei an den Magnetsinn des Rotkehlchens erinnert. Auch dort gab es einen Radikalenmechanismus. Die Autoren fanden, analog 
zu den vorherigen Beispielen, ebenfalls keinen Zusammenhang der Photonenemission mit der Tagestemperatur. Was sich allerdings zeigte, war eine negative Korrelation zu Cortisol $^{200}$. Mit einem Anstieg der Photonen-Emission geht eine Verringerung der Cortisol-Produktion einher und umgekehrt.

Dieser Zusammenhang von Cortisol, Photonenemission und einem Radikalenmechanismus lässt bei heuristischer Betrachtung tatsächlich einen von Popp angenommenen gesundheitsrelevanten Mechanismus in Verbindung mit Biophotonen als möglich, wenn nicht sogar wahrscheinlich erscheinen. Was bedeuten könnte, dass die Biophotonen ein Indikator für einen Selbstheilungs- oder Korrekturmechanismus sind. Radikalreaktionen waren bei Grünem Tee im Spiel wie auch beim Vogelkompass. In beiden Fällen gingen Tunnelprozesse, Verschränkungen und damit verbundene Kohärenzen einher. Zustände, die für die jeweiligen Lebensformen Geschwindigkeitsgewinn und Effizienz mit sich brachten.

Die den Biophotonen zugesprochenen Kohärenzen lassen sich demzufolge nicht nur als Ausgangspunkt, sondern auch als Ergebnis des Tunnel- und Verschränkungsprozesses definieren, denn die Kohärenz baut sich über das Verschränkungsgeschehen auch auf. Als Konsequenz werden Photonen freigesetzt, die sich in einem kohärenten Umfeld bewegen und dieses Umfeld ihrerseits kohärent halten. Natürlicherweise sollte man davon ausgehen, dass diese Photonen eine Frequenz aufweisen, die dem Umfeld entspricht und somit in gleicher Weise kohärent ist. Dieser Prozess lässt sich als zirkulär oder koevolutionär bezeichnen und ist vergleichbar mit dem Auf- und Abbau von Verschränkungszuständen, wie es bereits an anderer Stelle beschrieben wurde.

\section{Homologe Verbindung zur Physik}

Äquivalent zur Physik ließen sich Kopplungen über Kohärenz von EMF als auch Kopplungen über Radikalenpaare beobachten. Die erste entspricht einer Verschränkung mittels EM-Wellen, die zweite einer Verschränkung entsprechend dem Teilchenmodell.

Mit Bezug auf den im Kapitel ,Verschränkung und Dekohärenz' beschriebenen Zusammenhang, dass Verschränkung auch dann vorliegt, wenn Photonen, Elektronen oder Atome von der gleichen Quelle emittieren, lässt sich weiter schlussfolgern: Alle vom Menschen abgegebene Strahlung ist verschränkt und trägt die Information des Gesamtsystems Mensch in sich. Trifft diese auf weitere Entitäten und interagiert mit diesen, liegt seine Information auch bei den anderen Entitäten vor.

\subsubsection{Emission und Absorption von Quanten allgemein bei Menschen}

Abschließend zum Thema Lichtemission folgt noch ein interessanter Bezug zum grundsätzlichen Strahlungsverhalten (Emission und Absorption) von Menschen. Zu diesem Thema hat Warnke eine interessante Rechnung aufgemacht (Warnke 1998: 50): Jedes Atom im menschlichen Körper sendet 1.450 Quanten pro Sekunde bei $37^{\circ} \mathrm{C}$. Bezogen

${ }^{200}$ Cortisol ist ein Hormon, das bei Stress freigesetzt wird, um Stoffwechselvorgänge zu aktivieren und um dem Körper energiereiche Verbindungen zur Verfügung zu stellen. Es wirkt dadurch dämpfend auf das Immunsystem und dient zur Hemmung von Entzündungen. 
auf die Größe einer $60 \mathrm{~kg}$ schweren Frau kommt er auf 1021 Quanten pro Sekunde, die an die Umgebung abgegeben werden. Davon repräsentiert ein kleiner Anteil Quanten das niederfrequente sichtbare Licht, also Biophotonen, wie wir eben gesehen haben. Der wesentlich größere Anteil besteht aus Quanten im thermischen Bereich, also Wärmestrahlung und in fast gleicher Größe Mikrowellenstrahlung, diese allerdings nur innerhalb des Körpers. Daraus berechnet er eine durchschnittlich abgegebene Quantenenergie mit $0,072 \mathrm{eV}$, was $1,154 \times 10^{-20} \mathrm{~J}$ entspricht. Je nach Körpergröße werden so zwischen 26.900 bis $35.900 \mathrm{~kJ}$ von einem Menschen abgestrahlt. Umgekehrt bekommt der Mensch zwischen 21.000 bis $29.000 \mathrm{~kJ}$ von der Sonne zugeführt. Dies bedeutet eine Differenz zu Ungunsten eines Menschen von 5.900 bis $6.900 \mathrm{~kJ}$ oder 1.409 bis 1.648 kcal, was in etwa durch Nahrung aufgenommen werden muss. Damit bestätigt sich die Idee von Plenio (Chin u. a. 2013), dass ,Photosynthese die Basis aller lebenden Formen' darstellt, weit mehr, als uns gemeinhin bewusst ist.

Energiebalance-Untersuchungen (Webb u. a. 1980; Durnin 1973) und eine Dokumentation 2010 (Straubinger 2010), die eine heftige Kontroverse auslöste, unterstützen die Überlegungen von Warnke. Gleichwohl erscheinen sie für unser heutiges Verständnis schwer vorstellbar.

In der Dokumentation von 2010 scheint unsere Erfahrung - oder muss man sagen Annahme - dass Menschen für ihr Überleben unbedingt grobstoffliche Nahrung und Wasser zu sich nehmen müssen, erhebliche Risse zu bekommen. P.A. Straubinger stellt in seiner in Österreich erschienen Film-Dokumentation ,Am Anfang war das Licht' seine in 10 Jahren recherchierten Ergebnisse zu Menschen vor, die sich angeblich nur von Licht ernähren ${ }^{201}$. Ein für unser Verständnis schwer vorstellbares Phänomen. In dieser Dokumentation geht es um Personen, die über Wochen, Monate und Jahrzehnte völlig ohne feste Nahrung und teilweise sogar ohne Wasser leben können. Darunter sind auch mehrere, durch Universitäten begleitete, streng wissenschaftlich kontrollierte Studien. Die Studien liefen im Wesentlichen alle gleich ab: Die Versuchsteilnehmer wurden in den Klinken in einem separierten Raum 10 - 15 Tage rund um die Uhr, teilweise mit mehreren Kameras, beobachtet und waren die ganze Zeit an verschiedensten Geräten angeschlossen. Kontinuierlich wurden ihre Blutwerte und sonstige Daten erhoben. In einem Fall kamen bildgebende Verfahren zur Beobachtung des Verhaltens von Darm und Blase zum Einsatz.

So zeigten die Laborwerte des Meditationslehrers Hira Ratan Manek keinerlei physiologische Normabweichungen, wie etwa Spuren von Ketonen. Ketone sind Stoffwechselprodukte und finden sich im Blutbild, wenn Fett in Zucker umgewandelt wird. Somit wären sie ein sicheres Indiz für einen Fastenprozess, was sich aber nicht zeigte. Trotz keinerlei Nahrungs- und Flüssigkeitsaufnahme hielt sich auch das Gewicht des Probanden. Prof. Dr. Anton Luger, ein mehr als skeptischer Professor für Stoffwechselprozesse, der 2008 an der Wiener Uniklinik diese Untersuchung durchführte, blieb mit seinen Wissenschaftskollegen ratlos zurück.

${ }^{201}$ Hintergrundinformationen zum Film incl. dem im Nachgang folgenden Disput finden sich unter ... http://www.lightdocumentary.com/index.html 
Gleiches ereignete sich in Indien als der 83-jährige Yogi, Mataji‘ Prahlad Jani, der nach Angabe der Dokumentation bereits 70 Jahre ohne Nahrung auskam, 15 Tage unter kontinuierlicher Beobachtung stand. Auch hier waren der Studieninitiator Dr. med. Sudhir Shah und seine 30 unterstützenden indischen Ärzte absolut ratlos. Sie konnten sogar mit Ultraschall beobachten wie sich seine Blase füllte und wieder leerte, ohne dass er trank oder auf die Toilette gehen musste. Die Untersuchung fand am Indian Devence Institute of Physiology and Allied Sciences unter Hinzunahme von Physikern statt, mit allen erdenklichen klinischen Tests, unter anderem tägliche Bluttests und CT-Scans.

Ein interessanter Effekt zeigte sich an zwei unterschiedlichen Fällen im Film. Sowohl der Schweizer, der sich einer kontrollierten Studie unterzog, als auch der 70-jährige Yogi verloren während der Studie 2 - $3 \mathrm{~kg}$ Gewicht. Vermutete der Schweizer, dass dies an den für ihn sehr unangenehmen räumlichen Bedingungen lag - Klimaanlage, nur stickiger Raum, wenig natürliches Licht - aber ohne dass er daran etwas änderte, reagierte der Yogi anders. Nach den Gewichtstabellen erreichte er am 7. Tag mit $38 \mathrm{~kg}$ seinen niedrigsten Wert. Darauf bat er um frische Luft, natürliche Sonne und um die Erlaubnis, sein Yogi-Bade-Ritual ${ }^{202}$ vornehmen zu können. Unter Aufsicht wurde ihm dies gewährt und führt umgehend wieder zu einer Gewichtszunahme von einem Kilo innerhalb der nächsten 3 Tage. Diese letzten Angaben sind einer Antwort auf Reaktionen zum Film entnommen und unter dem angeführten Link zum Film dokumentiert.

So gut wie alle vorgestellten Fälle beschrieben einen Übergangsprozess, der starke mental Anteile hatte, und an dessen Ende sich der Körper von der festen auf die, wie sie es nannten, ,Lichtnahrung' umstellte. Bekannt scheint dieses Phänomen fast in allen Kulturen, auch in der westlichen. So scheinen mehrere 100 Menschen aus dem deutschsprachigen Raum mit dieser Form der Nahrungsaufnahme Erfahrung zu haben.

Machen wir uns in diesem Zusammenhang zwei anerkannte Phänomene bewusst:

1. In den Wintermonaten ist der Bedarf nach Nahrung bei vielen Menschen deutlich höher als in den Sommermonaten, obwohl die körperlichen Aktivitäten meist geringer sind. Weniger Licht, weniger frische Luft und kältere Temperaturen müssten entsprechend der von Warnke vorgenommenen Beobachtungen und Berechnungen den Bedarf nach zusätzlicher Energie befeuern.

2. Die Verdauung selbst beansprucht einen erheblichen Energieverbrauch und reduziert somit den Nährgehalt der aufgenommenen Nahrung.

Würden wir also auf die Nahrungsaufnahme verzichten, würden sich konsequenterweise die von Warnke veranschlagten ca. $1.500 \mathrm{kcal}$ weiter reduzieren. Sowohl Popp als auch Radin weisen im Film darauf hin (ebd.), dass es im Wesentlichen um Energie und Information geht, die wir aufnehmen müssen und nicht um irgendwelche Moleküle. Die Information scheint, wie wir bereits gesehen haben, verantwortlich für die Art, wie sich Quarks zusammenfügen und wie sich daraus Moleküle, Mineralien oder weitere höhere Lebensformen konstituieren. Nach Popp (ebd.) benötigt es immer Licht, um biologische

${ }^{202}$ Das Bade-Ritual fand in Zusammenhang mit Licht im Freien statt, aber ohne Wasserverwendung. 
Prozesse anzustoßen. Ausgehend von den Berechnungen von Warnke und der Macht der Intention, also eines irgendwie gearteten geistigen Einflusses, die Mikrosysteme beeinflusst, ist der Schritt zu einer Erklärung des Phänomens Lichtnahrung nicht mehr so weit. Passend dazu formulierte der Physik-Nobelpreisträger Josephson im Film: „,Ich glaube, die Physik befindet sich in einer Sachgasse, solange sie geistige Effekte ignoriert" (ebd.).

Grundsätzliche Energiebalance-Studien unterstützen diese Annahmen (Webb u. a. 1980; Durnin 1973).

Eine weitere Unterstützung erhalten die Aussagen des Films durch die Arbeit von AlKhalili und McFadden. Sie vergleichen in ihrem Buch die Art, wie Pflanzen und Tiere/Menschen die Grundbausteine des Lebendigen beziehen und stellen fest, dass diese nicht so unterschiedlich ist (Al-Khalili und McFadden 2015: 159).

Beide benötigen Kohlenstoff, Elektronen und Energie:

\section{Kohlenstoff}

Pflanzen gewinnen ihn aus der Luft und wandeln ihn durch Photosynthese um. Tiere und Menschen entnehmen ihn üblicherweise aus organischen Zellen, in der Regel eben aus Pflanzen, die ihn bereits umgewandelt haben. Der Prozess bei Menschen/Tieren erfolgt dabei durch die Zellatmung, bei der Nahrung verbrannt und dadurch verfügbar wird.

\section{Elektronen}

Elektronen werden zum Aufbau der Biomoleküle benötigt. Pflanzen nutzen hierzu das Licht, um Wasser zu verbrennen und so an dessen Elektronen zu gelangen. Tiere/Menschen verbrennen organische Moleküle, um ebenfalls an deren Elektronen zu gelangen.

\section{Energie}

Pflanzen gewinnen sie durch das Einfangen der Photonen von der Sonne. Tiere/Menschen gewinnen die energiereichen Elektronen aus der Nahrung und aus der Atmung.

Wie die beiden Autoren feststellen, sind bei all diesen Prozessen Bewegungen der Elementarteilchen beteiligt und die unterliegen den Gesetzen der Quantenwelt (ebd. 160). Da Menschen letztlich aus den gleichen Bausteinen aufgebaut sind und vermutlich letztlich auch aus den gleichen Wurzeln stammen, scheint es nicht gänzlich unmöglich, wenn wir uns gewisse Grundfähigkeiten, die Ähnlichkeiten mit den Prozessen auch anderer Lebensformen aufweisen, noch bewahrt haben.

Legen wir zusätzlich die Berechnungen von Warnke daneben, so muss festgestellt werden, dass ein erheblicher Teil der täglichen Energie offensichtlich bereits auf diese Weise aufgenommen wird. Kohlenstoff wird durch die Atmung, Photonen durch Atmung und die Haut gewonnen. In Verbindung mit dem Beobachtereffekt, dessen Intention Auswirkungen auf das Verhalten der Quantenwelt nach sich zieht, scheint der 
überschaubare Rest an Energie und Kohlenstoff vielleicht doch über solche Prozesse erschließbar. Der bei allen drei Kandidaten beobachtbare Gewichtsverlust in den klimatisierten Räumen, der sich als reversibel herausstellte, nachdem die Kandidaten an die frische Luft durften, scheint ebenfalls ein entsprechendes Indiz zu liefern.

Lässt sich jetzt aber auch nachweisen, dass quantencodierte Informationen von uns wahrgenommen, somit in unserem Gehirn ankommen und interpretiert werden können? Dies führt zur Frage nach der Reichweite von Kohärenzen in Makrosystemen und würde die Möglichkeit eröffnen, Menschen tatsächlich als makroskopische Quantenfelder zu interpretieren.

\subsubsection{QT mit Herz-Stimulanz-Mitteln und anderes bei Menschen}

Wir haben bereits den quantenphysikalischen Mechanismus einer antioxidativen Wirkung von Tee bei Menschen kennengelernt und den Einfluss von Licht auf Zellebene als auch bei der Übertragung von Informationen. 2012 veröffentlichten Hu und Wu eine Arbeit, in der sie nicht-lokale biologische Effekte bei Menschen nachwiesen (Hu und Wu 2012).

Sie verschränkten in diesem Experiment ein Herz-Stimulanzmittel mit Versuchskandidaten. Das Stimulanzmittel Primatene ist ein Ephedrin-Präparat, das in Amerika als Asthma-Medikament im freien Handel erhältlich ist und auch zur Vermeidung eines Blutdruckabfalls bei Spinalanästhesien verwendet wird. Abb. 80 demonstriert den Versuchsaufbau und ermöglicht den Vergleich zur QT-Struktur, wie sie bereits vorgestellt wurde. Im Experiment wurde Wasser in der Mikrowelle für eine Minute erhitzt, um es zu verschränken. Ein Teil des Wassers bekam Kandidat Bob zu trinken. Er war an ein Pulsmessgerät angeschlossen. In einem ca. $15 \mathrm{~m}$ entfernten Raum füllte ein Assistent das Primatene zu einem beliebigen Zeitpunkt in die zweite Hälfte des verschränkten Wassers.
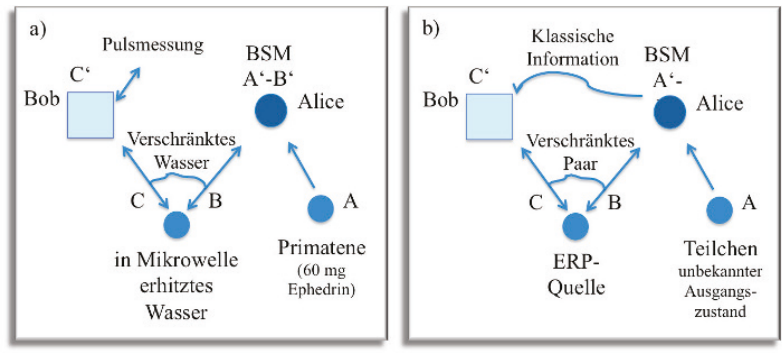

Abb. 80 | Medikamenten-QT (a) im Vergleich zur klassischen QT (b)

(eigene Darstellung). Hier sieht man im Vergleich der Strukturen die Ähnlichkeit in der Versuchsanordnung. Statt der klassischen Informationsvermittlung über die gewählten Einstellungen bei b) reicht eine Plusmessung bei Bob a), um eine erfolgte Verschränkung bei Alice (A'-B') und das gewählte Medikament bestimmen zu können. 
Dieser Moment war weder der Versuchsperson noch der Person, die die Messung vornahm, bekannt. Es handelte sich somit um ein verblindetes Experiment. Bei allen Versuchsabläufen fand unmittelbar ein signifikanter Anstieg der Pulsfrequenz für $2-4 \mathrm{Mi}-$ nuten statt. Kontrollexperimente waren dagegen ohne Befund.

Zwei Schwachpunkte im Versuchssetting wären nach klassischem Verständnis aktuell noch zu diagnostizieren: Erstens war die Anzahl der Versuche noch sehr gering, was die Forscher dazu veranlasste zur Wiederholung in größerem Ausmaß und von anderen, unabhängigen Instituten aufzurufen. Zweitens waren alle Beteiligten aus einer Familie. Dass eine Beziehung für solche Experimente von erheblicher Relevanz ist, zeigen die EEG Experimente im Kap. 8.3. Nach den Vorgaben von Lucadou (Kap. 7.3.2) ist dieser Versuchsaufbau keine Schwachstelle, sondern ganz im Gegenteil sogar zu empfehlen, da die verfügbaren Verschränkungskanäle vermehrt würden. Gleichwohl bleibt damit die Frage offen, ob die Verschränkung ausschließlich über das behandelte Wasser vollzogen wurde.

Unabhängig von den aktuellen Schwächen werden mehrere Zusammenhänge deutlich. Wir können von einer Verschränkung mit nicht-lokalen Effekten in Makrosystemen (hier Menschen) ausgehen, die biologisch messbare Wirkungen erzeugt. Des Weiteren zeigt der Strukturvergleich mit dem QT-Experiment eine vollständige Deckung. Die klassische Information (Einrichtung einer Pulsmessapparatur und anschließender Datenvergleich) entspricht zu $100 \%$ dem gängigen QT-Versuchsaufbau. Zentral ist auch die Möglichkeit für eine Bestätigung der These eines internen Beobachters. Gehen wir davon aus, dass alle Beteiligten dem Quantensystem inklusive der Messapparatur zuzuordnen sind, dann ist im Moment des Zusammenbringens von Primatene und der einen Hälfte des verschränkten Wassers diese Information auch bei Bob. Sein Körper, als interner Beobachter, reagiert dementsprechend auf die neue Informationslage. Er könnte aufgrund der veränderten Pulswerte sofort sagen, wann das Mittel im anderen Raum zugegeben wurde. Diese Informationsübermittlung ist tatsächlich schneller als Licht, denn es braucht nicht mehr Alice, um die Richtigkeit zu überprüfen und es kann über eine beliebige Distanz ablaufen.

In ähnlicher Weise konnten $\mathrm{Hu}$ und $\mathrm{Wu}$ in den Jahren davor Anästhetika mittels Magnetimpulsen, Licht, Mikrowellen und sogar Blitzlicht auf Versuchspersonen einwirken lassen (Hu und Wu 2007b). Sie verwenden verschiedene Versuchsanordnungen, um ihre These einer möglichen Verschränkung und einem Bewusstsein, das über die Aktivitäten der Spins im Gehirn entsteht, zu überprüfen. Einige der Varianten sind in Abb. 81 dargestellt. 

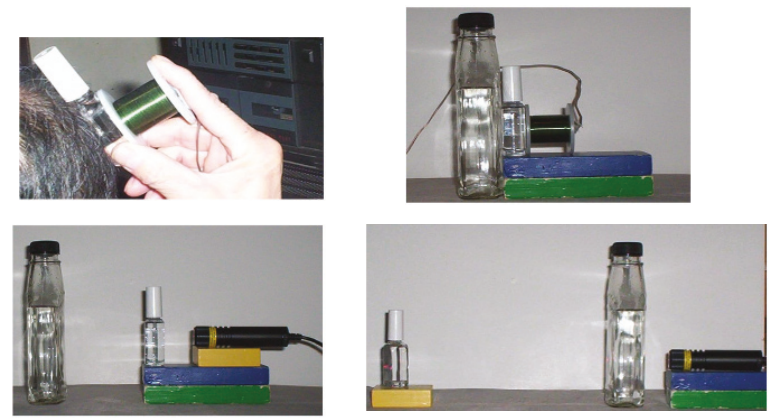

Abb. 81 Versuchsanordnungen zur Übertragung von Anästhetika und anderen Medikamenten auf Menschen (Images von $\mathrm{Hu}$ und $\mathrm{Wu}$ (2007b)) mithilfe von magnetischen Pulsen oder Licht.

1. Oben links: Das Anästhetikum befindet sich in einer Glasflasche und wird mit magnetischen Pulsen durch die Flasche, welche direkt auf dem Kopf platziert ist, in Richtung Gehirn gesendet. Dazu wurde Musik mit Frequenzen zw. $5 \mathrm{~Hz}$ und $10 \mathrm{kHz}$ angelegt, die mithilfe der Magnetspule besagte magnetische Pulse erzeugte.

2. Oben rechts: Das Anästhetikum wird zwischen Magnetspule und einer Wasserflasche positioniert und durch die musikinduzierten Pulse mit dem Trinkwasser verschränkt.

3. Unten links: Das Laserlicht durchstrahlt das Mittel und trifft auf das Trinkwasser.

4. Unten rechts: Das Trinkwasser wird zwischen Laserlicht und Anästhetikum platziert. Nach klassischem Verständnis dürfte im letzten Beispiel das Wasser nicht vom Mittel beeinflusst werden, da es erst im Nachgang mit diesem interagiert. Quantenphysikalische Prozesse sind jedoch beliebig zeitreversibel und wirken in beide Richtungen, wie es im Delayed-Choice-Experiment und bei den FaymannDiagrammen offensichtlich wurde.

Ihr prinzipieller Versuchsaufbau entsprach der oben vorgestellten Struktur der Medikamenten-Teleportation, mit Ausnahme von Variante 1. In den Anordnungen 2- 4 trinken die Probanden die eine Hälfte des Wassers bevor es mit den Stoffen verschränkt wird. Die andere Hälfte wird in einem Nebenraum physikalisch behandelt (verschränkt), ohne dass die Probanden wissen wann. Sie sind also nie mit dem direkt behandelten Wasser in Kontakt gekommen. Das Ganze wurde mit sechs unterschiedlichen Mitteln wie Anästhetika und anderen Medikamenten durchgespielt, darunter ein Kontrollmittel (unbehandeltes Wasser), welches keine Wirkung auslöste.

Die Probanden erlebten die Mittel, wie wenn sie die reine Substanz körperlich verabreicht bekommen hätten. Je nach Substanz wirkten sie bis zu 12 Stunden nach. Markant zeigten sich zwei Effekte: Die sehr gute Wiederholbarkeit und die sehr viel stärkere Wirkung, wenn statt Licht Mikrowellen zum Einsatz kamen. 
Die Forscher vermuten die Wirkung aufgrund der Spins der Elektronen und der Atomkerne. Die Wasservorbehandlung stellt sicher, dass das Wasser bevor es verteilt wird, eine besondere Form der Verschränkung aufweist, die sich von anderem Wasser unterschiedet. Die durch Mikrowellen kollektiv angeregten Wassermoleküle gehen in schwache Wechselwirkung miteinander, wodurch sie ein physikalisches Ganzes ausbilden (vergleichbar eines Bose-Einstein-Kondensats). Diese Verschränkung scheint auch nach der Aufteilung des Wassers in zwei Hälften noch bestehen zu bleiben. Als Mechanismus lässt sich das Modell des Hohlraumresonators vorstellen, der in der Lage ist, kleinste Spinveränderungen an einer gekoppelten Membrane zu registrieren. Die getrunkene Hälfte verteilt sich im Körper. Mit dem Moment der Beeinflussung der zweiten Hälfte des Wassers (Zugabe der Medikamente) geht eine Veränderung im Gesamtsystem (getrunkenes und behandeltes Wasser) einher, die Spins richten sich neu aus und übertragen die neue codierte Information auf den Träger des getrunkenen Wassers. Ihre Überlegungen schlossen die Versuchsergebnisse von Julsgaard u. a. mit ein, die bei makroskopischen Elektronenspins eine Lebensdauer von ca. 0,5 ms gemessen haben (Julsgaard u. a. 2001). Es handelte sich um ein Gas aus Cäsium-Atomen, dem schwersten Alkalimetall das existiert. Erstaunlicherweise scheint die Lebensdauer von Verschränkungszuständen auch hier sehr viel länger zu sein als in rein physikalischen Experimenten. Erklären lässt sich dies nur mit dem aus der Dekohärenztheorie bekannten Zusammenhang, dass die Verschränkung nicht aufgelöst, sondern nur in den Hintergrund getreten ist. Eine spezifische Veränderung in einem Teilsystem scheint demzufolge auch im Hintergrund noch zu wirken und schwache, aber relevante Impulse setzen zu können.

In einem vorangehenden Experiment untersuchten $\mathrm{Hu}$ und $\mathrm{Wu}$ den $\mathrm{PH}-\mathrm{Wert}$, die Temperatur- und die Schwerkraftänderung, wenn verschränktes Wasser nicht-lokal physikalisch behandelt wird (Hu und Wu 2007a). Dies ist hier insofern von Interesse, als sie mit ihrem Versuchsaufbau auch sogenannte klassische Materie nicht-lokal manipulieren konnten. Der Versuchsaufbau war analog Abb. 80. Verschränktes Wasser wurde geteilt und räumlich getrennt. Auch hier konnten signifikante Korrelationen beobachtet werden. Das verschränkte und nicht-lokal positionierte Wasser reagierte auf das beeinflusste Wasser in vergleichbarer Weise. Wohingegen unverschränktes (unbehandeltes) Wasser keinerlei Veränderung und damit Korrelation zeigte. Im Einzelnen ergaben sich folgende Ergebnisse:

- Der PH-Wert des fern positionieren Wassers änderte sich in die gleiche Richtung entsprechend der Behandlung des mit ihm verschränkten Anteils, sofern Energieaustausch mit der Umgebung möglich ist.

- Die Temperatur von Wasser kann entgegen der Temperaturrichtung der Umgebung beeinflusst werden, wenn Energieaustausch mit der lokalen Umgebung möglich ist und der verschränkte Wasseranteil entsprechend beeinflusst wird.

- Die Gravitation von Wasser kann ebenfalls in entgegengesetzte Richtung zu seiner lokalen Umgebung beeinflusst werden, wenn sein verschränkter Anteil eine entsprechende Behandlung erfährt. 
$\mathrm{Hu}$ und $\mathrm{Wu}$ weisen darauf hin, dass als Folge dieser Ergebnisse prinzipiell jede Materie nicht-lokal mittels Verschränkung beeinflusst werden kann. Zudem: ,the second law of thermodynamics may not hold when two quantum-entangled systems together with their respective local environments are considered as two isolated systems and one of them is manipulated. "Und drittens: ,, gravity has a non-local aspect associated with quantum entanglement thus can be non-locally manipulated through quantum entanglement mediated processes " (Hu und Wu 2007a: 298).

Laut der Aussagen der Forscher wurden diese Tests von anderen, unabhängigen Gruppen bestätigt. Nach ihrer Sicht kann es sich nur um eine quantenphysikalische Verschränkung handeln, die biologische/chemische und bedeutungsvolle Information überträgt (Hu und $\mathrm{Wu}$ 2012). In ihrem 2012 durchgeführten Versuch wiederholten sie im Wesentlichen die Experimente von 2007, präsentierten aber verbesserte Untersuchungsund Auswertungsdaten.

\section{$\underline{\text { Homologe Verbindung zur Physik }}$}

Bemerkenswert ist die Vergleichbarkeit der Ergebnisse mit denen unserer SyA-Experimente. Dabei fallen besonders die direkten, ohne Wahrscheinlichkeitsberechnungen erhaltenen 100 \%-igen Korrelationen sowie die Klarheit der Reaktionen der Versuchskandidaten auf. Sowohl die Struktur der QT als auch der Bezug zur GHZ-Konfiguration, bei der alleine eine Verschränkung sichergestellt werden muss, entsprechen den quantenphysikalischen Vorgaben. Mit ihrem Setting erfüllen die SyA-Experimente zudem die Vorgaben von Lucadou, einer möglichst vielseitigen Verschränkungskonfiguration. In gleicher Weise erreichen dies die QT-Experimente mit vieldimensionalen Verschränkungszuständen. Zweitens wird hier eine Wechselwirkung zu rein physikalischem, unbelebtem Stoff realisiert, wie es in den SyA-Experimenten praktiziert wurde.

\subsubsection{QT und Homöopathie?}

Eines der wohl kontroversesten Themen in der westlichen Hemisphäre ist die Frage nach der Wirksamkeit homöopathischer Mittel. Befürworter und Gegner stehen sich unversöhnlich gegenüber. Mit der eben vorgestellten Medikamententestung, der Informationsübertragung von HIV-Erregern in reines Wasser (Kap.8.2.1.7) und der QT-Struktur stellt sich die Frage einer Vergleichbarkeit zur Homöopathie. Abb. 82 veranschaulicht eine erstaunliche Übereinstimmung mit der QT generell bzw. bei SyA (siehe dazu Abb. 69b) und der angenommenen QT-Struktur bei Homöopatika.

Auch hier besteht die Option, dass per Verschränkung eine Information im Gesamtsystem verteilt wird. (C) repräsentiert dabei den direkten Kontakt zwischen Globuli und Patient bzw. Fallbringer und Repräsentanten der Aufstellungsgruppe. Sowohl der direkte Weg, Wirkstoff-Globuli-Patient' (A-C) als auch der indirekte Weg ,WirkstoffGlobuli-Arzt-Patient' (A-B-D) sind deshalb potentielle Verbreitungsrichtungen. Als klassischer Kanal kann dabei das Rezept mit Namen und Beschreibung verstanden werden. Wie SyA und die Medikamententestung zeigen, scheint ihre Beteiligung nicht wirklich notwendig. 

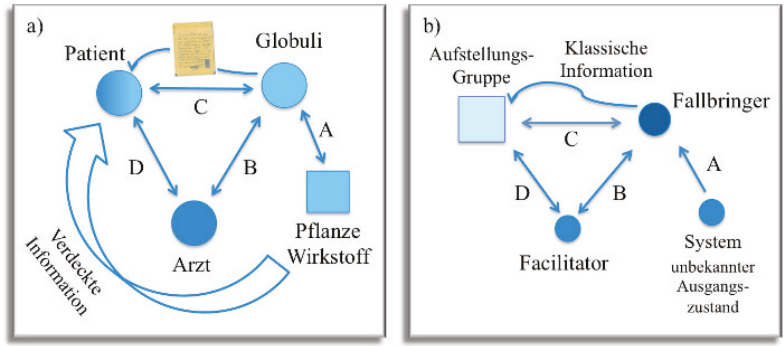

Abb. 82 QT-Struktur in der Homöopathie (a) verglichen mit QT-Struktur bei SyA (b)

(eigene Darstellung). Auch hier entsprechen sich die Strukturen der Versuchsanordnungen auf vollständige Weise. Der einzige Unterschied liegt im Kenntnisstand über die zu übermittelnde Information. Bei der SyA b) ist zunächst unklar, welche Information übermittelt wird, wohingegen der zu übermittelnde Pflanzenwirkstoff a), respektive die zugehörige Information, sehr wohl bekannt ist und gezielt genutzt werden soll.

Wenn, wie es scheint, die Mikrowellenbehandlung des Wassers verantwortlich für die Unterscheidbarkeit gegenüber unbehandeltem Wasser ist, so könnte das Schütteln bei der Potenzierung den gleichen Effekt erzeugen. Wie in vielen anderen Fällen, gibt die Substanz chemisch keine Information für ihre unterschiedliche Wirkung. Sollte tatsächlich nur die Information und die durch Schütteln induzierte Energiezustandsveränderung den Unterschied machen, nicht aber ein makroskopisches Molekül, so lässt sich dieser Unterschied nur anhand der Wirkung am Patienten messen. Genau hier aber liegt die Ursache der Meinungsverschiedenheit. Erfahrungen der Patienten und im Labor gemessene Ergebnisse sind uneinheitlich, aber doch signifikant, und mit großer Streubreite versehen (Ammon u. a. 2016). Die Streubreite bezieht sich auf die heilende Wirkung wie die von Ammon und Kollegen untersuchten neueren Forschungen zeigen. In allen Diskussionsbeiträgen macht sich die Kritik auch hier am noch nicht vorhandenen theoretischen Modell fest, offensichtlich nicht anders wie in der Intuitions- und Entscheidungsforschung.

Unter Berücksichtigung von Erwartungshaltung und Intentionen bei gleichzeitiger hoher Sensitivität von Experimenten, welche auf Quanteneffekten basieren, erscheint es allerdings auch nicht verwunderlich, dass die unterschiedlichen Studien Beobachtereffekte enthalten, die bis heute kaum berücksichtigt wurden. Bereits 1985 wurde eine Studie im Kontext der Placeboforschung veröffentlicht, bei der eindeutig gezeigt wurde, dass das Wissen des Behandlers auf den Behandelten übertragen wurde. ,, The two placebogroups differed only in the clinicians' knowledge of the range of possible doubleblind treatments " (Gracely u. a. 1985). Bei gleichzeitiger Verwendung beider (C) Kanäle war die QT-Struktur gleich der bei Homöopatika. In eine vergleichbare Richtung ging eine Harvard-Studie (Jensen u. a. 2012).

Neueste Veröffentlichungen, die eindeutige Evidenzen für homöopathische Effekte vorweisen (Thieves u. a. 2016), weisen ebenfalls in diese Richtung und bieten gleichzeitig experimentelle Konzeptionen für verbesserte Ergebnisse an (Beauvais 2017). Beauvais entwickelte sein Modell auf der Grundlage der WQT respektive GQT (Weak/ 
Generalised Quantum Theory) (Walach 2003) und beschäftigte sich sehr intensiv mit passend designten Versuchsaufbauten. Zahlreiche andere Studien, die in vitro mit Zellkulturen und Mikroorganismen durchgeführt wurden, zeigten ebenfalls signifikant evidente Reaktionen auf homöopathische Mittel (Betti u. a. 2017; Olsen 2017; Passeti u. a. 2017). Weshalb sollen Menschen nicht in gleicher Weise auf diese Form homöopathischer Intervention reagieren? Sehr viel spricht für den Intentions- als auch den Erwartungseffekt genauso wie für zum Teil ungeeignete experimentelle Konfigurationen bei Menschen, respektive Verschränkungszustände Homöopatika mit Placebo.

\subsubsection{Conclusio zu Biologische Systeme und Physik}

Wenn nun, wie bei Bakterien, Pflanzen, Tieren und auch Menschen, experimentelle Beobachtungen unter in vivo Bedingungen, als auch theoretische Modelle und Berechnungen zusammenpassen, ist es in der Physik mehr als ein Indiz, dass ein belastbares Modell für einen Mechanismus beschrieben wird. Dies gilt umso mehr, als die zentralen, auf mikroskopischer Ebene bekannten, quantenphysikalischen Zusammenhänge auch auf makroskopischer Ebene in Erscheinung treten.

\section{Evidenz quantenphysikalischer, EM- und Verschränkungs-Mechanismen}

Mittlerweile gibt es tausende von Forschungsarbeiten, die eine klare Evidenz für eine Zell-zu-Zell-Kommunikation auf der Basis von EM-Interaktion liefern. Eine gute Übersicht dazu findet sich bei Fels u. a. (2015), Scholkmann u. a. (2013), Cifra u. a. (2011) oder Farhadi u. a. (2007). Darunter fallen Interaktionen zwischen menschlichen Zellen auf Distanz, die also nicht lokal in Kontakt miteinander stehen. Der Versuch, die Interaktionen zwischen Zellen ausschließlich mit chemischen Wechselwirkungen begründen zu wollen, scheint immer mehr an seine Grenzen zu stoßen. Wie im Kapitel zu MaterieEnergie-Information bereits herausgearbeitet wurde, interagiert Materie auf einem subatomaren Level nicht nur mit Licht, also EM-Strahlung, sondern sie ist im Grund selbst aus einer solchen EM-Strahlung gemacht. Für uns wahrnehmbare anorganische als auch organische Materie entspricht quasi einem lokalisierten Kondensat eines dahinterliegenden energetischen Feldes. Über Licht können Informationen zwischen solchen EM-Feldern ausgetauscht werden, was einer klassischen Verschränkung entspricht. Fassen wir hier deshalb die wesentlichen für Kohärenz und Verschränkung verantwortlichen Mechanismen zusammen, die als zentrale Voraussetzung für die Phänomene bei SyA und Intuition angesehen werden.

Bei den Bakterien und Algen waren es die oszillierenden Proteine, die die Kohärenz stabil halten. Beim Tee ging es um Radikale und Tunneleffekte. Auch bei den Tierexperimenten ging es um verschränkte Radikale, Tunneleffekte aufgrund eines Lichteinfalls auf die Retina und Spin-Ausrichtungen. Bei der DNA waren ebenfalls Schwingungen, großflächige Kohärenzen und damit verbunden Verschränkungen beteiligt. Bei allen waren Umgebungstemperatur und quantenmechanisch gesehen langanhaltende, stabile Zustände beobachtbar. Sogar der Geruchssinn erscheint frequenzabhängig. Immer ging es um eine Kopplung und ein Aufeinander-Beziehen zu einem externen 
Umfeld. Schrödinger's Idee von der ,Ordnung aus Ordnung' (Al-Khalili und McFadden 2015: 67-68) scheint sich in der Tat zu bestätigen. Stabile Ordnungen (Frequenzbänder, DNA- und andere Molekül-Strukturen) die gegenüber ihrem Umfeld abgeschirmt werden können, zeigen sich relativ stabil gegen Umwelteinflüsse und Dekohärenzeffekte und bringen auch wieder Ordnung und Kohärenzen hervor. Eine solche Abschirmung stellen Eigenfrequenzen gegenüber einem verrauschten Umfeld dar oder Leitungsbahnen, wie der DNA-Strang oder die Nervenbahnen. Dekohärenz entsteht offensichtlich vorzugsweise in ungeordneten Systemen, die dann auch leicht mit der Umwelt interagieren können.

Bei fast allen waren Lichtwellen, Wasserstoff und Proteine involviert. Und weiter zeigte sich, dass es oft um Schnelligkeit und Effizienz ging, aber auch um den Schutz kohärenter Zustände. Immer hatten quantenmechanische Prozesse Auswirkungen im Makrobereich.

Die Sender-Bakterien waren in der Lage Kommunikation via Fernwirkung zu realisieren, indem sie verschiedene physikalische EMF produzierten und damit ihre Information durch die Trennwände ihrer Behälter transmittieren. Dies bedeutet nicht mehr oder weniger, als dass Leben oder zumindest Veränderung und damit Wahrnehmung quasi aus dem Nichts entstehen kann. Dies besonders, wenn die Versuche berücksichtigt werden, bei denen digital gespeicherte Information von DNA-Sequenzen mittels EMF auf fremdes Cytoplasma transferiert und sich als neue Eigenschaften manifestierten. Voraussetzung ist nur das Vorhandensein einer Entität, die eine bestimmte Empfänglichkeit aufweist und die Einflussnahme von physikalischen Signalen wie EMF, die Informationen transportieren.

Mit dem heutigen Wissen lässt sich resümieren, dass auch in biologischen Systemen Auf- und Abbau von Verschränkungszuständen nicht nur möglich, sondern als sicher anzunehmen sind. Entscheidend für eine Verschränkung und in der Folge eine Informationsübertragung ist schließlich nicht die Intensitätsstärke, sondern die Frequenzähnlichkeit. Wie bei den Biophotonen gesehen, reichen dabei kleinste Energieeinheiten. Vice versa stabilisieren Frequenzunterschiede schließlich auch verschränkte Systeme gegen eine Kohärenz mit dem Umfeld und halten dekohärente Zustände aufrecht. Dennoch können selbst Frequenzunterschiede mithilfe des verallgemeinerten Josephson-Effekts kompensiert werden, was wiederum eine Wechselwirkung und Quanteneffekte ermöglicht.

Wie in den verschiedenen Experimenten zu sehen ist, kann sowohl eine Quanten- als auch eine klassische Verschränkung als Mechanismus zur Informationsübertragung herangezogen werden. Beide sind in der Lage, Spins der Elektronen und der Kerne zu beeinflussen. Wie im DNA-Beispiel entwickelt wurde, reicht bereits die Beeinflussung eines Spins, um Auswirkungen auf ein riesiges Quantenfeld und damit ein Makrosystem zu generieren. Informationen, die in Spins und deren Ausrichtung codiert sind, wechselwirken mit anderen Spins, erzeugen auf diese Weise neue Strukturen auf der chemischen und schließlich auf der biologischen Ebene. Die dabei involvierten Energieanteile sind die Messgrößen, die in klassischer Weise in der Physik beobachtet werden können. 
Sinnvollerweise werde diese energetischen Messgrößen ergänzt durch allgemeine Verhaltens- oder Veränderungsanzeichen, wie sie in lebenden Systemen relevant sind. Durch diese Veränderungsanzeichen dokumentiert sich letztlich die Wirkung auf makro-physikalischer Ebene.

Alle physikalisch-biologischen Experimente wurden in der Biologie und Chemie bis heute überwiegend klassisch interpretiert, ohne vollständig zufriedenstellende Antworten liefern zu können. Die quantenmechanisch interpretierten Ergebnisse erscheinen demgegenüber wesentlich plausibler und decken sich üblicherweise auch mit den Messwerten.

Zurückkommend auf die Photonen und Elektronen erstreckt sich deren gemeinsame Frequenz über räumlich ausgedehnte Bereiche, die deutlich größer sind als die Dimensionen der Zellen, und weisen damit Verschränkungszustände auf. Zwar sind die räumlichen Bereiche vom Kontext abhängig und auf bestimmte Distanzen limitiert, sie erstrecken sich allerdings soweit, dass sie in ihrem Umfeld Veränderungen anstoßen können. Entscheidend ist immer wieder eine Korrelation passender Frequenzen zueinander, unabhängig von der Art des physikalischen Signals (elektromagnetisch, akustisch etc.). Interessant scheinen vor allem Frequenzen im ELF-Bereich von $3-30 \mathrm{~Hz}$. Sowohl die Beeinflussung der DNA als auch die Medikamentenübertragung zeigten in diesem Bereich erhebliche Resonanzfähigkeit. Für offene Quantensysteme stellt sich zudem der lokale Kontext als die zentrale Bedingung heraus, unter der Emission oder Absorption von EM-Wellen stattfinden und schließlich Informationen transportiert werden.

Mit den hier vorgestellten Beispielen wird auch die neueste Interpretation von Verschränkung bestätigt. Es macht keinen Sinn mehr zwischen quantenphysikalischer und klassischer Verschränkung und damit verbundener Wechselwirkung in Bezug auf Informationsübertragung zu unterscheiden. Unter beiden Bedingungen kann berechtigterweise von Verschränkung gesprochen werden. Die Information ist jeweils über einen kohärenten Bereich verteilt und stellt ein Ganzes dar, ob sichtbar oder unsichtbar. Unterschiedlich bleibt derzeit nur der Mechanismus bei lokalen und nicht-lokalen Bedingungen. Lokal lassen sich EM-Wellen beobachten und Frequenzen messen, nicht-lokal besteht keine solche Möglichkeit. In beiden Fällen lassen sich aber Wirkungen beobachten, aufgrund denen zwischen klassisch und quantenphysikalisch unterschieden werden kann. Nur macht dieser Unterschied tatsächlich keinen Sinn, wenn wir heute eindeutige Evidenz haben, dass auf der kleinsten Ebene sowieso nur quantenphysikalische Prozesse aktiv und relevant sind.

Wesentlich scheint zunächst nur eines zu sein: Die kleinste Einheit - ein Spin - ist in der Lage auf Makrosysteme einzuwirken und am Ende auch die Welt zu verändern.

\section{Quantenphysikalische Messanordnungen und Informationsverarbeitung}

Eine wesentliche Rolle für der quantenphysikalischen Interaktionen spielen die Oszillationen und somit die Frequenzen, die in Wechselwirkung treten oder auch zur Isolierung beitragen. Die Physik weiß heute, dass solche EMF in der Lage sind, nahezu unbegrenzt 
Informationen zu codieren und zu speichern. Das World Wide Web liefert dazu ein schönes analoges Beispiel. Zweifelsfrei können wir deshalb festhalten: Informationen werden über die Form der Interaktion (EMF oder QT) transferiert und in den Aufbauund Oberflächen-Strukturen von Molekülen und Zellverbänden in Form von Spins und Spinensembles schließlich gespeichert und von dort aus wieder abgerufen. Eine solche QT erwies sich als zentraler Mechanismus bei Mutationsbildung von DNA. In Bezug auf die DNA sei noch ergänzt, dass in ihr sämtliche Information als Gene seit Anbeginn der Zeit gespeichert und mit unglaublicher Präzision geteilt und weitergegeben wird. Erfolgt eine Teilung nach einer Veränderung, enthalten beide DNA-Stränge die neuen Informationen. Die Veränderungen ergeben sich erst im Kontakt mit der Umwelt, wie die Forschungen zeigten. Ein quantenphysikalisch unterlegter Anpassungsprozess an die Umwelt erweist sich als bedeutend schneller und flexibler als die Annahme eines nur rein zufallsgetriebenen.

Licht in polarisierter, genauso wie in unpolarisierter Form stellt in vielen Fällen den zentralen Informationsträger und Vermittler zwischen unterschiedlichen Systemen dar. Am Beispiel der Chi-induzierten Blockade des Wachstums von Krebszellen ist dies sogar beobachtbar bei Menschen. Damit ist zumindest in biologischen Systemen auch hier keine Unterscheidung mehr notwendig. Da Wärmestrahlung nur ein energetisch anderes Spektrum der EM-Strahlung darstellt und nur aus messtechnischen Gründen nicht für die Untersuchung von Informationsübertragungen herangezogen wird, ergibt sich eine weitere logische Option: Auch in diesen Frequenzen sind Informationen codiert und können in Kopplung mit ähnlichen Frequenzen übertragen oder besser geteilt werden. Ein Prozess, der bei Berührung und Austausch von Körperwärme relevant werden würde. Das Schallwellen-Experiment bietet für diese Interpretation eine plausible Grundlage.

Bereits 1975 stellte Fröhlich die These auf, dass die in biologischen Systemen enthaltenen Dipolelemente und die damit verbundenen elektrischen Schwingungen unter bestimmten Umständen als Bose-Einstein-Kondensate auf niedrigstem energetischen $\mathrm{Zu}-$ stand erscheinen (Fröhlich 1975, 1986). Bose-Einstein-Kondensate repräsentieren kohärente, quantenmechanische Makrozustände, die als ein System fungieren, zusammengesetzt aus unzähligen Einzelelementen. Damit begründet er schon lange vor den aktuellen Erkenntnissen eine Theorie für Quantenverhalten in biologischen Systemen, die sich immer mehr bestätigt. Vergleichbar den Bose-Einstein-Kondensaten lassen sich Spinensembles oder weitreichende Kohärenzen interpretieren, die ein quantenphysikalisches Ganzes aufspannen, innerhalb dessen Photonen, Elektronen, Quasiteilchen etc. frei fluktuieren können. Je nach äußerem oder innerem Umfeld werden über unterschiedliche Kopplungen (Dipol-Dipol-Verbindungen; Photon-Atom-Photon-Kopplung; Elektron-Atom-Elektron-Kopplung; Elektron-Elektron-Kopplung analog den CooperPaaren; Exzitons, Elektron-Loch-Kopplungen; NV-Defekt-Kopplungen; StickstoffFehlstellen-Kopplung ...) typische Verschränkungszustände realisiert, die weiträumig Wechselwirkung und Informationstransfer sicherstellen. Darauf bauen die zu beobach- 
tenden qualitativen Informationsverarbeitungsprozesse bereits bei den einfachsten Mikroorganismen und Pflanzensystemen.

Voraussetzung sind Konfigurationen, die Messanordnungen entsprechen, wie Quanten-Interferometer (bei den Vögeln), Mikrowellen-, respektive Hohlraumresonator oder oszillierende Membrane (z. B. bei der DNA). Wie bereits im Kap. 8.1.2.4 herausgearbeitet wurde, sind Makrosysteme, die Resonatoren und oszillierende Membrane aufweisen, in der Lage, aufgrund kleinster Veränderungen größere Einheiten zu steuern. Die biologischen Entitäten waren alle fähig, eine Qubitänderung auf Spinebene im Makrosystem wahrzunehmen. Als biologisches Messinstrument lässt sich deshalb die PhotonAtom-Photon-Verschränkung bei den Lichtsammelkomplexen oder den Samen interpretieren. Sie weist den gleichen Aufbau auf, wie er bei quantenphysikalischen Experimenten genutzt wird. Andererseits wird die Eigenresonanz von Hohlräumen (z. B. in Zellen oder Microtubuli) als Falle und Ausrichtungshilfe für die Spins von (Bio-)Photonen, Elektronen oder Atomen genutzt und zum Abgleich mit Außenveränderungen eingesetzt. Die hier zusammengefassten Rahmenbedingungen und Messanordnungen (Resonator-Membranen-Kopplung), in Verbindung mit den von den Elementarteilchen und Ensembles getragenen Informationen, entsprechen den Bedingungen in den Zellen und vor allem auch in den Neuronen.

Mit den Beispielen zur DNA wird deutlich, dass nicht nur energetische Wechselwirkungen eine wesentliche Rolle in biologischen Systemen spielen. Ganz zentral scheinen Informationsstrukturen, die durch äußere bzw. selbst initiierte innere Magnetfelder und Spinselektivität unterstützt werden. Die von Blank/Goodman einerseits und Göhler andererseits gefundenen Zusammenhänge sind relevant für neuronale Aktivitäten, wie noch in Kap. 8.3 gezeigt wird. Ihre Arbeit verdeutlicht den Zusammenhang von intern und extern evozierter EMF, bis hin zu makroskopischen Phänomenen wie DNA oder Muskelbewegungen. EMF und Spinpolarisationen beeinflussen DNA-Entwicklungen genauso wie Proteine, die schließlich Muskelbewegungen verantworten; genau die Phänomene also, die Repräsentanten in SyA bemerken.

Die DNA-Experimente und die dabei gezeigte Umwandlung von Spin- und EMF-gekoppelter reiner Information in lebende biologische Systeme, veranschaulicht die Möglichkeit, Informationen von beliebigen Entitäten (nicht-organisch, organisch, lebende Systeme) wechselseitig aufzunehmen, zu transferieren bzw. zum Ausdruck zu bringen und zu interpretieren. Als einzige Voraussetzung ist das Vorhandensein eines geeigneten Umfeldes anzusehen, das die passenden Freiheitsgrade zur Verfügung stellt. Damit bilden diese Versuche eine fundierte Grundlage für die technischen SyA, bei denen ebenfalls reine Information (Computer-Codes, Defekte in Leitungen - Kap. 3.3.3) von Repräsentanten wahrgenommen werden können. 


\section{Quantenphysikalische Entscheidungsstrukturen}

Die quantenmechanischen Prozesse beeinflussen über die Orientierung der Spins und über die Variante der chemischen Bindungen biochemische Prozesse im Körper, die lebende Organismen offensichtlich interpretieren und nutzen können. Bereits bei Pflanzen werden Entscheidungen auf der Basis von Unterschieden getroffen, die in den einfachsten Strukturen klassischen Qubits entsprechen (delokalisierte Protonen, die unterschiedliche Isotope kreieren). In weiterentwickelten Formen bilden sich bereits räumlich getrennte, aber kohärent verbundene Zellverbände aus, die komplexere ,Berechnungen' vornehmen und auf komplexere Umweltbedingungen reagieren können. Diese topologischen Strukturen lassen sich als Übergang zur Entwicklung eines Gehirns interpretieren und veranschaulichen einen quantenphysikalisch getragenen Wahrnehmungs- und Entscheidungsprozess. Es geht deshalb selbst bei der Photosynthese nicht nur um Sammeln von Lichtenergie, sondern auch um Entscheidungen über deren Menge. Somit liegen Qubits und Entscheidungsstrukturen in den einfachsten Systemen (Antennen von Lichtsammelkomplexen, Samen) zugrunde, die über Kohärenzen abgespeicherter Informationen ausgelöst werden. Prinzipiell ist diese Entscheidungsstruktur bereits auf quantenphysikalisch delokalisierte Protonen in Enzymen anzuwenden.

\section{Übersicht über die zentralen Mechanismen}

Fassen wir die Verschränkungsprozesse bei lebenden Systemen kurz zusammen:

$\checkmark$ Energiearbeit bis in die kleinsten Bauteile

$\checkmark$ Freiwerden von Photonen, Elektronen, Atomen

$\checkmark$ Die kleinsten Bauteile weisen spezifische EMF auf

$\checkmark$ Interaktion über verschiedenste Arten von EMF

$\checkmark$ Führt zu Kohärenz- und Tunnelprozessen

$\checkmark$ Führt zu ständigen biochemischen Prozessen

$\checkmark$ Freie Elektronen verteilen sich über das Gesamtsystem $=$ Energiefeld

$\checkmark$ Energiefelder von lebenden Systemen (wie Pflanzen, Menschen ...) interagieren, allerdings nimmt diese Interaktion mit der Entfernung oder Energiebarrieren ab

$\checkmark$ Schließlich verbleibt eine Kopplung über den Mechanismus der Verschränkung

Wie wir aus den ersten Beispielen gesehen haben, ergibt die neuere Forschung mehrere Optionen für physikalischen Signalübertrag:

1. Licht als Überträger von Information auch in Form von Biophotonen und Verschränkung.

2. Von außen angelegte EMF, die die beteiligten Systeme kohärent verbindet, genauso wie selbsterzeugte Oszillationen.

3. Die Schwingungsfrequenz der Proteine führt einerseits zur Informationsübertragung, andererseits auch zu einer Stabilisierung gegen Umwelteinflüsse, wie sie von Plenio (Chin u. a. 2013) und anderen bei Bakterien erkannt wurden.

4. Tunnelprozesse, wie sie bei Bakterien, Tee und den Radikal-Paaren beim VogelKompass diagnostiziert wurden. 
5. Schwach gekoppelte Wellenfunktionen über Energiebarrieren hinweg erzeugen ebenfalls Veränderungen wie bei der DNA und analog zu Cooper-Paaren und Exzitons.

6. QT, die zur Übertragung von Information von Medikament zum Klienten führen und passende Körperreaktionen auslösen unter GHZ-Bedingungen.

\section{Unsere 5 Sinne plus Fühlen als Verschränkungsphänomen}

Wir haben damit alles zusammen, um die verschiedenen Wahrnehmungskanäle bei Menschen als die Regionen zu definieren, in denen eine physikalische Interaktion mit der Umgebung vollzogen wird und dürfen dies als Verschränkungsprozess definieren. In der modernen Interpretation der Physik wird davon ausgegangen, dass eine physikalische Verschränkung zwischen zu untersuchendem System und Beobachter existiert (Heisenberg-Schnitt) und sich damit eine Information über das Gesamtsystem erstreckt - unabhängig, wie weit die einzelnen Teile räumlich und zeitlich voneinander entfernt sind. An einem Beispiel vereinfacht dargestellt, lässt sich dies auf den Prozess des Sehens übertragen. Beim Sehen kommt es zu einer physikalischen Interaktion, nämlich zu einer EM-Wechselwirkung zwischen dem Objekt und dem Beobachter und damit zu einer Verschränkung. Licht, das mit dem von uns beobachteten Objekt in EM-Wechselwirkung tritt, wird auf der Retina abgebildet und an unser Gehirn geleitet. Gleiches gilt für das Phänomen Hören, bei dem Schallwellen in EM-Signale modelliert und ebenfalls dem Gehirn zugeführt werden. Entsprechendes gilt bei Berührungen. Im Gehirn findet daraufhin eine Laplace-Transformation statt, die das EM-Wellenpaket in seine Einzelpakete zerlegt. Diese Einzelpakete werden durch gespeicherte Resonanzen in den unterschiedlichen Zellen erkannt und dem Bewusstsein als Hörerlebnis zur Verfügung gestellt und gleichzeitig auch gespeichert. Sowohl beim Sehen als auch beim Hören greift die EMF-Atome/Molekül-EMF-Kopplung.

Für alle unsere Sinne existiert der gleiche Zusammenhang, die Interaktion mit kleinsten Energiefeldern, die durch leichte oder größere Spinveränderungen Frequenzen beeinflussen und Informationen transportieren.

\section{Ohne eine physikalische Interaktion keine Wahrnehmung.}

Diese Energiefelder führen nach der ursprünglichen Logik der Quantenphysik nur Energieanteile mit sich. Nach dem bisher untersuchten Zusammenhängen darf jetzt dieser Rahmen auf sämtliche Information ausgedehnt werden, die das Sendersystem besitzt bzw. welche die Entität als Ganzes ausmacht, wie es bereits im Kap. 4.2.4.1 mit der Normierung des Informationsbegriffs angedacht wurde. Grundlage dafür liefert der quantenphysikalische Mechanismus, dass EMF aus der gleichen Quelle verschränkt sind und die Information des Gesamtsystems tragen bzw. repräsentieren. Logischerweise sollte nun für den Empfänger, als auch umgekehrt für den Sender, die Möglichkeit der wechselseitigen Informationswahrnehmung bestehen. Beide bilden ein verschränktes System, in dem alle Information verteilt ist. Dass quantenphysikalische Tunneleffekte und Kohärenzen in der Biologie auf Zellebene vorliegen, ist anschaulich dargelegt 
worden. Auch dass die Systeme mit diesen Informationen etwas anfangen können, wurde gezeigt.

Mit den vorgestellten Beispielen und anderen Arbeiten konnte nachgewiesen werden, dass der quantenphysikalische Gültigkeitsbereich sich auch auf lebende biologische Systeme erweitern lässt und das bei normalen Temperaturen und Umweltbedingungen.

\section{Mit Bezug auf SyA lässt sich feststellen}

1. SyA stellen eine quantenphysikalische Messapparatur für biologische Systeme dar, und zwar in einer allgemeinen Form. Allgemeine Form bedeutet hier, dass sämtliche Informationen eines Systems (anorganisch als auch organisch) gemessen werden können, abhängig vom Wissens- bzw. Interpretationsstand der Empfänger.

2. Scheint in unserem klassischen Verständnis keine physikalische Wechselwirkung zwischen den Personen in einer Aufstellungsgruppe zu existieren (analog Abb. $77 \mathrm{a}-\mathrm{b}$ ), so verändert sich dies in dem Moment, indem die Repräsentanten in eine ,gesammelte Aufmerksamkeit' und in eine ,wahrnehmende Beobachtung' gehen. Energetisch entsteht Ruhe im System, was als gleicher energetischer Grundzustand interpretiert werden kann. Wahrnehmungsmäßig entwickelt sich fast augenblicklich ein Bezug zu den anderen Repräsentanten. Schlussfolgernd lässt sich ableiten: Über das Gesamtsystem dehnt sich eine gleichförmige Schwingung (Kohärenz) aus, was zum Verlust der Individualität und zur Konstituierung einer übergreifenden Wellenfunktion führt. In dieser sind alle Zustände und Informationen gleichmäßig verteilt. Entsprechend Abb. $77 \mathrm{c}$ ist damit jedoch auch die Möglichkeit einer Fehlinterpretation verbunden. Individuelle persönliche Intentionen sind nämlich ebenfalls Teil des Gesamtzustands und können sich bemerkbar machen.

3. Dass sich bei Berührung von Fallbringer und Repräsentant sehr häufig unvermittelte und deutlich spürbare Wahrnehmungen zeigen, entspricht der dargestellten Beobachtung, dass mit Zunahme der Intensität sich neue Informationen besser vom Umfeld (Ausgangs-Zustand) abheben. Gleichzeitig wird eine Vervollständigung von Verschränkungszuständen realisiert, analog den physikalischen Experimenten (EMF-Abstrahlung von Menschen $\gg>>$ direkte Verschränkung und QT $\gg>$ Informationsverteilung bei allen Betroffenen).

4. Je kohärenter, im Sinne von gleichschwingend bzw. gesammelt, eine Aufstellungsgruppe ist, desto deutlicher kommen die Informationen durch. Selbiges sollte auch Gültigkeit in Bezug auf die Fokussierung besitzen. Je fokussierter der Fragesteller und die Gruppe, je präziser sind die Antworten.

5. Der Außenbeobachter und die Spin-Messungen bei quantenphysikalischen Experimenten werden bei der quantenphysikalischen Interaktion von Makrosystemen durch einen Innenbeobachter und typische Zustandsveränderungen kompensiert; Zustandsveränderungen wie physiologische Reaktionen oder Imagination von Bildern und Ideen. Unser Bewusstsein fungiert dabei als Beobachter, der, solange er nicht ins Geschehen eingreift, indem er eine Entscheidung trifft, 
maximal eine schwache Quantenmessung vornimmt, die das System nicht weiter stört.

Mit den neuesten Erkenntnissen aus der Forschung mit biologischen Systemen lassen sich die bereits an einigen Stellen dieser Arbeit vorgestellten Annahmen führender Wissenschaftler bestätigen. Die Natur hat zahlreiche Wege gefunden, quantenphysikalische Phänomene für ihre Entwicklung und ihre Anpassung an sich verändernde Umfelder zu nutzen. Tatsächlich ist wohl davon auszugehen, dass ihre Fähigkeiten eher einer kontinuierlichen Weiterentwicklung der elementaren Basismechanismen entsprechen, als dass sie erst im Nachgang erzeugt wurden. Womit es sich immer wieder um emergente Erscheinungen handelt, die immer höher organisierte Lebensformen hervorbringt. Als logische Konsequenz darf auch beim Menschen und seinen kognitiven Prozessen ebenfalls von emergenten Entwicklungen ausgegangen werden. Hinweise auf entsprechende Zusammenhänge werden im folgenden Kapitel untersucht.

\section{Kritische Anmerkungen}

Trotz der von Al-Khalili und McFadden herausgearbeiteten Zusammenhänge und Nachweise für Quantenverhalten biologischer Lebensformen weisen sie explizit darauf hin, dass angebliche Phänomene wie das nicht-lokale Spüren emotionaler Zustände zwischen Zwillingen oder das von Hunden in Bezug auf ihre Besitzer ${ }^{203}$, noch nicht ansatzweise wissenschaftlich begründet seien (Al-Khalili und McFadden 2015: 226). Besonders quantenmechanische Erklärungen scheinen ihrer Sicht nach unpassend. Anzumerken dazu ist, dass sie solche ,Fernwirkungen“ als nicht existent für unsere Alltagswelt ansehen. Mit den zahlreichen Beispielen aus SyA, Intuition- und Entscheidungstheorieforschung, darf diese Annahme als widerlegt gelten, nur scheinen ihnen diese Beispiele und die damit verbundene Menge an Evidenzen nicht bekannt zu sein. Wären sie ihnen bekannt, würde ihr Urteil vermutlich anders ausfallen.

In diesem Kapitel wurde die Frage nach ,Übertragungswegen zwischen lebenden Systemen' unter Zuhilfenahme quantenphysikalischer und EM-Prozesse untersucht und positiv beantwortet; die letzte offene Unterkategorie aus dem Codingprozess. Gleichwohl darf auch hier festgestellt werden, dass neben den beschriebenen Prozessen und korrelierenden Phänomenen in biologischen Systemen bisher nur rational-logische Annahmen abgeleitet wurden. Was noch fehlt, ist der Nachweis von Informationsübernahme in Menschen und auf neuronaler Ebene, mittels der bisher beschriebenen Prozesse. Erst mit diesem Nachweis kann die letzte Unterkategorie abgeschlossen, Hypothese 4 (Kap. 2.1) bejaht und die Grundlage für Hypothese 1 gelegt werden. Ergänzend wäre das Verstehen über den physiologischen Prozess bzgl. Bedeutungsgebung von Information (letzte Unterkategorie zur Information in Kap. 2.1) und damit die konkrete Übertragung auf unsere neuronalen Prozesse ebenfalls von enormer Hilfe. Was also passiert tatsächlich auf elementarer Ebene, wenn unser Gehirn denkt?

\footnotetext{
${ }^{203}$ Bei den Hunden spielen sie vermutlich auf Sheldrake's Dog Experiment an.
} 
Abschließen möchte ich dieses Kapitel mit einem Zitat von Feynman aus seiner Vorlesungen Band 1, Chapter 3-3, Biologie (Feynman u. a. 1970):

„, all things are made of atoms, and that everything that living things do

can be understood in terms of

the jigglings and wigglings of atoms. “

Er ging offensichtlich bereits Anfang der 60er Jahre davon aus, dass im ,Zittern und Zappeln', also den Frequenzen der Atome, die Informationen enthalten sind, die Leben ermöglichen.

\subsection{Neurowissenschaften - Der Mensch als Entscheider}

\section{Unser Gehirn ein physikalisches Organ, eine alternative Annäherung}

Wie deutlich wurde, ist jede Information, die in dieser Welt existiert und mit der wir in Kontakt kommen, in irgendeiner Weise auf einer EM-Ebene codiert. Die EM-Ebene ist ihrerseits ein emergentes Produkt der Quantenebene mit der Folge, dass diese Information einen Bezug zur Quantenebene haben sollte. Die Frage der Informationswahrnehmung und -interpretation ist insofern keine Frage des Vorhanden- oder nicht Vorhandenseins einer Information, sondern es ist eine Frage (a) der Resonanz- und (b) der Interpretationsfähigkeit. Dies wird nun Gegenstand der Überlegungen im Kontext der Neurowissenschaften.

In diesem Kapitel sollen deshalb die Möglichkeiten ausgelotet werden, inwiefern Verschränkungs- und Informationstransferprozesse auf Gehirnebene möglich sind, welche experimentellen Erfahrungen bereits vorliegen und wie theoretische Überlegungen diese Erfahrungen plausibel erscheinen lassen. Als Ergebnis wird Säule 11 ,Arbeitsweise unseres Gehirns' untersucht und die Kategorie aus dem Codierungsprozess ,Übertragungswege zwischen lebenden Systemen' auf Menschen ausgedehnt.

\subsubsection{Unser Gehirn - aktuelles Verständnis und Aufbau}

Wer sich mit der Geschichte des Gehirns beschäftigt, wird immer wieder den Versuch beobachten können, unser Gehirn mit Metaphern aus der Technik zu beschreiben. Je nach dem Stand der Technik fällt dies unterschiedlich aus. Wurde zu Beginn noch der Vergleich mit einem Räderwerk vorgenommen, folgten später kommunizierende Röhren, dann unter dem Einfluss der Kybernetik der klassische Computer (Eckoldt 2016). Heute orientiert sich die Forschung u. a. an neuronalen Netzen, die im Gehirn zu beobachten sind und versucht sie auf die Entwicklung künstlicher Intelligenz und Quantencomputer zu übertragen (Daskin 2018; Musser 2018; Schempp 1992). Neuronale Netze erscheinen als Datenautobahnen, die je nach Bedarf angepasst werden. Hier wird vor allem versucht die Selbstlernkompetenz nachzubilden; eine Fähigkeit, die alle lebenden Systeme auszeichnet. Im Weiteren wird sich zeigen, dass mittlerweile auch 
Quantencomputer als analoges Bild verwendet werden. Immer findet sich ein direkter Bezug zu den jeweils aktuellen Wissens- und Forschungsmodellen und damit auch zum aktuellen Zeitgeist. Aufgrund dieser Parallele glauben viele immer noch an eine letztlich mechanistische Komponente unseres Denkapparats. Gleichwohl darf die Verbindung zu physikalischen Grundlagen als Ausgangspunkt angenommen werden: ,, To expect the mind-brain connection to be understood within a framework of ideas so contrary to the principles of physics is scientifically unsupportable and unreasonable " (Schwartz u. a. 2005: 1324).

Als möglicher Ausweg scheint ein hilfreicheres Verständnis zu sein, das Gehirn als Ausgangspunkt anzusehen, von der sich die Technik leiten lässt. Je stärker sich die Computerentwicklung an der Funktionsweise des Gehirns orientiert, desto größer werden die Ähnlichkeiten und nicht umgekehrt.

\subsubsection{Aufbau unseres Gehirns nach klassischem Verständnis}

Wovon reden die Neurowissenschaften nun eigentlich, wenn sie von unserm Gehirn sprechen und es als gewaltiges physisches System bezeichnen? Im Folgenden werden ein paar Fakten und eine klassische Beschreibung vorgestellt:

Unser Gehirn setzt sich überwiegend aus Nerven- und Gliazellen (Myelinscheide) zusammen (Schandry 2011: 46). Nervenzellen (auch als Neuronen bezeichnet) sind elektrisch erregbare Zellen des Nervensystems, die Informationen (Signale) verarbeiten und weiterleiten. In Wirbeltieren stellen Nervenzellen den wichtigsten Teil von Gehirn, Rückenmark und peripheren Nerven dar (Abb. 83). Die Myelinscheide umhüllt das Axon und spielt eine wesentliche Rolle bei der Beschleunigung der Leitungsgeschwindigkeit.

Nervenzellen setzen sich jeweils aus drei Grundelementen zusammen - dem Zellkörper (Soma), den Dendriten und dem Axon. Vom Zellkörper, der den Zellkern umschließt, gehen zwei Arten von Fortsätzen ab: Dendrite und ein Axon. Dendrite nehmen elektrische Impulse von anderen Neuronen auf, wohingegen das Axon elektrische Impuls an andere Neuronen weiterleitet (ebd. 55). Das Axon selbst kann zwischen $1 \mu \mathrm{m}$ und etwas über $1 \mathrm{~m} \mathrm{lang}^{204}$ sein (ebd. 52). Gliazellen bauen die Myelinscheide auf (im Bild blau), die das Axon umhüllen. Zusammen mit dem Axon bilden sie eine Nervenfaser. Die Gliazellen sorgen für die elektrische Isolation. Das Zellskelett (oder Cytoskelett) der Nervenzelle wird $u$. a. aus Proteinen aufgebaut, die röhrenförmige Filamente bilden, die sogenannten Mikrotubuli (ebd. 49-50). Mikrotubuli sind in Längsrichtung der Axone ausgerichtet und besitzen einen Plus- und einen Minuspol. Mit den Polen erklärt sich auch ihre Leitfähigkeit für elektrische Impulse. Sie dienen gleichzeitig zur Stabilisierung wie auch zur Flexibilität und werden zusätzlich als Transportkanäle für verschiedene Stoffe genutzt. Ihre Durchmesser variieren zwischen 20 und $30 \mathrm{~nm}$ und ihre Länge liegt zwischen $0,2 \mu \mathrm{m}$ und mehreren Hundert $\mu \mathrm{m}$. Damit erstrecken sich die Mikrotubuli nicht über die gesamte Länge von Zellkörper bis Axonende. Vielmehr sind

${ }^{204}$ Der Ischiasnerv ist ein einziges Neuron, dessen Axon sich von der Wirbelsäule bis in den Zeh hinein erstreckt. 
Unmengen dieser kleinen Röhrchen überlappend angeordnet und aneinander gereiht (Alberts u. a. 2011: 1185). Im Gegensatz zum kontinuierlichen Auf- und Abbau der Mikrotubuli in normalen Zellen, die sich ständig replizieren, handelt es sich bei den Mikrotubuli in den Axonen der Neuronen um stabile Formen.

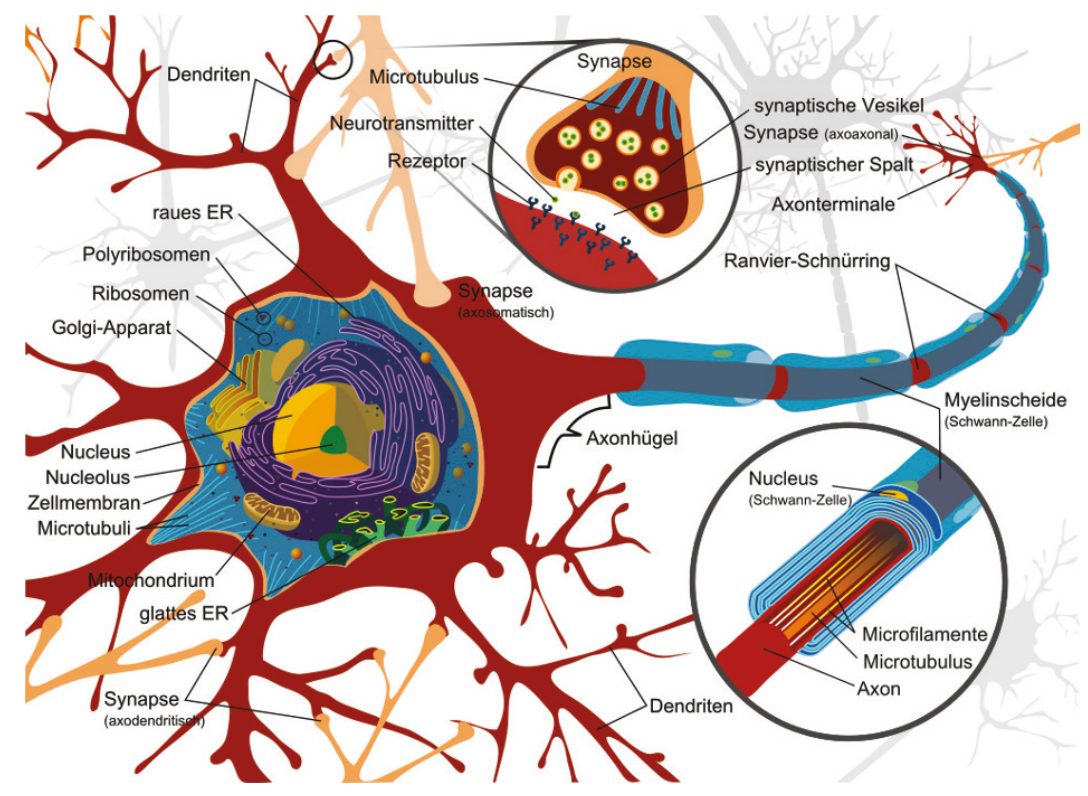

Abb. 83 | Diagramm einer ganzen Nervenzelle

Von LadyofHats, Gemeinfrei, https://commons.wikimedia.org/w/index.php?curid=3970958

Festzuhalten ist noch, dass sich die Anzahl der Neuronen im Gehirn ab der Geburt nicht verändert, wohl aber deren Dicke zunimmt (Spitzer 2002: 52). Einer zahlenmäßigen Veränderung unterliegen nur die Synapsen und ihre Übergänge. Nach diesen Vorstellungen geht mit der wachsenden Dicke der Nervenfasern eine verbesserte Impulsleitung einher. Auf diesen Beobachtungen basieren die molekularen Grundlagen und unsere heutige Vorstellung von Lernen und Gedächtnis (ebd. 96).

Strukturell enthält jede Nervenzelle das gesamte Genom und ihre Komplexität entspricht der einer Großstadt (Eagleman 2012: 7). Die Neuronen bilden ein Netzwerk aus mehreren 100 Milliarden Zellen, die über Synapsen verbunden sind. Allein ein Kubikzentimeter Gehirnmasse weist so viele Verbindungen auf, wie es Sterne in unserer Milchstraße gibt (vgl. ebd. 8). Von den ca. 15 Millionen Nervenzellen im Kleinhirn (Schiebler und Korf 2007: 786) besitzt jede einzelne Nervenzelle bis zu 80.000 Dendriten und ca. 150.000 Synapsen. Jede einzelne steht im Austausch mit Axonen anderer Nervenzellen, die Information nach klassischem Verständnis u. a. mittels elektrischer 
Impulse und Neurotransmittern übertragen. Berechnungen gehen davon aus, dass die Dauer chemischer, synaptischer Übertragungen mindestens $0,5 \mathrm{~ms}$ und die Geschwindigkeit innerhalb der Axone zwischen $0,5 \mathrm{~m} / \mathrm{s}$ und $120 \mathrm{~m} / \mathrm{s}$ beträgt (Rahnama u. a. 2011: 81). Eine Übertragung zwischen diesen Milliarden von Synapsen benötigt demzufolge Milliarden von Millisekunden allein im Gehirn. Wie kann dieses funktionieren? Damit können die langsamen synaptischen und axonalen Signalübertragungen niemals die schnellen, über große Gehirnregionen koordinierten, neuronalen Prozesse im Nervensystem erklären (ebd).

Wie eben angemerkt, geht nach allgemeinem Verständnis die Kommunikation zwischen Synapsen und aufnehmendem Dendrit im Gehirn mittels Neurotransmitter vonstatten (Schiebler und Korf 2007: 839-842). Neurotransmitter sind Übertragungsstoffe, also Moleküle, die eine relativ lange Zeit benötigen (s.o. 0,5 ms), um den Spalt zwischen Synapse und dem Rezeptor des Dendrits zu überwinden. ,Relativ' versteht sich hier in Bezug zur Geschwindigkeit, die ansonsten im Gehirn zu beobachten ist. Denn zusätzlich müssten Informationen, die nur auf diese Weise übertragen werden, quer durch das gesamte Gehirn, von Neuron zu Neuron transportiert werden und das auch zirkulär wieder zurück, wie oben bereits festgehalten wurde. Aufgrund dieser Diskrepanz zwischen bisherigem Verständnis und der beobachtbaren Interaktionszeiten der verschiedenen Gehirnareale bestehen erhebliche Zweifel über die Stimmigkeit dieses traditionellen Modells.

Einen ersten Hinweis könnten die elektrischen Synapsen liefern, die Ionenströme bidirektional zwischen Synapsen ermöglichen und als gap junctions bekannt sind (Engel u. a. 2018: 119). Durch gleichzeitiges Agieren vieler Neuronen ermöglichen sie nach bisherigem Verständnis die Aktionspotentiale (ebd. 121). Wesentlicher scheint mir jedoch, dass elektrische Synapsen für eine hochgradige Synchronisierung und Koordinierung großer Neuronenareale verantwortlich gemacht werden (ebd.) und damit größerflächige Kohärenz ermöglichen. Ihre Rolle wird in den Neurowissenschaften jedoch als untergeordnet angesehen (ebd.).

Dass elektrische Prozesse mitwirken, wird durch das Auftreten von EEG-Wellen offensichtlich. Nach dem herkömmlichen Verständnis ist bis heute jedoch völlig unklar, wodurch die mit einem EEG (Elektroenzephalografie) gemessenen EM-Wellen erzeugt werden (Hameroff und Penrose 2014b: 97).

Funktional sind es die Neuronen, die Veränderungen der Umgebung wahrnehmen, diese an andere Neuronen weiterleiten und schließlich körperliche Reaktionen auf diese Wahrnehmungen hin auslösen (Engel u. a. 2016: 28). Um diese Funktion realisieren zu können, wird den Neuronen die Fähigkeiten zur Speicherung von Informationen und zur Modulation der Signalübertragung zugeschrieben. Jede dieser Nervenzellen im Gehirn ist hoch spezialisiert und repräsentiert ganz bestimmte Aspekte der Außen- und Innenwelt, wie Farbe, Geräusche, Raum, aber auch Zusammenhänge, Muster, Werte, Orte oder Gefühle. Im Verbund bilden sie kleine und größere Cluster (Spitzer 2002: 12-13). Auf diese Weise sind über das ganze Gehirn unzählige Cluster verteilt, die nur im Zusammenspiel Informationen verarbeiten und wieder zur Verfügung stellen können und 
nach klassischer Vorstellung über neuronale Netze ${ }^{205}$ verbunden sind. Damit diese Cluster anspringen, müssen die elektrischen Impulse bestimmte Wahrnehmungsschwellen übersteigen, d. h. die Zahl der Neuronen, die feuern, muss groß genug werden, damit ausreichend Energie zusammenkommt. Je mehr Neuronen gemeinsam aktiv sind, desto mehr Eingangssignale kommen auf ein Neuron und desto schneller wird der Schwellenwert erreicht, der wiederum neue Ausgangssignale produziert. Es handelt sich hier also um einen zirkulären, sich selbst verstärkenden Prozess, der sich auch auf das Lernen an sich ausdehnt (ebd. 118 - 119). Denn mit jeder Trainingseinheit erweitert sich das neuronale Areal (bekannt unter dem Begriff der Neuroplastizität (ebd. 94)), die Cluster werden größer und können so schneller die Wahrnehmungsschwellen erreichen. Dafür benötigt es allerdings variantenreiches Lernen, und wenn es nur kleinste Modifikationen sind sowie Motivation und Aufmerksamkeit (ebd. 154). Wie sich herausgestellt hat, führt stupides Wiederholen dagegen zu einem Stopp der neuronalen Erweiterung. Diese Erweiterungen lassen sich mit bildgebenden Verfahren beobachten (ebd.).

Anschaulich wird dies beim Autofahren, bei Sportlern oder bei beruflicher Spezialisierung. Wofür zunächst noch viel Aufmerksamkeit und Energie nötig ist, wird es mit zunehmender Übung einfacher bis es schließlich ins Unterbewusste übergeht. Schließlich reichen nur kleinste Signale, um Veränderungen wahrzunehmen oder Situationen zu erfassen. Geübte Fachkräfte in der Linsenfertigung für Hochleistungsobjektive sind in der Lage mit der Hand $40 \mathrm{~cm}$ große, gewölbte Linsen bis auf wenige Atome genau zu polieren ${ }^{206}$. Das neue Ur-Kilo, eine Siliziumkugel, wird ebenfalls per Hand von einem Spezialisten auf die exakte Größe poliert (Zörlein 2008). Der Durchmesser der Siliziumkugel ist bis auf wenige nm exakt. Damit wird die Lernfähigkeit und der Sensibilitätsgrad deutlich, den unser Nervensystem und unser Gehirn zu leisten vermag und im Unterbewussten ablaufen lässt.

\subsubsection{Grenzen des klassischen Verständnisses}

Die oben beschriebene Geschwindigkeitsdynamik stellt nur eine von vielen Fragezeichen dar, weshalb in den Neurowissenschaften erhebliche Widerstände bzgl. adäquater Erklärungsmodelle existieren (Tang und Dai 2014b; Fair u. a. 2009; Schwartz u. a. 2005). Diese Gegenbewegung zu rein physiologischen Modellen resultiert darüber hinaus aus psychologischen Beobachtungen (Salone u. a. 2016; Schwartz u. a. 2005) als auch aus der Bewusstseinsforschung. Exemplarisch soll hier ein Zitat von Eagleman vorgestellt werden: „Die meisten Menschen würden für die Existenz einer vom Körper unabhängigen Seele votieren, und die meisten Neurobiologen dagegen. Für Letztere ist das Wesen des Menschen nichts als eine natürliche Eigenschaft, die sich aus einem gewaltigen physischen System ergibt, sonst nichts " (Eagleman 2012: 238). Aus materialistischer, reduktionistischer Sicht wird alles auf der Welt Existierende ausschließlich

\footnotetext{
${ }^{205}$ Spitzer weist darauf hin, dass Kinder und Computermodelle in gleicher Weise und in den gleichen Phasen gleiche Fehler produzieren. Er schließt daraus, dass beide in ähnlicher Weise lernen (Spitzer 2002: 74).

${ }^{206}$ Eigene Beobachtungen bei einem Kunden, der Hochleistungsobjektive herstellt.
} 
auf chemische und biologische Prozesse reduziert. Dazu gehört unser Bewusstsein und sonstige Phänomene wie Narzissmus, Mitgefühl, Träume etc. ,Demnach ist das Gehirn ein System, das den Gesetzen der Chemie und Physik unterliegt, und unsere Gedanken, Emotionen und Entscheidungen sind nichts als das Produkt natürlicher Reaktionen, die regionalen Gesetzen folgt, um den Zustand der geringsten potenziellen Energie herzustellen "(ebd.). Entsprechend gestehen die Neurowissenschaften dem Bewusstsein heute in der Regel nur eine Auswahlfunktion zu (ebd. 227). Es darf auswählen, was auf der Festplatte des Gehirns und gegebenenfalls in den Genen eingeätzt werden soll. Damit endet aus ihrer Sicht die aktive Rolle. Gleichzeitig gehen sie davon aus, dass Intuition und Tradition keine Bedeutung für Zukunftsvorhersagen haben. Der wissenschaftliche Fortschritt über den Aufbau unseres Gehirn und die Gene sollen hierfür wesentlich hilfreichere Modelle zur Verfügung stellen (ebd. 229).

Als rein physisches System sollte also der genetische Code ausreichen, um alle körperlichen Entwicklungen und Vorgänge erklären zu können, so die bisherige noch weit verbreitete Annahme. Dass dem vielleicht doch nicht so ist, verdeutlichen SyA und Intuitionsforschung. Auch das Wissen über den heute vollständig vorliegenden Gencode veranschaulicht die Unmöglichkeit dieser Annahme. So lässt sich tatsächlich nicht aus dem Gencode auf den Ausbruch von Krankheiten schließen (ebd. 245). Ein Wissen über unsere Gene reicht demzufolge nicht aus, um unser Verhalten oder innere Prozesse sicher vorhersagen zu können (ebd. 248). Analog zur Physik stellt Eagleman den gleichen Zusammenhang fest: Die Reduzierung auf immer kleinere Bausteine liefert kaum Antworten auf brennende Fragen (ebd. 246). Zwar mag es eine Veranlagung dazu geben, entscheidend sind jedoch ein Zusammenspiel von Umfeld, Gendisposition und spezifischen Gehirnstrukturen. Ergänzt wird dies durch die Unmöglichkeit, mit den heutigen bildgebenden Verfahren ableiten zu wollen, was der Mensch tatsächlich denkt. Es besteht bisher nur die Option zu erkennen, welche Gehirnareale (von denen man in etwa weiß wofür sie zuständig sind) an Gedanken und Verhaltensprozessen beteiligt sind, nicht mehr. Derzeit sind die betroffenen Gehirnregionen noch viel zu winzig, um sie direkt beobachten zu können (vgl. ebd. 149). Es lässt sich heute von außen anhand der elektrischen Signale auch noch nicht sagen, was genau wahrgenommen wird. Ist es ein Stuhl oder eine Bank, ein BMW oder ein Audi oder etwas ganz anderes und welche Farbe hat es? Die Vorstellung der Aufteilung unseres Gehirns in Regionen mit klaren Zuständigkeiten ist nach Eagleman ebenso falsch. „Das zusammenhängende Netzwerk der neuronalen Schaltkreise führt seine Aufgaben über vielfältige, eigenständige und unabhängig voneinander entwickelte Strategien aus “ (ebd. 154). „Dauernd sind kleine Gruppen damit beschäftigt, Entscheidungen zu treffen und an andere kleine Gruppen weiterzugeben " (ebd. 13). Für jede Aufgabe kann unser Gehirn zahlreiche leicht variierende Möglichkeiten liefern, nie nur eine. Zusätzlich existieren eine Reihe von Gegenspielern (ebd. 120-177), die ständig die vielen unterschiedlichen Informationen gegeneinander abgleichen und in jedem einzelnen Menschen eine Vielheit von Menschen abbildet. ,Ich' bin damit, Viele'. Welches der, Vielen' sich zeigt, hängt von Umfeld, Situation und meinem momentanen Befinden ab. Kleinigkeiten können darüber entscheiden, was sich im jeweiligen Moment materialisiert. Allein aus diesem Sachverhalt lässt 
sich eine deterministische Festlegung dessen, was sich in unserem Gehirn tut, verneinen. Ganz im Gegenteil findet sich hier eine analoge Beschreibung zu Schrödinger's Katze wieder, mit einer Superposition von Möglichkeiten.

Für Eagleman, wie für viele Neurowissenschaftler, ist es auch nach wie vor ein Rätsel, wie das Gehirn uns Informationen zur Verfügung stellt. Sie konnten nämlich nachweisen, dass die meisten Prozesse des Gehirns im Verborgenen und Vorbewussten laufen, bis hin zu Lernen von und Entscheiden zwischen bedeutungsvollen und nicht-bedeutungsvollen semantischen Signalen aus dem Umfeld im Schlaf. ,, Yet, the sleeping brain continues generating neural responses to external events, revealing the preservation of cognitive processes ranging from the recognition of familiar stimuli to the formation of new memory representations " (Legendre u. a. 2019). Die fertigen Ergebnisse werden irgendwann in Form von Ideen serviert. ,Wenn eine Idee von hinter den Kulissen herausgereicht wird, dann haben Ihre Schaltkreise sie oft stunden-, tage- oder sogar jahrelang durchgekaut, Informationen gesammelt, konsolidiert und in immer neuen Kombinationen zusammengestellt “ (Eagleman 2012: 14). Er führt dazu als ein Beispiel Goethe an, der von sich behauptet haben soll, dass er den Roman ,Die Leiden des jungen Werthers' ohne bewusstes Zutun geschrieben habe. Die Feder habe sich wie von selbst bewegt, er habe sie nur gehalten (ebd. 15). Als weiteres Beispiel verweist Eagleman auf Wurf und Schlag eines Baseballs. Die Weltrekordgeschwindigkeit des Wurfs liegt bei $161 \mathrm{~km} / \mathrm{s}$. Der Schläger hat damit nur $400 \mathrm{~ms}$ (0,4 Sekunden) Zeit, den Ball zu treffen. Das reicht aus, um den Weg des optischen Signals vom Auge über die Nervenzellen der Netzhaut bis zum visuellen Cortex des Gehirns, von dort über eine gewaltige Strecke bis zum Motorcortex zu leiten und schließlich die Muskeln zu stimulieren. Eine bewusste Reaktion benötigt aber mehr als $0,5 \mathrm{~s}$ (ebd. 16). Neurologisch gesehen braucht es also keine bewusste Wahrnehmung um komplexe Situationen (hier Bewegungsabläufe) zu meistern. Damit stellt sich erneut die Frage: Wie arbeitet unser Gehirn und was arbeitet da?

Aus Sicht der Neurowissenschaften ist heute klar, dass wir die Außenwelt nicht direkt wahrnehmen, sondern nur Signale mit unserem Nervensystem aufnehmen und unser Gehirn diese interpretiert. Dem Gehirn ist es egal über welchen Kanal ein Signal hereinkommt. Letztlich handelt es sich immer um eine Information, die in EM-Wellen codiert ist. Deshalb führen erfolgreich verlaufende Operationen nach langer Blindheit nicht unbedingt zu einem normalen Sehen. Zwei Fälle, bei denen ein im Alter von drei Jahren erblindeter Mann (MacLeod und Fine 2010) durch ein neues Operationsverfahren und ein 71-jähriger nach 53 Jahren Blindheit (Šikl u. a. 2013) wieder sehen konnten, verdeutlichen dies. Beide mussten das Sehen über Monate erst wieder lernen und schafften dies nur unvollständig. Die von den Augen wahrgenommenen Farben, Formen und Lichter wurden an das Gehirn geleitetet, konnten von diesem aber nicht interpretiert werden. Interessant ist auch, dass in unserem Gehirn nicht alles sofort und gleichschnell abläuft. Auf bekannte oder einfache Signale reagiert unser Gehirn recht schnell, auf unbekannte oder widersprüchliche Signale deutlich langsamer und noch länger, wenn 
komplexe Entscheidungen zu treffen sind (siehe Kap. 3.2.3). Was läuft da also im Hintergrund?

Tatsächlich stellt Eagleman am Ende auch die Frage, ob ,es eine Art von Kommunikation zwischen dem menschlichen Geist und der Materie des Universums " gibt? Eine Antwort auf diese Frage , könnte eine entscheidende Verbindung zwischen Quantenphysik und Hirnforschung darstellen " (Eagleman 2012: 258). Sehr in Zweifel stellt er in jedem Fall die Möglichkeit einer rein materialistisch-reduktionistischen Erklärung mit dem Hinweis, einer nichtverstandenen Komplexität auf diesem Gebiet und dem Einfluss der Umwelt (ebd. 253). Worauf begründet er diesen Zweifel? Ausgehend von seinen Forschungen, in denen er sich mit menschlichen Wahrnehmungen beschäftigt und dem Mechanismus, wie die Sinneseindrücke bewusst und unbewusst dem Menschen zur Verfügung gestellt werden, ergibt sich für ihn die Schlussfolgerung, dass das Wissen über unsere mentalen und kognitiven Prozesse noch in den Kinderschuhen steckt (ebd. 260). Zum einen sind es die unglaublich schnellen Zeitabläufe, in denen verschiedene Gehirnareale miteinander interagieren. Zeitabläufe, die aus rein mechanistischer Sicht (Information wird von einer zur anderen Zelle rein biochemisch weitergegeben) nicht realisierbar wären, denn das Gehirn hat zudem sowohl Vorwärts- wie Rückwärtsverbindungen, eine sogenannte Rekurrenz (Bell 1999). Zum anderen sind es die „Zombie-Programme ", wie er sie nennt. Programme, die völlig im Hintergrund laufen und unsere Entscheidungsfreiheit massiv einschränken, wenn nicht sogar zum Erliegen bringen. „,Wir können den menschlichen Geist nur begreifen, wenn wir die Aktivitätsmuster entziffern, die auf dieser Hardware stattfinden und die sowohl durch innere Abläufe als auch durch Interaktionen mit der Umwelt zustande kommen " (Eagleman 2012: 257). Zur Veranschaulichung stellt er zahlreiche neuronale Krankheiten vor, die massivste Auswirkungen auf unser Verhalten und unser Bewusstsein haben. Beispielhaft sei auf die Huntington-Krankheit (ebd. 244) verwiesen, bei der die Mutation eines einzigen Gens zum Zelltod im Frontallappen des Gehirns und als Folge zu massiven Persönlichkeitsveränderungen führt.

Für Familienaufsteller erscheint mir ein anderes, gut ankoppelbares Beispiel von besonderer Bedeutung zu sein: die Schizophrenie. Die Suche nach entsprechenden Genen war erfolgreich. Die Forscher haben Hunderte solcher Gene gefunden, von denen allerdings kein einziges den Ausbruch der Schizophrenie voraussagen kann (ebd. 246-247). Entscheidend sei vielmehr der soziale Stress, den z. B. Einwanderer in ihrem neuen Umfeld empfinden. Je stärker der äußerliche und kulturelle Unterschied zur lokalen Gesellschaft ist, desto stärker die Gefahr entsprechender Symptome, die sich auf Gehirnebene auch lokalisieren lassen. Dies betrifft allerdings nur diejenigen, die stark an diesem Unterschied der Kulturen leiden, nicht aber diejenigen, die stolz auf ihr kulturelles Erbe und ihre Herkunft sind.

Um Antworten für diese unklaren Prozesse in unserem Gehirn zu finden, wird auf verschiedenen Ebenen geforscht. Ganz praktisch beziehen sich viele dieser Untersuchungen auf das Verstehen des Zusammenhangs von Gehirnaktivitäten und psychischen Störungen (Neuro-Psychoanalyse). Rein technisch betrachtet, lassen sich hierfür drei 
Arten von Verbindungen mithilfe von Neuroimages untersuchen (Salone u. a. 2016: 23):

1. anatomische Verbindungen

2. funktionale Verbindungen

3. effektive Verbindungen

Unter (1) werden anatomische Muster von Verbindungen verstanden, die zwischen Neuronengruppen/Hirnregionen zu beobachten sind. (2) beziehen sich auf statistische Korrelationen zwischen verschiedenen aktivierten Hirnregionen. (3) schließlich untersuchen kausale Interaktionen zwischen spezifischen Neuronengruppen/Hirnregionen.

Als Ergebnis werden die rein reduktionistischen und kognitiv orientierten, neurowissenschaftlichen Ansätze als überholt betrachtet (ebd.), wie bereits bei Eagleman geschehen. So dominieren beispielsweise Gene und neuronale Strukturen nicht ausschließlich unser Verhalten. Letztlich führten die Forschungen zu einem erweiterten Verständnis, dass Synapsen und Gene durch veränderte Umweltrelationen (Gespräche, Achtsamkeitsübungen, spezielles Training, Therapie etc.) modifiziert werden können. Zu beobachten waren auch Veränderungen innerhalb der Interaktion zwischen größeren neuronalen Netzen. Veränderungen, die intersubjektiv sowohl emotional als auch im Verhalten nachvollzogen werden konnten (ebd.). Diese Untersuchungen liegen voll auf der Linie neuester Erkenntnisse, bei der Umwelt-, soziale und kulturelle Einflüsse hauptverantwortlich für die Entwicklung des Gehirns scheinen (González-Forero und Gardner 2018). Einflüsse, die nicht auf einen reinen Zufall abzielen, sondern in Wechselwirkung mit dem Kontext stehen, wie es sich bereits bei der Modifikation der DNA gezeigt hat. In eine vergleichbare Richtung zielt die aktuell sehr populäre Forschung zur Epigenetik. Diese Forschung zeigt, dass Umfeldbedingungen Gene an- und abstellen, Verhaltensreaktionen und Fähigkeiten beeinflussen und auch über Generationen weitergegeben werden können (Reumschüssel 2018; Meaney und Hellhammer 2005; Bastian u. a. 2004). Es handelt sich um Umfeldbedingungen, wie Ernährungssituation, Trauma- oder Beziehungserlebnisse, die nicht zwingend zu DNA-Veränderungen führen und dennoch wirksam werden (Yehuda u. a. 2014). Mentale Arbeit beeinflusst nach der Epigenetik nachweislich die biochemischen Prozesse im Körper. Wie der Prozess auf biochemischer Ebene vonstatten geht, ist mittlerweile gut nachvollziehbar, nicht aber wie die Information selbst als Auslöser fungiert.

Dass die bisherigen konventionellen Ansätze nicht ausreichen, wird nicht nur bei Eagleman sichtbar und ist bereits länger bekannt. „,Despite the large structural diversity of existing artificial neural networks (ANN), the limited functionality of the neurons and connections between them has constrained the scope of applications of ANN and their efficiency when modelling large scale, noisy, dynamic and stochastic processes such as ecological, environmental, physical, biological, cognitive, and others " (Kasabov 2010: 16). Antworten versucht man mithilfe von deterministischen ,spiking neural networks' 
$(\mathrm{SNN})^{207}$ oder mit ,probabilistic spiking neuron model' (pSNM) zu geben (ebd.). Letztlich handelt es sich hier um Coding-Hypothesen, die in unterschiedliche Klassen differenziert und erforscht werden ${ }^{208}$. Aktuelle Forschungen scheinen auf eine gleichzeitige Relevanz mehrerer dieser Codes hinzudeuten (Yan u. a. 2016). Die zugrundeliegenden Überlegungen gehen noch von einer rein energetischen Komponente bzw. einer Variabilität von Signalen aus, an die Information gebunden sind und die durch Gene, Proteine, physikalische Eigenschaften etc. beeinflusst werden. Als Übermittler zwischen den Synapsen bleiben aber auch hier die Neurotransmitter und stochastische Prozesse verantwortlich (Kasabov 2010). Mithilfe von Spiking-Ansätzen wird letztlich versucht Muster zu erkennen, vergleichbar dem Morsen oder der Shannon-Entropie und diese für die Informationsübertragung verantwortlich zu machen. Viele Arbeiten zur Entwicklung neuronaler Spiking-Lösungen konzentrieren sich dabei auf das Sehen (Kheradpisheh u. a. 2018; Yan u. a. 2016; Greschner u. a. 2006; Thorpe u. a. 2001) und die Entscheidungsfindung (Beyeler u. a. 2013). Dass es zwischen den Neuronenaktivitäten und den gemessenen EM-Feldern im Gehirn Raum-Zeitstrukturen geben muss, die einen Zusammenhang zwischen Gehirnaktivitäten und Verhalten repräsentieren, lässt sich aus der Synergetik ${ }^{209}$ ableiten (Haken 2016: 33). Dies bedeutet jedoch nicht zwingend, dass diese gefundenen Muster tatsächlich verantwortlich für die sich zeigenden Informationen sind, genauso wenig wie die ,Raumsprache' in der SyA als Träger der wahrgenommenen Information zu interpretieren ist. Dies wird in einer Aussage von Ebeling und Scharnhorst zur Modellierung sozialwissenschaftlicher Modelle mithilfe der Synergetik deutlich: ,Bei der Modellbildung steht in der Regel der erkenntnistheoretische Gewinn eines spezifischen Modells im Vordergrund, nicht aber die Beschreibung des erkenntnistheoretischen Rahmens, auf dem eben diese Art von Modellbildung beruht " (Ebeling und Scharnhorst 2015: 419). Letztlich basieren die Coding-Hypothesen und die Untersuchung der Spikes/Aktionspotentiale wohl auf dem Modell der Synergetik, die neuronale Potentiallandschaften als Ordnungssysteme nutzt und damit die Brücke zur Wahrnehmung und zur Physiologie respektive zur Psychologie zu schlagen sucht (Haken u. a. 2016: 41-45).

Ein anderes Merkmal, das die Reaktionsweise unseres Gehirns veranschaulicht und Unklarheiten über den dahinter liegenden Prozess aufwirft, ist die sogenannte, Wahrheits-

${ }^{207}$ Spiking neural networks (SNN) zu dt.: gepulste neuronale Netze. Spikes steht synonym auch für Aktionspotential. Dieser Ansatz basiert auf der Informationstheorie und versucht, vergleichbar zu Shannon, Informationen durch Pulse zu codieren und zu decodieren. Die Aktionspotentiale in neuronalen und synaptischen Gegebenheiten werden als Codes betrachtet, die über Intensität oder zeitliche Ausdrucksform Informationen speichern und im neuronalen Netzwerk weiterleiten.

${ }^{208}$ Z. B. Ratencode - Intensität eines Reizes korrespondiert mit der Höhe des Spikes (des Aktionspotentials und seiner Frequenz). Der genaue Zeitpunkt des Spikes ist unwichtig.

Zeit- oder Latenzcode - Hier sind die genauen Zeiten der Spikes wichtig; wann der Stimulus beginnt und der Spike auftritt.

Rang- oder Populationscode - Hier bekommen die Zellpopulationen eine Reihenfolge, je nachdem wann sie feuern.

${ }^{209}$ Auf die Synergetik wird in Kap. 9.1 noch näher eingegangen. 
illusion'. Die von Hasher und Goldstein durchgeführten Untersuchungen (Hasher u. a. 1977) zeigen sehr deutlich, wie unser Gehirn auf Aussagen reagiert, die es schon einmal gehört hat. Es ordnet ihnen beim zweiten Mal sofort eine höhere Glaubwürdigkeit zu, als einer Information, die es noch nie gehört hat, unabhängig davon, ob sie stimmt oder nicht, analog der Bayes'schen Wahrscheinlichkeit.

\subsubsection{Conclusio aus dem aktuellen Verständnis zu unserem Gehirn}

Auch aus dem klassischen Aufbau unseres Gehirns lässt sich mittlerweile das Gehirn im weitesten Sinn als informationsverarbeitendes System verstehen, das nicht lineare, sondern parallele, hoch komplexe Prozesse über alle Areale am Laufen hat (Tang und Dai 2014b). Probleme wirft in diesen Modellen die Frage nach dem tatsächlichen Kommunikations- bzw. Verarbeitungsprozess zwischen den Neuronen auf, da die klassischen Erklärungen keine brauchbare Antwort auf die tatsächlich beobachtbaren Reaktionsprozesse geben können. Dafür sind die gemessenen elektronischen und biochemischen Prozesse zu langsam.

Aufgrund der extrem hohen, faktisch instantanen Geschwindigkeit, in der die Neuronen parallel aktiv sind, wird der Ansatz einer chemisch getragenen Informationsübertragung auch innerhalb der klassischen Forschung als immer unwahrscheinlicher angesehen. Eine chemisch getragene Aktivierungsweitergabe von Neuron zu Neuron hätte eine zeitlich definierte Ausbreitungsgeschwindigkeit und aufgrund des Umfeldes zumindest minimale Phasenverschiebungen der Frequenzen zur Folge. Ein Neuron beginnt und stößt die Schwingung des nächsten Neurons an. Da die Gehirnareale sehr autonom vorliegen und keine direkten Verbindungen aufweisen, in fast allen Fällen beide Gehirnhälften betroffen und nur über einen dicken Nervenbalken (Corpus Callosum) verbunden sind, müssen weite Wege zurückgelegt werden. Technisch müssten sich für unterschiedlich weit entfernte Gehirnareale deshalb solche Phasenverschiebungen messen lassen, was aber nicht zutrifft.

Interessant ist auch der Tatbestand des nicht bekannten Mechanismus zur Entstehung der EEG-Wellen. Gleichwohl hält die Forschenden aus Neurowissenschaften und Medizin dies nicht davon ab, die EEG-Methode zur Diagnostik zu verwenden. Eine vergleichbare Aufgeschlossenheit gegenüber alternativen Methoden, deren Mechanismen ebenfalls oft unbekannt sind, fehlt dagegen häufig.

An dieser Stelle soll auch deutlich das aktuelle Verständnis der Neurowissenschaften herausgestellt werden, dass Wahrnehmung ,, durch einen aktiven Abgleich zwischen eingehenden Sinnesdaten und inneren Erwartungen zustande" (Eagleman 2012: 63) kommt. Womit wir zum einen bei den Ansätzen des Konstruktivismus und zum anderen bei der Intention des Beobachters in quantenphysikalischen Experimenten wären. In beiden Fällen gibt es keine Objektivität mehr, sondern nur noch Subjektivität und maximal eine Intersubjektivität.

In den Erklärungen von Eagleman (ebd. 13), dass kleine Gruppen von Neuronen ständig damit beschäftigt sind Entscheidungen zu treffen und diese an andere Gruppen weiterzuleiten, finden sich genau die Beobachtungen wieder, die bereits in Kap. 8.2 
(qualitativer Entscheidungsprozess in Algen), bei den Lichtsammelkomplexen gemacht wurden. Der grundsätzliche Prozess zur Entscheidungsfindung scheint sich nicht geändert zu haben. Einzig die Größe und Komplexität der betroffenen (Molekül- bzw. Neuron-)Gruppen scheint mit der Komplexität der Systeme zuzunehmen. Eine weitere homologe Verbindung lässt sich zu Schrödinger's Katze und der Superposition von Möglichkeiten herstellen. Wie beschrieben, laufen viele Parallelabgleiche und damit -rechnungen gleichzeitig und Umwelt, Situation und mein momentanes Befinden oder der Zufall entscheiden darüber, welche Möglichkeit sich am Ende zeigt.

Mit dem Beispiel zur Huntington-Krankheit und der dabei auftretenden Mutation eines einzigen Gens kann auch ein Link zur schnellen Mutationsmöglichkeit der DNA gelegt werden, wie sie im Kap. 8.2 ,Biologische Systeme' behandelt wurde. Erstaunlich wäre, wenn die Prozesse zur Mutation in der DNA und die Prozesse in den Neuronen unterschiedlich funktionieren würden.

Das Beispiel der Schizophrenie beschreibt exakt einen Zusammenhang, der sich bei Familienaufstellungen immer wieder findet oder der zumindest durch die Repräsentanten und die Fallbringer immer wieder konstruiert wird. Klienten mit Migrationshintergrund (meist eher die zweite und dritte Generation) weisen zahlreiche körperliche und psychische Probleme auf, zu denen auch Lernschwierigkeiten gehören. Nach Herstellen einer inneren Verbindung mit der Herkunftskultur lösen sich die Symptome auf und die Menschen kommen in die Lage, sich in beiden Kulturen adäquat zu bewegen. Betrachtet man die Symptome, so gehören Ich-Störungen, das Hören von Stimmen genauso dazu wie das Wahrnehmen von Gefühlen, Handlungen oder Impulsen, die als fremdverursacht empfunden werden. Es entsteht der Eindruck als wäre da noch jemand anderes. Ein Phänomen, das exakt auf die repräsentative Wahrnehmung bei SyA passt und das wir auch bei großen Organtransplantationen wiederfinden (Mauthner u. a. 2015).

Die neueren Forschungen von Salone u. a., bei denen Gene, Synapsen und ganze neuronale Netzwerke nach unterschiedlichen Interventionen modifiziert wurden, lassen zudem eine tatsächliche Veränderung (im Sinne eines mentalen Heilungsprozesses) nach SyA als plausibel erscheinen.

So modern der Ansatz von Eagleman für Neurowissenschaftler erscheint, so bleibt er mit dem immer wieder verwendeten Verweis auf die Stammbaumabhängigkeit unserer Gene und den unendlich langen Anpassungszeiträumen doch im Bereich der klassischen Erklärungsansätze. Dagegen sind seine Überlegungen zu einer möglichen „,Kommunikation zwischen dem menschlichen Geist und der Materie des Universums " (ebd. 258) sehr aktuell. Diese Überlegungen werden durch die technischen Aufstellungen sichtbar und beantwortbar.

Ob die Zombie-Programme tatsächlich unseren freien Willen beschränken oder gar völlig eliminieren und damit die Frage, ob wir einen oder keinen freien Willen haben, oder ob wir hier eine andere Interpretation benötigen, wird ebenfalls zu untersuchen sein. Letztlich dreht sich alles um eine Antwort auf die Frage: Was läuft da im Hintergrund? Es geht um eine Antwort, die das letzte Puzzleteil zur Erklärung von SyA und Intuition an die Oberfläche heben soll. 
Die Spiking-/Coding-Hypothesen sind ebenfalls nicht in der Lage fundierte Antworten zu liefern, da mit ihnen die hohe Geschwindigkeit neuronaler Prozesse nicht beantwortet werden kann. Auch wenn rechnergestützte Simulationen gute Korrelationen zu beobachtbaren Phänomenen liefern, bleiben es virtuelle, mathematische Korrelationen. Als tatsächlicher Mechanismus scheiden sie aufgrund der langsamen, synaptischen, neurotransmitter-getragenen Informationsübertragung aus.

Schließlich bekommt mit dem Beispiel zur, Wahrheitsillusion' der ,Bayessche Wahrscheinlichkeitsbegriff' eine neurowissenschaftlich unterlegte Nachvollziehbarkeit. Da sich unser Gehirn nicht an objektiven Tatsachen orientiert, sondern nur an sinnstiftenden Zusammenhängen, hängt der Grad der Überzeugung von der Kohärenzfähigkeit mit bereits eingelagerten Informationen ab und ist deshalb so schwer veränderbar ${ }^{210}$.

Mit dem bisher vorgestellten Verständnis über die Arbeitsweise unseres Nervensystems und unseres Gehirns liefern die folgenden, experimentellen Ergebnisse anschauliche Bestätigung, aber auch schwierig zu erklärende Zusammenhänge. Denn das bisherige Wissen und die aktuellen Modelle befassen sich schwerpunktmäßig mit den Prozessen innerhalb eines lebenden Systems und dessen lokaler Ankopplung über Sinnesorgane. Damit werden die folgenden Beispiele zum Teil zu echten Herausforderungen.

\subsubsection{Experimentelle Zugänge und Auswertungsmethoden}

Wie schon bei den Versuchen zur Entscheidungstheorie und Intuitionsforschung vorgestellt, werden EEG und $\mathrm{fMRT}^{211}$ zu Messungen von Gehirnaktivitäten herangezogen. Im Folgenden sollen damit verbundene Experimente und Zusammenhänge näher betrachtet werden, um Antworten für den Arbeitsprozess unseres Gehirns zu erkunden.

\subsubsection{Gehirnwellen und mit ihnen assoziierte Zustände}

Als allgemeines Wissen darf der Umstand angesehen werden, dass den verschiedenen Gehirnbereichen unterschiedliche Sinnesorgane und Funktionen zuzuordnen sind, die wiederum von hochspezialisierten Neuronen aufgebaut werden. Nehmen wir etwas wahr, feuern unsere Neuronen an den verschiedensten Stellen gleichzeitig. Wie diese scheinbar unabhängigen Gehirnbereiche zusammenwirken, ist noch Teil einer intensiven Forschung. Zu dieser Forschung gehört u. a. die Untersuchung der Gehirnaktivitäten mittels EEG.

${ }^{210}$ Aus diesem Grund sind Populisten, wie wir sie gerade zuhauf erleben (Brexit, US-Wahlkampf, ISParolen), mit ihren Lügen ausgesprochen gefährlich. Es geht nicht darum, ob die Lüge eine Lüge ist, sondern ob sie zum Weltbild und damit zum Referenzmuster der Zielgruppe passt. Fakten als Gegengewicht sind deshalb nicht ausreichend. Es muss gelingen, die Gegenargumentation ebenfalls an einer Vorüberzeugung der Zielgruppe anzukoppeln und das Referenzmuster emotional aufzuladen. Idealerweise wird ergänzend eine bessere Antwort in Bezug auf die in der Motivationsforschung gefundenen Treiber, , weg von' oder , hin zu', gefunden.

${ }^{211}$ Funktionale Magnetresonanztomographie (fMRT) ermöglicht physiologische Funktionen, z. B. aktivierte Hirnareale im Körper, mit hoher räumlicher Auflösung, bildhaft darzustellen. 
Solange wir leben ist das Gehirn ununterbrochen aktiv und produziert, je nach körperlichem und geistigem Zustand, unterschiedliche Frequenzen. Die mittels EEG gemessenen Werte lassen sich in verschiedene Kategorien aufteilen, denen spezifische Bewusstseinszustände zuordenbar sind. Traditionell werden der Alpha-, Beta-, Theta- und Delta-Zustand unterschieden (Schandry 2011: 517-530). Seit Kürzerem wurde aber auch erkannt, dass zwei weitere Frequenzbereiche, Gamma (Sweeney-Reed u. a. 2015, 2016; Ribary 2005) und Slow Cortical Potentials (SCP) (Schmidt u. a. 2016), ebenfalls eine erhebliche Rolle zu spielen scheinen und für unsere Überlegungen wichtig werden.

In der Literatur findet sich ein gewisser Spielraum für die Werte der Wellenbänder und Zuschreibungen, je nachdem welche empirische und theoretische Wissenschaft die Klassifizierung vornimmt. Abhängig vom Ansatz werden unterschiedliche Merkmale unterschieden:

1. Objektiv messbare Körperzustände wie die Frequenzen und ihre Verteilung über das Gehirn, ihre Durchmischungen und Intensitäten sowie der damit verbundene Bewusstseinszustand von aktivem Wachzustand bis Koma.

2. Subjektive Wahrnehmungen im Erleben, wie sinnliche Reize oder innere mentale Bilder und Gedanken.

Abb. 84 bietet eine Übersicht der Bewusstseinszustände während Ruhe- und Aufmerksamkeitsphasen.

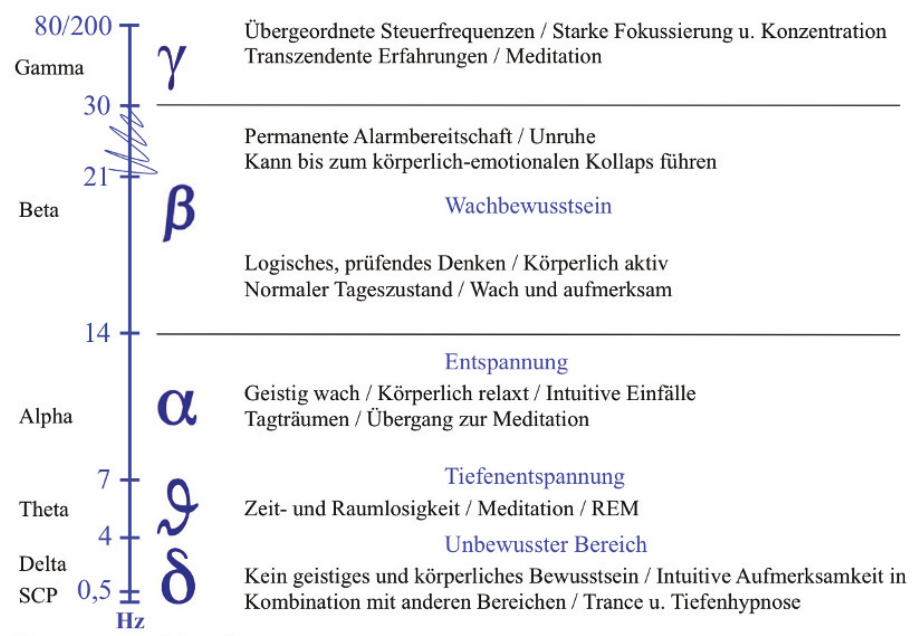

Frequenz pro Sekunde

Abb. 84 | Gehirnwellen mit ihren zugeordneten Bewusstseinszuständen

(eigene Darstellung). Die senkrechte Skala gibt die Frequenzbänder in $\mathrm{Hz}$ an, die an unserem Gehirn gemessen werden können. Links davon sind die den jeweiligen Frequenzbereichen zugeordneten Namen platziert und rechts davon die Seinszustände und Funktionen, die man den jeweiligen Bereichen heute zuordnet. 
Im Folgenden eine kurze Charakterisierung der Frequenzbänder (vgl. Schandry 2011: 517-530; vgl. Birbaumer und Schmidt 2010: 495-534) in Bezug auf intersubjektive Körperzustände:

$S C P^{212}$ (Slow Cortical Potentials) $(0,01-0,5 / 1 \mathrm{~Hz})$

Grundschwingung im Hintergrund, die relevant für übergreifende Aktivitäten im Gehirn und die Gesundheit scheint (Rusov u. a. 2012).

Delta-Wellen $(0,5 / 1-3 \mathrm{~Hz})$

Typisch für Säuglinge im Wachzustand und bei Erwachsenen für die traumlose Tiefschlafphase. In Verbindung mit den anderen Hirnwellen stehen sie für intuitive Aufmerksamkeit und der Fähigkeit sich in andere Menschen einzufühlen. In therapeutischen Kontexten können sie beim Nacherleben der eigenen Geburt sichtbar werden. Sie werden auch mit dem sechsten Sinn und der Verbindung zum kollektiven Unbewussten in Zusammenhang gebracht.

Theta-Wellen $(3-7 \mathrm{~Hz})$

Typisch für Kleinkinder im Wachzustand. Bei Erwachsenen signifikant für Schläfrigkeit und in leichten Schlaf- und Traum-(REM-)phasen. Sie sind typisch für tiefe Meditationen oder Gipfelerfahrungen und bei starken Gefühlen. Sie sind kennzeichnend für unbewusste Aktivitäten. Die Theta-Aktivität steigt während einer Therapie und dem Auftauchen verdrängter Gefühle oder unbewusster Erinnerungen, aber auch bei Störungen oder wenn Gefahr in Verzug ist.

Alpha-Wellen $(7-14 \mathrm{~Hz})$

Verstärkt Alpha-Wellen werden bei entspanntem, wachem Zustand, insbesondere bei geschlossenen Augen beobachtet. Bereits durch Öffnen und Schließen der Augen lassen sich Verschiebungen Richtung Alpha- respektive Beta-Zustand herbeiführen. Zur Erinnerung von unbewussten Erfahrungen, die während des Thetazustandes auftauchen, ist ihre gleichzeitige Anwesenheit zwingend notwendig. Die gleichzeitige Anwesenheit geht oft einher mit Einsicht und Kreativität.

Beta-Wellen $(14-30 \mathrm{~Hz})$

Normale Variante im Wachzustand. Aktive und nach außen gerichtete Aufmerksamkeit. Entstehen auch bei körperlichen Aktivitäten. In den oberen Bereichen weisen sie auf mentale Anspannung (z. B. bei Kritik), Angst, Stress oder totale Begeisterung hin.

Gamma-Wellen $(30-80 / 80-200 \mathrm{~Hz})$

Signifikant für starke Fokussierung und Konzentration, hoher Informationsfluss, Spitzenleistungen, Lernprozesse oder bei der Meditation sowie transzendente Erfahrungen. Mit zunehmender Meditationsübung nimmt die Amplitude signifikant zu.

${ }^{212}$ Bei Slow Cortical Potentials (SCP), 0,01 bis $1 \mathrm{~Hz}$, handelt es sich um langsam veränderliche, kortikale (die Hirnrinde betreffende) Potentialschwankungen im Zeitraum von einer bis wenigen Sekunden, weshalb sie in einem normalen EEG nicht sichtbar sind. Zur Identifikation benötigt es deshalb spezielle Filter. 
Den SCP wird bisher kein eigener Bewusstseinszustand zugeschrieben. SCP ist ein ständiger Hintergrundprozess der in Verbindung mit den Bereitschaftspotentialen ${ }^{213}$ (BP) und der Über- bzw. Unterschreitung bestimmter Schwellenwerte gebracht wird. Gleichwohl gehen Wahrnehmungen von Sinneseindrücken als auch aktive Denkprozesse mit verstärkten SCP-Aktivitäten einher. Näheres hierzu folgt in Kap. 8.3.3.1. Interessant für unsere Überlegungen erscheint der von einem kleinen Teil der Forschung untersuchte Zusammenhang des SCP/Delta-Spektrums zu Wechselwirkungen mit der Ionosphäre ${ }^{214}$ und ihre Wirkung auf den Menschen (Rusov u. a. 2012). Auslöser waren eindeutige Korrelationen zwischen geomagnetischen Pulsationen, Solarzyklen und Erkrankungen des Gehirns.

Mit Ausnahme des Beta-Zustandes, bei dem es zu einem eher nach außen gerichteten Aufmerksamkeitspotential kommt, sind alle anderen Bewusstseinszustände an sogenannten ,paranormalen' Phänomenen beteiligt. Viele große Entdeckungen und Erfindungen gehen einher mit Eingebungen, die im Halbschlaf- oder Traumzustand erfahren wurden, bei denen Alpha- und Theta-Wellen dominieren. Als Beispiele seien nur die Erfindung einer wichtigen technischen Detaillösung bei der Entwicklung der Nähmaschine durch Elias Howe und die Entdeckung des Benzolrings durch August Kekulé genannt. Howe sah sich im Traum von Wilden mit Speeren umgeben, die in ihrer Spitze ein Loch hatten. Kekulé bekam die ringförmige Anordnung der Kohlenstoffatome bei Träumereien im Bus (Deutsche chemische Gesellschaft 1890: 1306). Aufgrund der Ausdehnung und einer damit verbundenen großflächigen Synchronisierung der Hirnareale bei Alpha- und Theta-Aktivitäten, lässt sich eine Kohärenz der Wellen und damit die Möglichkeit eines übergreifenden Informationsaustausches annehmen.

Einen weiteren, für die Forschung interessanten Aspekt liefern die bei Alpha- und Theta-Wellen immer wieder auftretenden Korrelationen zwischen mentalen und Körperwahrnehmungen einerseits und weit entfernten Phänomenen andererseits sowie bewusstseinserweiternden Techniken (Silva und Miele 2004; Silva und Stone 2002). Als Folge stellen sich einige Forscher die Frage nach einem möglichen Zusammenhang mit den Schuhmann-Resonanzen ${ }^{215}$ bei $7,83 \mathrm{~Hz}, 14,1 \mathrm{~Hz}$ und 20,3 Hz (Hinterberger u. a. 2015: 229,240-241). Auffallenderweise liegen diese genau in der Größenordnung von Theta- und Alpha-Wellen, die bei außersinnlichen Wahrnehmungen, wie sie auch Intui-

${ }^{213}$ Als Bereitschaftspotential wird ein messbares elektrisches Signal (z. B. mit einem EEG) bezeichnet, das kurz vor einer willkürlichen Bewegung in einem speziellen Bereich des Motorcortex, dem supplementärmotorischen Cortex, auftritt. Entdeckt wurde es 1964 von H. Kornhuber und L. Deecke.

${ }^{214}$ Genauso wie die SCP und der untere Bereich der Delta-Wellen im Hintergrund aktiv sind, so sind um die Erde herum im Bereich der Ionosphäre $(100-1.000 \mathrm{~km})$ Frequenzen in genau der gleichen Größenordnung aktiv. Man nimmt an, dass diese über geomagnetische Feldlinien mit den erdnahen Zonen in Kontakt kommen und Wirkung entfalten.

${ }^{215}$ Bei den Schuhmann-Resonanzen handelt es sich um stehende Wellen entlang des Umfangs der Erde. Bei exakt diesen Frequenzen werden die EMW an den Begrenzungen, Erdboden und Ionosphäre (0 - $100 \mathrm{~km}$ ), reflektiert. Die Begrenzungen agieren wie ein Hohlraumresonator, der schließlich als Wellenleiter wirkt. Bei einer Frequenz von 7,83 Hz legt das Licht eine Strecke von ca. $38.000 \mathrm{~km}$ zurück, was annähernd dem Erdumfang von ca. 40.000 km entspricht. Damit würde sich eine EMgetragene Informationsübertragung und weitreichende Synchronisierung erklären lassen. 
tion und SyA repräsentieren, ermittelt werden. Anschlussfähig zu diesen Überlegungen sind die im Kap. 8.2.1 beobachteten Interaktionen zwischen EMF mit der DNA über sehr weite Frequenzbereiche von 3 - $30 \mathrm{~Hz}$ und den damit vermuteten DNA-Defekten und Mutationen (Blank und Goodman 2011).

Im Gegensatz zu den Gamma-Wellen und den SCP, waren die mit den vier anderen Frequenzbereichen einhergehenden Bewusstseinszustände schon lange bekannt. Welche Funktion den erst in jüngerer Zeit entdeckten Gamma-Wellen zuzuordnen ist, wird erst langsam verständlich (Ribary 2005). Bei Untersuchungen von buddhistischen Mönchen (Lutz u. a. 2004) waren diese im Vergleich zu einer Kontrollgruppe in der Lage, 30 mal höhere Gamma-Aktivität zu generieren und das über den gesamten Kopfbereich über lange Zeit. Gamma-Wellen sind nach neueren Forschungen (Mazaheri und Diepen 2015; Siegel u. a. 2012) für die Synchronisierung weiter Hirnareale und zur Integration unterschiedlicher Stimuli zuständig. Nach heutiger Interpretation ordnen die Forscher ihnen keinen eigenen Bewusstseinszustand zu, sondern eher eine übergeordnete Steuerungsfunktion. Wird eine Information von unserem Gehirn als bedeutsam erachtet, findet mithilfe der Gamma-Wellen eine großflächig übergreifende Synchronisation des Gehirns statt, so die Vermutung. (Allerdings wird ähnliches auch für das SCP angenommen.)

Als Ergebnis werden sie für das ,Binding ' verantwortlich gemacht. Darunter versteht man die Bindung verschiedener Informationen, die zu einer Wahrnehmung gehören, wie z. B. Farbe, Form, Klang, Gewicht etc. an Zeitpunkt und Ort. Forscher gehen davon aus, dass unser Gehirn auf diese Weise unserer bewussten Wahrnehmung komplex zusammengesetzte Bilder zur Verfügung stellt. So werden sie einerseits als Taktgeber gesehen, um aus den verschiedensten Signalen die relevanten herauszufiltern und zum anderen eben das Verbinden weit auseinander liegender Gehirnareale. Ansätze aus Experimenten und Computermodelle weisen auf solche Zusammenhänge hin. Da Gamma-Wellen immer parallel zu den anderen Frequenzbändern vorliegen, schließen die Forscher auf eine Codierung der Informationen in diesem Frequenzband und somit auf die Möglichkeit, auch über weite Entfernungen hinweg, Informationen miteinander in Verbindung bringen zu können. Die Forschung ist dazu jedoch noch nicht abgeschlossen. Unterschiedliche Ergebnisse (Ray und Maunsell 2015), die mittlerweile auch auf ein zweites Gammaband $(80-200 \mathrm{~Hz})$ ausgedehnt wurden, fordern noch weitere Klärung.

Als Quintessenz lässt sich aktuell dennoch festhalten: ein Teil der Forscher geht, als Voraussetzung für eine neuronale Kommunikation, von auf Frequenzbändern basierenden Synchronisationen aus. Welches Frequenzband tatsächlich relevant wird, ist abhängig vom Stimulus. Denn neuere Forschungen von Sweeney-Reed u. a. zeigen auch eindeutige Abhängigkeiten zwischen Theta- und Gamma-Frequenzen, deren Kopplung und unserer Erinnerungsfähigkeit (Sweeney-Reed u. a. 2016, 2015).

\section{Interpretation der ausgewerteten Forschungen}

Mit den beschriebenen Synchronisierungen liegt der gleiche Mechanismus vor, der bereits für andere bio-physikalische Prozesse erkannt wurde. Die betroffenen Nerven-zellen schwingen in Frequenzbändern, die identisch sind mit denen ihrer Nachbarn und 
interagieren sogar mit anderen Frequenzbändern und das ausgedehnt über das Gesamthirn. Damit liegt physikalisch gesehen wieder eine Kohärenz vor, mit all den damit verbundenen Möglichkeiten des Informationsaustausches.

Mit den Korrelationen zwischen Alpha-/Theta-Wellen und den Schuhmann-Resonanzen respektive dem SCP-/Delta-Wellenspektrum mit den Frequenzen der Ionosphäre und entsprechend einhergehenden psycho-physischen Phänomenen lässt sich ein Modell der Informationsübertragung auf der Basis von EM-Wellen denken. Dies sogar für weltumspannende, nicht technikgebundene Kopplung von Entitäten. Allein die Phänomene in EM-abgeschirmten Kontexten lassen sich hiermit noch nicht erklären.

\subsubsection{Die Rolle von EEG und Fourier-Transformation}

Das EEG liefert noch ein weiteres interessantes Charakteristikum. Typische EEG-Signale werden üblicherweise in Form von Abb. 85 dargestellt. Für jeden Messpunkt am Kopf erscheint eine gezackte Linie.

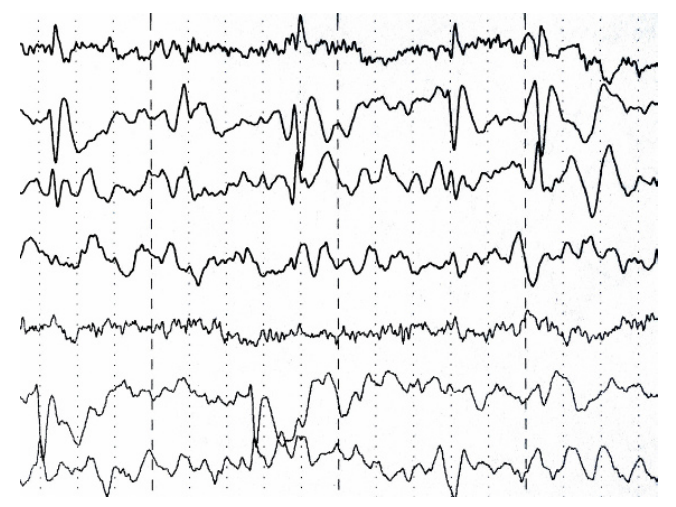

Abb. 85 | Ein klassisches EEG-Diagramm

abgeleitet von verschiedenen Messpunkten am Kopf. (AdobeStock 204919136)

Was in der Regel nur den Fachleuten bekannt ist, ist die Tatsache, dass sich in einer solchen EEG-Darstellung alle Phasen (Delta, Theta, Alpha, Beta und Gamma) gleichzeitig wiederfinden, nur mit unterschiedlicher Intensität und auch weitestgehend gleichverteilt auf rechter und linker Gehirnhälfte. Diese Sinfonie der gleichzeitigen Wellen erscheint bei der EEG-Messung als eine einzige Kurve. Es darf deshalb von einer Superposition verschiedener Wellen ausgegangen werden, die je nach Zustand und Situation auch regional unterschiedlich sein können. Ein Verständnis, das auf Hameroff und Penrose zurückgeht (Hameroff und Penrose 2014a). Ihr Modell führt die EEG-Frequenzen nicht nur auf die Neuronen zurück, sondern sogar auf superschnelle Frequenzen der Mikrotubuli, die die Neuronen mit aufbauen.

Zweifelsohne handelt es sich dabei um keine typische quantenmechanische Superposition, bei der sich Wahrscheinlichkeitswellen überlagern, wohl aber um eine Interferenz 
im Sinne einer ,klassischen Verschränkung' (siehe Kap. 8.1.2 ,Verschränkung und Dekohärenz'). Als Folge lassen sich deshalb codierte Informationsübertragungen annehmen.

Ausgangspunkt für diese Idee sind EEG-Diagramme, deren Messung und Auswertung auf den ersten Blick eine einfache Sache scheint. Tatsächlich zeigen sich in der Praxis bei der Messung alle möglichen Störsignale und Artefakte. Die Interpretation der Diagramme ist alleine schon wegen der Superposition keine so einfache Angelegenheit. Die Auswerter leiten ihre Zuordnung deshalb über den mehr oder weniger gut sichtbaren Mittelwert ab. Alternativ lassen sich solche Überlagerungskurven auch mithilfe eines mathematischen Verfahrens in ihre Spektralbereiche unterteilen, der Fourier-Transformation ${ }^{216}$ bzw. genauer der Fast-Fourier-Transformation (FFT) ${ }^{217}$. Mit dieser Methodik wird auch deutlich, dass sich jede Wellenform aus einzelnen Sinusschwingungen zusammensetzt, die unterschiedliche Beiträge zum Gesamtspektrum leisten. Ein von Haffelder weiterentwickeltes Verfahren (Haffelder 2012) ermöglicht es, die Veränderung der einzelnen Spektrallinien über die Zeit kontinuierlich zu erfassen (Abb. 86).

Aus der Darstellung lassen sich Brüche, Asymmetrien oder sonstige Besonderheiten ableiten, die in Beziehung zu diversen gesundheitlichen und kognitiven Problemen gebracht werden können. Unterbrechungen in den Frequenzen deuten demnach auf Informationsverluste auf neuronaler Ebene hin. Im Umkehrschluss weist dies wieder auf eine frequenzgetragene Verbindung zwischen den Gehirnregionen und Neuronen hin.

Leider hat er nur sehr wenige Veröffentlichungen zu seiner Arbeit, sodass seine Methode und sein Ansatz unkommentiert bleiben müssen. Bekannt ist mir aus eigenem Kontakt seine therapeutische Arbeit u. a. im Bereich von Lernschwierigkeiten von Kindern oder mit gehirngeschädigten Patienten. Mithilfe von speziell angepassten klassischen Musikstücken werden erkannte Störungen in den jeweiligen Frequenzbändern überspielt oder besser überlagert und so die Funktionen des Gehirns verbessert bzw. wiederhergestellt.

Mit dieser Methode wurden SyA und Korrelationen zwischen den Repräsentanten untersucht (persönliche Information). Auch hier sind die Ergebnisse der Wirksamkeitsstudie nicht veröffentlicht und können nicht als wissenschaftlich fundierter Beweis herangezogen werden.

${ }^{216}$ Typische Anwendung sind MRT- und fMRT-Messungen. Gemessen wird die Veränderung der Spins der Wassermoleküle, die in Zellen eingelagert sind.

${ }^{217}$ Hinter der Fourier-Transformation steht die Erkenntnis, dass jede periodische Funktion $\mathrm{f}(\mathrm{x})$ Pribram nennt sie deshalb Raum-Zeit-Muster - in ein Spektrum an Wellenformen umgewandelt werden kann. Darin sind die Amplituden, Frequenzen und die Beziehungen zwischen den Phasen codiert. Die Fast-Fourier-Transformation berechnet daraus die Korrelationen der unterschiedlichen Wellen zueinander. 


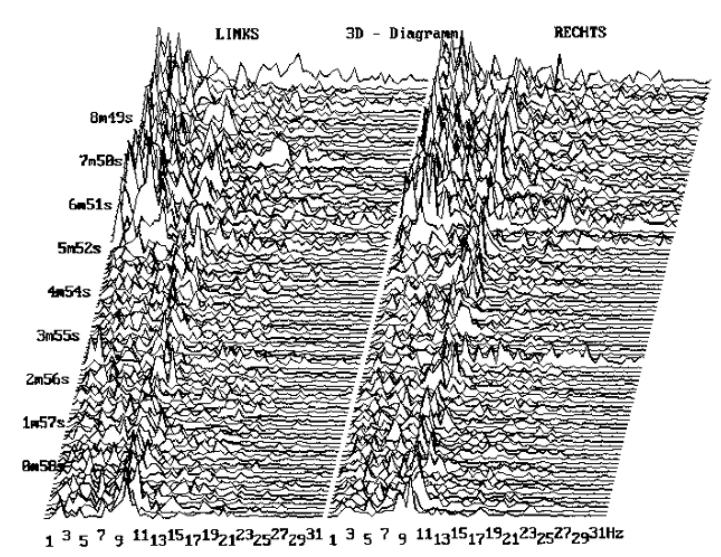

Abb. 86 | Ein nach der Methode von Haffelder erzeugtes Abbild der Gehirnaktivitäten Das Chronospectrogramm stellt eine ca. 11-minütige Messsequenz für die linke und rechte Gehirnhälfte dar, im Frequenzbereich zw. $1-31 \mathrm{~Hz}$ (Haffelder 2012).

Dass die vermittelten Ergebnisse dennoch aufgeführt werden, hat einen einfachen Grund. Jüngste Studien zeigen exakt die gleichen Ergebnisse (Dikker u. a. 2017). Die Gehirnströme von High-School-Schülern wurden über ein Semester lang, während des regulären Unterrichtes, gemessen. Signifikante Synchronisierungen zeigten sich bei gemeinsamen Beschäftigungen und bei übereinstimmender Sympathie. Die EEGs korrelierten auch wenn Wände dazwischen waren. Zusammen mit den im Folgenden aufgeführten Ergebnissen liefern sie einen weiteren starken Hinweis auf nicht-lokale Brainto-Brain Verschränkungen.

EEG-Messungen bei SyA (Haffelder 2007):

- „In dem Moment, in dem der Stellvertreter in die Verkörperung geht, ändern sich seine Hirnstrombilder und gleichen sich an das Hirnstrombild der Person an, die er vertritt.

- Durch eine therapeutische Intervention oder durch ein Ritual der Verneigung änderte sich das Hirnstrombild wieder in Richtung größerer Ausgeglichenheit.

- Am Ende, wenn Lösungen möglich waren, zeigte sich, dass Blockaden, die vorher im Hirnstrombild sichtbar waren, sich aufgelöst hatten.

- Wenn der Stellvertreter aus der Verkörperung herausgenommen war, fiel er wieder in sein altes Wellenmuster zurück.

- Herausforderung:

Gute Ableitungen zu bekommen, da sie sehr störanfällig sind z. B. für Bewegungsartefakte. " 
$\mathrm{Zu}$ vergleichbaren Ergebnissen kommen Studien von Stratford, die therapeutische Interaktionen zwischen Klient und Therapeut untersuchten und dabei eine sich aufbauende signifikante Kohärenz von EEG, Herzvariabilität und Hautleitwiderstand beobachten konnten (Stratford u. a. 2014, 2012, 2009). Eine aktuelle, systematische Auswertung vergleichbarer Experimente weist auf die grundsätzlich positiven Ergebnisse neuerer Untersuchungen hin, kritisiert jedoch den Mangel an theoretischen Hypothesen für deren Auftreten. Entsprechend werden die verschiedenen Auswertungsverfahren kritisiert (Kleinbub 2017). Ein Verhalten, wie es schon an früher Stelle bei Wagenmakers (2014) in Kap. 4.1.3 beobachtbar war.

\section{Interpretation der ausgewerteten Forschungen mit Bezug zur SyA}

Diese Ergebnisse sind zumindest gut nachvollziehbar. Ohne verändertes EEG gäbe es keine veränderten Wahrnehmungen. Ohne größere Ausgeglichenheit der Hirnströme wären vermutlich auch keine Entspannung und Harmonisierungen bei den Stellvertretern möglich, was ein typisches Phänomen für Wahrnehmung der Repräsentanten darstellt. Und auch Punkt 4, die Reorganisation des eigenen alten Wellenmusters, sollte zu erwarten sein, wenn keine fremden Gefühle mehr vorhanden sind.

Auch lässt sich mit der Methode der FFT der Ansatz begründen, EEG-Wellen als Überlagerung von spezifischen neuronalen Aktivitäten zu sehen.

\subsubsection{Brain-to-Brain Kommunikation via EEG und Internet}

Grau und Kollegen zeigten 2014, dass Informationen per Gehirnwellen von Mensch zu Mensch mittels EEG und Internet übertragen werden können (Grau u. a. 2014) (Abb. 87). Verwendet wurden Gehirn-Computer-Interfaces (BCI) und Computer-Gehirn-Interfaces (CBI). EEG-Messungen (BCI) ermöglichen das Messen aller elektrischen Aktivitäten des Gehirns an der Kopfoberfläche. Gemessen werden die Spannungsschwankungen, die durch die Aktivitäten der Neuronen ausgelöst werden.
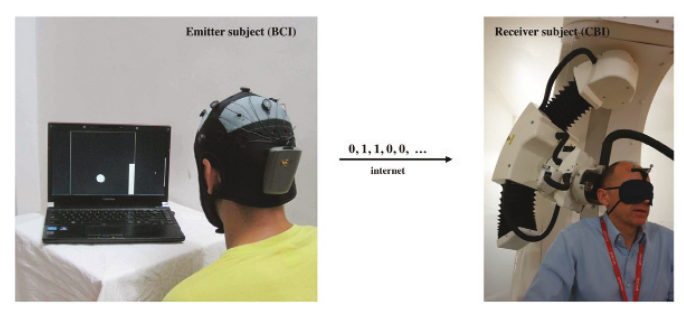

Abb. 87 | Versuchsaufbau zum Test bewusster Brain-to-Brain-Kommunikation via EEG und TMS (Image entnommen Grau u. a. 2014). Im linken Bild verfolgt ein Beobachter in Indien einen weißen Punkt und einen weißen Balken auf dem Monitor. Seine Gehirnwellen werden per Internet nach Frankreich gesendet und von einem Empfänger mittels transkranieller Magnetsimulation aufgenommen. Sein Gehirn konnte die darin enthaltenen visuellen Reize interpretieren und so das Spiel in Indien mittels seines Cursors steuern. 
TMS (transkranielle Magnetstimulation) wiederum stimuliert durch starke Magnetfelder bestimmte Gehirnregionen (CBI). Bei ihrem Experiment saß der Emittent in Indien und beobachtete einen sich bewegenden Punkt und einen weißen Balken auf einem Bildschirm. Seine Gehirnwellen wurden mittels EEG gemessen, in binäre Signale umgewandelt und an den Receiver (Standort Frankreich) übermittelt. Dort wurden sie wieder in EM-Wellen zurückgewandelt und von außen auf das Gehirn des Receivers übertragen. Der Receiver konnte jetzt den vom Emittenten beobachteten Lichtpunkt und Balken in seiner Vorstellung wahrnehmen und den Cursor, der den weißen Balken bewegt, korrekt steuern. Diese Steuerungssignale wurden direkt an den Computer in Indien gesendet.

In dieser Versuchsanordnung wurde eine nicht invasive Methode genutzt, um eine B2B-Kommunikation zwischen Menschen herzustellen. Das Gehirn des Empfängers war offensichtlich in der Lage, die EM-Impulse richtig zu decodieren, allerdings erst nach einer gewissen Trainingszeit. Aufgrund der rechnerbasierten Modulation waren die eingespielten Signale beim Empfänger nicht mehr identisch gegenüber denen, die das Auge direkt empfangen würde. Die Gehirne und Neuronen der Versuchsteilnehmer zeigten sich nach einer gewissen Trainingszeit dennoch in der Lage, den Transfer herzustellen und beim Empfänger einen visuellen Impuls auszulösen. Damit ist der Nachweis für den weiter oben beschriebenen Sachverhalt erbracht, dass unser Gehirn letztlich EM-Wellen aufnimmt und decodiert. Genau wie beim Beispiel der operierten Blinden bedarf es eines ergänzenden Trainingsprogramms, um den Signalen Sinn zuordnen zu können.

Die Verbindung von zwei Gehirnen mittels B2B-Interfaces, die gemeinsam Aufgaben lösten und das über tausende von Kilometern Entfernung, gelang erstmals bei Ratten (Yong 2013). Im gleichen Jahr gelang auch die erste nicht invasive B2B-Kommunkation zwischen Menschen (Rao u. a. 2014), bei der eine Versuchsperson eine andere zu einer gezielten Bewegung animieren konnte. Aus Sicht der Experimentatoren scheint die bewusste Bereitschaft der Versuchsteilnehmer, sich auf die mentale Kooperation (,, true brain-to-brain communication") einzulassen, die wesentliche Voraussetzung für das Gelingen zu sein (Rao und Stocco 2014: 3). An gleicher Stelle weisen sie darauf hin, dass wenig darüber bekannt ist, wie Informationen und komplexe Ideen und Rechenvorgänge encodiert sind. Aktuell gelang B2B-Verbindung zwischen den Gehirnen von drei Personen, mit der sie erfolgreich das Computerspiel Tetris spielen konnten (Jiang u. a. 2018).

Dass nicht nur die EM-Wellen unserer Gedanken über den Kopf hinaus abstrahlen, was durch die EEG-Messmethode veranschaulicht wird, sondern auch Biophotonen bei Visualisierungsübungen verstärkt vom Kopf abstrahlen, zeigen weitere Untersuchungen (Dotta u. a. 2012). Dotta konnte bei Visualisierungsübungen den Anstieg entsprechender ultraschwacher Photonen-Emissionen beobachten. Bei diesen Experimenten stellten sie auch Korrelation zwischen Anstieg der Photonenemission nach außen und interner Gehirnaktivitäten fest, was aus ihrer Sicht eine Beteiligung von Biophotonen bei Gehirnprozessen belegt, wie es einige Forscher vermuten und in Kap. 8.2.3 bereits vorgestellt wurde. 


\section{Interpretation der ausgewerteten Forschungen}

Insofern kann folgende These formuliert werden: Wir können nicht sicher sein, was andere tatsächlich wahrnehmen. Die übereinstimmende Beschreibung eines Sachverhaltes resultiert deshalb weniger von der gleichen Wahrnehmung, als von gleicher oder ähnlicher Konditionierung. Das was mit ,gelb' bezeichnet wird, ist für alle ,gelb', die auf diese spezielle Farbe in Verbindung mit dem Namen, gelb' geeicht wurden.

Was aber als sicher angenommen werden darf, ist die Möglichkeit einer Kommunikation via Gehirnwellen und einer darin vollständig enthaltenen abstrakten Information. Entsprechendes gilt für EM-Wellen der Photonen, wie sie bei den Beispielen zur Flugabwehr, dem Chicken Sexing und bei empathischen Wahrnehmungen zwischen Menschen veranschaulicht wurden (Kap. 4.1.3). Dieses B2B-Beispiel untermauert das bereits in Kap. 8.1 herausgearbeitete Verständnis, dass in EM-Wellen komplexe Informationen gespeichert sind, die mit einem jeweils passenden Empfänger decodiert werden können. Gleichzeitig ist wie bei den Biophotonen (ultraschwache Photonenemission) (Kap. 8.2.1.3) davon auszugehen, dass die EM-Wellen unseres Gehirns nicht einfach am Kopf aufhören zu existieren, sondern sich entsprechend den normalen physikalischen Gesetzen im Raum ausbreiten.

In Verbindung mit der Codierung klassischer Informationen nach Shannon (Kap. 4.2.2.2) respektive quantenphysikalischer Information von Neumann (Kap. 4.2.2.4) lässt sich die Möglichkeit einer Fehlinterpretation veranschaulichen. Gehen wir davon aus, dass einem Objekt zwei spezifische Bedeutungen 0 und 1 zugeschrieben werden und beide sowohl beim Sender als auch beim Empfänger entsprechend hinterlegt sind, so darf von einer nahezu $100 \%$-igen Wahrscheinlichkeit einer gelingenden Interpretation ausgegangen werden. Wenn wir jedoch davon ausgehen, dass wir zwei Bedeutungen haben, die in einem größeren Kontext mit weiteren Bedeutungsoptionen eingebunden sind, erhöht sich die Gefahr einer Fehlinterpretation. Der Kontext wird dabei durch verschiedene Zahlenfolgen repräsentiert. In unserem Fall werden die beiden Bedeutungen durch die Zahl an Position 6 unterschieden.

Bedeutung Kontext A repräsentierende Zahlenfolge 0010110

Bedeutung Kontext B repräsentierende Zahlenfolge 0010100

Nun besteht die Gefahr einer Überlagerung zweier ähnlicher Zustände 00101(1|0)0 im Bewusstsein der Beteiligten mit der Gefahr einer Fehlinterpretation. Dieses Phänomen entspricht analog dem ,Verlesen' oder ,Verrechnen', wenn man Buchstaben- oder Zahlendreher produziert. Quantenphysikalisch lässt sich für die Zahlen an Position 6 eine Pauli-Matrize $\left(\begin{array}{ll}1 & 0 \\ 0 & 1\end{array}\right)$ heranziehen, die den Überlagerungszustand auch mathematisch klar darstellt. Aus den beiden Werten 0 und 1 würden, vereinfacht dargestellt, vier Varianten mit 10, 00, 11, 01 und damit eine Vervielfältigung der Fehlinterpretationsmöglichkeiten. Ist beispielsweise B bei einem der Beteiligten noch nicht identisch abgelegt, so erhöht sich die Wahrscheinlichkeit einer Interpretation in Richtung der bekannten Bedeutung A, schlicht deshalb, weil B vom Gehirn des Beteiligten gar nicht zur Verfügung gestellt wird. 


\section{Übertragen auf SyA lässt sich schließen}

Die im Raum Anwesenden besitzen die prinzipielle Möglichkeit mental miteinander zu kommunizieren, wenn sie in Kontakt mit Gehirnwellen anderer kommen.

Unterliegt das, was ich in der Aufstellung repräsentiere, der gleichen gelernten Konditionierung, werde ich vermutlich die gleichen oder zumindest ähnlichen Wahrnehmungen bzw. Sinnzusammenhänge konstruieren. Komme ich aus einem anderen, fremden Kontext, versucht mein Unterbewusstsein für das Wahrgenommene einen für mich passenden Sinnzusammenhang zu liefern, der nichts mit der repräsentierten Situation zu tun haben muss. Damit wird verständlich, dass Aussagen von Repräsentanten immer auf den Kontext übersetzt werden müssen, für den die Aufstellung vorgenommen wurde. Drei wichtige Konsequenzen lassen sich deshalb ableiten:

1. Die Aussagen bedürfen in vielen Fällen einer Interpretation.

2. Auch hier bedarf es, analog zur Quanten-Teleportation, eines klassischen Kanals, der den Kontext transportiert. (Information kann in diesem Sinne tatsächlich nicht schneller als mit Lichtgeschwindigkeit transportiert werden.)

3. Gleiche Sozialisierung oder umfangreiche Übung erhöhen die Wahrscheinlichkeit einer ,richtigen' bzw. halbwegs passenden Interpretation beim Repräsentanten. (Information wird instantan übertragen und bedarf deshalb keines klassischen Kanals.)

\subsubsection{Brain-to-Brain Kommunikation ohne Hilfsmittel}

\section{Untersuchungen mittels EEG}

2008 wurden drei EEG-Studien realisiert (Hinterberger u. a. 2008), in denen Korrelationen der Gehirnaktivitäten zwischen räumlich weit entfernten Personen gemessen werden konnten (Abb. 88). Durchgeführt wurden die Versuche mit 36 Paaren, die sich eng verbunden fühlten. Die Entfernung zwischen den beteiligten Labors Tübingen bzw. Freiburg und Northampton/England betrug $810 \mathrm{~km}$ respektive $780 \mathrm{~km}$. Die Gehirnsignale wurden bei beiden Versuchspersonen gemessen, während nur eine der beteiligten Personen Bilder unterschiedlicher Kategorien gezeigt bekam, die sie durch einen Tastendruck bewerten sollte. Der Tastendruck sollte zusätzliche EEG-Impulse kreieren und analog einer Messung den psychischen Zustand manifestieren. Die andere Person verweilte dagegen in ruhender, empathischer Verbundenheit mit ihrem Partner. Die Versuchsanordnung in Freiburg wurde zusätzlich mit einem Faradayschen Käfig durchgeführt.

In allen drei Studien zeigten sich bei affektiven, also emotional bewegenden Bildern Effekte im Bereich der Delta-, Theta- und Alpha-Wellen im Gehirn. Theta- und AlphaWellen-Korrelationen ergaben sich insbesondere bei negativ-affektiven Bildern. Die Effekte traten nur bei miteinander in Beziehung stehenden Personen auf. Auffallend war, dass nur geringe Effekte gemessen werden konnten, die in Summe dennoch signifikant waren und aufgrund der Methode frei von Artefakten oder anderen Verfälschungen sein sollten. 


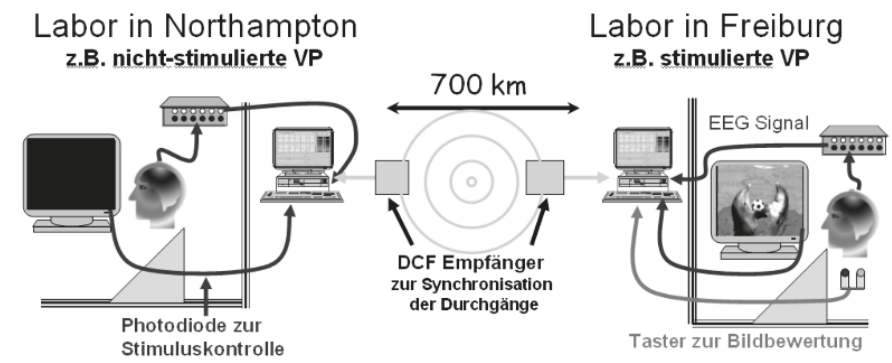

Abb. 88 | Versuchsaufbau zur EEG-Korrelation auf Distanz zwischen den Labors Northampton - Freiburg i. Br. bzw. Tübingen (Image aus Hinterberger u. a. 2008). Die beiden Computersysteme wurden über ein DCF-Zeitsignal auf eine Genauigkeit von etwa $20 \mathrm{~ms}$ synchronisiert. Emotional-affektive Bilder lösten messbare Korrelationen zwischen den Gehirnen von Paaren aus, bei Entfernungen von über $700 \mathrm{~km}$.

Diese Ergebnisse stimmen mit zahlreichen ähnlichen Versuchen überein, die von verschiedenen Gruppen seit 1965 (Orme-Johnson u. a. 1982; Targ und Puthoff 1974; Duane und Behrendt 1965) durchgeführt wurden. Wie bei Hinterberger u. a., kamen bei Grinberg-Zylberbaum u. a. ebenfalls Faradaysche Käfige zum Einsatz (Grinberg-Zylberbaum u. a. 1992, 1994). Persinger prüfte mit Erfolg die Möglichkeit, fremde Personen miteinander zu verschränken, die sich in einer Vorbereitungsphase mehrmals in körperlicher Nähe zueinander befanden (Persinger u. a. 2007). Grinberg-Zylberbaum ließ sie gemeinsam meditieren oder Seite-an-Seite sitzen, ohne Worte. Ohne eine solche, direkte Kommunikation' konnten keine korrelierten EEG-Muster gemessen werden, was für die Relevanz eines persönlichen Kontaktes spricht und zeigt, dass während eines solchen Vorgehens etwas zu passieren scheint. Ihre Versuchskonfigurationen kommen dem Geschehen in SyA sehr nahe, bei dem sich die Gruppenmitglieder, ebenfalls bereits im Vorfeld, in körperlicher Nähe zueinander befinden und aufeinander einstellen. Die von Persinger verwendeten Magnetfelder und deren Einsatzart entspricht zudem $\mathrm{Hu}$ und Wu's experimenteller Anordnung, wie wir sie im Kapitel ,Biologische Systeme' kennengelernt haben. Manolea wies zudem nach, dass trainierte Personen eine höhere Kohärenz der Wellenlängen erzeugten(Manolea 2015). Radin führte ebenfalls zahlreiche solcher Untersuchungen durch (Radin 2006, 2004). Seine Ergebnisse bestätigen die von den anderen Forschern gefundenen Korrelationen. Zusätzlich konnte er einen Zusammenhang zwischen Hautleitfähigkeitsreaktion (EDA) des Senders und der EEG-Korrelation herstellen. Je größer die Hautleitfähigkeit, desto größer die EEG-Korrelation.

Konzentrieren sich die Forscher weniger auf den Unterschied der Amplitudenänderung, sondern ausschließlich auf die zeitliche Korrelation zwischen gesendetem, mentalem Signal und der Änderung des EEG-Signals beim Empfänger, werden die Ergebnisse sehr viel klarer wie es scheint. Berücksichtigt man gleichzeitig mental trainierte, sich nahestehende Personen und verwendet ein (mental gesendetes) stressauslösendes Signal wie einen Babyschrei, können mehr als deutliche Signifikanzen erzielt werden, wie Tressoldi und seine Gruppe zeigen (Tressoldi u. a. 2014). Zwischen Sender und 
Empfänger lagen $190 \mathrm{~km}$. Als Ergebnis erzielten sie eine 78,4 prozentige Trefferquote bei 88 Testläufen. Die Gruppe von Tressoldi konnte in neueren Untersuchungen (Giroldini u. a. 2016) $)^{218}$ jedoch auch signifikante Amplitudenunterschiede bei den Empfängern nachweisen $^{219}$, die üblicherweise mit einem Zeitverzug von 250 - $300 \mathrm{~ms}$ auftraten und sich im Alphaband zeigten (ebd. 9-10). Wie wir noch sehen werden, liegt diese Zeitverschiebung genau in dem Zeitfenster, das unser Gehirn zur unterbewussten Signalverarbeitung benötigt. Neben dem dominierenden Alphaband finden sich bei diesen besonders Veränderungen in den Theta- und Gamma-Wellen. Ihr neuesten Analysen, basierend auf Artificial Intelligence, bestätigen die Frequenzabhängigkeit solcher Experimente (Bilucaglia u. a. 2019).

Nicht mit EEG Messungen, sondern mit dem Einsatz eines Photomultiplier ${ }^{220}$ gelang es Tressoldi und seiner Gruppe mehrmals mental die Anzahl der Photonen, die ein solcher Photomultiplier gezählt hat, signifikant zu erhöhen (Tressoldi u. a. 2016). Die Distanz zwischen der mit mentaler Intention arbeitenden Gruppe und dem Zähler betrug in ihrem letzten Versuch $7.300 \mathrm{~km}$.

\section{Interpretation der ausgewerteten Forschungen}

Dass es sich bei den Experimenten von Tressoldi und seiner Gruppe sehr wohl um eine physikalische Verschränkung und nicht-lokale Übertragen handelt, soll mit meiner Arbeit hier unterlegt werden. An dieser Stelle sei nochmals darauf hingewiesen, dass es keine klassische Signalübertragung benötigt, wenn der Mensch selbst Teil des verschränkten Quantensystems ist. In einem solchen Fall reicht ein Verschränkungszustand aus, der bereits durch körperliche Nähe herbeigeführt werden kann, wie in einigen eben beschriebenen Fällen gezeigt wurde. Im Kap. 8.2 ,Biologische Systeme' wurde der Zusammenhang zwischen Körperstrahlung, gegenseitiger Sinneswahrnehmung und Verschränkung bereits herausgearbeitet. Ein Zähler, hier ein Photomultiplier, übernimmt in gleicher Weise die innere Wahrnehmung eines Quantensystems.

Aufgrund früherer als auch der aktuellen Forschung erscheint es deshalb notwendig und sinnvoll, von einer tatsächlichen Interaktion auszugehen; eine Interaktion, deren Korrelation physikalisch mit einer Kohärenz verschränkter Systeme beschrieben werden

${ }^{218}$ Tressoldi u. a. liefern in ihrer Veröffentlichung auch einen guten Überblick über bisherige Studien im Bereich Brain-to-Brain Interaktion über Entfernungen (Tressoldi u. a. 2014: 9-10).

${ }^{219}$ Im Nachgang zu ihrer Veröffentlichung erfolgte eine kontroverse Diskussion, die dem Originalpaper beigefügt ist, zu Fragen der Verschränkung und Nicht-Lokalität und der Entsprechung zur GQT (Generalisierte Quantentheorie Kap. 5.3.6). Die GQT bezieht sich auf eine allgemeine Verschränkung und explizit nicht auf physikalische Interaktionen. Sie versucht beobachtete Phänomene, beispielsweise zwischen sozialen Systemen und im parapsychologischen Bereich, zu erklären. In der Diskussion wurde die Meinung vertreten, dass solche Übertragungen zwischen komplexen Systemen (Menschen) den Tatbestand der Nicht-Signalübertragung erfüllen würden oder gar keiner Verschränkung entsprechen und von daher nur als Korrelationen zu betrachten sind.

${ }^{220}$ Mit Photomultiplier (Photonenvervielfältiger) werden schwache Lichtsignale und auch einzelne Photonen mithilfe von Verstärkung elektrischer Signale detektiert. 
kann. Sie reihen sich damit ein in die hier vorgestellten Phänomene und Zusammenhänge, und sie werden nicht die letzten sein, die wir genauer betrachten werden.

Als ein übergreifendes Ergebnis lässt sich feststellen, dass offensichtlich nur geringe Kohärenzen und sehr kleine Effekte ausreichen, um Informationsübertragung zwischen Personen zu ermöglichen. Dies deckt sich mit den sehr geringen Energien und Spinänderungen, die in biologischen Systemen notwendig sind und Vergleichbares bewirken können.

Mit der Photonenerhöhung über Distanz liegt ein Experiment vor, das den SyA mit technischen Bauteilen und Codes entspricht, die ebenfalls erfolgreich verliefen.

\section{Untersuchungen mittels fMRT}

Dass es neben den EEG-Forschungen auch noch andere Möglichkeiten zur Untersuchung von nicht-lokalen Interaktionen gibt, wird im Folgendem vorgestellt.

Die Experimente von Achterberg u. a. sollten überprüfen, ob es so etwas wie Fernwirkung oder Fernheilung (,Distant Intentionality' - DI) geben kann und dies im Gehirn der Empfänger nachweisbar ist oder eben nicht (Achterberg u. a. 2005). Es ging ihnen nicht um den Nachweis einer Heilung, sondern nur um den Nachweis einer Korrelation zwischen Heiler und Empfänger in Bezug auf DI. Mithilfe der fMRT fanden sie tatsächlich signifikante Korrelationen. Nach den oben vorgestellten EEG-Experimenten sind diese Ergebnisse letztlich doch nicht überraschend. In ihrer Studie luden sie elf Heiler aus Hawaii ein, die Erfahrungen mit Fernheilung hatten. Jeder dieser Heiler konnte eine Person wählen, mit der er eine spezielle Verbindung fühlte. Sie sollten versuchen über Distanz heilende Intentionen zu übertragen und dadurch Spuren in speziellen Gehirnarealen zu erzeugen, die mit fMRT sichtbar gemacht werden können. Die Empfänger waren in einem MRT-Scanner platziert und vollständig von allen sensorischen Kontakten zu ihrem Heiler isoliert. Die Heiler selbst befanden sich in einem elektromagnetisch isolierten (Faradayscher Käfig ${ }^{221}$ ) und kontrollierten Raum. In für den Empfänger unbekannten 2-minütigen Intervallen wurden DI gesendet. Es zeigten sich signifikante Unterschiede in bestimmten Gehirnarealen während der DI-Phasen im Vergleich zu den nicht DI-Phasen.

In ihrer Conclusio stellten die Forscher fest, dass sowohl auf der individuellen als auch auf der Gruppenebene statistisch signifikante Ergebnisse vorliegen und es sich nicht um zufällige Erscheinungen handeln kann. Womit eine nicht-lokale Interaktion zwischen Menschen nicht nur mittels EEG-, sondern auch mittels fMRT-Messungen nachgewiesen werden konnte. In ihrer Veröffentlichung verweisen sie auf mindestens 2.200 Publikationen zu unterschiedlichen Fernheilungen, deren Designs allerdings häufig sehr schwach waren und weiterer Studien bedürfen. Dennoch lässt sich feststellen, dass es sich bei der Studie von Achterberg u. a. also keineswegs um ein einmaliges Ergebnis handelt (Achterberg u. a. 2005).

${ }^{221}$ Abgeschirmt werden zeitlich sich verändernde EM-Wellen. Nicht abgeschirmt werden langsam variierende Magnetfelder, wie beispielsweise das Erdmagnetfeld. 


\subsubsection{Unser Gehirn arbeitet in Intervallen}

Bisher bestanden zwei unterschiedliche Lehrmeinungen über die Arbeitsweise unseres Gehirns. Die eine ging davon aus, dass Sinneseindrücke kontinuierlich verarbeitet und zur Verfügung gestellt werden, so wie wir auch glauben kontinuierlich Veränderungen wahrnehmen zu können. Die andere nahm die Aufnahme und Verarbeitung einzelner Sinneswahrnehmungen zu bestimmten Zeitpunkten an, vergleichbar einzelner Snapshots in einer Bilderreihe. Unser Gehirn konstituiert daraus dann eine ,sinnvolle' Information. Ausgehend von Experimenten und Verhaltensversuchen überzeugen beide Annahmen allerdings nicht. So kann ein Stimulus A unter bestimmten Bedingungen erst nach einem späteren Stimulus B für uns wahrnehmbar werden, obwohl er in der Zeit davor lag (Bachmann u. a. 2004). Es blieb unklar, wie unser sehr schnelles zeitliches Bildauflösungsvermögen beim Sehen gegenüber der trägen bewussten Wahrnehmung erklärt werden kann. Zudem ermöglicht es einen Zugang auf die Frage, ob wir tatsächlich einen freien Willen besitzen, denn Forschungsarbeiten (Soon u. a. 2008; Libet u. a. 1983) haben gezeigt, dass unser Unbewusstes schon lange vor der bewussten Wahrnehmung aktiv ist (siehe auch Kap. 3.2.3 und 4.1.3). Man vermutete deshalb, dass unser freier Wille nur eine Illusion wäre und alles schon viel früher festgelegt sei; eine Annahme wie sie auch Eagleman zum Ausdruck bringt.

Herzog u. a. haben diese Experimente und Versuche ausgewertet und einen neuen Erklärungsansatz gefunden, bei dem zwei Prozessschritte unterschieden werden (Herzog u. a. 2016) (Abb. 89). Eine gänzlich unbewusste Verarbeitungsphase, in der das Gehirn mit sehr hoher Geschwindigkeit und kontinuierlich alle Sinneseindrücke analysiert. In dieser Phase existiert keine zeitliche Wahrnehmung. Das Gehirn ordnet den wahrgenommenen Merkmalen jedoch zeitliche Markierungen zu.

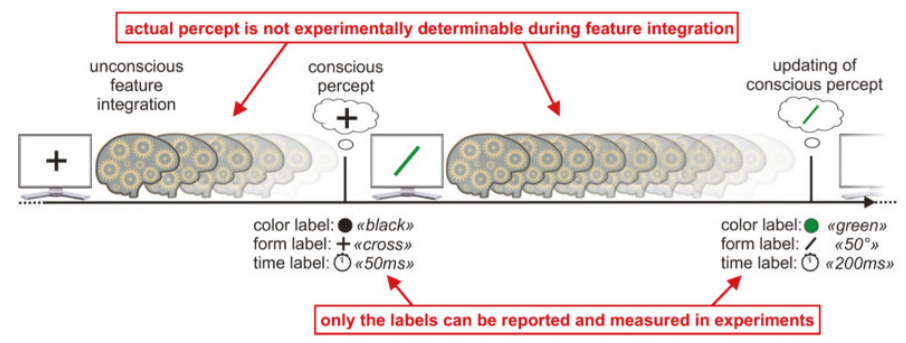

Abb. 89 | Zwei-Stufen-Modell der visuellen Wahrnehmung nach Herzog u. a.

Image aus (Herzog u. a. 2016). Ein Stimulus wie das abgebildete Kreuz wird gezeigt. Alle Informationen dazu, wie Farbe, Dauer etc. werden kontinuierlich und unbewusst wahrgenommen. Das Unterbewusstsein verarbeitet alle damit verbundenen Informationen zu separaten Zeitpunkten und das bis zu mehreren hundert Millisekunden und stellt schließlich dem Bewusstsein einen Wert zur Verfügung, der auch als ,Zustandsvektor' des Wahrgenommen beschriebenen werden darf. Was zwischen den zur Verfügung gestellten Wahrnehmungen passiert, kann nicht festgestellt werden.

Im zweiten Schritt, der der unbewussten Verarbeitung folgt, werden alle Merkmale für einen bestimmten Zeitpunkt in bewusste Wahrnehmung umgewandelt. Wir bekommen 
quasi das Ergebnis der unbewussten Verarbeitung auf unseren inneren Monitor präsentiert.

Die Forscher konnten für den gesamten Prozess, vom ursprünglichen Reiz bis zur bewussten Wahrnehmung, ein Zeitfenster von bis zu $400 \mathrm{~ms}$ ermitteln. In der Zeit dazwischen fand eine unbewusste Verarbeitung statt. Das ist 8 - 10 mal mehr, als bisher für eine unbewusste Reaktion $(40-50 \mathrm{~ms})$ angenommen wurde. Die Interpretation der Forscher geht dahin, dass das Gehirn bzw. das Unterbewusste uns nur perfekte Informationen in Bezug auf unsere Erwartung zur Verfügung stellen will und keine sowohl-alsauch bzw. ungenaue Angaben. Sie beziehen sich dabei auf den Bayes'schen Wahrscheinlichkeitsbegriff, der sehr eng mit der Erwartungshaltung und somit mit der Intention zusammenhängt. Zudem wird aus ihrer Sicht deutlich, wie das Gehirn Zeit verarbeitet und sie mit unserer Erwartungshaltung abstimmt.

Weitere Veranschaulichungen liefern die bekannten Kippbilder (Abb. 90). Unsere Wahrnehmung springt zwischen zwei Möglichkeiten hin und her, ohne uns irgendwelche Überlagerungen zur Verfügung zu stellen. Wir sehen nicht gleichzeitig beide und auch keine Verschmelzung, sondern nur das Eine oder das Andere und damit manifestiert sich jeweils ein Messergebnis in unserer psycho-physischen Welt. Diese Kippbilder waren auch Teil eines Experimentes bei dem Pribram (Majumdar u. a. 2006) EEG-Analysen vornahm, um unabhängig von Umwelteinflüssen nur intern initiiert Prozesse zu untersuchen. Die Gruppe konnte zeigen, dass bereits bis zu $800 \mathrm{~ms}$ vor dem wahrgenommenen Flip im Cortex unbewusste Prozesse ablaufen. Untersuchungen direkt im Gehirn, unter Verwendung zweier gänzlich unterschiedlicher Bilder, zeigten sogar 2000 ms respektive $1000 \mathrm{~ms}$ im neuronalen Vorlauf vor einer bewussten Wahrnehmung (Gelbard-Sagiv u. a. 2018).
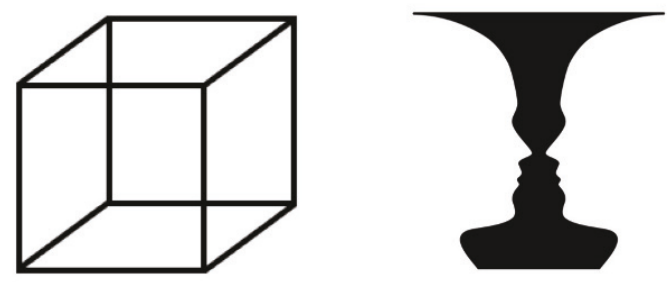

Abb. 90 | Der Necker-Würfel und das Vase-Gesichts-Paradoxon In beiden Bildern springt unsere Wahrnehmung zwischen zwei Möglichkeiten hin und her. (Necker-Würfel: Anton (rp) 2005; Vase-Gesichts-Paradoxon: AdobeStock_214282651)

Bei solchen Versuchen ist allerdings zu beobachten, dass wir den Kippeffekt in gewissen Grenzen beeinflussen können. Lassen wir unsere Wahrnehmung nicht einfach geschehen, sondern entscheiden uns bewusst für eine Variante, bietet unser Gehirn diese auch an. Dies gelingt mit konkreten Bildern wie Vase-Gesicht-Kombinationen einfacher als beim Necker-Würfel. Tatsächlich bildet sich damit auch der Quanten-Zeno-Effekt ab. Die Wahrscheinlichkeit für die von uns präferierte Variante steigt mit unserer Inten- 
tion und Konzentration. Mit hohem Konzentrationsaufwand lässt sich der Kippeffekt hinauszögern und bezüglich seiner Häufigkeit stark reduzieren.

Bei manchen dieser Bilder kommt es für zahlreiche Beobachter erst gar nicht zu einem Kippeffekt, nämlich dann, wenn keine Kenntnis darüber herrscht, dass noch ein zweites Bild codiert ist. So fällt es beispielsweise beim Vase-Gesichts-Paradoxon beim ersten Mal Vielen schwer, die Vase oder das Gesicht zu sehen. Erst nach Hinweis auf die zweite Möglichkeit und einigem Üben lässt sich der Kippeffekt relativ leicht reproduzieren. Unser Gehirn stellt also die zweite Information aufgrund von Unkenntnis, Nicht-Sensibilität, zu starker Fixierung oder schlicht einer Nicht-Notwendigkeit gar nicht erst zur Verfügung. Ohne Sinn und Bewusstsein gibt es keinen Kippeffekt.

Mit diesen Ergebnissen werden Experimente (Eagleman 2012: 65-68), wie sie Eagleman in seinem Buch vorstellt, verständlich, in denen ein Ereignis, das eigentlich erst einem vorangehenden folgt, doch von uns als das erste Ereignis wahrgenommen wird. In gleicher Weise lassen sich die von Bell (1999) erkannten Loops ${ }^{222}$ und die gleichzeitige Vor- und Rückwärtsrichtung der Signale damit in Beziehung setzen. Ursache und Wirkung, Dauer und Reihenfolge und damit die Zeitwahrnehmung ist demzufolge ein von unserem Gehirn erzeugtes Konstrukt.

\section{Interpretation der ausgewerteten Forschungen}

An die Ergebnisse der Gruppe um Herzog von bis zu 400 ms sind auch gut die Daten von Giroldini (2016) anschlussfähig (Kap. 8.3.2.4). Diese Forschergruppe hat bei ihren Fernwahrnehmungsexperimenten einen Zeitverzug von 250 - $300 \mathrm{~ms}$ beobachtet, ohne diese erklären zu können. Es handelt sich um das gleiche Zeitfenster, das unser Gehirn benötigt, um Informationen zu bewerten und zur Verfügung zu stellen.

Mit Hinweis auf meine Überlegung aus der vorangehenden Conclusio (Kap. 8.3.1.3), als die Bayessche Wahrscheinlichkeit in Zusammenhang mit der ,Kohärenzfähigkeit bereits eingelagerter Informationen' gebracht wurde, lässt sich jetzt eine zweite neurologische Grundlage diagnostizieren: ,Erwartungshaltung und Intention' entscheiden darüber, was uns unser Gehirn zur Verfügung stellt. Damit wird auch verständlich, dass in verschiedenen Experimenten bei Sportlern oder in der Präkognitionsforschung die Probanden bereits reagieren, ohne dass sie es selbst bemerken. Dieses Phänomen wurde auch von der Werbebranche beim Hinzufügen einzelner Bilder in Filmen benutzt. Das Unbewusste nahm diese wahr und veranlasste die Kunden die Produkte auf den Bildern zu kaufen (Kap. 3.2.3).

\subsubsection{Körperaktivitäten schon vor dem Ereignis}

Die Brücke zwischen der Arbeitsweise unseres Gehirns, den Ergebnissen von Pribram (2007) und den jetzt folgenden Ausführungen lässt sich über die Arbeit von Libet u. a.

${ }^{222}$ Bell beschreibt die Wechselwirkungen bei Stoffwechselprozessen genauso wie von Ökosystemen als Kreisläufe (Loops) die nicht nur in eine Richtung gedacht werden können. Sie müssen als Feedbackschleifen verstanden werden, womit er ein rein kausales Denken ad absurdum führt. 
herstellen (Libet u. a. 1983). Die Gruppe beschäftigte sich mit der Frage des freien Willens und den korrespondierenden Aktivitäten im Gehirn. Libet bat Versuchsteilnehmer ihre Finger zu einem selbstgewählten Moment zu bewegen und nahm dies mit einem EEG auf. Sie sollten auf den Moment eines ,aufkommenden Impulses', ihre ,Intention' den Finger zu bewegen achten und ihre ,Entscheidung', die Bewegung auch durchzuführen, wahrnehmen. Beim Vergleich der wahrgenommenen ,Intention' den Finger bewegen zu wollen und den EEG-Daten wurde deutlich, dass das Gehirn die folgende Intention sehr viel früher anzeigte als es von den Teilnehmern wahrgenommen wurde, und zwar im Motorcortex ${ }^{223}$. Dieser Moment der beginnenden Gehirnaktivität, deutlich vor der bewussten Wahrnehmung, wird Bereitschaftspotential (BP) genannt. Die unbewusste Vorlaufzeit betrug zwischen 150 und $800 \mathrm{~ms}$, je nach Experimenttyp und liegt damit im Bereich dessen, was Pribram u. a. fanden (Pribram 2007). Bei Experimenttyp 1 ging es nicht darum, selbst aktiv zu werden oder die Handlung zu planen, sondern nur darum, auf ankommende Impulse zu achten. Hier wurden Werte im Mittel von $350 \mathrm{~ms}$ gemessen, bei einem Minimum von $150 \mathrm{~ms}$. Bei Experimenttyp 2 warteten die Teilnehmer auf einen vom Versuchsleiter ausgelösten Hautstimulus zu einer unbestimmten Zeit. Die Werte der gemessenen Vorlaufzeit lagen im Schnitt bei $800 \mathrm{~ms}$.

Radin und Kollegen gingen bei den Untersuchungen von ,Vorahnungs-Effekten' noch einen Schritt weiter. Zum einen zeigten sie, dass nicht nur auf neuronaler Ebene vorbewusst Prozesse ablaufen, sondern auch im Bereich des Herzens. Solche Effekte ereignen sich vor einem tatsächlich eintretenden Ereignis und sind besonders relevant für die Intuitionsforschung. 1997 unternahm Radin eine Reihe von Experimenten, bei denen Versuchsteilnehmern auf einem Monitor angenehme und stressauslösende Bilder gezeigt wurden (Radin 1997). Die Auswahl traf ein computergestützter Zufallsgenerator, ausgelöst durch die Versuchsperson selbst. Gemessen wurden verschiedene Körperfunktionen, wie EEG, EKG, Blutdruck, Puls und Hautleitfähigkeit. Die Probanden reagierten in Bezug auf Herz und Gehirn zeitlich deutlich vor der noch zu treffenden Auswahl des Bildes durch den Zufallsgenerator, und zwar abhängig vom Bildtyp. Ein nach unserem klassischen Verständnis unmögliches Ergebnis.

Zahlreiche Forscher wiederholten die Versuche mit den gleichen Resultaten. Das Forscherteam um McCraty untersuchte, wo und wann im Gehirn und im Körper intuitive Informationen bearbeitet werden und nahm zusätzlich noch EKG-Messungen vor, um die Herzvariabilität ${ }^{224}$ zu erfassen (McCraty u. a. 2004a, 2004b). Zum Einsatz kamen nur Personen mit Meditationserfahrung. In diesen Versuchen zeigte die Varianz der

${ }^{223}$ Der Motorcortex ist für die Vorbereitung und Steuerung von willkürlichen sowie komplexen Bewegungen verantwortlich.

${ }^{224}$ Mithilfe eines EKGs (Elektrokardiogramm) werden die elektrischen Aktivitäten des Herzens gemessen. Analog zum EEG beim Gehirn werden Spannungsänderungen erfasst. Häufig geht es bei EKGMessungen um die Häufigkeit (Herzfrequenz) oder um die Regelmäßigkeit der Ausschläge (Herzrhythmus). Bei der Herzfrequenzvariabilität (HFV) geht es dagegen um die Fähigkeit, die Frequenz, also den Abstand zwischen den Herzschlägen zu verändern und damit die zeitliche Auflösung zu erfassen. Die Variabilität dieser Veränderung ist ein Indikator für den Gesundheitszustand respektive für eine Belastung. Die Abstände zwischen zwei Ausschlägen sind in der Regel nicht gleich lang, sondern unterliegen ständigen Veränderungen, deren Quantifizierung als HFV bezeichnet wird. 
Herzfrequenz eine um ca. 5 Sekunden vorgeschaltete Reaktion in Bezug auf den noch auszuwählenden Bildtyp (Abb. 91). Zum Zeitpunkt ,0' erscheint für die Versuchsperson das Bild auf dem Monitor. Dargestellt ist die Varianz der Herzfrequenz. Angenehme Bilder werden durch die obere Kurve repräsentiert, verstörende, emotionale Bilder durch die untere Kurve. Bereits ca. 5 Sekunden vor Erscheinen des Bildes reagiert das Herz, was durch die voneinander abzuweichen Kurven veranschaulicht wird.

Als eine Besonderheit ergaben sich bei ihren Messungen ,keine' Signifikanzen für die Hautleitfähigkeitsmessung; wie sich später herausstellte, ein typisches Merkmal für meditationserfahrene Teilnehmer, nicht aber für normale Kandidaten ohne diese Kompetenz. Eine zweite Besonderheit bezog sich auf das Zusammenspiel von Herz und Gehirn. Ihre Daten weisen darauf hin, dass dem Herzen eine wesentliche Rolle in Bezug auf Intuition zukommt. Es empfängt und regiert bereits vor dem Gehirn und scheint die Information an Letzteres weiterzugeben.

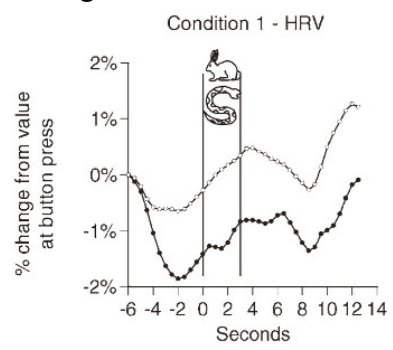

Abb. 91 | Herzratenvariabilität (HRV) einer Gruppe von 26 Teilnehmern Image aus McCraty u. a. (McCraty u. a. 2004a). Bereits 5 Sekunden bevor ein Bild auf einem Monitor gezeigt wurde, reagierten die Versuchspersonen mit einer Änderung der Herzfrequenz, also dem zeitlichen Abstand zwischen zwei Herzschlägen. Bei emotionalen Bildern (untere Kurve) zeigten sich gegenüber angenehmen Bildern (obere Kurve) deutlich stärkere Abweichungen.

Die bisherigen Versuche ließen zahlreiche Fragen unbeantwortet, u. a. wodurch die Aktivitäten im Motorcordex ausgelöst werden. Soon u. a. (2008) und Bode u. a. (2011) gingen dieser Frage ebenfalls mithilfe der fMRT nach. Sie wollten wissen wo im Gehirn die ersten Aktivitäten zu beobachten sind. Die Versuchspersonen waren aufgefordert zwischen Tasten zu wählen, sobald sie das Verlangen danach hatten. Es wurde deutlich, dass Entscheidungen den Zeitraum der ersten unbewussten Gehirnaktivitäten bis zur bewussten Wahrnehmung nun sogar auf bis zu $10 \mathrm{~s}$ ausdehnen. Die erste Entscheidungsstufe ereignete sich demnach im präfrontalen Cortex $^{225}$ und im Parietalcortex ${ }^{226}$, ca. $5 \mathrm{~s}$ vor Aktivierung des Motorcordex.

${ }^{225}$ Der präfrontale Cortex ist verantwortlich für höhere kognitive Funktionen und emotionale Prozesse, „So sind Funktionen wie vorausschauendes Denken, Planen, Problemlösen, Kreativität, der Gebrauch von Strategien, Entscheiden, das Verarbeiten von Rückmeldungen aus der Umwelt, moralisches Denken, religiöse Gefühle, Humor, Scham, Bewusstsein oder die Fähigkeit, sich in andere Menschen hineinzuversetzen, an das Frontalhirn gebunden" (Goebel 2008: 44).

${ }^{226}$ Der Parietalcordex (auch Scheitellappen genannt), lässt sich in zwei Teile gliedern. Erstens der, somatosensorische Cortex', in dem alle Körperinformationen zusammenlaufen und Selbstbeobachtung 
Offensichtlich laufen schon lange vor dem Moment, an dem wir denken eine Entscheidung getroffen zu haben, Abwägungsprozesse über mögliche Chancen und Risiken der Entscheidung, auch lange bevor mögliche Handlungen angestoßen werden. Die Forscher führen dazu weiter aus: ,At later stages, right before the conscious decision, both of these regions begin to encode timing and handedness information " (Soon u. a. 2008: 2). Ihr Ansatz passt perfekt zum Zwei-Stufen-Modell der visuellen Wahrnehmung von Herzog u. a., das in Kap. 8.3.2.5 ,Unser Gehirn arbeitet in Intervallen' vorgestellt wurde. Zudem führen sie die unbewussten Veränderungen der Hautleitfähigkeit auf diesen kortikalen Ursprung zurück.

Mit diesen Ergebnissen kommt ein Zusammenhang an die Oberfläche, der sich, genauso wie SyA, mit keinen klassischen Theorien erklären lässt. Unser Körper kann schon lange vor einem Ereignis die richtige Wahrnehmung realisieren bzw. Entscheidungen präparieren. Üblicherweise nennt man das dann Intuition. In Abb. 92 sind die bisherigen Erkenntnisse nochmals schematisch veranschaulicht, ohne den Intensitäten einen realen respektive korrekten Wert zuzuordnen.

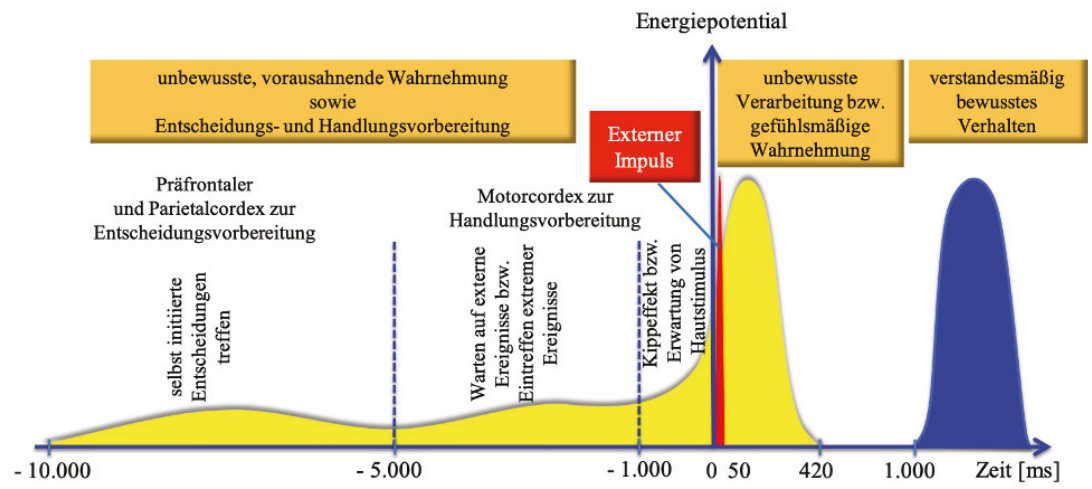

Abb. 92 | Intuitions-Reiz-Reaktions-Mechanismus

(eigene Darstellung). Schematische Zeichnung von neuronalen Reaktionen im Vorfeld auf einen externen Reiz, basierend auf verschiedenen wissenschaftlichen Veröffentlichungen. Den bekannten unbewussten und mit zeitlichem Abstand folgenden bewussten neuronalen Aktivitäten (ausgefüllte Fläche) gehen i.d.R. vorbewusste neuronale Prozesse voraus (schraffierte Fläche), die auf das kommende Ereignis mit richtiger Tendenz hinweisen. Je nach Aufgabe zeigen sich diese Anzeichen bis $10 \mathrm{~s} \mathrm{im} \mathrm{Voraus.}$

Bis zu $10 \mathrm{~s}$ vor einer Entscheidung werden BP-Aktivitäten sichtbar, die sich mit der Auswahl und dem Abwägen beschäftigen (aktuell nur beobachtet im Zusammenhang mit selbst zu treffenden Entscheidungen). Ab ca. $5 \mathrm{~s}$ im Vorlauf zu externen Reizen beginnen sich Körpersysteme darauf einzustellen. (Aufgrund der verschiedenen Versuchskonfigurationen darf zum einen von einer tatsächlichen Vorahnung bzw. Intuition

die zentrale Aufgabe darstellt. Zweitens der ,posteriorer parietale Cortex', der ein umfassendes Bild der Umwelt erzeugt und dadurch eine gezielte Interaktion mit der Umwelt erlaubt. 
ausgegangen werden. Zum anderen besteht die Option, dass die Versuchsperson der Verursacher für das später im Zufallsgenerator ausgelöste Bild ist.) Es folgen bis zu fast einer halben Sekunde unbewusste Sondierungs- und Auswahlprozesse tatsächlich wahrnehmbarer Reize, an dessen Ende unser Gehirn uns eine Wahrnehmung zur Verfügung stellt. Unser Verstand benötigt dann nochmals zwischen 0,5 und $10 \mathrm{~s}$ bis wir bewusst darauf reagieren können.

\section{Homologe Verbindung zur Physik}

Auf den ersten Blick scheinen diese Vorahnungen nicht in unser Weltbild zu passen. Auf den zweiten Blick ergeben sich jedoch überraschende Analogien in die Physik. In der klassischen Physik kann man, sofern man alle Parameter kennt, den Zustand eines Systems sowohl für die Zukunft als auch für die Vergangenheit berechnen und damit vorhersagen. Dieser Zusammenhang wird als ,Determinismus' verstanden. Konsequenterweise scheint unter dieser Perspektive alles, auch unser Leben festgelegt. Dies ist auch ein Diskussionspunkt beim Thema freier Wille. In den gängigen Interpretationen der Quantenphysik bricht diese Zeitsymmetrie allerdings zusammen. Hier macht es einen Unterschied aus welcher Zeitrichtung ich auf ein System schaue. Zur Vollständigkeit der Vorhersage benötige ich entsprechend den Feynman-Diagrammen sowohl die Vor- als auch die Nach-Beziehung:

$$
\Psi_{\mathrm{g}}=\Psi_{1} \Psi_{2}+\Psi_{2} \Psi_{1}
$$

Mit $\Psi_{\mathrm{g}}$ als Zustand des Gesamtsystems, $\Psi_{1}$ als Zustand des Systems zum Zeitpunkt 1 und $\Psi_{2}$ als Zustand des Systems zum Zeitpunkt 2.

Aus diesen Zusammenhängen resultiert auch die Interpretation einer nicht mehr existierenden kausalen Wirkung von der Vergangenheit in die Zukunft. Nach dem Verständnis von Aharonov u. a. lässt sich diese Zeitsymmetrie für quantenphysikalische Systeme jedoch wieder herstellen und damit können Beobachtungen in der Zukunft Wirkungen auf die Vergangenheit ausüben (Aharonov u. a. 2010, 1988, 1964). Weitere Modelle aus der Quantenphysik, wie beispielsweise die ,quantum retrocausality' (Sheehan 2017), wurden in Kap. 8.1 zu diesem Phänomen bereits vorgestellt. Hier ist die bereits erwähnte Arbeit zur undefinierten kausalen Reihenfolge bei optischen Quantenschaltungen von Goswami und seinen Kollegen ebenfalls anschlussfähig (Goswami u. a. 2018).

Dass solche Vorahnungen, Intuitionen und unbewussten Prozesse kein Ergebnis einer unsauberen Arbeit oder physiologischer Artefakte sind, weist eine Meta-Analyse von Mossbridge u. a. (Duggan und Tressoldi 2018; Mossbridge u. a. 2014) nach. Genauso wie von Lucadou (2000) kamen sie zur Erkenntnis, dass weitere Forschung unter Einbeziehung vielseitiger Stimuli bei gleichzeitiger Betroffenheit vieler Individuen durchgeführt werden soll, wodurch die Effektstärken deutlich erhöht und Decline-Effekte vermieden werden können. Eine Bedingung, die zu 100 Prozent auf SyA zutrifft. 


\subsubsection{Conclusio zu den Experimenten und Auswertungsmethoden}

Sowohl die Experimente als auch ihre Auswertungsmethoden weisen auf EM- und quantenphysikalisch basierte Funktionsweise unseres Gehirns hin. Allein aufgrund der unzureichenden Geschwindigkeit lassen sich biochemisch-neuronale Prozesse als vollständiges Erklärungsmodell ausschließen. Dabei weisen die Messmethoden EEG und fMRT bereits in die EM und quantenphysikalische Richtung indem sie zeigen, dass mit ihrer Hilfe übertragbare und interpretierbare Information erfasst werden kann.

Wiederholt treten Verzögerungen der messbaren, unbewussten Wahrnehmung von bis zu 300 ms auf, die zu den Ergebnissen der Gruppe um Herzog (2016), von bis zu $400 \mathrm{~ms}$ (Kap. 8.3.2.4), passen. Darüber hinaus lieferten die Experimente auch eindeutige Grundlagen zum Verständnis der Bayesschen Wahrscheinlichkeit, die bei Menschen die objektive in eine subjektive Wahrscheinlichkeit verändert. ,Kohärenzfähigkeit bereits eingelagerter Informationen' und die ,Erwartungshaltung und Intention' führen zu einem bis zu 400 ms dauernden Prozess, an dessen Ende eine Wahrnehmung steht, die mehr über den Empfänger der Information als über die Information selbst aussagt.

Unser Glaube an eine solide und zuverlässige Realität scheint tatsächlich auf einer Unbestimmtheit zu basieren, die wie es aussieht, auch dem Zufall seinen Raum lässt. Im Gegensatz zu der in der Wissenschaft bisher üblichen Annahme, dass unser Gehirn keine quantenphysikalischen Merkmale besitzen kann, weisen die bisher aufgezeigten experimentellen Ergebnisse auf genau diesen Zusammenhang hin.

Neben dem für die Quantenphysik typischen Heisenbergschen Unbestimmtheitsprinzip, schön veranschaulicht durch die Kippbilder in Abb. 90, lässt sich eine weitere Analogie zu Schrödinger's Katzenexperiment finden. Es gibt eine Instanz in uns, die aus allen Möglichkeiten eine auswählt, die sie uns zur Verfügung stellt. Womit sich ein typischer quantenmechanischer Überlagerungszustand beschreiben lässt. In diesem Fall ist es nicht Schrödinger's Katze, die tot, lebendig oder irgendwo dazwischen ist. Die Katze ist hier eine Sinneswahrnehmung und damit eine Information, die als bedeutsam oder nicht bedeutsam interpretiert wird. Alle Zustände dazwischen, inklusive der als nicht bedeutsam eingestuften Information, dringen nicht in unser Bewusstsein. Womit Zeh's Interpretation seiner Dekohärenztheorie, dass nach der Messung alle weiteren Optionen verloren gehen, ebenfalls erfüllt scheint (Zeh 2013: 5). Drittens scheint auf neuronaler Ebene der kausale Zeitpfeil auch keine zwingende Voraussetzung mehr darzustellen. Unter bestimmten Bedingungen vermag, neben der klassischen Vor-Beziehung (Wirkung von der Vergangenheit auf die Zukunft), auch die aus den Feynman-Diagrammen bekannte quantenmechanische Nach-Beziehung (Wirkung von der Zukunft in die Vergangenheit) relevant zu werden. Damit ließen sich die Berichte über Präkognitionserfahrungen plausibel erklären, bei denen die Kausalität aufgehoben ist.

Aufgrund dieser Zusammenhänge möchte ich hier die folgende These aufstellen: 
Die Heisenbergsche Unbestimmtheit und Schrödinger's Katze sind bei uns im Kopf platziert und stellen den Übergang von der Quantenwelt zur klassischen Welt dar. Unser Gehirn ist mithin quantenphysikalisch getriggert. Folglich stellen Menschen sowie alle Lebensformen einen Mixed-Zustand dar, der sich entsprechend beider Gesetzmäßigkeiten verhalten kann. Als Erweiterung von Econs (Homo oeconomicus) und Humans dürfen wir jetzt von einem ,Homo Physicus' sprechen, wie er bereits in Kap. 4.2.4 im Rahmen der Informationstheorie abgeleitet wurde.

Die Frage heißt jetzt nur: Wer entscheidet, was Bedeutung hat und was nicht? Ist diese höhere Instanz Gott, unsere Seele, unser Wesenskern oder was sonst? Und wie schaut es mit unserem freien Willen aus? Als Bewusstsein möchte ich es auf jeden Fall nicht titulieren, denn etwas, das in unser Bewusstsein tritt, kann nicht gleichzeitig das Bewusstsein sein. Hier benötigt es in jedem Fall eine Unterscheidung.

Aus den Versuchsergebnissen, bei denen körperliche Reaktionen bereits vorbewusst vor dem Ereignis beobachtet wurden, lässt sich noch eine weitere Frage ableiten. Was ist, wenn unser Körper und unser Gehirn zufallsgetragene Ergebnisse produzieren, basierend auf einer Erwartungshaltung und diese Ergebnisse dann mit den Geräten (z. B. den Zufallsgeneratoren) oder den Versuchsbeteiligten wechselwirken? Die Versuchsperson, bei der ein Reaktionsprozess angenommen wird, mutiert unvermittelt zum ergebnisauslösenden Akteur.

Mit Bezug auf die SyA-Experimente mit technischen Bauteilen wurde bereits offensichtlich, dass Menschen in der Lage sind, sowohl mit abstrakten Codes (Software) als auch mit, nach unserem Verständnis, unbewussten Materialien in Beziehung zu treten.

Drei Aspekte lassen eine quantenphysikalische Verschränkung von Menschen mit ihrer Umgebung postulieren, die weit über unser heutiges, westliches Weltbild hinaus geht:

- Vorbewusste Wahrnehmung

- Nicht eindeutig zu beantwortende Verursachung (Retrokausalität, Geist-Materie-Beeinflussung oder Superposition)

- Korrelation im Zusammenspiel mit Materie

Die Verschränkung ist nur mit der Theorie und den Modellen der Quantenphysik erklärbar. Alle anderen Erklärungsversuche würden zwingend der Kategorie ,Metaphysik' zuzuordnen sein.

Des Weiteren lässt sich in Verbindung mit den Gammawellen (übergreifende Synchronisation) eine These verifizieren, wie sie in Kap. 8.1 bereits beschrieben wurde. Es geht um eine differenzierte Betrachtung der Verschränkung in vielteiligen Quantenfeldern.

Mit Eintreffen und Fixierung einer bestimmten Wahrnehmung in unserem Gehirn ändert sich die $\Psi$-Funktion für diesen bestimmten Aspekt. Die Verschränkung der Gesamtsysteme bleibt bestehen, aber die spezifische, gemessene Information wird durch 
die neue bzw. neu kreierte Information überlagert und damit kollabiert in der Tat die alte Informationslage. Die Information, die in vielteiligen Quantenfeldern vorhanden ist, bezieht sich zwingend auf vielfältige Informationen. Die Veränderung einer dieser Informationslagen muss deshalb nicht den Zusammenbruch der Gesamtverschränkung nach sich ziehen, stattdessen treten die anderen Möglichkeiten nur in den Hintergrund. Aufgrund der vielfältigen anderen Verschränkungen zwischen lebenden Systemen und dem Gesamtquantenfeld, löst sich also nicht gleich die Gesamtverschränkung auf. Viel eher ist zu erwarten, dass die neue Information im Gesamtsystem integriert wird und sich in der Folge auch die $\Psi$-Funktion für das Gesamtsystem ändert. Dass dem so ist, wird in sozialen Systemen deutlich, indem sich das Verhalten des Gesamtsystems ebenfalls ändert. Passiert dies nicht und bleibt die Änderung nur für ein Teilsystem relevant, so scheint dieses Teilsystem in der Lage, bis zu bestimmten Grenzen Unterschiede aushalten zu können. Die dabei beginnende Reduzierung der Kohärenz beginnt sich als Spannungszustand zu etablieren. Vergrößern sich solche Differenzen, führt dies in sozialen Systemen meist zum Kampf oder zur Trennung, womit schließlich tatsächlich eine Dekohärenz zu diagnostizieren ist. Für menschliche Systeme wie Familien kann es jedoch, schon aus theoretischen Überlegungen heraus, nicht zu einer vollständigen Dekohärenz kommen. Aufgrund gemeinsamer Gene und einer umfangreichen Vergangenheit werden immer bestimmte Teilaspekte der Quantenfelder stärker verschränkt bleiben. Fernwirkungen und unbewusste Prozesse, wie für unser Gehirn dargestellt, bleiben deshalb eine realistische und normale Option.

Dieses Verständnis ist kongruent zu Schrödinger's Verschränkungstheorie, bei der nur eine Übereinstimmung zur Herstellung einer Verschränkung ausreicht. Sie ist auch kongruent zu den neueren Erkenntnissen, dass ...

- $\quad$ eine schwache Quantenmessung keine Änderung in einem Quantensystem hervorruft (hinschauen ist also erlaubt).

- eine Refokussierung auf beim ersten Mal nicht wahrgenommene Informationen, diese zugänglich machen kann.

- das Zurückspulen auf Zustände vor der (neuronalen, mentalen) Entscheidung möglich ist.

An sich sollten die bisherigen Überlegungen zum Thema Neurowissenschaften und deren Erklärungsmodelle bereits ausreichen, um einen Verschränkungsmechanismus mit dem damit verbundenen Informationsaustausch erklärbar und nachvollziehbar zu machen. Entwicklungen in der jüngsten Vergangenheit lassen den Prozess jedoch noch sehr viel klarer erscheinen.

\subsubsection{Alternative und quantenphysikalische Überlegungen}

Stellvertretend für viele der neueren Forschungen, die mit merkwürdigen Ergebnissen in den Neurowissenschaften konfrontiert sind, eine Aussage von (Raichle 2011: 4-5): „, Thus, the absence of monosynaptic connections between brain areas [...] does not preclude the existence of functional connectivity as expressed in the maps of resting state 
coherence. [...] What should be noted from this is that relationships exist not only within systems, as expected, but also among the systems even in the resting state." Die traditionelle Sicht auf den Signaltransfer erfährt gegenwärtig zweifelsohne eine Revision. Wie bereits deutlich wurde, bewegt sich die aktuelle Theoriebildung zur Arbeitsweise unseres Gehirns weg von der biochemisch getragenen Synapsentheorie, hin in Richtung EMFrequenzen. Somit handelt es sich um eine konsequente Fortsetzung der Überlegungen, wie wir sie bereits in der Quantenbiologie kennengelernt haben. Alles läuft auf Verschränkungsprozesse im Körper und Gehirn hinaus, seien es klassische oder quantenmechanische.

Schwartz und Kollegen formulierten unterstützend dazu sehr deutlich die Notwendigkeit quantenphysikalische Modelle zu berücksichtigen: ,, The quantum model is better suited to the analysis of neuropsychological data than models based on the classic approximation " (Schwartz u. a. 2005: 1323). Gleichwohl blieben sie mit ihrem Versuch, dies mithilfe der Kopenhagener Interpretation und dem von Neumann-Ansatz zu tun, auf einer virtuellen, mathematischen Ebene. $\mathrm{Zu}$ ähnlichen Schlussfolgerungen kommen allerdings auch Autoren, die eher auf der Linie meiner Ergebnisse liegen und mit dem Rückgriff auf die stochastische Elektrodynamik (SED) ${ }^{227}$ stärkeren Bezug zur Führungswellentheorie (Kap. 8.1.1.2) haben (Keppler 2013). Die verschiedenen quantenphysikalischen Ansätze geben derzeit allerdings nur Antworten auf einer prinzipiellen, nicht jedoch auf der konkreten Ebene, die auch hier zentral für die Akzeptanz eines solchen Modells sein dürfte. Fragen wie:

„How do biophotons play a role in neuronal communication and information processing? What is the mechanism of biophotonic transmission in neural circuits? It includes not only its transmission along axons and dendrites, but also across the synapses; how do we construct novel models for neural information coding, storage and processing according to biophotonic activities and transmission? The answers to these questions should help to explain the fundamental mechanisms of neural communications, and the functions of nervous system, such as vision, learning and memory, cognition and consciousness, and the mechanisms of human neurological and psychiatric diseases" (Tang und Dai 2014a).

Im Folgenden werden zur Beantwortung dieser Fragen neue unterschiedliche Erklärungsweisen zu Prozessen im Gehirn untersucht, die sich über die klassischen EM-Frequenzen hinaus zu Biophotonen über Spins bis hin zu Anyonen erstrecken. Damit werden Erklärungen möglich, die sowohl im eher klassischen physikalischen Verständnis liegen als auch solche, die die moderne Quantenphysik einschließt. Am Ende wird daraus abgeleitet der Versuch unternommen, einen Beitrag zur , Theory of Mind' zu formulieren.

${ }^{227}$ Die SED (stochastische Elektrodynamik) ist eine Erweiterung der de Broglie-Bohm Interpretation und bezieht das Nullpunktfeld mit ein. Die Theorie geht von einer deterministischen Nicht-Lokalität aus. 
Fassen wir zunächst noch einmal die Erkenntnisse zur Speicherung von (Quanten-)Information aus Kap. 8.1 zusammen, da sich alles Weitere auf diese Ausgangsbasis bezieht. Demnach wird (Quanten-)Informationen in vier Varianten gespeichert:

1. An der Oberfläche von zwei-dimensionalen Strukturen.

2. Über die Strukturen und Bindungen der Atome.

3. In den Elektronen.

4. In den Spins der Atomkerne.

Jeder Prozess, der darauf zurückgreifen kann, ist in der Lage Informationen abzurufen und mit anderen gespeicherten Informationen in Beziehung zu bringen. In der Physik bedarf es dazu eines, über relevante Zeiträume, kohärenten Superpositionszustands, damit diese Quarticles eine Rechenoperation vornehmen können. Diese Rechenoperation bekommt ihre Ausrichtung durch eine Zielsetzung respektive eine Intention.

\subsubsection{Neue Interpretation der unbewussten Gehirnaktivitäten}

Ausgangspunkt waren vertiefte Untersuchungen zum Thema freier Wille und selbstgewählte Veränderungen. Viele Überlegungen und Experimente beschäftigen sich seit den Libet-Experimenten mit dieser Frage, was vor der bewussten Wahrnehmung und dem maximalen Bereitschaftspotential (BP) abläuft. Bisher interpretiert die Wissenschaft dieses BP meist als Ausdruck von Aktivierungs- und Vorbereitungsprozessen. Schmidt u. a. veröffentlichten nun eine neue Theorie zu diesem Phänomen des scheinbar ferngesteuerten Menschens ${ }^{228}$ und nennen sie ,Selective Action-Related Slow Cordical Potential Sampling Hypothesis' oder kurz ,SCP Sampling Hypothesis' (Schmidt u. a. 2016). Sie berücksichtigen in ihren Überlegungen eine Vielzahl von Untersuchungen, die im Widerspruch zu Libets Beobachtungen waren und stellen ein Drei-Stufen-Modell vor (Abb. 93), das viele der aktuell offenen Fragen berücksichtigt und den freien Willen wieder einführt.

Aufkommende vor-konzeptionelle Impulse lösen einen, Drang' aus Etwas zu tun, der in die bewusste Wahrnehmung übertritt. Dieser innere Drang, zusammen mit einem oft noch nicht klaren Ziel, entwickelt sich zu einer spezifischen Intention etwas zu tun ${ }^{229}$. Dem folgt eine mehr oder weniger bewusste Entscheidung zur Umsetzung oder Ablehnung dieser Intention.

Für unsere Überlegungen ist besonders die erste Stufe (in Abb. 93 unten links) von Bedeutung. Ein aufkommender innerer Impuls löst ein Bereitschaftspotential aus. Dieser Impuls, von Schmidt u. a. als , selbst initiierte freiwillige Aktion' bezeichnet, ist aus ihrer Sicht vor-konzeptionell und steht nicht in Bezug zu irgendwelchen Zielen oder Aktionen, sondern resultiert aus kontinuierlichen Schwankungen der langsamen kor-

${ }^{228}$ Libet selbst führte später die Möglichkeit eines bewussten Vetos ein, das in der Zeitspanne zwischen Wahrnehmung und Handlung stattfinden kann, allerdings ohne Ableitung aus Experimenten, sondern nur aus theoretischen Überlegungen.

${ }^{229}$ Wenn wir uns von dem Fokus der rein inneren Betrachtung lösen, ist es sinnvoll auch äußere Impulse zu berücksichtigen, deshalb meine entsprechende Ergänzung. 
tikalen Potenziale (SCP). Es handelt sich deshalb aus ihrer Sicht um keine neuronalen Indikatoren zur Initiierung der Aktion für den Entscheidungsprozess (Schmidt u. a. 2016: 639), denn das BP tritt auch bei sensorischen Schwellenwerten und in Abwesenheit von Planungs- und Ausführungsaktivitäten auf.

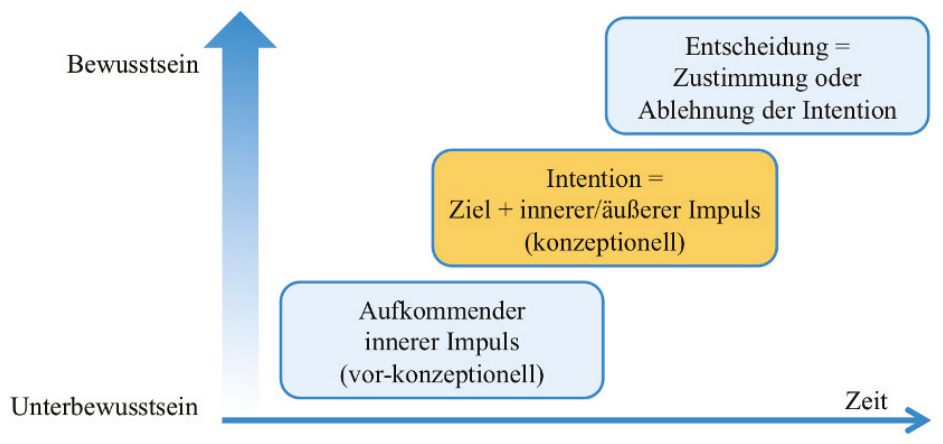

Abb. 93 | Drei-Stufen-Modell zur freiwilligen Aktionsinitiierung

nach einem inneren oder äußeren Impuls in Anlehnung an Schmidt und Kollegen (Schmidt u. a. 2016). Vorkonzeptionelle innere Impulse lösen einen Drang in Richtung eines Zieles und damit eine Intention aus, die beginnt in das Bewusstsein zu treten. Eine mehr oder weniger bewusste Entscheidung schließt sich schließlich an. Eine solche Intention könnte jedoch auch von außen ausgelöst werden.

Anhand zahlreicher Experimente konnten sie zudem zeigen, dass dieses BP bei Personen mit introspektivischen Fähigkeiten, wie beispielsweise Meditationsgeübte, mit dem Moment der wahrgenommenen Intention zusammenfällt und auch nachträglich noch verändert werden kann. Solche Personen sind damit in der Lage, unbewusste Impulse zu kontrollieren und zu korrigieren (ebd. 645). Ihre Wahrnehmung springt sehr viel früher an und der unbewusste Prozess bleibt nicht lange unbewusst. Die Forscher nehmen an, dass das BP mit einer inneren Erfahrung zusammenhängt, die als ,Drang' oder als ,aufkommende Intention' bezeichnet wird. Der ,Drang' wird dann in Verbindung mit einem Ziel oder einer Aufgabe zur einer ,spezifischen Intention', die in Richtung Entscheidung drängt.

Die Ergebnisse von Schmidt u. a. unterscheiden die Kurvenverläufe der SCP dahingehend, ob eine Intention vorliegt oder nicht (Schmidt u. a. 2016). Eine vorliegende Intention weist eine höhere negative Amplitude aus (Abb. 91) und reduziert damit den $\mathrm{zu}$ erreichenden Schwellenwert. Wir werden also sensibler für Signale, da diese früher in unser Bewusstsein treten können. Introspektivisch geübte Personen benötigen demzufolge ein wesentlich geringeres BP bis zur bewussten Wahrnehmung und können entsprechend frühzeitiger wahrnehmen und reagieren. Sie vermuten ebenso wie Hameroff und Penrose, dass die SCP-Schwankungen bzw. deren Aufsummierung für die im EEG sichtbaren Kurven verantwortlich sein können.

Passend zu diesen Annahmen einer verbesserten Sensibilisierung und einer Sichtbarwertung im EEG, weisen Schmidt u. a. (ebd.) auf zwei Korrelationen in Verbindung mit 
SCP hin. Die erste Korrelation besteht zwischen SCP und verbesserter Reaktions- und kognitiver Leistungsfähigkeit, und zwar in Bezug auf Phasenabhängigkeit und nicht in Bezug auf die Amplituden. Ein gleicher Zusammenhang wie er bei allen biologischen Systemen zu beobachten war. Eine zweite Korrelation besteht zwischen den Phasen der SCP und den Amplituden der Gehirnwellen-Bänder von $1-40 \mathrm{~Hz}$. Offensichtlich gehen sowohl Wahrnehmungen von Sinneseindrücken als auch aktive Denkprozesse mit verstärkten SCP-Aktivitäten einher. Es lässt sich daraus der Rückschluss ziehen, dass mit dem SCP alle Wahrnehmungs- und Denkprozesse in Verbindung stehen und bei Überbzw. Unterschreitung bestimmter Schwellenwerte entsprechende EEG-Ausschläge beeinflusst werden.

In Verbindung mit den Erkenntnissen zum Einfluss der Gamma-Wellen auf unsere Denk- und Erinnerungsvorgänge, die den gleichen Zusammenhang hervorgebracht haben, kann auch hier von zwei ergänzenden Mechanismen ausgegangen werden, die die Natur entwickelt hat.

Als ein weiteres Ergebnis schlussfolgern die Autoren: SCP ist ein ständiger Hintergrundprozess, der zufällige Aktionen initiieren kann. Bei bewusstem Verhalten kann das SCP, als Link zwischen bewusster Intention und Initiierung einer Aktion, diese unterstützen oder blockieren. Aus Sicht von Schmidt u. a. handelt es sich bei den spontanen SCP deshalb weder um zufällige noch um rein aufgabenabhängige Aktivitäten, sondern um Beeinflussungen, die aus einer Kombination unserer biologischen Voraussetzungen, unserer Erfahrungen, unserer Ziele und der aktuellen Situation herrühren. Ihre erste, oben beschriebene Schlussfolgerung, dass es sich deshalb beim SCP um eine aufgabenunspezifische neuronale Aktivität handelt, wurde insofern erweitert.

\section{$\underline{\text { Interpretation der ausgewerteten Forschungen }}$}

Meinem Verständnis nach kann der Weg von links unten nach rechts oben in Abb. 93 tatsächlich auch in die andere Richtung laufen. Entscheidungen und äußere Impulse (Vorgaben, Wünsche etc.) werden mit einem Ziel verbunden und als Intention an das Unterbewusste gesendet. Dieses begibt sich auf die Suche und tritt in Resonanz mit ähnlichen Frequenzen oder Informationsfeldern, die durch Quantenfelder repräsentiert sind. Nach erfolgreicher Wechselwirkung mit diesen Quantenfeldern läuft der Weg wieder zurück und erscheint als BP. Dies würde dem Delayed-Choice-Ansatz oder einer Rückwärtsverursachung im Sinne von Price $(2012,2008)$ und Cramer $(2015)$ entsprechen. Es würde auch erklären, warum Roth (Kap. 3.2.3) in Zusammenhang mit seiner Intuitionsforschung den Vorschlag macht, sich mit dem Thema kognitiv vertraut zu machen, sich dann ins Bett zu legen und sein Unterbewusstes arbeiten zu lassen. Träume stellen dann oft Lösungen zur Verfügung oder ein kongruentes Gefühl zwischen Herz und Verstand weist am nächsten Morgen einen intuitiven Weg zu einer besseren Entscheidung. Ein Ansatz, der auch in der Traumforschung sein Pendant findet.

In jedem Fall passt dieses Modell sehr gut zu der eben vorgestellten Beobachtung eines in Intervallen agierenden Gehirns. Such- und Auswahlprozesse auf Quantenebene sind nicht zeitgebunden. 
Aufgrund der Arbeiten von Radin (2006, 2004) und McCraty u. a. (2004a, 2004b) halte ich ihre Annahme einer Beeinflussung der Aktivität der SCP durch unsere Erfahrungen, Ziele und der aktuellen Situation für plausibel. Unbewusste Wünsche und Einflüsse, aufgrund einer Verschränkung mit dem Umfeld, sollten als Konsequenz bisheriger Überlegungen immer angenommen werden können. Entsprechend könnte weiter auf eine quantenphysikalische Erklärung im Sinne einer Feynmanschen Vor- und Nach-Beziehung zurückgegriffen werden, demnach Auslöser in der Vergangenheit als auch aus der Zukunft heraus entsprechende Prozesse anschieben können. Damit lässt sich auf einen bekannten Zusammenhang zurückgreifen, der mittlerweile nicht mehr so unwahrscheinlich erscheint. In Abb. 93 sind dem Cluster ,Intention' deshalb zusätzlich zu den inneren Impulsen von mir noch äußere Impulse hinzugefügt worden, die durch das Umfeld ausgelöst werden können.

\subsubsection{Kernspins und Biophotonen im Gehirn}

Die neuesten Forschungsergebnisse scheinen nun Hameroff und Penrose (Hameroff und Penrose 2014a) in ihrer Annahme zu bestätigen, dass Quantenprozesse im Gehirn nicht nur möglich, sondern sogar wahrscheinlich sind. Eine Annahme, für die sie in der Vergangenheit heftig in die Kritik kamen. Fassen wir nochmal kurz die Erkenntnisse aus der Quantenbiologie zusammen: Wie wir in Kap. 8.2 gesehen haben, werden Proteine als die Art von Umfeld angesehen, in der Verschränkung sehr gut möglich ist. Proteine zählen zu den Makromolekülen und befinden sich in allen Zellen. Bei Menschen bestehen insbesondere Haare und Haut, alle Muskeln, Herz, Nerven und Gehirn überwiegend aus Proteinen. Eine spezielle Gruppe von Proteinen kommt ausschließlich in Neuronen vor und baut die Retina als Teil des Nervensystems auf (Rahnama u. a. 2011: 66). Aufgrund der direkten Verbindung wird die Retina deshalb auch als Teil des Gehirns betrachtet (Kolb 2003). Die Proteine sind für den Empfang von synaptischen Signalen sowie dem Bilden und Weiterleiten von Aktionspotentialen verantwortlich. Andere Proteine sind spezialisiert auf die Bildung von Mikrotubuli, die zum Aufbau des Zellkörpers und seines Zellskeletts benötigt werden. Eine Erweiterung des quantenphysikalischen Gültigkeitsbereichs auf den Menschen ergibt sich zum einen aus der Tatsache, dass Menschen ebenfalls als biologische Systeme angesehen werden müssen und zum anderen daraus, dass Menschen Absorbienten und Emittenten energetischer Strahlung sind.

\section{Bio-chemische Option}

Dass grundsätzlich unsere Wahrnehmung und Informationsspeicherung mit Quantenprozessen in Verbindung zu bringen sind, zeigte Fisher (2015). Er identifizierte ein Isotop von Phosphor, das sogenannte Posner-Molekül $\mathrm{Ca}_{9}\left(\mathrm{PO}_{4}\right)_{6}$, als einen Kandidaten, um langlebige Quantenverschränkungen im Gehirn zu realisieren. Seine Arbeit weist darauf hin, dass das Molekül in der Lage sein müsste, neuronale Qubits über 5 Minuten bis zu einem Tag zu schützen und gleichzeitig als Quanten-Speichereinheit zu fungieren. Bei diesem Prozess werden die Posner-Moleküle in einem chemischen Prozess geteilt, unter Beibehaltung ihrer vorherigen Verschränkung auch bei räumlicher Trennung. Womit 
zumindest schon einmal ein biochemisch-unterlegter Prozess für die Speicherung von Informationen in den Neuronen angeboten wird.

EM- und holographische Option

Im Konzept von 1993 spielte Pribram (1991) und sein holografischer Ansatz eine wichtige Rolle. McTaggert fasst die Konsequenzen sehr anschaulich zusammen (McTaggart 2007: 133-134):

„, Unser Gehirn spricht in erster Linie nicht in Worten oder Bildern mit sich selbst und dem Rest des Körpers, ja nicht einmal in Bits oder chemischen Impulsen, sondern in der Sprache von Wellen-Interferenzen. [...] Wir nehmen ein Objekt wahr, indem wir in Resonanz zu ihm treten, unsere Schwingungen mit denen des Objektes, synchronisieren'. Die Welt zu kennen, bedeutet buchstäblich sich auf ihrer Wellenlänge zu befinden. “ Und weiter: „Pribram's Theorie geht davon aus, dass beim ersten Anblick eines Gegenstandes bestimmte Frequenzen mit den Neuronen in unserem Gehirn in Resonanz treten. Diese Neuronen senden Informationen über die betreffenden Frequenzen an die nächste Gruppe von Neuronen. Diese bilden wiederum Fourier-Reihen der betreffenden Frequenzen und senden die daraus resultierenden Information" (ebd.) bis zu der Gruppe von Neuronen, die das virtuelle Bild erzeugen.

Fourier-Transformationen waren auch der Ausgangspunkt für Pribram's Ansatz. Schempp (Pribram 2014; Schempp 1998), der die mathematischen und theoretischen Grundlagen dafür lieferte, bezeichnete das Verfahren als ,Quantum Holography' und Gabor (auf dessen Arbeiten sich Pribram bezog) nannte die damit beschriebenen Quantenprozesse in subatomaren Systemen, Quanteninformation' (Gabor 1946). Aus Pribram's Sicht werden im Allgemeinen meist die falschen Schlussfolgerungen gezogen, dass nämlich der gesamte Cortex holographischer Natur wäre (Pribram 2007). Er geht davon aus, dass unser Gehirn holistisch arbeitet, wobei die holographischen Muster nur lokal im Bereich der feinen Dendrit-Axon-Netzwerke immer und überall verstreut auftreten und die Teile miteinander verschränkt sind. Deshalb existiert hier Raum und Zeit als auch Kausalität im Sinne von Aristoteles nicht länger. Pribram (ebd.) interpretiert diese Wellen nicht als Wellen in Raum und Zeit, sondern nur im klassischen Verständnis als mathematische Fourier-Funktion, deren Wirkung sich jedoch in die Realität transformiert. Pribram zitiert in diesem Paper von 2007 Kollegen mit ihrer Aussage, dass es nicht um Schaltungen oder Kreisläufe geht (ebd.). Dies wäre eine zu große Vereinfachung, denn viele parallele Signale und Rückmeldungen überspringen benachbarte Areale und wirken über Entfernungen hinweg. Aus diesem Grund kann man nicht von bekannten Kreisläufen reden und spezielle Einflüsse können nicht als Verbindungen betrachtet werden. Der Unterschied zu klassischen Impulsen sei damit offensichtlich.

Dies passt auch zu den neuen Erkenntnissen über das Zusammenspiel der verschiedenen Wellenspektren, angefangen von SCP im niedrigsten Bereich, über Delta, Theta bis hin zu den Gammawellen. Mit diesen neuen Erkenntnissen der Wechselwirkungen unterschiedlicher Wellen lässt sich wohl doch die allgemeine Sicht begründen: Die holographischen Muster sind, zumindest bei einem gesunden Gehirn, über alle Gehirnareale ausgedehnt und nicht nur in den Dendrit-Axon-Netzwerken. 


\section{Biophotonen und quantenphysikalische Option}

Die mittlerweile wiederholt nachgewiesene Strahlung und Kommunikation von Zellen mittels sogenannter Biophotonen, wie sie von Popp bezeichnet wurden, können ebenfalls nicht mehr infrage gestellt werden (Kobayashi u. a. 2009; Fels 2009; Hu und Wu 2007b; Trushin 2003), mittlerweile auch nachgewiesen für unser Gehirn (Tang und Dai 2014a; Dotta u. a. 2011). Diese Biophotonen bewegen sich in einem Frequenzbereich zwischen UV- und IR-Wellen und schließen sichtbares Licht mit ein. Auf diesen Biophotonen und den Mikrotubuli bauten Penrose (1995) und Hameroff (Hameroff und Marcer 1998) bereits 1995 und 1998 ihre Theorie von Quantenprozessen im Gehirn und einem damit verbundenen Bewusstsein auf. Die mit anderen Forschern entwickelten Ideen stellten sie erstmals in einer Publikation 1994 (Jibu u. a. 1994) der Öffentlichkeit vor. Sie führen menschliches Denken auf nicht-lineare, kohärente optische Quantenprozesse zurück. Aus ihrer Sicht sind Mikrotubuli die Kandidaten, die quantenphysikalische Vorgänge ermöglichen. Die zentralen Rollen spielen dabei das elektrische Dipolfeld der Wassermoleküle, die hohle Struktur der Mikrotubuli und das quantisierte, EMStrahlungsfeld. Über diese internen Quantenprozesse sollen alle Nervenzellen verbunden und in Kommunikation miteinander sein. Mithilfe der Mikrotubuli lässt sich ihrer Meinung nach eine globale Kohärenz im Körper erzeugen, der es den Photonen erlaubt, die Mikrotubuli wie Lichtkabel ${ }^{230}$ zu nutzen und an ihnen entlang zu gleiten und auch mit anderen Photonen zu kommunizieren. Damit kommt es zu einer kollektiven Kooperation auf subatomarer Ebene überall im Gehirn. Auch Musha kommt mit seinen theoretischen Berechnungen zu einem Qubit-Modell des Gehirns (Musha 2009). Ausführliche Überlegungen und Ableitungen finden sich auch bei Rahnama u. a. (2011). So gehört beispielsweise die Retina bereits zum Nervensystem und ist in der Lage, Informationen gebunden an Lichtquanten direkt in das Gehirn weiterzuleiten (ebd. 66) Dass diese theoretischen Ansätze, parallel zu ihrer Entwicklung, bereits experimentell bestätigt wurden, kann bei Sun nachvollzogen werden (Sun u. a. 2010).

Inspiriert von den Arbeiten und Überlegungen von Pribram, Hameroff und Penrose forschte eine Gruppe um Rizzi mit menschlichen, neuronalen Stammzellen und den Möglichkeiten von Signalübertragungen. In ihren Veröffentlichungen (Pizzi u. a. 2009, 2004) stellten sie Versuchsanordnungen vor, wie wir sie bereits im Kap. 8.2 ,Biologische Systeme' kennengelernt haben. Die Forscher konnten eindeutige nicht-lokale Korrelationen von laserinduzierten Impulsen auch unter elektromagnetischer und optischer Isolierung nachweisen. Nach jetzigem Stand lassen sich diese Ergebnisse nur auf physikalische Verschränkungszustände zurückführen. ${ }^{230}$ Auf diese ,Lichtkabel' wird im folgenden Abschnitt, im Zusammenhang mit Anyonen nochmals
eingegangen. 
Die Rolle und Funktion der Mikrotubuli bei diesem quantenphysikalischen Prozess

Tang und Dai veröffentlichten 2014 ein neues bildgebendes Messverfahren, mit dessen Hilfe sie biophotoneninduzierte Kommunikation zwischen Gehirnneuronen unter dem Mitwirken von Mikrotubuli (Abb. 94) nachweisen konnten (Tang und Dai 2014b).

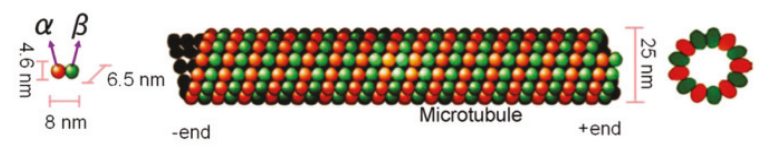

Abb. 94 | Mikrotubuli

Image entnommen Sahu u. a. (Sahu u. a. 2013a). Gezeigt wird der Querschnitt durch das Mikrotubulus (rechts) und eine schraubig versetzte Anordnung der Protofilamente, die immer paarweise zusammengesetzt $(\alpha$ - und $\beta$-Tubulin $=$ Tubulin-Dimer $)$ sind. Das Innere des Zylinders ist mit Wasser gefüllt, dessen Spins hoch kohärent ausgerichtet sind. Zu sehen ist auch die unterschiedliche elektrische Ladung an den Enden, die sich als Folge der unterschiedlichen Dipolrichtung der $\alpha$ - und $\beta$-Protofilamente ergibt.

In ihren Versuchen zeigten sie, dass der Mechanismus über Aktionspotentiale nur sehr geringen Einfluss auf die Kommunikation hat. Zusätzlich konnten sie die Herkunft der beobachteten Biophotonenaktivitäten im Corpus Callosum und dem Thalamus auf die Axone der Neuronen zurückführen. Als Ergebnis postulierten sie einen zweiten Übertragungsweg für Informationen, neben dem bekannten elektro-chemischen, der über die Axone und neuronale Schaltkreise verläuft.

Untersuchungen von Sahu u. a. konnten 2013 die unterschiedliche Leitfähigkeit (elektrisch wie optisch) von Mikrotubuli mit und ohne Wasser im Inneren nachweisen (Sahu u. a. 2013a). Ohne Wasser fungieren die Mikrotubuli als Isolator, mit eingelagertem Wasser als extrem starker Leiter. Ergänzend zeigten verschiedene Untersuchungen eine energetische Wellenausbreitung entlang der äußeren Oberfläche der Mikrotubuli (Friesen u. a. 2015: 256). Die Biophotonen im Gehirn können so eine zig-millionen schnellere Übertragungszeit realisieren als dies herkömmliche elektro-chemische Prozesse bei Neuronen ermöglichen und sind nicht anfällig für thermisches Rauschen bei Körpertemperatur. Die Stabilität gegen eine Wechselwirkung mit dem Umfeld führten die Forscher auf die, gegenüber dem Umfeld, sehr viel höhere Schwingungsfrequenz im Inneren der Mikrotubuli zurück (Sahu u. a. 2013a). Erstaunlich waren aus Sicht der Forscher auch die identischen Energieniveaus eines einzelnen Tubulin-Moleküls und dem von 40.000 Tubulin-Dimere, die ein einziges Mikrotubuli aufbauen; ein für konventionelle Materialien untypisches Verhalten. Gleichzeitig war das gesamte Mikrotubulus 1.000 mal leitfähiger als das einzelne Tubulin-Molekül und die Übertragung war unabhängig von der Mikrotubulilänge. Letzteres weist wieder auf ein quantenphysikalisches Verhalten hin. Passend dazu konnten sie einheitliche, resonante Schwingungen über die gesamte Oberfläche der Mikrotubuli beobachten, welche sie auf das Wasser im Inneren zurückführten, denn ohne Wasser gab es keinen solchen Effekt. (Wir werden sehen, dass es hierfür noch eine andere Erklärung gibt.) Das gesamte Mikrotubuli verhielt sich als Folge wie ein einzelnes schwingendes Molekül, wobei die energetischen Interferenzen 
an der Tubulioberfläche lokalisiert und über ihre Gesamtausdehnung kohärent waren. Diese Nanozylinder speicherten die Information in ihren einzelnen Tubuli, vergleichbar wie die Nukleinbasen ATGC den DNA-Code speichern, wie sie schreiben. Damit finden wir, wie in der Quantenbiologie, Frequenzen, die für die Informationsspeicherung zuständig sind und zusätzlich die Rahmenbedingungen, um lichtbasierten, quantenphysikalischen Informationstransfer zu realisieren.

Nun vervollständigten Kuma u. a. diese Experimente mit einem theoretischen Modell, in dem die Axone als Wellenleiter für die Photonen fungieren können und realistische, optische Mängel berücksichtigt werden (Kumar u. a. 2016). Sie erweitern ihre Betrachtung vom Mikrotubulus auf das gesamte Axon (Abb. 83). Ein Axon ist fest eingewickelt von einer Myelinscheide, die einen höheren Brechungsindex aufweist als das Innere des Axons, als auch der Zwischenraum zur flüssigen Umgebung im Außen. Zusammen mit der ,Saltatorische Erregungsleitung ${ }^{231}$ bietet diese kompakte Struktur die Möglichkeit eines Wellenleiters, so ihre Überlegung, womit die Photonen Quanteninformation übertragen könnten. Analog zur Photonen-Photonen-Verschränkung mittels Rubidium-Atomen, übernehmen die Tubuli die Funktion des Speichermediums, über das die Biophotonen gekoppelt werden können. Auch Ostovari u. a. stellen einen auf quantenphysikalischen Überlegungen und Berechnungen beruhenden Ansatz vor, in dem die Möglichkeit einer Verschränkung von Biophotonen und Tubuli untersucht wird (Ostovari u. a. 2014). Sie konnten daraus die realistische Möglichkeit einer konstanten Verschränkung über verschiedene menschliche Gehirnareale ableiten.

In ihren Ausführungen gehen sie auch auf Unvollkommenheiten ein, die im Gesamtprozess auftreten können. Dazu zählen sie Lichtverlust, der im Kontakt mit naheliegenden Axonen auftreten kann. Diese Nähe bedeutet aber nicht nur eine Verlust-, sondern auch eine Kopplungsmöglichkeit, wie sie anmerken. Zur Bildung eines größeren Quantennetzwerks und damit zur Verschränkung von weiter auseinander liegenden Spins muss eine kohärente Interaktion zwischen unterschiedlichen Axonen realisiert werden. Hierzu verweisen die Autoren auf notwendige weitere Untersuchungen in Bezug auf die synaptischen Verbindungen, deren Spalten auf den ersten Blick eine Unterbrechung des Kohärenzgefüges darstellen. In zusätzlichen Überlegungen nahmen sie noch verfügbare Kommunikationsraten in Augenschein. Vorsichtig gerechnet kommen sie im Gehirn auf über $10^{12}$ (Billion) Photonen, die pro Sekunde emittiert werden. Diese Menge scheint ausreichend, um eine große Anzahl von Bits zu übertragen oder eine große Anzahl von Quantenverschränkungen zu erzeugen, und dabei reichen weniger als $100 \mathrm{Bits} / \mathrm{s}$ um bewusste Erfahrungen zu machen.

Neben der reinen Informationsübertragung wurde auch die Informationsspeicherung untersucht. Passend zu den aktuellen Überlegungen von Kuma u. a. (2016), Bits als Informationseinheit zu betrachten, haben Sahu u. a. (2013b) für die Tubulin-Dimere eine Speicherfähigkeit von Informationen nachgewiesen. Sie konnten demonstrieren, dass die Mikrotubuli-Zylinder als Speicher-Schaltelement fungieren und ca. 500 unterscheid-

${ }^{231}$ Verbesserung der Leitung des Aktionspotentials durch die Ranvier-Schnürung zwischen den Myelinscheiden (Gliazellen). Die elektrische Ladung springt dabei von Gliazelle zu Gliazelle. 
bare Bits speichern und verarbeiten können und das ohne Energieverlust. Darüber hinaus weisen sie eine eindeutige Verbindung zwischen den einzelnen Tubulin-Dimeren mit ihrer dipolaren Orientierung und der Leitfähigkeit der Mikrotubuli nach. Die Mikrotubuli verhalten sich demnach wie ein leitfähiger Nanodraht, indem die einzelnen Tubulin-Dimere exakt wie die Bits in Computerchips als ultra-schnelle multi-level Schaltvorgänge agieren, die Grundvoraussetzung für schnelle Rechenvorgänge bei Computern. Die Forscher führten ihre Messungen unter normalen Umweltbedingungen durch (Umgebungsatmosphäre und keine Tieftemperatur) und wiesen darauf hin, dass sie keine Leitfähigkeit unter veränderten Bedingungen, wie ultrahohes Vakuum, erhielten (ebd. 2). Auch andere Forscher kommen zu einem vergleichbaren Ergebnis, die TubulinDimere als typisches 2-Bit quantenmechanisches System zu betrachten. Rahnama erhielten für die Schaltwechsel zwischen den Elektronenübergängen Zeiten von $10^{-9}-10^{-}$ ${ }^{10} \mathrm{sec}$. "We consider the tubulin dimer to represent a two-state system with ground $|\mathrm{g}\rangle$ and excited $|e\rangle$ states, respectively" (Rahnama u. a. 2011: 69).

\section{Interpretation der ausgewerteten Forschungen}

Damit liegen die Voraussetzungen für die Existenz eines biologisch basierten Quantencomputers sowie eine nachvollziehbare Basis für die extrem schnellen und komplexen Prozesse im Gehirn vor. Die Natur hat offensichtlich in den Millionen von Jahren ihrer Entwicklung ein effizienteres Verfahren zur Speicherung von Informationen gefunden, als es der Mensch, zumindest bis heute, erreicht hat. Zudem sei nochmal darauf hingewiesen, dass alle Prozesse, bei denen kein oder nur sehr geringer Informations- und/oder Energieverlust beobachtbar ist, starke Indikatoren für quantenmechanische Wechselwirkungen darstellen.

Mit ihren Arbeiten bestätigten die Forschungsgruppen von Sahu u. a. (2013b) und Kuma u. a. (2016) wohl endgültig die von Penrose (1995), Hameroff (Hameroff und Marcer 1998) und Pribram (1991) in den 90er Jahren entwickelten Thesen von quantenmechanischen Optionen im Gehirn.

Als Ergebnis dieser Forschungsergebnisse lassen sich mehrere Schlussfolgerungen ziehen:

1. Das Prinzip der Lichtführung in Mikrotubuli und Axonen sowie der superschnelle Informationsaustausch zwischen Nervenzellen sind mehrfach nachgewiesen und theoretisch hinterlegt.

2. Dieses Prinzip sollte nicht nur in Gehirnzellen, sondern in allen Nervenzellen Gültigkeit besitzen. Damit lässt sich erklären wie Information, die in Quanten, respektive in Frequenzen codiert ist, von der Außenwelt über unsere Sinnesorgane und den damit verbunden Nervenzellen bis in unser Gehirn geleitet werden kann und das extrem schnell und hocheffizient.

3. Als Folge lassen sich zwei Übertragungsmöglichkeiten für Informationen definieren: eine klassische mittels Frequenzen der Proteine der Neuronen und eine rein quantenmechanische mittels Licht. Die bisher rein bio-chemische, molekulare Informationsweitergabe wäre gleich zweimal überholt. 
4. Als Speichermechanismen von Information scheint die Dipolorientierung der Proteine und die Kernspins der Tubulin-Dimere verantwortlich zu sein. Damit würde sich auch das Wachstum der Neuronen erklären lassen, wie es in Kap. 8.3.1.1 beschrieben ist. Demnach gehen Lernprozesse einher mit wachsenden Neuronen und veränderten Verschaltungen über die Synapsen. Ein solcher Wachstumsprozess korrespondiert zwingend mit der Zunahme an Mikrotubuli und die sie aufbauenden Tubulin-Dimeren. Insofern liegt die Schlussfolgerung nahe, dass die neuen Informationen in Tubulin-Dimere/Mikrotubuli gespeichert werden, deren Anzahl infolgedessen zunimmt und dadurch die Neuronen wachsen.

5. Aktuell bestehen noch Fragen zur quantenphysikalisch getragenen, übergreifenden Kohärenz räumlich entfernter Areale und der damit verbundenen Überbrückung der Spalten an den Synapsen.

Unter Berücksichtigung der Arbeiten zu biophysikalischen Prozessen erhalten wir zu Punkt 5 eine theoretische Unterstützung aus den Erkenntnissen bei biologischen Systemen. Zur besseren übergreifenden Kohärenz und einer schnelleren quantenphysikalischen Wellenausbreitung sollte demnach ein Wechsel zwischen kohärenten Bereichen und Unterbrechung dieser Bereiche vorliegen; ein Bedingung, die durch die synaptischen Verbindungen und vermutlich auch durch parallel liegende Mikrotubuli als auch nebeneinander liegende Axone erfüllt werden kann.

Aus dem Bisherigen lässt sich auch eine mögliche Antwort zur Entstehung der EEGWellen ableiten (Abb. 95). Zu berücksichtigen sind nämlich noch die hochfrequenten Energien, die in den Proteinen der Tubulin-Dimere gespeichert sind und noch nicht zu den langsamen EEG-Rhythmen passen. Die Antwort, die sich aufdrängt und die von Hameroff und Penrose 2014 in ähnlicher Form auch veröffentlicht wurde, lautet (Hameroff und Penrose 2014a):

Die hochfrequenten Energien (Megahertz) der Tubulin-Dimere, incl. der darin codierten Informationen interferieren miteinander. Sie bauen damit eine Superposition auf, die schließlich als EEG-Rhythmus lokal über einzelnen Gehirnarealen oder über größere Bereiche de-lokalisiert erscheint.

Auch hier kam die aktuelle Forschung zu einem vergleichbaren Ergebnis:

,, The EEG waves associated with two distant neurons are strongly correlated and this supports the view that EEG waves are related to the properties of the brain as a coherent quantum system. It is not possible for a scalp EEG to determine the activity within a single dendrite or neuron. Rather, a surface EEG reading is the summation of the synchronous activity of thousands of neurons that have similar spatial orientation, radial to the scalp " (Rahnama u. a. 2011: 81).

Fourier-Transformation der einzelnen Frequenzen könnten vermutlich auch dies sichtbar machen. 
Hameroff und Penrose kamen in ihren Überlegungen nicht um die Tatsache herum, verschiedene Wissenschaften heranzuziehen. Ihr Spektrum umfasst die Allgemeine Relativitätstheorie, Quantenmechanik, Neurowissenschaften, Kognitionswissenschaften, Molekularbiologie und Philosophie (Hameroff und Penrose 2014a: 73).

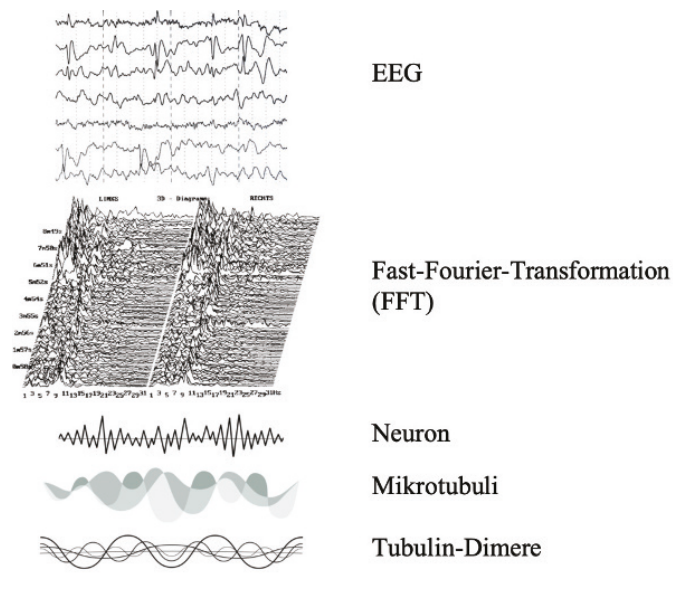

Abb. 95 | Superposition neuronaler Aktivitäten - vom Tubulin-Dimer zum EEG Jede übergeordnete Ebene bringt jeweils eine Superposition basierend aus verschiedenen Frequenzen hervor, die von jeweils kleineren Entitäten und damit Informationseinheiten herrühren (eigene Darstellung).

Ihre Theorie ,Orch OR' (,Orchestrated objective reduction' - feinabgestimmte objektive Reduktion) können wir aufgrund der bisherigen Erkenntnisse zum Teil als bestätigt betrachten. Sie besagt, dass unser Bewusstsein aus einer Abfolge von diskreten Ereignissen entsteht, die jedes Mal einer quantenmechanischen Messung entsprechen und mithilfe der neuronalen Mikrotubuli in einen makroskopischen Zustand transferieren. Damit lässt sich die Brücke zwischen der mikroskopischen Quantenwelt und der makroskopischen biomolekularen Wirklichkeit definieren. Offen bleibt, ob das Bewusstsein tatsächlich damit erklärt werden kann. Unsere Wahrnehmung lässt sich daraus allerdings sehr wohl ableiten.

\subsubsection{Anyonen, Quantenbiologie und Quantencomputing treffen sich auf neuronaler Ebene}

Ausgangspunkt für die folgenden Überlegungen sind das Verhalten der Neuronen, die als gitterartig angeordnetes An-Aus-Schaltelement betrachtet werden können (Musser 2018) und die Nichtexistenz eines Energieverlustes bei den eben vorgestellten Untersuchungen von Sahu u. a. (2013b). Letzteres weist auf supraleitende, quantenphysikalische Prozesse hin, für die es bisher noch keine vollständige Theorie gibt. Und auch eine von Tang/Dai sowie von Hameroff/Penrose noch nicht abschließend beantwortete Frage 
wartet weiter auf ihre Erklärung: Wie kommt eine Verschränkung der Zellen zustande? Sie vermuten die Gap Junctions ${ }^{232}$ als ursächlich für die Verschränkung. Dem möchte ich vier alternative Erklärungen zur Seite stellen und damit auch diese Lücke schließen.

Wie wir bisher sehen konnten, hat die Natur fast alle vom Menschen entwickelten Konzepte und Modelle bereits selbst entworfen und genutzt.

\section{Photon-Tubuli-Photon-Kopplung}

Die erste Erklärung basiert auf den oben vorgestellten Beobachtungen und den Modellen in Kap. 8.1. Nach bisherigen Überlegungen lässt sich als erste Möglichkeit die Photon-Photon-Kopplung unter Zuhilfenahme der Tubuli als Verbindungsglied denken. Ausgedehnt auf das gesamte Neuron sollten die Photonen auch die Gap Junctions überwinden können und auf dieses Weise die Neuronen miteinander verschränken.

\section{Anyonen und verallgemeinerter Josephson-Effekt}

Neue Entwicklungen beim Versuch Quantencomputer zum Laufen zu bringen, scheinen uns noch eine zweite Antwort auf obige Frage zur Verfügung stellen. In der Biologie, in der Quantencomputerentwicklung und im Gehirn existieren jeweils die gleichen Problemstellungen. Wie lassen sich kohärente Zustände über relevante Zeiträume aufrechterhalten und das bei Umgebungstemperatur, die als Voraussetzung für quantenphysikalisches Verhalten angesehen wird?

Klassische Quantensysteme, im Gegensatz zu offenen Quantensystemen wie in der Biologie, sind sehr empfindlich gegenüber Wechselwirkungen mir ihrer Umwelt und reagieren bei der geringsten Interaktion mit dem Umfeld dekohärent. Der Überlagerungszustand dekohäriert (kollabiert) und das für ein Qubit typische Charakteristikum vieler gleichzeitiger Zustände fällt in sich zusammen. Als Folge kann ein System nur noch klassisch agieren, also so, wie es bisher in Biologie, Chemie und klassischer Physik gelehrt wird.

Ein Ansatz bei der Entwicklung von Quantencomputern besteht demzufolge im bestmöglichen Abschirmen der Qubits von ihrem Umfeld. Zum Zweiten wird versucht mit allerlei raffinierter Tricks die Lebensdauer der Qubits zu erhöhen und damit ihre Fehleranfälligkeit zu reduzieren, denn die Überlebensdauer des Überlagerungszustandes und damit der Superposition muss deutlich größer sein als der einzelne Rechenschritt. Für diesen Rechenschritt geht man von ca. $1 \mathrm{~ms}$ aus. Aktuell lassen sich bereits Überlagerungszustände in gereinigtem Silizium von bis 30 Sekunden realisieren (Muhonen u. a. 2014) .

${ }^{232}$ Gap Junction sind kleine Zellverbindungen zwischen Dendriten benachbarter Zellen. Man nimmt bisher an, dass sie zur Synchronisierung der Zellen dienen. Durch sie findet Kommunikation, also der Austausch von Signalen in Form von Ionen und kleinen Molekülen statt. Es handelt sich somit um das biomolekulare Pendant zur Frequenz- und Quantenkommunikation. Allerdings ist aus heutiger Sicht eine direkte Erregungs- und damit Signalübertragung auf weit entfernte Zellen ist nicht möglich. 
Entsprechend arbeitet der erste verkaufte 512 Qubit Quantencomputer bei sehr tiefen Temperaturen, nahe dem absoluten Nullpunkt. Er wurde im Mai 2013 von der kanadischen Firma D-Wave an Lockheed Martin, Google und die NASA geliefert ${ }^{233}$. Dabei handelt es sich um einen sogenannten adiabatischen Quantencomputer, der nur bestimmte Rechenoperationen zulässt. Das Realisierungsprinzip arbeitet hier mit einem Wechsel von Grundzustand und angeregtem Zustand eines speziell konstruierten Systems. Laut Veröffentlichung von Google Ende 2015 (Denchev u. a. 2015; Neven 2015) sind die erzielten Ergebnisse $10^{8}$ (100 Millionen) mal schneller als herkömmliche Rechner und zweifelsohne auf eine quantenmechanische Arbeitsweise zurückzuführen. Die zunächst von Physikern und Computerspezialisten angemeldeten Zweifel scheinen widerlegt, worauf verschiedene Veröffentlichungen und Entwicklungen hinweisen (King u. a. 2018; D-Wave 2018; Musser 2018).

Einen ganz anderen Ansatz versuchen die Forscher mit einem topologischen Quantencomputer zu realisieren. Topologisch, weil es um eine Ausbreitung im Raum geht, bei der die Information nur an der Oberfläche, nicht aber im Inneren transportiert wird. Nicht elektrische Ladungen, sondern Spin-Ströme fließen dabei an der Oberfläche ohne Energieverlust. Hierbei greift man auf exotische Quasiteilchen, den ,Anyonen' zurück (siehe dazu auch Kap. 8.1.1.4). Ihre Ausdehnung erfolgt nur im zweidimensionalen Raum und damit nur an der Oberfläche eines Systems. Die von den Anyonen ausgebildeten Zöpfe, sogenannte Brane, sind sehr robust gegenüber Wechselwirkungen auch bei Umgebungstemperatur und besitzen eine ausgezeichnete Erinnerungsfähigkeit. Sie bieten damit einen natürlichen Schutz gegen Fehler ${ }^{234}$ und äußere Störungen (Dekohärenz).

Für den auf den Physiker Kitaev zurückgehenden Vorschlag Qubits aus Anyonen (Kitaev 2003; Wilczek 1991) herzustellen, bestehen mehrere Möglichkeiten der Realisierung. Im Zusammenhang mit dem Quanten-Spin-Hall-Effekt besteht die Option eines topologischen Isolators, der auch bei Umgebungstemperatur in Erscheinung treten kann. Die zweite Option wären spezielle Supraleiter, an deren Grenzflächen sich die Spins der Anyonen entlang bewegen können. Dass Anyonen keine theoretische Fiktion darstellen, zeigten Hsieh u. a. (Tillemans 2011; Hsieh u. a. 2009) mit einer Wismut-Antimon-Legierung erstmals 2004, die ihre schützenden Eigenschaften auch bei Raumtemperatur behielten.

Mit der Realisierung von Materialien basierend auf Anyonen liefert die aktuelle Forschung neben der Quanten-Teleportation einen weiteren Nachweis, dass quantenphysikalische Prozesse auch für unsere normalen Umweltbedingungen als real angenommen werden müssen. Als Konsequenz lassen sich Verschränkungs-, Tunnel- oder Superpositionsprozesse als natürliche und für uns relevante Mechanismen definieren, die im Weiteren auf neuronale Prozesse angewendet werden. Betrachten wir die Holzylinder der Mikrotubuli, so könnten sie die zweidimensionale Struktur liefern, an deren Oberfläche die Spin-Ströme der Anyonen entlang fließen können. Gleichzeitig entspricht

\footnotetext{
${ }^{233}$ Heute sind sie bei 2.000 Qubits angekommen (Bleicher 2018).

${ }^{234}$ Als weitere Strategie werden Algorithmen entwickelt, die auftretende Fehler beheben sollen. Man spricht hier auch von einer sogenannten Quantenfehlerkorrektur.
} 
dies den tatsächlich gemachten Beobachtungen in der Forschung. In Verbindung mit der Zeit könnten sie zudem die stabilen Brane konstituieren und böten eine natürliche Robustheit gegenüber Einflüssen des lokalen Umfeldes.

Mithilfe des verallgemeinerten Josephson-Effekts (Josephson 1962) (Abb. 57 zeigt den Josephson Effekt im ursprünglichen Sinn) bestünde zudem ein Mechanismus, um die Räume zwischen den Nervenzellen zu überwinden und ein übergreifendes kohärentes System zu bilden. Ein kohärentes Gesamtsystem, in dem sich Informationen entsprechend der quantenphysikalischen Wellenausbreitung bewegen können, wie es bei den Bakterien in Kap. 8.2 beobachtbar war.

Neben der quantenphysikalischen Wellenausbreitung lassen vier weitere Beobachtungen diese Möglichkeit als wahrscheinlich erscheinen:

a) Sahu u. a. führten aus, wie oben bereits beschrieben, dass der Prozess der Informationsweiterleitung in den Mikrotubuli als auch die Informationsspeicherung ohne Energieverlust vonstatten geht - ein typisches Phänomen auch von Supraleitern (Sahu u. a. 2013b) (Kap. 8.1).

b) Die Zylinder der Mikrotubuli entsprechen der Forderung an Anyonen nach zweidimensionalen Materialien (Wilczek 1991: 60), genauso wie die Axone als Ganzes, da sie im Grunde nur aus hohlen Zylindern aufgebaut sind.

c) Die Anyonen tragen die Möglichkeit in sich zwischen zwei Zuständen zu wechseln, was mikroskopischen Schaltkreisen entspricht und von Sahu u. a. ebenfalls im Zusammenhang mit Informationsspeicherung beobachtet wurde (Sahu u. a. 2013b). Kitaev hat genau auf diese Möglichkeit der Anyonen verwiesen, als er sie als Qubits vorschlug (Kitaev 2003). Zudem verwenden die Forscher bereits heute Qubits, die auf Schaltkreisen von Supraleitern basieren und nutzen dort den Josephson-Effekt (Gibney 2014) auch zur Fehlervermeidung (Barends u. a. 2014). Bei den Supraleitern fließt der Strom, respektive die Information, in beide Richtungen gleichzeitig. Damit wären auch die rekursiven Schleifen, wie sie die Neurowissenschaftler festgestellt haben, mit einem Mechanismus hinterlegt, der keinen Zeitverlust hätte. Quantenphysikalisch fließt die Information allerdings nicht, sondern ist instantan über einen kohärenten Raum verteilt.

d) Die aneinander liegenden Protofilamente der Mikrotubuli (Abb. 94) bilden mit ihrer unterschiedlichen Ladungsrichtung genau die Grundstruktur einer Supraleitung. Mithilfe des hier beschriebenen Mechanismus einer Josephson-Brücke wird die von Hameroff und Penrose angenommene Überlagerung in Form eines ,Dipol-Qubit in Mikrotubuli' (Hameroff und Penrose 2014a: 48) (Abb. 96) vorstellbar und wurde auch schon als Schaltelement nachgewiesen (Sahu u. a. 2013b).

Nur würde die Überlagerung nicht innerhalb eines Protofilaments (rote bzw. grüne Reihe in Abb. 94) aufgebaut, sondern über zwei aneinander liegende Protofilamente bzw. letztlich über den gesamten Mikrotubulus und vermutlich auch über die anderen angrenzenden Mikrotubuli und Neuronen. 
Großflächige Kohärenzen über räumlich ausgedehnte Gehirnareale wären mit diesem Mechanismus letztlich ebenfalls verständlich und eine Folge von stabilen Verschränkungsprozessen, wie sie heute für Quantencomputer noch gesucht werden. Möglicherweise bestehen mit dem kohärenten, in den Zylindern der Mikrotubuli befindlichen Wasser und einem hier entworfenen Anyonen-Prozess zwei unabhängige oder sich sogar unterstützende quantenmechanische Optionen. Eine Vielfalt, wie es für die Natur, auch aus der Perspektive von Eagleman als klassischem Neurowissenschaftler, selbstverständlich ist. Er hat erkannt, dass sämtliche neurowissenschaftlichen Prozesse in vielfältiger Weise angelegt sind, immer mit kleinen Modifikationen versehen.

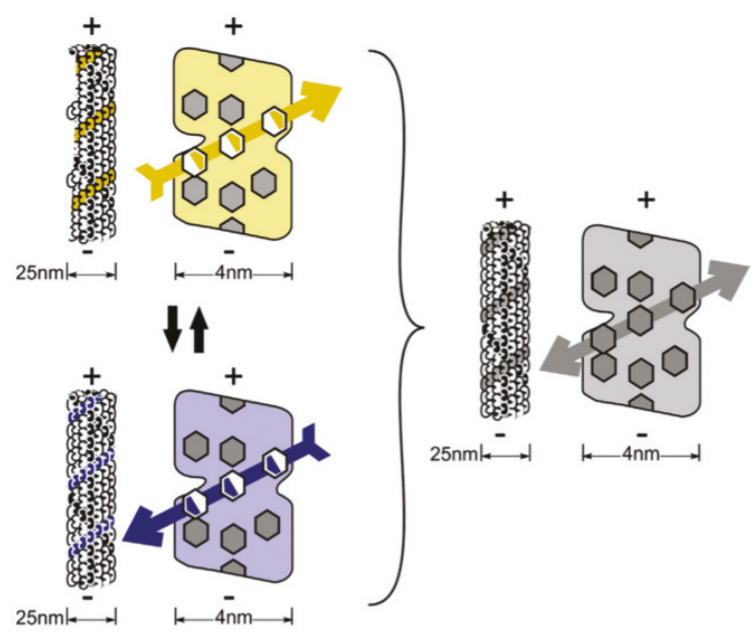

Abb. 96 | Dipol-Qubit in Mikrotubuli

als klassischer (links) und als Quanteninformations-Zustand (rechts). Image dem Paper von Hameroff und Penrose entnommen (Hameroff und Penrose 2014a). Links der geschweiften Klammer die beiden möglichen Ladungsrichtungen. Rechts der Klammer die aus der Supraleitung bekannte Überlagerung, bei der der Strom in beide Richtungen gleichzeitig ohne Energieverlust fließen kann.

Dass ein solcher Anyonen-Mechanismus nicht nur theoretisch gedacht werden kann, sondern solche Spin-Ströme auch gemessen werden können, bleibt die Aufgabe weiterer Forschung. Als Grundlage können vermutlich die Arbeiten von Brüne u. a. (2012) und Zhou und Zhang (2012) genutzt werden, die entsprechende Methoden bereits 2012 veröffentlichten.

Meine Überlegungen zu einem möglichen Anyonen-Prozess auf neurologischer Eben möchte ich mit der Aussage von Wilczek, einem Nobelpreisträger und Vordenker zu den Anyonen schließen:

„, Unsere Erfahrung hat gezeigt, dass in der Natur jede einzelne der einfachen und konsistenten Möglichkeiten, mit deren die Quantenmechanik die Materie zu beschreiben sucht, auch realisiert ist! Ich bin daher sicher, dass man noch an vielen anderen Stellen auf Anyonen stoßen wird" (Wilczek 1991: 62). 


\section{Organische Supraleiter und koplanarer welleleitender Resonator}

Eher spekulativ ist dagegen ein anderes aus Kap. 8.1.2.3 abgeleitetes Modell. Der Aufbau von Mikrotubuli weist auf eine Kombination aus organischem Supraleiter und koplanarem welleleitenden Resonator (KWR) hin. Die benötigten übergreifenden EMKomponenten könnten über die Schuhmann-Resonanz zur Verfügung gestellt werden. Der KWR richtet die Wassermoleküle, vergleichbar dem MRT, im Inneren aus und reagiert auf Veränderungen im Umfeld. Der Aufbau der Mikrotubuli wiederum ist vergleichbar eines organischen Supraleiters (Lebed 2008; Dressel und Drichko 2004; Ishiguro u. a. 1998; Little 1964). Der Aufbau organischer Supraleiter, die technisch hergestellt werden, besteht aus zweidimensional angeordneten, organischen Molekülen. Sie leiten Strom bei Zimmertemperatur wie gewöhnliche Metalle, im abgekühlten Zustand werden sie jedoch supraleitend. Der Ladungstransport findet bei ihnen ebenfalls nur an der Oberfläche statt.

Meine Annahme ist nun, dass Mikrotubuli zum einen äquivalente Hohlräume zu den Mikrowellen-Resonatoren bilden, in denen sich entsprechende Eigenresonanzen aufbauen können. Zum anderen ermöglicht die Struktur der Mikrotubuli, als gegenläufige Dipole konfiguriert, die Bildung von Energiebändern analog zu Supraleitern. Bereits ihre Verdrillung bildet ein Pendant zu den Energiebändern, wie wir sie bei den Anyonen und den Phasenübergängen kennengelernt haben, die hochstabil gegen Umwelteinflüsse sind. Es lässt sich deshalb weiter eine Kombination von Cooper-Paaren erwarten, die zwischen den beiden verdrillten Proteinsträngen der Mikrotubuli einerseits und auch zu den Wassermolekülen im Inneren der Mikrotubuli existieren. In ihnen ist deshalb eine übergreifende Kohärenz durch den verallgemeinerten Josephson-Effekt möglich. Als Folge ergibt sich ein hochkohärentes System, welches über das gesamte Nervensystem verteilt ist und durch schwache Kopplungen mit dem Umfeld feinste Veränderungen registrieren kann. Diese Kopplung ergibt sich analog den verschiedenen Verschränkungsmethoden aus Kap. 8.1.2.3, z. B. der Resonatoren mit Atomen, Spins und NVLeerstellen oder durch Cooper-Paare bei denen im System verteilte Spins der Elektronen wechselwirken. Möglicherweise können auch die in den Mikrotubuli transportieren Stoffe hierbei eine relevante Rolle spielen.

\section{Stickstoff $(\mathrm{N})$-Fehlstellen (V)-Defekt wie bei Verschränkung von Diamanten}

Die NV-Leerstellen-Defekte bilden aus meiner Sicht die aussichtsreichste Antwort auf die Frage von Hameroff und Penrose (2014a): Wie kommt eine Verschränkung der Nervenzellen (über die Synapsen-Dendriten-Spalte) zustande? Damit wird auch ein Modell angeboten, das die Rolle der Leerstellen zwischen Synapsen und Dendriten in ein neues Licht rückt.

Neben der Suche nach Modellen, die eine übergreifende Quanten-Kohärenz in den neuronalen Systemen beschreiben kann, stellte sich immer wieder eine Irritation darüber ein, weshalb hier keine direkte Verbindung existiert, sondern ein breiter Spalt übersprungen werden muss. Betrachtet man das Geschehen in diesem Bereich genauer, drängt sich die Idee einer homologen Verbindung zu den in Kap. 8.1.2.3. vorgestellten 
NV-Defekten und einer damit ermöglichten stabilen Verschränkung auch unter normalen Umweltbedingungen auf.

Zur besseren Veranschaulichung noch einmal eine kurze Darstellung der wichtigsten Merkmale zu diesem Thema: In Kap. 8.1.2 ergab sich die Möglichkeit (Quanten-)Informationen an der Oberfläche von zwei-dimensionalen Strukturen zu speichern. Darüber wurde nachgewiesen, dass der Spin der Atomkerne ebenfalls in der Lage ist Quanteninformation zu speichern. Aus Sicht der Forscher können auf diese Weise Milliarden von NV-Defekten (bei Diamanten) kollektiv verschränkt werden (Astner u. a. 2017; Vienna University of Technology 2017) und so Ensembles mittels virtueller Photonen über Hohlräume und Defekte hinweg koppeln. Die darauf aufbauenden NV-basierte Sensoren sind in der Lage, einzelne Spins auch in thermischen Umgebungsbedingungen $\mathrm{zu}$ detektieren (Bruderer u. a. 2016; Wu u. a. 2016; McGuinness u. a. 2013).

Kohlenstoff ist der Grundstoff unserer Zellen und damit auch der Neuronen. Stickstoff wird durch das Blut ebenfalls ins System transportiert und fungiert als Stickoxid NO im Gehirn als Neurotransmitter, der sehr schnell in die Zellen diffundieren kann und weitreichende Aufgaben übernimmt. ,, The discovery that nitric oxide (NO) functions as a signalling molecule in the nervous system has radically changed the concept of neural communication. [...] NO is synthesized on demand and is neither stored in synaptic vesicles nor released by exocytosis, but simply diffuses from nerve terminals. The distance of this NO diffusion (40 $300 \mu \mathrm{m}$ in diameter) implies that structures in the vicinity of the producing cell, both neuronal and non-neuronal, are influenced following its release " (Esplugues 2002: 1079). Nach dem Verständnis der Neurowissenschaften sind Neurotransmitter biochemische Stoffe, die in der Nähe des synaptischen Spaltes freigesetzt werden und für die Reizübertragung zwischen Nervenzellen verantwortlich sind. Sie können hemmend und erregend wirken (Engel u. a. 2016: 124-129). Die beteiligten Protagonisten sind somit die gleichen wie bei den NV-Defekten in Diamanten: Kohlenstoff, Stickstoff und Leerstellen, die durch die Diffusion des Stickstoffs in den Spalt entstehen. Denn interessanterweise wird N (bzw. die modifizierte Form NO) in beiden Kontexten in Verbindung mit Leerstellen aktiv (Abb. 97). Dieser Prozess hilft offensichtlich Entfernungen zu überbrücken. Der Prozess der Diffusion scheint damit prinzipiell vergleichbar dem Prozess in der Präparation der Diamanten im Verschränkungsexperiment der Wiener Forscher.

\section{$\underline{\text { Interpretation der ausgewerteten Forschungen }}$}

Es wurde offensichtlich, dass es zahlreiche Prozessoptionen für rein quantenphysikalisch getragene Verschränkungen gibt. Von der (1) Photon-Tubuli-Photon-Kopplung über (2) Anyonen und einem verallgemeinerten Josephson-Effekt, dem (3) organischen Supraleiter und koplanaren Resonatoren bis hin zu (4) Verschränkungen mittels NVDefekten. Voraussetzung für die Gültigkeit solcher Prozessbeschreibungen ist eine tatsächliche Fähigkeit der Natur sich entsprechend zu verhalten. Mit den Erkenntnissen aus Kap. 8 und den beobachteten Phänomenen, die ansonsten nicht erklärbar wären, darf die These der Übertragbarkeit wohl angenommen werden. 
Bilden (1) bis (3) Optionen in und zwischen den Mikrotubuli bzw. innerhalb der Neuronen ab, so bietet (4) die Option für neuronenübergreifende Verschränkung. Auf Letztere soll bei dieser Interpretation vertieft eingegangen werden.

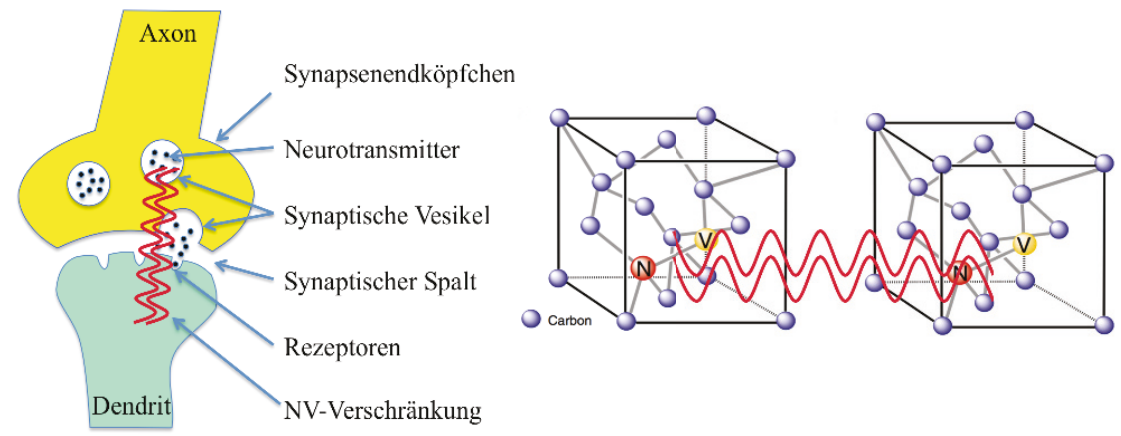

Abb. 97 | NV-Verschränkung bei Neuronen analog der NV-Verschränkung zw. Diamanten.

Image links: eigene Darstellung; Image rechts basierend auf (Xiang u. a. 2013). Wie bei der Verschränkung zwischen Diamanten, bei denen eine solche Verschränkung mittels der Stickstoff-FehlstellenKopplung realisiert wird, kann der gleiche Prozess für die Verschränkung zwischen Synapsen angenommen werden. Die Neurotransmitter (NO-Moleküle) werden in der Nähe des synaptischen Spaltes freigegeben und wandern zum Dendrit. Im Axon bleibt eine Leerstelle zurück. Wenngleich kein reiner Stickstoff $(\mathrm{N})$ wie bei Diamanten vorliegt, so ist doch $\mathrm{N}$ auch hier beteiligt.

Die Fehlstellen-Kohärenz in Diamanten weist eine analoge Struktur zu den Quantenprozessen in biologischen Systemen auf, bei denen sich ebenfalls Unterbrechungen und Fehlstellen als hilfreich für großflächige Kohärenzen herausgestellt haben. Es scheint sich hier um vergleichbare Konstellationen zu handeln. Es liegt deshalb nahe, dieses Prinzip auch für Prozesse im Gehirn anzunehmen. Verschränkungen über Stickstoff und Fehlstellen könnten somit ebenfalls die hohe Geschwindigkeit der Informationsübertragung bzw. Informationsnutzung erklären. Jedes Neuron repräsentiert eine gespeicherte Information, die zunächst von den Nachbarneuronen isoliert ist. Über die Verschränkung mittels NV-Defekten und unter Beihilfe der Biophotonen würden alle in den unterschiedlichen Nervenzellen lokal gespeicherten Informationen miteinander in Kontakt gebracht und können so ein Gesamtbild aufbauen.

Mit den Anwendungen solcher NV-Defekte zur Messung einzelner Spins in biologischen Systemen bei Umgebungsbedingungen steht zudem bereits ein technisches Pendant zur Verfügung und untermauert damit eine realistische Option.

Ergänzend ergibt sich eine Hypothese in Bezug auf die Neurotransmitter, die ein völlig neues Verständnis über biochemische Prozesse und die Neurotransmitter im Besonderen ermöglichen. Die Umwandlung der Aktionspotentiale der Neuronen in chemische Verbindungen ist möglicherweise nur das sichtbare Nebenprodukt bzw. ein unterstützender Prozess und rechtfertigt nicht die Annahme einer chemischen Informationsweitergabe. Ihr Hauptzweck könnte die Bereitstellung von Verschränkungsbrücken im Gesamtsystem sein. 


\subsubsection{Spiegelneuronen - eine quantenphysikalische Annäherung}

Was wirkt da eigentlich?

Theorieentwurf zum Verständnis des Auftretens von Spiegelneuronen

Nach den nun vorliegenden Experimenten, theoretischen Modellen und daraus abgeleiteten Erkenntnissen soll nun der Versuch unternommen werden, das Auftreten von Spiegelneuronen damit in Übereinstimmung zu bringen. Dem liegt die Annahme zugrunde, dass Spiegelneuronen die erste Erscheinung auf Gehirnebene sind, die physiologisch beobachtet werden kann ${ }^{235}$. Oder anders formuliert: Sie repräsentieren die ersten wahrnehmbaren Wirkungen einer zugrundeliegenden Resonanz mit anderen Frequenzfeldern und nicht-lokalen Korrelationen.

\section{Ausgangsbasis und Hintergrund}

In Kap. 5.2.8 wurden die wichtigsten Hintergründe und Forschungen bereits vorgestellt. Deshalb auch hier nur eine kurze Zusammenfassung zur besseren Orientierung. Wird eine Person bei einer Tätigkeit beobachtet, so können die gleichen neuronalen Aktivitäten bei dem Beobachter registriert werden, wie sie bei dem Handelnden selbst auftreten. Tatsächlich können aber auch Intentionen erkannt werden, also eine vom Handelnden nur gedachte Aktion. Da es so aussieht, als spiegeln die Neuronen des Rezipienten die Neuronen des Handelnden wieder, wurden sie Spiegelneuronen genannt. Wie in den unterschiedlichsten Kontexten dieser Forschung offensichtlich wurde, gelingt diese Spiegelung auch über Entfernung und in EM-abgeschirmten Experimenten.

Drei Gehirnareale standen zunächst im Mittelpunkt der Spiegelsystemforschung: Bewegung, Hören und Sehen (Abb. 98). Bis heute sind Neurowissenschaftler kontinuierlich dabei weitere Areale des Gehirns zu entdecken, in denen Spiegelneuronen in Erscheinung treten (Waytz und Mitchell 2011). So zählen beispielsweise die von Hutchison beobachteten mitfühlenden Schmerz-Nervenzellen zum limbischen Spiegelsystem (Hutchison u. a. 1999).

Dabei lassen sich zwei Formen von Spiegelneuronen unterscheiden: Diejenigen, die imitieren und diejenigen, die ein Verstehen repräsentieren (Iacoboni und Mazziotta 2007):

1. Strikt kongruente Spiegelneuronen - feuern bei der exakt gleichen Handlung, egal ob selbst ausgeführt oder beobachtet. Circa ein Drittel der Spiegelneuronen entsprechen diesem Typ.

2. Allgemein kongruente Spiegelneuronen - feuern bei Aktionen, die entweder logisch damit verbunden sind oder auf das gleiche Ziel hinsteuern. Die Aktionen müssen also nicht exakt gleich sein wie bei den strikt kongruenten. Circa zwei Drittel aller Spiegelneuronen entsprechen diesem Typ.

\footnotetext{
${ }^{235}$ Wesentliche Inhalte wurden aus der Erstveröffentlichung 2015 übernommen (Gehlert 2015a).
} 


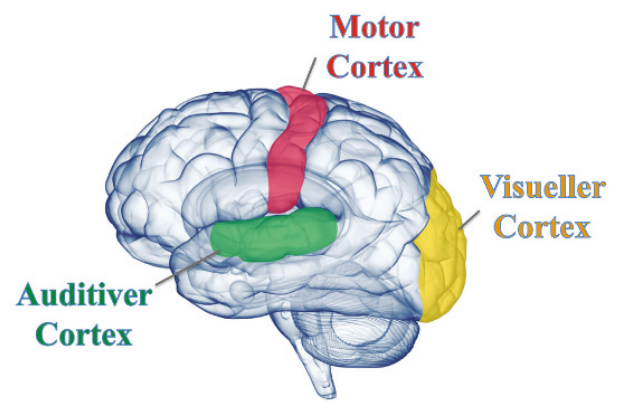

Abb. 98 | Die ersten entdeckten Spiegelneuronen

fanden sich u. a. im Motor-, Auditiven- und Visuellen-Cortex. (eigene Darstellung)

Bemerkenswert erscheint, dass die allgemein kongruenten Spiegelneuronen im Verhältnis doppelt so häufig auftreten als die strikt kongruenten. Damit scheint die Entwicklung mehr Wert auf Intention als auf äußere Formen zu legen. Das heißt, es scheint uns mitgegeben zu sein, versteckte Informationen wahrzunehmen und damit hinter die Kulissen sehen zu können.

In der Spiegelneuronenforschung selbst gibt es derzeit keine Zweifel bei den Experten bezüglich deren Existenz, wohl aber darüber, wie relevant sie für die verschiedenen Untersuchungsfelder (Medizin, Lernen, Empathie ...) tatsächlich sind (Hawco u. a. 2017; Schulte-Rüther u. a. 2017; Kanske u. a. 2016; Vivanti und Rogers 2014). Man vermutet, dass Spiegelneuronen zudem auch in höheren kognitiven Prozessen und beim Einfühlungsvermögen eingebunden sind (Hawco u. a. 2017; Nelissen u. a. 2011). Iacoboni selbst schreibt in seinem Abstract (Iacoboni u. a. 2005), dass diese Fähigkeit des Wahrnehmens und der damit verbundene neurale und funktionale Mechanismus heute noch kaum verstanden ist. Daran hat sich wenig geändert (Singer 2012). Was sich dennoch immer mehr herausschält, ist die Relevanz des Zusammenspiels von Spiegelsystem und Mentalizingsystem für soziale kognitive Prozesse und damit das Wahrnehmen von Gefühlen und Absichten von anderen (Hawco u. a. 2017).

Bemerkenswert ist noch, dass auch bei Spiegelneuronen limitierende Faktoren existieren. So wurde deutlich (Kanske u. a. 2016), dass zu starke Emotionen bzw. zu starke Empathie die mentale Einschätzung, wie es dem Gegenüber geht oder was bei ihm vor sich geht, beeinträchtigen kann. Es braucht also so etwas wie eine ,professionelle Distanz', wie sie in den Ausbildungen therapeutischer Berufe vermittelt wird. Eine gelassene ruhige Aufmerksamkeit bei gleichzeitig empathischem Verhalten, etwas, was heute unter dem Konzept des ,Mindfulness' geschult wird (sog. ,Aufmerksamkeitstrainings').

Aktuell werden vor allem auf dem Gebiet der Neurowissenschaften und Medizin versucht Antworten für Krankheitsbilder, Lernprozesse u. ä. zu finden. Konsequenterweise bedienen sich auch einige Grenzwissenschaften der Ergebnisse zur Erklärung bisher nicht erklärbarer, unverstandener Phänomene. Die Forschung konzentriert sich dabei auf den Moment des Auftretens und der dann ablaufenden Prozesse im Körper. Das 
Phänomen selbst, wie die Information (mentales Bild, Befindlichkeit, Intention) von einer Entität in das Gehirn der anderen Entität kommt, bleibt unberücksichtigt. Gleichwohl ist diese Schwäche auf der Erklärungsseite erkannt. ,Another challenge for social neuroscience (and cognitive neuroscience in general) is moving from the mere description of brain regions or networks involved in the processing of socially relevant stimuli to causal models which could account for the entire loop of social information processing within and between brains. Getting at causality is obviously the goal of most scientific endeavors but very often hard to achieve" (Singer 2012: 444). Nicht nur in ihren Augen liegt die Schwierigkeit dies zu erreichen sowohl in der Form der Messmöglichkeiten und Techniken ${ }^{236}$ als auch in der Herausforderung neue Paradigmen zu generieren (ebd. 444-445).

Singer weist in ihren weiteren Ausführungen zu Recht darauf hin, dass es nicht ausreicht zu verstehen, wie Gedanken, Gefühle und Überzeugungen mit unserem sozialen Kontext zusammenhängen und wie wir darauf aufbauend selbiges von anderen Menschen voreingenommen aufnehmen. ,, We also need to understand how we communicate thoughts and feelings to another mind to enable this other person to build a representation of our thoughts and feelings in his or her own brain and then, in a next step, feed this back to us so that we can correct this representation in case of mismatch " (ebd. 445).

\section{Zusammenhang von Spiegelneuronen und Gehirnwellen}

Die Gehirnforschung hat heute einige Kenntnisse darüber, wann und wo welche Gehirnwellen gemessen werden und in welchen Wechselwirkungen diese stehen. Wie unter Kap. 8.3.2.1 herausgearbeitet weiß man, dass Alpha-Wellen vorzugsweise kurz vor dem Einschlafen und sofort nach dem Aufwachen dominant in Erscheinung treten. Man weiß auch, dass in diesem Zustand eine körperliche Entspannung bei gleichzeitig besser Wahrnehmungs- und Lernfähigkeit gegeben ist. Eine über das Gehirn ausgestreckte kohärente Alpha-Schwingung verbessert die Wahrnehmungsfähigkeit sowie ein ganzheitliches und nachhaltiges Lernen, was heute in modernen Lehransätzen Anwendung findet, genauso wie im Kontext von Empathie und Theory of Mind: Spiegelneuronen ,, underlies a simulation mechanism that allows us to experience and understand others' minds “ (ebd. 13).

Die in Kap. 8.3.2.1 beschriebenen Alpha-Wellen $(8-13 \mathrm{~Hz})$ werden gewöhnlich dem in Ruhe befindlichen visuellen Cortex (Gehirnrinde, die zum visuellen System gehört) zugeordnet. Heute ist jedoch bekannt, dass die Alpha-Band-Aktivitäten in allen Gehirnarealen auftreten, mit vergleichbaren Eigenschaften (Hobson und Bishop 2017: 10).

Das Pendant zu den Alpha-Wellen des visuellen Cortex sind im Motorcortex die $\mathrm{Mu}-$ Wellen ${ }^{237}$, ebenfalls $8-13 \mathrm{~Hz}$ (ebd. 1). Hobson und Bishop weisen in ihrer Untersuchung darauf hin, dass Mu-Wellen nicht nur mit dem klassischen Spiegelneuronen-

\footnotetext{
${ }^{236}$ Singer liefert einen umfangreichen Überblick über unterschiedlichste Forschungen, Methoden und Techniken und zugehörige Links.

${ }^{237} \mathrm{Mu}-\mathrm{Wellen}$ werden alternativ auch Mu-Rhythmus oder My-Aktivität genannt.
} 
system in Wechselwirkung stehen, sondern sich auch in Verbindung mit anderen Gehirnarealen befinden (ebd. 6). Rhythmus und Amplitude der Mu-Wellen reflektieren die Ruheaktivität des Motorcortex. Der Motorcortex kontrolliert und reguliert die freie Bewegung. Reale oder auch nur vorgestellte Bewegungen genauso wie beobachtete Bewegungen von anderen blockieren diese Mu-Aktivitäten und damit das Spiegelneuronensystem, weil sich die Aktivitäten im Motorcortex erhöhen und die Asynchronizität zunimmt. Damit geht eine Reduzierung der Amplitude der Mu-Wellen bei gleichzeitiger Verschiebung hin zu Beta-Wellen einher (ebd. 11). Bin ich aktiv, bewege ich mich oder beobachte andere dabei, erhöht sich das Aktionspotential in Bezug auf meine eigenen Aktivitäten im Motorcortex, gefolgt von einer Reduzierung meiner Sensibilität in Bezug auf andere.

\section{Interpretation der ausgewerteten Forschungen}

Die Fähigkeit, empathisch mitzufühlen oder Intentionen von anderen wahrzunehmen, geht einher mit dem Phänomen der Spiegelneuronen. Entsprechend ist eine der Interpretationen, dass die neuronalen Aktivitäten des Rezipienten den Sender oder besser die Quelle der Information selbst abbilden: ,to understand what others are doing, we simulate their movements using our own motor program; to understand what others are feeling, we simulate their feelings using our own affective programs" (Singer 2012: 439440).

Gehirnaktivitäten des Handelnden oder Denkenden lassen sich in den gleichen Gehirnarealen auch beim Wahrnehmenden beobachten. Die damit verbundene Schlussfolgerung führt zur Idee, dass die wahrnehmende Person deshalb auch die gleichen Empfindungen und Ideen bekommt, wie sie die zu beobachtende Person hatte. Voraussetzung dafür muss eine Ähnlichkeit in der Programmierung/Codierung der entsprechenden Neuronen sein. Entsprechend lassen sich die vorgestellten Brain-to-Brain-Experimente (Kap. 8.3.2.3 und 8.3.2.4, Übertragung per Internet und nicht-lokal zw. Deutschland und England) interpretieren. Aufgrund der niedrigen Wahrnehmungsschwelle bedarf es einer hohen Aufmerksamkeit für diese schwachen Signale. Eigene Aktivitäten überlagern sehr schnell diese Schwelle und führen zu einer scheinbaren Unsensibilität und Nicht-Wahrnehmungsfähigkeit.

Da EEG-Wellenformen durch eine große Anzahl von synchron feuernden Neuronen veranlasst werden, ist es zulässig von kohärenten Wellenpakten zu sprechen. Das Gesamtwellenpaket entspricht allerdings einer Superposition unterschiedlichster Frequenzen und damit Informationen. Es erstreckt sich über den gesamten betroffenen Cortex bzw. über weite Gehirnareale mit ähnlichen Frequenzbereichen und veranschaulicht dabei auch deren Interferenzfähigkeit. Impulse, die in einzelnen Gehirnarealen wahrgenommen werden, wirken deshalb sofort in allen mitinvolvierten Arealen.

Im Umkehrschluss erfolgt eine Desynchronisation und damit Unterdrückung der MuWellen durch eigene Bewegung und Beobachtung von Aktionen anderer. Entsprechend verändern beispielsweise visuelle Aktivitäten die Synchronisierung über dem visuellen Cortex dann in Richtung Beta-Wellen oder bei Reduzierung Richtung Theta- und Delta- 
Wellen. Eigene Bewegungen bzw. Aktivitäten führen zur Dominanz des Egos. Verständlich wird deshalb auch, weshalb bei eigenen starken Aktivitäten die Wahrnehmungs- und Empathiefähigkeit nachlässt und sich die Spiegelneuronenaktivitäten reduzieren. Wir bekommen schlicht nichts mehr von anderen mit, weil sich die Interferenzmöglichkeiten reduzieren und sich ein dekohärenter Zustand ausbildet.

Ein adäquates Modell zum Verständnis der Spiegelneuronen ergibt sich nun, aufgrund der bisherigen Überlegungen, fast zwangsläufig:

1. EM-Prozess: Die in Spins und EM-Wellen codierten Informationen treffen auf Retina, Ohr oder Haut/Haare.

2. Werden von dort über das Nervensystem ins Gehirn geleitet.

3. Die im Gehirn ankommenden EM-Wellen werden (a) in Form eines Hologramms oder (b) als Quantenrechenprozess miteinander in Beziehung gebracht, wobei die Spins bzw. Atome als Qubits fungieren. Interferenzen bzw. Interaktionen erfolgen nur, wenn ankommende und vorhandene Information Gemeinsamkeiten aufweisen.

4. Als Ergebnis erhält die wahrnehmende Person Bilder oder körperliche Wahrnehmungen, die den Zustand des Gegenübers repräsentieren.

5. Aufgrund der Gefahr von Überlagerung solcher Wahrnehmungen durch Aktivitäten des Motorcortex (Mu-Wellen-Unterdrückung), also eigener Handlungen, bedarf es der Fähigkeit, ausreichend lange in einem ruhigen, entspannten Modus zu bleiben.

6. Das Auftreten von Spiegelneuronen auch bei nicht-lokalen Versuchsanordnungen verweist zudem auf einen QT-Prozess zw. lebenden Systemen.

\subsubsection{Conclusio zu Alternativen und quantenphysikalischen Überlegungen}

Aus den Neurowissenschaften wissen wir also, dass auch bei Menschen kohärente EMFelder auftreten, die messbare EM-Wellen erzeugen und als Folge biologisch-chemische Prozesse im Gehirn veranlassen. EM-Wellen ihrerseits interferieren, so sie zeitlich und räumlich gleiche Amplituden aufweisen. Aus der Arbeit mit Photonen (Lichtwellen) und aus der Quantenphysik wissen wir darüber hinaus, dass sich auf diese Weise Informationen austauschen und im Gesamtsystem verteilen lassen, wodurch sich eine Superposition aller Informationen im kohärenten System ergibt. Diese Superposition hält, solange sie nicht gestört wird. Störungen führen zur Manifestation und werden damit für uns wahrnehmbar. Sie treten sozusagen in UNSERE Welt. Unklar ist derzeit noch, ob diese Interferenzen als Hologramme zu interpretieren sind, wie es einige Forscher vermuten (Pribram 2007; Schempp 1992) und dies mittlerweile auch schon für einzelne Photonen nachgewiesen wurde (Chrapkiewicz u. a. 2016), oder ob es sich um ein weiteres Supportsystem handelt, das quantenphysikalische Rechnungen auf QubitEbene der Spins, Elektronen oder Atome ermöglicht, wie es im vorherigen Kap. 8.3.3.3. dargestellt wurde.

In jedem Fall sind auf Basis der in diesem Kap. 8.3.3 entwickelten Zusammenhänge mehrere Szenarien denkbar. Zum einen bietet sich die Option eines klassischen EM- 
Prozesses an, bei dem die Frequenzen und Eigenfrequenzen der Neuronen die codierte Information transportieren. Zum anderen lassen sich die Mikrotubulistrukturen auch als (optischer) Mikrowellen-Resonator denken, mit dessen Hilfe ein quantenphysikalischer Prozess beschrieben werden kann. Weitere Forschungen müssten zeigen, inwiefern die Strukturen in den Zellen solche Resonator-Effekte ermöglichen können. Vielleicht unterstützen Anyonen, wie sie im Modell entwickelt wurden, sogar die Isolation der Hohlräume und verstärken zusätzlich die Wirkungsweise als Resonator.

Gammawellen und die SCP-Wellen stellen zwei Frequenzbereiche zur Verfügung, mit deren Hilfe das gesamte Gehirn und damit alle Neuronen in Verbindung gehalten werden. Sie stellen so sicher, dass neue Informationen die jeweilige Gehirnregion erreichen. Mit der Erwartungshaltung werden im Bereich SCP die speziellen Schwellenwerte reduziert, die aufgrund von Vorerfahrungen bereits resonanzfähig sind, um die themenspezifische Empfindlichkeit und Wahrnehmungsfähigkeit zu erhöhen. Mögliche Antworten bzw. passende Informationen sind durch ähnliche Frequenzen oder Spinkonfigurationen gekennzeichnet. Bei Kontakt werden in den Arealen reduzierter Schwellenwerte erste Aktionen gestartet. Mithilfe der dabei ausgestoßenen NO-Neurotransmitter entsteht eine Verstärkung von spezifischen Verschränkungszuständen. Erhöhung der Kohärenzzustände und damit ein weiteres Anwachsen der BP sind die Folge, womit ein Anstieg an physiologischen Signalen einhergeht, bis sie in unser Bewusstsein treten. Veränderung des Fokus stoppt den Nachschub an Neurotransmittern bestimmter Neuronen und da die alten Neurotransmitter nach der Ausschüttung schnell abgebaut werden, lösen sich die alten, speziellen Verschränkungszustände auf. An deren Stelle treten Verschränkungen von Neuronenclustern, die wieder mit der neuen Frage in Resonanz stehen. Dieser Vorgang entspricht der Änderung der Magnetfelder im Diamantenexperiment. Bestimmte Verschränkungen und damit Messungen können auch auf Körperebene an- und ausgestellt werden. Die gemessenen bio-chemischen Geschwindigkeiten zur Freistellung der Neurotransmitter zur Signalüberbrückung des Synapsen-DendritSpaltes entsprechen durchaus den Zeiten, die für relevante quantenbasierte Kohärenzzeiten benötigt werden.

\section{Übertragung auf SyA}

Dieser Prozess ist analog bei SyA oder bei systemischer Arbeit beobachtbar ist. Je nachdem welches System vom Umfeld unterschieden wird, je nachdem ändern sich die Beobachtungen und Informationen. Mit Konzentration auf eine bestimmte Fragestellung ändert der Forscher im übertragenen Sinne seine Magnetfeldrichtung. Bei jeder Fragestellung werden bestimmte Neuronen und damit verbundene Frequenzbänder sensibilisiert, die in Wechselwirkung treten können. Die Erwartungshaltung des Gehirns übernimmt dann die weitere Steuerung. Es sucht aus allen verfügbaren Frequenzen respektive Quanteninformationen die heraus, die am besten zur Frage passen und stellt diese Information dem Bewusstsein zur Verfügung. Die Informationen werden in der für das jeweilige Individuum am besten passenden Form angeboten. Hier kommen das Wissen, der Kontext und die Erwartungshaltung ins Spiel. Mit Zunahme der direkten Erfahrung 
in einem Thema werden die Bilder immer deckungsgleicher. Mit Abnahme der Erfahrung werden die zur Verfügung gestellten Bilder immer analoger. Hier setzt das Bedeutungs- und Übersetzungsproblem an, weshalb jede Wahrnehmung, auch in einer SyA, mit gebotener Vorsicht zu interpretieren ist.

\subsubsection{Neues Modell als Beitrag zur Theory of Mind}

So langsam schließt sich der Kreis und es darf der Bogen zurück zur strategischen Unternehmensführung und Entscheidungstheorie geschlagen werden. In beiden Kontexten werden Theorien benötigt, die das Verhalten Anderer und damit verbundene Unbestimmtheiten berücksichtigen müssen. Mit diesem Themenkreis beschäftigt sich auch die Theory of Mind (ToM), welche als letzter Aspekt in dieses Kapitel integriert wird. ToM, auch verstanden als , active perspective taking' oder ,mentalizing', ,refers to a person's ability to make attributions about mental states such as intentions, desires or beliefs to others (and oneself) and to understand that others have beliefs, desires and intentions that are different from one's own " (Singer 2006: 438). Konsequenterweise setzt sich ToM mit der Natur des Mentalen auseinander und basiert auf dem Verständnis, dass die Realität im Gehirn/Geist nur abgebildet wird und eben nicht der Welt als Ganzes vollständig entspricht. Forschungen im klinischen Kontext weisen ebenfalls darauf hin, dass eine rein körperliche Gebundenheit des Mentalen zu kurz greift. Ein Verständnis, welches sich als äquivalent zur Informations-, Quanten- und Systemtheorie darstellt. Als Dimensionen zur ToM sind vier Differenzierungen relevant: automatisch/kontrolliert, selbst/andere, internal/external und kognitiv/affektiv (Bateman und Fonagy 2016). Differenzierungen, die sich über die gesamte hier vorliegende Forschung spannen.

Mit den bisher entwickelten Zusammenhängen und Erkenntnissen darf der Versuch einer Modellierung der ToM unternommen werden, die über bisherige Beschreibungen hinausgeht, indem sie nicht mehr zwischen affektiver und kognitiver ToM unterscheidet. Affektive Theorien beziehen sich auf emotionale Wahrnehmungen, wohingegen sich kognitive ToM auf Intentionen beziehen (Singer 2012). In dieses Modell lässt sich auch die Luhmannsche Kontingenz und Doppelkontingenz auf einfache Weise einbauen.

Prozess zur emotionalen und intentionalen Informationswahrnehmung von anderen

Spins an allen Außenorganen (5 Sinne, besonders auch der Haut) sind über kohärente Prozesse mit dem Gesamtkörper und über die Nervenbahnen mit dem Gehirn verbunden. Aufgrund der Entwicklungsgeschichte des Systems sollte die Gesamtinformation des Menschen in seinen Spins, die die körperliche Außengrenze aufbauen, ebenfalls codiert sein. Dieser Phasenübergang an den Außengrenzen lässt sich vollständig mit den Prozessen bei Anyonen und teilweise auch mit den Festkörpermodellen von Kosterlitz/Thouless und Haldane (Kap. 4.1.1.4) gleichsetzen. Photonen (Bosonen) wechselwirken oder besser verwandeln sich in Quarticles (Fermionen wie Quarks, Protonen, Neutronen, Elektronen und weiter zu Atomen, Molekülen ...). Mit diesem Übergang werden ALLE Informationen, die das Photon trägt, mit den Informationen des 
wechselwirkenden Systems Mensch verschränkt. Je nach Intensität, also Häufigkeit und Gleichheit der einfallenden Quarticles, nimmt die Möglichkeit einer wahrnehmbaren Informationsveränderung zu.

Dazu müssen die von den Quarticles getragenen Informationen über die Nervenbahnen an das Gehirn geleitet werden. Als weiterer Prozess könnte dies auch durch Sauerstoff erfolgen, der durch Atmung und Haut ins Blut und von dort in das Gehirn gelangt. Dies würde entsprechend den Untersuchungen und Theorien von (McCraty und Childre 2010) dann gelingen, wenn entsprechende Kohärenzen über die EM-Wellen der Zellen oder des Blutes ganz allgemein erzeugt werden können. Das Herz scheint dafür grundsätzlich geeignet, ausreichende EM-Frequenzen und Leistung zur Verfügung zu stellen.

Im Gehirn lassen sich nun zwei sich ergänzende Strukturen für stabile, langlebige, verschränkte Quantenzustände bei Umgebungsbedingungen modellieren:

\section{Konzept der Phasenübergänge, Anyonen und des Hohlraumresonators}

In diesem ersten Teil geht es um den Übergang der Information von den Biophotonen respektive EM-Wellen zu den Mikrotubuli und deren Transport.

Mit dem Konzept der Phasenübergänge wird auf die Überlegungen in Kap. 4.1.1.4 von Wilczek (2017), Kosterlitz/Thouless (1973), Haldane (1988), Kane und Mele (20015) zurückgegriffen. Zum einen lassen sich die Übergänge der Biophotonen in die Atome der Nervenzellen und Mikrotubuli mit dem Konzept von Wilczek (Anyonen) beschreiben. Zum anderen bieten sich für die Wechselwirkungen der Atome und Moleküle der Nervenzellen untereinander die Konzepte der Phasenübergänge zwischen Festkörpern an.

Die Zöpfe der Spinreihen die, vergleichbar mit Supraleitungen und Cooper-Paaren, gegenläufige Ladungen aufweisen und übergreifende Verschränkungszustände bewahren können, entsprechen den Strukturen der Mikrotubuli. Deren unterschiedliche Dipolrichtung in Form von $\alpha$ - und $\beta$-Protofilamenten und der Ladungstransports auf der zweidimensionalen Außenseite lassen sich als Entsprechung zu den Spinreihen interpretieren. Als zusätzliche Verstärkungseffekt unterstützt die Natur diese Konfiguration mit eingelagertem, kohärentem Wasser, was zu einer weiteren Ausdehnung der Verschränkungszonen führen sollte. Auf diese Weise lässt sich die von Hameroff und Penrose (2014a) vermutete zentrale Rolle der Mikrotubuli in den Nervenzellen untermauern. Erste Resonanzen beim Eintreffen bestimmter Informationen wechselwirken mit genau den Neuronen, deren Struktur (Spinreihen / Spinfelder an der Oberfläche) genau den Informationen entsprechen, die über die Biophotonen angeboten werden. Die Resonanz bildet sich aufgrund der topologischen Ähnlichkeit, die sowohl im Spin der Biophotonen als auch in den Spins an der Oberfläche der Mikrotubuli und der Zellwände des Axons gespeichert ist.

Erst einmal in Kontakt mit den Mikrotubuli kann die Information an der Außenseite der Mikrotubuli entlangwandern und gleichzeitig auch an die Biophotonen im Inneren des Mikrotubuli abgegeben werden (Photon-Atom-Photon-Kopplung). Der Transport im Inneren lässt sich als quantenphysikalischer Transport innerhalb eines koplanaren 
Resonator (CPW-Resonator) denken, da die Spins der Wassermoleküle einheitlich ausgerichtet sind.

\section{Konzept der NV-Defekte}

In diesem zweiten Teil geht es um die Überwindung des Synapsen-Dendrit-Spaltes und der großflächigen Ausdehnung der Information, denn die Information muss bis ins Gehirn geleitet und dort großflächig allen Arealen zur Verfügung gestellt werden.

Die eben beschriebenen ersten Interaktionen wirken auf das SCP, was das Bereitschaftspotential der Neuronen erhöht und das Freigeben von Stickstoffatomen an den Synapsenenden ermöglicht. Diese gleichzeitige Produktion von Stickstoff erfolgt an all den Synapsen, die in irgendeiner Weise mit der eingehenden Information korrelieren (gleiche, ähnliche, fragmentale oder strukturelle Passung). Eine solche Option ergibt sich aus einem aktuell entdeckten Prozess in der klassischen Quantenforschung: Der Erzeugung von verschränkten Diamanten mithilfe von Stickstoff-Leerstellen-Brücken (Kap. 8.1.2.3). Analog zu den Diamanten bestehen auch die Neuronen primär aus Kohlenstoff als Zellstruktur. Die freigegebenen N-Atome hinterlassen auch dort Leerstellen, was zum Aufbau größerer, gehirnübergreifender Verschränkungszonen führen sollte. Die zunächst im Schwerpunkt der jeweiligen Nervenzelle befindliche Kohärenz wird blitzartig ausgedehnt. In diesem Moment stehen unendlich viele Spins, sowohl an den Oberflächen als auch innerhalb der Nervenzellen und ihrer Tubuli, zur Verfügung, um Rechnungen analog eines Quanten-Computers durchzuführen. Ist die Rechnung beendet und ein finales Ergebnis produziert, reduziert sich die N-Freisetzung. Es kommt zur Bildung eines zunächst noch reversiblen Faktums (schwache Quantenmessung) oder anders formuliert zur Dekohärenz und damit Unterscheidbarkeit dieses Ergebnisses. Die übergreifende Kohärenz nimmt in den Regionen der ersten Verarbeitung wieder ab. Der Stickstoff zwischen den Synapsen scheint somit kein Signalübergeber im klassischen Sinn der Biologie und Neurowissenschaften, sondern nur ein Abfallprodukt des vom Körper initiierten Fokussierungs- und Verschränkungsprozesses. Der Körper produziert NV-Defekte, um übergreifende und weitreichende, kohärente Prozesse zu organisieren. Die dabei freigesetzten Stickstoffe finden mit dem Leerraum zwischen den Synapsen eine passende Lokalisation zur Zwischenspeicherung oder dienen als N-Brückenköpfe zwischen Synapsen und Dendriten

Ein erneuter Fokussierungsprozess, wie wir ihn im Kap. 8.1.2 (Verschränkung) kennengelernt haben, leitet eine neue SCP und BP-Aktivierung und letztlich einen neuen Rechenvorgang ein. Verschränkungen werden wieder spezifisch intensiviert, um bestimmte Messprozesse zu realisieren.

\section{Schrödinger's Katze im Kopf - ein Erklärungsmodell}

Mit diesem beschriebenen Vorgang lässt sich nun Schrödinger's Katze im Gehirn lokalisieren. Wie auch bei Schrödinger's Gedankenexperiment finden zwar nicht im Kasten unendlich viele Überlagerungszustände statt, wohl aber im Gehirn. Wie im Zwei-Stufen-Modell der visuellen Wahrnehmung (Abb. 89), nimmt unser Gesamtsystem konti- 
nuierlich alle Information aus der Umgebung auf und überlagert sie. Das radioaktive Isotop bei Schrödinger wird im Gehirn durch Intentionen, Ziele, Erfahrungen und Wissen ersetzt, welche in den Neuronen und ihren Spins codiert sind. An diesen Kristallisationskeimen orientiert sich der Quantenrechner, um schließlich ein, für seine innere Logik stimmiges Ergebnis zu produzieren. Wie bei Schrödinger's Katze gibt es nur zwei für uns zugängliche fixe Zustände. Die Situation vor der Rechnung (die Katze lebt, respektive die uns bekannte Information vor der Aktivität unseres Gehirns) und die Situation nach der Rechnung (die Katze ist tot oder lebendig, respektive das Ergebnis nach der Rechnung). Alles dazwischen scheint zu 100 Prozent eine quantenphysikalische Überlagerung zu sein.

Mit den konkreten Rechen- und damit Messergebnissen werden in der Folge andere Gehirnregionen (Motorcortex etc.) angetriggert, die Bilder, Gefühle, Handlungsimpulse etc. für uns zur Verfügung stellen und letztlich den Körper aktivieren. Je stärker die Gefühle beteiligt sind, desto stärker findet ein Überlagerungsprozess der alten Informationsstrukturen mit der neuen Information statt. Grund sind die mit der Stärke der Gefühle einhergehende Energieanregung und damit verbundene stärkere EM-Wechselwirkungen. Letztere tragen ja ebenfalls die neuen Informationen in sich und sind in der Lage alle Zellen des Körpers zu erreichen und zu modifizieren; vergleichbar der gegenseitigen Beeinflussung im Experiment des ,Wandernden Tropfens' und der Führungswelle Kap. 8.1.1.2 und 8.1.1.5. Nicht von ungefähr könnte wie schon in Kap. 8.1.1.5 angedacht, unsere Lernfähigkeit mit dem größeren Anteil von Wasser im Kleinkindalter einhergehen. Die Resonanzfähigkeit von Wasser auf EM-Wellen ist aufgrund der Freiheitsgrade des Wassers wohl höher, als stark gebundenes Muskelgewebe. Gleichzeitig ist eine größere Durchdringung des Gesamtgewebes mit Wasser und eine damit einhergehende, weitreichendere kollektive Wechselwirkung die Folge. Als Konsequenz sollte dadurch ein verbessertes implizites Lernen möglich werden. Neue Informationen dringen schneller und vor allem tiefer in das Gesamtgewebe ein und die beiden Informationsfelder (Tropfen und Führungswelle) wechselwirken stärker.

Als Ausgleich für das weniger implizite Lernen sollten ältere Menschen, aufgrund ihrer vielfältigeren Erfahrung, über mehr Resonanzmöglichkeiten und ein verbessertes intuitives Erkennen verfügen. Dieser mögliche Zusammenhang von Wasser und Lernen findet eine indirekte Bestätigung in der Erfahrung von Menschen, die viel mit Intuition arbeiten z. B. Therapie, Aufstellungsarbeit etc. Sie achten sehr darauf, dass sie selbst und ihre Klienten vor der mentalen Arbeit und vor dem Spüren von Körperwahrnehmungen, ausreichend Flüssigkeit zu sich genommen haben.

\section{Lernen und Informationsspeicherung}

Mit Bezug auf die verschiedenen Verschränkungszustände und Messprozesse aus Kap. 8.1 und 8.2 lässt sich auch ein Modell des Lernens und Speicherns von Informationen beschreiben (Abb. 99).

Abstrakte Informationen liegen als Superposition auf Quantenebene vor und repräsentieren als Möglichkeit unendlich viele Entitäten. Eine durchgeführte schwache (Quanten-)Messung entspricht dann einer kurzen Wahrnehmung ohne weitere Verarbei- 
tung und kommt nicht über das Ultra-Kurzzeit-Gedächtnis hinaus. Zwar lässt sich dabei ein bioelektrischer Prozess beobachten, ähnlich einem fluoreszierenden Bild, aber die Information wird noch nicht verankert und geht wieder verloren, sofern keine weitere Auseinandersetzung mit ihr erfolgt. Entsprechend löst sie auch noch keine nachhaltige Wirkung im verschränkten Gesamtsystem aus. Mittels einer Refokussierung kann dieses Messergebnis aufgelöst und die Überlagerung bei Schrödinger's Katze wieder neu hergestellt werden.

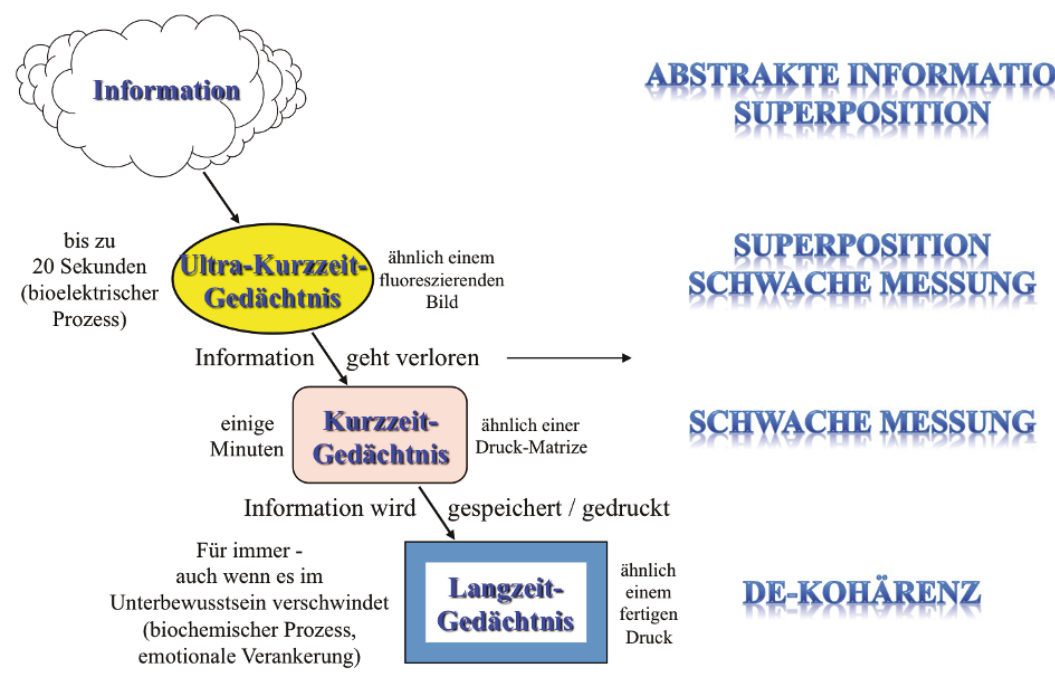

Abb. 99 | Gedächtnis quantenphysikalisch gedacht

(eigene Darstellung). Von der rein abstrakten Information dekohäriert eine Information bis in das Langzeitgedächtnis. Auf diesem Weg durchläuft die Information unterschiedliche Messprozesse, die unterschiedlich starken quantenphysikalischen Messprozessen entsprechen. Gleichzeitig wird sie auf diesem Weg mit Bedeutung versehen. Erst im letzten Schritt, wenn sie emotional aufgeladen und biochemisch verarbeitet wurde und schließlich neue bzw. modifizierte Neuronen oder Methylengruppen (Epigenetik) gebildet wurden, liegt eine Dekohärenz incl. Speicherung einer spezifischen Information vor.

Wird die Information länger verarbeitet, hinterlässt sie im Kurzzeit-Gedächtnis eine Druck-Matrize. Für diesen Prozessschritt darf immer noch von einer schwachen (Quanten-)Messung ausgegangen werden, da auch hier die Information wieder überlagert werden kann, ohne nachhaltige Spuren zu hinterlassen. Erst im letzten Schritt findet eine vollständige Messung und eine Dekohärenz statt. Voraussetzung ist ein biochemischer Prozess und eine emotionale Verankerung. Diese Information wird nun fest im Gesamtsystem des Menschen eingebaut (neuronal oder als Methylengruppen an den Chromosomen) und wirkt von dort mittels unterbewusster Prozesse. 
Eine solche emotionale Verankerung entspricht den neuesten Forschungen der Berufsund Erwachsenenbildung (Arnold 2018b; Arnold und Erpenbeck 2016) und wird als unverzichtbare Bedingung für Lernen angesehen.

\section{Einheitlicher Prozess und ethische Frage}

Ausgehend von einem solchen quantenphysikalischen Prozess und wie die Spiegelneuronen zeigen, darf angenommen werden, dass Menschen grundsätzlich in der Lage sind, sich in andere einzuspüren und deren innere Zustände und Intentionen zu erfassen und vice versa, entsprechend einer schwachen Quantenmessung. Eine Unterscheidung zwischen Emotionen und Intentionen ist nicht mehr notwendig, denn es darf hier von einem graduellen und keinem grundsätzlichen Unterschied ausgegangen werden. Der zugrundeliegende Prozess ist der gleiche, nur werden unterschiedliche Gehirnareale eingebunden.

Damit ergibt sich auch eine Antwort auf die doppelte Kontingenz. Mit dem Erfassen von, dem Gegenüber u. U. selbst noch nicht bewussten Intentionen, können Entscheidungen auf einer fundierteren Ebene getroffen werden als ohne diese Grundlage. Die Unsicherheit bei Entscheidungen lässt sich zumindest reduzieren. Zusätzlich ergibt sich auch die Option, beim Gegenüber bestimmte Intentionen überhaupt erst zu implementieren und damit zu manipulieren; was die Frage nach einer Ethik aufwirft, die viel weiter als bisher gedacht werden muss. Zusätzlich werden darüber hinaus nicht nur bewusste kommunikations- und marketingtechnische Vorgehensweisen relevant, sondern auch unbewusste Intentionen und Prozesse, die ihre Wirkung entfalten können.

\subsubsection{Conclusio zu unserem Gehirn als physikalisches Organ}

Es wurde deutlich, dass verschiedene physikalische Messgrößen (EEG, fMRT, Hautleitwiderstand, EKG und Herzvariabilität) nicht-lokale Effekte begleiten. Als weitere sichtbare Beobachtungen lassen sich neuronale Effekte, bekannt als Spiegelneuronen, aufführen. Die Neurowissenschaft selbst stellt darüber hinaus fest, dass die bio-chemischen Erklärungsmodelle nicht ausreichen, die Vorgänge in unserem Gehirn vollständig zu erklären. Auch die Berücksichtigung der EM-Wellen reichte nicht für alle Phänomene und eine plausible Erklärung aus. Nur unter Hinzunahme quantenphysikalischer Modelle konnte die gesamte Bandbreite der Erscheinungen abgedeckt werden.

Die folgende Zusammenfassung soll die wesentlichen Erkenntnisse noch einmal veranschaulichen, dass nun sämtliche Hauptkategorien aus dem Codingprozess sowie Hypothese 4 erfolgreich verifiziert werden konnten. Auch für die letzten Zweifel, die Prozesse bei Menschen, ließen sich zahlreiche Forschungen finden, die quantenphysi-kalisch basierte Informationsübertragungen und zugehörige Übertragungswege nachwiesen. 


\section{Kurzfassung}

Kurzgefasst, ergibt sich deshalb folgendes quantenphysikalisch basiertes Modell:

Unser Gehirn weist alle Merkmale eines organischen Quantencomputers auf, was erklären kann, dass ...

a) extrem schnelle Verarbeitungs-/Rechenprozesse realisiert werden.

b) bei Menschen in bestimmten Phasen des Lernens die gleichen Fehler beobachtbar sind, wie sie bei künstlichen neuronalen Netzwerken auftreten.

c) wir auf Intentionen anderer reagieren können.

d) scheinbar zeitreversible (Vergangenheit - Gegenwart - Zukunft) Ergebnisse produziert werden (Präkognition).

e) wir mit allen anderen Entitäten in Austauschbeziehung treten können (Mind-Matter-Interaction).

f) wir zu allen Informationen der Quantenwelt Zugang haben.

g) entsprechend des Messprozesses bei Schrödinger's Katze, am Ende einer Superposition ein Messergebnis in der klassischen Welt freigeschaltet wird (mentale Bilder und Körpersensationen).

Um diese zu erreichen ...

- repräsentieren Neuronen Speichereinheiten mit ganz spezifischen Informationen. Informationen, die wiederum über eine Vielzahl von Neuronen ausdifferenziert sind.

- sind in den Neuronen die Informationen sowohl in den Spins der Tubulin-Dimere als auch über die Oberflächenstrukturen der Mikrotubuli gespeichert, vergleichbar den Anyonen und deren verdrillten Branen. Hierdurch sind die Informationen auch extrem beständig gegenüber Umwelteinflüssen und Temperatur.

- liegt innerhalb der Mikrotubuli eine Superposition und damit Verschränkung sämtlicher Informationen vor (respektive eine organische Supraleitfähigkeit), erkennbar anhand gleichzeitiger Biophotonenstrahlung an beiden Enden.

- werden mittels der NV-Defekte neuronenübergreifende NV-Verschränkungen ermöglicht und dadurch großflächige Quantenrechenprozesse eingeleitet. Je großflächiger, desto mehr und desto unterschiedlichere Bereiche können involviert werden, mit der Chance auf überraschendere, innovativere oder vollständigere (Rechen-)Ergebnisse.

- stellen bio-chemische Vorgänge Supportprozesse für übergreifende Verschränkungen dar.

- sorgen EM-Prozesse für schnelle übergeordnete Kopplungen zwischen relevanten, betroffenen Neuronenclustern. EM-Wechselwirkungen beeinflussen das BP und das SCP, wodurch NO-Neurotransmitter in die Synapsenspalten freigegeben werden.

- ermöglichen Alpha-, Theta- und Delta-Beteiligung eine Anschlussfähigkeit an das Schuhmannfeld und an die Ionosphären- bzw. an die Grundschwingung der Erde und damit auch an die des Universums. 
Aus biologisch-evolutionärer Perspektive darf als Kernziel des gesamten Prozesses die Erhöhung der eigenen Resonanzfähigkeit für schwache Signale und damit eine verbesserte Informationswahrnehmung vermutet werden. Achtsamkeits- und Sensibilisierungstrainings (Ruhe, Meditation, SyA) helfen, die Motor-Cortex-Aktivitäten und damit die Mu-Wellen-Unterdrückung zu reduzieren und länger wahrnehmungsfähig zu bleiben. Alpha-, Beta-, Theta- und Delta-Frequenzbänder sind die Folge der darunterliegenden Prozesse und repräsentieren damit verbundene Bewusstseinszustände.

Die heute vorhandenen experimentellen und theoretischen Ergebnisse bieten die Möglichkeit, die Aufnahme von verdeckten Informationen und Intentionen durch Beobachter naturwissenschaftlich zu beschreiben. Als Grundlage kommt derzeit nur ein quantenphysikalisch basierter Ansatz infrage, bei dem Informationen mittels EM-Wellen und quantenphysikalischer Verschränkung mit anderen Systemen in Kontakt gebracht werden. Der weitere Ablauf und das was sich zeigt, wird im Weiteren durch das beobachtende bzw. aufnehmende Objekt (Messgerät, Mensch etc.) bestimmt. Logischerweise kann sich nur das zeigen, was durch das Objekt abbildbar ist. Bei Menschen scheinen auf neuronaler Ebene Spiegelneuronen das erste beobachtbare Glied in der Kette zu bilden.

Übertragen auf die Repräsentanten in SyA heißt dies, dass Menschen im gleichen Erregungszustand (z. B. ruhige gesammelte Aufmerksamkeit und damit Alpha- bzw. Mu-Rhythmus) schwingen und so eine gemeinsame Kohärenz herstellen können. In Verbindung mit ihrer Zielgerichtetheit wird die Voraussetzung für die Resonanz- und Wahrnehmungsfähigkeit für bestimmte Fragestellungen und damit verbundene Impulse geschaffen; Impulse, die sich als erstes mittels Neuronenaktivitäten bemerkbar machen.

Das Auftreten von Spiegelneuronen kann somit als Beweis für die Kohärenz zwischen lebenden Systemen interpretiert werden. Konsequenterweise sind damit auch Phänomene wie Übertragung und Gegenübertragung in der Psychotherapie oder im Kommunikations- und Unternehmensalltag verstehbar.

\section{Detaillierte Ergänzungen}

1. Zurückblickend auf die Versuche von $\mathrm{Hu}$ und $\mathrm{Wu}$ (Kap. 8.2.3) mit der Übertragung von Anästhetika im Bereich von $5 \mathrm{~Hz}$ bis $10 \mathrm{kHz}$, lässt sich feststellen, dass Informationen offensichtlich in Frequenzbändern codiert sind, die in der gleichen Größenordnung liegen, wie sie zur Verarbeitung und Speicherung bei Menschen verwendet werden. Die Frage nun, ob codierte Information in Frequenzen oder Photonen mehr sein kann als nur die Frage nach Spin up oder Spin down, muss aufgrund der vorliegenden Versuche ebenfalls mit JA beantwortet werden. Josephson's Annahme, dass ,Leben seine eigenen Möglichkeiten hat' und sogar die von ihm kritisch gesehene konventionelle Perspektive, dass ,alles Wissen auf quantenmechanische Kenntnisse reduziert werden kann' (Josephson und Pallikari-Viras 1991: 206), sollten damit ebenfalls eine Bestätigung finden. Schließlich schalten sich die von mathematischen Wahrscheinlichkeitsamplituden ausgehenden Wahrscheinlichkeitsberechnungen letztlich auch in unserer erlebten Realität frei. Ein, selbst aus der 
Perspektive der Standardinterpretation der Quantenmechanik, abstraktes Ergebnis transformiert in die Makrowelt.

2. Nach den bisher beschriebenen Möglichkeiten lassen sich zwei Wege denken, wie Information aus der Umwelt bis in unser Bewusstsein dringen kann (siehe auch Kap. 8.3.4 zu ToM):

a) Zum einen auf dem Weg der klassischen, lokalen Verschränkung. Hierunter verstehe ich die Kopplung von EM oder anderen Wellen mit den unseren Körper aufbauenden resonanzfähigen Wahrnehmungssystemen (Sinnesorgane, Haut, Haare). Wie die Neurowissenschaftler und die Biophysiker festgestellt haben, findet auf Zellebene der Austausch von Informationen ausschließlich auf Frequenzebene statt. Frequenzen, in denen alle Informationen codiert enthalten sind. Informationen, die schließlich über die Neuronen entlang der Nervenbahnen bis an das Gehirn geleitet werden. Je nach Trainingszustand und damit je nach Menge der für die jeweilige Information spezialisierten Neuronen, wird die Wahrnehmungsschwelle überschritten oder eben nicht. Bei Überschreitung tritt die Information ins Wachbewusstsein, jedoch nicht ohne dass sie vorher von einem unterbewussten Prozess auf die unbewusste Erwartungs- und Verständniswelt des Gehirnbesitzers angepasst wird (Schrödinger's Katze im Kopf). Die Wahrnehmung ist damit zwangsläufig mit der Vorgeschichte des Wahrnehmenden eingefärbt und in keiner Weise mehr objektiv.

b) Der zweite Weg stellt eine rein quantenphysikalische Verschränkung dar. Dass dies möglich scheint, haben Hameroff, Penrose und andere (Kap. 8.3.3) mittlerweile recht eindeutig zeigen können, wenngleich dort noch Zweifel und Fragestellungen existierten. Als Folge meiner Überlegungen und Modelle scheinen die Voraussetzungen für einen nicht-lokalen Informationstransfer realistisch gegeben und bisherige Fragen hierzu beantwortbar zu sein. Das bereits in Kap. 4.2.2, Abb. 27 entwickelte Modell eines dritten, direkten Informationsaustausches findet somit bis incl. der Neurowissenschaften seine Bestätigung.

Mithilfe von Mikrotubuli, den Grundbausteinen unserer Zellen, kann ein systemweiter, kohärenter und damit verschränkter Zustand konstituiert werden. Treten zwei oder mehrere solcher Systeme (z. B. Menschen) miteinander in Kontakt und interferieren, bildet sich ein übergeordnetes Quantensystem, in dem die Informationen auf alle verteilt vorliegen und jeder sofort Zugriff darauf bekommt, sobald er seinen Fokus darauf richtet. Offensichtlich ist die Resonanzfähigkeit unserer Neuronen so gut, dass kleinste Änderungen (energetisch als auch informationstechnisch) genügen, um ausreichend große Neuronencluster in unserem Gehirn zum Feuern zu bewegen. Ab diesem Moment ist der Wahrnehmungsprozess wie bei der klassischen Verschränkung. Auch hier geht es nicht ohne individuelle Einfärbung. Im Gegensatz zur klassischen Verschränkung können hier Intentionen auch über Entfernungen Wirkung entfalten.

Gehen wir mit der Argumentation von Hameroff und Penrose (Kap. 8.3.3), so lassen sich Mikrotubuli als Resonanzwandler interpretieren. Spezifisch ausgebildete und sensibilisierte Neuronen nehmen Quanteninformation über EM- 
Frequenzen auf und machen sie für den Organismus verfügbar. Dies geschieht durch Auslösen von EM- und dadurch letztlich biochemischer Impulse. Nicht überraschend scheint mir das Manifestieren von Neurotransmittern und anderen biomolekularen Substanzen. Denn letztlich müssen sich Quanteninformation und EM-Impulse auf Körperebene wiederfinden, was sich quantenmechanisch als Materialisierung der Information interpretieren lässt. Im Gegensatz zur bisherigen Annahme zur Rolle der Neurotransmitter (Träger der Information) stellt sich im oben entwickelten Modell deren Rolle ,nur' als Supportprozess zur Erzeugung einer neuronalen quantenphysikalischen Verschränkung dar, mit deren Hilfe die Synapsenspalten überbrückt werden können. Die bisherige Fokussierung auf das ,WIE der Überbrückung' hat möglicherweise das ,WARUM ein Spalt' überlagert und so zu unzureichenden Antworten geführt.

3. SCP lässt sich als erste übergreifende Frequenzebene interpretieren, die eine Anschlussfähigkeit an die Grundschwingung der Erde herstellt. Aufgebaut könnten die SCP durch die Vibration der Neuronen werden, die wiederum auf den Vibrationen der Biophotonen und Mikrotubuli basieren. In all diesen Frequenzen sind Informationen aus der eigenen Innen- als auch von der Außenwelt codiert. Zunächst wird kein Schwellenwert erreicht, da sich alle Informationen überlagern und ohne Bedeutung für das lebende System sind. Dennoch ist davon auszugehen, dass genau an dieser Schnittstelle der Übergang von der Mikro- (Quantenwelt) zur Makrowelt vonstatten geht. Hier findet die Decodierung relevanter Informationen statt; Informationen, die überlebenswichtig für das System sind, trainiert von Anbeginn der Zeit und in unseren Genen resonanzfähig gespeichert. Genauso wie Informationen, für die wir aufgrund unseres aktuellen Interesses oder unserer Vorstellung von der Zukunft neu resonanzfähig werden. Analog zur aufgeprägten Intention, nach denen sich die Quanten verhalten, verhält sich unser Quantenfeld hoch reaktiv und proaktiv auf einer absolut elementaren Ebene. Auf Ebene der SCP finden erste vorbereitende Aktivitäten statt. Erwartungshaltungen und Intentionen sind mit bestimmten Gehirnarealen korreliert, in denen großflächig der Level für einen wahrnehmbaren Schwellenwert heruntergesetzt wird - erkennbar durch niedrigere SCP. Unsere Sensibilisierung wird mittels einer Fokussierung heraufgesetzt. Entsprechend benötigen eingehende Informationen zur Wahrnehmung niedrigere Energiewerte, respektive weniger betroffene und aktivierte Neuronen. Vergleichbar der Abbildung auf dem Screen beim Doppelspalt werden früher Muster erkennbar.

4. Ausgehend von den nachgewiesen photonen- und frequenzbasierten Kommunikationen zwischen den Neuronen, dem in Intervallen arbeitenden Gehirn und den nichtlokalen Korrelationen von Informationen, kann aus heutiger Sicht nur eine logische Schlussfolgerung abgeleitet werden: Jedes Lebewesen (Mensch, Tier, Pflanze etc.) entspricht einem quantenphysikalischen Mixed-Zustand. Es ist in der Lage, in Quanten und Frequenzen codierte Information aus der Umwelt aufzunehmen oder selbst zu produzieren, diese über Nervenzellen (oder ähnliche Netzwerke) bis in die Informationsverarbeitungszentren (z. B. Gehirn) zu leiten und dort in biochemische Prozesse der Makrowelt zu überführen. Alle Ideen, lebende Systeme ausschließlich als 
Makrosystem, ohne quantenphysikalische Anbindung zu denken, müssen verworfen werden. Verworfen werden muss auch die Idee, dass in den energetischen Prozessen nur Energien und keine Informationen übertragen werden. Über die Qualität der Information entscheidet die jeweilige Resonanz- und Verarbeitungsfähigkeit des Lebewesens. Angebliche, kohärenz- und damit superpositionsverhindernde Bedingungen gibt es nicht. Ganz im Gegenteil erweisen sich Störungen in bestimmten Kontexten sogar als hilfreich für Lebensdauer und Geschwindigkeit kohärenter Übertragungsprozesse. Die Natur hat Lösungen für die in technischen Kontexten auftretenden Problemstellungen gefunden. Die bisherigen Annahmen sind nur unserer Weltanschauung, unserem Nicht-Wissen und unserer unzureichenden Messtechnik geschuldet, und zwar genau in dieser Reihenfolge.

5. Radin's Versuche und die Neurowissenschaftler zeigen (Kap. 8.3.2), dass Zeit tatsächlich auch für unser Gehirn relativ ist. Deshalb möchte ich die Hypothese aufstellen, dass für kleine, endliche Zeiten auf Gehirnebene keine Kausalität, sondern eine quantenmechanische Überlagerung stattfindet, in der Vergangenheit, Gegenwart und Zukunft eins werden. In Anbetracht dessen, dass mit der Theorie von Aharonov u. a. Zeitsymmetrie (auch Rückwärtsverursachung) quantenphysikalisch erklärbar wird, liegen somit Evidenzen vor, die Menschen zumindest zum Teil als Quantensystem identifizieren und einen ,Homo Physicus' begründen. Als Folge kann in bestimmten Situationen unsere Wahrnehmung Ereignisse greifen, die nach dem kausalen Zeitpfeil erst später kommen würden, womit auch präkognitive Erlebnisse möglich werden. Dass die rein klassisch-physikalische Vorstellung und damit der reine kausale Determinismus greift, ist aufgrund quantenphysikalischer Grundlagen ausgeschlossen.

6. Sheldrake hat seinen Beobachtungen eine, Theorie der morphischen Felder' zur Seite gestellt (Kap. 5.3.5). Grinberg-Zylberbaum gab seinem Erklärungsansatz den Namen ,Syntergic Theory' (Grinberg-Zylberbaum u. a. 1992). Beide Forscher als auch Persinger, Hu und Wu und viele andere (Kap. 8.3.2.4) brachten die Ergebnisse letztlich mit quantenphysikalischen Wirkmechanismen in Zusammenhang. Es handelt sich um Forscher, die sich mit erlebbaren und messbaren Phänomenen auseinandersetzten und ernsthaft versuchten eine Erklärung zu entwickeln. $\mathrm{Zu}$ ihrem Leidwesen handelt es sich bisher oft nur um eher kleine Größen, die sich statistisch zwar als signifikant erwiesen, aber dennoch viel zu oft nur kleine Unterschiede produzieren konnten. Hinzu kommt das Problem der Anfälligkeit für alle möglichen Arten von Einflüssen und einem Umfeld, dem Gehirn, das nur schwierig exakt zu bemessen ist. Aufgrund der bisherigen Nicht-Erklärbarkeit solcher Phänomene bekamen diese Forscher in der Vergangenheit immer sehr kritische Rückmeldungen aus der Wissenschaftsgemeinde, meist mit den Attributen , unwissenschaftlich' oder ,fehlerhafter Versuchsaufbau' versehen. Auf der anderen Seite zeigte eine Metastudie von Storm u. a. (Storm u. a. 2012), dass sich die Effektgrößen von 1987 - 2010 kontinuierlich nach oben entwickelten. Unter Berücksichtigung der Bayes'schen Wahrscheinlichkeit lässt sich schlussfolgern: Die untersuchten Phänomene werden immer vorstellbarer, als Folge werden immer mehr Experimente aufgesetzt, mit 
immer optimistischeren Erwartungswerten und schließlich auch signifikanteren Ergebnissen, und die Spirale setzt sich nach oben fort. Ich hoffe, mit den bisherigen und weiteren Überlegungen wird eine Zurückweisung derartiger Phänomene wegen einer fehlenden Theorie erheblich schwerer und die von Vielen erlebte Welt findet weiteren Einzug in die Forschung.

Die verschiedenen Arbeiten konnten zeigen, dass kleinste Einflüsse (Erwartungen, Vorstellungen und sogar noch in der Zukunft liegende Ereignisse) ausreichen, um Wirkung auf Körperebene zu erzielen. Unser physiologisches Gesamtsystem ist ausgesprochen labil und agiert auf einer völlig unbewussten Ebene. Wenn Erwartungshaltungen oder andere Vorstellungen Ergebnisse auf Körperebene in bestimmte Richtungen beeinflussen können, so ist davon auszugehen, dass Beeinflussung auch für Zweifel, Überzeugungen oder andere Intentionen eine Gültigkeit besitzt. Als Konsequenz wird verständlich, wenn Versuche zur Replikation solch hoch diffiziler Experimente häufig fehlschlagen. Der Glaube an deterministische Doppelblindversuche und deren Exaktheit muss demnach zwingend infrage gestellt werden.

7. Als Muster bzgl. Vorahnungen oder Übertragungen lässt sich die deutliche Abhängigkeit von emotional besetzten Ereignissen oder Verbindungen zwischen Menschen identifizieren. Bei emotionaler Betroffenheit zeigten sich eindeutig signifikantere Ergebnisse, als in neutralen Konstellationen. Damit lässt sich auch eine Korrelation zu Phänomenen bei SyA herstellen. Sehr häufig wird von erfahrenen Aufstellern darauf hingewiesen, nur wirklich relevante Themen aufzustellen, bei denen der Fallbringer ein ernsthaftes Anliegen hat. Ernsthaft lässt sich in diesem Zusammenhang mit ,emotional betroffen' präzisieren. Nur dann zeigen sich klare Reaktionen und Antworten. Im anderen Fall bleibt das Geschehen meist ohne Energie, respektive Klarheit.

8. Und abschließend noch eine Schlussfolgerung zum Thema ,Freier Wille'. In den Ausführungen wurde deutlich, dass wir nicht nur reagieren, sondern sehr aktiv bei unseren Wahrnehmungen und vor allem Entscheidungen mitwirken. Auch wenn dies auf den ersten Blick nur vorbewusst geschieht, können wir durch bewusst gesetzte Intentionen und durch Nutzung der Zeit zwischen gefühlsmäßiger Reaktion und bewusstem Handel in das Geschehen steuernd eingreifen; ein Ergebnis, das besonders mit meditationsgeübten Versuchsteilnehmern signifikant wurde. Nicht-vorhandener freier Wille kann demgegenüber als Verschränkungs- und Superpositionsphänomen mit Systemen interpretiert werden, das die eigenen, intrinsischen Zustände beeinflusst bzw. überlagert. Im gesunden Zustand gibt es verschiedene Möglichkeiten die eigenen Freiheitsgrade zu steigern:

- Auf eine Vielseitigkeit von Informationen und Quellen achten. Zu starke Monokultur und damit zu starke Fixierung auf bestimmte Personen oder Perspektiven veranlasst unser Gehirn, zukünftig nur solche Informationen zur Verfügung zu stellen (analog Suchmaschinen wie z. B. Google). Hier greift das Bayessche Wahrscheinlichkeitstheorem.

- Sich nicht von einer momentanen Begeisterung hinreißen lassen, vor allem wenn die Begeisterung von einem oder mehreren Gegenüber ausgeht (typische Ver- 
kaufssituationen). Wir reiten dann vermutlich auf der Begeisterungswelle des Anbieters, was uns spätestens am nächsten Tag auffallen wird; deshalb besser einmal darüber schlafen.

- Unsere kognitiven Fähigkeiten nutzen und spontane Handlungen vermeiden, ohne auf das Bauchgefühl zu verzichten. Wie Roth (Roth 2007) es empfiehlt: Eine Kongruenz zwischen Kopf- und Bauchentscheidung herstellen.

- Sich immer wieder auf sich und seine Wünsche, Ziele, Prioritäten besinnen. Dies entspricht kontinuierlichen Quantenmessungen und hilft eine Eigenständigkeit aufrechtzuhalten.

- Mehr mit bewussten Intentionen arbeiten und so aktive Suchprozesse initiieren.

\section{Kritische Überprüfung}

In diesem Kapitel sind ausschließlich Arbeiten herangezogen worden, die die Möglichkeit eines nicht bio-chemischen Mechanismus unterstützen und so Nicht-Lokalität möglich erscheinen lassen. Da es sich hier auch heute noch um eine Minderheitenmeinung handelt und relativ gesehen nur wenige Forscher an diesen Themen arbeiten, bleibt die Frage nach der Qualität und Glaubwürdigkeit der vorliegenden Forschungsergebnisse, denn die übliche Kommentierung bezieht sich auf genaue diese zwei Aspekte (Qualität und Glaubwürdigkeit). An dieser Stelle werden jetzt nicht die ganzen Gegenargumente weiter aufgeführt, die von den Kritikern formuliert werden. Mir scheint, als würden zwei zentrale Aspekte ausreichen, um der aktuellen Kritik zu begegnen. Zum einen existiert mit der SyA ein Verfahren, in dem sich all die Phänomene beobachten lassen, die sowohl in der Intuitionsforschung als auch in der parapsychologischen Forschung untersucht werden und für die es bisher noch keine Erklärungsmöglichkeiten gibt. Sowohl Schlötter's Dissertation (Kap. 3.3.2) als auch die individuellen Erfahrungen der Teilnehmer bei SyA sprechen dafür, dass es sich um keine Einbildungen handelt. Viel gewichtiger erscheint mir jedoch eine Stellungnahme von Kritikern in Bezug auf die Qualität der hier vorgestellten Forschungen. Hergovich ${ }^{238}$ hat anlässlich einer GWUP-Konferenz 2011 (Harder 2011), in der es um eine kritische Auseinandersetzung mit der Parapsychologie ging, folgende Aussage getätigt: ,Zweifellos sind diese Arbeiten methodisch gut gemacht. "Er bezog sich dabei auf die Veröffentlichungen, die auch aus seiner Sicht in , guten Journals wie das Psychological Bulletin erscheinen “. Einer der Hauptzweifel resultiert nach ihm aus der Tatsache, dass sich auf der Verhaltensebene nichts zeigen würde. Zweifelsohne wäre interessant zu untersuchen, wie eine solche Meinung entstehen kann und auf welchem Ausschnitt der Realität sie fußt. Mit den Erfahrungen als Repräsentant in SyA als auch in Bezug auf die Forschungsergebnisse zu ihrer Nachhaltigkeit, wie zu den Erkenntnissen aus der Intuitionsforschung ist es auf jeden Fall unmöglich von einer Nicht-Wirkung auf der Verhaltensebene auszugehen.

${ }^{238}$ Professor am Institut für Psychologie der Universität Wien. 
Open Access Dieses Kapitel wird unter der Creative Commons Namensnennung 4.0 International Lizenz (http://creativecommons.org/licenses/by/4.0/deed.de) veröffentlicht, welche die Nutzung, Vervielfältigung, Bearbeitung, Verbreitung und Wiedergabe in jeglichem Medium und Format erlaubt, sofern Sie den/die ursprünglichen Autor(en) und die Quelle ordnungsgemäß nennen, einen Link zur Creative Commons Lizenz beifügen und angeben, ob Änderungen vorgenommen wurden.

Die in diesem Kapitel enthaltenen Bilder und sonstiges Drittmaterial unterliegen ebenfalls der genannten Creative Commons Lizenz, sofern sich aus der Abbildungslegende nichts anderes ergibt. Sofern das betreffende Material nicht unter der genannten Creative Commons Lizenz steht und die betreffende Handlung nicht nach gesetzlichen Vorschriften erlaubt ist, ist für die oben aufgeführten Weiterverwendungen des Materials die Einwilligung des jeweiligen Rechteinhabers einzuholen.

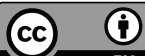

